
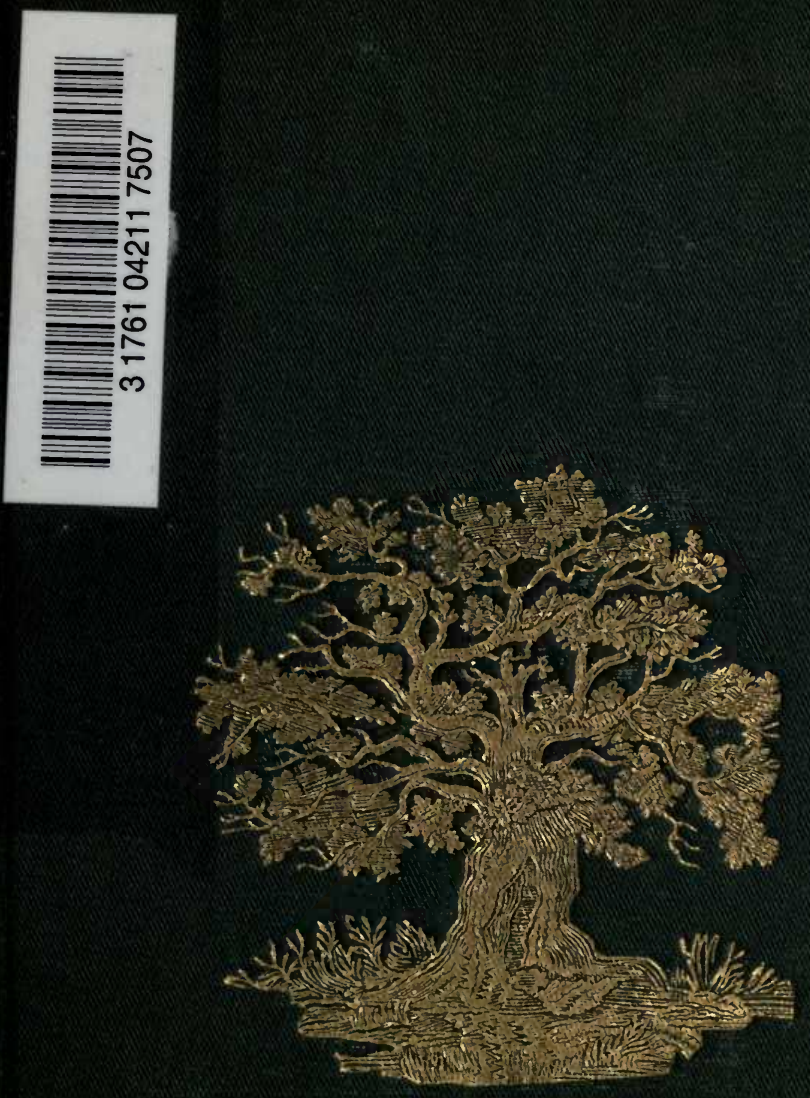


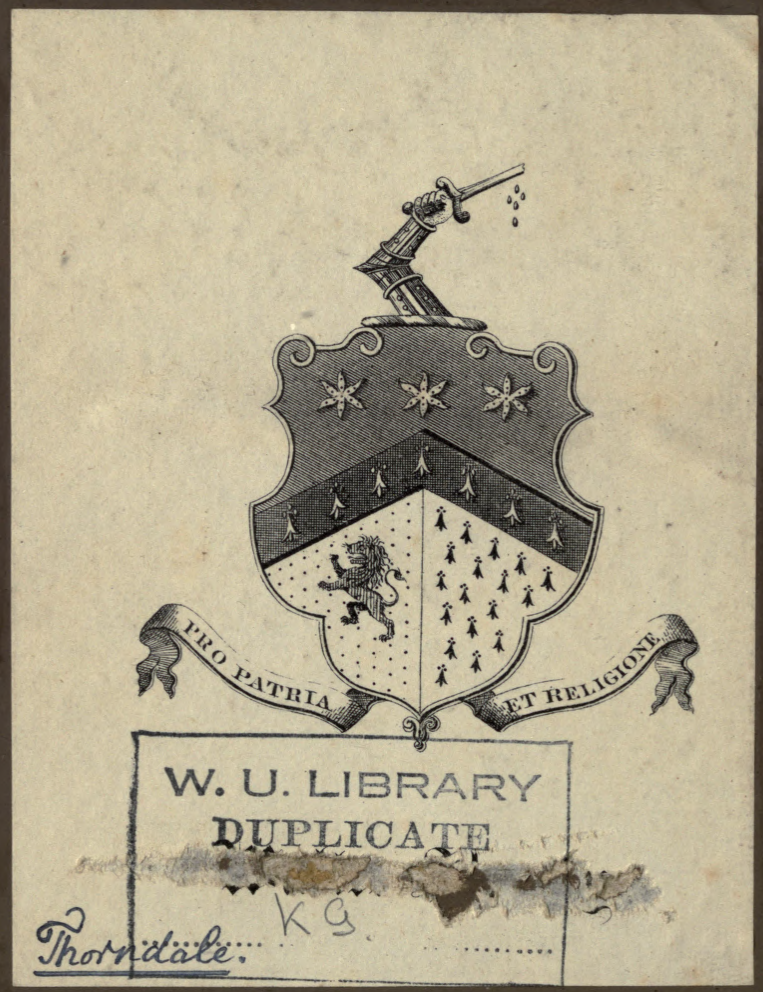





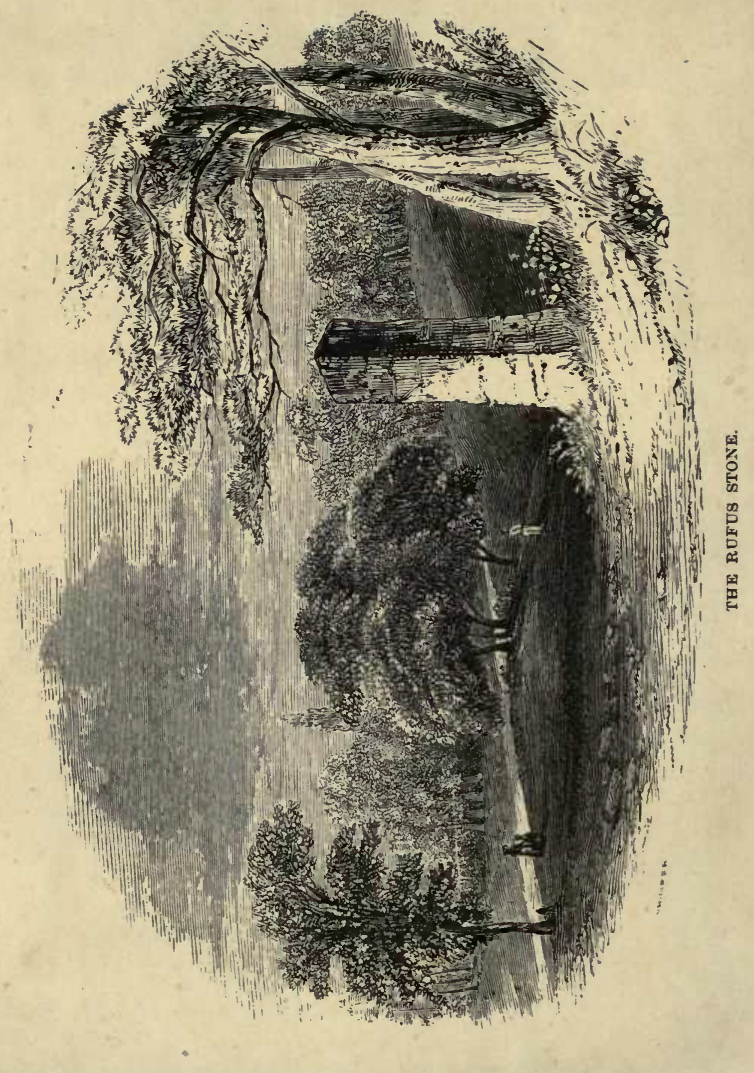




\title{
FOREST TREES OF BRITAIN.
}

\author{
REV. C. A. JOHNS, B.A. F.L.S.
}

AUTHOR OF "FLOWERS OF THE FIELD," "BRITISH BIRDS IN THEIR HAUNTS," ETC. ETC.

PUBLISHED UNDER THE DIRECTION OF

THE COMMITTEE OF GENERAL LITERATURE AND EDUCATION APPOINTED BY THE SOCIETY FOR PROMOTING

CHRISTIAN KNOWLEDGE.

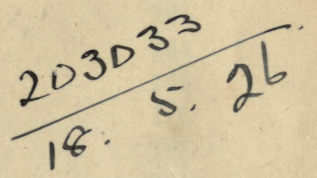

\section{LONDON :}

SOCIETY FOR PROMOTING CHRISTIAN KNOWLEDGE:

SOLD AT THE DÉPOSITORIES :

77, GREAT QUEEN STREET, LINONLN'S INN FIELDS ;

4, Royal exchange; 48, piccadilly;

AND BY ALL BOOKSELLERS. 



\section{CONTENTS.}

THE OAK. . . . . . . . . . . . . . . 1

The Ilex, Evergreen OAK, or Holm-OAK . . $\quad 39$

The Sycamore. . . . . . . . . . . . . 42

The Common, or Field Maple . . . . . . . 51

THe AsH . . . . . . . . . . . . . . . 56

The Box. . . . . . . . . . . . . . . 70

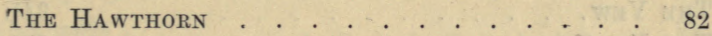

The Blackthorn . . . . . . . . . . . . 103

The Cherry . . . . . . . . . . . . . . . 112

The Bird-Cherry. . . . . . . . . . . . 121

The Mountarn Ash . . . . . . . . . . . . 125

The White-Beam. . . . . . . . . . . 132

Wild Service-tree . . . . . . . . . . . 133

The Pear . . . . . . . . . . . . . . 134

The Apple . . . . . . . . . . . . . . . . . . . . . 137

The Beech . . . . . . . . . . . . . . 143

The Poplar . . . . . . . . . . . . . . . 159

The White Poplar, or Abele Tree-the Griy

Poplar . ... . . . . . . . . . . . . . . . . 161

The Black Poplar . . . . . . . . . . . 164

The Trembling Poplar, or Aspen . . . . . 167

The Chestndt . . . . . . . . . . . . . . 170

The Horse Chestndt . . . . . . . . . . . 187

The Holly . . . . . . . . . . . . . . 194

The Birch . . . . . . . . . . . . . . 204

The Alder . . . . . . . . . . . . . . 212

The Elm . . . . . . . . . . . . . . . 218

The Wroh Elm . . . . . . . . . . . . 231

The Hornbeam . . . . . . . . . . . . . 234

The Hazel . . . . . . . . . . . . . . . 239 
THE WALNUT $\cdot \cdot \cdot \cdot \cdot \cdot \cdot \cdot \cdot \cdot 251$

The Lime-Tree. . . . . . . . . . . . . 258

The Barberri . . . . . . . . . . . . . 265

The Tamarisk . . . . . . . . . . . . . 267

The Strawberry-tree . . . . . . . . . . 274

The SpINDLE-TREe . . . . . . . . . . . 277

The Dogwood . . . . . . . . . . . . . 279

The Oriental Plane . . . . . . . . . . 282

The Occidental Plane. . . . . . . . . . 287

The Buckthorn . . . . . . . . . . . . 292

The Privet . . . . . . . . . . . . . 295

The Acacia . . . . . . . . . . . . . . . 297

The Willow . . . . . . . . . . . . . . 302

The Elder . . . . . . . . . . . . . . 320

The Woodbine, or Honeysuckle . . . . . 326

The Wayfaring-Tree-the Guelder Rose. . . 328

The IvY . . . . . . . . . . . . . . . 332

THe YeW. . . . . . . . . . . . . 341

The Fir Tribe. . . . . . . . . . . . . 350

The Scotch Fir, oR Pine. . . . . . . . 365

Pinus Pinaster . . . . . . . . . . . . . . 381

The Stone Pine . . . . . . . . . . . . 388

The Spruce Fir . . . . . . . . . . . . 390

The Silver Fir . . . . . . . . . . . . . 398

The Larch . . . . . . . . . . . . . . 403

The Cedar of Lebanon . . . . . . . . . 410

The Juniper . . . . . . . . . . . . . 418

INDEX . . . . . . . . . . . . . 421 


\section{LIST OF ILLUSTRATIONS.}

The Rufus Stone Frontispiece PAGE

Oak in Wistman's Wood . . . . . . . . . . 7

Flower-galls and Leaf-galls _. . . . . . . . . 19

Artichoke-galls . . . . . . . . . . . . 20

Oak-spangles . . . . . . . . . . . . . . 21

Oak-galls . . . . . . . . . . . . . . 23

The Evergreen Oak . . . . . . . . . . . . 39

Sycamore at Kippencross . . . . . . . . . . 43

Sycamore Flowers and Seed-vessel . . . . . . . 46

Leaves and Flowers of the Field Maple . . . . . 53

Maple in Boldre Churchyard . . . . . . . . 54

The Ash . . . . . . . . . . . . . . . 57

Flowers and Seed-vessels of the Ash . . . . . 64

Wooden Stamp used in Thirteenth Century . . . . 75

The oldest Woodeut on record . . . . . . . . 76

Old Woodeut of St. Christopher . . . . . . 77

Thorn at Newham . . . . . . . . . . 84

May-pole . . . . . . . . . . . . . . 92

Common Hawthorn. . . . . . . . . . . . 94

Hawthorn Blossom . . . . . . . . . . . . 96

Fruit of Hawthorn . . . . . . . . . . . 97

The Hawfinch . . . . . . . . . . . . 102

Sloe-flower . . . . . . . . . . 104.

Sloe. . . . . . . . . . . . . 106

Fruit and Foliage of Bullace-tree . . . . . . 109 
Myrobalan Plum . . . . . . . . . . . . . . 110

Magnum-bonum Plum. . . . . . . . . . . 111

The Wild Cherry-tree . . . . . . . . . . . 113

Flower of the Wild Cherry . . . . . . . . . 114

Fruit of the Wild Cherry . . . . . . . . . . 115

Blossoms of the Bird-Cherry . . . . . . . . . 122

Fruit of the Bird-Cherry . . . . . . . . . 123

Portugal Laurel . . . . . . . . . . . . . 124

The Mountain Ash . . . . . . . . . . . . . 126

Flowers of the Mountain Ash _. . . . . . . 129

Fruit of the Mountain Ash . . . . . . . . 130

The White-Beam . . . . . . . . . . . 132

Flower of Pear-tree . . . . . . . . . . . 135

Blossom of the Apple-tree. . . . . . . . . . 137

The Purley Beeches . . . . . . . . . . . 144

Twig of the Beech in Winter. . . . . . . . . 149

Foliage and Flowers of the Beech . . . . . . . 152

Morels . . . . . . . . . . . . . . 156

Truffles . . . . . . . . . . . . . . . . 157

Beech-tree in West Hey Wood . . . . . . . . 158

Lombardy Poplar . . . . . . . . . . . . . . 160

Leaf of White Poplar . . . . . . . . . . 162

Catkins of Grey Poplar . . . . . . . . . . 163

Black Poplar . . . . . . . . . . . . . . 165

Leaf of Black Poplar . . . . . . . . . . . . . . . 166

Aspen . . . . . . . . . . . . . . . . 168

The Chestnut . . . . . . . . . . . 170

Flower of Chestnut . . . . . . . . . . . . 179

Fruit of Chestnut . . . . . . . . . 180

The Horse Chestnut . . . . . . . . . . . 188

Horse-shoe Mark on Chestnut . . . . . . . . 189

Leaf and Flower-buds of Horse Chestnut . . . . . 190

Flower of Horse Chestnut . . . . . . . . . 191

The Holly. . . . . . . . . . . . . . . 195 
Holly Berries-Winter of 1845-6

Opegrapha Scripta . 199

Holly in Bud .

200

Flowers of the Holly

201

Butcher's Broom 203

The Common Birch 205

Leaf and Flower of the Birch . . . . . . . . 207

The Weeping Birch. . . . . . . . . . . . 208

Dwarf Birch . . . . . . . . . . . . . . 211

The Alder . . . . . . . . . . . . . . . 213

Flower and Leaf of the Alder ... . . . . . . . . 214

Leaves of the Alder . . . . . . . . . . . 217

The Elm . . . . . . . . . . . . . . . . . . 219

Seed-vessel . . . . . . . . . . . . . . 220

Flowers of Common Elm . . . . . . . . . . 221

Seed and Leaf of Common Elm . . . . . . . . 222

Cornish Elm . . . . . . . . . . . . . . . . 222

Flowers and Seed-vessels of Wych Elm . . . . 223

Branch of Ulmus Suberosa . . . . . . . . . 224

Work of Elm-destroying Beetle . . . . . . . . . . 229

Spotted Elm-leaf . . . . . . . . . . . 230

Wych Elm at Enys, Cornwall . . . . . . . . 232

Leaf of Wych Elm . . . . . . . . . . . . 233

The Hornbeam . . . . . . . . . . . . . . 235

Leaf, Flower, and Seed of the Hornbeam . . . . 236

Flowers and Foliage of Hazel . . . . . . . . . . 242

Balaninus Nucum . . . . . . . . . . . . . . . . 242

Hazel-nut . . . . . . . . . . . . . . . 244

The Nuthatch . . . . . . . . . . . . . . . 245

Nut in Bark . . . . . . . . . . . . . . . 246

Peziza Coccinea . . . . . . . . . . . . . 248

The Filbert . . . . . . . . . . . . . . . . . . 249

The Cob-nut . . . . . . . . . . . . . . 250

The Walnut . . . . . . . . . . . . . 252 
Fruit of Walnut . . . . . . . . . . . . . 253

Twig of Walnut . . . . . . . . . . . . 254

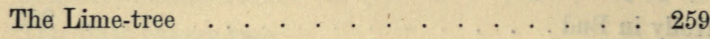

Leaf and Flower of the Lime-tree . . . . . . . 261

Blossom of Barberry . . . . . . . . . . . 265

Flowers and Fruit of the Barberry . . : . . . . 266

The Tamarisk . . . . . . . . . . . . . 268

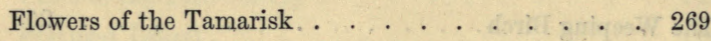

Dutch Myrtle, or Sweet Gale _ . . . . . . . 272

Flower and Fruit of Arbutus . . . . . . . . 275.

Branch of the Spindle-tree . . . . . . . . 278

Leaf and Flower of the Dogwood _. . . . . . . 279

Twig of the Cornel . . . . . . . . . . . . 280

The Plane. . . . . . . . . . . . . . . 283

Leaf of the Oriental Plane and Plan of the Morea . . 285

Leaf and Flower of Oriental Plane . . . . . . . 286

The Occidental Plane . . . . . . . . . . . . . 287

Leaf-stalk of Occidental Plane . . . . . . . . . 289

Leaf of Occidental Plane . . . . . . . . . . . . . 290

Alder-Buckthorn . . . . . . . . . . . . . . . . 293

Common Buckthorn . . . . . . . . . . . 294

Flower of the Privet . . . . . . . . . . . . . . 296

The Acacia . . . . . . . . . . . . . . . 298

The Huntingdon Willow ........ . . . 303

Blossom of the Crack Willow '. . . . . . . . 305

Flower and Seed-vessels of Willow . . . . . . . . . 306

Willow . . . . . . . . . . . . . . 307

Foliage of Huntingdon Willow . . . . . . . . . 310

Herbaceous Willow . . . . . . . . . . . 315

Willow Gall ... . . . . . . . . . . . 316

Weeping Willows at Kew . . . . . . . . . . . 318

Leaf and Flower of the Elder . . . . . . . . . 322

The Woodbine . . . . . . . . . . . . . 327

Wayfaring-tree . . . . . . . . . . . . . 329 
Guelder Rose

Ivy-leaves .

334

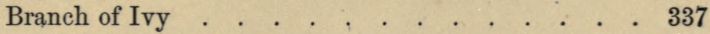

Ivy-berries . . . . . . . . . . . . . . 339

Yew-tree at Crowhurst . . . . . . . . 343

Leaf and Flower of the Yew . . . . . . . . 347

Buds of Stone Pine... . . . . . . . . 354

Cone of Stone Pine. . . . . . . . . . . . 356

Seed of Scotch Pine . . . . . . . . . . . 356

Seedling . . . . . . . . . . . . . . 356

The Scotch Fir . . . . . . . . . . . . . 366

Section of a Bog containing Fir-stumps . . . . . 374

Scotch Fir . . . . . . . . . . . . . . 376

The Pinaster . . . . . . . . . . . . . 382

Cones of Pinaster . . . . . . . . . . . . 383

Pinus Lemoniana . . . . . . . . . . . . 386

Dead Branch of Pinus Lemoniana . . . . . . . 387

Leaves of Stone Pine . . . . . . . . . . . 389

The Spruce Fir . . . . . . . . . . . . . 391

Cones of Spruce Fir . . . . . . . . . . . 393

Gall of Spruce Fir . . . . . . . . . . . . . 397

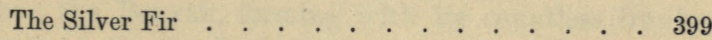

Cones of Silver Fir . . . . . . . . . . . . 400

Twig of Larch . . . . . . . . . . . . . . 404

The Larch. . . . . . . . . . . . . . . 405

Chelsea Cedars . . . . . . . . . . . . . 411

Cones of Cedar . . . . . . . . . . . . . . 414

The Juniper . . . . . . . . . . . . . . 419 



\section{THE}

\section{FOREST TREES OF GREAT BRITAIN.}

THE OAK.

Quercus Robur-Quercus SEssiliflora.

Natural Order-Amentacen.

Class-Mongeia. Order-Polyandria.

As long as the Lion holds his fabled place as king of beasts, and the Eagle as king of birds, the sovereignty of British Trees must remain to the Oak. Within the tropics, where Nature performs all her works on a scale of magnificence unrivalled elsewhere, the stately Palm, uplifting its leafy canopy on a shaft two hundred feet in height; the Banyan, forming with its countless trunks a forest in itself ; the Baobab, a tree venerable four thousand years ago: each of these may assert its claim to the kingly title. But in England, the country of green fields, in which men labour among their oxen and their sheep; of lordly parks, with their broad smooth lawns and clustering trees; of narrow church-paths winding along by the side of brilliant streamlets, across flowery meadows, and through woods offering a shade from the heat, and a shelter from the storm, here the Oak reigns paramount. In truth he is a kingly tree, the emblem of majesty, strength, and durability. To what remote ages are we carried back - to what varying scenes are we introduced, when we search for the first appearance of this patriarch 
in the pages of history! Under the Oaks of Mamre, ${ }^{1}$ according to Jewish traditions, the father of the faithful reared his tabernacle, and meditated on another, that is a heavenly, country, which God had prepared for him. One of these very trees was long looked upon with veneration by the Israelites, and (according to St. Jerome) was in existence in the reign of the Emperor Constantine, two thousand vears afterwards. ${ }^{2}$

Near Shechem there stood also a tree of the same species, which probably was remarkable for its size, being called in Genesis xxxv. 4, "The Oak which was by Shechem."' Thus early, too, does it appear to have been marked with some peculiar sacredness, for it was chosen as a meet shelter for the grave of Deborah, Rebekalı's nurse (verse 8 th); the particular tree being afterwards distinguished by a set name, "Allon-bachuth," or, the Oak of Weeping. ${ }^{3}$

' 1 It should be borne in mind that the Oak of the Holy Seriptures is not identical with the British Oak, but is a tree nearly resembling the Evergreen Oak (Quercus Ilex). Celsius and other writers after him are of opinion that the tree alluded to is the Terebinth, or Turpentine-tree. It is difficult, however, for the reader of the English version of the Bible to connect the name with any other notion than that of a tree agreeing closely in eharacter with the Oak of his own country. Whatever may be the botanical difference between the two, it is still "the Oak" of Palestine as much as Quercus Robur is "the Oak" of Britain.

. 2 Mamre is remarkable in Sacred History for Abraham's entertaining there three angels under an Oak, which Oak also became very famous in after ages; insomuch that superstitious worship was performed there. This the great Constantine, esteemed the first Christian emperor of Rome, put a stop to by a letter written to Eusebius, bishop of Cæsarea, in Palestine, for that purpose.Heming's Scripture Geography.

3 The difficulty of identifying the plants mentioned in the sacred volume appears to be increased in the present instance by the similarity of the names elah and allon. In Genesis xxxv. both words oceur, and are rendered in our version "the Oak." In Isaiah vi. 13, they occur in juxtaposition : in this passage Coverdale translates elah "the Terebinth," allon "the Oak," the Authorized Version giving elah "the Teil-tree;" allon "the Oak." Canon Rogers is of opinion that allon should always be thus rendered. 
It is here worthy of notice that in Genesis xii. 6 , the passage, which is in our version rendered "The plain of Moreh," is in the Septuagint rendered "The high Oak." 1 It is not, therefore, improbable that this Oak, or grove of Oaks, was first consecrated to God by the priestly worship of Abraham, and retained its sacred character until.at least the time of Abimelech. ${ }^{2}$ It must not be objected that the period is too long (nearly six hundred years) to assign as the duration of one tree; for, as we shall see hereafter, there is evidence of Oak-trees actually existing which have obtained nearly double that age.

In European countries the Oak was an important tree at a very early age, being valued for its fruit. In Asia the estimation in which it was held appears to have had some other origin, for, although we read in the Sacred Volume of "dates, almonds," \&c. being used as articles of food, no such mention is made of acorns; nor is it probable that they were ever eaten by men in a country naturally affording fruits so much more palatable. But in Greece and Italy, before agrioulture was invented or introduced, acorns held an important place among the more savoury viands of the inhabitants. The traditions of the poets tell us that strawberries, blackberries, cornels and acorns were the homely fare of the first inhabitants of these countries; of which, acorns must have been the most valuable, for being of a less perishable nature than the rest, they would bear being stored away for winter use. For this reason, perhaps, it was that the Greeks believed that of all the trees with which they were acquainted the Oak was the first created. We need not, then, wonder that, holding this belief in its antiquity and extreme usefulness, they regarded it with veneration, and, in their ignorance of Divine Revelation, entertained the, to us, extravagant notion that the Deity chose it as a medium for making known His will to man. At the same time it is much to be wondered at that the Israelites, who had not

1 T $\eta \nu \nu \rho \hat{\nu} \nu \tau \eta \dot{\nu} \nu \dot{\psi} \psi \eta \lambda \hat{\eta} \nu$.

8 Judges ix. 6, marginal reading. B 2 
the excuse of ignorance, should have fallen into nearly the same fatal error, and that, too, with respect to the very same tree. The Oak grove at Dodona in Epirus was long resorted to by the inhabitants of the whole of Greece when they wished to inquire the will of their imaginary god, Jupiter; and we have seen that the Israelites resorted to the Oak-woods of Palestine with a similar object.

Baal, the false god of the Canaanites, is considered by learned men to be identical with the Roman Saturn, the Celtic Yiaoul, and the British Yule, whose festival was kept at the time when we celebrate Christmas. Bv one of these nations this name was worshipped as significant

- of the god of fire; by another it was identified with the sun; by a third venerated under the form of an Oak. Its priests, who were called "Druids," professed to maintain perpetual fire, and once every year all the fires belonging to the people were extinguished, and relighted from the sacred fire of the Druids. This was the origin of the Yule-log, with which, even so lately as the commencement of the present century, the Christmas fire in some parts of the country was always kindled, and is even now in Devonshire and Yorkshire; a fresh log being thrown on and lighted, but taken off before it was consumed, and reserved to kindle the Christmas fire of the following year. The Yule-log was generally of Oak, though sometimes of $\mathrm{Ash}$; and as the ancient Britons believed that it was essential for their hearth-fires to be renewed every year from the sacred fire of the Druids, so their descendants thought that some misfortune would befal them if any accident happened to the Yule-log. The worship of the Druids was generally performed under an Oak; and a heap of stones was erected, on which the sacred fire was kindled, which was called a "cairn," as Professor Burnet says, from kern, an acorn. ${ }^{1}$

1 This etymology, however, is doubtful, and must be received with caution. Cairn usually signifies "a rock;" the Hebrew keren has the same meaning. 
The Mistletoe was held in great reverence, and as it was not commonly found on the Oak, solemn ceremonies attended the search for it. When all was prepared (the Mistletoe having been, no doubt, previously found by some of the assistants), the Druids went forth, clad in white robes, to search for the sacred plant ; and when it was discovered, one of the Druids ascended the tree and gathered it with great ceremony, separating it from the Oak with a golden knife. The Mistletoe was always cut at a particular age of the moon, at the beginning of the year, and it was only sought for when the Druids pretended to have had visions directing them to seek it. When a great length of time elapsed without this happening, or if the Mistletoe chanced to fall to the ground, it was considered as an omen that some great misfortune would befal the nation.

The well-known chorus of "Hey derry down," according to Professor Burnet, was a druidic chant, signifying literally, "In a circle the Oak move around." Criminals were tried under an Oak-tree, the judges being seated under the tree, and the culprit placed within a circle made by the chief Druid's wand. The Saxons also held their national meetings under an Oak; and the celebrated conference between the Saxons and the Britons, after the invasion of the former, was held under the oaks of Dartmoor. The wood of the Oak was appropriated to the most memorable uses. King Arthur's round table was made of it, as was the cradle of Edward II. at Caernarvon Castle, where he was born ; this sacred wood being chosen in the hope of conciliating the feelings of the Welsh, who still retained the prejudices of their ancestors, the ancient Britons. It was considered unlucky to cut down any celebrated tree; and Evelyn gravely relates a story of two men, who cut down the Vicar's Oak, in Surrey; one losing his eye, and the other breaking his leg, soon after.

The Oaks of Dartmoor, in Devonshire, have now nearly disappeared. In one spot only is there any vestige of what was once, perhaps, a favourite gathering- 
place of the Druids. This spot, called Wistman's Wood, is situated on Dartmoor, about a mile above Two-Bridges, on the left bank of the river. Imagine a mountain-stream ereeping slowly among blocks of moss-stained granite; on either side extends a piece of flat boggy ground to an inconsiderable distance; and at the extremity of these the hills rise to the height of two or three hundred feet, capped here and there in the distance with tors, or rugged summits of granite. The hill-side is confusedly heaped with blecks of the same stone, and it is in the interstices between these that the trees composing Wistman's Wood have chosen to fix their habitations-a colony of patriarchs in a wilderness. The wood itself forms a ragged and interrupted belt, of about half a mile in length, including some straggling trees, separated at long intervals. The best way of approaching it is from above, for by so doing one may without difficulty obtain a pretty good view of the whole at once, and plunge in among the trees at pleasure. The trees are all Oaks, from ten to fourteen feet high, gnarled, knotted, and twisted even beyond the usual characteristic of that tree. The trunks vary from two to five feet in circumference One which was measured consisted of three trunks, branched just above the base, each bole being about three feet in eircumference. But by far the strangest peculiarity is, that all the branches, with the exception (and this not always) of the extreme spires, are matted with deep beds of moss, principally Anòmodon curtipéndulum, in fine fructification. Some idea of the denseness of this extraordinary integument may be formed from the fact that the moss is, in most eases, from ten to twelve inches in thickness, when the diameter of the branch does not exceed an inch and a half. It seems very probable that the superincumbent weight may operate in producing the depressed character of growth : certain it is, that a single Holly-tree near the centre of the wood, which is free from parasites, has attained the height of twenty feet, and towers above his pigmy companions, like some tall pine in 
a wood of ordinary growth. When first we saw this tree, indeed, having nothing to compare it with of definite size and shape but the surrounding Oaks, we fancied that it was a Fir tree, and the Oaks borrowed from it, by com. parison, a dignity not their own. On a rough guess, there are from 300 to 500 veteran trees in the wood, and, as we were glad to find, a great number of saplings.

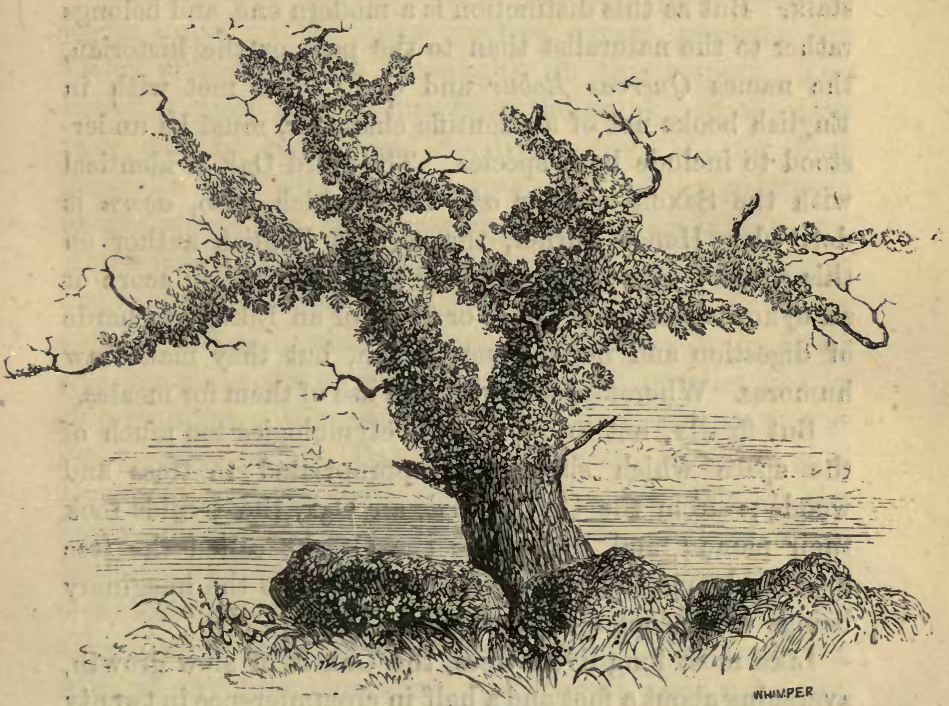

OAK IN WISTMAN'S WOOD.

Two species of Oak are indigenous to Britain, and they have been named by Botanists Quercus Robur, and Quercus sessiliflora. The name Quercus is derived from the Celtic "quer," beautiful, and cuez, a tree. Robur, according to some, is derived from the Latin robur, strength: but we may, with greater propriety, trace it to the Celtic rove, another name for the Oak, whence the Latins obtained their name for the tree, and subsequently adopted the same 
word to express the abstract idea of strength. ${ }^{1}$ The name Quercus Robur, therefore, rendered into English, means, "the tree of beauty and strength." Quercus sessiliflora is distinguished from the first species by having its fruit almost sessile, or sitting in groups on the leafy twig, without the intervention of any proper stalk; whilst Quercus Robur, or Quercus pedunculata, as it is sometimes called, bears its fruit two or three together on a long peduncle, or fruitstalk. But as this distinction is a modern one, and belongs rather to the naturalist than to the poet or the historian, the names Quercus Robur and Oak, when met with in English books not of a scientific character, must be understood to include both species. The word Oak is identical with the Saxon aack or ak; from which, also, acorn is derived. Hence Turner, the earliest English author on this subject, says: "Oke, whose fruite we call an acorn or an eykorn (that is, $y^{\bullet}$ corne or fruite of an Eike), are harde of digestion and norishe very much, but they make raw humores. Wherefore we forbid the use of them for meates."

But finally, not to expend on etymologies too much of the space which should be appropriated to trees and woods;-from the Celtic derw, an Oak, the Druids took their name; and hence also the Greeks called the tree drys, and gave the appellation of Dryads to the imaginary beings who peopled their woods.

Like most long-lived trees, the Oak is of slow growth, averaging about a foot and a half in circumference in twenty years, and increasing about one inch in a year for the rext century of its existence; after which its rate of growth diminishes. The extreme slowness of this increase may be better estimated by contrasting it with that of the Larch, which is very rapid in its formation of timber. An Oak at Wimbush, in Essex, in thirteen years had increased four inches and a half in circumference; and in the same time a Larch had increased thirty-three inches, or nearly eight times as much. The Oak does not usually

1 In the North of Italy, the Oak is still called Rovore 
attain any great height, being more remarkable for the thickness of its bole, and its widely-spread head. Exceptions, however, are not wanting. In the Duke of Portland's park, at Welbeck, there stood, in 1790, an Oak, called "The Duke's walking-stick," which was a hundred and eleven feet high, the trunk rising to the height of seventy feet before it formed a head. Others nearly . equalling this have been noticed.

A remarkable characteristic of the Oak is the stoutness of its limbs. "We know no tree, except, perhaps, the Cedar of Lebanon, so remarkable in this respect: The limbs of most trees spring from the trunk; in the Oalk they may be rather said to divide from it; for they generally carry with them a great share of the substance of the stem: you often scarcely know which is stem and which is branch; and towards the top, the stem is entirely lost in the branches. This gives peculiar propriety to the epithet 'fortes,' in characterising the branches of the Oak; and hence its sinewy elbows are of such peculiar use in ship-building. Whoever, therefore, does not mark the fortes ramos of the Oak, might as well, in painting. a Hercules, omit his muscles. But I speak only of the hardy veterans of the forest. In the effeminate nurslings of the grove we have not this appearance. There the tree is all stem drawn up into height. When we characterise a tree, we consider it in its natural state, insulated, and without any lateral pressure. In a forest, trees naturally grow in that manner; the seniors depress all the juniors that attempt to rise near them ; but in a planted grove all grow up together, and none can exert any power over another.

"The next characteristic of the Oak is the twisting of its branches. Examine the Ash, the Elm, the Beech, or almost any other tree, and you may observe in what direct and straight lines the branches in each shoot from the stem; whereas the limbs of an Oak are continually twisting here and there in various contortions, and, like the course of a river, sport and play in every possible 
direction, sometimes in long reaches, and sometimes in shorter elbows."

"Another peculiarity of the Oak is its expansive spread. This, indeed, is a just characteristic of the Oak ; for its boughs, however twisted, continually take a horizontal direction, and overshadow a large space of ground. Indeed, where it is fond of its situation, and has room to spread, it extends itself beyond any other tree, and, like a monarch, takes possesion of the soil. The last characteristic of the Oak is its longevity, which extends beyond that of any other tree; perhaps the Yew may be an exception. I mention the circumstance of its longevity, as it is that which renders it so singularly picturesque. It is through age that the Oak acquires its greatest beauty, which often continues increasing even into decay, if any proportion exist between the stem and the branches. When the branches rot away, and the forlorn trunk is left alone, the tree is in its decrepitude in the last stage of life, and all beauty is gone."

The diameter of the trunk of the Oak, where it first leaves the ground, is generally much greater than it is a few feet higher. To this circumstance, and to the fact that its roots are not nearly so liable to rot in the ground as those of other trees, it may be attributed that it is very rarely blown up by the roots. The eminent engineer, Mr. Smeaton, is stated to have taken his idea of the form of the Eddystone Lighthouse from observing the proportions of an Oak trunk. Britton, in his "Beauties of Devon," thus writes: "The object from which Mr. Smeaton conceived his idea of rebuilding the Eddystone Lighthouse was the waist or bole of a large spreading Oak, which, though subject to a very great impulse from the agitation of violent winds, resists them all, partly from its elasticity, and partly from its natural strength. Considering the particular figure of the tree, as connected with its roots, which lie hid below ground, Mr. Smeaton observed that it rose from its surface with a large swelling base, which 
at the height of its own diameter is generally reduced by an elegant curve, concave to the eye, to a diameter less by at least one-third, and sometimes to half its original base. From thence its sides, tapering more gradually, assume a perpendicular direction, and for some height form a cylinder. After that a greater circumference becomes necessary for the insertion and establishment of the principal boughs, which produce a swelling of its diameter. Hence may be deduced an idea of what the proper shape of a column of the greatest stability ought to be to resist the action of external violence, when the quantity of matter is given whereof it is to be composed. Upon this model, therefore, on the 25th of August, 1759, Mr. Smeaton completed his lighthouse, being the third structure of the kind which had been raised on the dangerous rock from which it derives its name." How wisely he acted in choosing Nature for his instructress may be inferred from the fact that it has now stood upwards of a hundred years, without requiring any essential repairs.

The trunk of the Oak, thus perfectly adapted as it is by its form to resist the most violent action of the wind, derives additional strength from the slow rate of growth of its timber. A very small quantity of woody fibre is deposited every year, but it is proportionately dense and solid, and the concentric annual layers are very firmly united. Hence it is admirably prepared to withstand lateral violence, as well as to support its enormous superincumbent weight of branches; while its tap-root, descending perpendicularly to a great depth, and its tortuous underground arms proceeding horizontally at a greater depth beneath the surface than those of most other trees, are equally efficacious in resisting any upheaving force to which its spreading and abundant foliage might otherwise render it peculiarly liable.

Were it not for this wonderfully massive structure of the main trunk, the Oak would be unable to bear up the ponderous weight of its enormous limbs, which, each a 
mighty tree in itself, would rend in pieces any less substantial support. For it must have been remarked by every one who has looked thoughtfully on a full-grown Oak, that the trunk does not divide into several smaller ones, all approaching to a perpendicular direction; but that its unwieldy arms quit the bole almost horizontally, so that the centre of gravity of each lies a long way without the base of the tree, and is therefore constantly exerting its utmost power to tear itself away from the central column. This tendency to preserve a horizontal direction is most conspicuous in a full-grown tree, owing to the greater size of the object. But the peculiarity has not escaped the curious eye of the artist, even in the smallest twigs. "In the spray of trees," Gilpin remarks, "Nature seems to observe one simple principle; which is, that the mode of growth in the spray corresponds exactly with that of the larger branches, of which, indeed, the spray is the origin. Thus the Oak divides his boughs from the stem more horizontally than most other deciduous trees; the spray makes exactly, in miniature, the same appearance, it breaks out in right-angles, or in angles that are nearly so, forming its shoots commonly in short lines, the second year's shoots usually taking some direction contrary to that of the first. Thus the rudiments are laid of that abrupt mode of ramification for which the Oak is so remarkable. When two shoots spring from the same knot, they are commonly of unequal length; and one with large strides generally takes the lead. Very often, also, three shoots, and sometimes four, spring from the same knot. Hence the spray of this tree becomes thick, close, and interwoven; so that at a little distance it has a full, rich appearance, and more of the picturesque roughness than we observe in the spray of any other tree. The spray of the Oak generally springs from the upper, or the lateral parts of the bough; and it is this which gives its branches that horizontal appearance which they generally assume." 
This characteristic, which renders the Oak so great a favourite with the painter, makes it no less serviceable to the shipbuilder, who selects the crooked limbs, and applies them, under the designation of knee-timber, to the purpose of supporting the decks of ships. Trees which grow at a considerable distance from each other are the most productive of this kind of timber; for, thus situated, the branches have ample room to follow the direction of the straggling roots, to which they naturally incline. In some parts of France, it is said, young trees are forced to assume this curved mode of growth by the suspension of weights to their heads; and in this country also, experiments have been tried in order to produce similar results; but in most cases with very doubtful success. This custom was known to Virgil :

"Continuo in sylvis magnâ vi flexa domatur In burim, et curvi formam accipit ulmus aratri."

Georg. I.

The foliage of the Oak is as characteristic as any other feature of the tree, whether we regard the sinuated form of each individual leaf, or the aggregate tufts. The principal difference between the leaves of Quercus pedunculata (or Quercus Robur) and Quercus sessiliflora is, that in the former they have scarcely any stems, whereas the leaves of the latter are decidedly stalked, and the lobes on each side are more nearly opposite. Both species burst their leaf and flower-buds about the same time, in April or May-Quercus sessiliflora being, however, generally somewhat later. At this time their pale-green tint, delicately shaded with crimson, seems scarcely to accord with the bulky and more robust character of the rest of the tree; but, as the season advances, they assume a full, florid green, which they retain till very late in the year. At the approach of winter they put on a rich russet-brown or red hue, and light up many a landscape, which without them would be cold and cheerless. Young trees do not 
cast their leaves, even when every semblance of life has departed from them, but retain them, probably as a protection for the embryo buds of the succeeding year, which are formed many months before they begin to expand.

The Oak is remarkable for sending out young shoots of spring foliage (called Lammas shoots) late in the season, when its proper leaves are fully matured; and this is more particularly the case when the latter have been injured. On the 2nd of August, 1844, the exposed Oaks at Penrose in Cornwall suffered severely from a violent storm from the west. In the course of a few hours all the leaves which had been unprotected from its influence shrivelled up (without, however, acquiring the true autumnal tint) and died. But not long after, a second spring, as it were, set in, and the trees were partially restored to their former flourishing condition. White, noticing a similar occurrence, says: "When Oaks are quite stripped of their leaves by chaffers, they are clothed again, soon after midsummer, with a beautiful foliage; but Beeches, Horsechestnuts, and Maples, once defaced by those insects, never recover their beauty again for the whole season."

In many of the rural districts oak-leaves and oak-apples (to be mentioned hereafter) are worn by boys on the 29 th of May, the anniversary of the Restoration of Charles II., who is said to have concealed himself in an Oak-tree from the Parliamentary soldiers.

I must not omit to mention here that the Romans were accustomed to bestow a wreath composed of oak-leaves, called a civic crown, on any one who saved the life of a citizen; which was considered the highest service that could be rendered to the State.

"And oaken wreath his hardy temples bore, Mark of a citizen preserved he wore."

Rowe's Lucan.

Here, too, I may mention the absurd belief, once popularly prevalent, that the Barnacle-goose owed its origin to 
this tree. The word barnacle is said to be derived from bairn, a child, and acle, the aac, or oak. The quaint old botanist, Gerard, tells the story so faithfully, that I cannot do better than transcribe his own words: "There are found in the North of Scotland, and Islands adjacent, called Orchades, certain trees whereon do grow certain shells tending to russet, wherein are contained little living creatures; which shells, in time of maturitie, do open, and out of them do grow those little living things, which, falling into the water, do become fowles, which we call barnakles; in the North of England, brent-geese; and in Lancashire, tree-geese; but the other that do fall upon the land perish, and come to nothing. Thus much from the writings of others, and also from the mouths of people of those parts, which may very well accord with truth." This he gives from the report of others ; now for what is proved by the evidence of his owu senses: "There is a small island in Lancashire, called the Pile of Toulders, wherein are found the broken pieces of old and bruised ships, some whereof have been cast there by shipwracke; and also the trunks and bodies, with the branches, of old and rotten trees, cast up there likewise, whereon is found a certain spawn, or froth, that in time breaketh into certain shells, in shape like those of the muskle, but sharper pointed, and of a whitish colour, wherein is contained a thing in form like a lace of silke, finely woven as it were together, of a whitish colour, one end whereof is fastened unto the inside of the shell, even as the fish of oisters and inuskles; the other end is made fast unto the belly of a rude mass, or lumpe, which in time cometh to the shape and form of a bird. When it is perfectly formed the shell gapeth open, and the first thing that appeareth is the foresaid lace, or string; next come the legs of the bird hanging out; and as it groweth greater, it openeth the shell by degrees, till at length it is all come forth, and hangeth only by the bill; in short space after it cometh to full maturitie, and falleth into the sea, where 
it gathereth feathers, and groweth to a fowl bigger than a mallard, and lesser than a goose, having black legs, bill, or beake, and feathers black and white, spotted in such a manner as our magpie ; called in some places a pie-annet; which the people of Lancashire call by no other name than a tree-goose; which place aforesaid, and the parts adjoining, do much abound therewith that one of the best is bought for three-halfpence. For the truth hereof, if any doubt, let them repair to me, and I shall satisfy them by the testimonie of good witnesses." 1

This strange fable took its rise from a certain shell-fish being frequently found attached to pieces of wood which had long lain in salt-water. This shell-fish, now called Lepas anatifera, is provided with a long leathery tube, by which it attaches itself to the bottom of vessels, and to other timber ; it is also furnished near the other extremity with a number of curved, feathery fibres, which, when expanded, bear some resemblance to the tail of a bird. ${ }^{2}$ From this fancied similarity, and the coincidence that the shell-fish was found in abundance in places which the Barnacle-goose frequented, probably to make them its food, the fable originated - a fertile imagination making up for the barrenness of the facts. Before the Reformation, Dr. Walsh tells us, the fishy origin of the bird was so firmly believed, that the question was warmly and learnedly disputed whether it might not be eaten in Lent.

The story may have gained a more ready credence from

Herbal, p. 1391.

2 "It is hardly worth while to mention the clayks, a sort of geese, which are believed by some, with great admiration, to grow upon trees on this coast, and in other places; and, when they are ripe, to fall down into the sea, because neither their nests nor eggs can anywhere be found. But they who saw the ship in which Sir Francis Drake sailed round the world, when it was laid up in the River Thames, could testify that little birds bred in the old rotten keels of ships, since a great number of such, without life and feathers, stuck close to the outside of the keel of that ship. Yet I should think that the generation of these birds was not from the logs of wood, but from the sea, termed by the poets 'the parent of all things." "-Camden's Britannia. 
the fact that the Oak is more prolific in animal life, supplying more insects with food, than any other tree.

- According to Mr. Stephens, an excellent authority, nearly half of the British insects which feed on vegetables, either exclusively or partially inhabit the Oak. If to this number we add the insects which live on the above, it will be found that the total of insects which, during some period of their existence, derive their support either from the tree itself, or from their fellow-colonists in it, will amount to scarcely less than two thousand.

To insects must be referred, also, the various species of gall-flies, whose instinct teaches them to originate a local disease in some parts of the Oak, ${ }^{1}$ and thus to provide their offspring with food and a dwelling-house. A history of the Oak would be imperfect without a full notice of the curious productions known by the name of Galls; and as the subject is an interesting one, I do not scruple to dwell upon it, although, strictly speaking, it belongs as much to Entomology as to Botany.

A small fly alights on a twig, or leaf, or bud, of an Oak, and with an excessively acute instrument, with which it is provided by Nature for this express purpose, punctures the vegetable fibre, and deposits an egg, or perhaps two or more eggs, so minute as to be almost invisible to the human eye. Why from the puncture of one kind of fly a large irregular excrescence should be produced; why from that of another a smooth spherical gall, or a scaly bud, or a flat circular scale, is all a mystery-a mystery so deep that no plausible explanation of it has ever been attempted. To say that an alteration takes place in the character of the juices; that a disease is produced which arrests them, and causes them to arrange themselves in a certain set form-this is not to account for the phenomenon: it is merely an unsatisfactory statement of the result, the real

${ }^{1}$ In some parts of the New Forest, the Oaks afford a resting-place to countless white Admirals, of which it is not difficult to capture from twelve to twenty in a single sunny morning. 
difficulty being left untouched. You must, therefore, be content to read the description of the different kinds of galls which have been observed, and test its accuracy, when you can, by comparing it with the natural objects themselves.

In the first place, it appears that the different kinds of insects select different parts of the tree in which to deposit their eggs, and that the character of the galls produced equally varies. The largest species is generally called the Oak-apple, and grows on the extremity of a twig. It is of a soft spongy substance, and an irregular shape, shaded with brown and pink on the outside; and it is divided on the inside into a number of cells, each of which contains either a small grub, a pupa, or a perfect fly, according to the season. It not unfrequently happens that one of the ichneumon-flies lays an egg in the body of the original inhabitant of one of these cells. From this egg proceeds a small worm, which lives on the substance of its predecessor, inhabits his house, and, when grown to a perfect insect, escapes, and takes flight in search of a similar abode for its own progeny. What faculty, or sense, or instinct can this little animal possess, which directs it to a solid vegetable substance, in the centre of which is stored up proper nourishment for its young? What geometrical skill enables it to discover in what part of the mass its prey lies buried? By the aid of what calculating power does it contrive to pierce the body of the included grub only so deep as to deposit its egg in a place of security, without wounding any vital part? The most remarkable kind of Oak-gall, next to that described, is produced by another insect of the same genus (Cynips). This fly deposits its eggs in the stalk of the stamen-bearing flowers, which is long and drooping. The excrescence which follows resembles a currant in size, shape, and even in mode of growth, it often happening that several are placed at short distances from each other on the same thread-like stem. There is a remarkable fact connected with this species of gall. Those flowers of the Oak which bear 
stamens only are destined to wither and fall off as soon as they have shed their pollen, being no longer of any use.

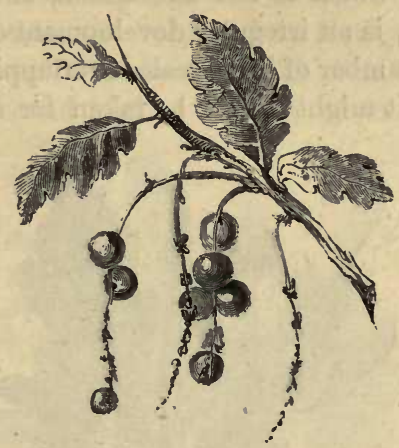

FLOWER-GALLS.

Those stalks, however, to which galls are attached, remain firmly united with the tree, and grow vigorously as long as the grubs contained in them continue to feed.

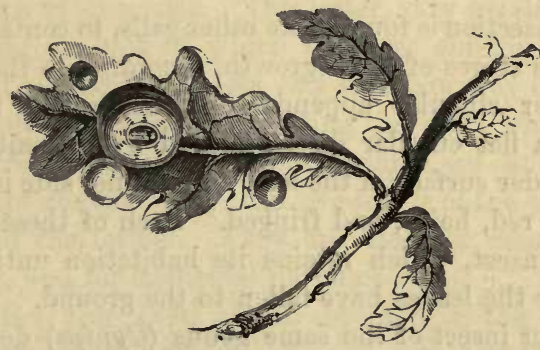

LEAF-GALLS.

Another gall, resembling the last in form (being spherical), is found attached to the leaves of the Oak. These vary very much in size, some being as large as a marble; and each contains a single insect, which, when it arrives at its perfect state, eats its way out through a great portion of the solid substance of the gall. 
The habitation of all the parasitic insects hitherto mentioned is formed out of the pulpy substance of the tree: one, however, which is not uncommon, and is called the Artichoke-gall, is an irregular development of the bud, and consists of a number of leafy scales overlapping each other. At first sight it might almost be taken for a young cone;

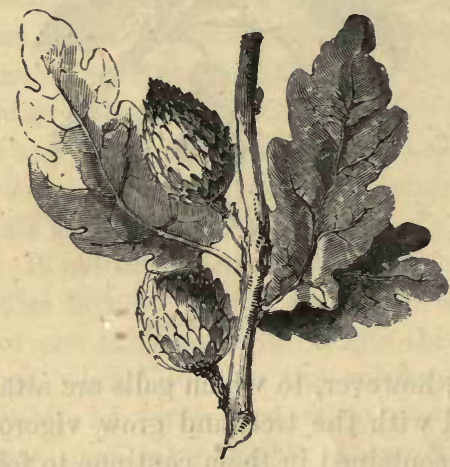

ARTICHOKE-GALLS.

but on dissection is found, like other galls, to contain insects in various stages of their growth, according to the season.

Another singular appendage of the leaf is the Oakspangle, a flat circular disc, attached by its central point to the under surface of the leaf. The inner side is smooth; the outer red, hairy, and fringed. Each of these contains a single insect, which retains its habitation until March, long after the leaves have fallen to the ground.

Another insect of the same genus (Cynips) deposits its eggs at the base of the trunk, immediately above the root. In the early spring of the year, 1845, I detected two galls formed by this species in Merthen Wood, Cornwall. The larger was about as big as a walnut, and produced in April sixty small flies, much resembling winged ants. They were not very active during their early existence, and possessed the remarkable instinct, common to many other insects, of counterfeiting death when touched. 
The galls of commerce, I may here remark, are similar in their nature to those already mentioned. They are produced by a dwarf species of Oak (Quercus infectoria), which rarely attains the height of six feet, growing in Asia Minor and Persia. The insect which occasions this gall is of a pale colour, and may be often found in the galls sold

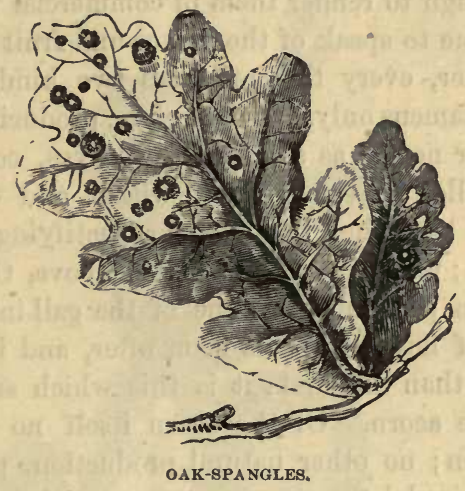

in the shops of druggists. The latter vary greatly in the qualities on account of which they are employed; those which still contain the insect, and are known by the name of black, blue, or green galls, being the best: while those from which the insect has escaped, which are called white galls, do not contain more than two-thirds of the astringent qualities of the former. They are used for making ink, for dyeing, and for medicinal purposes.

About the year 1840 a gall appeared in the southern and western counties which has since spread itself over the whole of England. This is not only more conspicuous than any other native kind, but threatens to produce seriously injurious effects. This species is spherical in shape, perfectly smooth, and about one inch in diameter. It is seen in the greatest abundance on the annual twigs of young trees, which sometimes have as many as a dozen or more in close proximity. These galls act injuriously, 
by diverting the sap of the tree from essential organs to their own use, and consequently check the healthy growth of the trees. Unlike the other galls-which, for the most part, disappear with the foliage-they are most conspicuous during the season when the trees are bare of leaves. They contain a considerable quantity of gallic acid, but scarcely enough to render them of commercial value. ${ }^{1}$

I now come to speak of the flower and fruit of the Oak. Of the former, every tree produces two kinds; the first containing stamens only, and, therefore, producing no fruit. These appear nearly as soon as the leaves, consisting of yellow tasselled threads, which wither and drop off as soon as they have shed the pollen or fructifying dust which they contain; unless, as I have stated above, they happen to have been perforated by one of the gall-insects. The other kind of flower appears soon after, and is even less conspicuous than the first; it is this which subsequently produces the acorn. Of the acorn itself no description need be given; no other natural production, perhaps, has served as a model for so many ornamental works of art; and this is to. be attributed not so much to the popularity of the Oak, as to the finished elegance of form of the fruit itself. 'Acorn-shaped' would, I should think, be a word as readily understood as 'round' or 'square.' Acorns and roses are in modern architecture what pomegranates and lilies were in Jewish. Different in proportions though it is in the various species of Oak, there is yet always similarity enough to reveal the genus of the tree which produced it. The ball may be almost buried in the cup, or may be disproportionately long; the latter may be almost smooth, or rugged, or even mossy; yet, were an acorn of any species to be placed before a person who had never seen any other

1 These being of a closer texture, and harder than any other Oak galls, are persistent. Coated with leaf gold, they produce a pleasing effect, when mixed with evergreens, for Christmas decorations ; and being, moreover, spherical, and for the most part nearly equal in size, they might, perhaps, be used as a beading for pieture frames. 
than that of the British Oak, he would immediately pronounce the tree from which it was gathered an Oak.

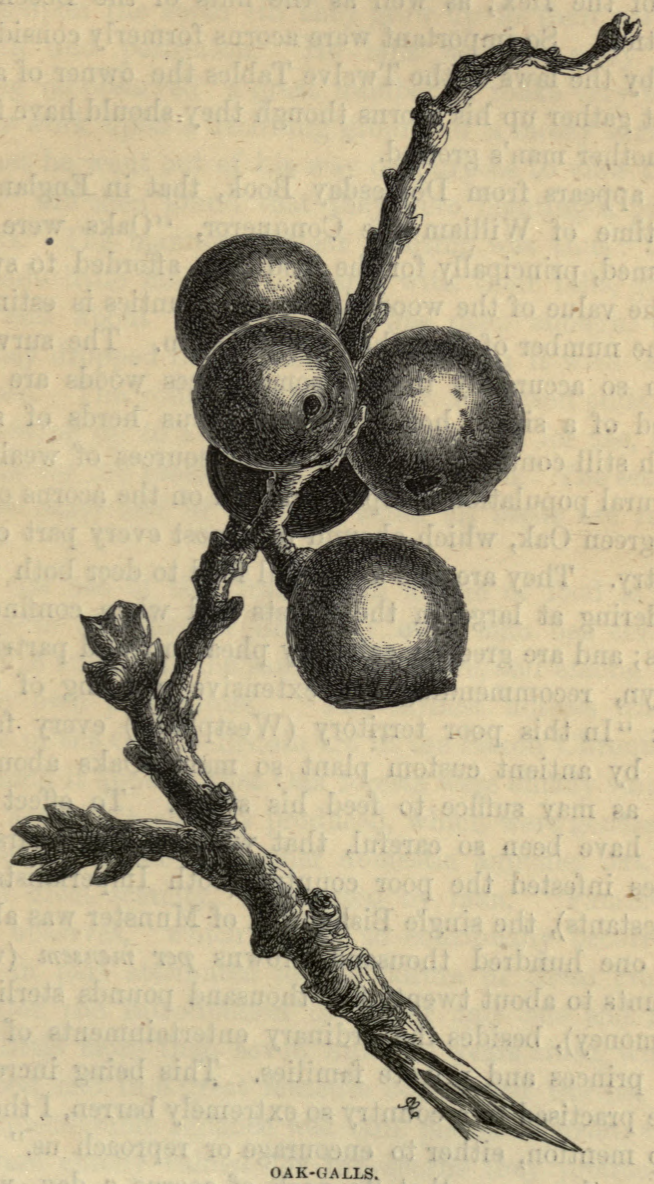

As an article of food, the acorn has been, and in many places still is, highly prized. In the time of Strabo, Rome was principally supplied with hogs which had been fattened 
on mast in the woods of Gaul. This mast is supposed to have included the acorns of the Common and Turkey Oaks, and of the Ilex; as well as the nuts of the Beech and Chestnut. So important were acorns formerly considered, that by the laws of the Twelve Tables the owner of a tree might gather up his acorns though they should have fallen on another man's ground.

It appears from Domesday Book, that in England, in the time of William the Conqueror, "Oaks were still esteemed, principally for the food they afforded to swine; for the value of the woods in several counties is estimated by the number of hogs they would fatten. The survey is taken so accurately that in some places woods are mentioned of a single hog. The numerous herds of swine which still continue one of the chief sources of wealth to the rural population of Spain, are fed on the acorns of the Evergreen Oak, which abound in almost every part of the country. They are also a grateful food to deer both when wandering at large in the forests and when confined in parks; and are greedily eaten by pheasants and partridges. Evelyn, recommending the extensive planting of Oaks, says: "In this poor territory (Westphalia) every farmer does by antient custom plant so many Oaks about his farm as may suffice to feed his swine. To effect this, they have been so careful, that when of late years, the armies infested the poor country (both Imperialists and Protestants), the single Bishoprick of Munster was able to pay one hundred thousand crowns per mensem (which amounts to about twenty-five thousand pounds sterling of our money), besides the ordinary entertainments of their own princes and private families. This being incredible to be practised in a country so extremely barren, I thought fit to mention, either to encourage or reproach us." The same author says, that "a peck of acorns a day, with a little bran, will make a hog, 'tis said, increase a pound weight per diem for two months together."

"The Rev. Mr. Robinson, in his 'Natural History of 
Westmoreland and Cumberland,' says, that 'birds are natural planters of all sorts of trees, disseminating the kernels upon the earth till they grow up to their natural strength and perfection. He tells us that early one morning he observed 'a great number of rooks very busy at their work upon a declining ground of a mossy surface, and that he went out of his way on purpose to view their labour. He then found that they were planting a grove of Oaks. The manner of their planting was thus: they first made little holes in the earth with their bills, going about and about till the hole was deep enough, and then they dropped in the acorn, and covered it with earth and moss. The young plantation,' Mr. Robinson adds, 'is now growing up to a thick grove of Oaks, fit for use, and of height for the rooks to build their nests in. The season was the latter end of autumn, when all seeds are fully ripe.'" 1

But the use of this fruit as an article of food is not confined to the inferior animals: even man has condescended to submit to the same humble fare, and among the rest our own progenitors. "The earliest notices which we have of the Oak in Britain are in the Saxon Chronicle, from which it appears that Oak forests were chiefly valued for the acorns which they produced, which were generally consumed by swine and other domestic animals, but, in years of great scarcity, were eaten by man. 'Famines,' Burnet observes, 'which of old so continually occurred, history in part attributes to the failure of these crops: Long after the introduction of wheat and oats and rye -nay, little more than seven hundred years since, when other food had in a great measure superseded the use of mast-considerable reliance was still placed thereon, and Oaks were chiefly valued for the acorns they produced. In the Saxon Chronicle, that year of terrible dearth and mortality, 1116, is described as 'a very heavy-timed,

1 Jesse's Gleanings in Natural History. 
vexatious, and destructive year,' and the failure of the mast in that season is particularly recorded: 'This year, also, was so deficient in mast, that there never was heard such in all this land, or in Wales.' " 1

The acorns of the Balonia Oak (Quercus AEgilops) are annually brought to England from the Levant and the Morea, and are in great demand for tanning, being said to contain more tannin in a given bulk of vegetable than any other substance. ${ }^{2}$ The cups of this acorn are much larger than those of our British species, and are covered externally with long reflexed scales.

I have not yet spoken of the application of the various parts of the Oak to the arts of civilized life, it having been my object to devote as much of my space as possible to the tree in its natural state. But inasmuch as a notice of any tree, and especially this King of Trees, would be of necessity considered imperfect without at least some few remarks on this head, I will proceed to give a brief history of the general uses to which the wood and other parts of the Oak may be applied.

The particular and most valued qualities of the Oak are hardness and toughness. Shakespeare uses two epithets to express these qualities, which are perhaps stronger than any we can find:

"Thou rather with thy sharp and sulph'rous bolt

Splitt'st the unwedgeable and gnarled Oak

Than the soft Myrtle."

"Many kinds of wood are harder, as Box and Ebony ; many kinds are tougher, as Yow and Ash; but it is supposed that no species of wood, at least no species of timber, is possessed of both these qualities together in so great a

1 The Greeks, in allusion to the use of acorns as food, called one species of Oak phagos or phegos, and the Latins ésculus, as much as to say, the tree of eating; like our word mast for acorns; whence masten, to feed or fatten, and masticate, to chew. From glans, 'the French derive their glaner, and we our glean, gleaner, for the collection of scattered corn. - Saturday Magazine.

2 The cups of this Oak, called "valonia," are now so extensively used, that oak-bark has materially deteriorated in value. 
degree as British Oak. Almost all arts and manufactures are indebted to it; but in ship-building and bearing burdens, its elasticity and strength are applied to most advantage. I mention these mechanical uses only because some of its chief beauties are connected with them. Thus, it is not the erect, stately tree that is always the most useful in ship-building, but more often the crooked one, forming short turns and elbows, which the shipwrights and carpenters commonly call knee-timber. This, too, is generally the most picturesque. Nor is it the straight, tall stem, whose fibres run in parallel lines, that is the most useful in bearing burdens; but that whose sinews are twisted, and spirally combined. This, too, is the most picturesque. Trees under these circumstances generally take the most pleasing forms." 1

The admirable qualities of Oak as a material for building, and other purposes, were known to our ancestors in ages long past, scarcely any other timber being found in any buildings of very high antiquity. "The doors of the inner chapels of Westminster Abbey are said to be coeval with the original building: if this be true, they must be more than twelve hundred years old. The shrine of Edward the Confessor, in the same abbey, is also of Oak, and must be nearly eight hundred years old. In the county-hall at Winchester is preserved Arthur's roundtable, so well known in stories of English chivalry. It bears the figure of that Prince, and the names of several of his knights. Henry VIII. is said to have taken great pleasure in showing this table to his illustrious visitor, Charles V., as the actual oaken table made and placed there by the renowned British Prince, Arthur, who lived in the early part of the sixth century; that is, about 1,300 years ago. Hence the poet Drayton sings :

"And so great Arthur's seat ould Winchester prefers, Whose ould round table yet she vaunteth to be hers."

${ }^{1}$ Gilpin's Forest Scenery. C 2 
It must have been cut from a tree of immense girth, as it measures eighteen feet in diameter. It has been perforated in many places by bullets, supposed to have been shot by Cromwell's soldiers.

In digging away the foundation of the old Savoy Palace in London, which was built six hundred and fifty years since, the whole of the piles, many of which were of Oak, were found in a state of perfect soundness, as also was the planking which covered the pile-heads. ${ }^{1}$ In clearing the channel at Brundusium, in Italy, "the workmen have drawn up many of the oak-piles that were driven in by Cæsar. They are small Oaks stripped of their bark, and still as fresh as if they had been cut only a month, though buried above eighteen centuries seven feet under the sand. These piles were driven in by Julius Cæsar to block up Pompey's fleet." 2

Speaking of the uses of the Oak generally, Loudon says, "The wood of the Oak is more durable, in every state in which it can be placed, than that of any other tree which abounds in large quantities in Europe. It is hard, tough, tolerably flexible, strong, without being too heavy, not easy to splinter, and not readily penetrated by water; and hence its value in ship-building. Some woods are harder, but they are more fragile; and others are more flexible, but do not possess so much hardness, toughness, and durability. Where the grain is twisted, no timber is so well adapted for posts, either in house-building or in setting up mills, engines, or large machines. No wood lasts longer where it is subject to be alternately wet and dry; and Oak piles have been known to endure many centuries. Shingles, poles, and laths last longer of this wood than of any other; and casks, and every other description of cooper's work, are most durable, and best adapted for containing wines, ales, and other liquors, when they are made of Oak. Oak timber is particularly esteemed for 
the spokes of wheels, for which the small and slow-growing Oak of mountainous districts is greatly preferred to the more rapid-growing and larger Oak of the valleys. Oaks of from fifteen to thirty years' growth make the most durable poles. The young tree, when from five to ten feet high, makes excellent hoops, which Evelyn says we ought to substitute for those of Hazel and Ash, as they are six times more durable: it also makes the very best walkingsticks, and very good handles to carters' whips. Of the roots, Evelyn says, were formerly made hafts to daggers, handles to knives, tobacco-boxes, mathematical instruments, tablets for artists to paint on instead of canvas, and elegant camleted joiner's work. Oak wood, every one knows, is preferred before all others for ship-building, in the temperate regions of both hemispheres. From its toughness, it does not splinter when it is struck by a cannon-ball, and the hole made by a ball is consequently easy to plug. Through out Europe, and more especially in Britain, Oak timber was used for every purpose, both of naval and civil architecture, till the wood of the Pine and Fir tribe came to be generally imported from the Baltic and North America, about the beginning of the last century. Since that period, the use of Oak timber has given way to that of Pine and Fir in house-building; but where not superseded by.iron, it maintains its superiority in the construction of ships, and various kinds of machines, and even in housebuilding where great durability is required. Oak wood is also still employed in joinery and cabinet-making.

Much difference of opinion exists as to which species of British Oak produces the best timber. Early writers on the subject claim the superiority for Quercus Robur, or the "old English Oak," as they call it, on the ground that it is of more rapid growth, has a cleaner stem and fewer knots, is more durable, and contains a larger proportion of heart-wood than the other species, Quercus sessiliflora, or Durmast Oak. More recent authors, however, maintain that the true "old English Oak" is Quercus sessiliflora, 
and account for the fact that it is now less common than the other on the supposition that our forefathers were well aware of the superiority of the former species, and applied it so extensively to all works requiring durability, that it has long become comparatively scarce. But a few years since, it was generally believed that the beautiful carved roof of Westminster Hall was constructed of Chestnut. Recent examination has, however, proved that it is composed entirely of Durmast Oak. This roof has stood for more than three hundred years. The foundation on which the stone piers of old London Bridge were laid consisted of huge piles of timber, which when taken up were found to be perfectly sound, though they must have been driven upwards of six hundred years. The wood employed is from trees of the same species. Most of the timber found in old buildings which was formerly believed to be Chestnut, is now known to be the wood of the Durmast Oak. In the year 1844 there was raised from the bottom of a lake at Davey Strand, between Dublin and Cavan, a huge canoe, which had been hollowed out of the trunk of a tree of the same kind. It measured no less than forty feet in length, the bottom being four feet three inches in diameter at one end, and about three feet at the other. On a fair computation, the circumference of this tree must have been at least twenty-one feet at the base, and fifteen feet at the height of forty feet from the ground. The antiquity of this relic is almost too great to be speculated on. Much of the wood-work in the old border fortresses of Wales, and the doors of pews in ancient churches, are made from the same tree. The principal difference apparent to the eye between the timber of the two species is, that Quercus Robur is plentifully furnished with medullary rays, called by carpenters "silver-grain," of which the other species is almost entirely destitute, resembling in this respect the Chestnut : from this similarity have probably sprung the numerous mistakes of the one wood for the other. On the whole it would seem that, whatever 
good quality is found in either of the species, the other possesses in somewhat greater or less degree, and there is little doubt that both will long continue to be applied indifferently to purposes where solidity, strength, and durability are required.

But the Oak begins to be valuable long before it has attained such a size as renders it fit for ship and housebuilding. "The ground Oak, while young, is used for poles, cudgels, and walking-staffs, much come into mode of late, but to the waste of many a hopeful plant which might have proved good timber; and I the rather declaim against the custom because I suspect they are such as are for the most part cut and stolen by idle persons, and brought up to London in great bundles, without the knowledge or leave of the owners, who would never have gleaned their copses for such trifling uses." 1

According to Loudon, the proper age at which Oak copse should be cut down varies from "fifteen to thirty years, the rule being that the principal stems of the plants, at one foot from the ground, should not be less than six inches in diameter. In favourable soils in the south and west of England this size will be obtained in from twelve to fifteen years; but in the colder climate and inferior soil of the Highlands of Scotland from twentyfive to thirty years are required. The cutting over of copse is performed at the same season as that in which full-grown trees are felled, when in both eases the bark is an object as well as the timber." The timber-merchant and the painter, if called to give an opinion on any particular Oak, would, in all probability, greatly differ. To the former, a clean, straight, and regular stem would suggest calculations as to the number of cubic feet of timber it would be found to contain when the axe, and square, and saw should have done their work. A well-grown tree, therefore, in the vigour of its age, will be to him the perfection 
of all trees. The painter will perhaps stop and admire the stately growth of the same tree; he will notice the symmetry of its form, and watch the brilliant lights playing about its thick foliage, but he will feel no desire to transfer it to his canvas. There must be no perpendicular or parallel lines about the object of his choice; no hemispherical evenly-shaped head; no arms of equal diameter springing from the main stem at the same angle, and extending to an equal distance all round. But show him a veteran patriarch, whose gnarled trunk is eaten out by the frost of centuries, whose knotted limbs are fringed with ferns, and mottled with innumerable mosses and lichens; even if but a scanty foliage clings to branches which have been shattered again and again by the tempest, or if, instead of a leafy summit, it rears aloft a fantastic assemblage of hoary, sapless antlers; - and you will hear him exclaim, "I go no farther to-day; this is the tree for a picture!" And move he will not, until with his pencil he has produced the same image which the poet has conjured up with his pen.

"A huge Oak, dry and dẹad,

Still clad with reliques of its glories old,

Lifting to Heaven its aged, hoary head;

Whose foot on earth hath got but feeble hold,

And, half-disbowelled, stands above the ground ;

With wreathed roots, and naked arms,

And trunk all rotten and unsound."-SPENSER.

About the end of April the season for barking commences, and to this process Oaks, both old and young, are equally subjected ; those of from twenty to thirty years' growth, however, being preferred. Oak bark is occasionally used in medicine, and is employed also as a dye, but is most valuable for the principle called tannin, which is indispensable in the manufacture of leather. Every part of the tree, indeed, abounds in astringent matter, and even the leaves and sawdust will tan leather, linen cloth, and 
netting or cordage which is to be much exposed to the weather.

There is a particular interest connected with trees of great antiquity which attaches itself to nothing else. A flourishing Oak in the vigour of its age, furnished with a well-proportioned, tapering trunk, and with symmetricallyarranged branches, and flinging its chequered shade far and near over the verdant sward, is a beautiful object, and irresistibly draws the attention to itself. But it does not carry the mind of the spectator back to past events, -it does not talk with us about bygone ages and scenes at which no man now living was present; and if we think of its future fate, there is so much of uncertainty about that, so much of doubt as to the length of time for which it is destined to retain its position, - whether it will be laid low by the tempest, or by the woodman's axe, and, if the latter, to what purposes it may be applied,- - that the mind can select nothing sufficiently definite to engage itself upon. The tan-yard, the saw-pit, and the baker's oven are decidedly not subjects to dwell upon; and these; in fact, are the only passages in its history which ean be predicted with certainty. But the case is very different with the uncouth monster on whom the destroyer has done all but his utmost. Though but a hollow shell, blasted above, and worm-eaten below, and indebted for its scanty verdure more to ferns and moss than to the feeble relics of life which yet remain in it, it is a monument of the past more eloquent than buildings the most time-hallowed; or, save one, than books of the most remote antiquity. It is now a living tree, and it was the same thirty generations back. Yes ! a thousand years ago it was a stately tree:-when the present dynasty commenced, it was older than the oldest men then alive, and it has lived through all the stirring events which have taken place from that time to this, connecting the names of Stephenson and Tennyson with those of Newton and Milton and Shakespeare, and these with Caxton and Chaucer; and having sprung from 
an acorn born by a tree which perhaps flourished when our Holy Religion was preached in Palestine by the Saviour, whose coming was to banish from the earth all those barbarous rites which were then being enacted beneath the shade of its branches.

Evelyn, who wrote his Sylva in the reign of Charles II., thus dedicated the fourth edition to that monarch :- "To you then, Royal Sir, does this Fourth Edition continue its humble addresses, since you are our Nemorensis Rex : as having once had your temple, and court too, under that sacred Oak which you consecrated with your presence, and we celebrate, with just acknowledgment to God, for your preservation."

The tree here alluded to, called the "Royal Oak," formerly stood at Bcscobel, in Shropshire, but was destroyed soon after it attained its notoriety by the ill-judged curiosity of the Royalists. For the same author, speaking of an Oak which put forth its buds about Christmas, says :"King James went to visit it, and caused benches to be placed about it; which, giving it reputation, the people never left hacking of the boughs and bark till they killed the tree, as I am told they have served that famous Oak near White-Lady's, which hid and protected our late Monarch from being discovered and taken by the rebel soldiers who were sent to find him, after his almost miraculous escape at the battle of Worcester." In the course of the spoliation, a huge bulk of timber, consisting of many loads, was carried away in handfuls. Several saplings were raised in different parts of the country from its acorns, one of which grew near St. James's Palace, where Marlborough House now stands, and there was another in the Botanic Garden, Chelsea. The former has been long since felled, and of the latter even the recollection seems now almost lost.

Through the kindness of the Rev. J. Dale, Curate of Donington, the parish in which the Boscobel Oak stands, I am enabled to lay before my readers a full and authentic 
account of a tree which, from its connexion with one of the most important events in English History, will always be remembered with interest.

On a single printed leaf which is pasted in at the end of one of the Parish Registers of Donington, is the following note, in the handwriting of the late Rector, Dr. Woodhouse:- "Extracts from the Philosophical Transactions, vol. 5, part 2 d, chap. 3, written by the Rev. George Plaxton, Rector of Donington and (Kinnardsey) from 1690 to 1703." Then follows the type. "The Royal Oak was a fair spreading tree; the boughs of it all lined and covered with ivy. Here, in the thick of these boughs, the King sat in the day-time, with Colonel Carlos, and in the night lodged in Boscobel House; so that they are strangely mistaken who judged it an old hollow Oak, whereas it was a gay and flourishing tree surrounded with a great many more, and, as I remember in Mr. Evelyn's History of Medals, you have one of King James I. or Charles I. where there is a fine spread Oak with this epigraph, 'Seris nepotibus umbra,' which I leave to your thoughts. ... The poor remains of the Royal Oak are now fenced in by a handsome brick wall, at the charge of Basil Fitzherbert, Esq., with this inscription over the gate, upon a blue stone in letters of gold :

Felicissimam arborem quam in asylum potentissimi regis Caroli Secundi Deus Opt. Max.

per quem reges regnant hic crescere

voluit tam in perpetuam rei tantæ memoriam quam in specimen firmæ in reges fidei muro cinctam posteris commendant Bazilius et Jana Fitzherbert. Quercus amica Jovi. ${ }^{1}$

1 I'ranslation.-This most highly-favoured tree, planted by the God through whom kings reign, to afford shelter to his Majesty King Charles the Second, was enclosed with a wall by Bazil and Jane Fitzherbert, as well to preserve to posterity a memorial of the auspicious event as to be a token of their own stedfast loyalty. 
"'Twas put up about twenty or thirty years ago; but the place deserved a better memorial. I have writ it in such lines as they have cut it, and as the letters now stand; a few years will ruine both the wall and the inscription.

"The emblematical medal my good friend alludes to is the xuvIr. in Mr. Evelyn's Numismata, which King Charles caused to be stamped in honour of the installation of his son ; whereupon is the Royal Oak under a prince's coronet, over-spreading subnascent trees and young suckers."

In the year 1812 , or thereabouts, and before he was aware of Mr. Plaxton's notice, Mr. Dale discovered portions of the above inscription " on a blue stone, in letters of gold," among the long and neglected grass on the Mount in Boscobel Garden. After spending some time in arranging the fragments, he communicated the discovery to the occupants of the house, who appear to have taken little interest in the relic. The house and grounds have passed into other hands, and the fragments of the stone in all probability lie buried beneath the present garden walks, which were laid out by the present proprietor after the pattern of those which existed in the time of Charles II. Of the tree itself very few, and these imperfect, records remain. Old Plaxton speaks of it as "a fair spreading tree, the boughs of it all lined and covered with ivy," and that in the thick of it the King and Carlos sat. This agrees well with the description of it which the King himself gives in his narrative, "A great Oak that had been lopped some three or four years before, and, being grown out again very bushy and thick, could not be seen through; and here we staid all the day." This would be an excellent hiding-place; for, says Mr. Dale, "I have frequently observed that an old Pollard Oak, standing on a bank and orerhanging the road between the churches of Albrighton and Donington, about one hundred yards from each, would afford a secure retreat for two or three persons from the observation of all passers-by." 
It will be seen by the extract from Evelyn's Sylva, that in 1662 it had ceased to be a living monument of the event to which it owes its celebrity. Not many years after, its poor remains were fenced in by a "handsome brick wall;" but all in vain. Every vestige of the original tree has disappeared from the spot for more than a century, Mr. Dale thinks, from inquiries made in the vicinity from persons whose age, if they were now alive, would exceed a hundred, that the last remnants were taken away about the year 1734 .

The handsome brick wall above alluded to stood until 1817, having been repaired in 1787 by Basil and Eliza Fitzherbert, who also attached a new inscription. Mr. Dale has been unable to discover any written account of the second tree thus inclosed. By general tradition, however, it sprung from an acorn of the Royal Oak, and this is credible enough ; for whoever took the pains to rear young trees for St. James's Park and the Chelsea Gardens, doubtiess did all in his power to perpetuate the race on the spot where the event took place. From the inscription of 1787, it would seem that Basil and Eliza Fitzherbert believed the tree then standing to have been the identical one in which the Sovereign took shelter. But although they were mistaken in this respect, it must have attained a considerable size, or they could not have fallen into such an error. From this and other circumstances it appears tolerably certain that the tree now standing is the immediate descendant of the Royal Oak, and that it was planted about the time of the Restoration in 1660, as nearly in the same site as the remains of the old tree would allow, some of the old people alluded to above recollecting that it did not stand in the centre of the old inclosure.

Some notion of the value of a well-grown Oak in its prime may be formed from the following account of the felling, in the year 1758, of a tree in Langley Wood, on the borders of the New. Forest, and of another in Monmouthshire. The former of these, Mr. South tells us, 
"stood singly in the Wood, and extended its massive branches near forty feet each way. Its head was all knees and crooks, aptly suited to naval purposes; its bole or shaft was short, not exceeding twenty feet in length; but it was full six feet in diameter at the top, and perfectly sound. It was felled in an unusual manner for the preservation of its crooks, which were cut off one by one whilst the tree was standing, and lowered by tackles, to prevent their breaking. The two largest arms were sawed off at such distances from the bole as to make first-rate knees; scaffolds were then erected, and two pit-saws being braced together, the body was first cut across, half through, at the bottom, and then sawed down the middle, perpendicularly, between the two stumps of arms that had been left, at the end of one of which stood a perpendicular bough, bigger than most timber-trees. To prevent this being injured, a bed was male of some hundreds of fagots to catch it when it fell. This half was so weighty that it crushed a new timber-carriage all to pieces the instant it was lodged upon it; and, none in the country being found strong enough, the King's carriage was sent purposely from Portsmouth to convey it to the dockyard. This tree was sold in the first place for $40 \mathrm{l}$. ; was bought of that purchaser by a timber-merchant for $100 l$., who is supposed to have cleared $100 \mathrm{l}$. more; which he might very well do, for the contents amounted to thirty-two loads of hewed timber, which, at half-a-crown a foot-no unusual price for naval crooks-amounts to $200 l$. precisely, besides fagots, \&c. sufficient to defray the expenses. The breadth of the tree across, near the ground, where it was cut, was twelve feet, and it had about three hundred rings of annual growth." 


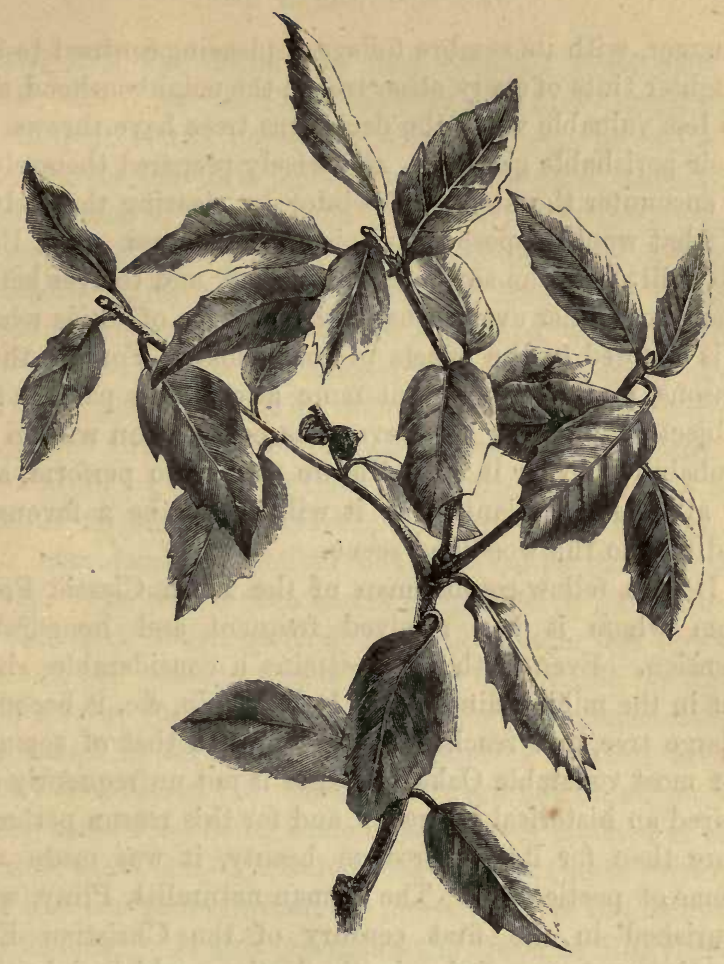

THE EVERGREEN OAK.

THE ILEX, EVERGREEN OAK, OR HOLM-OAK.

Quercus Ilex.

Natural Order - AMENTACEA.

class-Monecia. Order-Polyandria.

THe Ilex is not a native of Great Britain ; nor, although it flourishes and becomes a large tree in congenial situations, is it likely that it will ever become so far naturalized as to propagate itself to any extent. Nevertheless, as an ornament to the landscape it is a great acquisition, affording in 
summer, with its sombre foliage, a pleasing contrast to the brighter tints of every other tree in the neighbourhood, and no less valuable when the deciduous trees have thrown off their perishable garniture, and wisely prepared themselves to encounter the storms of winter by clearing themselves of what would oppose their boisterous progress. The Ilex, too, will stand the sea-breeze uninjured, and thrives better than most other evergreens in the vicinity of cities where it is exposed to the effects of coal-smoke. For all these reasons, therefore, now that more attention is paid to the subject of planting than ever was before, man will in all probability do for it what Nature refuses to perform, and in all artificial plantations it will always be a favourite addition to the woodland scene.

It is a fellow-countryman of the Latin Classic Poets from whom it has received frequent and honourable mention. Even with us it attains a considerable size; but. in the milder climates of Italy, Spain, \&c. it becomes a large tree, and reaches an age equal to that of some of our most venerable Oaks. Hence it not unfrequently acquired an historical interest; and for this reason perhaps, more than for its picturesque beauty, it was made the theme of poetic song. The Roman naturalist, Pliny, who flourished in the first century of the Christian Era, mentions a tree growing in the Vatican, which claimed a higher antiquity than Rome itself. It had brazen letters in the ancient Etruscan characters affixed to its trunk, from which it would appear that, before the Roman name was known, it was a sacred tree. Its age must therefore have been 800 years at least. Three others are mentioned by the same author, growing at Tibur, which tradition made to be older than Tiburtus, who founded that city 1,200 years B.c. Lowth considers the Teil-tree of Scripture to be identical with the Ilex, which abounds in many parts of Palestine; Dr. J. D. Hooker has, however, decided that the prevailing Oak of Palestine is Q. pseudo coccifera; a tree which in habit much resembles Q. Ilex. 
The Ilex was introduced into England previously to 1580 ; but it was then a great rarity, and little thought of, In Italy it is the prevailing evergreen, and in Sicily it abounds on the hills and all along the coast, ascending Mount Etna to an elevation of 3,200 feet. It is easily propagated from the acorn, but is very impatient of being transplanted, owing to its sending its long roots perpendicularly downwards, which are furnished with but few rootlets, save at the extremities, and if these are injured the young plant dies. This difficulty is obviated by sowing the acorns either in the spot where the trees are destined to stand, or by confining their roots in pots until they are required for planting. During their early stage they grow with considerable rapidity, but afterwards much more slowly. The bark is even and of a light colour; the leaves are of a dark bluish green above, and more or less downy beneath, the younger shoots being as remarkable for their light hue as the full-grown tree is for the characteristic sombreness of its foliage. The shape of the leaf varies greatly in different individuals, and even not unfrequently on the same tree, being sometimes scarcely notched at all, at other times deeply serrated, and at others quite prickly. It is this last variety which has procured for it the name of "Holm-Oak." It also resembles the Holm or Holly-tree, in having its most prickly leaves on the lowest branches. The acnrn, which does not arrive at perfection until the second year, resembles that of the Oak, but is somewhat more slender, and the cup is scaly. Some trees bear sweet and edible acorns ; those produced by others are bitter, and both kinds are sometimes to be found on the same tree. An allied species, Quercus gramuntia, which is so like the Ilex as to have been thought formerly merely a variety of the same tree, bears acorns, which even in perfection are as good as a chestnut, or even superior to it. These, according to Capt. S. C. Cook, are "the edible acorns of the ancients, which they believed fattened the tunny fish on their passage from the ocean to the Mediterranean; a fable, 
only proving that the acorns grew on the delicious shoras and rocks of Andalusia, which, unhappily, is no longer the case. I have frequently seen them produced by individuals and offered to the company, as bon-bons are in some countries, with a sort of apology for their small intrinsic value."

The wood of the Ilex is dark, close-grained, heavy, and hard. It is also durable and flexible, and, says Evelyn, " is serviceable for many uses, as stocks of tools, malletheads, mall-balls, chairs, axle-trees, wedges, beetles, pins, and, above all, for palisadoes, and in fortifications. Besides, it affords so good fuel that it supplies all Spain almost with the best and most lasting of charcoals in vast abundance." Modern writers on the subject confirm this account, and recommend also its employment in shipbuilding.

\section{THE SYCAMORE.}

Acer Pseudo-Plátanus.

Natural Order-ACERACEx.

Class-Octandria. Order-Monogynia.

If in my history of forest trees I were to confine myself to those which are universally acknowledged to be indigenous to Britain, I should soon bring my labours to a close. England, though once a well-wooded country, never probably could boast of containing within it any great variety of species. The Oak, fortunately, no one thinks of denying to be our fellow-countryman : if any one were bold enough to do so, we could easily refute him by pointing to living trees older than any of our national records ; or, if that did not suffice, to trunks of trees preserved in peat-bogs, which were prostrated on their native soil centuries, probably, before the acorns were planted from which any trees now living sprung. But this is not the case with the Sycamore. No writer on the subject, 
so far as I can learn, looks on this tree in any other light than as a foreigner, but as a foreigner naturalized so completely that it will continue to sow its own seeds, and nurse its own offspring, as long as England exists. The Oak, indeed, has greater right to claim an indigenous origin than we ourselves. There can be little doubt that the Oaks which now stock our forests, or convey our sailors to every region of the world, are lineal descendants of the first trees which ever grew in our island.

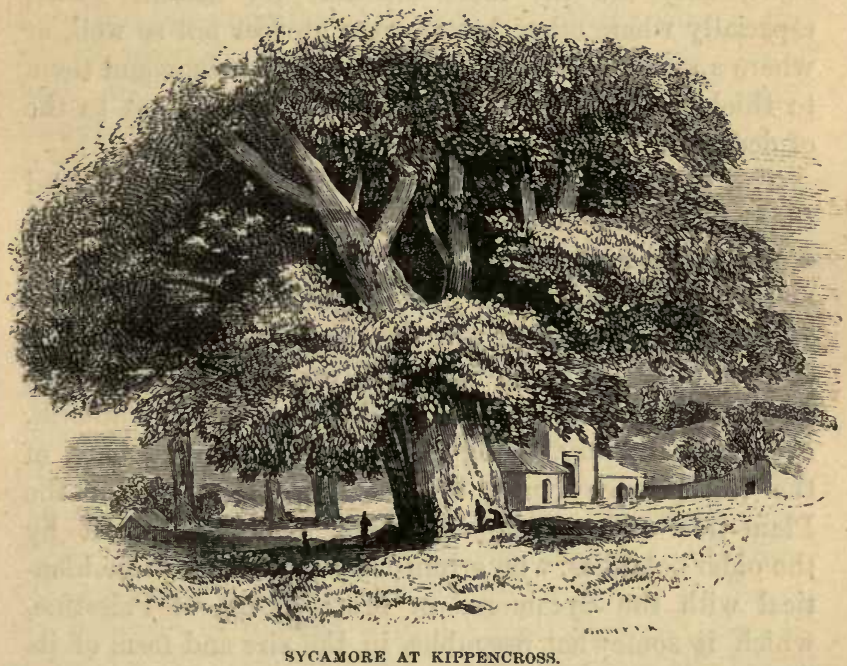

The Oak, on account of the age and size which it attains, the share which it had in the religious worship of our forefathers, its picturesque beauty, and its intimate connexion with naval architecture, is confessedly the most interesting of all the trees which grow in Britain. But the Sycamore is sadly deficient in these respects. It has neither extraordinary magnitude nor longevity to recommend it. It was not contemporary in this country with the worshippers of trees; and I know not that it ever laid 
claim to be mentioned in connexion with any national boast. It has even been denied the possession of any picturesque beauty. Evelyn says of it, "The Sycamore is much more in reputation for its shade than it deserves ; for the honey-dew leaves, which fall early, like those of the Ash, turn to mucilage and noxious insects, and putrefy with the first moisture of the season; and are therefore, by my consent, to be banished from all curious gardens and avenues." If the trees, however, "be very tall and handsome, they are the more tolerable for distant walks, especially where other better trees prosper not so well, or where a sudden shade is expected. Some commend them to thicken copses, especially in parks, as least apt to the of deer, and that it is good fire-wood."

The name Acer, given to it by the Romans, is derived from Acer, Acris, sharp or hard (ac, Celtic, a point), on account of the hardness of the wood, which was used for making spears and other sharp-pointed instruments ; or, as some are pleased to say, from acre ingénium, a sharp wit, from its being so much in use by most ingenious artificers in fine works. Its specific name, Pseudo-Platanus, means Mock-Plane, being given to it in consequence of the resemblance borne by its leaves to those of the Plane-tree. The name Sycamore was given to it by the older botanists, who erroneously believed it to be identical with the Sycamore, ${ }^{1}$ or Mulberry-fig, of Palestine, which it somewhat resembles in the size and form of its leaves.

No tree propagates itself more readily in this country, as may be easily inferred from the great number of seedlings which are to be found springing spontaneously from the ground in the vicinity of Sycamores which have begun to bear seeds. In its earliest stage it is a puny herbaceous plant, furnished with two, or sometimes more, narrow smooth leaves, entire at the enges: these are the cotyle-

1 From syke, a fig, and moros, a mulberry, being said to resemble the mulberry-tree in the leaf, and the fig in its fruit. 
donous leaves. Shortly afterwards (for during the whole of its existence it is a rapid grower), a few pointed and notched leaves, tinged with pink, are produced in the centre of these ; and as the nursling increases in size, others appear, having the five-pointed, unequally notched lobes which characterise the matured foliage of the tree. At the end of a year it will have attained, under favourable circumstances, the height of eighteen inches, As a sapling it is remarkable for its straight growth, smooth purplishbrown bark, and large leaf-buds. In this stage of its growth it is a great favourite with schoolboys, who, in the spring, when the sap begins to rise, slip off a cylinder of bark, and by removing a portion of the pith and wood, manufacture the shrill and unmusical instrument, a whistle. It produces flowers before it is twenty years old, but does not generally perfect its seeds until it has attained at least that age. In fifty or sixty years it reaches its full growth, and in the course of thirty or forty years more thoroughly ripens its wood.

The leaves of the Sycamore in autumn are frequently observed to be covered with dark-coloured spots. This appearance is produced by numerous blackish fungi (Xyloma acerinum), which, as soon as the first sharp frost has scattered the leaves on the ground, commence their office of converting the now useless vegetable substance into rich mould. At all periods of its growth its leaves are liable to be covered with a viscid substance, termed honey-dew, the origin of which has by some been attributed to insects, by others to the plant itself. ${ }^{1}$

In May, before the leaves are thoroughly expanded, the Sycamore puts forth its elegant drooping clusters of green flowers, when the bee may be observed climbing about, and closely peering into every opening bud. This insect is much indebted to the Sycamore, since its flowers, which

1 When this honey-dew is very abundant, it is liable to drop on any shrub beneath (such as hox, holly, \&c.), and to turn their leaves black. The branches of such shrubs have been observed to be much infested with lichens. 
abound in honey, not only are very numerous, but appear at a season when the supply of honey-bearing flowers is limited.

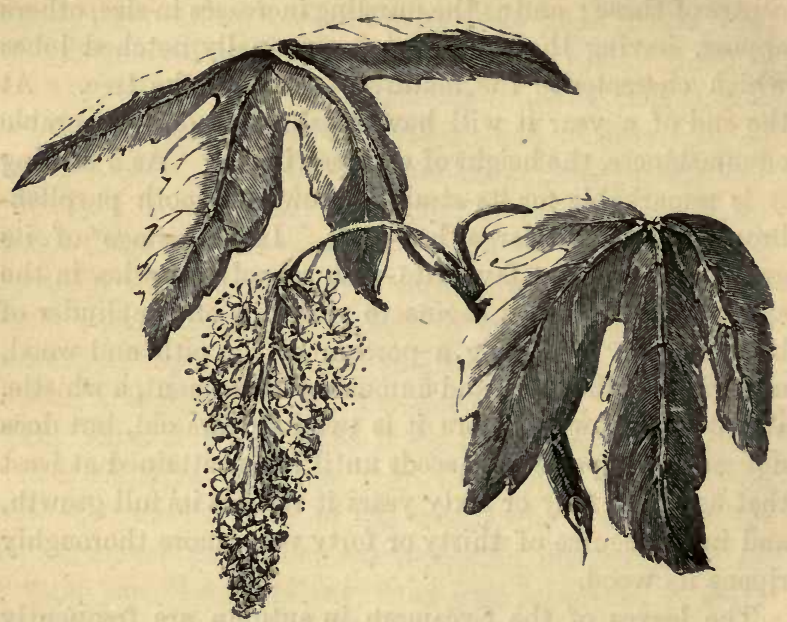

FLOWERS OF SYCAMORE.

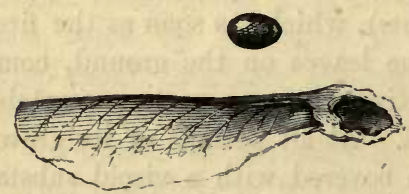

WINGED SEED-VESSEL OF SYCAMORE.

As soon as the flower is withered and has fallen off, the seed-vessels enlarge and acquire a reddish hue, which indeed in the autumn characterises the whole tree.

"Nor unnoticed pass

The Sycamore, eapricious in attire ;

Now green, now tawny, and ere autumn yet

Has changed the woods, in scarlet honours bright."

COWPER. 
Each of the two or three seed-vessels, which succeed every flower, is furnished with a membranous diverging wing, and it is owing to the presence of this that so many young plants may be discovered in the spring at a considerable distance from the parent tree. When they have acquired their full size, which is early in autumn, they form clusters sufficiently large and conspicuous to alter the pictorial character of the tree. They do not fall off when ripe, like acorns, chestnuts, and other heavy seeds, but remain attached to the branches till the equinoctial gales set in which serve the double purpose of separating them from the stalks and carrying them to some convenient place of growth. If, however, from growing in a sheltered spot, or from any other cause, they still retain their position, an event which frequently occurs, the seed-stalk rots from the effects of the winter's rain; and the violent winds which accompany the succeeding vernal equinox do not fail to deposit the majority of the seeds in places well adapted for their growth, in full time to receive all the advantages of the genial season which follows. The seed itself is well protected against the severest vicissitudes of weather, first by the horny, or almost woody, case in which it is inclosed; and secondly, by the copious, soft, and glossy down which lines the seed-vessels, a covering alike impervious to cold and wet.

It may be that many trees which have been introduced into a strange country fail to propagate themselves extensively because the attendant circumstances are not the same in the new country that they were in the old. Were the Sycamore, for instance, to be introduced into a country where no such periodical recurrence of rain and storms took place, and where, also, there was no interference of human agency, it might soon become extinct, inasmuch as its seeds, if kept dry for a year, generally lose their vegetative power. The Oak, if planted in a country uninhabited by man, and where no such friendly depredator as the rook or the squirrel acted the part of a skilful 
forester, would soon disappear. Its acorns would indeed fall to the ground, and perhaps germinate, but would rarely become trees; for the Oak, like many other trees, will not flourish under the shade of its own species. I may here observe that the mast-bearing trees generally, such as the Oak, the Chestnut, and the Beech, are indebted for their propagation to animals whose instinct leads them to bury their food: those provided with winged seeds, such as the Sycamore, the Ash, and the Elm, to storms and tempests; and the drupe-bearing trees (those, namely, which are furnished with stone-fruit), to frugivorous birds, which fly away with the fruit, and drop the seed. Thus by the wise arrangement of the Almighty do these several classes of trees derive the greatest benefit from what we, at first sight, might imagine to be most productive of injury.

From the extreme fecundity of this tree, Martyn argues that if it were truly indigenous, it would ere this have filled the whole country, instead of being a simple occupant of plantations and hedges. In Switzerland, Germany, Austria, and Italy, it is found abundantly in the mountainous forests, and may therefore with propriety be considered a native of those countries, whence it was probably introduced into Britain in the end of the fifteenth or beginning of the sixteenth century. There are several varieties of Sycamore, which are propagated by grafting. The most remarkable among these are, the Yellow-leaved, or Costorphine Plane, 1 which is not eommon, except in the neighbourhood of the place from which it takes its name; and the Purple-leaved, so called from having the under-surface of its leaves, especially in spring, tinged with dark purple. The value of all these as ornamental trees, is much enhanced by the earliness of the season when they come into leaf.

Chaucer speaks of it as a rare exotic, in the fourteenth

${ }^{1}$ In Scotland the Sycamore is frequently called "The Plane." 
century. Gerard, in 1597, says : "The Great Maple is a stranger in England, only it groweth in the walkes and places of pleasure of noblemen, where it especially is planted for the shadowe-sake, and under the name of Sycamore-tree." Parkinson, speaking of the same in 1640 , says : "It is nowhere found, wild or natural, in our land, that I can learn; but only planted in orchards or walkes for the shadowes sake." It abounds in sweet juice, of which, says Evelyn, "the tree being wounded, in a short time yields sufficient quantity to brew with, so as with one bushel of malt is made as good ale as with four bushels with ordinary water." According to Sir T. Dick Lauder, "The Sycamore has been proved to be capable of yielding sugar. Incisions were made, at five feet from the ground, in the bark of a tree of this species, about fortyfive years old. A colourless and transparent sap flowed freely, so as in two or three hours to fill a bottle capable of containing a pound of water. Three bottles and a half were collected, weighing in all three pounds four ounces. The sap was evaporated by the heat of a fire, and gave two hundred and fourteen grains of a product, in colour resembling raw sugar, and sweet in taste, with a peculiar flavour. After being kept fifteen months, this sugar was slightly moist on the surface. The quantity of sap employed in the evaporation was 24,960 grains, from which 214 grains of sugar were obtained; therefore, 116 parts of sap yielded one part of sugar."

An allied species, Acer saccharínum, or Sugar Maple, which is found in great quantities in Canada, New Brunswick, Nova Scotia, and other parts of North America, yields a similar saccharine juice, in such quantities that maple-sugar is an important article of manufacture. It has been computed, that in the northern parts of the two states of New York and Pennsylvania there are ten millions of acres which produce these trees in the proportion of thirty to an acre. The season for tapping is in February and March, while the cold continues intense, 
and the snow is still on the ground. A tree of ordinary size yields from fifteen to thirty gallons of sap, from which are made from two to four pounds of sugar. The tree is not at all injured by the operation, but continues to flourish, after having been annually tapped for forty years without intermission. The produce is consumed principally in the neighbourhood of the place where it is manufactured, the sugar from the cane being preferred whenever it can be readily procured.

Our Sycamore is not sufficiently productive of sugar to be ever employed in this way, even if the manufacture were legalized ; but it is by no means a worthless tree. Its wood was much used for making platters before earthenware plates were generally introduced, and in rural districts is still applied to the same purpose. When the tree is young the wood is white, but acquires a yellow or brown hue as it increases in age. It is close-grained, but not hard, and does not readily warp, and, being easily worked either by the hánd or lathe, was formerly held in high estimation for the purpose above mentioned. It is sought by the joiner and cabinet-maker, and it is also used for making musical instruments and cider-screws. It forms also a very valuable fuel, burning slowly and giving out a great deal of heat. Not only on account of its uses in the arts and manufactures, and its dense foliage in summer, was its growth encouraged, but it was planted in the vicinity of houses, from the supposition that it was the Sycamore of Scripture; this however is not the case, the tree into which Zacchæus climbed to see our Saviour pass on His way to Jerusalem being the Ficus Sycomorus. However, as the error once generally prevailed, both that tree and our tree bearing the same name have been selected by the inventors of the language of flowers to indicate curiosity.

Dr. Shaw, speaking of the Sycamore of the East, says, "The mummy-chests, and whatever figures and instruments of wood are found in the catacombs, are all of them of Sycamore, which, though spongy and porous to appearance, 
has, notwithstanding, continued entire and uncorrupted for at least three thousand years."

"From its value in furnishing wood for various uses, from the grateful shade which its wide-spreading branches afforded, and on account of the fruit, which, Mallet says, the Egyptians live upon and hold in the highest estimation, we perceive the loss which the ancient inhabitants must have felt 'when their vines were destroyed with hail, and their Sycamore trees with frost." "1

"The Great Maple, or European Sycamore, will grow in any soil not saturated with moisture; but it seems to prefer one that is dry and free, rather than one that is stiff and moist. It will grow in exposed situations, and especially on the sea-coast, and maintain its erect position against the sea-breeze, better than most other trees. It is in use for this purpose in Scotland, and also for planting round farm-houses and cottages on the bleak hills. In such situations, an instance can hardly be found of the head of the tree leaning more to one side than another. Even when the wind blows strongly in one direction for nine months in the year, this tree maintains its perpendicularity and symmetrical form." 2

Though a fast grower, the Sycamore does not attain a remarkably large size, and it is as little noted for its longevity. It does not materially increase in size after having reached the age of sixty years, but requires from thirty to forty years more to bring its timber to perfection.

At the age of from one hundred and fifty to two hundred years, it usually closes its term of life, though much older trees are on record.

1 Ps. Ixxviii. 47.

${ }^{2}$ Loudon. 


\title{
THE COMMON, OR FIELD MAPLE.
}

\section{ACer Campestre.}

\author{
Natural Order-ACERINEA. \\ Class-Octandria. Order-Monogynia.
}

Thоugh the tree last described is much larger and more generally known than the present species, it has so long universally borne the name of Sycamore, that the generic name of "Maple" is now almost exclusively applied to the smaller tree, the only species, in fact, which is indigenous to this country. Many persons probably are not aware that the two trees belong to the same family; for if we except the keys or clusters of winged seeds, they have to the casual observer few points of resemblance.

The Sycamore justly claims the right of being considered a large tree : the circumference of its trunk is considerable; it frequently covers a wide space of ground with its spreading limbs; it casts a dense shade, and its leaves exceed in size those of most of our common trees. But the Maple rarely attains a size which entitles it to be considered a tree at all ; its foliage is meagre and unpretending, while its value in hedge-making induces its owners to preserve as much as possible its character of an overgrown shrub. Such, accordingly, we generally find it when it grows in hedges, and when met with among other trees it is mostly as underwood. Its leaves, like those of the Sycamore, are five-lobed, but obtuse and much smaller. Its flowers appear in April, about a fortnight before the leaves, and abound in saccharine juice. They are similarly constructed to those of the Sycamore, but grow in erect, instead of drooping, clusters ; and the keys, which differ principally in size from those of the other species, are tinged with red. Besides being indigenous to Britain, the Maple grows 
naturally in the middle and south of the European Continent and in the north of Asia.

In France it appears to serve the purposes of man more than in this country. According to Loudon, "The young shoots, being tough and flexible, are employed by the coachmen in some parts of France instead of whips. The tree is much used in the same country for forming hedges, and for filling up gaps in old fences. It is also employed in

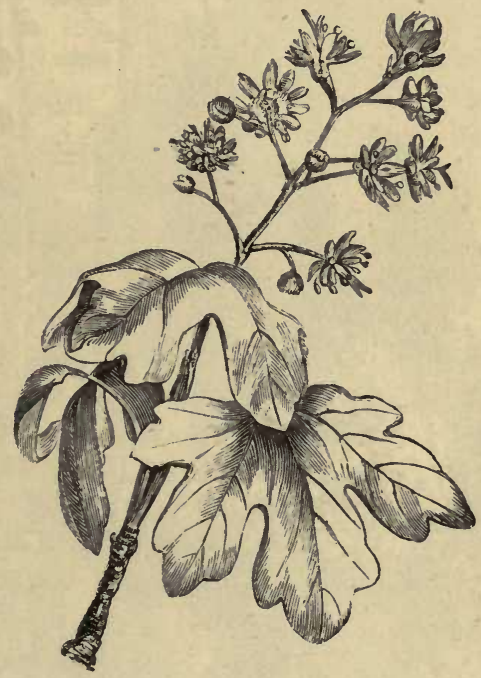

LEAVES AND FLOWERS OF THE FIELD MAPLE.

topiary works, in geometrical gardens, its branches being found to bear the shears better than those of most other trees. The leaves and young shoots are gathered green, and dried for winter provender for cattle. The sap yields more sugar, in proportion to the quantity taken, than that of the Sycamore; but the tree does not bleed freely. In Britain the tree is seldom planted for any other purpose than that of ornament, in which it is effective, by adding to the variety of a collection, rather than by its positive beauty." 


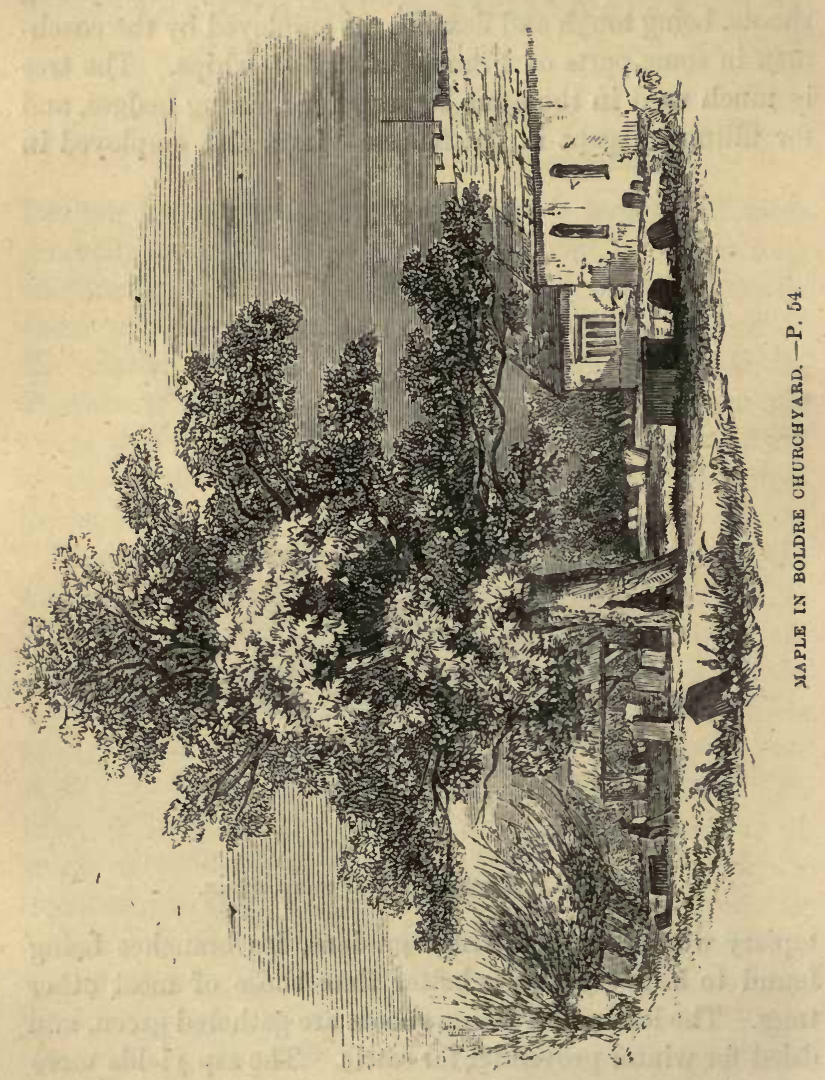


The wood makes excellent fuel, and the very best charcoal. The timber is far superior to Beech for all purposes of the turner, who seeks it for dishes, cups, trays, trenchers, \&c. as the joiner for tables, inlayings, and for the delicateness of the grain, when the knurs and nodosities are rarely diapered, which does but advance its price: our turners will work it so thin, that it is almost transparent."

As an ornament to the landscape, the Maple has not much to recommend it. Gilpin says of it, "The Maple is an uncommon tree, though a common bush. Its rood is of little value, and it is therefore rarely suffered to increase. We seldom see it employed in any nobler service than in filling up its part in a hedge, in company with thorns, and briars, and other ditch trumpery." And although he afterwards says, "In the few instances I have met with of this tree in a state of maturity, its form has appeared picturesque; " yet his praise of it is so exceedingly slight, that I have very little doubt that his eye, acute as it was to discern what is beautiful in the general features of nature, could have alighted with greater pleasure on almost any other kind of tree that can be named. Nevertheless, he has given to the Maple a deeper interest than it ever possessed before; for " under the large Maple in Boldre churchyard, the Rev. W. Gilpin, after fulfilling his duties in the most exemplary manner for twenty years, as rector of this parish of Boldre, chose for his last resting-place this sweet sequestered spot, amidst the scenes he so much loved, and has so well described." 1

By the ancients hardly any wood was more valued than that of the Maple, insomuch that Virgil represents one of his kings as seated on a Maple throne. The great naturalist, Pliny, says that its trunk, for beanty and firmness of grain, is inferior only to the Citron-wood. One kind, from the varied character of its veining, was named the Peacock Maple. The knots called Brusca and Mollusca were most 
valued, and manufactured into such ornaments as the limited size of the material would allow.

In the Molluscum the veins were wide apart from each other. The Bruscum was deemed most valuable when the arrangement of the veins resembled some animal (as was occasionally the case), and gave the wood a dark hue. The latter was preferred for making tables. "And such spotted tables," says Evelyn, "were the famous Tigrin and Pantherine curiosities; not so called from being supported with figures carved like those beasts, as some conceive, and was in use even in our grandfathers' days, but from the natural spots and maculations. Such a table was that of Cicero, which cost him ten thousand sesterces (about $62 l$. sterling); such another had Asinius Gallus. That of King Juba was sold for fifteen thousand; and another which I read of, valued at a hundred and forty thousand sesterces, which, at about three halfpence sterling, arrives to a pretty sum (875l. sterling); and yet that of Mauritanian Ptolemie was far richer, containing four feet and a half diameter, three inches thick, which is reported to have sold for its weight in gold. Of that value they were, and so madly luxurious the age, that when they at any time reproached their wives for their wanton expensiveness in pearl and other rich trifles, they were wont to retort, and turn the tables upon their husbands." 1

Spenser appears to have considered the timber of the standing tree peculiarly liable to decay, for he speaks of

"The Maple seldom inward sound."

1 The Bird's-eye Maple of modern cabinet-makers is the wood of the Sugar, or Rock Maple. The trunk of this tree is rejected for civil and naval architecture ; but the wood of the old trees is valued for inlaying mahogany. The appearance from which it derives its name proceeds from the twisting of the silver grain, which produces numerous knots like the eye of birds. 


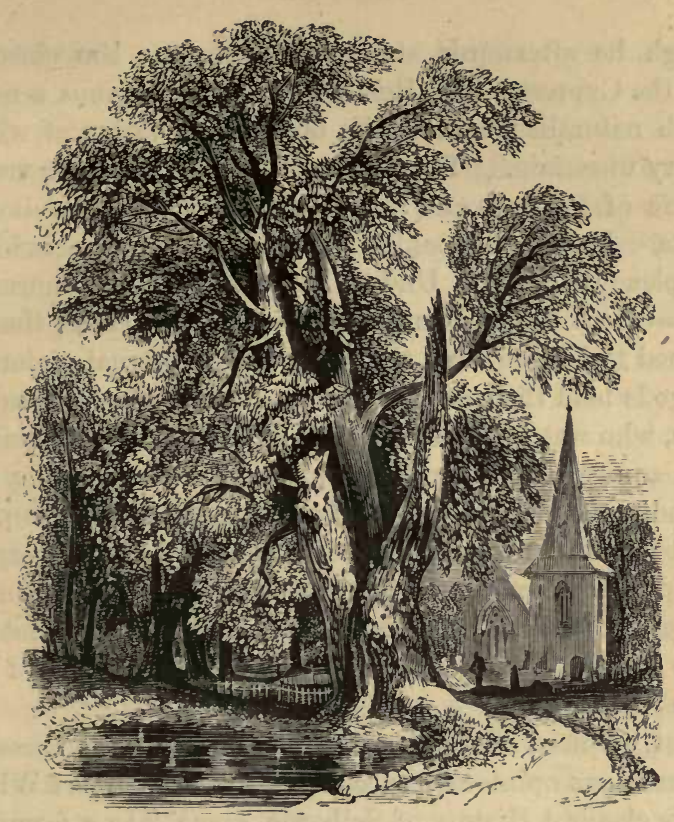

THE $\triangle$ SH.

\section{THE ASH.}

Fraxinus Excelsior.

Natural Order-OLEACEE.

Class-Diandria. Order-Monogynia.

The Ash is, in utility, inferior only to the Oak, and, like that tree, an undoubted child of British soil. Not remarkable for robustness, grandeur, or longevity, it rests its claims on qualities scarcely less striking. In height, gracefulness of form, and elegance of foliage, it has no superiors, scarcely any competitor. Its favourite haunts, too, give it an additional charm.

The Ash was well known to the Greeks, who called it mélea. Homer arms his heroes with an ashen spear, and Cupid's arrows were originally made of the same wood, 
though he afterwards stood indebted to a less cheerful tree, the Cypress. The Romans called it Fráxinus, a name which naturalists still retain, but the derivation of which is very uncertain. They employed its wood in the manufacture of weapons and many kinds of agricultural implements. In the Teutonic Mythology, the Ash holds a conspicuous place. Under the shade of an enormous tree-of which the branches overspread the earth, the top reached to heaven, and the roots to the infernal regionsthe gods held their court. On the summit was perched an eagle, who watched the course of all earthly affairs, assisted by a squirrel, who employed his time in descending and ascending to examine into, and report upon, what was passing beneath. Pliny gravely informs us that the serpent would rather creep into the fire than shelter itself in its branches : ${ }^{1}$ and Dioscorides, the physician, states that the juice of the Ash is an antidote against the bite of the same reptile.

But we need not go back to ages so remote as these for superstitious opinions respecting this tree. Gilbert White, in his classical History of Selborne, says : "In a farmyard near the middle of this village, stands at this day a row of pollard-ashes, which, by the seams and long cicatrices down their sides, manifestly show that in former times they have been cleft asunder. These trees, when young and flexible, were severed and held open by wedges, while diseased children, stripped naked, were pushed through the apertures, under a persuasion that, by such a process, the poor babes would be cured of their infirmity. As soon as the operation was over, the tree in the suffering part was plastered with loam, and carefully swathed up. If the parts coalesced and soldered together, as usually fell out, where the feat was performed with any adroitness at all, the party was cured; but where the cleft continued to gape, the operation, it was supposed, would prove

1 "This," says Evelyn, "is an old imposture of Pliny, who either took it upon trust, or else we mistake the tree." 
ineffectual. Having occasion to enlarge my garden not long since, I cut down two or three such trees, one of which did not grow together. We have several persons now living in the village, who in their childhood were supposed to be healed by this superstitious ceremony, derived down, perhaps, from our Saxon ancestors, who practised it before their conversion to Christianity." The same custom was known to Evelyn, who half believes in the efficacy of the ceremony. ${ }^{1}$ If we may credit Phillips, the present enlightened age is not exempt from the same silly belief. He says : "In the south-east part of the kingdom, the country people split young Ash-trees, and make their distempered children pass through the chasm in hopes of a cure. ${ }^{2}$ They have also a superstitious custom of boring a hole in an Ash, and fastening in a shrew-mouse; a few strokes with a branch of this tree is then accounted a sovereign remedy against cramp and lameness in cattle, which are ignorantly supposed to proceed from this harmless animal." 3 Such a tree was named from the unfortunate victim "a shrew-ash." White thus describes one which about the middle of the last century stood in the village of Selborne: "At the south corner of the Plestor, or area near the church, there stood, about twenty years ago, a very old, grotesque, hollow pollard-ash, which for ages had been looked on with no small veneration as a shrew. ash. Now a shrew-ash is an Ash whose twigs or branches, when gently applied to the limbs of cattle, will immediately relieve the pains which a beast suffers from the running of a shrew-mouse over the part affected; for it is supposed that a shrew-mouse is of so baleful and deleterious a nature, that wherever it creeps over a beast, be it horse, cow, or sheep, the suffering animal is afflicted with cruel anguish, and threatened with the loss of the use of the limb.

1 Hunter's Evelyn's Sylva, vol. i. p. 151.

2 A writer in the Gardener's Chronicle for April, 1846, states that there was then living in Sussex a man who, when an infant, about fifty years ago, was passed through an Ash-tree, at Todhurst, as a remedy for hernia.

3 Sylva Florifera, vol. i. p. 8. 
Against this accident, to which they were continually liable, our provident forefathers always kept a shrew-ash at hand, which, when once medicated, would maintain its virtues for ever. A shrew-ash was made thus:-Into the body of the tree a deep hole was bored with an auger, and a poor devoted shrew-mouse was thrust in alive, and plugged in, no doubt with several incantations long since forgotten. As the ceremonies necessary for such a consecration are no longer understood, all succession is at an end, and no such tree is known to exist in the manor or hundred."

Lightfoot says that, in many parts of the Highlands of Scotland, at the birth of a child the nurse puts one end of a great stick of this tree into the fire, and while it is burning, receives into a spoon the sap or juice which oozes out at the other end, and administers this as the first spoonful of food to the new-born infant.

The English name of this tree is derived from the Saxon Ass. The common opinion, that it is so called from the colour of its bark closely resembling that of wood-ashes, is incorrect.

The Ash is indigenous throughout the greater part of Europe, ${ }^{1}$ the north of Africa, and some parts of Asia. It rises freely from seed, and in favourable situations it grows rapidly. Its roots are remarkable for their tendency to take a horizontal direction, and, being abundantly furnished with fibres which approach closely to the surface, effectually eheck the growth of almost all other vegetation. Hence has originated the erroneous notion that the

1 Professor Jameson is disposed to think that in Scotland the Ash is not indigenous: "The Ash and the Beech have a place in the Flora S'cotica of Lightfoot and Hooker, and they have long ornamented our woods and plantations. But there is great reason to doubt their being truly indigenous to this country, or having formed any part of the ancient forests. No traces of them occur in our peat-mosses; yet Ash-seeds and Beech-mast would in all probability have proved as indestructible as Hazel-nuts or Fircones, which are abundant in many peat-mosses." - Note in Jomeson's Journal. 
drippings of its leaves are peculiarly noxious. The roots dislike the presence of stagnant water, but delight to approach as closely as possible to the gravelly bed of a running stream. Owing to these instincts, if they may be so called, the Ash outstrips any other tree when it grows on the shallow rich soil which lines the course of our mountain streams. "It is by no means convenient to plant Ash in plow-lands, for the roots will be obnoxious to the coulter; and the shade of the tree is malignant both to corn and grass, when the head and branches overdrip and emaciate them.-The Ash delights in the best land, which it will soon impoverish, yet grows in any, so it be not over stiff, wet, and approaching to the marshy, unless it be first well drained. By the banks of sweet and crystal rivers and streams I have observed them to thrive infinitely." 1

The young plants are readily distinguished from other saplings, in winter and early spring, by their ash-coloured tint, their remarkable black buds, and the flattened or compressed shape of the twigs, a peculiarity which is most pereeptible near the terminal pair of buds. In summer the leaves are a no less certain distinguishing character. They are technically termed pinnate, and are composed of about five pairs of acute, notched leaflets, with a terminal odd one, which last is occasionally not developed.

The foliage of the Ash is very late in making its appearance: consequently in early spring it cannot compete in beauty with other forest trees which are less sluggish in donning their green attire. It is equally remarkable, too, for the earliness of the season at which it sheds its foliage.

"Its leaf is much tenderer than that of the Oak, and sooner receives impressions from the winds and frost. Instead of contributing its tint, therefore, in the wane of the year, among the many-coloured offspring of the woods, it shrinks from the blast, drops its leaf, and in each scene

1 Evelyn's Sylva. 
where it predominates, leaves wide blanks of desolated boughs, amidst foliage yet fresh and verdant. Before its decay, we sometimes see its leaf tinged with a fine yellow, well contrasted with the neighbouring greens. But this is one of Nature's casual beauties. Much oftener its leaf decays in a dark, muddy, unpleasing tint. And yet sometimes, notwithstanding this early loss of its foliage, we see the Ash, in a sheltered situation, when the rains have been abundant and the season mild, retain its green (a light pleasing green) when the Oak and the Elm in its neighbourhood have put on their autumnal attire." 1

The precise time at which it sheds its leaves varies much in different individuals, and this difference arises not only from situation, but from other causes, for sometimes in the hedgerow many trees will have cast their foliage while others show no symptom of decay.

Gilpin's remarks on the spray of the Ash are well worth the attention of the artist. After pointing out the peculiar character of the Oak, he proceeds to say: "The spray of the Ash is very different. As the boughs of the Ash are less complex, so is its spray. Instead of the thick intermingled bushiness which the spray of the Oak exhibits, that of the Ash is much more simple, running in a kind of irregular parallels. The main stem holds its course, forming at the same time a beautiful sweep; but the spray does not divide, like that of the Oak, from the extremity of the last year's shoot, but springs from the side of it. Two shoots spring out opposite to each other, and each pair in a contrary direction. Rarely, however, both the shoots of either side come to maturity; one of them is commonly lost as the tree increases, or at least makes no appearance in comparison with the other, which takes the lead. So that notwithstanding this natural regularity of growth, so injurious to the beauty of the Spruce-fir and some other trees, the Ash never contracts the least disgusting formality from it. It may even secure great picturesque 1 Gilpin. 
beauty, for sometimes the whole branch is lost as far as one of the lateral shoots, and this occasions a kind of rectangular junction, which forms a beautiful contrast with the other spray, and gives an elegant mode of hanging to the tree.

"This points out another difference between the spray of the Oak and that of the Ash. The spray of the Oak seldom shoots out from the under sides of the larger branches; and it is this, together with the strength and firmness of the branches, which keeps them in a horizontal form. But the spray of the Ash as often breaks out on the under side as in the upper; and being of a texture weaker than that of the Oak, it generally, as the bough increases, depends upon the larger branch, and rising again forms, in full-grown trees especially, very elegant, pendent boughs." .

This description is so very accurate and truthful, that the reader, if he is at all conversant with woodland scenery, can scarcely fail to recognise the portrait.

When the Ash has attained a considerable size, the spray assumes, in early spring, an appearance very different from that which characterised the younger tree. This is occasioned by the numerous clusters of flowers which appear at the extremities of the branches at least a month before the leaves. These flowers are minute and remarkably simple in their structure, being destitute both of calyx and corolla: but being exceedingly numerous, and of a dark purple colour, they are very conspicuous, and add materially to the ordinary graceful character of the tree. They grow in dense clusters on the extremities of those branches which were produced in the former year: and, buried among them, lie the rudiments of the future leading shoot. They are difficult to describe except in the technical language of the botanist, but will amply reward any one who will take the pains to examine them closely; for, minute as they are, they are very elegant, and the rich purple contrasts beautifully with the delicate greenish-yellow tint of the flower stalks, though when the tree is observed from a distance, the latter are so closely concealed by the flowers as to be 
scarcely apparent. In its earlier stage of growth, the mass of unexpanded flowers is not unlike an irregularly granulated fruit; it eventually becomes diffuse, and is finally succeeded by bunches of pendent seeds, not inappropriately called keys. ${ }^{1}$ They differ from the keys of the Sycamore

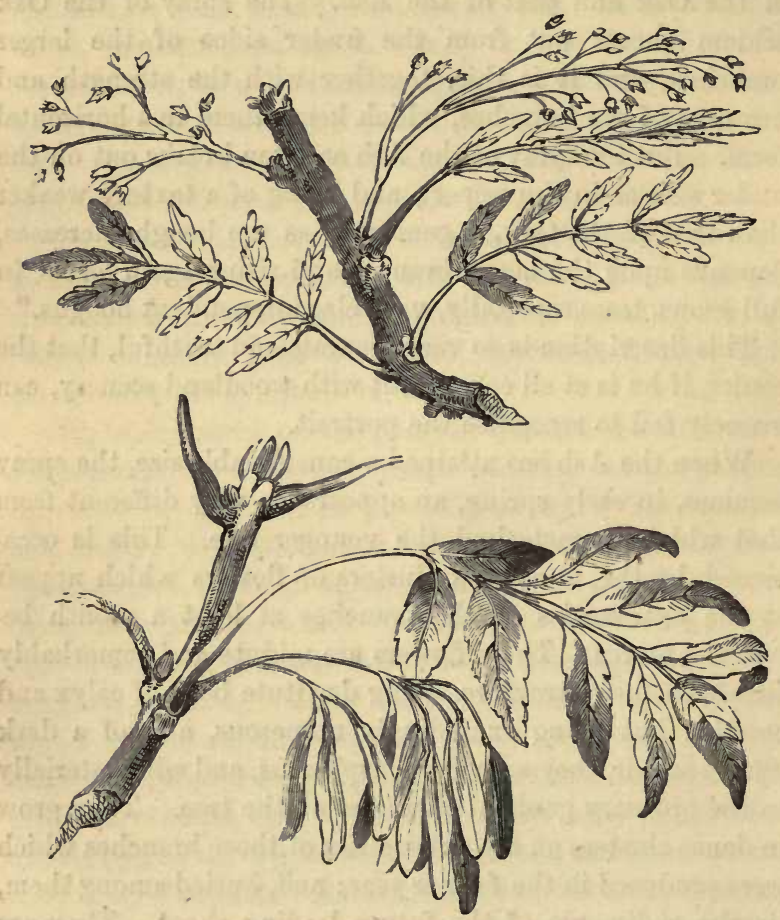

YLOWERS AND SEED-VESSELS OF THE ASH.

in growing singly, instead of in pairs, but like them are winged, and remain firmly attached to the tree, until the season when winds prevail sufficiently powerful to strip them from the branches and carry them a considerable

1 The Latins termed the seed of the Ash lingua avis (bird's tongue), from some fancied resemblance in shape. 
distance from the parent tree. How wise a provision this is, is very conspicuous in the case of the Ash ; for, as we have seen above, the roots of this tree naturally extend horizontally so near the surface as to exhaust the soil, and consequently to render it unfit for the nourishment of seedlings of the same species. So firmly indeed are the keys attached to the twig, that not only may the tree be discriminated in winter by its bunches of brown seeds, but it is far from unusual to see the ragged remnants of the previous year mixed up with the fresh flowers and foliage.

It has been observed already, that the season at which the Ash sheds its leaves varies considerably in different individuals. It is worthy of remark, that individual trees also vary greatly in the quantity of seeds produced, and that those which bear but few seeds compensate for their sterility by a greater profusion of foliage, which they also retain until a much later period in the year. This phenomenon may be explained on the ground, that when there is an abundant produce of seed, the tree reserves its energies in order to mature them, consequently the foliage is thrown off early in the autumn: but when there is no such demand for the nourishment of seed, the tree expends all its vigour on the leaves, which are consequently numerous, and so healthy as to be little affected by the early frosts of autumn. ${ }^{1}$

By the facility of transit which its winged appendage affords to the seed of the Ash, we are to account for the appearance of trees in the very strange situations in which they are sometimes found, springing, for instance, from church towers, ruins, and crags inaccessible to man. Dr. Plott, in his "Natural History of Oxfordshire," mentions a singular instance of this regetable waywardness: "An

1 My readers, if they have had any experience in gardening, must be well aware that this law applies to most, if not all, plants that come under their care. A healthy state of foliage is indispensable to the production of perfect flowers and fruit; anything more than this has a contrary effect; a superabundance of leaves being usually attended by a defective produce of both flowers and fruit. 
Ash-key rooted itself on a decayed willow, and finding, as it increased, a deficiency of nourishment in the mother plant, began to insinuate its fibres, by degrees, through the trunk of the willow, into the earth. There, receiving an additional recruit, it began to thrive and expand itself to such a size that it burst the willow in pieces, which fell away from it; and what was before the Ash, being now exposed to the air, became the solid trunk of a vigorous tree."

Ash-keys were held in high repute by the ancient physicians for their medicinal properties. They were also preserved with salt and vinegar, and sent to table as a sauce, when, says Evelyn, "being pickled tender they afford a delicate salading."

From a foreign species of Ash, Fraxinus Ornus, of Linnæus, Ornus Europcea of modern authors, is procured a substance which, from its appearance somewhat according with the description of the miraculous food of the Israelites in the wilderness, is called Manna. This substance is chiefly collected in Calabria and Sicily; where, according to the Materia Medica of Geoffroy, the manna runs of itself from the trunks of some trees, while it does not flow from others unless wounds are made in the bark. Those trees which yield the manna spontaneously grow in the most favourable situations, and the sap runs from them only during the greatest heats of summer.

It begins to ooze out about mid-day, in the form of a elear liquid, which soon thickens, and continues to appear until the cool of the evening, when it begins to harden into granules, which are scraped off the following morning. When the night has been damp or rainy, the manna does not harden, but runs to the ground and is lost. This kind is called manna in tears, or manna lagrimi, and is as white and pure as the finest sugar. About the end of July, when the liquid ceases to flow of itself, incisions are made through the bark and soft wood; and into these incisions slender pieces of straw or twig are inserted, in which the manna runs, and coating them over, hardens on 
them. This is the common manna of the shops, which is thus collected in the form of tubes, and is called manna in cannoli. Another, and inferior sort, is procured by making an oblong incision in the trees in July or August, and taking off a piece of the bark, about three inches in length and two inches in breadth. This kind, which is called manna-grass, is the coarsest; but as it is produced with less trouble, it is the cheapest. Sometimes, instead of cutting out a piece of bark, and leaving the wound open. two horizontal gashes are made, one a little above the other, in the upper of which is inserted the stalk of a maple leaf, the point of the leaf being inserted in the lower gash, so as to form a sort of cup to receive the manna, and to preserve it from dust and other impurities. The greater part of the manna of commerce is procured in the latter manner, and is imported in chests, in long pieces, or granulated fragments of a whitish or pale yellow colour, and in some degree transparent. The inferior kind is of a dark brown colour, in adhesive masses, and is moist and unctuous when felt. Manna from the Ash has a peculiar odour, and a sweetish taste, accompained with a slight degree of bitterness. "It was formerly used in medicine, but is now chiefly used to disguise other drugs in administering them to children." (Loudon).

As a timber-tree the Ash is exceedingly valuable, not only on account of the quickness of its growth, but for the toughness and elasticity of its wood, in which latter quality it surpasses every European tree. In its younger stages (when it is called ground ash) it is much used for walking-sticks, hoops, and hop-poles; and it matures its wood at so early an age, that an Ash-pole, three inches in diameter, is as valuable and durable for any purpose to which it can be applied, as the timber of the largest tree. "The use of Ash is (next to that of the Oak itself) one of the most universal. It serves the soldier ${ }^{1}$-and heretofore

1 Spears were anciently made of Myrtle, Cornel, and Hazel, but Pliny prefers the Ash for that purpose. 
the scholar, who made use of the inner bark to write on, before the invention of paper. The carpenter, wheelwright, and cartwright find it excellent for plows, axletrees, wheel-rings, and harrows; it makes good oars, blocks for pulleys, and sheffs, as seamen name them: for drying herrings no wood is like it, and the bark is good for the tanning of nets ; and, like the Elm (for the same property of not being apt to split or scale), is excellent for tenons and mortises; also for the cooper, turner, and thatcher ; nothing is like it for our garden palisade hedges, hopyards, poles and spars, handles and stocks for tools, spadetrees, \&c. In summer, the husbandman cannot be without the Ash for his carts, ladders, and other tackling, from the pike, spear, and bow, to the plow; for of Ash were they formerly made, and therefore reckoned amongst those woods which, after long tension, have a natural spring, and recover their position, so as in peace and war it is a wood in highest request. In short, so useful and profitable is this tree, next to the Oak, that every prudent lord of a manor should employ one acre of ground with Ash to every twenty acres of other land, since in as many years it would be more worth than the land itself."-But, we may add, it should be planted in sheltered situations, where the soil is moderately dry. " Some Ash is curiously eambleted and veined, so differently from other timber, that our skilful cabinet-makers prize it equal with Ebony, and give it the name of green Ebony, which their customers pay well for; and when our woodmen light upon it, they may make what money they will of it." - "Lastly, the white and rotten dotard part composes the ground for our gallants' sweet powder; and the truncheons make the third sort of most durable coal, and is, of all others, the sweetest of our forest fuelling, and the fittest for ladies' chambers; it will burn even whilst it is green, and may be reckoned amongst the kinds of wood which burn without smoke." 1

1 Evelyn's Sylva. 
Phillips, speaking of the value of Ash-timber, says : "In remote times, when this island was overrun with woods, timber-trees were principally valued for the food which they yielded to herds of swine; and thus, by the laws of Howel Dda, the price of an Ash was rated at $4 d$., while an Oak or a Beech was put at 120d. At the present time, Ash-timber meets with as ready a sale, and brings nearly as high a price, as the best Oak; and although we do not so frequently meet with large Ash-trees as we do with large Oaks and Elms, yet it will be seen that the natural size of the tree is nearly the same. But as it grows so much more rapidly than the Oak, so will it sooner decay than that tree, if not felled at maturity. It is observed, that when the woodpeckers are seen tapping these trees, they ought to be cut, as these birds never make holes in the Ash until it is on the decay."

I must not omit to mention the parent of all the "Weeping-Ashes," which, if not approaching in beauty the normal condition of the tree, are so frequently employed to decorate suburban gardens. This singular tree was discovered about the middle of the last century in a field belonging to the Vicar of Gamlingay, near Wimpole, in Cambridgeshire. It was then a very old tree, and some of its progeny have attained the age of sixty years. Grafts (for by means of them only is it propagated) have been carried to France, Germany, and even to America.

Another variety of the Ash (Fráxinus heterophylla) is occasionally to be met with, bearing simple leaves, but is only remarkable for wanting the graceful lightness of foliage which characterises the common Ash. This, too, is increased by grafting, but is altogether unworthy of being encouraged. Some botanists consider this, but without sufficient grounds, to be a distinct species. 


\section{THE BOX.}

\section{Buxus Sempervirens.}

\section{Natural Order-EUPHORBIACE}

\section{Class-Monecia. Order-Tetrandria.}

MANY of my readers, probably, are acquainted with the subject of the present chapter only as a neat edging for flower-beds, or as a shapely bush in the formal garden of some antiquated manor-house: yet the Box-tree has a very good claim to be considered a native British tree. Its right is certainly disputed by some of the old botanists, and by the more recent authors who quote their opinions : but inasnuch as it is in undeniable possession of at least one extensive district in England, and has been so long enough to give to that one the name of Box-hill, I think we are justified in advocating its claims to be considered a native tree. Besides this, not only did it give name to Boxley in Kent, and Boxwell in Gloucestershire, which would prove at least that it has grown at these places from time immemorial, but it is expressly mentioned by several authors as a native. Gerard, for instance, who wrote in Elizabeth's reign, says : "It groweth upon sundry waste and barren hills in Englande." Evelyn says : "These trees rise naturally at Boxley in Kent, and in the county of Surry, giving name to the chalky hill ${ }^{1}$ (near the famous Mole or Swallow) whither the ladies and gentlemen, and other water-drinkers from the neighbouring Ebesham

1 Boxhill. The Hon. Daines Barrington, in a paper inserted in the Philosophical Transactions for 1769, says: "Now we happen to know that this hill was so called from an Earl of Arundel's" (the famous antiquary) "having introduced this tree in the reign of James or Charles the First." Barrington does not state whence he obtained. his knowledge, nor does he account for the fact that a naturalist of the preceding century found it growing on "the waste and barren hills in Englande," at least forty years before James I. came to the throne. 
Spaw, often resort during the heat of summer to walk, collation, and divert themselves into those antilex natural alleys and shady recesses among the Box-trees, without taking any such offence at the smell which has of late banished it from our groves and gardens." Gilpin, too, is of the same opinion; speaking of Box-hill, he says: "This plant grows here in full luxuriance, in its native uncultivated state, marking the road on the right with great beauty." This is, I believe, the only place in Great Britain in which the Box grows in profusion in its wild state. Here it attains the height of about fifteen or sixteen feet, and gives to the scenery quite a foreign character, the mellow tint of its foliage harmonizing well with the grey of its stem and the richer green of any other tree which may happen to be associated in the landscape with it ; and at seasons when other trees are out of leaf it displays an unconsciousness of winter which no artificial shrubbery can compete with.

Evelyn says, quaintly, but with great propriety: " $\mathrm{He}$ that in winter should behold some of our highest hills in Surry clad with whole woods of these trees, for divers miles in circuit (as in those delicious groves of them belonging to the Honourable, my Noble Friend, the late Sir Adam Brown, of Beckworth Castle), might, without the least violence to his imagination, fancy himself transported into some new or enchanted country ; for, if in any spot of England,

'Hic ver assiduum, atque alienis mensibus æstas,'

'_- tis here

Eternal spring and summer all the year.",

Most other shrubs, if left to themselves, in a few years outgrow their beauty, becoming bare near the ground, and assuming an unsightly, straggling appearance. But the Box retains its shape for many years, and, as it here forms a thick and extensive coppice, it gives to the country a character as pleasing as it is unusual. 
In the East it attains a much larger size than with us, and is mentioned in the sacred volume in conjunction with several of the largest forest trees : "I will set in the desert the fir-tree, and the pine, and the box-tree together : that they may see, and know, and consider, and understand together, that the hand of the Lord hath done this, and the Holy One of Israel hath created it" (Isaiah xli. 19, 20).

As a cultivated tree it was formerly much valued by practitioners of the topiary art, ${ }^{1}$ for which it is better adapted than any other tree, owing to the closeness of its growth and its suffering no injury from the frequent use of the shears.

It is a slow grower, attains a great age, and will thrive in most soils, and at almost any temperature. It was so trained as to represent architectural devices, figures of men and animals, arcades, and various other forms. The method adopted in order to produce these various semblances was to inclose the tree in a light frame of wicker work, constructed in the shape required, and to cut back the shoots which protruded till a solid mass of verdure was produced. The wickerwork was then removed, and the Box-tree compelled to retain its grotesque shape by frequent use of the shears or knife. Even now we may occasionally fall in with a vegetable globe or some other such absurdity: but gardeners nowadays, instead of wasting their time in distorting Nature, employ it more profitably in assisting her to produce new varieties, of

"1 Topiary work, or, the art of cutting the Box and other trees into artificial forms, was carried to such an extent among the Romans, that both Pliny and Vitruvius use the word topiarius to denote the art of the gardener : a proof that, as far as ornament was concerned, the art of clipping was considered the highest accomplishment that could be possessed by a gardener among the ancient Romans. This appears to have been equally the case in Europe in modern times; gardeners, even so late as the time of the Commonwealth, being called by Commenius 'pleachers' (from the old word pleach, 'to interweave'). About the middle of the seventeenth century the taste for verdant sculpture was at its height in England; and, about the beginning of the eighteenth, it afforded a subject for raillery for the wits of the day, soon afterwards beginning to decline."-Loudon. 
studying how to rear and propagate new species, of useful and ornamental plants.

Various extracts and perfumes were formerly made from the leaves and bark of this tree, and were considered specifics for a yet greater variety of diseases. Modern science has, however, discarded them all. There seems yet to remain a lingering belief that a decoction of the leaves strengthens the hair; but in bygone days its efficacy was deemed greater even than that of any of the modern nostrums recommended for the same purpose.

Old Gerard, who was sufficiently credulous in other and less plausible matters (for example, that the Bernicle-goose owed its origin to the Oak), very wisely observes, that the Box "is more fit for dagger-hafts than to make medicines."

Box-wood contains a powerful sudorific principle with a bitter taste, which has been separated and named Buximia. M. du Petit Thouars some years since stated to the Philomathic Society of Paris, that more Box-wood than hops entered into the composition of almost all the beer in France. Olivier de Serres recommends the branches and leaves of the Box as by far the best manure for the vine; not only because it is very common in the South of France, but because there is no plant that by its decomposition affords a greater quantity of vegetable mould. Wordsworth relates that "in several parts of the north of England, when a funeral takes place, a basinful of sprigs of Box is placed at the door of the house from which the coffin is taken up; and each person who attends the funeral takes one of these sprigs, and throws it into the grave of the deceased." 1

1 Twigs of Rosemary were formerly carried, in like manner, by persons attending funerals. In many parts of the Continent the custom still continues. Hogarth, in one of his pictures, represents the mourners carrying small sprigs. In South Wales it is yet common for those who accompany the corpse to carry sprigs of Rosemary, or Yew, which they strew on the coffin after it is lowered into the grave. 
"Fresh sprigs of green box-wood, not six months before, Filled the funeral basin at Timothy's door."

In the north of Devon newly-made graves may frequently be seen decked with sprigs of Box and other village evergreens : and it takes its place among Holly and Laurel as an ornament of our churches generally, at Christmas.

By the ancients Box-wood was highly valued as a material for musical instruments, Buxus, ${ }^{1}$ the name by which it was known, often standing for a "flute ;" and in our own country it is said by Evelyn to have been "of special use for the turner, engraver, mathematical instrumentmaker, comb and pipe maker, who give great prices for it by weight, as well as measure; and by the seasoning, and divers manners of cutting, vigorous insolations, politure and grinding the roots of this tree (as of even our common and neglected Thorn), do furnish the inlayer and cabinet-maker with pieces rarely undulated, and full of variety. Also of Box are made wheels or shivers (as our ship-carpenters call them), and pins for blocks and pulleys ; pegs for musical instruments ; nut-crackers, weavers' shuttles, hollar-sticks, bump-sticks, and dressers for the shoemaker, rulers, rolling-pins, pestles, mall-balls, beetles, tops, chess-men, screws, bobbins for bone-lace, spoons, nay the stoutest axle-trees."

"The Box-wood used by the cabinet-makers and turners in France is chiefly that of the root. The town of St. Claude, near which is one of the largest natural Box-woods in Europe, is almost entirely inhabited by turners, who make snuff-boxes, rosary beads, forks, spoons, buttons, and numerous other articles. The wood of some roots is more beautifully marked, or veined, than that of others, and the articles manufactured vary in price accordingly. The wood of the trunk is rarely found of sufficient size for blocks in France ; and when it is, it is so dear, that the entire trunk of a tree is seldom sold at once, but a few feet are disposed

1 Buxus was also used to signify "a comï" and "a boy's top," which were usually made of the same material. 
of at a time, which are cut off the living tree as they are wanted. Boxes, \&c., formed of the trunk are easily distinguished from those made of the root, the former always displaying a beautiful and very regular star, which is never the case with the latter." 1

Box is the hardest and heaviest of all European woods, the only one among them that will sink in water, or that is sold by weight. By far the most important use to which Box-wood is applied is as a material for woodengraving, an art which has now attained such perfection, and is in such great request for the illustration of books, that it may not be uninteresting if I here introduce a short sketch of its history.

A method of multiplying copies of a pattern by means of a stamp was known to the ancient Babylonians, as may be proved by an examination of some bricks brought from the site of the city of Babylon, and preserved in the British Museum. These bear in them characters evidently produced by pressure from a wooden block while the clay was in a soft state. At a later period, the Chinese and Indians were accustomed to print on paper, cotton, and silk (though it does not appear that they had carried the art to such perfection as to delineate figures), long before the custom was practised in Europe. In the thirteenth and fourteenth centuries, when writing was an accomplishment confined to the learned, a wooden stamp was used in the place of a sign-manual for attesting written documents; and in the fifteenth century, or perhaps earlier, the art was applied to stamping figures on playing cards. If the earliest cards bore designs at all resembling the grotesque

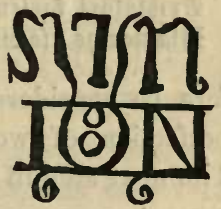
figures on modern specimens, wood-engraving was as yet very far from having any pretension to be considered one of the fine arts, or in the least degree connected with them. Most probably the latter are exact copies, for so utterly

${ }^{1}$ Loudon.

E 2 
unnatural are the kings and queens depicted on them, that it is scarcely possible they can be anything else than traditional absurdities. ${ }^{1}$ A modern playing-card may there-

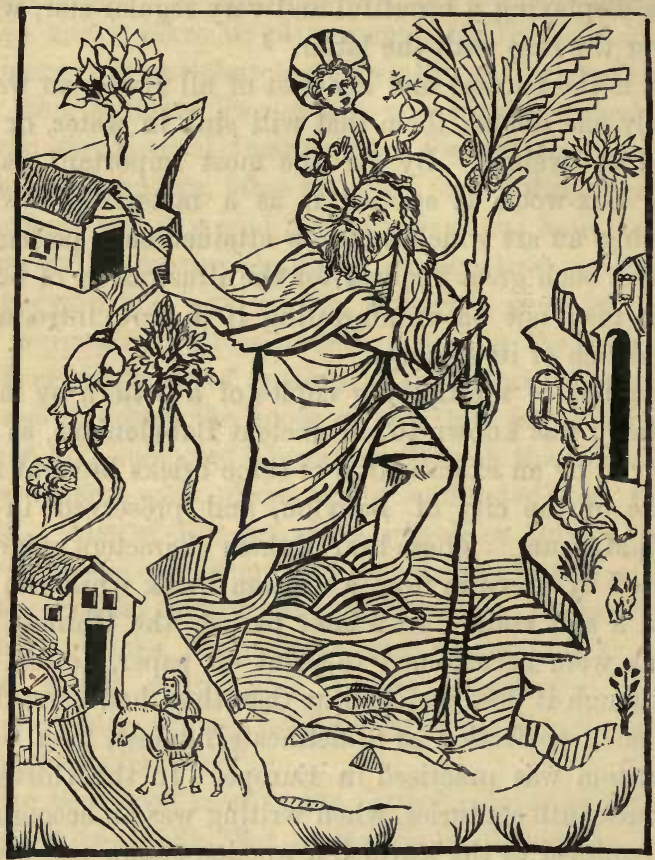

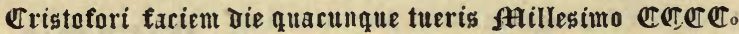
Ella nentpe die morte mala non moricris. ${ }^{2} \quad x x_{0}$ terno.

fore be considered as affording a fair specimen of the perfection of wood-engraving in the fifteenth century. The next step in advance was the delineation of figures of

1 A similar instance of obstinate adherence to an old and therefore familiar pattern, a long way behind the existing state of the arts, may be observed in the never-ending "willow pattern" on earthenware.

2 Translation:-

Gaze on the face of Christopher every day,

So on that day thou shalt not die an evil death. 1423 . 
the Saints, on which account the art received the patronage of the Church. The oldest woodcut of which there is any authentic record, is one of St. Christopher carrying an infant Saviour through the water, and bearing the date of 1423. It is of folio size, and coloured in the manner of our playing-cards.

Such engravings appear to have been distributed as devotional pictures among the laity, and to have been occasionally preserved by the monks, who pasted them into

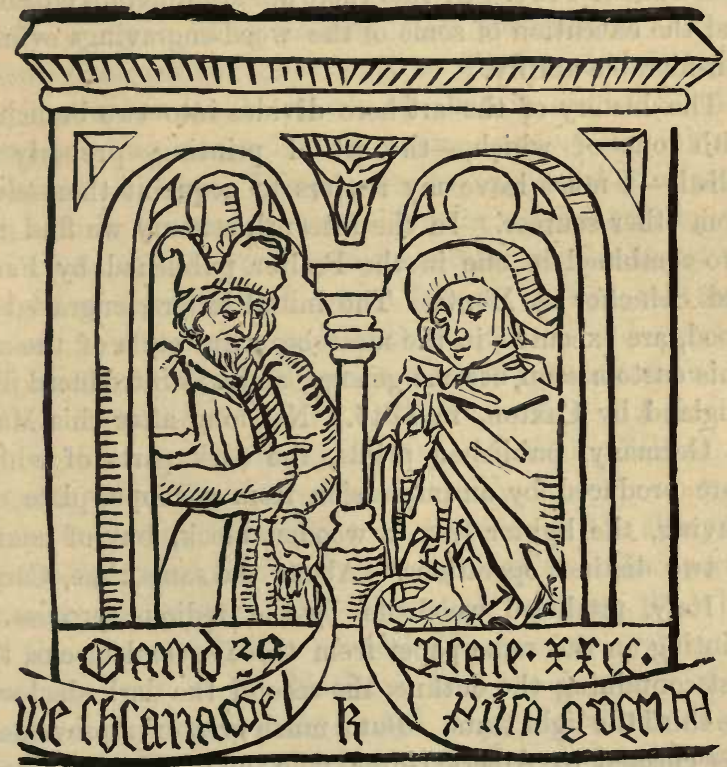

the earliest printed books with which they were funished. That of St. Christopher, above alluded to, was discovered in the monastery at Buxheim, near Meiningen, and is now in the possession of Earl Spencer. Collections of them appear also to have been published before the invention of printing from moveable types, for the use of those who either were unable to read, or could not afford to purchase 
a manuscript copy of the Scriptures. The most important of these is the Biblia Pauperum, or "Poor Preachers' Bible," a collection of historical subjects from the Old and New Testaments, accompanied by explanatory inscriptions in Latin. This appears to have been a most popular book, for not only are there many copies of it struck from different blocks, but it was repeatedly printed, long after the introduction of printing with moveable types. Another work of the same kind, "The Apocalypse, or History of St. John," was published about 1434. Of this there are six different editions, and the execution of some of the wood-engravings evinces considerable ability.

The history of the art here divides into two branches, with one of which,- the art of printing, properly so called,-I must leave my readers to acquaint themselves from other sources. In the fifteenth century we find the two combined in one in the Psalter published by Faust and Schueffer at Mentz. The initial letters, engraved in wood, are executed in the most beautiful style of the art. This custom soon became general, and was introduced into England by Caxton, in 1746. Not long after this Mair, in Germany, published prints, the dark parts of which. were produced by an impression from a copper-plate engraving, the lighter from a wooden block, but of course by two distinct operations. About the same time, Carpi, in Italy, produced woodcuts by the tedious process of printing on the same paper from three several blocks, the

- first containing the outline, the second the dark shadows, the third the light tints. But a much greater improvement was effected by Albert Durer, who, by a simpler process, produced woodcuts in which the figures were more skilfully designed and grouped, the laws of perspective more carefully attended to, and a variety of minor details introduced, which gave to the subject more of the stamp of truth and nature. The names of various other artists might be mentioned, who from time to time distinguished themselves by the eminence which they attained, until 
the close of the seventeenth century, when the custom of illustrating books with copper-plate engravings came into vogue, and wood-engraving was entirely neglected, so far as it regarded the delineation of subjects of interest, being employed solely for common decoration. That this should have happened is remarkable, inasmuch as the superiority of wooden blocks over copper plates in illustrating printed books is very great. In copper-plate engraving, the lines from which the design is transferred are sunk into the metal, either by the corroding effects of a mineral acid, or by a sharp-pointed steel instrument. Consequently the sunken lines must be filled with ink before an impression can be struck off; but in ordinary letterpress printing, a raised surface alone receives the ink and transfers the copy. Hence arises an impossibility of printing both by the same process. But in wood-engraving, the thickness of the wood being carefully regulated by the height of the type with which it is to be used, the block is set up in the same page with the types; and only one impression is required to print the letter-press and the cut which is to illustrate it. Added to this, the friction (though produced simply by the soft fleshy ball of the thumb) which is required to charge the lines of a copperplate engraving with ink, soon wears away the sharpness of the lines, and renders every new impression less perfect than its predecessor. But in printing woodcuts, the whole of the pressure being vertical, there is no perceptible wearing away of the block, so that the goodness of the impression depends only on the materials employed, and the care of the printer. ${ }^{1}$ But even on the supposition that the mechanical advantages of each were equal, the preference must be awarded to woodcuts for the illustration of

1 In an interesting Memoir of Bewick, prefixed to the sixth volume of Jardine's "Naturalist's Library," it is stated that "many of Bewick's blocks have printed upwards of 300,000 ; the head-piece of the Newcastle Courant above 1,000,000; and a small vignette for a capital letter in the Newcastle Chronicie, during a period of twenty years, at least $2,000,000 . "$ 
printed books, inasmuch as there is a harmony produced in the page by the engraving and letter-press being of the same colour, which is very seldom the case when copperplate vignettes are introduced with letter-press.

In spite however of all these advantages, the art of engraving on wood declined, and was all but lost, when it was revived in England by the celebrated John Bewick, an artist who not only restored the taste for the art, but executed, in the course of a long and industriously-spent life, numerous works, which his most zealous followers can scarcely do more than hope to equal. His excellence did not consist in the mere mechanical skill which he displayed : that, great as it was, resulted from his intense desire to embody his exquisitely acute perceptions of Nature. His woodcuts, therefore, are not simply representations of birds and beasts, just so far like the originals as to enable another person to discover what is meant:-but indices of his mind, like the solemn sounds of Handel's music, the majestic flow of Milton's poetry, the comprehensive exactness of Linnæus's descriptions. No one can have failed to notice this, who has turned over the pages of "The General Natural History of Quadrupeds," or of "British Birds." Nature seems to be alive in all of them ; the very tail-pieces, trifling though the subjects of many of them may be, are replete with interest, owing to the remarkable power which the author possessed of catching and portraying the peculiar characteristics of Nature, whether animate or inanimate. Much of this taste and skill Bewick imparted to his pupils, and to the same qualities the modern school of wood-engraving is indebted for its principal excellence.

Several mechanical improvements have of late years - been made in wood-engraving and printing; but, however the father of the modern art may be surpassed in skill, it is next to impossible for any one to excel him in excellence of design.

Owing to the numerous illustrated works now almost 
daily issuing from the press, the number of artists in this line has greatly augmented, and Box-wood has proportionately increased in price.

In 1815, the trees which were cut down on Box-hill produced upwards of $£ 10,000$. A great deal of that imported from Turkey, Odessa, and other places, is inapplicable to the purposes of the wood-engraver; nevertheless, in London alone, as much is annually consumed in works of art as amounts to many thousands of pounds.

There are, besides the Tree-Box, two varieties of DwarfBox, which were formerly much employed in forming patterns in flower-gardens imitating the designs of embroidery. This fashion is now quite gone out, having, like topiary-work, given place to the much more rational taste of cultivating various exotic plants; but representations of quaintly-figured gardens may yet be seen in old engravings. Dwarf-Box is now only planted as an edging to garden-beds, for which its low wiry habit well adapts it, preventing the loose earth from falling into the path, without rising high enough to shade the plants in its neighbourhood, or affording a secure refuge for vermin. It may be propagated by dividing the roots, or by planting cuttings in autumn. The best time for clipping Box is in June, when the new shoots obliterate all traces of the shears.

The flower of the Box is inconspicuous, being of a greenish yellow colour, and growing in clusters in the axils ${ }^{1}$ of the leaves; it ripens its seed at Box-hill. Flowers have never been observed on the dwarf variety.

1 Axil, Latin, axilla, the arm-pit ; in botanical phraseology, "the angle between the leaf-stalk and stem." 


\section{THE HAWTHORN.}

\section{Crategus Oxyacantha. \\ Nutural Order-Rosaces. \\ Class-Icosandria. Order-Pentagynia.}

THERE is, I think, no tree the simple mention of which excites such pleasurable emotions as the Hawthorn. Never attaining a remarkable size, neither stately in growth, nor graceful in form, it yet possesses an interest to which many a loftier and more elegant child of the forest cannot aspire. We may see it applied to the most homely and unromantic purposes, clipped by the hedger's shears of every particle of natural spray, and reduced, as it were by line and plummet, to the uniform proportions of a mere verdant wall; yet the tree to which the mind reverts when the Hawthorn is mentioned is independent of any such associations. It does not, it is true, carry us away to forests or woodland mountains, to the wild fastnesses of Nature, where men and the things of men have no place. Were we acquainted with it only in such situations, it would want half its interest; but it recurs to the memory as the necessary appendage of the village, to which, in our earlier years, it was our highest privilege to make our holiday excursionsthe veteran record of our infantile sports, remaining unchanged while the stern realities of life have been working in ourselves a change too perceptible-a common shelter from sun or shower to the rude patriarchs of the hamlet, the same group (nearly, for some are not) that half a century ago tottered as feebly to their childish amusements as now they do to their shady seat beneath its branches, and from the self-same cabins too-and the contemporary of all the bygone sports that old and young loved to look back upon, or forward to, with equal interest.

The Hawthorn, too, is a tree which, from its association 
with the village festivities of the first of May, possesses a kind of antiquarian interest, which is deepened by the recollection that it illustrates "the simple annals of the poor." The first day of the month, from which it derived its name, "May-bush," was formerly a general rustic holiday, looked forward to, and prepared for, with as much zest as accompanies many a nobler entertainment; and it was a matter of no little solicitude whether the Hawthorn would be fully blown in good time; for a "bunch of May" was the crowning orrument of the May-pole, and encircled the head of the May-queen, her consort for the day being crowned with the more manly Oak.

Before the alteration of the style $e^{\mathrm{I}}$ in 1752 , the Hawthorn rarely failed to be in flower in good time: but since that period, May-day falling eleven or twelve days earlier, its blossoms are rarely fully expanded even in the south of England, until the second week in the month. ${ }^{2}$ In

1 The ancient Church calendar was constructed on the erroneous supposition that the year contained $365_{4}^{1}$ days exactly, being nearly twelve minutes too much. The error, therefore, in 129 years amounts to a whole day. In consequence of the inconvenience. which was found to result from this error during a long course of years, Pope Gregory XIII. in the month of March 1582 issued a brief, in which he abolished the old calendar, and substituted that which has since been received in all Christian countries, except Russia, under the name of the Gregorian Calendar or New Style (N.S.). Gregory, in order to restore the commencement of the year to the same place in the seasons that it had occupied at the time of the Council of Nice (A.D. 325), directed the day following the feast of St. Francis, that is to say the 5th of October, 1582, to be reckoned as the 15th of that month. The New Style was adopted in Britain in 1752 ; from that year till 1800, May-day fell eleven days earlier; and during the present century it falls twelve days earlier than when calculated by the Old Style (O.S.); May-day of the Season being now the 13th day of the month.

2 I have, however, seen it in Devonshire so early as the 29th of April ; and in the year 1846 it was gathered in Cornwall on the 18th of April. So unusually mild was the season of that year, that the Oaks at Clowance, Cornwall, had made shoots between two and three inches long on the 11th of April ; though it not unfrqeuently happens that the Oak is not sufficiently in leaf "to hide King Charles" on the 29th of May. The blossom of the Hawthorn, though early, was so exceedingly scarce that many trees might be searched in vain for a single sprig, and scarcely one tree in a hundred bore an average crop of flowers. 


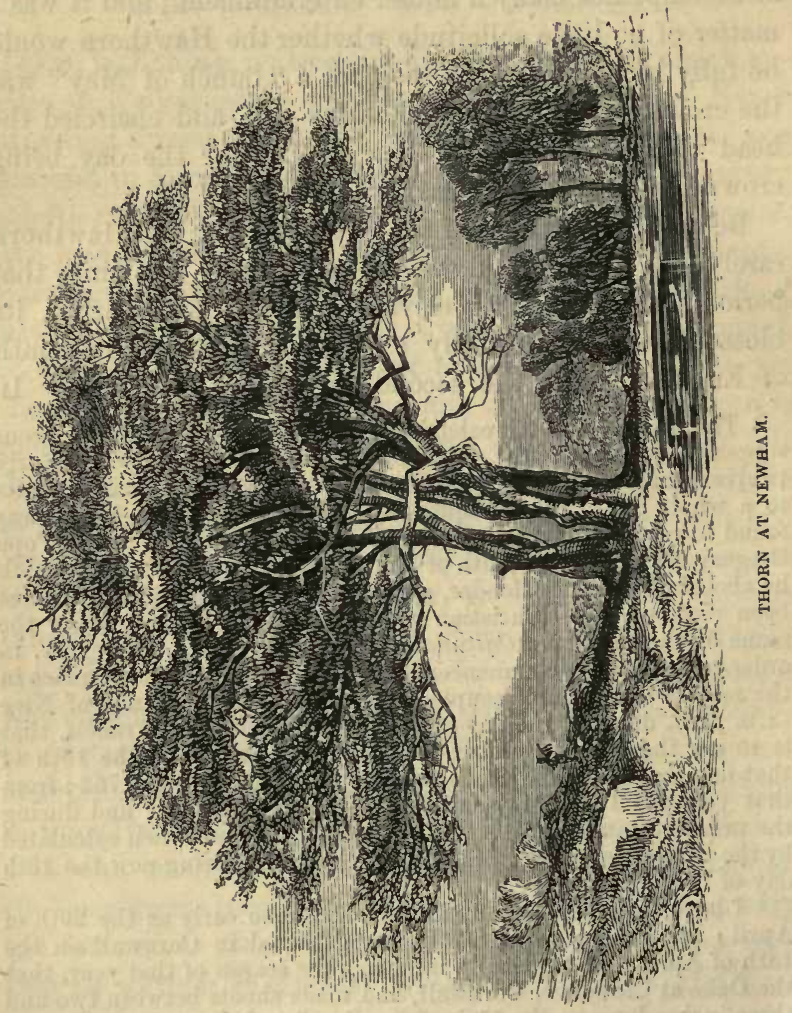


mountainous districts, - the Highlands, for instance,-it is frequently in full perfection so late as the middle of June.

By the ancient Greeks its flowers were made the emblem of Hope, and it was probably regarded in the same light by the Romans, as we read that its wood was chosen to make the torch carried before the bride at nuptial processions. In some countries it is regarded with a kind of veneration, from being believed to be the tree used to form the crown placed on our Blessed Saviour's head before His Crucifixion. Whether or not this opinion be a correct one is scarcely a fit subject for discussion in this or any other work. But if it really be the case, it is not improbable that it was selected by the Roman soldiers with the object of making the emblem of hope and happiness the instrument of inflicting pain. Such a motive would accord well with the spirit which demanded the Cross and the purple robe. In some parts of France, the country people affirm that the Hawthorn utters groans and sighs on the evening of Good Friday; and when a thunderstorm is impending, they gravely adorn their hats with a bunch of its leaves, in the belief that, thus protected, the lightning cannot touch them. It is also related, that on the morning which followed the horrible massacre of the French Protestants by the Roman Catholics on St. Bartholomew's day, a Hawthorn in the churchyard of St. Innocent's, in Paris, suddenly put forth its blossoms for the second time.

It is far from improbable that the legend of "The Glastonbury Thorn" was originally connected with some superstitious veneration of the Hawthorn, yet more ancient than itself. According to this legend, Joseph of Arimathæa, attended by twelve companions, came to preach the Gospel in Britain, and landed on the Isle of Avelon. ${ }^{1}$ Here he fixed his staff in the ground (a dry Thorn sapling, which had been his companion through all the countries he had

1 The high ground on which the Abbey of Glastonbury stands is thus named, and tradition asserts that it was in remote times really an island, the meadows around it having been since formed by the retiring of the sea. 
traversed) and fell asleep. When he awoke he found, to his great surprise, that his staff had taken root, and was covered with white blossoms. From this miracle he drew a very natural conclusion, that as the use of his staff was taken from him, it was ordained that he should fix his abode in this place. Here, therefore, he built a chapel, which, by the piety of succeeding times, increased to its subsequent magnificence. Gilpin, in his "Observations on the Western Parts of England," gives the following amusing account of the veneration with which it was regarded at a no more distant period than the close of the last century:- "I should ill deserve the favours I met with from the learned antiquarian who has the care of these ruins, though he occupies only the humble craft of a shoemaker, if I did not attempt to do some justice to his zeal and piety. No picturesque eye could more admire these venerable remains for their beauty than he did for their sanctity. Every stone was the object of his devotion. But above all the appendages of Glastonbury, he reverenced most the famous Thorn which sprang from St. Joseph's staff, and blossoms at Christmas.

"It was at that time, he said, when the King resolved to alter the common course of the year, ${ }^{1}$ that he first felt distress for the honour of the house of Glastonbury. If the time of Christmas were changed, who could tell how the credit of this miraculous plant might be affected? In short, with the fortitude of a Jewish seer, he ventured to expostulate with the King upon the subject; and informed his Majesty, in a letter, of the disgrace that might possibly ensue if he persisted in his design of altering the natural course of the year. But though his conscience urged him upon this bold action, he could not but own that the flesh trembled. He had not the least doubt, he said, but the King would immediately send down and have him hanged. He pointed to the spot where the last Abbot of GIastonbury was executed for not surrendering his Abbey ; and he gave us to understand there were men now alive who could suffer

${ }^{1}$ The alteration of the Calendar alluded to at p. 83 . 
death, in a good cause, with equal fortitude. His zeal, however, was not put to this severe trial. The King was more merciful than he expected, for though his Majesty did not follow his advice, it never appeared that he took the least offence at the freedom of his letter."

Both Gilpin and his simple-minded informant were in error in supposing the tree then standing to have been the identical one with which the legend is connected. The original "Holly-Thorn," which stood on Weary-all-hill (the spot where Joseph and his companions are said to have sat down all-weary with their journey), originally had two distinct trunks, one of which was destroyed by a Puritan in Queen Elizabeth's reign, and the other, together with many yet more interesting relics of antiquity, shared the same fate during the Great Rebellion. If we may credit James Howell, the author of "Dodona's Grove" (printed in 1644), the mistaken fanatic who completed the work of destruction did not go unpunished: "and he was well serv'd for his blind Zeale, who going to cut doune an ancient white Hauthorne-tree, which, because she budded before others, might be an occasion of Superstition, had some of the prickles flew into his eye, and made him Monocular." 1

1 In Ireland, to the present day, it is the popular belief that "no one will thrive after rooting up an old Thorn." Some years since a gentleman residing in Carrickfergus, co. Antrim, employed as his gardener an old artilleryman, named Peter S-, who had been invalided in consequence of wounds received in battle, and passed among his comrades as a brave soldier. One day Peter received lirections to uproot a "reverend Hawthorn," which, together with the hedge in which it stood, was to make way for some improvements in the garden. He immediately set to work, and soon cleared the hedge of all that grew in it except the Thorn, the roots of which had penetrated deeply into the ground, and which remained untouched. Next day, the gentleman asked him why the tree had not been removed as he desired. Peter answered, "that it was hardly possible - that it would be dangerous to attempt it." His master remonstrated with him, explaining why it was necessary that the Thorn should be included in the order for removal, and left him with a strict injunction to set about the task inmediately, which he, very reluctantly, then prepared to do. Next day, however, to his surprise, the master found the devoted tree still maintaining its ground, erect and uninjured. On sharply questioning the offender 
There are, however, still in existence two trees of the same description, evidently much above a hundred years old, which no doubt were either grafts, or sprung from seeds, of the original tree. From one of these, which stands within the precincts of the Abbey, in a garden adjoining St. Joseph's Chapel, I received, on the 11 th of February, 1846, a sprig, in full leaf, and furnished with perfectly formed flower-buds. The tree from which it was gathered measures two and a half feet in circumference, and I was assured by the vicar of Glastonbury, Dr. Parfitt, that it had been budding and blossoming since Christmas. It blossoms a second time in May, and from these latter flowers only is fruit produced. Formerly, the blossoms were so highly valued that they were sold at Bristol, and even exported to various parts of Europe, and the variety is still propagated by grafts in the gardens of the curious; but only on account of the strange efforts which it annually makes to commence spring in mid-winter.

Miss Strickland, in her "Lives of the Queens of England," mentions that its branches were deemed worthy of being presented to royalty. "Christmas," says Père Cyprian, "was always observed in this country, especially at the King's palaces, with greater pomp than in any other realm in Europe." Among other ancient ceremonies now forgotten,

why he had not followed his directions, poor Peter, with the utniost solemnity, assured him that " he had conımenced the work, but at the moment his pick-axe struck the root of the tree he received a violent blow from some invisible hand, that made him stagger and almost fall to the ground-moreover, that on going home, he found that just at the same hour, and he had no doubt, at the very same instant, his wife had experienced a similar blow." After this his master did not urge him further in the matter, but got some other person to extirpate the mysterious tree, and the task was accomplished without any further evil result. Crofton Croker, who is most learned in the superstitions of Ireland, remarks that, according to the popular belief, "On May-eve the evil Elves seem to be particularly active and powerful : to those to whom they are inimical they give a blow unperceived, the consequence of which is lameness." There can be little doubt that these two superstitions are connected in their origin with that recorded in the text respecting the Glastonbury Thorn. 
he mentions a pretty one, in; which a branch of the Glastonbury Thorn, which usually flowers on Christmas Eve, used to be brought up in procession, and presented in great pomp to the King and Queen of England on Christmas morning. Père Gamache, in mentioning this ceremony, says, this blossoming Thorn was much venerated by the English, because in their traditions they say that St. Joseph of Arimathea brought to Glastonbury a thorn out of our Lord's crown, and planting it in the earth, it burgeoned and blossomed, and yearly produced blossoms to decorate the altar on Christmas Eve mass-

"That only night in all the year Saw the stoled priest the clialice rear."

WORDSWORTH.

The Père seems to enjoy very much the following anecdote of Charles I., though it was against the Catholics :"Well!" said the King, extending his hand, one Christmas Day, to take the flowering branch of Glastonbury Thorn, "this is a miracle, is it?" "Yes, your Majesty," replied the officer who presented it, " a miracle peculiar to England, and regarded with great veneration by the Catholics here." "How so," said the King, "when this miracle opposes itself to the Pope?" (Every one looked astonished in the royal circle, Papist and Protestant.) "You bring me this miraculous branch on Christmas Day, old style. Does it always observe the old style, by which we English celebrate the nativity, in its time of flowering?" asked the King. "Always," replied the venerators of the miracle. "Then," said King Charles, "the Pope and your miracle differ not a little, for he always celebrates Christmas Day ten days earlier by the calendar of new style, which has been ordained at Rome by papal orders for nearly a century." This dialogue probably put an end to this old custom, which, setting all idea of miracle aside, was a picturesque one; for a flowering branch on Christmas Day is a pleasing gift, whether in a court or a cottage.

The same authoress thus accounts for the fact that the 
Hawthorn was selected to be the distinguishing badge of the House of Tudor. After the battle of Bosworth, in which Richard III. was slain on Redmore Heath, and his body ignominiously stripped, " the crown was hidden by a soldier in a Hawthorn bush, but was soon found, and carried back to Lord Stanley, who placed it on the head of his sonin-law, saluting him by the title of Henry VII., while the victorious army sang $\mathrm{Te}$ Jeum on the blood-stained heath. It was in memory of the fact that the red-berried Hawthorn once sheltered the crown of England, that the House of Tudor assumed the device of a crown in a bush of Fruited Hawthorn. The proverb of "Cleave to the crown though it hang on a bush,' alludes to the same circumstance."

The sight of the Hawthorn always recalls images of rural life; but we must go back to a somewhat remote period to find it invested with its full honours. During the reign of Henry VIII., May sports were the favourite diversion of all classes, not only in the country, but even in London. On the eve of May-day, the citizens used to go in companies to the neighbouring woods and groves, some to Highgate or Hampstead, some to Greenwich, some to Shooter's Hill ; there the night was spent in cutting down green branches, in preparing the May-pole, and in a variety of sports and pastimes. On their return early in the morning, the revellers adorned the May-pole with flowers and foliage from one end to the other, the pole itself being previously painted with the most brilliantly variegated colours. The pole was dragged to its destination by a large number of oxen, each ox having a nosegay of flowers tied to the tips of his horns : men, women, and children, all dressed in their gayest habiliments and laden with green boughs, completed the procession. As they passed through the streets of London, they found

"Each street a park,

Made green, and trimm'd with trees;"

the church porches decorated

"With Hawthorn buds and sweet eglantine, And garlands of roses ;" 
they heard music sounding from every quarter, and here and there they beheld in their way some May-pole, preserved from the last year, already elevated, and a wide circle of beaming faces dancing round it. The church of St. Andrew the Apostle was called St. Andrew Undershaft, from the circumstance that from time immemorial a Maypole or shaft had been set up there, which towered considerably above the church tower. Long streamers or flags were now attached to the pole, which was then finally reared to its proper position, amidst the loud cheers of the multitudes gathered round. Summer-halls, bowers, and arbours were now formed near it; the Lord and Lady of the May were chosen, and decorated with scarves, ribbons, and other braveries; and then the dances, feastings, and merriment of the day fairly began. The King himself frequently took part in these festivities, for, as we learn from "Hall's Chronicle," " his Grace being young, and not willing to be idle, rose in the morning very early to fetch May or green boughs, himself fresh and richly apparelled, and clothed all his knights, squires, and gentlemen in white satin, and all his guard and yeomen of the crown in white sarcenet. And so went every man with his bow and arrows shooting to the wood, and so repaired again to the court, every man with a green bough in his cap; and at his returning, many hearing of his going a-Maying were desirous to see him shoot; for at that time his Grace shot as strong and as great a length as any of his guard." During the Great Rebellion the Parliament ordered that "all and singular May-poles be taken down." When Charles II. ascended the throne, the famous May-pole of the Strand ${ }^{1}$ was restored with great pomp and rejoicing, amidst multitudes of people, whose shouts and acclamations were heard from time to time throughout the whole day. When this pole had ceased to be the centre of the merry

1 "Amidst the area wide they took their stand, Where the tall May-pole once o'erlook'd the Strand."

PoPe. 
May-day circles, and the interest with which it was originally regarded had faded away, it was given to Sir Isaac Newton, and by his directions removed to Wanstead, to support the then largest telescope in the world. ${ }^{1}$

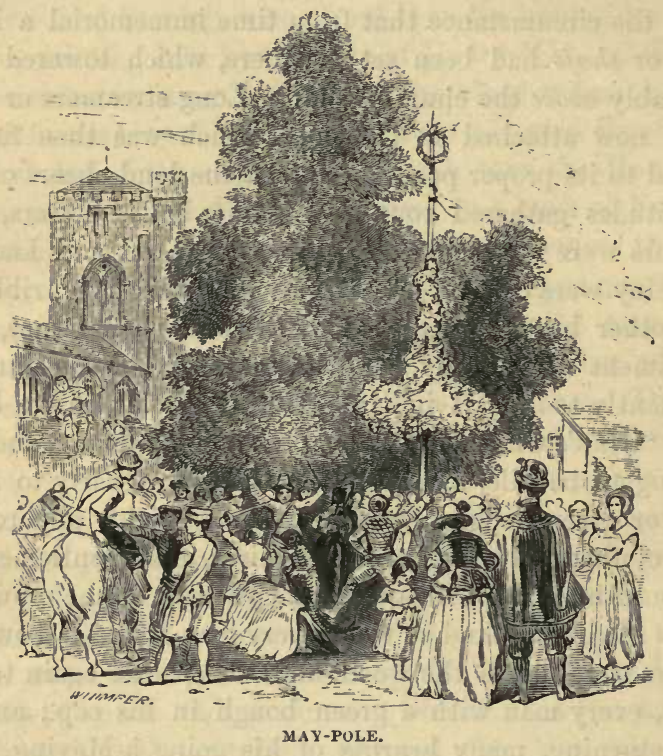

Of late years the celebrity of the Hawthorn as the symbol of May-day festivities has greatly declined. In London the number of those

"That do the fair and living trees neglect, Yet the dead timber prize,"

is so vastly increased, that the May-bush "swells its gems" and "salutes the welcome sun" without exciting a passing thought. The only class who, nowadays,

"With due honour usher in the May,"

are the poor chimney-sweeps, who, on this their single 1 Knight's London, vol. i. p. 174. 
holiday, put off their sable suit for one day in the year, to - deck themselves with flowers and green branches, and after all gain but little sympathy for their "maimed rights." In the rural districts we may see, here and there, the tall May-pole, standing all the year round, but never decked with flowers, never made the centre of festivity. In a few remote parishes, the poor farmer's boy yet rises earlier on May-morning than on other days, and hastens to attach a branch of Hawthorn to the cottage-doors, claiming as a reward, when the inmates are astir, a slice of bread and cream; and in some few towns and villages, principally in the West of England, children on May-day carry round from door to door, garlands of flowers decorated with birds' eggs, and beg contributions of halfpence. But, as far as regards legends, or the merry days of old, the Hawthorn has fallen into the "sere and yellow leaf." It is nevertheless still a favourite with all. Not, as I have before said, that it has great pretensions to elegance of form or picturesque beauty; but it possesses qualities which, I may almost say, engage our affections. It is the tutelary guardian of our fields, our orchards, and our gardens; and loves to grow and seems to thrive best near the rural habitations of men. When the cottager sets about inclosing his bit of garden-ground, the Hawthorn is ready to crown his lowly fence with its protecting and closely-woven boughs, which, with their thickest prickles, form an almost impenetrable barrier round the little domain. When arrived at maturity, its stoutest branches are often hacked unmercifully, nearly through their whole dimensions, and forcibly fixed in a direction contrary to their natural growth; yet the lacerated limbs, regardless of this rude treatment, send forth their shoots as vigorously as ever, and accommodate themselves to the humour or convenience of the planter, with all the fidelity of a spaniel. The Hawthorn may be considered, indeed, a domesticated tree, that readily adapts itself to the wishes and wants of man, requiring little care or attention during 
any period of its growth. Nor are these all its services; every plant that grows near it seems to acquire increased vigour from its friendly shelter and vicinity. The snowdrop, fearless of the tempest, displays its earliest flowers amid the thick covert of the Hawthorn; while the primrose, the violet, and the speedwell are generally its beautiful associates.

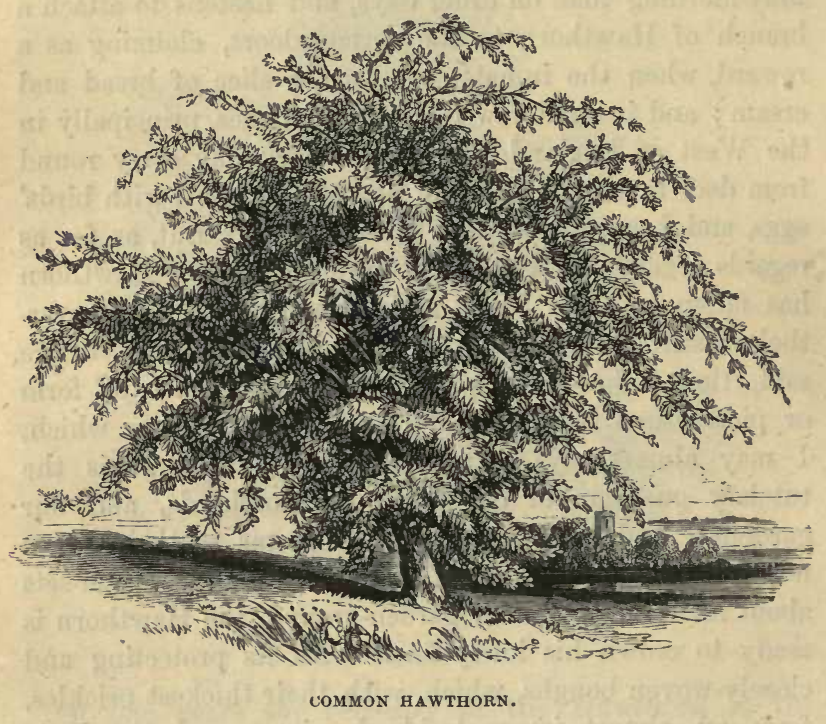

Deprived of its Hawthorn hedges, our rural scenery would lose one of its most interesting features, and present to the eye of the painter and the poet little more than a tame and monotonous expanse of country. Not only do they agreeably diversify our immediate vicinities, but when blended by distance give a rich and unrivalled charm to English landscape.

The Hawthorn is also one of the earliest harbingers of summer. What can surpass the beautiful and delicate green of its first unfolding leaves? After surveying from 
our windows the monotonous and dingy prospect of a long succession of house-tops and chimneys, how refreshing is it to turn our eyes to the green symbol of spring, which tells us that Nature, in her own lovely domain, is quietly preparing her robe of summer beauty! In the balmy month of May, the Hawthorn has no rival. It may then be said to live in an atmosphere of its own fragrance, the whole country being filled with its delicious odour. It has never been my lot to scent the aromatic breezes which are said to float through the air for a distance of many miles from the shores of Ceylon; but I can scarcely think that they are more grateful in themselves, or connected with more delightful associations, than the Hawthorn perfume of an English spring. And as to its wreaths of snowy blossoms, I know nothing more beautiful - some with their blossoms fully expanded, dotted with their delicate pink stamens-others, as yet unfolded, resembling little globes of silver set in pedestals of emerald. India may boast of more gorgeous flowers, but surely of nothing more elegant and graceful.

"When first the tender blades of grass appear, And buds, that yet the blast of Eurus fear, Stand at the door of life, and doubt to clothe the year Till geutle heat, and soft repeated rains, Make the green blood to dance within their veins : Then, at their call embolden'd, out they come, And swell the gems, and burst their narrow room ; Broader and broader yet, their leaves display, Salute the welcome sun, and entertain the day. Then from their breathing souls the sweets repair To scent the skies, and purge th' unwholesome air : Joy spreads the heart, and with a general song Spring issues out, and leads the jolly months along."

DRYDEN.

In spring and summer the Hawthorn breathes the very soul of rustic poetry; its rich profusion of erinson berries contributes largely to the glorious colouring of autumn, and soarcely less to relieve the dreary sameness of winter. 
The Hawthorn, according to some etymologists, is s ) - called from its fruit, or haw: or, if Booth be correct, the tree gives the name to the fruit; the first syllable of the word being a corruption of hage, or hoeg, and the word itself signifies a hedge-thorn. ${ }^{1}$ Cratcogus and Oxyacantha, to which may be added Pyracantha, are the names by

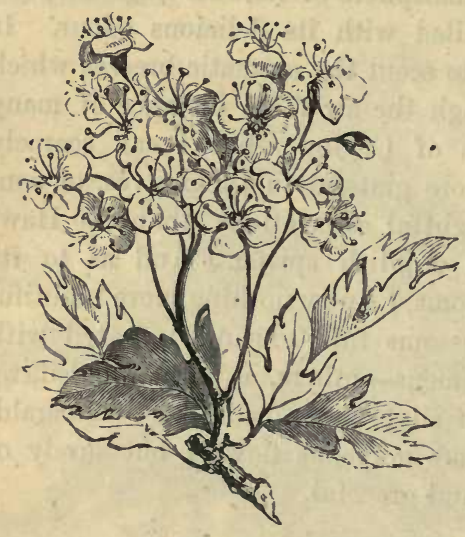

HAWTHORN BLOSSOM. which the Greeks are supposed to have designated the tree. By the Romans it appears to have been called Spina. Its French name, Aube-épine, refers to its flowering early in the spring, or morning of the year; aube signifying "the dawn of day." With us it is known indifferently by the names, May-tree, Maybush, from its season of flowering, and from the important place which it held in the old May games; Quickthorn, Quickset, and simply Quick, from its application to the construction of quick, or live hedges, instead of dead branches of trees ; and Whitethorn, from the profusion of its white flowers. By some botanists it is placed in the same genus with Mespilus the Medlar, with which it has many botanical characters in common.

It is found in most parts of Europe, from the Mediterranean to as far north as $60 \frac{1}{2}^{\circ}$, in Sweden, in the north of Africa, and in Western Asia. It was introduced many years since into Australia, where it grows as luxuriantly

1 Scott, in his "Discovery of Witcheraft," calls it "Hay-thorn." Cratægus is from the Greek kpdros, strength. Oxyacantha signifies sharp-thorn; Pyracantha, fiery-thorn. 
as in its native country, and where it must have no little efficacy in keeping alive the memory of the shady lanes and village greens of Old England.

It would be superfluous for me to give a detailed description of a tree with which every one is so familiar as the Hawthorn. I will therefore simply make a few remarks on its mode of growth and other peculiarities, which I will leave to my readers to verify at their leisure.

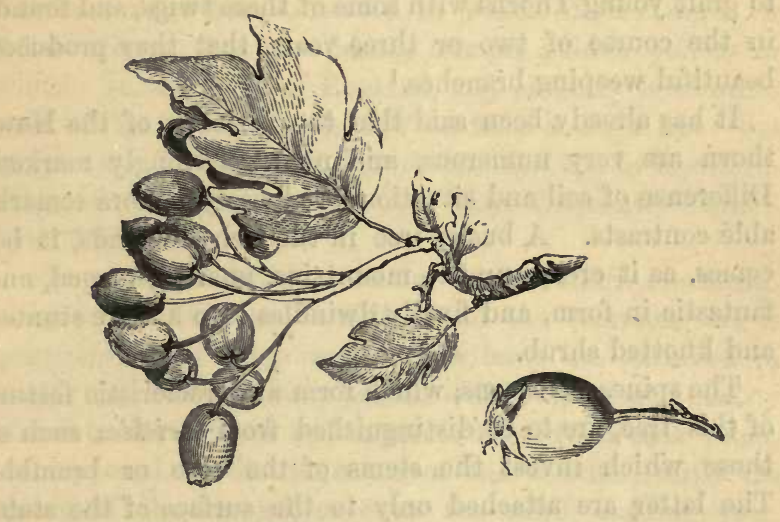

FRUIT OF HAWTHORN.

NATURAL SIZE.

In size, mode of growth, foliage, colour, and even odour of its flowers, the Hawthorn is perhaps more liable to variation than any other tree. Some exhibit a strong, free, and upright growth, being furnished with large and luxurious foliage, and but few spines ; others, on the contrary, assume the character of stunted, prickly bushes, with numerous small and deeply-cut leaves. Not unfrequently, from having been cut down to the ground in an early stage of their growth, numerous suckers rise from the same root, which, in after years, as they increase in bulk, become partially united at their bases, and have the appearance of a trunk dividing itself into many branches. 
Occasionally, but rarely, the Hawthorn assumes a pendent or "weeping" character. There is a fine tree of this kind in the garden which belonged to the Regent Murray in Scotland, and it is said to be very beautiful. Like many other trees, the Hawthorn is occasionally liable to an unhealthy mode of growth, when tufts or clusters of twigs are produced, resembling, if observed at a little distance, a large bird's nest. Mr. Anderson, the late curator of the Chelsea Botanic Garden, had the curiosity to graft young Thorns with some of these twigs, and found, in the course of two or three years, that they produced beautiful weeping branches. ${ }^{1}$

It has already been said that the varieties of the Hawthorn are very numerous, and no less strongly marked. Difference of soil and situation produces yet more remarkable contrasts. A bushy tree in the rich lowlands, it becomes, as it creeps up the mountains, gnarled, ragged, and fantastic in form, and finally dwindles into a mere stunted and knotted shrub.

The spines, or thorns, which form a characteristic feature of this tree, are to be distinguished from prickles, such as those which invest the stems of the rose or bramble. The latter are attached only to the surface of the stem, and even to that sometimes not very firmly. Thorns, however, are to be considered as imperfect branches, being furnished with proper bark, wood, and pith of their own. They enlarge in the second year of their growth, and for the most part produce buds and leaves, and eventually flowers and fruit; whereas prickles never increase in size after the first year, and are not converted into branches.

Not even is the colour of the blossom which gives the name "White-thorn" free from variations. Indeed, most commonly it assumes a pink hue in fading; but in gardens

1 Similar results followed from budding, or grafting, from the tufts produced by the Elm (Ulmus campestris). 
and shrubberies varieties are frequent in which the flower is of a permanent and decided pink or crimson. The perfume of the blossom is generally exceedingly fragrant; but occasionally this fragrance is almost overpowered by a strong fishy smell, which is most perceptible when the branch is held close to the nose, or carried into a close room. The haw, too, varies greatly in size, shape, and colour, being sometimes oblong, sometimes nearly globular, sometimes downy, at other times smooth and polished. Varieties have been observed in which it exchanges its usual crimson hue for black, orange, golden yellow or white. In the West of England, and probably most other parts of the country, each haw contains a single nut : but in the neighbourhood of Barnet and Hadley, in Hertfordshire, I have observed that they more frequently contain two.

The pink and double varieties of Hawthorn are multiplied by grafting and budding, but the common sort is generally raised from seed. The haws are gathered in winter and laid in a heap, mixed with a sufficient quantity of soil to cover them and separate them from each other, and exposed to the influence of the weather, until the spring of the second, or even the third, ensuing year. Unless this plan is adopted, the young plants do not appear till the year after they are sown, and consequently occasion the loss of the ground for that time. Various experiments have been tried with the seed, in the hope of finding some method of securing their growth in the year following that of their being gathered, but none have succeeded. The extreme hardness and durability of the shell is the probable cause of this sluggishness of growth. Could any plan be devised for breaking the shell without injuring the kernel, it is not unlikely that the desired object would be effected.

I have already spoken of the claims of the Hawthorn to picturesque beauty. Whether they are allowed or not there can be no doubt that not only the several varieties 
of the British tree, but many foreign species, are eminently ornamental to the lawn and shrubbery.

In husbandry, the principal use of the Quickthorn is for making hedges, for which purpose very many thousands are annually raised in Britain, an employment which forms an important branch of the business of nurserymen. This raising of Thorns for profit is a comparatively modern occupation, Evelyn being the first to tell us of a gentleman who had "considerably improved his revenue by sowing Haws only, and raising nurseries of Quicksets, which he sells by the hundred far and near." In the first year of their growth, the seedlings attain the height of from six to twelve inches, and during the two or three following years increase at the annual rate of from one foot to three feet; afterwards they grow more slowly till they have attained the height of from twelve to fifteen feet, when the shoots are produced principally in a lateral direction. This peculiarity, added to the rigidity of its thorns, makes it so valuable for the purpose above mentioned, the denseness of its side-branches being greatly promoted by frequent prunings of the upward shoots. In order to insure a uniformly dense hedge, the best plan is to plant three- or four-years-old trees in two rows, about a foot or a foot and a half apart, and in the following season to cut them down within an inch or two of the ground. If kept clear of weeds, they will make numerous strong shoots during the succeeding year, and soon form an impenetrable barrier. Hedges of this tree will stand the sea-breeze better than most others; but still are far from being uninjured by their rude visitor, for

"Where from sea-blasts the Hawthorns lean, And hoary dews are slow to melt,"

the side most exposed to the weather may frequently be observed rounded off as neatly as if by the gardener's shears. This effect is produced by the particles of salt with which the sea-breeze is charged being arrested by the 
twigs and killing the young buds : but the opposite side flourishes with tolerable luxuriance. ${ }^{1}$

The stock of the Thorn is employed not only for grafting varieties of its own species, but also, and with great advantage, for several of the garden fruits.

"Man does the savage Hawthorn teach

To bear the Medlar and the Pear;

He bids the rustic Plum to rear

A noble trunk and be a Peach."-Cowley.

The leaves, like those of the Beech and some other trees, are invested with a short downy covering while young, which afterwards almost entirely disappears, leaving a bright and glossy surface. They are said to be used not unfrequently for the purpose of adulterating tea; and indeed, not many years since, a patent was taken out for preparing them as a substitute for the more costly leaf; cattle will browse on them, not forgetting to pay due regard to the sharp spines with which the younger branches are plentifully armed.

With the exception that a strong fermented liquor may be made from haws, neither the blossom nor the fruit has been applied to any important use by man : but the flowers as well as the leaves afford sustenance to a variety of insects ; and the haws, which are followed, as to the time of ripening, by the berries of the Ivy, and those again by the berries of the Mistletoe, produce an abundant supply

1 Some few years ago, a gardener, accustomed only to the midland counties, was engaged by a gentleman, whose estate lies on the northern sea-coast of Devonshire, to superintend his garden and plantations. On his arrival he was sent by his employer to walk through his domain, that he might gain some notion of what would be required of him. His inspection being completed, he was asked what he thought of his new employment: "I like the place well," he replied, " and doubt not that I should be able to give satisfaction, except on one point. How my predecessor contrived to keep the Thorn-hedges so neatly clipped with only four hands to help him, I cannot tell, nor can 1 undertake to do as well : I must therefore decline the situation." He was not a little surprised on being told that the north-west wind was his " predecessor," a coadjutor whose services he probably afterwards found verging on the officious. 
of food to the feathered tribe during the severest and most protracted of our winters. It was formerly believed that the Hawfinch, a bird which derives its name from the fruit of this tree, remained with us during those months only when its favourite food is to be procured. It is now, however, known that it resides in England all the year round.

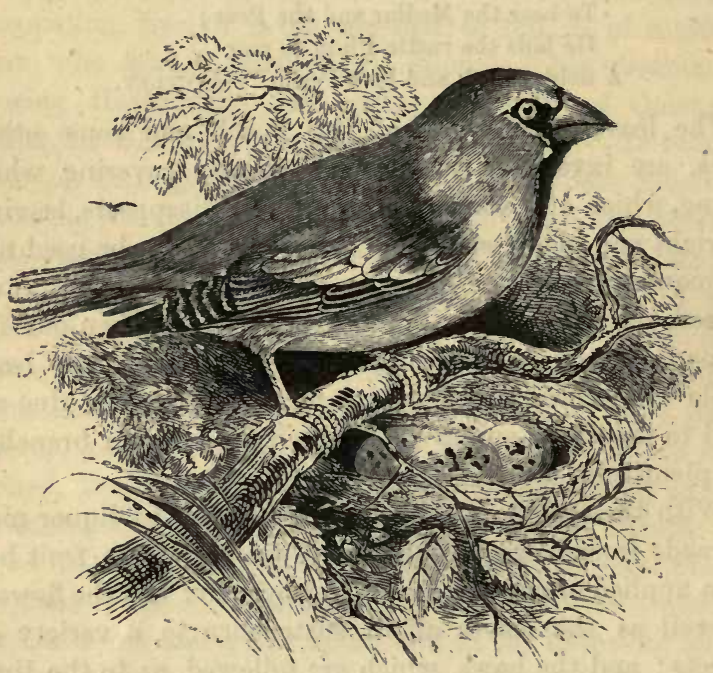

THE HAWFINCH.

The Hawthorn attains a great age, and, when large enough to rank among timber-trees, is of considerable value. According to Evelyn, "The root of an old Thorn is excellent both for boxes and combs, and is curiously and naturally wrought: I have read that they make ribs to some small boats or vessels with the White Thorn; and it is certain, that if they were planted single, and in standards, where they might be safe, they would rise into large-bodied trees in time, and be of excellent use for the turner, not inferior to box." Loudon says, "Its wood is very hard and difficult to work : its colour is white, but 
with a yellowish tinge; its grain is fine, and it takes a beautiful polish; but it is not much used in the arts, because it is seldom found of sufficient size, and is besides apt to warp. It weighs, when green, sixty-eight pounds twelve ounces per cubic foot; and when dry, fifty-seven pounds five ounces. It contracts, by drying, one-eighth of its bulk. It is employed for the handles of hammers, the teeth of mill-wheels, for flails and mallets, and, when heated at the fire, for canes and walking-sticks. The branches are used in the country for heating ovens ; a purpose for which they are very proper, as they give out much heat, and, like the Ash and Furze, possess the property of burning as readily when green as in their dry state."

It has also been stated that it might be substituted for Box-wood as a material for wood-engraving, in case of any deficiency in the supply of the preferable but more costly wood. It is often spoiled through inattention after cutting; if it be allowed to lie in entire logs or trunks, it soon heats and becomes quite brittle and worthless; it ought, therefore, to be cut up immediately into planks, and laid to dry.

\section{$\approx$ \\ THE BLACKTHORN. \\ Prunus spinosa. \\ Natural Order--ROSACEE. \\ Cliss-Icosandria. Order-Monogynia.}

THE subject of the last chapter has high claims to be ranked among the most interesting of British trees, being not only a beautiful ornament to the landscape at all seasons, but possessing a legendary character which secures for it more than the passing attention even of the antiquary. The subject of the present memoir, however, though its name might lead us to hope that it had more 
points of resemblance to the Hawthorn, possesses but little interest for botanist, forester, painter, or antiquary. In its natural state it is a rigid, wiry bush, remarkable for no beauty of flower or foliage, and not making up for its outward deficiencies by any inherent virtues residing in fruit, stem, or root.

Its very flowers, which are numerous and appear early in Spring, can barely be called ornamental. Expanding, as they do, before any other tree has ventured to show

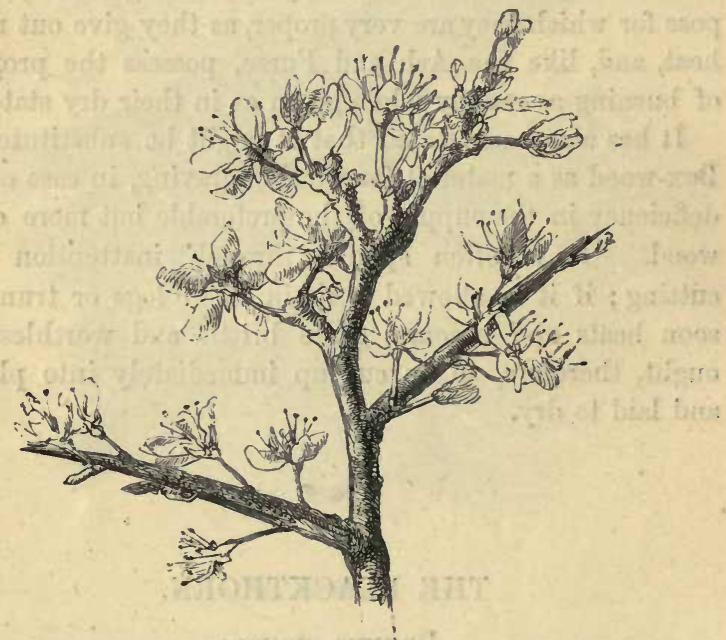

8LOE-FLOWER.

signs of returning life, we are inclined to look on them in the light of daring adventurers, rather than harbingers of the time which "purples all the ground with vernal flowers." Their white ragged petals contrast strangely with the sombre hues of the bare boughs around themthey look cold and cheerless, and carry the mind back to the frosts and snow of the winter which has just passed, instead of forward to the bright days of spring which are 
coming. A single primrose, a leaf-bud of Hawthorn or Elm-either of these is a prophet in whom we place unbounded confidence ; they are emblems of soft west winds and sunny showers: but the Blackthorn bespeaks our attention to the possible return of black east winds, frosty nights, and nipping blights. ${ }^{1}$

Nor does the Sloe-tree find a champion in the husbanrlman. It is by no means particular in its choice of soil and situation, but thrives everywhere. Its long creeping roots extend so rapidly, that in the course of a few years a single plant would, if left unmolested, cover an acre of ground. ${ }^{2}$ Thus left to itself, it has no disposition to assume the character of a tree, but forms a low thicket, to the exclusion of every more valuable plant, and, if growing in the neighbourhood of sheep-walks, most unceremoniously levies contributions from every woolly visitor who comes within reach of its knotted and thorny branches. If, by being deprived of its suckers, it is compelled to throw all its strength upwards, it will sometimes attain the height of thirty feet; and even in natural situations, where it cannot extend itself laterally, it rises to fifteen or twenty feet. The name "Blackthorn" appears to have heen given to it from the hue of its bark, which being much darker than that of the Hawthorn, probably originated the name of "White-thorn" given to the latter tree.

1 "This tree usually blossoms while cold north-east winds blow ; so that the harsh, rugged weather obtaining at this season is called by country people, 'Blackthorn winter.'"-WHiTE's Selborne.

2 "The name of Mère-du-Bois (Mother of the Wood) is applied to the Sloe-thorn in France, in the neighbourhood of Montargis, because it has been remarked there, that when it was established on the margins of woods, its underground shoots, and the suckers which sprung up from them, had a constant terdency to extend the wood over the adjoining fields ; and that, if the proprietors of lands adjoining forests where the Sloe-thorn formed the boundary did not take the precaution of stopping the progress of its roots, these would, in a short time, spread over their property; and the suckers which arose from them, by affording protection to the seeds of timber trees (which would be deposited ainong them by the wind, or by birds), would ultimately, and at no great distance of time, cause the whole to be covered with forests."-Loudon. 
The epidermis, or outer coating of the bark, has, in this species, as in most others of the same genus, a tendency to split horizontally, and to curl back while yet partially attached to the tree. The leaf is small, of a dark green colour, slightly downy underneath, especially at the junction of the veins, and in its young state. The flowers are white and conspicuous only from their abundance : as they expand before the leaves, and are consequently unrelieved by any verdure, they are not beautiful. The fruit when

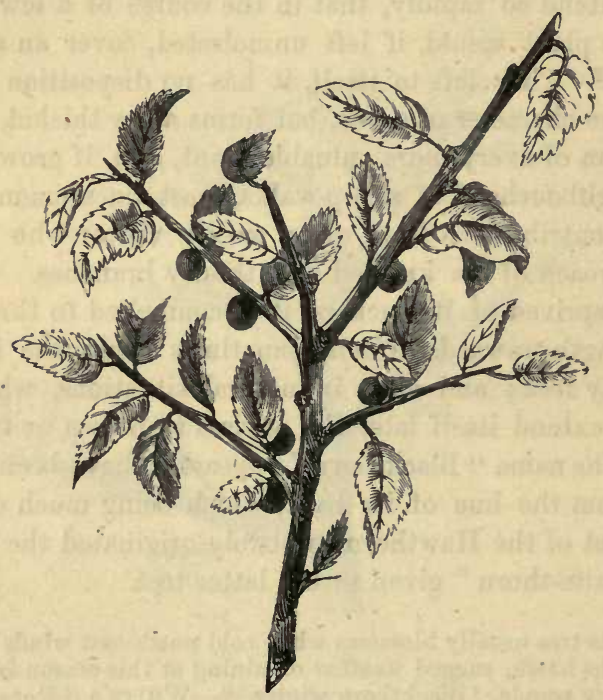

SLOE.

ripe is black, and being covered with a delicate bloom, presents, late in the autumn, a more pleasing appearance than the tree can display at any other season.

It is found throughout Europe, with the exception of the extreme north; it occurs also in the north of Africa, and many parts of Asia, and has been introduced into America, where it is frequently found in hedges perfectly naturalized. 
The Blackthorn is not nearly so valuable for the construction of live hedges as the Hawthorn, owing, in the first place, to its rambling habit; and, secondly, to its tendency to send up perpendicular branches, which are bare of thorns towards the base. The wood rarely attains a size which will allow it to be applied to any useful purposes as timber; but the straight stems are extensively used as walking-sticks, which are much admired for their bright colour and numerous knots. The thorny dead branches are also recommended as being well adapted for forming a fence round young trees planted in parks, the sharp and rigid thorns effectually preventing the inroads of cattle. The leaves are used to adulterate tea, for which they form a substitute less liable to detection than almost any other British plant, possessing a bitter, aromatic principle, which, inasmuch as it is to be attributed to the presence of prussic acid, must render them very unwholesome. The fruit is intensely austere and astringent, so much so that a single drop of the juice placed on the tongue will produce a roughness on the throat and palate which is perceptible for a long time. When mellowed by frost, however, it becomes red and pulpy, but at no period of its existence claims to be considered a grateful fruit. The juice of it, in its unripe state, is said to enter largely into the composition of spurious port wine, and it may, it is said, be fermented into a liquor resembling new port.

So impudently and notoriously is this fraud carried on in London, and so boldly is it avowed, that there are books published called "Publicans' Guides," \&c., in which receipts are given for the manufacture of port wine from cider, brandy, and sloe-juice, coloured with tincture of red sandars or cudbear. ${ }^{1}$ This villanous compound may be

${ }^{1}$ Red Sandars is a preparation of sandal-wood, used as a dye. Cudbear, so called after a Mr. Cuthbert, who first brought it into use, is a lichen (Lecanora tartarea), found growing in several parts of the Continent, and in Great Britain, on granitic and volcanic rock, and is also used as a dye. The chemical test called litmus is a preparation of this vegetable. Catechu is a substance procured by boiling 
converted into "old port" in a few days by the addition of catechu.. The corks may be stained by being soaked in a strong decoction of brazil-wood and a little alum; and even bottles are manufactured which contain a sufficient quantity of lime to be sensibly acted on by the acid, and to produce a counterfeit "crust!"

In France the unripe fruit is sometimes pickled and sent to table as a substitute for olives, and in Germany and Russia it is crushed and fermented with water, and a spirit distilled from it. In Dauphiné, the juice of the ripe fruit is used for colouring wine. Letters marked on linen or woollen with this juice will not wash out. The substance sold hy druggists under the name of German Acacia is prepared from the juice of the unripe fruit ${ }^{1}$

The bark, according to Dr. Lindley, is one of the substances which has been reported to resemble "Jesuits' bark" in its effects. It may be used for tanning leather; a decoction of it with alkali dyes yellow, and it may be employed with advantage as a substitute for galls in the manufacture of ink. There are several varieties, differing principally in the size of the leaf and fruit; but the only one deserving notice is the double flowered, which is cultivated and said to be highly prized in Japan and China for the abundance of its blossom.

On the whole, the Blackthorn, in its natural state, possesses few valuable qualities. It certainly does not recommend itself to our favourable consideration on the score of beauty, and being employed to adulterate some substances, and as an indifferent substitute for others, we are inclined to suspect its honesty; and as it is, moreover, a great enemy to the agriculturist, we do not scruple to include it among the "thorns and thistles" of the primeval curse. Yet, strange to say, as if to be both a memorial of the curse, and of the implied promise; that the industry of chips of the heart-wood of Acacia catechu; it is a dark-coloured, powerful astringent.

1 The true or Egyptian Acacia is the production Acacia Nilotica, and is used in medicine as a mild astringent. 
man should not be without effect in mitigating the consequences of that curse, the austere sloe has been converted by human skill and labour into the luscious plum, one of our most valued fruits. It is a well-known fact, that the thorns of several fruit-trees, the Wild Pear for instance, disappear under cultivation; the variety of the Blackthorn called the Bullacetree, ${ }^{1}$ is also entirely destitute of thorns, and produces edible fruit; while most of the kinds of plums cultivated in our gardens are referred by some eminent horticulturists $^{2}$ to the same origin. Every cultivator of Dahlias or Verbenas must be aware that it is impossible to assign limits to the variations which these

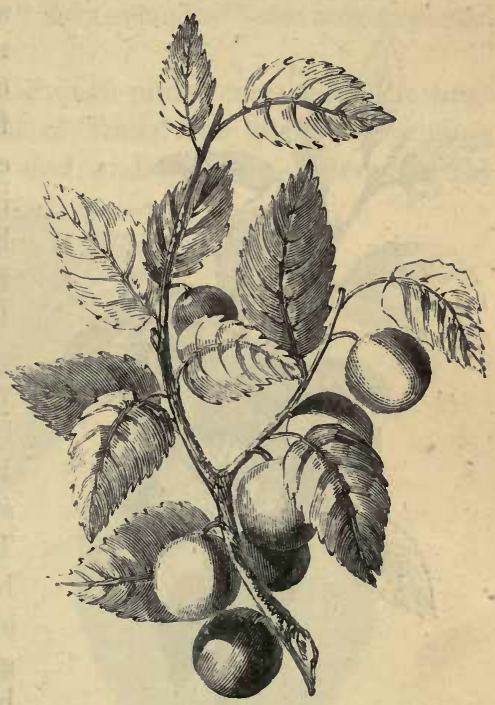

FRUIT AND FOLIAGE OF BULLACE-TRFE.

plants will undergo when subjected to the skilful treatment of the florist; and there is every reason, deduced both from theory and practice, why the same rule should be extended to fruit-trees. In the Horticulturial Society's Transactions, 274 distinct varieties of the plum actually in cultivation are enumerated, a number sufficiently great to admit of every possible gradation from the worthless sloe to the delicious green-gage. All these are referred by some horticulturists to another variety, Prunus doméstica, which, as its name would imply, is no longer found in a 
really wild state; and even when it is occasionally met with in hedges, approaches much more closely in character to the undoubtedly wild Bullace-tree, or Blackthorn, than it does to the garden varieties. The inference which we may safely draw from this fact is, that if the yellow

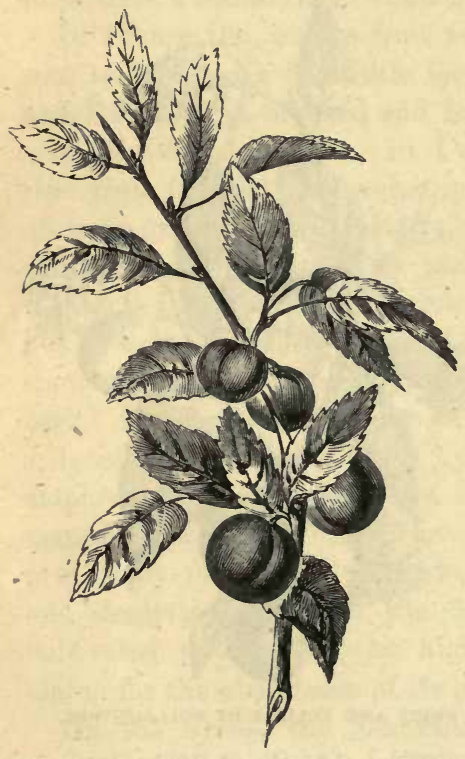

MYROBALAN PLUM. magnum bonum plum may be referred for its origin to the small black fruit of the "domesticated plum," as we find it in our hedges, we have at least equal reason for referring the latter to the sloe-tree.

For many of our best varieties of plum we are indebted to the French. First among these stands the Green-gage. It is known in France by several names : that of "Reine Claude" was given to it from its having been introduced into France by Queen Claude, wife of Francis I. During the Revolution, so great was the horror entertained against everything bearing the slightest allusion to royalty, that in order to retain its popularity it was obliged to change its name to "Prune citoyenne," Citizen-plum. It received its name Green-gage from the following circumstance. The Gage family, in the last century, procured from the monastery of Chartreuse at Paris, a collection of fruit-trees, the names of which were in every instance but one carefully attached to them. That of the Reine Claude, however, had been either omitted by the packer, or been rubbed off 
during the transit to England. The consequence was, that it stood without a name until it bore fruit, when the gardener very appropriately called it "Green-gage," in honour of the family who had introduced it. Since the revival of royalty in France, the Citizen-plum has recovered ts ancient name, and "Reine-claudes" are now exported n large quantities.

The best prunes and French-plums come from Provence and the neighbourhood of Tours, the quality depending upon the sort of fruit used, and the care observed in the

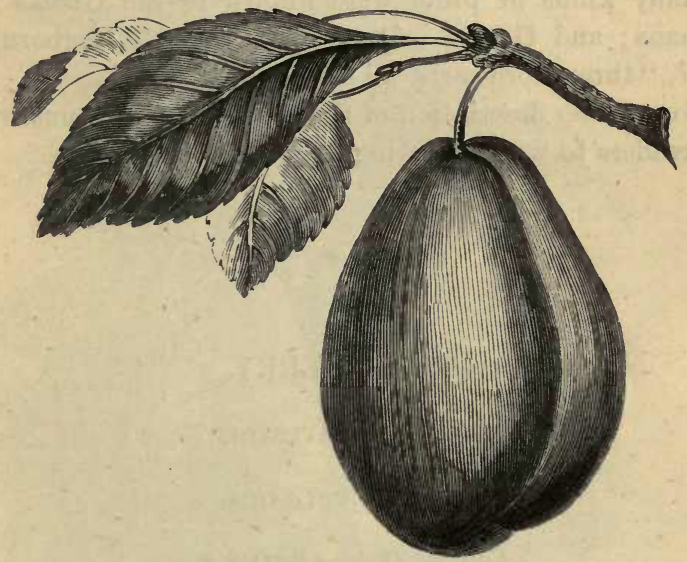

MAGNUM BONUM PLUM.

preparation. The commoner kinds are shaken from the tree and baked in an oven; but the finer sorts are gathered singly by the stems before sunrise, and laid, without touch. ing one another, exposed to the sun and air several days before baking, great care being taken not to remove the delicate bloom with which they are covered.

Brignoles 1 are the dried fruit of a tree which grows principally near the town of the same name in Provence. They are peeled when fresh, and dried in the sun. When the moisture which they contain is entirely evaporated, the 1 Corrupted into Prunellas. 
stones are taken out by hand, and the plums are pressed together in such a manner as to make them quite round. They are afterwards packed into small wooden boxes, ornamented with cut paper, and form an important article of revenue to the growers.

The Damascene, or Damson, takes its name from Damascus, where it grows in great quantities, and from whence it was brought into Italy about 114 B.c. It is used principally for preserves, and for making a kind of jelly called "Damson cheese."

Many kinds of plum were known to the Greeks and Romans; and Gerard had in his garden at Holborn, in 1597, "three-score sorts, all strange and rare."

For a fuller description of the garden-plums, I must refer my readers to works treating on horticulture.

\section{THE CHERRY.}

\section{CÉrasus sylvestris.}

CÉrasus vulgaris.

Natural Order-Rosaces.

Class-ICOSANDRIA. Order-MONOGYNIA.

THe subject of the present memoir affords another eminent example, in addition to that recorded in the last chapter, of the beneficence of the Almighty in permitting man to control the course and operations of Nature, so as to render them, in a measure, subservient to his gratification and advantage. Human industry, we have seen, has converted the Thorn into the fruitful Plum, and in the Cherrytree we have another instance scarcely less remarkable ; by dint of careful perseverance, a juiceless unpalatable berry becomes a delicious and nourishing fruit. The success 
which has attended the efforts of earlier cultivators ought, therefore, to supply us with a delightful incentive to industry, and, at the same time, a powerful motive to gratitude to our great Creator and Preserver.

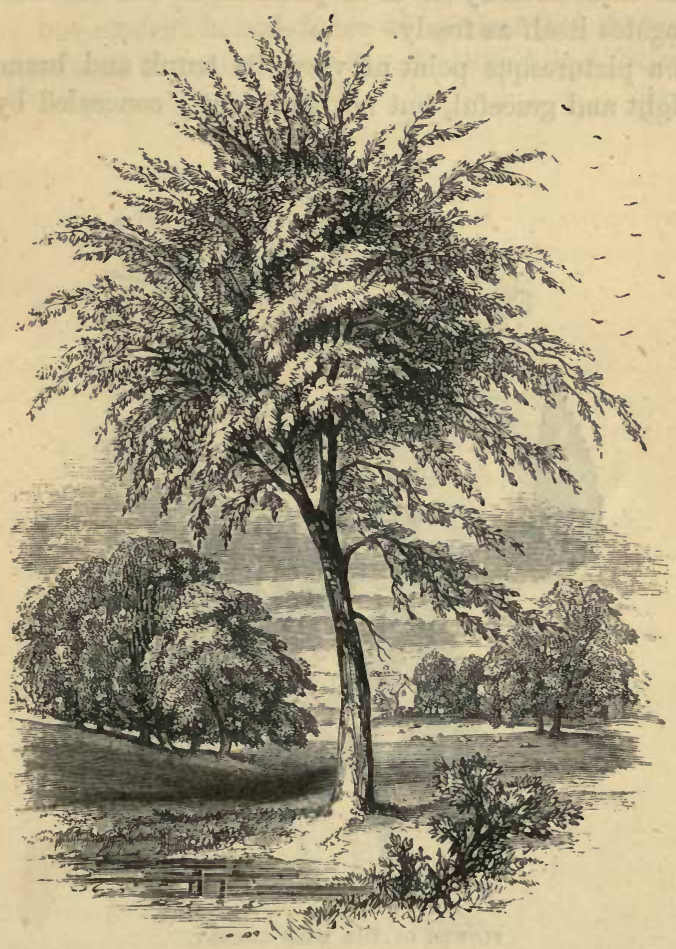

THE WILD CHERRY-TREE.

The Cherry-tree, though more familiarly known as a valued tenant of the orchard and garden, possesses undeniable claims to be considered a naturalized, if not a native, Forest Tree, resting its title both on its size and on the wildness of its haunts. It is not unfrequently met with in woods and hedges, and in the north of England is found 
on the mountains at an elevation of a thousand feet above the level of the sea. In congenial soils and situations it rises to the height of seventy or eighty feet, and in Scotland is planted for its timber. In some of the wilder parts of the same country it is as plentiful as the Birch, and propagates itself as freely.

In a picturesque point of view, its trunk and branches are light and graceful, but not sufficiently concealed by its

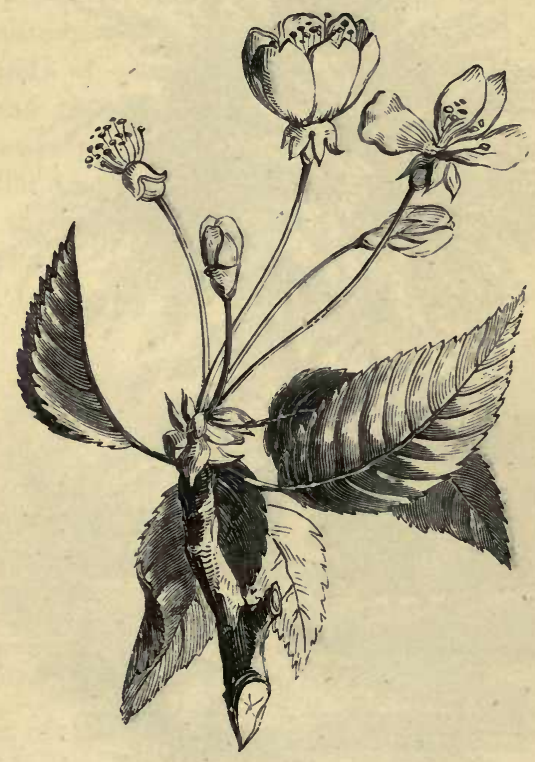

FLOWER OF THE WILD CHERRY.

scattered and somewhat scanty foliage. In early spring, however, the very deficiency of foliage renders more conspicuous its beautiful cluster of large flowers; while, in autumn, the bright crimson hue of its fading leaves irresistibly catches the eye, and imparts to the landscape a brilliancy which amply atones for any other defects. Amid mountainous scenery it is often particularly striking, 
contrasting exquisitely (especially when kindled into a brighter blaze by the straggling rays of the sun) with the dull grey of the rocks among which it has taken its station, and the rich brown of the river which it overhangs.

There are several varieties of the tree even in the wild state; but modern botanists are of opinion that these may all be reduced to two species, the Black and Red-fruited.

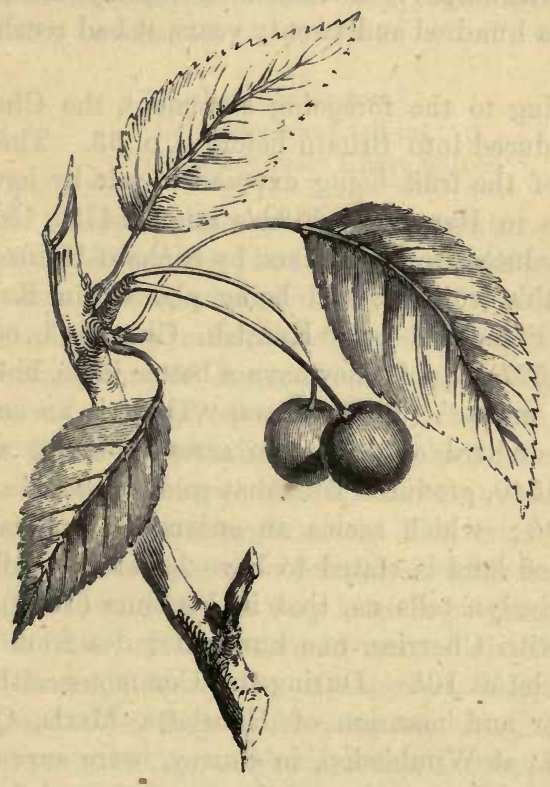

FRUIT OF THE WILD CHERRY.

It derives its name from Cerasus (now Kerasoun), a city of ancient Pontus, in Asia, whence it was brought by Lucullus, the Roman general (B.c. 67), at the close of the Mithridatic war. Lucullus thought this tree of so much importance, that, when he was granted a triumph, he placed it in the most conspicuous situation among the royal treasures which he had captured during the war; nor 
can there be any doubt, that, in permanent utility, it was the most valuable of his acquisitions. Some authors, however, are of opinion that the wild Cherry ${ }^{1}$ was the same as the Cornel, which was indigenous in Italy at the time, but not cultivated as a fruit-tree, and that Lucullus only introduced improved sorts. At all events, it does not appear to have been cultivated previously to the time of Lucullus, though afterwards it increased so rapidly that, in the course of a hundred and twenty years, it had reached even Britain.

According to the foregoing statement, the Cherry-tree was introduced into Britain before A.D. 53. The earliest mention of the fruit being exposed to sale by hawkers in London is in Henry the Fifth's reign, 1415. New sorts were introduced from Flanders, by Richard Haines, Henry the Eighth's fruiterer, and being planted in Kent, were called "Flanders" or "Kentish Cherries," of which Gerard (1597) says, "They have a hetter juice, but watery, cold, and moist." Philips says, "There is an account of a Cherry-orchard of thirty-two acres in Kent, which, in the year 1540, produced fruit that sold, in those early days, for 1,000l.; which seems an enormous sum, as at that period good land is stated to have let at one shilling per acre." Evelyn tells us, that in his time (1662) an acre planted with Cherries, one hundred miles from London, had been let at $10 l$. During the Commonwealth (1649), the manor and mansion of Henrietta Maria, Queen of Charles I., at Wimbledon, in Surrey, were surveyed previously to being sold, and it appears that there were upwards of two hundred Cherry-trees in the gardens. Since that time the Cherry-tree has found universal admission into shrubberies, gardens, and orchards. Kent still continues the principal county for cherries; yet nowhere do they grow in greater luxuriance and beauty than on the banks of the Tamar, in Devonshire, where

1 The fruit of this tree was subsequently called the Cornel-Cherry by sorne authors. 
they freely "thrive into stately trees, beautiful with blossoms of a surprising whiteness, greatly relieving the sedulous bee, and attracting birds." 1

In popular mythology the Cherry-tree is, for some unknown reason, associated with the cuckoo. In Germany, "the cuckoo never sings until he has thrice eaten his fill of cherries." In Yorkshire, children were formerly, and perhaps still are, accustumed to sing round a Cherry-tree the following invocation :-

"Cuckoo, cherry-tree,"

Come down and tell me

How many years I have to live."

Each child then shook the tree, and the number of cherries which fell betokened the years of its future life.

The naturalized species of Cherry in Great Britain are the Black and Red-fruited, belonging to the genus Prunus of Linnæus, Cerasus of Jussieu. ${ }^{3}$ Prunus avium, Prunus Cérasus or Cérasus sylvestris, is the Black-fruited Cherry, which, in favourable situations, attains the dimensions of a tree. Its leaves are large, pointed, somewhat drooping, and slightly downy on the under-side. The fruit is small, round, black when ripe, of an insipid bitterish flavour, and containing a stone which is very large in proportion to the size of the fruit. It is known in various districts by the name of Gean (a corruption of Guignes), Merries (from merisier, said to be derived from amère, bitter, and cérise, cherry), Corone, or Coroun (from corone, a crow, in allusion to its blackness), Black-heart, \&c.

Those botanists who are of opinion that Luculius only introduced new kinds of Cherries into Europe, consider this species a native, and not without reason ; for it grows

1 Evelyn's $S_{! l} / v a$.

2 A popular nursery rhyme begins with the same words.

3 Cérasus may be distinguished from Prunus, by its leaves being conduplicate, or folded tog ther in their young state, instead of being convolute or rolled together; and by the fruit being always destitute of the bloom which characterises all the varieties of Plum. 
freely and abundantly in Italy, Spain, Portugal, Turkey, Greece, Russia, the Mediterranean islands, Great Britain and Ireland, attaining a larger size in the north than in the south. Nevertheless, its general diffusion and apparent wildness of growth is not conclusive evidence in favour of its being considered a native of these countries. It has been remarked by M. le Conte, that in America, when Beech woods are cut down, they are speedily replaced by Cherry-trees. $\mathrm{He}$ accounts for this on the supposition that birds, who eat the fruit with avidity, may have resorted to the woods for shelter, and there dropped the stones, which either lay dormant, or germinated and remained in a diminutive state until the Beeches were cut down, when they advanced rapidly, and finally became the principal occupants of the soil. Now, if the Cherry-tree has become thus thoroughly naturalized in America, into which there can be no doubt that it was introduced, there is very fair ground for the opinion that its extensive diffusion through Europe may be attributed to the same cause, and that the assertion of the older authors, that it is of Asiatic origin, is correct.

The second species, which, though often found in our woods and hedges, is not really wild in any part of Europe, is the Red-fruited Cherry. It is called by botanists Prunus Cérasus, or by those who assign the Plum and the Cherry to distinct genera, Cérasus vulgúris. To this species many of the best sorts of our garden Cherries are referred, including the Flemish and Kentish Cherries, Maydukes (from Médoc, the province in France where the variety originated), and many others. It is a much smaller tree than the last, from which it may be distinguished by its unpointed leaves, which do not droop and are never downy beneath, and by its red, acid fruit.

In England, Cherries are to be considered rather as a luxury than as a staple article of food; but on the Continent, particularly in France, they are highly prized as supplying food to the poor; and a law was passed in that 
country in 1669 , commanding the preservation of all Cherrytrees in the royal forests. The consequence of this was that the forests became so full of fruit-trees, that there was no longer room for the underwood,- - when they were all cut down, except such young ones as were included among the number of standard saplings required by the law to be left to secure a supply. This measure was a great calamity to the poor, who, during several months of the year, lived either directly or indirectly on the fruit. Soup made of Cherries, with a little bread and a little butter, was the common nourishment of the wood-cutters and charcoalburners of the forest. Of late years the practice of planting Cherry-trees by the roadside has been extensively adopted in Germany; and one may now travel from Strasburg to Munich, a distance of two hundred and fifty miles, through an avenue of Cherries, interspersed with Walnuts, Plums, and Pears. By far the greater part of the first are ungrafted trees, which succeed in the poorest soil, and in the coldest and most elevated situations. A large portion of the tract of country which bears the name of Black Forest is an elevated, irregular surface, with no other wood than the Cherry-trees, which have been planted by the roadside. - Cherries are preserved in various ways. Sometimes they are simply dried in the sun, in which state they are much used for puddings: they are also preserved in brandy, or converted into marmalade, lozenges, \&c. Fermented and distilled, they furnish the liqueurs called Ratafia, Kirschwasser, and Maraschino. Wine and vinegar are also made from them; and an oil is extracted from the kernels, which is used to give the flavour of bitter almonds to puddings, \&c.; the leaves are also used for the same purpose.

From the bark of the Cherry-tree an elastic but not very viscid gum exudes, which is said to have many of the properties of gum-arabic. ${ }^{1}$ Hasselquist relates that more

1 Any excessive flow of gum is very injurious to the tree; and, indeed, in time proves fatal. 
than a hundred men, during a siege, were kept alive for nearly two months, without any other sustenance than a little of this gum, taken sometimes into the mouth, and suffered gradually to dissolve.

"The timber is very valuable, being of a firm texture, red-coloured, close-grained, easily worked, and susceptible of a high polish. These qualities render it a desirable material to the cabinet-maker, and the furniture made of it is little, if at all inferior, both in respect to beauty and durability, to that of the plainer kinds of mahogany. In this country, where the wood just mentioned has in a great measure superseded all other kinds in our articles of furniture, and where the Cherry-tree has never been cultivated to any extent as a timber-tree, it is rare to meet with specimens of furniture made of its wood; but in France, and other parts of the Continent where it abounds, it is extensively used for this and various other purposes, and is eagerly purchased by the cabinet-maker, the turner, and the musical-instrument maker. Its value, however, is not restricted to the uses made of it by those artisans; it is equally applicable to out-of-door uses and general carpentry; and where exposure to the atmosphere, or the alternation of dryness and moisture is required, it is superior to most other timber we possess, and is only inferior to the best Oak, or its rival the Larch." 1

When treated as coppice, it is very useful for hop-poles, props for vines, and hoops for casks. The Turks have the tubes of their pipes, which are from four to seven feet long, made of Cherry stems. ${ }^{2}$ Like the Ash, it burns very well as fire-wood in its green state; but if kept two or three years and then used as fuel, it smoulders away like tinder, without producing much heat.

The double-flowered Cherry is a favourite ornament of our gardens and lawns in spring, when its numerous snowwhite flowers present a beautiful appearance. Like many

1 Selby.

2 The best are made of the Mahaleb, or perfumed, Cherry. 
other double flowers, it produces no fruit; but the structure of its blossoms is particularly interesting to the physiological botanist, illustrating, better perhaps than any other plant, the fact that the seed-vessel, among other compound organs, is a metamorphosed or transformed leaf, altered in structure and functions, so as to perform offices in vegetable economy entirely different from those of the true leaf. In the double Cherry it appears to return to its primitive form; for in the centre of each flower is a minute leaf, exactly similar to those of the branches, notched and veined in the same manner, and even folded together like the young stem-leaves. Other double flowers, beside those of the Cherry, occasionally present the same appearance, especially Roses; but in all these the phenomenon is an irregular mode of growth, whereas in the Cherry it is constant.

The Cherry is a favourite tree of the Woodpecker, who perforates its trunk for the sake of feeding on the larvæ of insects, and hollowing out his nest: but the remarks made at page 68 are equally applicable to the case of this tree.

\section{THE BIRD-CHERRY.}

Cérasus padus.

The Bird-Cherry in its wild state rarely attains the dimensions of a tree; but there are in existence cultivated specimens between thirty and forty feet high, and a foot or more in diameter. It is most worthy of attention for its copious long clusters of snow-white flowers, which are much smaller than those of the Cherry, and soon fade. The fruit, called also Fowl-Cherry, Cluster-Cherry, and in Scotland Hag-Cherry, is small and worthless. "Birds of several kinds soon devour this fruit, which is nauseous, and probably dangerous to mankind, though perhaps not 
of so deadly a quality as the essential oil, or distilled water of the leaves." 1 It is most abundant in the north of England and Scotland. In Gerard's time it grew wild in the woods of Kent, where it was used as a stock to graft Cherries on : and in Lancashire it was found in almost every hedge. The wood is much used in France by the cabinet-maker, but little known in this country, owing,

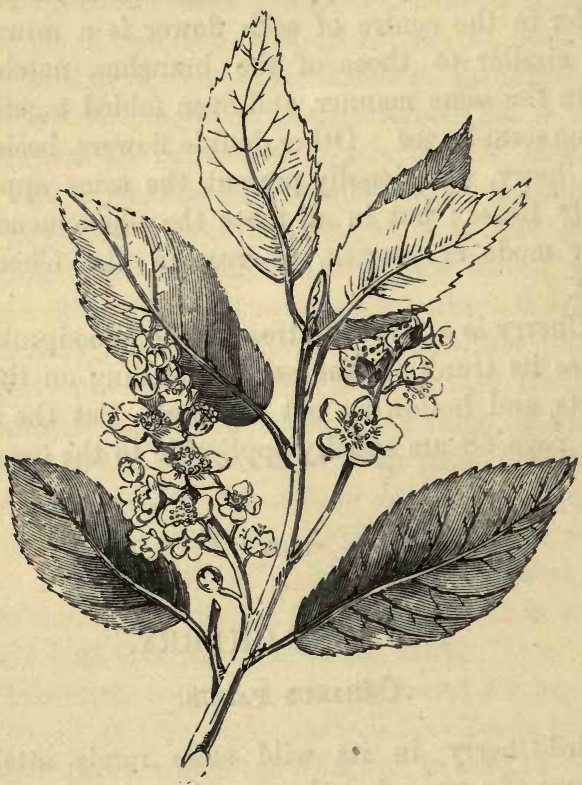

BLOSSOMS OF THE BIRD-CHERRY.

among other causes, to the difficulty of obtaining it sufficiently large. The leaves are more frequently attacked by caterpillars, than those of any other species of Cherry; hence, a writer in the Agricultural Journal of Bavaria recommends that from one to four young trecs (according

1 English Flora. 
to their size) should be planted at intervals of one or two hundred yards in orchards, when, he says, almost all the caterpillars and butterflies will resort to them. The appearance of the Bird-Cherry will be hideous, but the fruittrees will be safe.

Several other species of Cérasus are extensively cultivated in England as ornamental trees and shrubs, but none of them have any pretension to be admitted among British

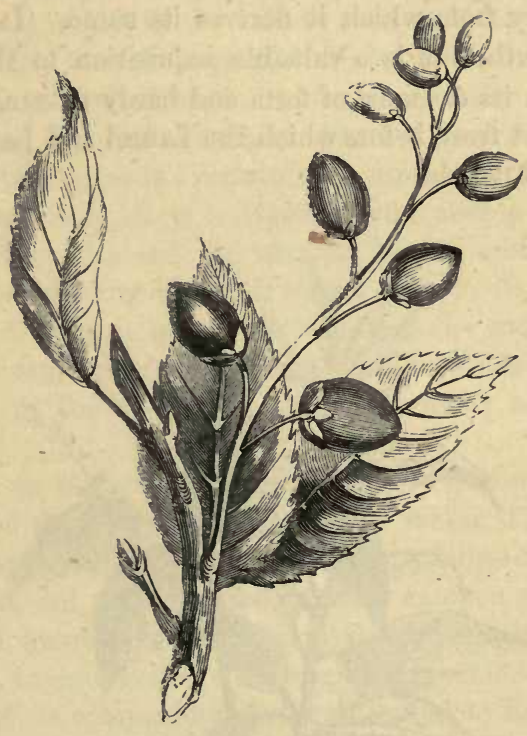

FRUIT OF THE BIRD-CHERRY.

Trees. My notice of them, therefore, must be very brief : Cérasus Laurocérasus, the Laurel-Cherry, or, as it is now almost exclusively called, Laurel, was introduced into Europe from Trebizond, in Asia Minor, in 1576 ; consequently, it is a mistaken notion to identify it with the famed Laurel of the ancients. This error is the more frequent, from our having given to the true Laurel, Laurus 
nóbilis, the name of Bay. Laurel leaves abound in prussic acid, and the water distilled from them is a most virulent poison. The custom of using them to flavour custards, puddings, \&c., should therefore be strongly deprecated. Insects, the appearance of which is liable to be injured by immersion in spirits of wine, may readily be killed by being shut into a closed box with bruised leaves, the aroma from which speedily takes effect.

Cérasus Lusitánica, or Portugal Laurel, is a native of the country from which it derives its name. It is not of rapid growth, but is a valuable acquisition to the shrubbery, from its elegance of form and hardy nature, resisting the severest frost, before which the Laurel and Laurustinus shrink and perish.

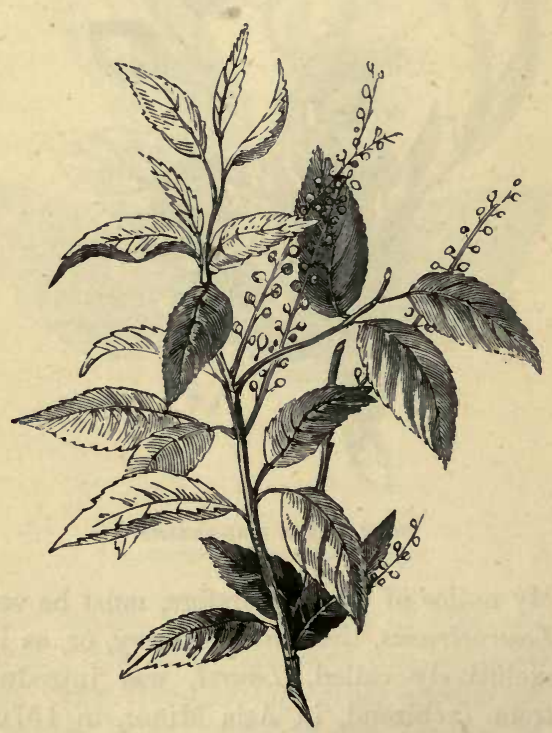

PORTUGAL LAUREL. 


\section{THE MOUNTAIN ASH.}

\section{Prrus aucuparia.}

Natural Order-ROSACEF.

Class-Icosandria. Order-Pentagynia.

Thrs universally admired tree chooses its dwelling, as its name would imply, in the wildest and most exposed situations, where, though impatient of being itself sheltered by any other kind of trees, it affords a friendly protection to grass and other plants which choose to grow beneath its shade. As long as it overtops its companions in the wood or mountain-side, it is a vigorous and stately tree: but when it has attained its utmost height, and its more aspiring neighbours begin to screen it from its due share of air and light, it quietly retires from the contest, pines away in confinement, and suffers itself to be destroyed by the drip of the very trees that it formerly nursed and protected.

Hence we rarely meet with a full-grown Mountain Ash in a crowded forest of ancient trees. Where it has gained the vantage-ground of a broken rock partially covered with rich, light soil, or taken its stand in an open glade, amid plants of humbler growth, it attains a considerable size. Or again, in an elevated situation, uncongenial to the rapid growth of its companions, but well suited to its own wild tastes and habits, it will continue to flourish for a century or more.

\section{"The Mountain Ash}

No eye can overlook, when 'mid a grove Of yet unfaded trees she lifts her head, Deck'd with autumnal berries that outshine Spring's richest blossoms ; and ye may have mark'd By a brook-side or solitary tarn, How she her station doth adorn: the pool Glows at her feet, and all the gloomy rocks Are brighten'd round her."-WORDSwORTH. 
The Mountain Ash is placed by most modern botanists in the same genus with the Apple and Pear, the fruit of

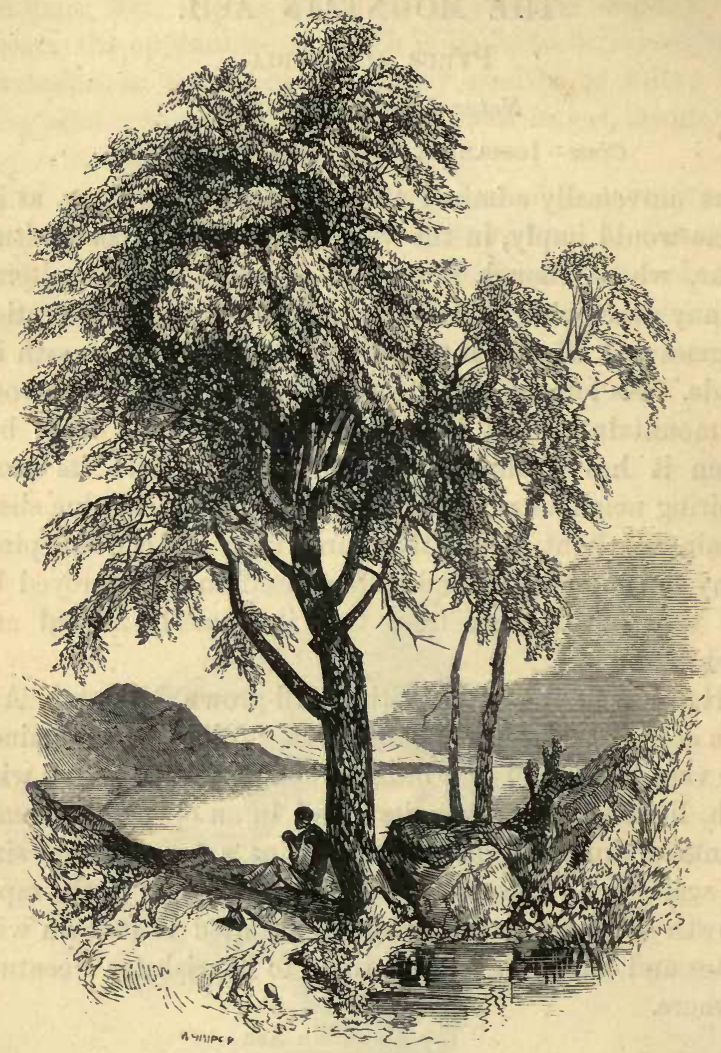

THE MOUNTAIN ASH.

which it resembles in conformation. ${ }^{1}$ Others assign it a place with the Medlar (Méspilus), or make it and the

The Siberian Crab (Pyrus baccata) produces fruit which may be considered as a connecting link between the berry of the Mountain Ash and the apple of Pyrus malus, the common Apple-tree. 
group with which it is connected a distinct genus (Sorbus). The name Aucuparia (from auceps, a fowler) indicates the use to which its berries are applied by bird-catchers in France and Germany, who bait their traps with them as a certain lure for thrushes and fieldfares. Its popular names are very numerons : Mountain Ash, the commonest, is far from correct, as it belongs to an entirely different tribe from the Ash, which tree it resembles only in its leaves; Rowan, Roan, its common name in Scotland, and various other forms of the same word, occur in old authors. It is also called Quick-Beam, Wild or Fowler's Service-tree : "Service" appears to be a corruption of Sorbus, the ancient Latin name of an allied species, Pyrus Sorbus. Witchen, Wicken, Wiggen, \&c., evidently bear allusion to the power it was once supposed to possess of counteracting witchcraft.

Lighfoot and Gilpin are both of opinion that the Mountain Ash was held in high estimation by the Druids. The former says, "It may to this day be observed to grow more frequently than any other tree in the neighbourhood of those druidical circles of stones so often seen in the north of Britain; and the superstitious still continue to retain a great veneration for it, which was undoubtedly handed down to them from early antiquity. They believe that any small part of this tree, carried about them, will prove a sovereign charm against all the dire effects of enchantment and witchcraft. Their cattle also, as well as themselves, are supposed to be preserved by it from evil ; for the dairy-maid will not forget to drive them from the shealings, or summer pastures, with a rod of the Rowantree, which she carefully lays up over the door of the sheal-boothy or summer-house, and drives them home again with the same. In Strathspey, they make, on the 1st of May, a hoop with the wood of this tree, and in the evening and morning cause the sheep and lambs to pass through it."

The belief in the efficacy of the Mountain Ash as a preservative against witchcraft has led some commentators 
on Shakspeare to sulstitute, for the puzzling expression in "Macbeth," "Aroint thee, witch!" the words "A Roantree, witch!" The passage being thus uttered, the mention of a tree so fatal to the power of the witch might naturally excite her acrimony against the person who applied the test. The authoress of "Sylvan Sketches" quotes a stanza from a very ancient song, which runs as follows :-

"Their spells were vain : the boys return'd

To the queen in sorrowful mood, Crying, that 'witches have no power

Where there is Roan-tree wood.'"

In remote districts of England the superstition has not even yet died away. Waterton, in his "Essays on Natural History," relates an anecdote which fell under his personal observation, of a countryman in Yorkshire, who "cut a bundle of Wiggin, and nailed the branches all up and down the cow-house," in order to counteract the effect produced on his cow by the "overlooking" of a supposed witch.

The Mountain Ash is found in a native state throughout the whole of Europe, and in several of the northern countries of Asia and North America. The parts of Great Britain where it attains its largest size are the western highlands and the western coast of Scotland. On the hills of Cheshire and Derbyshire it does not often attain a great size; in such situations an entire tree, with roots, leaves, and flowers, is sometimes found not more than nine inches high. Ordinarily it grows very rapidly during the first five years of its existence, and at the age of twenty years forms a tree of the same number of feet with a single erect stem and a bushy head. The branches are smooth, and vary in colour from grey to purplish brown. The buds, before their expansion in the beginning of April, are large and downy. The leaves consist of from seven to nine pairs of narrow, acute, notched leaflets, terminated by an odd one. These are somewhat downy underneath in their young state, but soon become quite 
smooth. The flowers are numerous, resembling in shape those of the Pear, but much smaller; in odour, those of the least fragrant varieties of Hawthorn. In early summer they are conspicuous from their number, and arrangement in large white clusters: when these are shed, the tree is still a pleasing object, from the brightness and elegant

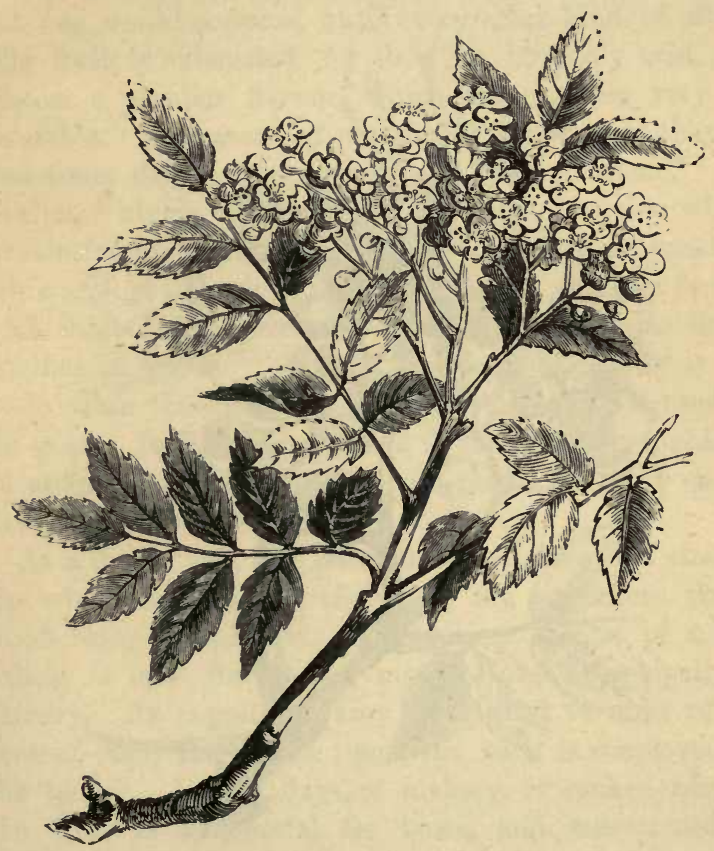

FLOWERS UF THE MOUNTAIN ABH.

shape of its leaves. As autumn advances, it asserts its claims to be considered a fruit-tree, in appearance, if not for utility. Its flowers are then succeeded by numerous bunches of coral-red berries, which, until devoured by the Thrush and Storm-cock, or scattered by the equinoctial gales, infallibly distinguish it from every other tenant 
either of the wood or the park. "In the Scottish highlands, on some rocky mountain covered with dark Pines and waving Birch, which cast a solemn gloom over the lake below, a few Mountain Ashes joining in a clump, and mixing with them, have a fine effect. In summer the light green tint of their foliage, and in autumn the glow-

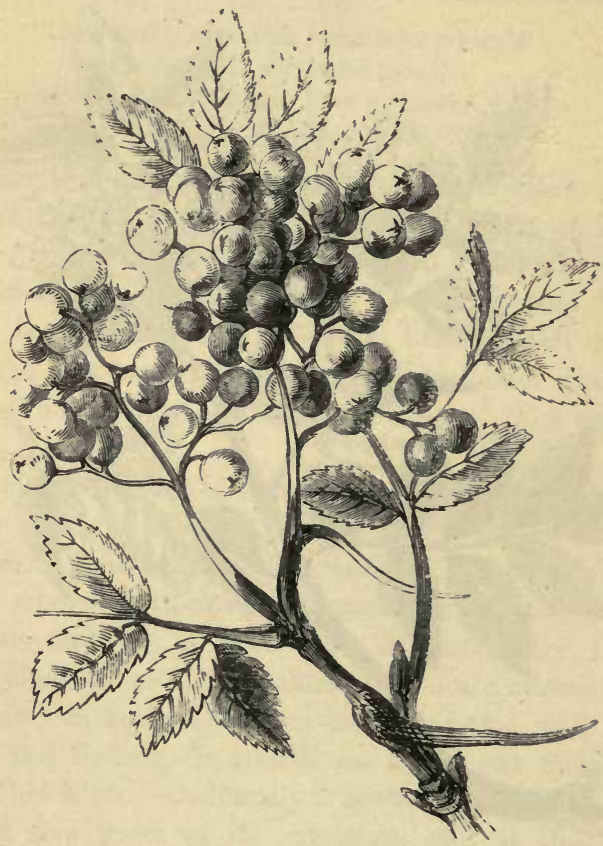

YRUIT OF THE MOUNTAIN ASH.

ing berries which hang clustering upon them, contrast beautifully with the deeper green of the Pines; and if they are happily blended, and not in too large a proportion, they add some of the most picturesque furniture with which the sides of those rugged mountains are invested." 1

1 Gilpin. 
A variety is cultivated which has yellow berries, and another with variegated leaves ; but neither of these, as is the case with many other treasured rarities, has anything beyond its rarity to recommend it.

The berries, besides being applied to the use from which the tree derives its name, "Birdcatcher's Service," are eaten in the extreme north of Europe as fruit, though not, one would suppose, until every other kind of attainable fruit is exhausted, for they are intensely acid, and possess a peculiar flavour, which makes them very unpalatable. In seasons of scarcity, it is said that they are sometimes dried and ground into flour. "Some," says Evelyn, "highly commend the juice of the berries, which, fermenting of itself, if well preserved, makes an excellent drink against the spleen and scurvy. Ale and beer brewed with these berries when ripe, is an incomparable drink, familiar in Wales." A beverage resembling perry is still made from them in that country, and is much used by the poor. In Kamtschatka and in the Scottish highlands an ardent spirit is distilled from them, which is said to have a fine flavour.

As a timber-tree, the Mountain Ash does not attain a size which renders it available by the carpenter; but its wood being fine-grained, hard and susceptible of a high polish, is used for smaller manufactures, principally in turnery. As coppice it may be applied to most of the uses of Ash, Hazel, \&c. ; and the bark is employed by the tanner. In the days of archery, it ranked next to the Yew as a material for bows, and was considered sufficiently important to be mentioned in the statute of Henry VIII. 


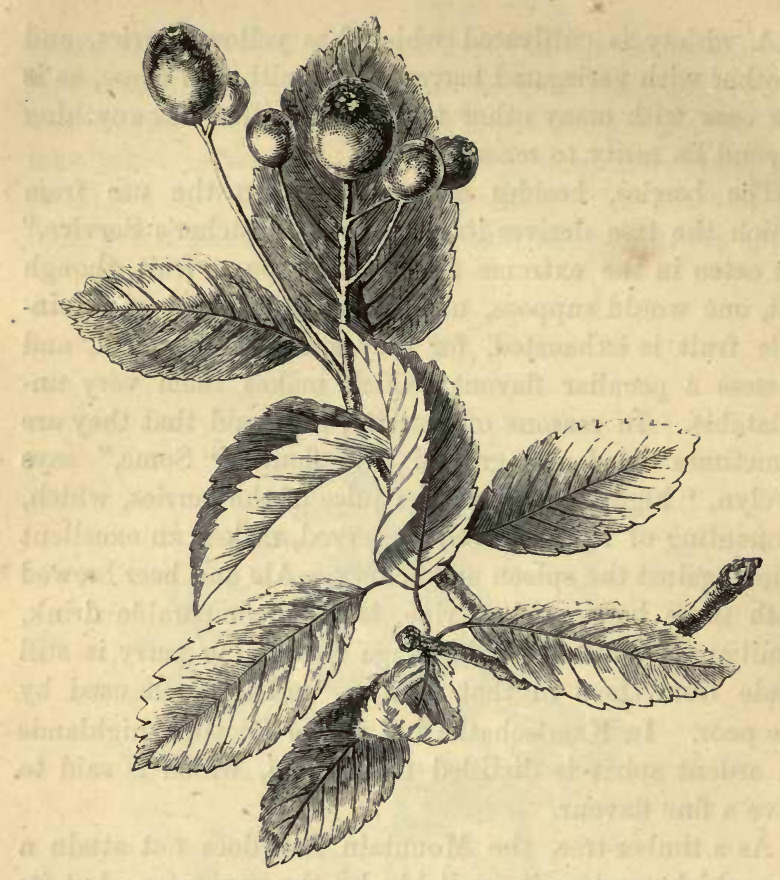

THE WHITE-BEAM.

Prrus aria.

The White-Beam ${ }^{1}$ (or White-tree), though closely allied to the Mountain Ash, and consequently bearing a strong resemblance to it as to flower and fruit, is nevertheless very unlike it in general character and appearance. It is a native of the same countries, with the exception of North America, preferring chalky or limestone soils, where it frequently attains the height of thirty or forty feet. The trunk is straight and smooth, and the young shoots are

1 "Beam," Saxon for "tree." So, in German, "Mehl-baum" means literally "Meal-tree," from the remarkably white and mealy appearance of the under-side of its leaves. 
covered with a white mealy down, as are also the undersides of the leaves, to such a degree as to give the tree its name. The flowers are larger than those of the Mountain Ash, and are succeeded by pale red berries, resembling in shape those of the Siberian Crab. Without being by any means common or well known, it occurs occasionally in various parts of England and Scotland. In the north of Devon and in Surrey I have seen it reaching a large size, and bearing abundance of fruit; but where the soil is not congenial, or the situation is confined, it scarcely merits the rank of a tree. The finest are said to grow near Blair, in Perthshire.

The fruit is used for the same purpose as that of the Roan-tree, and, if kept till it begins to decay, is somewhat more palatable, for in this state, like the Medlar, it loses a great deal of its austerity. It is eagerly devoured by birds, and on this account is in France protected by law, our neighbours having anticipated us in the discovery that the hostility of birds against insects more than compensates in its effects for the occasional depredations which the former commit in our orchards and gardens. The wood of the White-Beam is very heavy and of a close texture, and is much used, especially on the Continent, for the cogs of wheels in machinery.

\section{WILD SERVICE-TREE.}

Pyrus torminalis.

THIs species differs from the last in having its dark, glossy leaves lobed very like those of the Maple, whence it is sometimes called "Maple-Service." The fruit, which is brown and dotted when ripe, and not much larger than that of the Hawthorn, begins to decay when the frost has touched it, and is then agreeably acid and wholesome. Its geographical distribution is nearly the same with the White-Beam; but it is not found in Scotland or Ireland. 
It occurs occasionally in Cornwall as a hedge-bush, and in some other of the southern counties is said to attain the height of fifty feet; but it is nowhere common.

The "True Service-tree" (Pyrus Sorbus) is a doubtful native of Britain; but this is rarely met with even in a cultivated state, and requires no further mention.

The name "Service-tree" is often applied indiscriminately to all the above species of Pyrus, but belongs more particularly to the last.

\section{THE PEAR.}

\section{Pyrus communis.}

The Pear-tree, in its wild state, varies considerably in different countries, both in its mode of growth, and in the shape, size, and pubescence of its leaves. Some of these are probably distinct species, and inhabit most parts of Europe and Asia; but, as we have only to deal with the British form of the tree, it is unnecessary to pursue this subject. It is found in most counties of England, growing in woods and hedges. Its outline, when it stands alone, is pyramidal : the branches are at first erect, then curved downwards and pendulous; in a truly wild state, thorny. The young leaves are slightly downy beneath, but, when mature, are quite smooth on both sides. When it is cultivated the thorns on the branches disappear, as in the Plum. The flowers grow in clusters, and are large and of a pure white. The fruit is much smaller than that of any of the cultivated varieties, hard, austere, and unfit to eat; its only use is to mix with cultivated sorts in making perry. The wood was formerly sought after for wood-engraving, but is only adapted to coarse designs : it is also sometimes dyed black, in imitation of ebony.

For usefulness as a fruit-tree the Pear is rivalled only by the Apple,-furnishing abundance of fruit, which is 
valuable in its fresh state, as well as for baking and preserving. Many sorts were well known to the Greeks and Romans; Pliny enumerates thirty-two. It was cultivated in England at a very early period. Chaucer makes mention of it; and in an account-book of Henry VIII. there are the following charges, among others:-

"For medlars and wardens" $\mathrm{s}^{1}$. . . . . . . . $0 \begin{array}{llll}0 & 3 & 4\end{array}$

Item, to a woman who gaff the Kyng peres . : $\begin{array}{llll}0 & 0 & 2 . "\end{array}$

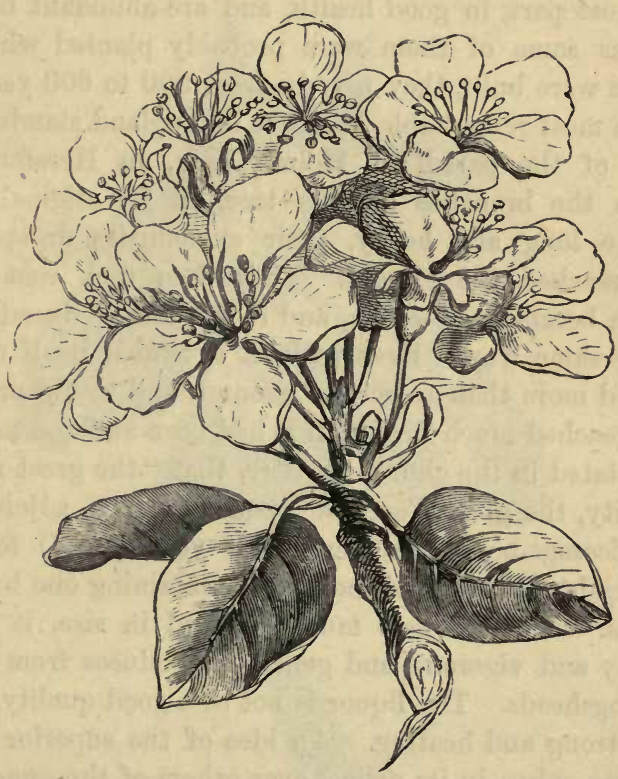

FLOWER OF PEAR-TREE.

In Gerard's time, "threescore sundrie sorts of pears, and those exceeding good," were growing in one garden; and of late years so much attention has been paid to the mul-

1 "Wardens" were so called from their property of keeping: peres" were probably some common kind of pear. 
tiplying of sorts, that the Horticultural Society's list for 1831 enumerates 677 named varieties.

The Pear-tree is long-lived, much more so in its cultivated than in its wild state; and its productiveness increases with its age. Dr. Neile mentions a number of very ancient Pear-trees standing in the neighbourhood of Jedburgh Abbey, and in fields which are known to have been formerly the gardens of religious houses in Scotland which were destroyed at the Reformation. Such trees are, for the most part, in good health, and are abundant bearers; and, as some of them were probably planted when the abbeys were built, they may be from 500 to 600 years old.

The most remarkable Pear-tree in England stands on the glebe of the parish of Holme Lacy, in Herefordshire. When the branches of this tree, in its original state, became long and heavy, their extremities drooped till they reached the ground. They then took root; each branch became a new tree, and in its turn produced others in the same way. Eventually it extended itself until it covered more than an acre of ground, and would probably have reached much further if it had been suffered to do so. It is stated in the church register, that "the great natural curiosity, the great Pear-tree upon the glebe, adjoining to the vicarage-house, produced this year (1776) fourteen hogsheads of perry, each hogshead containing one hundred gallons." Though now much reduced in size, it is still healthy and vigorous, and generally produces from two to five hogsheads. The liquor is not of a good quality, being very strong and heating. An idea of the superior size of this tree, when in its prime, over others of the same kind, may be formed from the fact that, in the same county, an acre of ground is usually planted with thirty trees, which, in a good soil, produce annually, when full grown, twenty gallons of perry each. So large a quantity as a hogshead from one tree is very unusual. The sorts principally used for making perry are such as have an austere juice. 


\section{THE APPLE.}

\section{- Pyrus malus.}

The Apple-tree being an undoubted native of Great Britain, demands to be noticed among our forest trees; though, from having been so long and so extensively cultivated, it is much better known as a tenant of the

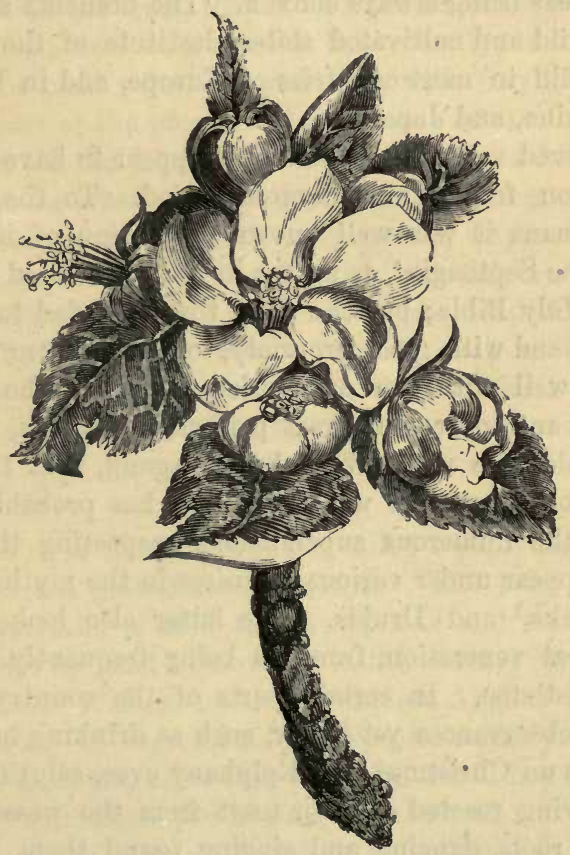

BLOSSOM OF THE APPLE-TAFE.

orchard than of the forest. Nevertheless, it is frequently to be met with in a perfectly wild state, possessing little or no value for its fruit, but forming in spring, with its rosy and fragrant buds, a beautiful ornament either to the woodland or the hedgerow. 
It differs materially from the Pear-tree in shape, and is characterised by its crooked and knotty branches, which, if the tree is growing in an open space, spread equally on all sides, and give to it an irregularly hemispherical form. The leaves are generally wider in proportion to their length than those of the Pear, less pointed, and, slightly downy beneath. The fruit may readily be distinguished by having its base, at the insertion of the stem, concave; that of the Pear being always convex. The branches are, both in the wild and cultivated states, destitute of thorns. It grows wild in most countries of Europe, and in Western Asia, China, and Japan.

Improved varieties of the Apple appear to have been in cultivation from a very remote period. To the Greeks and Romans it was well known. Mention of it occurs also in the Septuagint, as well as in the Authorized Version of the Holy Bible; but the fruit there alluded to is now thought, and with great propriety, to be the Citron, which accords well with the description given in the Sacred Volume, and arrives at great perfection in Syria, whereas the Apple does not. The absurd legend, that the fruit of the forbidden tree was the Apple, has probably given rise to the numerous superstitions respecting this tree, which appear under various disguises in the mythology of the Greeks ${ }^{1}$ and Druids. The latter also looked on it with great veneration, from its being frequently clothed with Mistletoe. In certain parts of the country superstitious observances yet linger, such as drinking health to the trees on Christmas and Epiphany eves, saluting them by throwing roasted crabs or toast from the wassail-bowl to their roots, dancing and singing round them, lighting fires, \&c. All these ceremonies are supposed to render the trees productive for the coming season.

I once had occasion to pass the night preceding Twelfthday at a lone farmhouse on the borders of Dartmoor, in

1 The fable of the dragon which guarded the golden apples in the Garden of the Hesperides is probably derived from this source. 
Devonshire, and was somewhat alarmed at hearing, very late at night, the repeated discharge of fire-arms in the immediate vicinity of the house. On my inquiring in the morning as to what was the cause of the unseasonable noise, I was told that the farm-men were firing at the Apple-trees in the orchard, in order that the trees might bear a good crop next season.

If these observances tended in the least degree to confer a benefit on the trees, they would not be mis-spent, for of all the fruit-trees cultivated in this country, the Apple is by far the most valuable, producing, with very little pains on the part of the proprietor, abindance of excellent fruit, fit either for the dessert, for dressing, or for making cider. To prove in what estimation it is held among gardeners, who resort to more sensible means for improving their trees than those above mentioned, it is only necessary to state that no less thau 1,400 named sorts, all differing from each other in shape, size, colour, flavour, or season of ripening, are enumerated in the Horticultural Society's Catalogue for 1831. All of these were cultivated in the Society's gardens, and new varieties are constantly being added.

The fruit of the wild Apple is called a Crab, the sourness of which has passed into a proverb. The juice of crabs, called verjuice, is used to cure sprains and scalds, being often kept by good housewives in the country for that purpose. Isaac Walton, in his "Complete Angler," mentions it as being an ingredient in the rustic delicacy, syllabub. "When next you come this way, if you will but speak the word, I will make you a good syllabub of new verjuice, and then you may sit down in a hay-cock and eat it." The old-fashioned ointment called pomatum was made with the pulp of Apples (poma), lard, and rose-water.

Though the Crab is the only Apple indigenous to Britain, several of the best sorts were first raised in this country. The Cornish Gilliflower is pronounced by Lindley the best eating apple; the Golden Pippin, so called from the small 
spots or pips that usually appear on the sides of these apples, is a native of Sussex; the Ribston Pippin was raised at Ribston Park, Yorkshire, from a pippin brought from France. The original tree, which produced this last sort, was standing in 1831, and probably still remains. Philips, who published his poem, "Cider," in 1706, enumerates many sorts, some of which are still in cultivation; others have been superseded by more valuable kinds, or at least their names are rarely heard. Among these last is-

“__ John-Apple, whose wither'd rind, intrencht

With many a furrow, aptly represents

Decrepit age,"

and is no doubt the "Apple-John" of Shakspeare.

The Apple-tree is not remarkable for size or longevity, but is stated to be larger and more productive in North America than in Europe.

Darwin relates that in South America the Apple-tree attains great perfection. "The town of Valdivia," he says, "is situated on the low banks of a river, and is so conpletely buried in a wood of Apple-trees that the streets are merely paths in an orchard. I have never seen any country where Apple-trees appeared to thrive so well as in this damp part of South America. On the borders of the roads there were many young trees evidently self-sown. In Chiloe the inhabitants possess a marvellously short method of making an orchard. At the lowest part of almost every branch, small conical, brown, wrinkled points project; these are always ready to change into roots, as may sometimes be seen where any mud has been accidentally splashed against the tree. A branch as thick as a man's thigh is chosen in early spring, and is cut off just beneath a group of these points, all the smaller branches are lopped off, and it is then placed about two feet deep in the ground. During the ensuing summer the stumps throw out long shoots, and sometimes even bear fruit. I was shown one which had produced as many as twentythree apples, but this was thought very unusual. In the 
third season the stump is changed (as I have myself seen) into a well-wooded tree, loaded with fruit. An old man near Valdivia illustrated his motto, 'Necessity is the mother of invention,' by giving an account of the several useful things he manufactured from his apples. After making cider and likewise wine, he extracted from the refuse a white and purely-flavoured spirit; by another process he procured a sweet treacle, or, as he called it, honey. His children and pigs seemed almost to live, during this season of the year, in his orchard."

It is somewhat singular that a very similar method of propagating Apple-trees is practised in so remote a country as China. The thick branch of a tree, when in full flower, is deprived of a ring of bark, and the place covered round with a lump of rich loam. This is kept moist by water, allowed to drip from a horn suspended above; and when the roots have pushed into the loam, which is usually the case when the fruit is nearly ripe, the branch is cut off and planted in a pot. Dwarf-trees, laden with fruit, are favourite ornaments among the Chinese. On the occasion of certain festivals they are exposed on stands before the houses, along with grotesque figures of porcelain and pasteboard, which are made to perform a variety of absurd movements, by the agency of mice confined within them. Besides the Apple, the Orange and other kinds of fruittrees are propagated in this way; and fine (that is, stunted and gnarled) specimens fetch a bigh price. They are said to live from two to three hundred years, never much exceeding a foot in height, and producing annually from twenty to thirty large apples. Several forest trees are treated in the same manner, particularly the Elm.

The destructive insect called American blight (for no other reason, one would suppose, than that it has long been the custom to ascribe the origin of most strangelooking things to the New World) is one of the greatest enemies of the Apple-tree. It is easily distinguished by its white cottony appendage, which is said to serve the 
double purpose of wafting the young insect through the air when about to found a new colony, and of protecting it from the cold when established in its new dwelling. It injures the tree, and, if not checked, finally kills it, by sucking its juices through the bark. Many methods of destroying it have been suggested, among which one of the simplest is to brush over every infected part with size. But even this remedy requires frequent repetition, as the insect infests even those parts of the tree which are beneath the ground. The subject is treated at length in the Gardener's Magazine, vol. ix. p. 334.

The Apple-tree, both in its wild and cultivated state, is liable to be infested with the Mistletoe, which frequently does great injury.

In the west of England this parasite is but little known, but the Apple-trees, especially in the vicinity of the sea, are often so thickly infested with lichens, that the bark is scarcely to be distinguished, except on the very young shoots. Most of them are of a pale ashen-grey or whitish tint; one, however, which oocurs but rarely in the eastern counties, Borréra flávicans, is very conspicuous for its tangled golden tufts, which in winter, when the tree is divested of foliage, are very ornamental.

I must not omit to mention that the Mistletoe Thrush, or Storm-cock, which at most seasons is one of our wildest birds, in spring deserts its favourite tree, the Mountain Ash, and resorts to the neighbourhood of human dwellings. There it selects, as a fit place for rearing its young, an Apple-tree close to the house, choosing the angle between the trunk and one of the principal branches. It builds its nest of materials which closely resemble the bark of the tree, and though exceedingly shy at other seasons, now sits so closely that one may advance to within a few yards of the nest without being noticed. The beautiful coppercoloured Chaffinch also prefers to build her elegant nest among the twigs of the Apple-tree, and decorates it in the neatest manner with the lichens which infest the tree she has selected. 


\section{THE BEECH.}

Fagus sylvática.

Natural Order-AMUNTACEE.

Class-Moncecia. Order-Polyandia.

THE Beech, though one of our most abundant forest trees, growing spontaneously in the wildest parts of many of the counties of England, perfecting its seed freely, and sustaining a vigorous growth (which proves that the soil and climate of the country are perfectly congenial to it), is nevertheless declared by many writers to be a doubtful native. This opinion they justify on the ground that Julius Cæsar, in his account of his invasion of Britain, states that "timber of every kind which is found in Gaul also grows in Britain, except the Beech and the Silver Fir." ${ }^{1}$ The fact is, that by far too much importance is attached to this passage. Cæsar penetrated but a very little way into Britain, stayed there but a very short time, and rarely ventured to any great distance from the camp; consequently he saw very little of the country. There can be no doubt, however, that he was anxious to convey to his countrymen as favourable an impression as possible to of his achievments; so that, the success of his military operations being slight, he would very willingly have them infer, from the minuteness with which he particularised the produce of the island, that he had penetrated far into the country, but had met with no adventures worth recording. This seems the readiest way of meeting the difficulty. Other writers suggest that some other tree than the Beech may be identical with the Fagus of Cæsar, and have endeavoured to show that he meant the Chestnut.

1 "Materia cujusque generis, ut in Gallia est, præter Fagum et Abietem."-CESAR, de Bell. Gal. 
But that this opinion is erroneous, will appear from the following consideration.

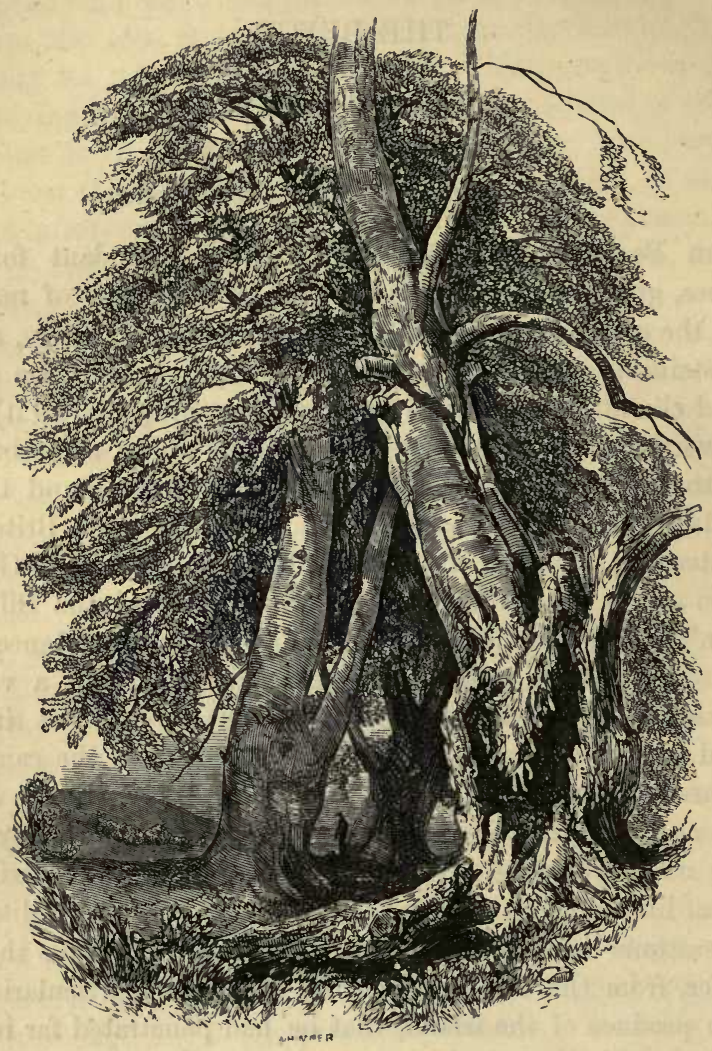

THE PURLEY BEECBES.

The Roman poets make frequent mention of the tree (Fagus) which Cæsar declares to be not a native of Britain. ${ }^{1}$

1 The $\phi \eta \gamma$ bs (phegos) of Theophrastus does not appear to be the same as the Fagus of the Romans, though both names have the same etymology, from $\phi \dot{\alpha} \gamma \omega$ (phago), to eat. Our Beech is most 
They describe it as being lofty, furnished with widespreading branches, casting a dense shade, loving the hillside, attaining a great age, and furnished with so smooth a bark that rustics selected it to carve their names on, and even for the reception of their poetical effusions. ${ }^{1}$ Virgil states that it was grafted on the Chestnut, and that its wood was converted into bowls, a use which is alluded to by other poets. No other tree with which we are acquainted accords with this description. But this is not all, for Pliny, the Latin naturalist, gives an accurate description of the Fagus, which cannot fail to identify it with our Beech. "Of the various kinds of mast, that of the Fagus is the sweetest, on which Cornelius Alexander says, that some men, who were besieged in the town of Chios, lived for some time. It resembles a nut, and is enclosed in a triangular rind. The leaf is thin and exceedingly smooth, shaped like the Poplar, decaying, after it has fallen to the ground, long before any of the other mast-bearing trees. The mast is much eaten by mice, which abound at the season of its ripening; it also entices dormice, and is much sought after by thrushes. Hogs fattened on it are lively, and their flesh is digestible, light,

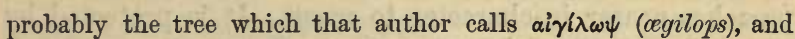
describes as "a mast-bearing tree, furnished with a very straight trunk, very lofty, having a smoother bark than any of the other mast-bearing trees, and growing but sparingly in enclosed country." (Theophrastus, de Plantis, lib. ii.) The $\phi \eta \gamma$ '́s of Theophrastus was probably the Aisculus of the Romans.

1 Among the many anecdotes connected with the history of printing which have come down to us, that related by Hadrian Junius deserves to be noticed in this place. About the year 1441, Lawrence Koster, a citizen of Haarlem, "walking in a suburban grove, began first to fashion Beech-bark into letters, which being impressed upon paper, reversed in the manner of a seal, produced one verse, then another, as his fancy pleased, to be for copies to the children of his son-in-law." This hint he subsequently improved upon, and finally invented blocks of lead and tin, and printed books. Among his workmen was John Faust, who, having been initiated in the art, although sworn to secrecy, decamped, carrying with him his master's stock in trade, and set up as a printer on his own account at Mayence. I should add that, although many literary men have credited this account, it bears, on close examination, internal evidence of being a fabrication, either of Hadrian or his informant. 
and wholesome. The bark is used for making baskets and panniers, but the timber is not durable."

The above description, though wanting the precision of modern science, is sufficiently conclusive that the Fagus of Italy is the Beech of Great Britain, for the account is not true of any other known tree. The only statement which demands further notice is that of Virgil, that the Beech is often grafted on the Castanea or Chestnut. This assertion has appeared so strange and unaccountable to commentators, that some have got rid of the difficulty at once by supposing that the passage is corrupt, and that Virgil meant to say, "the Chestnut is often grafted on the Beech :" others have jumped to an equally unwarrantable conclusion, that the Beech was called by the Romaus "Castanea," and the Chestnut "Fagus;" and that, accordingly, Cæsar asserted that the Chestnut did not grow in Britain. This ingenious explanation is so satisfactory, that it might be adopted at once, if sufficient evidence of the fact could be adduced. But this is not the case, for Pliny's description of the Castanea agrees as exactly with the Chestnut as that of the Fagus does with the Beech. "The fruit of the Castanea," he says, "we call also a nut, though it approaches nearer in character to mast. It is protected by a case- beset with strong prickles. It is strange that we hold as of no value a fruit which Nature has so carefully guarded from injury. As many as three nuts frequently grow together in one case. The proper rind of the nut is tough, and within this is a thin skin closely attached to the substance of the nut, as in the walnut, which, unless it be removed, spoils the flavour of the fruit. The best way of preparing them for food is by roasting. They are sometimes ground into meal, which is converted by women into a wretched substitute for bread, and eaten during their religious fasts."

From a comparison of these passages, it will plainly appear that the tree which we call Beech was undoubtedly the Fagus of the Romans, and the Chestnut, Castanea. 
Nor will there be any difficulty in discovering the propriety of grafting the Beech on the Chestnut, the oily though smaller nut of the former being considered by the ancients much more valuable than the farinaceous nut of the latter.

On the whole, therefore, the readiest solution of the difficulty is, that Cæsar did not penetrate into any part of the island where Beeches were abundant, and that the woods, to which he tells us the Britons retired to escape from their invaders, were composed of trees which admitted a more luxuriant growth of underwood than this unsociable tree ever allows.

Loudon states that it is a native of the temperate parts of Europe, from the south of Norway to the Mediterranean Sea, and from England to Constantinople. It is also found in Palestine, Asia Minor, and other parts of Asia. In Switzerland it occupies the south sides of the mountains which have their north sides clothed with the Silver Fir. In England it grows most luxuriantly, and in the greatest abundance in the chalk districts, forming extensive forests of great magnificence and beauty. It is not indigenous to Scotland or Ireland. It is the national tree of Denmark, and in the neighbourhood of Elsinore flourishes in superlative vigour.

The Beech was particularly admired by the ancients, who luxuriated in the lofty canopy afforded by its dense foliage. In modern times, its claims to the possession of picturesque beauty have been disputed on high authority; for while Gilbert White speaks most warmly in its praise, Gilpin expresses a very different opinion. However painters may differ, the Beech is a noble tree in nature-beautiful, as delineated by the hand of the Creator, however difficult it may be for the painter to represent it with the pencil in such a way as to produce a pleasing effect on the mind. And it is a tree which has many points of interest about it at all seasons of the year. Enter a grove of Beeches on a bright day in mid-winter; the mind is immediately engaged in meditating on the still solemnity that reigns 
around. Look where you will, Nature is in a state of deep repose, if not of suspended animation : there is as little semblance of growing life as in the cloisters of a cathedral. The ground is bare of everything save withered leaves and dead twigs and wrinkled husks; every herb, if any ever grew here, has hidden itself under the brown covering of the earth, as if afraid to show signs of life in that universal solitude. As far as the eye can reach, on all sides extends an irregular succession of lofty fluted columns, which seem to have been chiselled to their existing proportions; for nowhere is there to be detected a single rugged trunk indicative of expansive growth, nor one to which the mantling Ivy imparts a borrowed semblance of vitality: the very lichens which chequer their smooth barks seem to be monumental, rather than endowed with life. Overhead the long wavy boughs are intersecting each other at every possible angle, but all stark and rigid. The wiry twigs, which form a network over the whole, are apparently striving to escape from the solemn influence which reigns below. Yet there is no gloom here, for the sun, as if aware that this is the only season at which his rays can penetrate these recesses, makes up in brightness for what he wants of heat. And, if we look a little more closely, we shall discover that, though Nature is asleep, her vital functions have only withdrawn themselves from sight; mysterious operations are still going on, of which, though we cannot now comprehend them, we shall in a few months have no difficulty in discovering the results. Examine one of the long and sharp buds with which every branch is so plentifully furnished, and, although we may be unable to account for the apparent suspension of life in deciduous ${ }^{1}$ trees, or to discover what operations are being carried on in the silent laboratory of Nature, we shall have no difficulty in discovering that the providence of God is watching over every bud, and doing for it whatever is necessary, in order

1 Deciduous trees are those which shed their leaves at the approach of winter. 
that it may, at the return of spring, be converted into a leafy shoot. Wrapped up in a mantle of silk and waterproof scales, the tender nursling is protected against wind and rain and cold, and is provided with all that it needs in order to maintain a healthy existence, but not with that, whatever it may be, which could stimulate it to throw off

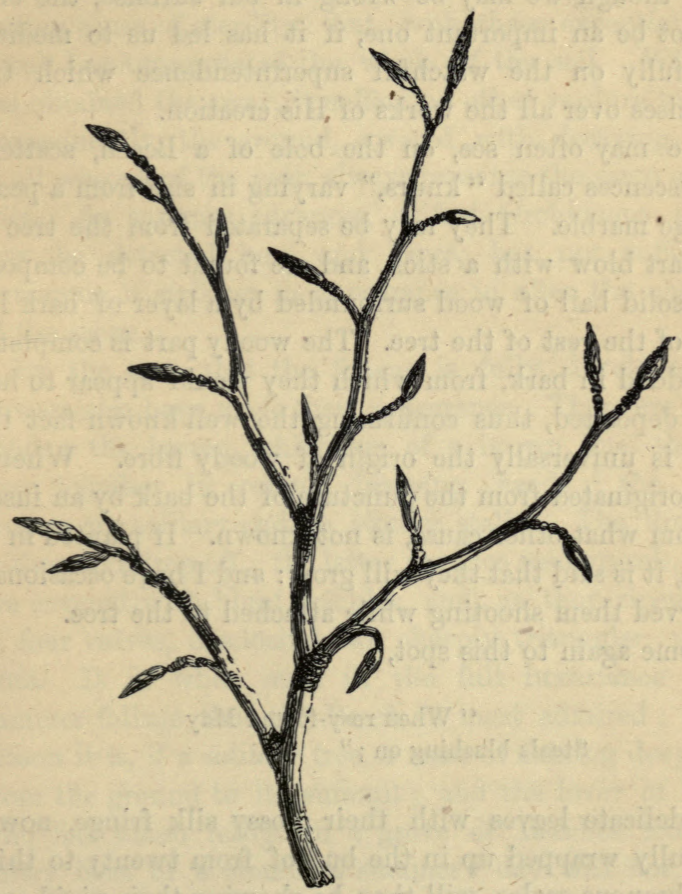

TWIG OF THE BEECH IN WINTER.

its integuments, and come forward into the light of heaven before the time assigned by its Maker. Examine again the younger trees on the skirts of the grove. They are still clothed with the shrivelled foliage of the preceding summer. One would imagine that, exposed to the autumnal blasts as they have been, they would be the first to 
shed their leaves. But no! after these had fulfilled their office as living organs, another remained to be performed, and they musti stay where they are until thrust off in the spring by the expanding buds. We know not what their office is ; perhaps it is to protect the embryo leaves of the coming year, while the tree is yet young and tender: but even though we may be wrong in our surmise, the error cannot be an important one, if it has led us to meditate faithfully on the watchful superintendence which God exercises over all the works of His creation.

We may often see, on the bole of a Beech, scattered excrescences called "knurs," varying in size from a pea to a large marble. They may be separated from the tree by a smart blow with a stick, and are found to be composed of a solid ball of wood surrounded by a layer of bark like that of the rest of the tree. The woody part is completely imbedded in bark, from which they would appear to have been deposited, thus confirming the well-known fact that such is universally the origin of woody fibre. Whether they originated from the puncture of the bark by an insect, or from what other cause, is not known. If planted in the earth, it is said that they will grow : and I have occasionally observed them shooting while attached to the tree.

Come again to this spot,

\section{"When rosy-footed May \\ Steals blushing on;"}

the delicate leaves with their glossy silk fringe, now so carefully wrapped up in the bud of from twenty to thirty membranous scales, will then be showing their vivid green on the lower branches, the bud scales as yet loosely clinging to their base. In a few days more the verdure creeps up the whole tree, gradually deepening in hue, and assuming a brighter polish. The silken fringe, which was so conspicuous when the leaf emerged from its winter's covering, becomes more scattered as the leaf increases in size, the latter being slightly notched, and having the 
veins beneath downy. The young twigs at first droop gracefully, but in about a fortnight's time assume an erect, or horizontal direction. But we shall look in vain for a carpet of herbage beneath their shade. Here and there a sickly holly has resisted the malignant influence of its drip, or a tangled bed of Periwinkle ${ }^{1}$ has established itself, and grows on luxuriantly, unaffected by the prevailing cause of sterility: but, with these exceptions, the Beech has appropriated the whole of the soil. Where it has obtained the sway, it suffers no other verdure to exist. Consequently, the ground, covered with decaying leaves at all seasons of the year, always presents the same appearance. As summer advances, a few Orchideous plants ${ }^{2}$ may be detected here and there, but not sufficiently numerous or striking in appearance to alter the character of the scene.

By the time that the foliage is fully developed, the flowers also have made their appearance. These are of two kinds : the barren, which are of a brown hue, three or four together in round drooping heads; ${ }^{3}$ the fertile flowers are solitary and on stouter stalks. The first soon wither and drop off ; the latter produce seed-vessels, which are covered with blunt prickles, and, as they ripen, open in four valves, disclosing two sharply triangular, pointed nuts. It is when seen in the full luxuriance of its summer foliage that the Beech is most admired; at this season it is, if a solitary tree, a mass of shining deep green from the ground to its summit; and the lover of Nature who has taken refuge in a grove of Beeches from the sultry heat of a cloudless summer's day will not fail to experience that inexplicable feeling of sadness, ningled with longing, which the contemplation of Nature's greater works always excites.

1 Vinca minor.

* Gymnadenia bifolia, Listera nidus-avis, \&c.

3 These, after they have fallen from the tree, are sometimes carefully collected by gardeners, dried, and preserved for packing fruit. They are soft as cotton, and do not communicate any kind of scent to the fruit. 
The name Beech is of northern origin ; bece being the Saxon, $b a k$ the Swedish and Russian, and buche the German name. Its mast was formerly called buck in this country. "In some parts of France," says Evelyn, "they grind the buck in mills." Buck-wheat, the seed of Polygonum Fagopyrum, derives its name from its similarity in shape to the mast of the Beech. The wood of the tree

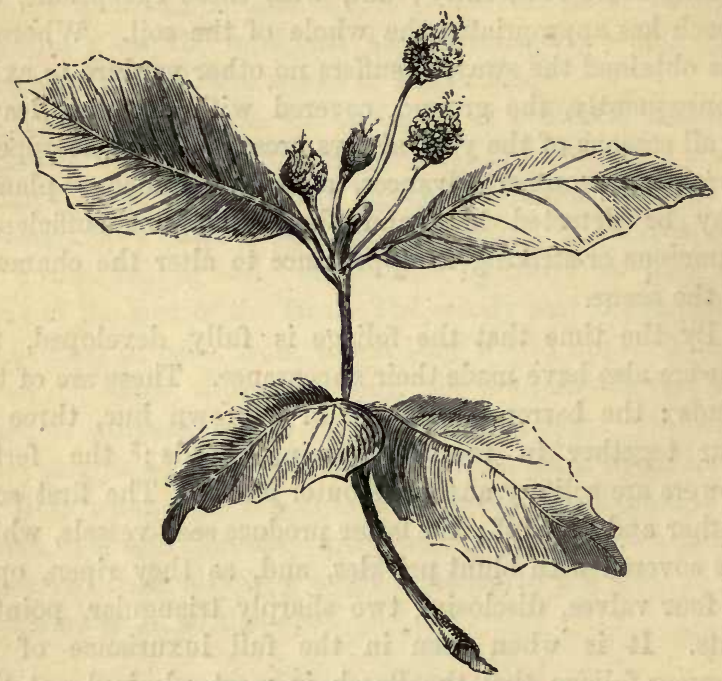

FOLIAGE AND FLOWERS OF THE BEECH.

having been formerly used for forming the sides of volumes, the word "book" came to be applied to the volume itself. ${ }^{1}$

${ }^{1}$ It is worth noticing how many words connected with literature bear allusion to the materials anciently used in writing, \&c. The substances first employed were tables of stone and metal ; from this source we derive the expression "Tables of Weights and Measures." Tables of wood were afterwards employed, covered with wax, which were written on by means of an instrument pointed at one end for forming the letters, rounded at the other for the convenience of erasing: this was called a style, a word which we retain with an altered meaning. Paper is derived from the Egyptian papyrus: we still speak of the leaves of a book, though the leaves of the palm-tree are no longer used for the purpose of 
The common Beech is always raised from seed, and the varieties are propagated by grafting or budding. The mast soon loses its germinating power, and is therefore never sown later than the spring of the year which follows its ripening. The seed leaves, which appear above the ground in April or May, are singularly pale, and at the first glance might be mistaken for a fungus. In ten years the tree reaches a height of about twenty feet. In sixty or eighty years it has usually attained its perfection as timber, but lives for a much longer period. It is not well adapted for coppice-wood, ceasing to send up shoots after about thirty or forty years; though if cut down before this time, the trees push up again, and the leaves on the shoots so produced seldom fail to remain on the branches during the winter. Young trees generally are, as it has been observed above, liable to the same peculiarity, but not all in the same degree. On this account, fences of young Beech-trees may be employed with advantage in flower-gardens, as with their persistent foliage they screen the tender plants during the winter. Gilbert White remarks, that Beeches love to grow in crowded situations, and will insinuate themselves through the thickest covert, so as to surmount it all; they are therefore properly applied to mend thin places in tall hedges : care should be taken, however, not to plant them in situations where the drip might be injurious to the vegetation beneath. Where squirrels are abundant, it is sometimes found necessary to protect the trunks of young Beeches by the application of tar and grease, these destructive little animals being given, especially in spring, to tearing off the bark in strips, in search of the tender inner bark.

writing on. Folio is from the Latin folium, a leaf. Liber, the Latin for a book, meant originally the inner bark of such trees as the Lime, the Ash, the Maple, the Elm, at one period a common writing material : hence we call a collection of books, a library. This substance being rolled for the convenience of carriage, a collection of writings was called a volume, a name afterwards given to like rolls of paper and parchment. 
An interesting fact recorded by Evelyn ${ }^{1}$ would tend to show that many of our natural Beech woods stand where Oaks originally grew: "That which I would observe to you from the wood at Wooton is, that where goodly Oaks grew, and were cut down by my grandfather almost a hundred years since, is now altogether Beech; and where my brother has extirpated the Beech, there rises Birch. Under the Beech spring up innumerable Hollies, which growing thick and close together in one of the woods next the meadow, is a viretum ${ }^{2}$ all the year long, which is a very beautiful sight when the leaves of the taller trees are fallen." Strutt also observes that the Beech is of that encroaching and dominant nature, that a wood which may have been originally in equal proportions of Oak and Beech, will in course of time become entirely Beeches.

The leaves of the Beech may be applied to a very useful purpose, even after they have ceased to afford their summer's shelter. Evelyn says, that, "being gathered about the fall, and somewhat before they are much frostbitten, they afford the best and easiest mattresses in the world to lay under our quilts instead of straw; because, besides their tenderness and loose lying together, they continue sweet for seven or eight years, long before which time straw becomes musty and hard. They are often thus used by divers persons in Dauphiné : and in Switzerland I hvae sometimes lain on them to my great refreshment." Modern travellers state that in those countries they are still applied to the same purpose.

The nuts of the Beech are rarely used in England except for fattening swine and poultry; but in France an excellent oil is manufactured from them, which is extensively employed both for culinary purposes and for burning; in Silesia it is used by the country people instead of butter. A similar application of Beech mast has been projected in England, but appears never to have been carried into effect. A certain speculator in the reign

${ }^{1}$ Letter in Aubrey's Surrey. $\quad{ }^{2}$ A leafy wood. 
of George the First proposed a scheme for paying off the national debt with the oil of Beech nuts !

The green wood is heavier than that of any of our timber trees, but loses nearly a fourth of its weight in drying. Though tolerably hard, it is easily worked, and is applied to a great variety of uses. The principal objection to it is, that it is liable to be perforated by a small beetle. In Scotland, Loudon informs us, the branches and spray are distilled for producing pyroligneous acid; and the wood, branches, and twigs are much used for smoking herrings. It will bear being cut into very thin plates, and is consequently much used for making the scabbards of swords. In Evelyn's time, the art of cutting the wood into these thin plates was not known in England, and when discovered was long kept secret. The neat-looking, but very inconvenient, basket for holding strawberries, called a pottle, is made of Beech. The same material was employed in the days of Evelyn, who refers the custom to remote antiquity. It is also preferred to every other wood for making the wooden shoes called sabots, worn by the French peasantry. By being dried in the smoke of burning green wood, these acquire the property of resisting the attacks of insects. It forms an excellent fuel, and is no less useful, when converted into charcoal, for the manufacture of gunpowder.

Several singular varieties of the British Beech are in cultivation, which deserve a passing notice. The Purple Beech has its leaves in their early stage of a bright rosecolour, which, as the season advances, deepens to a rich purple, approaching black. It is a native of Germany, where it was discovered about the middle of the last century. It is usually propagated by grafts, plants raised from seed having a tendency to revert to the common form of the tree. This variety presents a beautiful appearance when scantily interspersed among other trees in a lawn or grove, but should never be planted alone. The Cut-leaved Beech has its leaves indented, so as almost to resemble in 
shape the leaves of a fern. The Weeping Beech is said to be the most elegant tree of British growth. A writer in the Gardener's Magazine (vol. vii. p. 375) states, that, in the park of J. C. Mountray, county of Tyrone, Ireland,

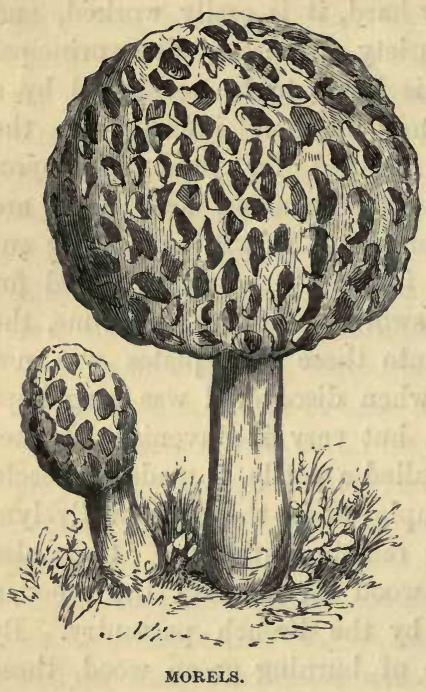
there are some the trunks of which measure upwards of ten feet in circumference, and that the branches, which extend fifty feet from the stem, touch the ground. There is also a fine specimen in the drive called the Hobby at Clovelly, in North Devon.

Comparatively few insects attack the Beech, and those which do are chiefly the grubs of moths. The fungi which attack the leaves and

bark are more numerous. Among those which grow on the ground in Beech woods, the most remarkable are the Morel $^{1}$ and the Truffle. ${ }^{2}$ The former of these is a mushroom-like fungus, growing in the woods of Germany and France, particularly after any of the trees have been burnt down. This fact having been observed led in Germany to the burning of the woods, in order to procure Morels : and consequently great numbers of trees were destroyed, till the practice was forbidden by law. They are highly prized for the table, both in their fresh and dry states. In the countries where they abound, many persons gain their livelihood by gathering and drying Morels : which last operation they effect by running a thread through 
their stalks, and hanging them in an airy place. In England they are comparatively rare; but Mr. Berkeley states that he has known them to be so abundant in Kent as to be used for making a sort of catsup. The Truffle, which is also highly prized in cookery, is very difficult to find, being at all stages of its growth buried beneath the ground. It is black and warty; white within, and marbled with dark veins. "It possesses a strong but agreeable smell, and is generally found by dogs and pigs trained to search for it; but, in those countries where Truffles abound, in the month of October (which is their

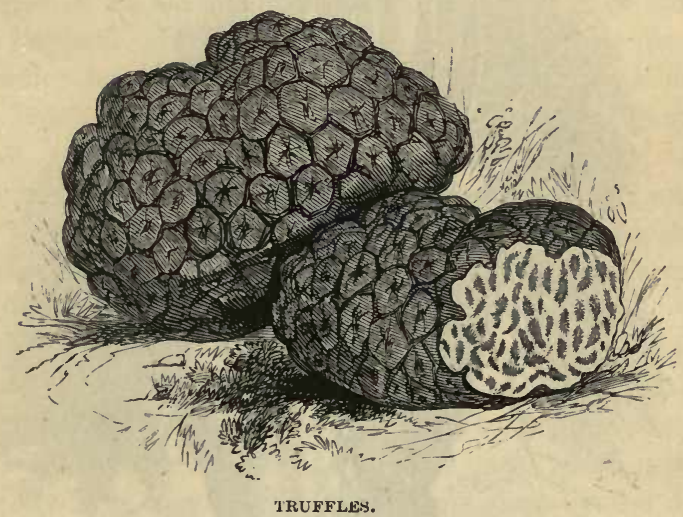

season for ripening) all the inhabitants repair to the woods, slightly stirring, or rather scratching the ground, in those places which experience points out to them as the most likely to contain the tubers. The high price of, and constant demand for Truffles, both in France and other countries, renders this a very lucrative employment : and experienced hunters are rarely deceived in the places where they make their search." 1 Berkeley (Eng. Flora, vol. v. part ii. p. 228) quotes an instance of a poor crippled boy who could detect Truffles with a certainty

Loudon's Arboretum Britannicum. 
superior even to that of the best dogs, and so earned a livelihood.

Several figures are given by Loudon, showing the tendency of the branches of the Beech to grow together when they touch in crossing. The annexed figure, taken from the Arboretum Britannicum, represents a very singular example of this peculiarity in a tree standing in West Hey Wood, between Cliff and Stamford.

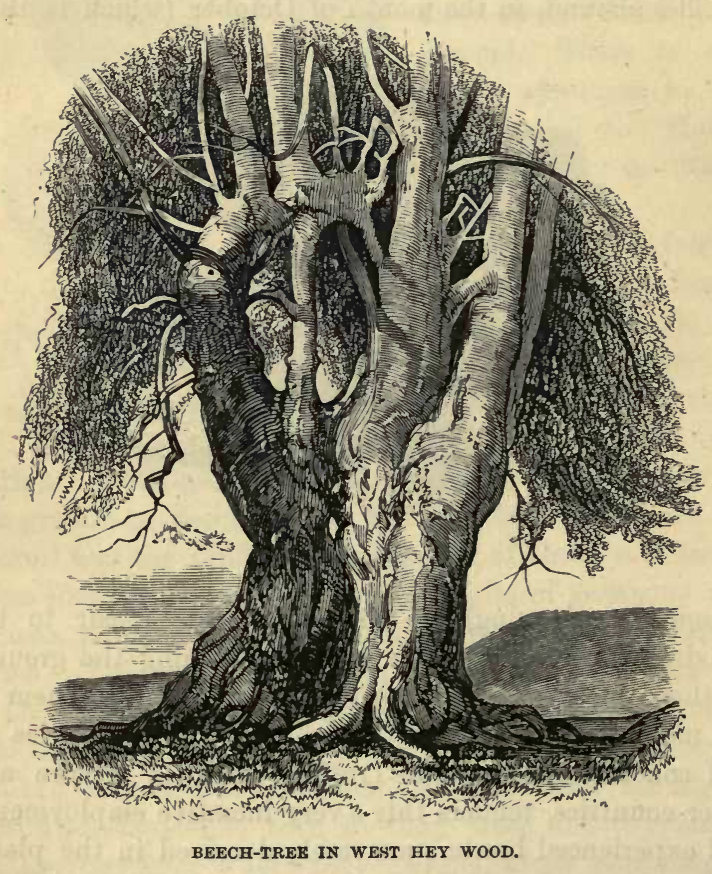




\section{THE POPLAR.}

\section{Populus.}

Class-Diøcia. Order-OctaNdRIA.

Natural Order-AMENTACEE.

No greater contrast can be well imagined than that afforded by the trees of this tribe, when compared with the one which forms the subject of the last chapter. The terms ancient, umbrageous, wide-spreading, picturesque, may be applied to the Beech with propriety; the very reverse of all these will characterise some one or other of the Poplars. The contrast extends even to their places of growth; for while the hill-side is the favourite haunt of the Beech, the Poplar, for the most part, prefers the river's bank. The foliage of the Beech, again, is heavy, unless examined in detail ; that of the Poplar scanty, and remarkable for being nearly always in motion-a peculiarity to be attributed to the slenderness and singular formation of its leaf-stalks. It bears its flowers in catkins: these are of two kinds, each growing on separate trees, the barren conspicuous by their length and the large size of the anthers, on which account they have been compared to large red caterpillars; the fertile ones, which are often equally long, may readily be distinguished by the downy wool which invests the seeds, and which is so like cottun that it has, though with indifferent success, been manufactured into cloth and paper. Most of the tribe are very prolific in suckers from the root. The wood is soft and light, and of little worth in the arts and manufactures. It certainly possesses one property which makes it valuable for some purposes, that, namely, of being very difficult to ignite; hence it may be employed with advantage in flooring rooms. The name Populus is said by some to be derived from a Greek word ( $\pi a \iota \pi a ́ d \lambda \omega$, to vibrate) bearing allusion to the tremulous motion of its leaves. Others say that the tree derived its name from being considered 
at Rome "the tree of the people" (arbor populi), a circumstance which brought it into notoriety during the French Revolution.

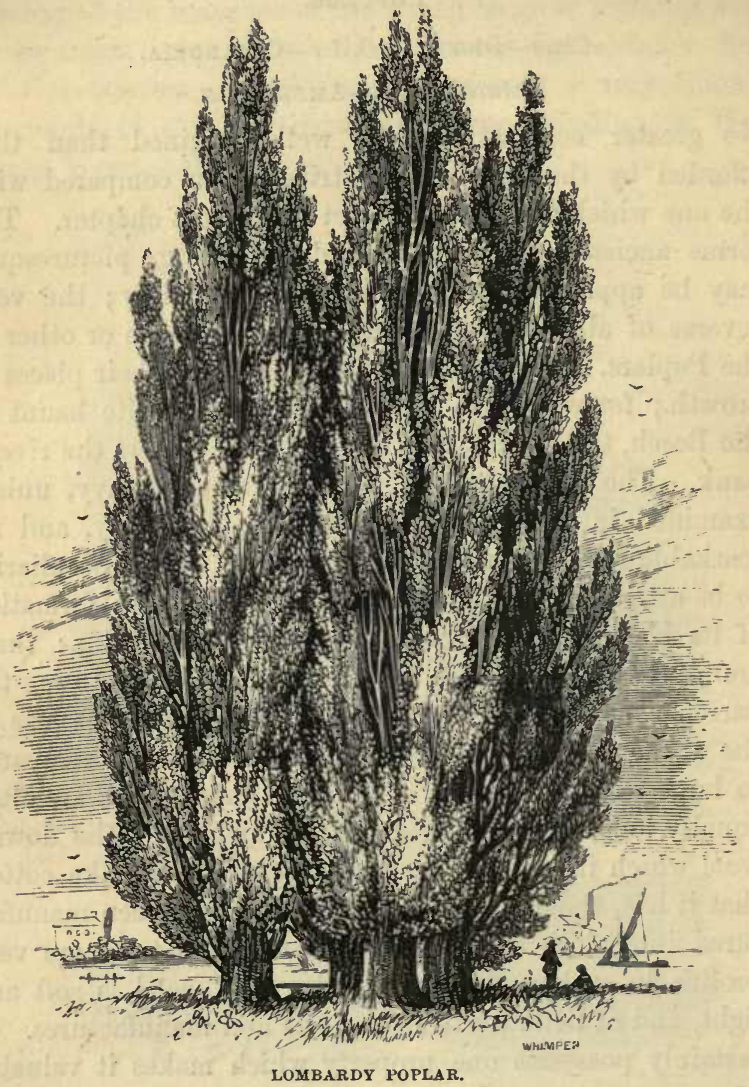

Four species are indigenous to Great Britain, and many others have been introduced, and are now extensively cultivated. Of these last a short notice will suffice, although one of them, the tall Lombardy Poplar, is probably more generally known than any of the native kinds. 
THE WHITE POPLAR, OR ABELE TREE.

Populus alba.

\section{THE GREY POPLAR.}

Populus canescens.

THeRe appears to be some doubt among authors whether both these trees ought to be considered as natives of Britain, or whether the latter only is indigenous. Evelyn describes the White Poplar, and mentions also a finer sort, "which the Dutch call Abele," and we have of late much of it transported out of Holland." About the middle of the sixteenth century, as many as 10,000 trees of the same kind are said by Hartlif to have been imported from Flanders, and transplanted into many countries. The fact is, the trees are so much alike in character, that we may safely conclude that the tree which we call the Grey Poplar was known to the earlier writers as a native tree by the name White Poplar, which title was subsequently transferred, for the sake of distinction, to the Abele; the British tree receiving the epithet of "grey" for the same reason. The mere casual observer would scarcely observe the difference between the two: botanists, indeed, are not agreed whether they are distinct species, or only varieties. It is, therefore, scarcely worth inquiring to which kind should be referred,Cowper's

$$
\text { "Poplar, that with silver lines his leaf ;" }
$$

or what tree Barry Cornwall commemorated when he sung

"The green woods moved, and the light Poplar shook Its silver pyramid of leaves."

1 The English name of Abele is derived from the Dutch name of the tree, Abeel; and this name is supposed by some to be taken from that of the city of Arbela, in the plains of Nineveh, near which, on the banks of the Tigris and Euphrates, great numbers of these trees grow.-Loudon. 
The leaves of both may be distinguished from the other British species by being deeply jagged, the grey less so than the white. The leaves of both are white, with down beneath, particularly the latter, which also are larger than those of the other. The fertile catkins of the Abele are oval, and each flower is furnished with four pistils; those of the Grey Poplar are long and cylindrical, and the flowers contain eight pistils each. In all other respects. the trees are so similar, that for the remainder of the chapter I shall include them under the same name.

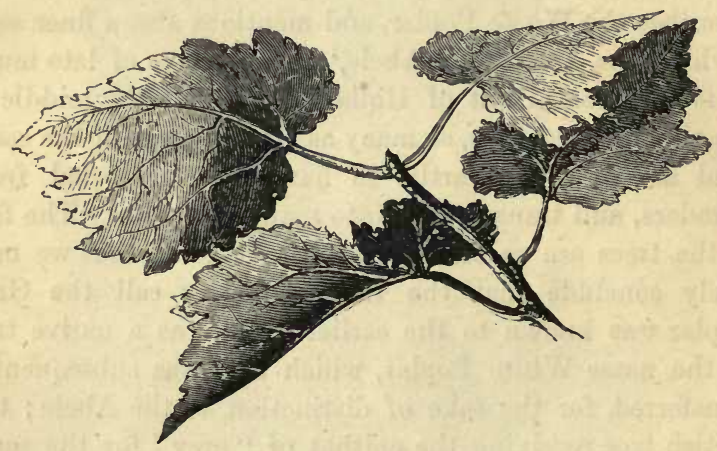

LEAF OF WHITE POPLAR.

The White Poplar was famous in the mythology of the ancients, being consecrated to Hercules, who, in commemoration of one of his victories gained, in a place where this tree was growing in abundance, used to wear a chaplet of its leaves, a custom which was adopted by persons who sacrificed to him. Pliny gravely states that the White Poplar, as well as several other trees which he mentions, always turned its leaves to an opposite quarter of the heavens immediately that the summer solstice was past. Though modern science has not confirmed this observation, the tree may frequently be noticed turning up the white surface of its leaves during the huffling winds which we 
often experience in summer, and this is a pretty sure indication of approaching rain. ${ }^{1}$

The White Poplar is a tree of very rapid growth, attaining a height of from eighty to a hundred feet. When about fifty or sixty years old it is in perfection; soon after this it begins to decay inwardly, but will continue growing for a century longer. Evelyn recommends it as a fit tree to be planted by "such late builders as seat their houses in naked and unsheltered places, and that would put a guise of antiquity upon any new inclosure; since by these, while a man is on a voyage of no long continuance, his house

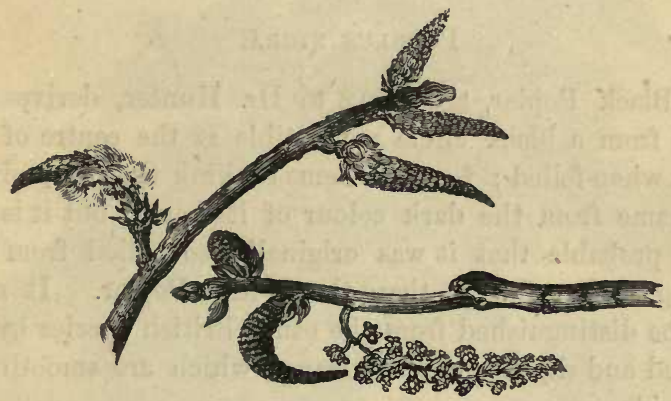

CATKINS OF GREY POPLAR.

and lands may be so covered as to be hardly known at his return." In England we rarely see many of them growing together, as they are generally planted to contrast with trees of darker foliage; but in France they are in some places so abundant as to be the prevailing trees in extensive tracts of country, and their wood, called "white wood," is used as fuel, to the exclusion of almost all other firing.

The timber, which is soft and light, was anciently used for making shields, for which its property of yielding before a blow eminently fitted it. Nails may be driven into it without splitting it; hence it may be used with

1 "I think there will be rain," a little girl was overheard to say, "for the weather tree is showing its white lining." 
advantage for packing-cases. Being very light, it is made into the rollers used by linendrapers; and on account of its uninflammable properties, more than its extreme whiteness, it is well adapted for flooring rooms.

The White Poplar is propagated either by cuttings, by layers, or by suckers, which rise in great numbers from the roots.

\section{THE BLACK POPLAR.}

\section{Populus nigra.}

THe Black Poplar, according to Dr. Hunter, derives its name from a black circle perceptible at the centre of its trunk when felled; Loudon seems to think that it received the name from the dark colour of its bark; but it is far more probable that it was originally so called from its having darker foliage than the White Poplar. It may well be distinguished from the other British species by its pointed and slightly notched leaves, which are smooth on both sides.

It was known to Pliny, who recommends it to be planted as a support for vines, a purpose to which, owing to the scantiness of its foliage, it is well adapted. An ancient fable in Roman mythology relates that Phaëton, having obtained permission from his father to drive the horses of the Sun for a day, became terrified, and that Jupiter, to prevent a general conflagration, hurled him from his chariot into the river $\mathrm{Po}$, where he was drowned. His sisters wandered up and down the banks inconsolable for his loss, till they were converted into Poplars, and wept amber for tears.

" Nor must the Heliads' fate in silence pass, Whose sorrow first produced the poplar race: Their tears, while at a brother's grave they mourn, To golden drops of fragrant amber turn." 
The Black Poplar is a tree of very rapid growth, and attains a great size. It is consequently often planted as an ornamental tree, though within the last thirty years its place has been much usurped by foreign species. The

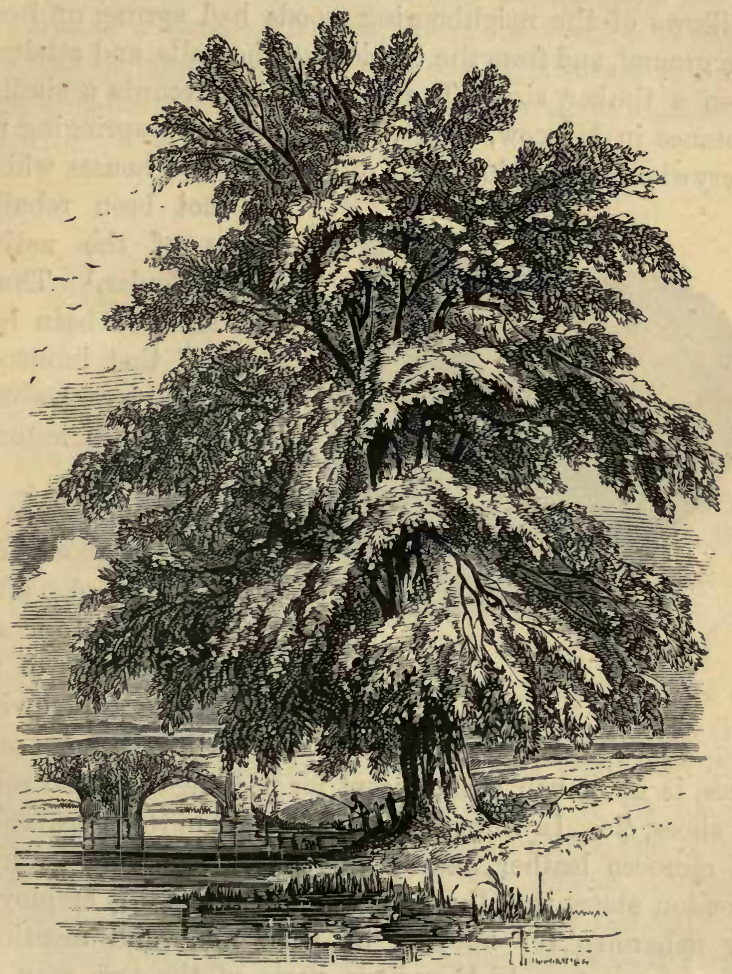

BLACK POPLAR.

bright green colour of its foliage, never at rest and sparkling in the light of the sun, especially after a summer shower, is very pleasing to the eye. The seeds when ripe are invested with thick cottony down, and being carried away by the wind, frequently produce trees in situations 
where they would be least expected. A writer in the Gardener's Magazine states that the kitchen-garden at Versailles was entirely neglected from the beginning of the French Revolution until 1819; and that, in the interval, the light downy seeds of the Black Poplars and Willows of the neighbouring woods had sprung up from the ground, and from the crevices of the walls, and attained even a timber size. The same author records a similar instance in Moscow, where, in 1814, he saw springing up everywhere, from the ashes of those ruined houses which

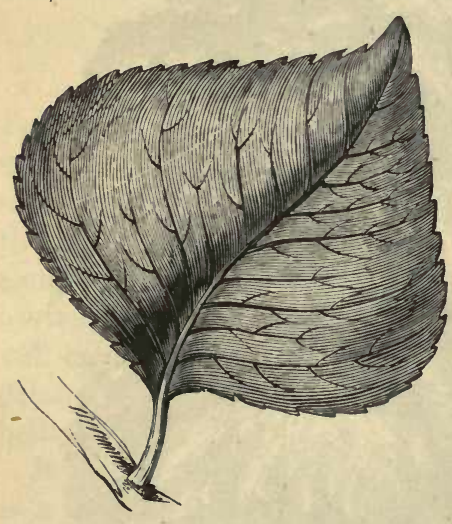

LEAF OF BLACK POPLAR.

had not been rebuilt, plants of the native Black Poplar. ${ }^{1}$ Thus, had Moscow been left to itself, that immense city would have become by this time.a natural forest.

The timber arrives at perfection in about fifty or sixty years, soon after which it begins to decay. In the arts it is of no great value; and, owing to its lightness and softness, is not much used, except for packing-cases and soles of shoes, \&c. In Russia the bark is used in the preparation of morocco leather, and in England for tanning leather. Loudon states that the bark of the old trunk is employed by fishermen for buoying up their nets, and mentions other uses to which various parts of the tree may be applied; but none of these are important.

There are many trees of this species existing in Great Britain which exceed seventy feet in height : one at Bury St. Edmund's is said by Strutt (from whose Sylva the engraving at page 165 is taken) to be ninety feet high and

1 Loudon states this to be the Aspen. 
fifteen feet in circumference at one yard from the ground. The trunk rises forty-five feet before it divides, and then throws out a profusion of branches. But the largest on record is one, mentioned in Feldborg's Denmark, in the south of Zealand, near the school of Herlussholm : it is upwards of a hundred feet high, and its trunk is twentytwo feet in circumference. In 1828 it is stated to have been a majestic tree, in full vigour, and without a decayed branch.

\section{THE TREMBLING POPLAR, OR ASPEN.}

\section{Populus tremula.}

The Aspen is described by Pliny under the name of Libyan Poplar, and is said to have a very small dark leaf, in great repute for its galls. It is a native of a very extensive range of country, being found throughout the whole of the south of Europe, Asia Minor, and in Lapland to the Frozen Ocean. It prefers wet soils, but is by no means confined to the low countries; for in Scotland it flourishes at an elevation of 1600 feet above the level of the sea. It derives its English name, Aspen, from the German name of the tree, Espe, and may readily be distinguished from the other British species by its round leaves, which are of a dark shining green above, and much paler beneath, though destitute of the downy covering which characterises the White Poplar. The leaf-stalk is remarkably long and slender, and being compressed vertically towards its upper extremity, is too weak to support the leaf in a horizontal position. Consequently, the slightest breeze sets it in motion, and hence originated its name, Trembling Poplar.

This peculiarity has obtained for the Aspen the unenviable distinction of being selected as the poetical emblem of restlessness, inconstancy, and fear. 
Lightfoot tells us that the Highlanders entertain a superstitious notion that our Saviour's cross was made of this tree, for which reason they suppose that its leaves can never rest. Superstitions of this class originated partly in that love of the marvellous which is the characteristic of ignorance, and partly, perhaps, in feelings of real piety;

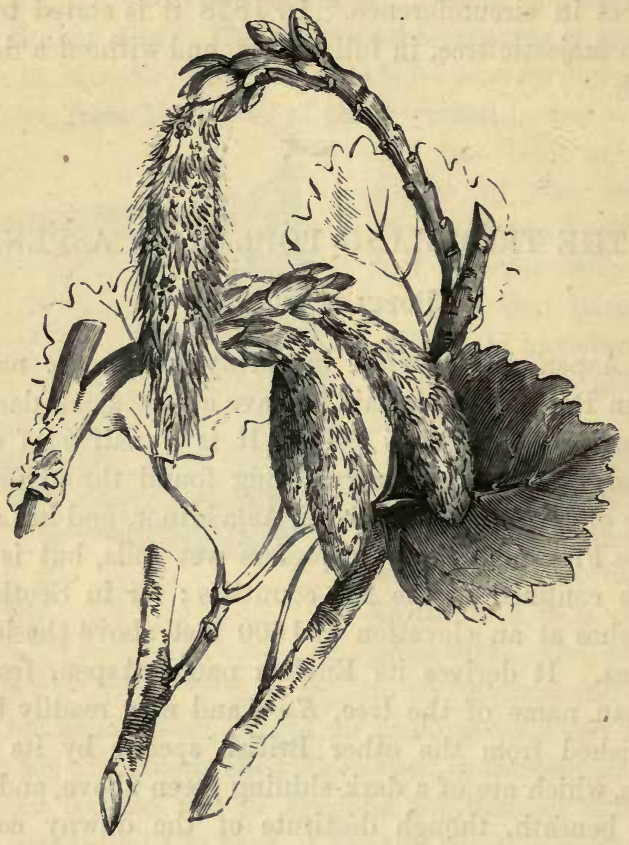

ASPEN,

but the sober-minded Christian will not allow his faith to he affected by a mere natural phenomenon. "All is miracle " that tends to confirm his belief in God's superintending providence, but he humbly refuses to derive from the visible world any teaching but that which Revelation confirms. Reason teaches him that the trembling of the Aspen is dependent on the peculiar mechanism of its 
leaves, and is to be accounted for by reference to natural causes; and though he fails to discover the purpose of this peculiarity in structure, he is satisfied with observing a new instance of creative power, and prefers to confess his ignorance of design rather than be indebted to Nature for evidence which Revelation alone can afford, and which God's Holy Spirit alone can make efficacious.

The Aspen does not generally attain so large a size as the Black Poplar, though there are specimens in existence seventy or eighty feet high. Evelyn says, that "the Aspen thrusts down a more searching foot" than that tree, "and in this likewise differs, that he takes it ill to liave his head cut off ; " meaning, that the roots extend to a great distance, and that the branches are impatient of pruning. The roots, however, do not descend far beneath the surface, and are remarkable for sending up numerous suckers, which, if the tree be planted in a lawn or garden, are very troublesome, and require to be eaten or mowed down. It is not a long-lived tree, beginning to decay internally when about sixty or eighty years old.

The bark of the Aspen is said to be a favourite food of the beaver, and its leaves are greedily devoured by many domestic as well as wild animals. The timber is used for nearly the same purposes as that of the other species. As fire-wood it burns brightly, but rapidly, giving out but little heat.

As an ingredient in the landscape, the Aspen presents the most pleasing appearance in situations where the playful change of its foliage is thrown out by a dark background.

A chemical principle, called populine, has been extracted from the bark and leaves of the Aspen, which has a sweet taste like that of liquorice, and crystallizes in the form of delicate white needles. Its properties are but little known. 


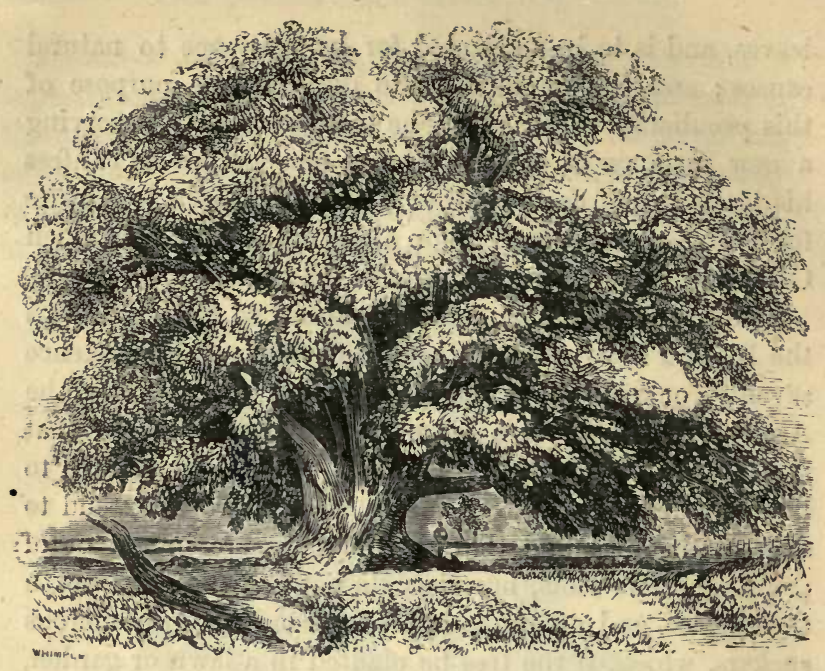

THE CHESTNUT.

\section{THE CHESTNUT.}

Castanea vesca.

Natural Order-Amentace

Class-Monecia. Order-Polyandria.

BEFore I begin the description of this the most magnificent tree which reaches perfection in Europe, it is necessary that I should examine somewhat minutely the grounds which have been urged in favour of its claims to be considered a nativè of Great Britain, which are neither few nor inconsiderable.

The first of these is derived from the large quantity of Chestnut timber which, it has been said, exists in old buildings. Evelyn, writing on this subject, says: "The Chestnut is, next the Oak, one of the most sought after by the carpenter and joiner. It hath formerly built a - good part of our ancient houses in the eity of London, 
as does yet appear : I had once a very large barn near the city framed entirely of this timber; and certainly the trees grew not far off, probably in some woods near the town ; for in that description of London written by FitzStephen, in the reign of Henry II., he speaks of a very noble and large forest which grew on the boreal part of it: 'Nigh to London,' says he, ' extends a huge forest, the woody resort of wild beasts, a hiding place for deer, boars, and wild bulls,' ${ }^{1}$ \&c. A very goodly thing it seems, and as well stored with all sorts of good timber as with venison and all kinds of chase; and yet some will not allow the Chestnut to be a free-born of this island, but of that I make little doubt."

Dr. Ducarel, in his Anglo-Norman Antiquities, observes, that "many of the old houses in Normandy when pulled down are found to have a great deal of Chestnut timber about them. As there are not any forests of Chestnuttrees in Normandy, the inhabitants have a tradition that this timber was brought from England; and there are some circumstances which, when rightly considered, will add strength to this tradition; for many of the old houses in England are found to contain a great deal of this timber; several of the houses in Old Palace Yard, Westminster, and in that neighbourhood, which were taken down in order to build Parliament and Bridge Streets, appeared to have been built with Chestnut."

Hasted, who contributed to the Philosophical Transactions a letter confirmatory of Ducarel's views, says: "The ancient Nurman buildings are mostly of this wood, which in all probability was fetched home from this country; most of the stone wherewith our monasteries and buildings of such sort were erected came from Normandy. This seems to have been a mutual traffick for some centuries between the two countries."

Sir Thomas Dick Lauder mentions, that "the roof of

1 "Proxime patet foresta ingens, saltus nemorosi ferarum, latebræ cervorum, damarum, aprorum, et taurorum sylvestriun." 
the Parliament House in Edinburgh is constructed of it; and the beams, and roofing, and strange projections of many of the wooden houses, which had stood for ages in the ancient part of the Scottish eapital, and which were recently pulled down, were found to be of Chestnut; and what is curious, the timber seems to have been procured from a suburban forest, resembling that on the north side of ancient London ; for it appears, from the city records, that large Oaks and Chestnuts formerly covered the space called the Borough-moor, a wild piece of ground, then lying about two miles to the south-west of the city." Gilpin also states, that he had seen in the belfry of the church at Sutton, near Mitcham in Surrey, beams like Oak, yet plainly appearing to be of a different kind of timber, and supposed to be Chestnut.

Another argument in favour of this opinion is derived from the fact that there are in England several places which take their name from these trees, consequently that the trees must have grown there in considerable abundance before such names were given. Such are, Norwood Chesteney in the parish of Milton near Sittingbourne, and Chestnut Hill near the same place. In Hertfordshire is a town called in old writings Cheston, Chesthunte, Shesterhunte and Cestrehunt; and Philpot, who wrote in 1659, says: "There is a manor called Northwood Chasteners, which name complies with the situation, for it stands in a wood where Chestnut-trees formerly grew in abundance."

Evidence still more direct is afforded by the mention of trees existing in a living state, at periods of time more or less remote. For example, there was in the parish of Milton in Elizabeth's time, a Chestnut-wood containing 278 acres, and called Cheston. The forest near London described by Fitz-Stephen is also quoted by Miller, Lauder, and others, but unfortunately, as we shall see by and by, without examining the original author. The great Tortworth Chestnut in Gloucestershire, to be described here- 
after, was known by that name as early as the reign of Stephen; and in the confirmation of a grant made by Henry II. to the monks of Flexeley, "the tithe of Chestnuts in the Forest of Dean " is secured to the monastery.

Such are the principal arguments in favour of the opinion that the Chestnut is a native tree. On the other side it is urged, that the name Spanish Chestnut would imply that the tree is of foreign origin. But this argument will not bear examination. There can be no doubt that Chestnuts were imported from Spain at the time when the name was given; but it does not at all follow that none were produced in England : we are equally justified in inferring that they were so called by merchants, to distinguish them, and recommend them above English Chestnuts, which are far inferior, just as we call hazel-nuts, imported from the same country, "Spanish nuts," to distinguish them from those which grow in England.

In the next place, it is expressly stated by ancient authors that the Chestnut-tree was first introduced from Asia into Europe by the Greeks, and transported thence into Italy by the Romans. This fact is allowed by the holders of the opposite opinion, who at the same time maintain that the tree might be unknown in continental Europe, and yet be indigenous to Britain, although unnoticed by the invaders of that country.

The fact that Chestnut timber has been found in ancient buildings in very great quantities would carry great weight, but that it has been recently discovered that the wood supposed to be Chestnut is in reality a kind of Oak, differing from common Oak in those very characters which had been fixed on as distinctive of Chestnut. Besides this, Chestnut timber of large dimensions is, neither in Great Britain nor the south of Europe, found to possess the qualities, strength and durability, which were supposed to have recommended it to the notice of ancient builders.

Evelyn's quotation from Fitz-Stephen is a very unhappy one, and the citation of the same passage from Evelyn by 
Miller, Laud, \&c., still more unfortunate, for the tree in question is neither described nor even mentioned by name. Evelyn honestly cited the passage as evidence that there formerly existed a great forest near London, in which he thought it probable that Chestnut timber, among other kinds, might grow; and the authors who followed him, perhaps from not being able to refer to the original work, mistaking the drift of his remark, took it for granted that the tree was mentioned, and considered the evidence thereby afforded conclusive, as indeed they well might.

There can be no doubt that Chestnut-trees have existed quite long enough in England to originate the names of places, but this they might have done without being aboriginal trees. In fact a planted grove of foreign trees, or even a single fine specimen, might have afforded sufficient reason for giving a name commemorative of the circumstance to an otherwise unimportant place. With respect to the Chestnut-forest said to exist in Elizabeth's time in the parish of Milton, Barrington, who wrote in 1771, says that he expended much time and labour in examining the forest, and discovered satisfactory evidence, from the fact that they stood at equal distances from each other and in straight lines, that the trees had been originally planted. The author of a tract published in 1612 was evidently of opinion that the tree in question was not indigenous, for he recommends planting it as a "kind of timber tree of which few grow in England."

With regard to the strongest evidence of all in favour of the opinion that the Chestnut is a native tree,-that, namely, afforded by the actual existence of ancient trees, and the notice of others in the grant to the Monastery of Flex $\in$ ley, ${ }^{1}$ - it may be argued that, supposing the Chestnut to have been introduced by the Romans, ample time had been allowed it to establish itself thoroughly, and even to spread itself over the country. The Sycamore, Gerard

1 "Singulis annis totam decimam Castanearum de Denâ, et ter. ram illam quam adquietavit ipse Comes Herefordiæ." 
says, was, in 1597, a "rare exotic," yet 250 years have sufficed so thoroughly to naturalize it, that few persons are aware that it is really of foreign origin. Three times that space of time may have elapsed between the introduction of the Chestnut and the first mention of a British specimen; so that even if Fitz-Stephen had told us that the forest near London consisted of these trees, it would nut necessarily follow that they were not descended from trees originally introduced. That they did not exist in great quantities may, I think, be inferred from the fact that the produce, with the exception of a tithe, was considered so important as to be reserved by the king. Had the tree been, as Evelyn surmises, abundant near London, the Forest of Dean would scarcely have been laid under contribution; the fact, therefore, that Chestnuts are mentioned at all would afford evidence rather that they were rare and consequently valuable, than that they were common forest trees.

On the whole then we may, I think, with reason conclude that the Chestnut, though long naturalized in England, is not an aboriginal native, but was introduced probably by the Romans at a very early period, and in process of time propagated itself so widely as to have raised a doubt whether it was not a really native tree. Its history may be briefly told as follows. It was first introduced into Europe by the Greeks from Sardis in Asia Minor, whence it was called the "Sardian nut," " and at a later period, "Jupiter's nut," 2 and " husked nut" from its being inclosed in a husk or rind instead of a shell. Loudon, and several other authorities, from a misconception of a passage in Pliny, or, more likely, from quoting it at second hand, attribute the introduction of this tree into Italy to Tiberius Cæsar-a gross inaccuracy, for it is evident from the writings of Virgil that Chestnuts were abundant in Italy long before the time of that emperor. By the Romans it was called Castanea, from Castanum, a

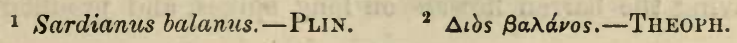


town of Magnesia, in Thessaly, where it grew in great abundance, and from which it is said that they first brought it. Pliny enumerates several varieties, the best of which he says grew at Tarentum and Naples. Theophrastus, who wrote in the third century before the Christian era, speaks of it under the name of Jupiter's nut, as a tree originally introduced, but in his time quite naturalized in the mountainous parts of Thessaly.

From Italy and Greece it appears to have spread over the greater part of temperate Europe, ripening its fruits and sowing itself wherever the grape ripens. It was in all probability introduced into Britain by the Romans for the sake of its fruit; and here, from being a tree of great duration, and from the paucity of other trees the fruit of which is available for food, it was naturally an object of care and attention. In France, Italy, and Spain, especially the two last countries, it attains a great size, and has all the appearance of being naturalized. On the Alps and Pyrenees it flourishes at an elevation of between 2,500 to 2,800 feet, the nuts having been perhaps carried to these lofty situations by the animals which lay up stores of winter food. It is still most abundant in Asia Minor, as well as in Armenia and Caucasus, and it is also found in America, as far worth as latitude $44^{\circ}$. It ripens its fruit in the warmer parts of Scotland; but rarely, if at all, in Ireland.

The Chestnut-tree is twice mentioned in the Authorized Version of the Old Testament (Gen. xxx. 37, and Ezek. xxi. 8): but in the former of these passages the Septuagint translation renders the Hebrew word armon, by plane, in the latter by pine. Rosenmuiller is of opinion that the rendering "plane" is the correct one.

The Chestnut was, by Linnæus, placed in the same genus with the Beech, under the name of Fagus Castanea, but modern botanists have again separated them, considering the genera sufficiently distinguished by the former having the barren flowers on long spikes, and producing 
farinaceous nuts ; the latter, by having its barren flowers in globular heads, and by bearing oily nuts-characters strong enough to mark different genera. It is well distinguished by its large, sharply serrated leaves, which are smooth and glossy, by its long tendril-like spikes of flowers in July, and in autumn by its bunches of nuts inclosed in cases thickly beset with complicated sharp prickles. Sir James E. Smith describes it as a stately and majestic tree, rivalling, if not exceeding, the British Oak in size and duration. The bark is remarkable for its deep and wide clefts, which seem to have furnished ideas for some ornaments in Grothic architecture. Gilpin, who also compares it to the Oak, says that its ranification is more straggling but easy, and its foliage loose. This is the tree which graces the landscapes of Salvator Rosa. In the mountains of Calabria, where Salvator painted, the Chestnut flourished. There he studied it in all its forms, breaking and disposing it in a thousand beautiful shapes, as the exigencies of his composition required. We find it indeed nearly always forming a prominent feature in his bold and rugged landscapes, many of his most striking scenes being drawn from the wild haunts and natural fastnesses of that romantic country, wherein he passed so many of his youthful days. Gilpin supposes that this great painter's fondness for the Chestnut is owing to its liability to be shattered by storms. Bose is of opinion, that as an ornamental tree it ought to be placed before the Oak. Its beautiful leaves, he says, which are never attacked by insects, and which hang on the trees till very late in autumn, mass better than those of the Oak and give more shade. An old Chestnut, standing alone, produces a superb effect. A group of young Chestnuts forms an excellent background to other trees; but a Chestnut-coppice is insupportably monotonous.

But it is in Italy that it is to be seen in all its grandeur. Sir T. D. Lauder speaks of having "roamed for miles through the high-roofed leafy shades of the endless Chestnut-forests, which hung everywhere on the sides and roots 
of the Apennines, where the impervious canopy was supported by the columnar trunks of the enormous trees; and there, and in many parts of the Alps, the peasants depend greatly on the chestnuts; for the bread they live on is very much, if not altogether, composed of the farina obtained from the nuts. We remember participating in one of the most interesting scenes we ever beheld, whilst penetrating that extensive Chestnut-forest which covers the body of the Valombrosan Apennine, for nearly five miles upwards. It was a holiday, and a group of peasants, of both sexes, dressed in the gay and picturesque attire of the neighbourhood of the Arno, were sporting and dancing on a piece of naturally level and well-cropped turf, which spread itself beneath these gigantic trees, whilst the inmost recesses of the forest were, ever and anon, made to resound to their mirth and their music. Some were beating down the chestnuts with sticks; others, for their own refreshment, were picking out the contents from the palisadoed castles in which the kernels lie intrenched; and when newly gathered from the tree, nothing can be more sweet or pleasing to the palate: whilst others, and particularly the girls, were carrying on an amusing warfare of love, by pelting one another with the fruit. It seemed to us as if the golden age had been restored; and that, abandoning all the luxuries and attendant evils of civilized life, mankind had voluntarily returned to their pristine simplicity of fare, when the esculus and the Chestnut-tree yielded them their innocuous food, and when the innocency of their lives corresponded with that of their rustic nutriment."

The Chestnut will thrive in most situations, except where the soil is stiff and tenacious; it prefers a deep sandy loam, but, as we have seen, attains a great size at a considerable elevation among the mountains of the south of Europe. In England it grows with the greatest rapidity in the rich loamy soils of the "valleys, but its timber is then brittle and useless ; in sheltered situations, 
where the soil is tolerably free, it attains some height; but in poor gravelly soil, where its roots will only run along the surface, the trunk attains a considerable diameter, with a disproportionate spread of branches. Bose remarks, that wherever he has observed Chestnuts on mountains in France, Switzerland, and Italy, they were never in soils or on surfaces fit for the production of corn; where the

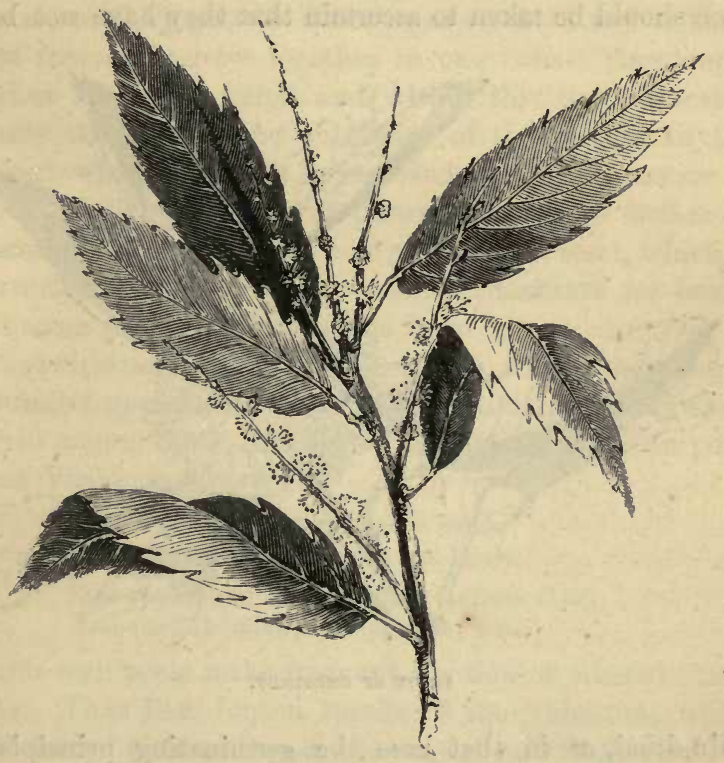

FLOWER UF CHESTNUT.

corn left off, there the Chestnuts began; and, in climates suitable for corn, the tree is only found on rocky and flinty soils.

According to Phillips, "the Chestnut seems to delight in the cinerated substances thrown out of volcanoes, as is shown by the thick woods of Chestnut-trees which cover the surface in the neighbourhood of Vesuvius. They 
grow luxuriantly on Mount Somma, on the heights of the Camaldoli near Naples, on the Pyrenees near medicinal springs, and in general in the neighbourhood of subterraneous fires, not to mention the numerous and gigantic trees that have for ages darkened the sides of Etna."

The Chestnut is usually propagated by sowing the nuts; but the choice varieties are continued by grafting. English nuts germinate freely, but if foreign ones be sown, care should be taken to ascertain that they have not been

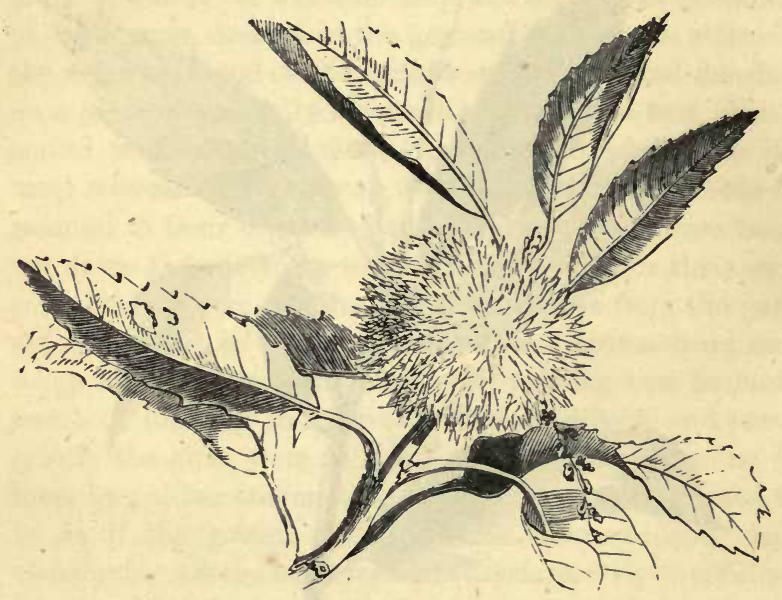

FRUIT OF CHFSTNUT.

kiln-dried, as in that case the germinating principle is destroyed.

The Chestnut blossoms in July, and soon the upper part of the spike bearing the barren flowers withers and lrops off, leaving the lower part of the spike still supporting the fertile flowers with the embryo of the future nuts attached. Towards the end of September the latter hegin to ripen, and in October fall to the ground, where they open with valves and expose the ripe nuts. Each case contains from two to five nuts, two or more of which 
are often mere empty rinds, but all, whether solid or otherwise, bear the remains of the flower, in the shape of a few dry bristles, on their points.

Chestnuts are spoken of very contemptuously by Pliny, who says: "The fruit of the Castanea we call also a nut, though it approaches nearer in character to mast. It is protected by a case beset with strong prickles. It is strange that we hold as of no value a fruit which Nature has so carefully guarded from injury. As many as three nuts frequently grow together in one case. The proper rind of the nut is tough, and within this is a thin skin closely attached to the substance of the nut, as in the walnut, which, unless it be removed, spoils the flavour of the fruit. The best way of preparing them for food is by roasting. They are sometimes ground into meal, which is converted by women into a wretched substitute for bread, and eaten during their religious fasts."

Notwithstanding the low repute in which the Roman naturalist appears to have held chestnuts, they are mentioned among rustic dainties by more than one Latin poet. Thus Virgil says :

" Sunt nobis mitia poma, Castaneæ molles, et pressi copia lactis."

"Ripe apples and soft chestnuts we have there, And curd abundant to supply our fare.".

Our own poets make frequent mention of roasted chestnuts. Thus Ben Jonson speaks of the "chestnut whilk hath larded (fattened) many a swine ;" and Shakspeare, of "the sailor's wife with chestnuts in her lap :" and Milton, writing on the death of his friend Deodati, says :

"In whom shall I confide? Whose counsel find

A balmy medicine for my troubled mind?

Or whose discourse with innocent delight

Shall fill me now, and cheat the wintry night-

While hisses on my hearth the purple pear, And blackening chestuuts start and crackle there ; While storms abroad the dreary meadows whelm, And the wind thunders throug the neighbouring elm?" 
Evelyn laments that in his time they were not used as an article of food so much as they deserved. "We give that fruit to our swine in England which is amongst the delicacies of princes in other countries, and, being of the larger nut, is a lusty and masculine food for rusticks at all times, and of better nourishment for husbandmen than cole (cabbage) and rusty bacon, yea, or beans to boot; instead of which, they boil them in Italy with their bacon; and in Virgil's time they eat then with milk or cheese. The bread of the flour is exceedingly nutritive; it is a robust food, and makes women well complexioned, as I have read in a good author. They also make fritters of chestnut-flour, which they wet with rose-water, and sprinkle with grated parmigiano, and so fry them in fresh butter for a delicate. How we here use chestnuts in stewed meats and beatille pies, our French cooks teach us; and this is in truth their very best use, and very commendable."

The principal countries where chestnuts are now employed as an important article of food are the south of France and the north of Italy; where they serve, in great measure, as a substitute for both the bread and potatoes of more northern nations. In these countries it becomes a matter of importance to preserve the chestnuts during winter; and accordingly great care is taken in gathering, keeping, and drying them so as to insure a constant supply. When the shestnuts are ripe, those that are to be preserved are collected every day from the ground on which they have fallen from the tree, and spread out in a dry airy place, till the whole are gathered together. But as it is often a considerable time before the chestnuts are all ripe enough to fall from the tree, if the season be so far advanced that there is danger of snow or heavy rains, after the fallen chestnuts have been collected and set on one side for drying, the tree is beaten with long poles, to knock off the remaining fruit. But the fruit thus collected is only considered fit for immediate use; and the greater 
part is carried to the local markets or sent to Paris. The husks of the chestnuts beaten off the trees being generally attached to the nuts, they are trodden off by peasants furnished with heavy sabots, or wooden shoes, when the nuts are wanted for present use ; but when they are to be preserved for a few months, they are generally kept in their husks in heaps in the open air, or in barrels of sand, which are sometimes actually sprinkled with water in very dry seasons, in order to preserve the full and plump character of the nuts.

In the Cevennes, where chestnuts are an article of food, the inhabitants have a process of kiln-drying them, so that they will keep good for two or three years. The process consists in exposing them on the floor of a kiln to the smoke of a smothered wood-fire. The heat is applied gently, so as to make the internal moisture transpire through the husk of the chestnut. The fire is kept gentle for two or three days, and then is gradually increased during nine or ten days. The chestnuts are then turned with a shovel, and the fire is continued until they are ready. This is known by taking out a few of them and threshing them; if they quit their inner skin, they are done. They are then put into a bag, and threshed with sticks to separate the external and internal husks. If the husks are left on, the chestnuts become black, by imbibing from the husk the empyreumatic oil of the wood-smoke, and do not keep so well. In order to be prepared for food, they are ground into flour; and of this, mixed up with a little milk and salt, and sometimes with the addition of eggs and butter, is made a thick girdle-cake, called la galette. La polenta is another preparation, made by boiling the chestnut-flour in milk till it becomes quite thick; when made with water, it is eaten with milk in the same manner as oatmeal porridge in the north of England and Scotland.

The most usual modes of cooking chestnuts in France are, boiling them in water, either simply, with a little salt, 
or with leaves of celery, sage, or any other herbs that may be preferred, to give them a flavour; and roasting them either in hot ashes, or in a coffee roaster. They are also occasionally roasted before the fire, or on a shovel, as in England; but when thus prepared, they are thought not so good. In whatever way they are roasted, the French cooks always slit the skin of all except one; and when that cracks and flies off, they know that the rest are done. Sugar is said to have been obtained in France from chestnuts, by the same process as that used for the extraction of sugar from beetroot, and at the rate of 14 per cent. ; which is more than the average produce of the beetroot. Chestnuts are sometimes used for whitening linen, and for making starch; and when roasted they are a good substitute for malt in making beer.

"In many countries," says Miller, "where Chestnuttrees are cultivated, the people graft the largest and fairest fruits upon stocks raised from the nut. And these grafted trees are called by the French marroniers, but they are unfit for timber." In France great attention is still paid to the cultivation of the Chestnut, and the varieties are divided into two sections, les châlaignes and les marrons, the latter being held in high esteem as producing nuts of the largest size, finest flavour and farinaceous qualities.

The Chestnut-tree retains its leaves until late in the autumn, when they become of a rich golden hue. Owing to the tufted, and consequently weighty, character of the foliage, and the brittleness of the timber, the tree is liable to be injured by autumnal storms; but the leaves are rarely attacked by insects, strongly contrasting in this respect with its rival the Oak. Its leaves are in France used as a litter for cattle, and, like those of the Beech, are sometimes employed for stuffing mattresses.

It is not easy to form a correct estimate of the value of the Chestnut as a timber-tree, there being a great uncertainty whether the beams discovered in ancient buildings, and said to be of Chestnut, do in every instance (they 
certainly do not in most cases) belong to this tree at all. On the whole, its value appears to have been much overrated, for, ornitting the uncertain evidence afforded by ancient specimens, recent timber possesses few valuable properties, at least for the purposes for which it was recommended by the earlier writers. They, finding what they believed to be Chestnut-timber occurring in buildings of unquestionable antiquity, naturally concluded that its value for strength and durability recommended it to the earlier builders, and further assumed, that, owing to the estimation in which it was held, it had become rare. Thus Hartlib, who wrote before the middle of the seventeenth century, says : "In divers places in Kent, as in and about Gravesend, in the country and elsewhere, many prime timbers of their old barns and houses are of Chestnut-wood, and yet there is now scarce a Chestnut-tree within twenty miles of the place, and the people altogether ignorant of such trees." And Evelyn, falling into the same error with regard to the timber of which one of his barns was made, assumes that Chestnut-forests formerly stood in the vicinity of London, and quotes as confirmation of his surmise the passage from Fitz-Stephen cited above, though that author makes no allusion to the tree.

The French naturalist, Buffon, was the first who directed attention to the strong resemblance borne by the timber of the Durmast Oak (Quercus sessiliflora) to that of the Chestnut in its best condition, both almost entirely wanting the silver plates which characterise the timber of the common Oak (Quercus pedunculata). The truth of this remark was subsequently confirmed by the discoveries of Fougeroux and Daubenton in 1780, and it is now an ascertained fact that the roof of Westminster Hall and other ancient buildings, formerly supposed to consist of Chestnut, is constructed of Durmast (or, as Lindley would have it called, English) Oak. The fact is now ascertained to be, that Chestnut-timber, though admirably adapted in its young state for many purposes to which Oak is applied, 
such as beams, posts, and fences, after a certain, and that comparatively an early age, becomes what is technically called shaky, and so deteriorated by the separation and decay of the internal layers as to be of very little value. It is evident therefore that before it could have attained the size necessary for it to be employed in the structure of such buildings as Westminster Hall, it must have lost all the properties which recommended it. If cut when not more than fifty years old, it consists almost exclusively of heart-wood, with a layer of alburnum, or sapwood, equalling in thickness the breadth of the bark; but when suffered to stand beyond its full growth it is, on good authority, the worst of all timber, being more brittle and more apt to crack and fly into splinters than any other. In the hop countries the growth of Chestnut-coppice is much encouraged, poles from this tree and the Ash being preferred to all others. Casks, it is said, made of Chestnut-wood contribute much to the colour and quality of the wine, as well as to the preservation of it; the fermentation is slow, and the wine made in those vessels is sweeter. It has also the property of lasting a long time, when used for water-pipes or other purposes underground. It is said also to be noxious to spiders and other insects, but this virtue belongs rather to the situation of Oak-beams in old buildings than to any quality actually residing in Chestnut. As fuel it is not held in great estimation, but the charcoal made from it, though not of first-rate quality, is in some places greatly sought after for forges. The bark, especially of young trees, is used for tanning, and sells at half the price of Oak-bark. 


\section{THE HORSE CHESTNUT.}

\section{Asculus hippocastandm.}

Natural Order-HiPPOCASTANEE.

Class-Heptandria. Order-MoNogyia.

The features presented by this tree are so decidedly different from those of the ordinary tenants of our woods and forests, that a mere glance is sufficient to assure us that where the Oak, the Ash, and the Elm are types of native trees, the Horse Chestnut must be an alien, gladly admitted though it be to a participation in all the privileges which we accord to our undoubted and most highly-prized native trees. Whether adding with its massive foliage to the deep shadow of a wood, decorating the slopes of a park, or uniting its broad leaves to form the canopy of a stately avenue, it is everywhere in place, and everywhere worthy of admiration.

In early spring, before

“The palms put forth their gems, and every tree Now swaggers in her leafy gallantry,"

the Horse Chestnut has given full and timely notice of the change which is in preparation. Every one of its stout twigs is terminated by a turgid bud hastening to anticipate its fellows in throwing off the wintry covering, like a lusty infant struggling to be released from the arms of its nurse. After the lapse of a week, the ground is strewed with the party-coloured scales which well did their duty in protecting the young shoots from the frosts and nipping winds of February; and though the air be motionless, others are still dropping all around, proving that these integuments are not passively scattered by the wind, but cast off by the living, active energy of the awakened bud.

The Horse Chestnut is a native of Asia, probably of Northern India, whence it was introduced into Europe about 
the middle of the sixteenth century. In the year 1588 there was a growing specimen at Vienna, which had been planted there twelve years before, but which had not yet then flowered. This is said to have been imported from England,

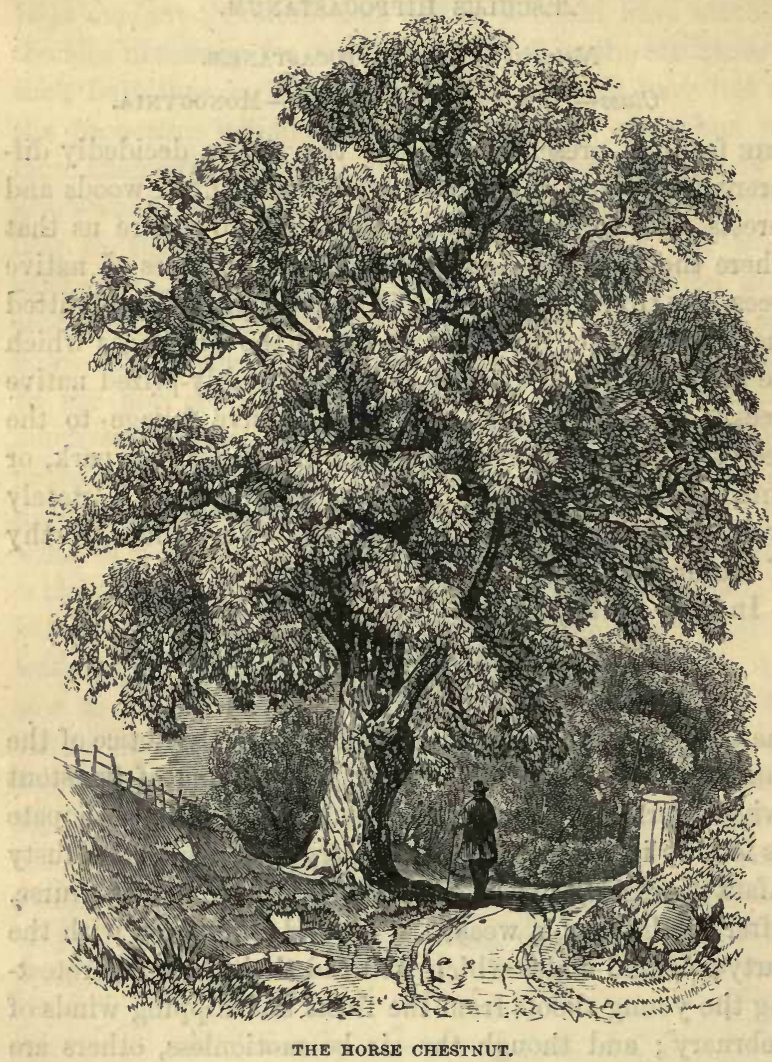

whither it had been brought from the mountains of Thibet in 1550. In France it was first raised from seed procured from the Levant, in the year 1615 . Gerard, in 1579, speaks of it as a rare foreign tree; and how little it was known 
even by those who had seen it, may be inferred from the fact that Parkinson in 1629 places it as a fruit-tree between the Walnut and the Mulberry, and says also that it is of as good use as those trees for the fruit, which is of a sweet taste, roasted and eaten as the ordinary sort. Some of the trees planted at Baden in the sixteenth century are said to be still in existence.

The name of Esculus, from esca, food, was applied originally to a species of Oak which, according to Pliny, was highly prized for its acorns, but how it came to be transferred to the Horse Chestnut is very uncertain. The name "Horse Chestnut" it undoubtedly received from the fact that young branches have impressed on the bark, wherever a leaf has fallen, a mark resembling the print of a

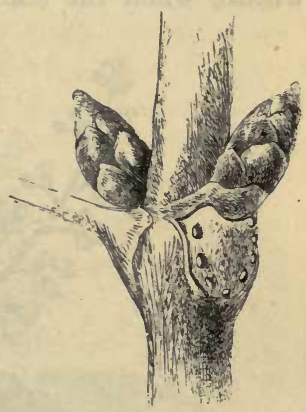
horse's shoe.

The Horse Chestnut is a tree of large size, frequently reaching a height of fifty or sixty feet, with an erect trunk and a broad pyramidal outline. It may be readily distinguished even in the depth of winter by its usually large buds, set on the extremities of thick and heavy-looking branches, which are evidently destined to bear a weighty tuft of foliage and leaves. A celebrated German naturalist detached from this tree, in the winter season, a flower-bud, no larger than a pea, in which he could reckon more than sixty flowers. The external covering was composed of seventeen scales, cemented together by a gummy substance, and protecting from moisture the down which formed the internal covering of the bud. Having carefully removed both the scaies and down, he discovered four leaves surrounding a spike of flowers, and the latter so clearly visible, that, with the aid of a microscope, he not only counted sixty-eiglit flowers, but could discern the pollen of 
the stamens, and perceive that some were opaque and some transparent. It would be more advisable for the young student to gather one of these buds in the early spring, when the sun is just beginning to melt away the gum with which the scales are sealed together.

As the sun begins to gain power, the gummy covering of the bud melts and yields to the expanding pressure from within, when the scales are thrown off, and the delicate

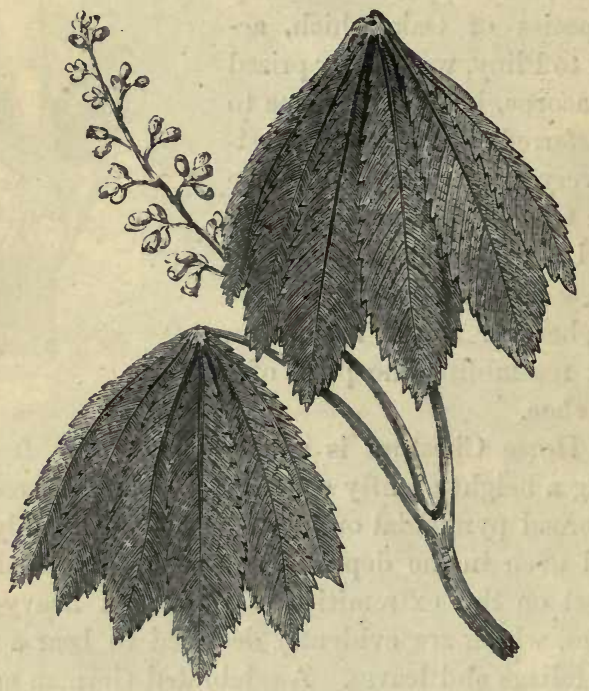

LEAF AND FLOWER-BUDS OF HORSE CHESTNUT.

green leaves are rapidly unfolded, encircling a conical mass of embryo flowers. In this stage the leaves present a singular appearance, drooping with their points towards the ground, as if not strong enough to assume a horizontal position. The buds, it has been already stated, expand very early in spring, but by no means prematurely, for within three or four weeks of their first unfolding they have attained their full length, amounting sometimes to eighteen inches. The leaves and flower-buds continue to 
increase in size until May, when the latter expand; and now, the tree having reached the meridian of its glory, stands forth prominently in all the gorgeousness of leaf and blossom. The downy covering which was observable on the leaves in their early stage has now disappeared, and they have assumed instead a rich, full green. Each leaf is composed of seven broad leaflets, unequal in size, which radiate from a common centre, a character of foliage

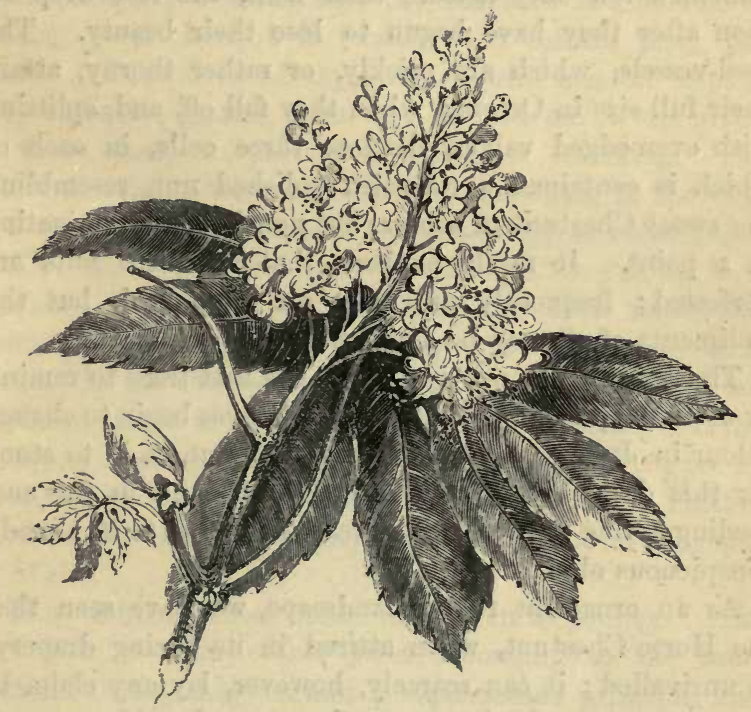

FLOWER OF HORSE CHESTNUT.

different from that of any other British tree. Its clusters of irregular blossoms, snowy-white dashed with pink and yellow, and affording thus early in the season a rich banquet to the venturesome bee, proclaim that the flowerbearing season now reigns paramount.

This being the only common tree in Britain of large size which bears conspicuous flowers, it has received several popular names derived from that fact, such as a gigantic 
hyacinth, lupine-tree, giant's nosegay : this last name in particular suggests a correct notion of its vastness and showy appearance. The flowers, though exquisitely beautiful so long as they continue in perfection, soon become tarnished, and the tree consequently loses much of its grace, yet it is still a fine tree, readily distinguished at a considerable distance by its tiers of large and massive toliage. Out of the numerous flowers contained in every bunch, a few only mature their fruit, the rest drop off snon after they have begun to lose their beauty. The seed-vessels, which are prickly, or rather thorny, attain their full size in October, when they fall off, and, splitting with even-edged valves, disclose three cells, in each of which is contained a roundish polished nut, resembling the sweet Chestnut in colour, but not, like it, terminating in a point. It rarely happens that all three nuts are perfected; frequently only two are developed, but the rudiments of all may be discovered.

The Horse Chestnut is one of the first trees to remind us of the approach of winter, for its leaves begin to change colour in July, and very soon to fall; but, as if to atone for this defect, its buds destined to expand in the succeeding spring have made so great advance as to be already conspicuous objects.

As an ornament to the landscape, we have seen that the Horse Chestnut, when attired in its spring drapery, is unrivalled; it can scarcely, however, lay any claim to the possession of picturesque beauty. In this respect, Gilpin, a great authority on such subjects, pronounces an opinion far from laudatory, as indeed we might naturally expect; for the particular beauties of the Horse Chestnut are not such that they could be represented with effect, if at all, in a picture.

The nuts of this tree, though noi deleterious, are unfit for human food, being very bitter. They may, however, be applied to so many useful purposes, that it is strange they are su much neglected. Their medicinal efficacy on 
the animals from which the tree takes its name, requires confirmation; yet they are excellent food for deer, so that, where these animals are kept, Horse Chestnuts might be planted in numbers with great advantage. A writer in the Gardener's Chronicle for 1843, states that they form a very nourishing food for sheep. "Whilst," he says, "I was at Geneva, in the autumn of 1837, I observed every one collecting carefully the fruit of the Horse Chestnut, and on inquiry I learnt that the butchers and holders of grazing stock bought it readily at a certain price per bushel. I inquired of my butcher, who himself kept a very extensive grazing farm, and he told me it was given to those sheep in particular that were fattening. The Horse Chestnuts were well crushed, something in the way, so I understood, that apples are previously to cider being made. In Switzerland they are crushed or cut up in a machine, kept solely for that purpose: then about twc pounds' weight is given morning and evening to each sheep, who eat the food greedily; it must be portioned out to them, as too much would disagree with them, it being of a very heating nature. The butcher told me it gave an excellent rich flavour to the meat. The Geneva mutton is noted for being as highly flavoured as any in England or Wales."

They are sometimes boiled and given to poultry. Like the fruit of many other trees belonging to the same Natural Order, they contain a saponaceous principle, and when decayed they turn to a jelly, which has been found to answer the purpose of soap. Reduced to a powder and mixed with a third of flour, they are found to make better paste than that composed of flour alone. In Ireland they are used to whiten flaxen cloth, and for this purpose are rasped into water, in which they are allowed to macerate for some time. During the scarcity of 1847 it was suggested that a great saving of flour might be effected by using the starch, which may be prepared from these nuts, as a substitute for wheaten starch in the process of glazing 
calico; but I am not aware whether or not the suggestion was acted on. M. Vergnaud has published a pamphlet, in which he proposes to convert the extracted starch into sugar, and employ it in distillation.

The Horse Chestnut will grow in most situations, but prefers a rich loamy soil. Here it grows with great rapidity: Martyn mentions some raised from the nut, that, at twelve or fourteen years of age, were covered with flowers, and were big enough to shade several chairs with their branches. A peculiarity of their growth, noticed by Hunter, is, that as soon as the leading shoot is come out of the bud, it continues to grow so fast as to be able to form its whole summer's shoot in about three weeks or a month's time. After this, it grows little more in length, but thickens and becomes strong and woody, and forms the buds for the next year's shoots. Owing to this rapid rate of growth, its timber is soft, and unfit for any use where strength and durability are required. It is said, however, to be suitable for water-pipes which are to be kept constantly under ground. The bark, which is very bitter, is employed for tanning, and also for dyeing yellow, and it has been used medicinally as a substitute for Jesuits' bark.

\section{$\infty$ \\ THE HOLLY. \\ Ilex Aquifolium. \\ Natural Order-ILICINEx. \\ Class-Tetrandria, Order-Tetragynia.}

THIs "incomparable tree," as Evelyn most justly calls it, is the most important of the English evergreens. Whether we wander in the woods, when all is bare and stark, save the trunks of trees, which are clothed with the borrowed verdure of the Ivy, and save the dark but cheerful array of armed leaves presented by the Holly; or whether, in the bright leafy days of summer, we detect it 
far off in the depths of the forest, reflecting light from its polished mail as brilliantly as if every leaf were a mirror, -at any season we should be sorry to miss it from our wondlands. But, welcomie as the Holly is at all seasons,

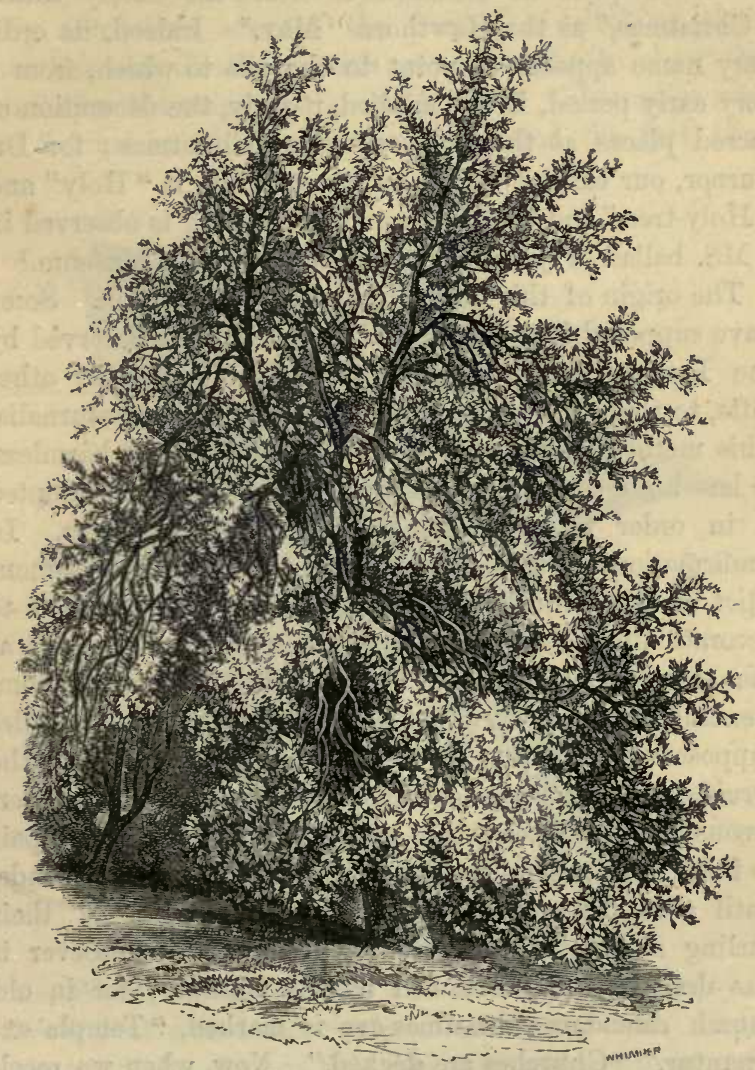

THE HOLLY.

it belongs more particularly to winter, for then the bright joyous appearance of its crimson berries, which from our earliest years have been associated in our minds with the 
festivities of Christmas, render the tree doubly conspicuous. In one respect, what may be said of the Hawthorn is true also of the Holly; both these trees are emblematical of the season in which they are most beautiful, for it is quite as common to hear the Holly called "Christmas," as the Hawthorn "May." Indeed, its ordinary name appears to point to the use to which, from a very early period, it was applied, namely, the decoration of sacred places at the holy season of Christmas; for Dr. Turner, our earliest writer on plants, calls it "Holy" and "Holy-tree," and the same mode of spelling is observed in a MS. ballad of yet older date, in the British Museum. ${ }^{1}$

The origin of this beautiful custom is uncertain. Some have supposed it to be derived from a custom observed by the Romans, of sending boughs, accompanied by other gifts, to their friends during the festival of the Saturnalia. This method of showing goodwill being at least harmless, it has been conjectured that the early Christians adopted it in order to conciliate their Pagan neighbours. In confirmation of this opinion, Bourne cites a subsequent edict of the Church of Bracara, ${ }^{2}$ forbidding Christians to decorate their houses at Christmas with green boughs at the same time with the Pagans; the Saturnalia commencing about a week before Christmas. Dr. Chandler supposes the custom to have been derived from the Druids, who, he says, decorated dwelling-places with evergreens during winter, "that the sylvan spirits might repair to them, and remain unnipped with frost and cold winds, until a milder season had renewed the foliage of their darling abodes." Certainly the custom, whencesoever it was derived, was sanctioned by the Church; for in old ehurch calendars Christmas-eve is marked, "Templa exornantur," "Churches are decked." Now, when we recol-

1 "Holy hath berys as red as any rose."

2 "Non liceat iniquas observantias agere Kalendarum et otiis vacare Gentilibus, neque lauro, neque viriditate arborum cingere domos. Omnis enim hæc observatio Paganismi est."-Brac. Can. 1sxiii. 
lect that of the three great Jewish festivals, - namely, the Passover, Pentecost, and the Feast of Tabernacles, - the two former were undoubtedly typical of the Christian festivals Easter and Whitsuntide, and were, if I may be allowed the expression, merged in them, may we not infer that the early Christians adopted the custom of decking their churches and dwellings with green boughs to show the connexion between the Jewish Feast of Tabernacles and the festival at which they commemorated the fact that

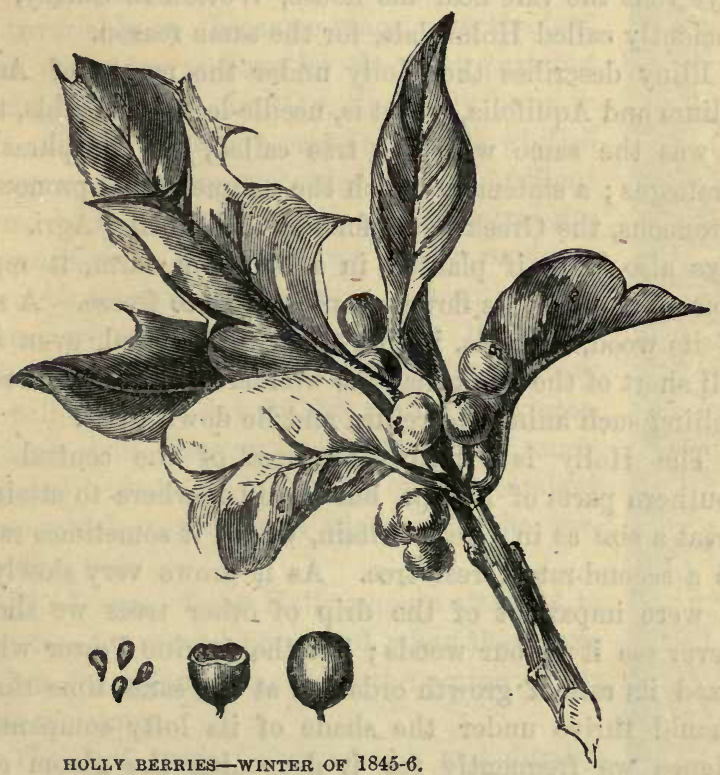

"the Word was made flesh and dwelt," or, as it may be more correctly rendered, "tabernacled among us?" In the absence of all evidence, this conjecture appears to be quite as consistent with reason as any of the others which have been made, and certainly more in accordance with the piety of the early Christians. In some rural districts, the thorny leaves of the Holly, and its scarlet berries, like 
drops of blood, are thought to be symbolical of our Saviour's sufferings; for the same reason, perhaps, in the language of several of the northern countries of Europe, the tree is called "Christ's thorn."

This tree was formerly known by the names of Hulver and Holme, besides its more usual appellation. It is still called Hulver in Norfolk, and Holme in Devonshire, in which last county it has given the name of Holme Chase to a beautiful part of Dartmoor, where it abounds. Evelyn says that the vale near his house, Wotton in Surrey, was anciently called Holmsdale, for the same reason.

Pliny describes the Holly under the names of Aquifolium and Aquifolia, - that is, needle-leaf,- -and adds, that it was the same with the tree called, by Theophrastus, Cratægus ; a statement which the commentators pronounce erroneous, the Greek name for the Holly being Agri. He says also, that if planted in a house or farm, it repels poison, and that its flowers cause water to freeze. A staff of its wood, he adds, if thrown at any animal, even if it fall short of the mark, has the wonderful property of compelling such animal to return and lie down by it.

The Holly is a native of most of the central and southern parts of Europe, but is said nowhere to attain so great a size as in Great Britain, where it sometimes ranks as a second-rate forest tree. As it grows very slowly, if it were impatient of the drip of other trees we should never see it in our woods; but the Divine Power which fixed its rate of growth ordained at the same time that it should thrive under the shade of its lofty companions. Hence we frequently see it deepening the gloom of a forest, where it is rarely visited by even a few straggling sunbeams, and where the only moisture which bathes its leaves is derived from the superfluous rain which has dripped from the overshadowing foliage of its more elevated comrades. When planted among trees which are not more rapid in growth than itself, it is sometimes drawn up to a height of fifty feet or more. More frequently 
it is contented with the humble elevation of thirty feet, or even less, sometimes forming a perfect pyramid, leafy to the base, at other times sending up a clean stem furnished with a bushy head. The bark is of a remarkably light hue, and is very liable to be invested with an exceedingly thin lichen, ${ }^{1}$ the fructification of which consists of numerous curved black lines closely resembling Oriental writing. The leaves are thick, tough, and glossy, and edged with stout prickles, of which the terminal one only is invariably in the same plane with the leaf. The upper leaves have for the most part but a single prickle. In May, the Holly bears in the axils of the leaves crowded, small, whitish flowers, which are succeeded by the brilliant coral berries too familiarly known to require description. The same tree rarely produces abundant crops of flowers in consecutive seasons ; consequently, if we find a Holly one winter loaded with berries, in all probability it will bear but few in the following winter, but we shall discover in the clusters of unexpanded buds ample intimation of the abundant crop which it intends to produce in the succeeding year.

The leaves of the Holly remain attached to the tree for several years, and, when they have fallen, for a long time defy the action of air and moisture.

The leaf, having a very tough and durable fibre, takes a long while to decay, and may frequently be picked up, a frame filled in with network entirely divested of cuticle.

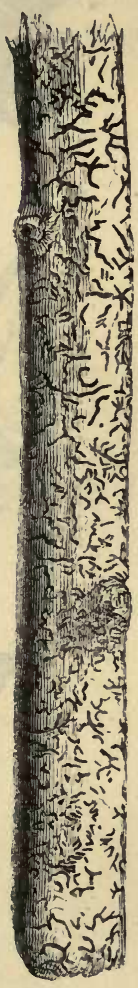

Opfgrapha SCRIPTA.

The Holly will grow in almost any soil, provided it is not too wet, but attains the largest size in rich, sandy loam. The most favourable situation seems to be a thin 


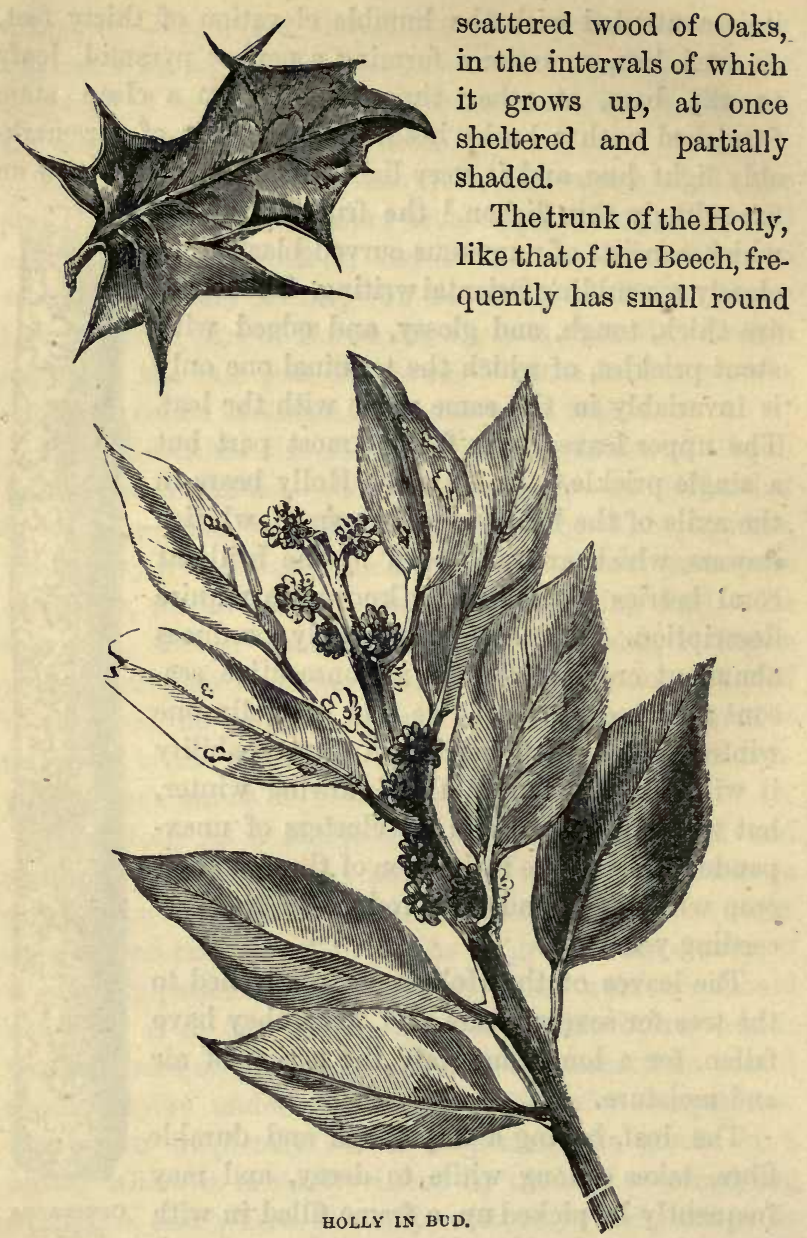

knots attached to it: these are composed of a smooth nodule of solid wood embedded in bark; they may readily be separated from the tree by a smart blow. Hollies are not unusual which, although they grow most luxu riantly and produce abundance of flowers, never mature 
berries. This barrenness is occasioned by an imperfection in the pistil, the cause of which is unknown.

The cultivated varieties of Holly are very numerous; of these three are distinguished by the unusual colour of their berries, yellow, black, and white ; the rest are characterised by their variegated foliage, or by the presence of a larger

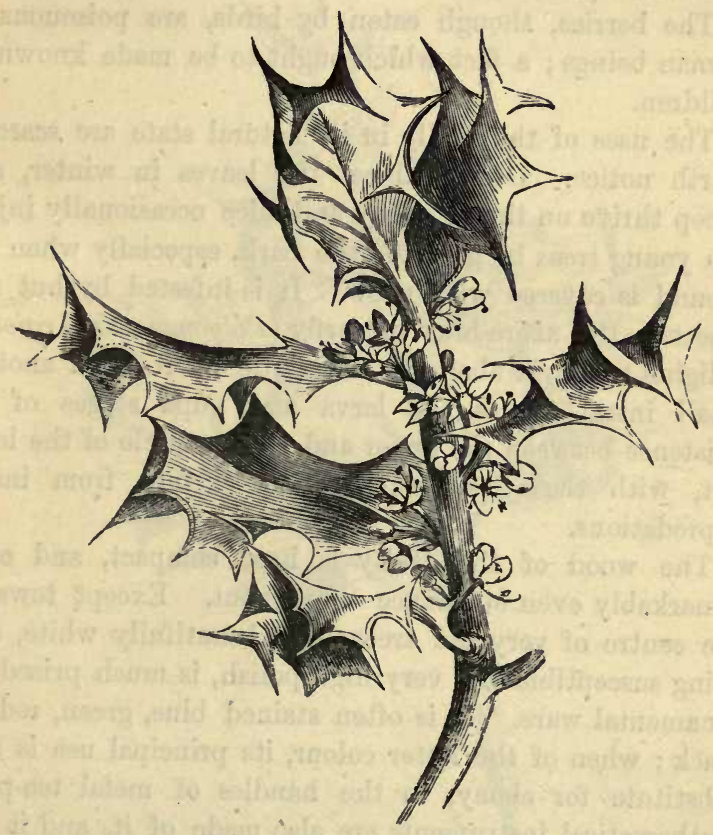

FLOWERS OF THE HOLLY.

number of prickles than ordinary. Of later years more attention has been paid to the discovery of new species of trees than to the cultivation of new varieties, in consequence of which many of the sorts mentioned by old authors are now extinct. Of all variegated trees, the Holly is the most pleasing, the yellow tint of its foliage being generally of a bright decided tone, and therefore not 
suggestive of disease, an idea which is associated with most other trees which have their leaves blotched with yellow. In winter, when flowers are scarce, the garden and shrubbery are much indebted to the more showy varieties for the double contrast afforded by their leaves and berries. They are propagated by grafting on the common sort, and attain an equal size.

The berries, though eaten by birds, are poisonous to human beings; a fact which ought to be made known to children.

The uses of the Holly in its natural state are scarcely worth notice. Deer will eat the leaves in winter, and sheep thrive on them. Rats and mice occasionally injure the young trees by gnawing the bark, especially when the ground is covered with snow. It is infested by but few insects: the azure-blue butterfly (Polyommatus Argiolus) delights to hover about it, and settle on it; and another small insect passes the larva and pupa stages of its existence between the upper and under cuticle of the leaf; but, with these exceptions, it is exempt from insect depredations.

The wood of the Holly is hard, compact, and of a remarkably even substance throughout. Except towards the centre of very old trees, it is beautifully white, and being susceptible of a very high polish, is much prized for ornamental ware. It is often stained blue, green, red, or black; when of the latter colour, its principal use is as a substitute for ebony, in the handles of metal tea-pots. Mathematical instruments are also made of it, and it has even been employed in wood-engraving, instead of box. The wood of the silver-striped variety is said to be whiter than that of the common kind. Of the bark, stripped from the young shoots, boiled and suffered to ferment, birdlime is made; but the greater quantity of this substance used in England is imported from Turkey.

In the north of England the Holly was formerly so abundant about the lakes, that birdlime was made from it 
in large quantities, and shipped to the East Indies for destroying insects. It is raised from seeds, which do not germinate until the second year: hence the berries are generally buried in a heap of earth for a year previously to being sown.

A low shrubby plant, which occurs not unfrequently in

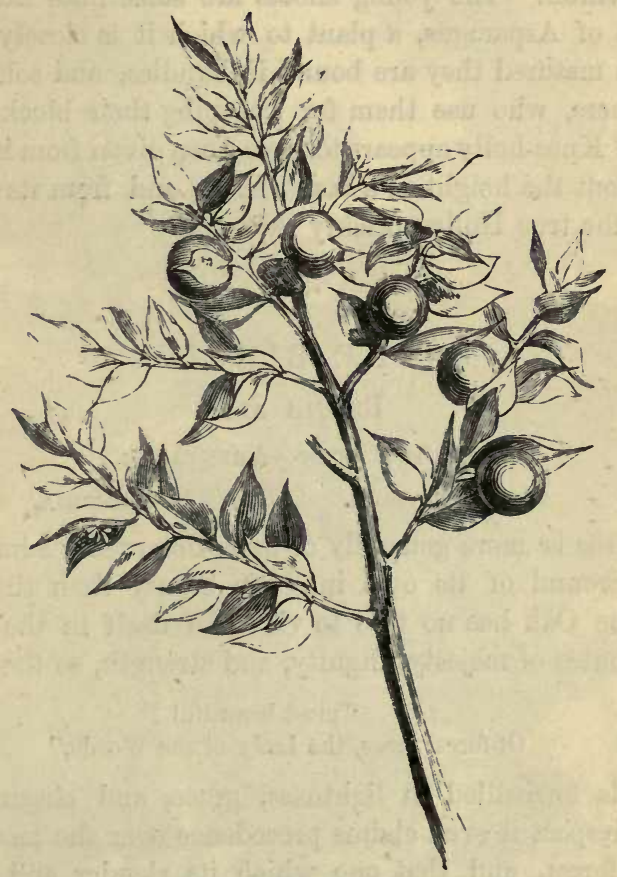

BÜTCHER'S BROUY.

woods and hedges, is sometimes called Knee-holly, though in no way allied to the true Hollies. Its botanical name is Ruscus aculeatus, and it is also called Butcher's Broom. It belongs to the natural order of Liliacea, and is the only indigenous shrub in the class Endogens. It may easily be detected by its tough, green, striated stems, which are 
destitute of bark, and send out from the upper part many short branches. The rigid leaves are a mere expansion of the stem, and terminate each in a single sharp spine. The small green flowers are solitary in the centre of the leaves, and the fertile ones are succeeded by bright scarlet berries as large as cherries which remain attached to the plant all the winter. The young shoots are sometimes eaten like those of Asparagus, a plant to which it is closely allied; when matured they are bound in bundles, and sold to the butchers, who use them for sweeping their blocks. The name Knee-holly appears to have been given from its rising to about the height of a man's knee, and from its having, like the true Holly, prickly leaves.

\section{ae \\ THE BIRCH. \\ Betula alba. \\ Natural Order-AMENTACEE. \\ Clnss-Moncecia. Order-Polyandria.}

No tree is more generally or more deservedly admired on the ground of its own intrinsic beauty than the Birch. As the Oak has no tree to vie with itself in the sterner attributes of majesty, dignity, and strength, so the

$$
\text { Of forest trees, the Lady of the Woods," }
$$

stands unrivalled in lightness, grace, and elegance. In one respect it even claims precedence over the monarch of the forest, and that one which its slender and delicate form would least lead us to expect : it stands in need of no protection from other trees in any stage of its growth, and loves the bleak mountain-side and other exposed situations, from which the sturdy Oak shrinks with dismay. But the style of beauty in which each of these trees excels is so widely different in kind, that neither of them can properly interfere with the other. 
Pliny describes the Birch as a slender tree inhabiting the cold parts of Gaul. The branches, he says, were used for making baskets and the hoops of casks; and the

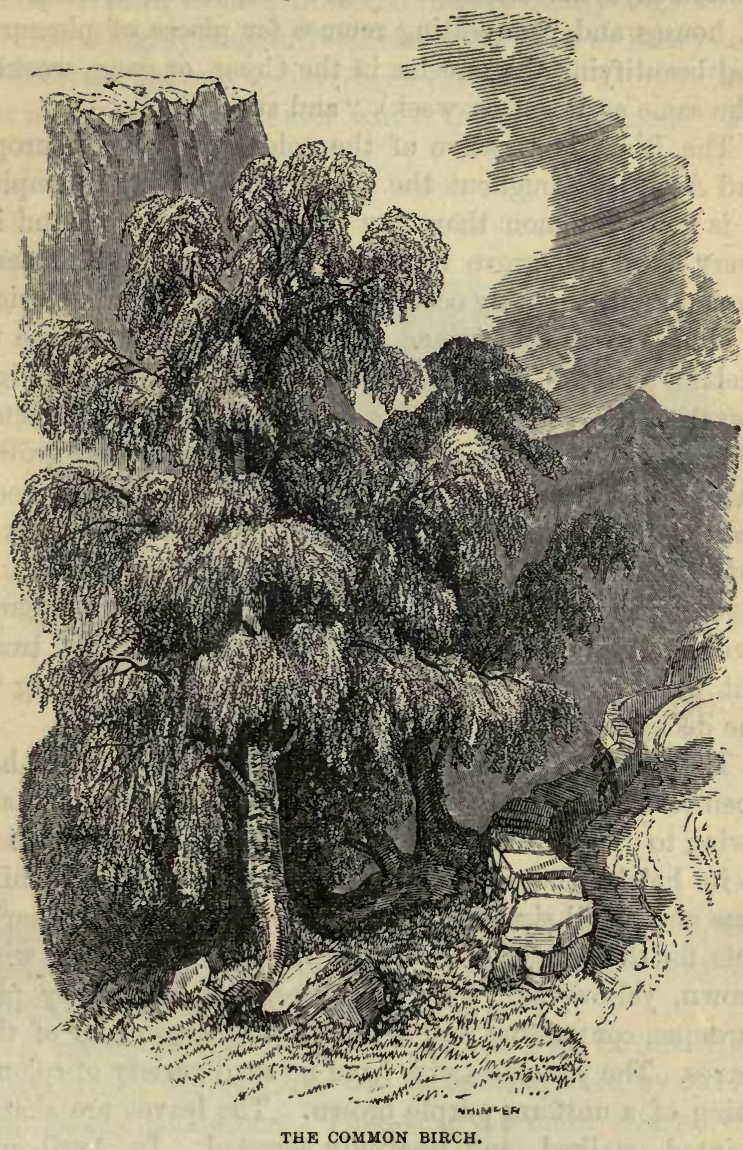

fasces or bundles of rods, which were carried before the Roman magistrates, were made of birch twigs; the use, therefore, of the weapon which, in modern times, is the 
terror of idle schoolboys, is of high classical authority. Branches of this tree were formerly used for decking the houses in Rogation week, as Holly is at Christmas. Gerard says the branches "serve well to the decking up of houses and banquetting roomes for places of pleasure, and beautifying the streetes in the Cross, or gang, weeke" (the same as Rogation week), "and such like."

The Birch is a native of the colder regions of Europe and Asia. Throughout the whole of the Russian empire it is more common than any other tree, being found in every wood and grove from the Baltic Sea to the Eastern Ocean, and frequently occupying the forest to the exclusion of almost every other tree. It grows from Mount Etna to Iceland; in the warmer countries being found at a high elevation in the mountains, and varying in character according to the temperature. In Italy, where it grows, though it appears from Pliny's account not to have been noticed by the ancients, it forms little woods at an elevation of six thousand feet; on some of the Highland mountains it is found at the height of three thousand five hundred feet. In Greenland it is the only tree; but wherever it grows it diminishes in size according to the decreased temperature to which it is exposed.

The peculiar characteristics of the Birch are, as it has been remarked, lightness and elegance, qualities which are owing to the slenderness of the main stem in proportion to its height, the wiriness of the branches, and the thinness and small size of the foliage. It is equally remarkable for the colouring of its bark, which is marked with brown, yellow, and silvery touches, which are very picturesque, contrasting well with the dark green hue of the leaves. The younger twigs have no such variety of colour, being of a uniform purple brown. The leaves are sharp, pointed, stalked, and unevenly serrated. In April and May the flowers appear in the form of drooping catkins, some of which produce stamens only and drop off early. The fertile ones bear very small winged nuts, and fall to 
pieces when ripe, scattering the numerous seeds. The barren catkins are formed in summer, but do not expand till the fertile catkins appear in the following spring. A kind of resin exudes from the leaves and young twigs, which is highly fragrant, especially after rain or heavy dew. This resin appears to have been collected in Pliny's time; as he speaks of a bitumen which the tree produces. The

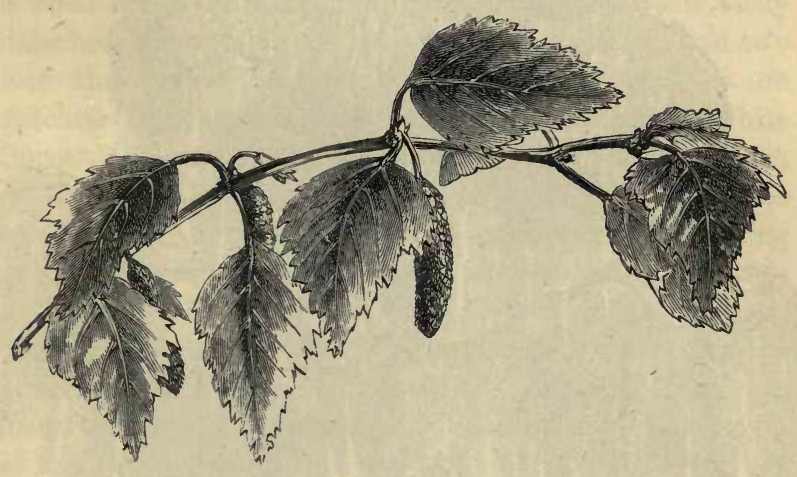

LFAF AND FIOWER OF THE BIRCH.

odour arising from it is very perceptible to a person passing near a tree, and affords another reason why the Birch should be planted near houses.

A variety of the Birch is often met with in the Highlands which differs from the common species, by having the shoots pendulous. This is a yet more elegant tree than the first described, and is frequently planted in parks and gardens. It possesses another advantage in being of quicker growth and attaining a larger size. There 
is also a slight difference in the leaves, which are smaller and somewhat downy.

The Birch is a tree of rapid growth, especially when young; and as it is little affected ezposure, it forms an excellent nurse for other trees. The soil which it prefers

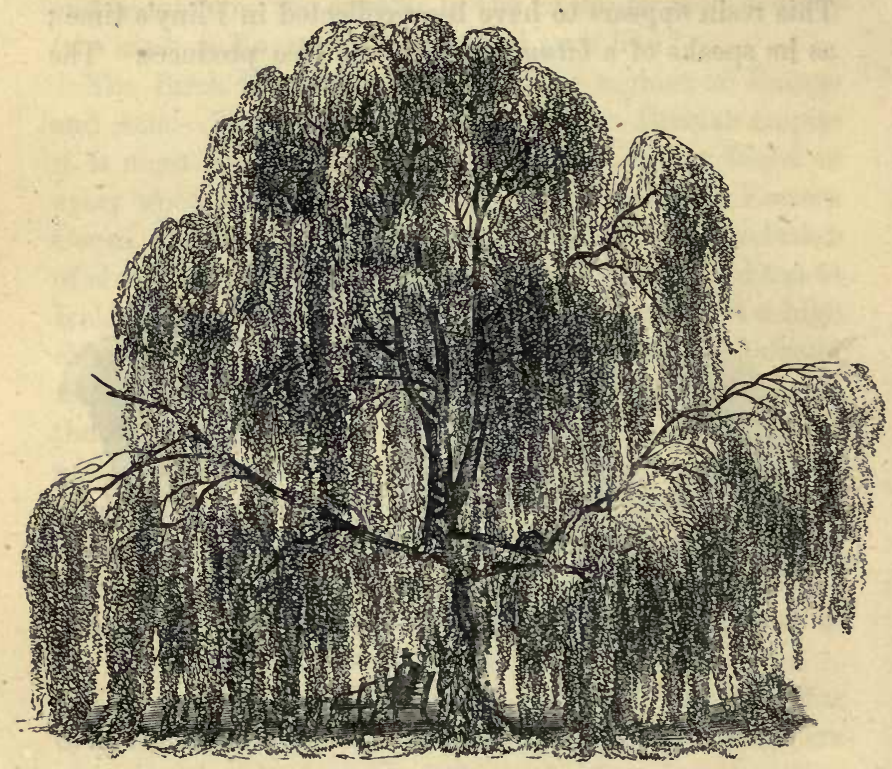

THE WERPING BIRCH.

is turf over sand, and in such situations it attains maturity in about fifty years; but it seldom exceeds fifty feet in height, with a trunk from twelve to eighteen inches in diameter. The bark possesses the singular property of being more durable than the wood which it encircles. Of this the peasants of Sweden and Lapland, where Birch is very abundant, take advantage, and, shaping ii like tiles, cover their houses with it. Travellers in Lapland have noticed in the Birch-forests, that when the soil is very scanty, the trees are liable to be blown down; so that, in 
some places, as many are seen lying on the ground as are left standing. Such as have lain long are found to have entirely lost the substance of the wood, the bark remaining a hollow cylinder without any symptom of decay. In North America this durability of the bark is turned to good account in the structure of canoes. The Canadians select a tree with a large and smooth trunk. In the spring, two circular incisions are made quite through the bark, several feet from each other. Two vertical incisions are then made on opposite sides of the tree; after which a wooden wedge is introduced, by which the bark is easily detached in plates usually ten or twelve feet long, and two feet nine inches broad. To form the canoe, they are stitched together with the fibrous roots of the White Spruce. The seams are coated with resin from the Balm of Gilead. Great use is made of these canoes by the savages and by the French Canadians in their long journeys into the interior of the country: they are very light, and are easily carried on the shoulders from one lake or river to another. A canoe calculated for four persons weighs from forty to fifty pounds. Some of them are made to carry fifteen passengers. This species is known as the Paper Birch.

The thin white bark of the common Birch, which peels off like paper, is highly inflammable, and will burn like a candle. The Birch abounds in a sweet watery sap, which was formerly much valued for its supposed medicinal virtues. The method pursued in collecting it is as iollows:About the beginning of March an oblique cut is made, almost as deep as the pith, under some wide-spreading branch, into which a small stone or chip is inserted, to keep the lips of the wound open. To this orifice a bottle is attached to collect the flowing juice, which is clear, watery, and sweetish, but retains something both of the taste and odour of the tree. Various receipts are given for the preparation of the wine. That recommended by Evelyn can hardly fail to produce an agreeable beverage. 
He directs that it should be boiled for an hour, with a quart of honey to every gallon of juice, a few cloves, some lemon-peel, and a small proportion of cinnamon and mace. It should then be fermented with yeast, and bottled. This process, according to the same author, does not injure the tree, for he mentions having observed a Birch which was so treated for yery many years, and nevertheless grew to an unusual size.

The wood of the Birch is white shaded with red, and, if grown in a very cold climate, lasts a long while. It is used for packing-cases, turnery, wooden shoes, and the felloes of wheels, but is inferior to other kinds of timber for all these purposes. A piece of birch-wood was once found in Siberia, changed entirely into stone, while the cuticle, or outer coating of the bark, of a satiny whiteness, was exactly in its natural state, perfectly well-preserved. This proves what was before said of the durability of the bark. Thin pieces of the cuticle are sometimes placed between the soles of shoes, and are found to resist wet. The bark is even wrapped round the lower end of posts which are inserted in the ground, to prevent the moisture from penetrating them. The bark of large trees is used by the Laplanders as a kind of cloak, a hole being made in the centre to admit the head. From smaller trees, about the size of a man's leg, they make boots by removing the wood and leaving a seamless tube of bark. In seasons of scarcity, the inner bark is sometimes ground with coru, and made into bread; but this, we must hope, happens but rarely.

From the leaves a yellow dye may be prepared. The wood makes excellent charcoal for gunpowder and crayons; and in northern countries, other parts of the tree are applied to various uses, not, indeed, from any particular fitness of the Birch, but from the absence of trees of any other kind: "The Highlanders of Scotland make everything of it; they build their houses, make their beds, chairs, tables, dishes, and spoons ; construct their mills; 
make their carts, ploughs, harrows, gates, and fences, and even manufacture ropes of it. The branches are employed as fuel in the distillation of whisky; the spray is used for smoking hams and herrings, for which last purpose it is preferred to every other kind of wood. The bark is

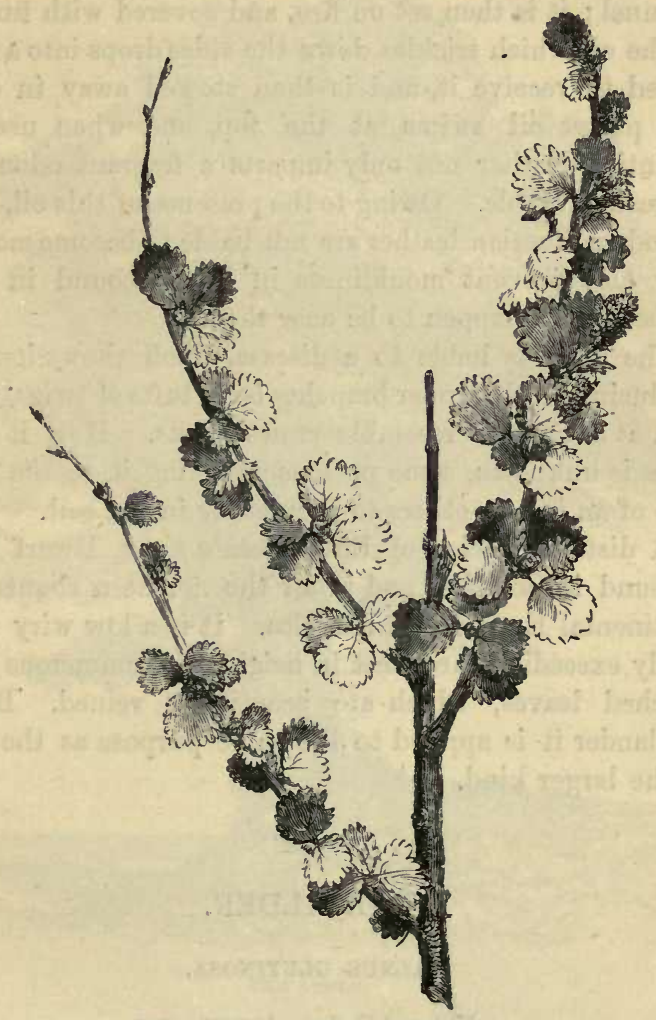

DWARF BIRCH.

used for tanning leather, and sometimes, when dried and twisted into a rope, instead of candles. The spray is used for thatching houses : and, dried in summer, with the leaves on, makes a good bed where heath is scarce."-Loudon. 
In Russia an oil is extracted from the Birch, which is used in the preparation of Russian leather. For this purpose, the white bark, taken either from recent trees, or from the decayed trees which are found in the woods, is gathered into a heap, and pressed into a pit shaped like a funnel ; it is then set on fire, and covered with turf.

The oil which trickles down the sides drops into a vessel placed to receive it, and is then stowed away in casks. The purest oil swims at the top, and when used for anointing leather not only imparts a fragrant odour, but makes it durable. Owing to the presence of this oil, books bound in Russian leather are not liable to become mouldy; they also prevent mouldiness in books bound in other leather which happen to be near them.

The Birch is liable to a disease which shows itself by producing on the upper branches large tufts of twigs, which seen at a distance resemble crows' nests. How it originates is unknown, some persons assigning it to the puncture of an insect, others to peculiarity in the soil.

A district species of Birch, Betula nana, Dwarf Birch, is found in Scotland and in all the northern countries of continental Europe and America. It is a low wiry shrub, rarely exceeding three feet in height, with numerous round notched leaves, which are beautifully veined. By the Laplander it is applied to the same purpose as the twigs of the larger kind.

\section{2 \\ THE ALDER. \\ Alnus glutinosa. \\ Natural Order-Amentace $\boldsymbol{A}$. \\ Class-Monecia. Order-Tetrandia.}

THIs tree is botanically distinguished from the preceding by having its fertile catkins oval, and its seeds not winged, whereas the fertile catkins of the Birch are cylindrical, and 
the seeds furnished with a border. Though so nearly resembling each other in the structure of the flowers as to have been placed by some botanists in the same genus, in general form, character of the foliage, and place of growth,

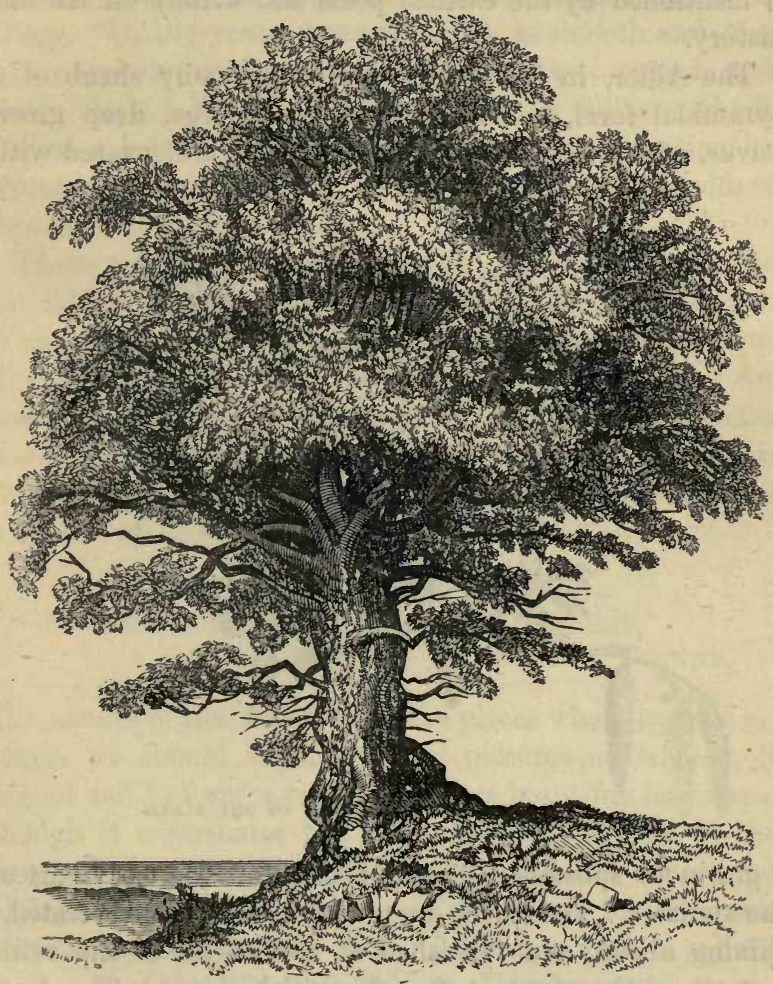

THE ALDER.

no two trees are more distinct; for while the Birch is singularly marked by elegance of form and lightness of foliage, the Alder is stiff, heavy, and even gloomy.

The Alder is a very widely diffused tree, growing by the sides of rivers and in swampy places unfit for the 
growth of other trees, throughout the whole of Europe, a great part of Asia, the north of Africa, and some parts of North America. Having this wide range, and growing in situations where it could not fail to be conspicuous, it is mentioned by the earliest poets and writers on natural history.

The Alder, in its young state, is a bushy shrub of a pyramidal form, heavily clothed with large, deep green leaves, which as well as the young shoots are covered with

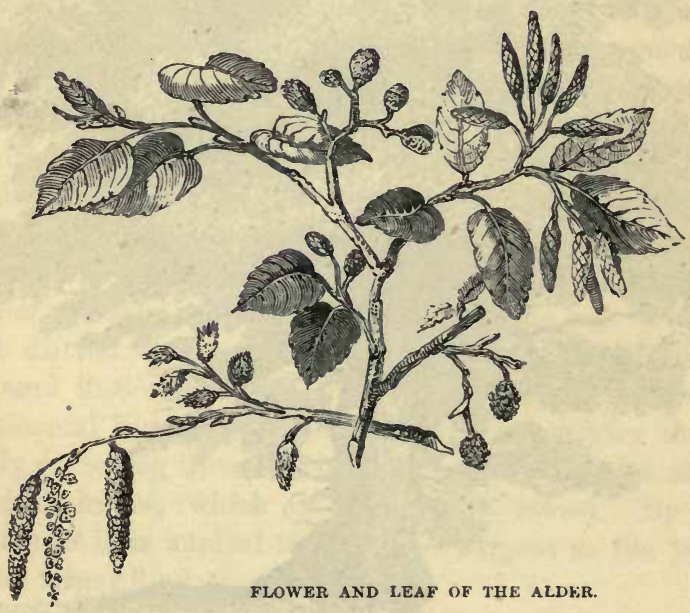

a glutinous substance, more especially in the early part of the summer. The leaves are roundish, blunt and serrated, ${ }^{1}$ shining above, and furnished at the angles of the veins beneath with minute tufts of whitish down. The leafstalks are nearly an inch in length, and furnished with stipules, which entirely inclose the leaves before their expansion. The flowers are of two kinds : the barren are long drooping catkins which appear in the autumn and. hang on the tree all the winter; and the fertile are oval

I Serrated, notched like a saw. 
like little Fir-cones, but are not produced until spring. When these ripen, the thick scales of which they are

- composed separate and allow the seeds to fall, but remain attached to the tree themselves all the winter, and by them the tree may be distinguished when stripped of all its foliage. In the young trees the bark is smooth and of a dark purple-brown hue, but in old trees it is rugged, and nearly black. When allowed to attain its full growth, it reaches a height of forty or fifty feet, if the situation be favourable; but in the mountains and in high latitudes it does not rise above a shrub.

There are probably few rivers in England which have not Alders growing somewhere or other on their banks. Where they most flourish is in good soil which is at all times a little raised above the level of the water; for although they will grow in swampy ground, they prefer places where their roots are not always covered with water. It has been observed that their shade is much less injurious to vegetation than that of other trees :-

"The Alder, whose fat shadow nourisheth-

Each plant set neere to him long flourisheth."

Browne.

The haunts of the Alder being the places where beyond all others we should expect to find picturesque scenery, it cannot fail to form a part of many a beautiful landscape, though it contributes but little itself, the outline of the tree being in most cases too formal, and the foliage not broken into varied masses. Yet it has its admirers. Gilpin considers it "the most picturesque of the aquatic trees, except the Weeping Willow. He who would see the Alder in perfection must follow the banks of the Mole, in Surrey, through the sweet vales of Dorking and Mitcham, into the groves of Esher. The Mole, indeed, is far from being a beautiful river; it is a silent and sluggish stream; but what beauty it has it owes greatly to the Alder, which everywhere fringes its meadows, and in many places forms 
very pleasing scenes." Sir T. D. Lauder is of the same opinion. "It is," he says, "always associated in our minds with river scenery, both of that tranquil description most frequently to be met with in the vales of England, and with that of a wilder and more stirring cast which is to be found amidst the deep glens and ravines of Scotland. In very many instances we have seen it put on so much of the bold, resolute character of the Oak, that it might have been mistaken for that tree, but for the intense depth of its green hue. Nowhere will the tree be found in greater perfection than on the wild banks of the river Findholm and its tributary streams, where scenery of the most romantic description everywhere prevails." Trees of similar character are not uncommon on the banks of rivers in other parts of Scotland, and in the north of England. On the whole, though the Alder does not take a high rank among our picturesque trees, we must recollect that it often flourishes where no other tree would live, and thus ornaments a landscape which would otherwise be tame and naked. It retains its leaves, too, until very late in the year ; and gloomy though their tone may be, we forget this defect when nearly all other trees are bare.

The principal use of the Alder, when growing, is to prevent the encroachment of rivers on their banks, especially where a stream flowing through a loose soil makes a sudden turn. Planters do not recommend its being employed to fill up places in moist woods, but that such ground should be drained and planted with other trees: "For such is the nature of the Alder that it attracts and retains the moisture around it. This effect is occasioned by the nature of its roots, which are chiefly composed of a huge mass of small fibres, whose capillary attraction prevents the escape of a redundant water in the vicinity of the plants. This property of creating swamps we have repeatedlv observed in the Alder, and, from experiments we have made, are fully convinced that a plantation of Alders would soon render the ground (even should it be 
previously of tolerably sound and dry quality) soft and spongy, and in time convert it into a decided bog." ${ }^{1}$

The wood of the Alder is soft and light, and if exposed alternately to wet and dry, will scarcely last a year; but if kept entirely submersed or buried in damp earth, no wood

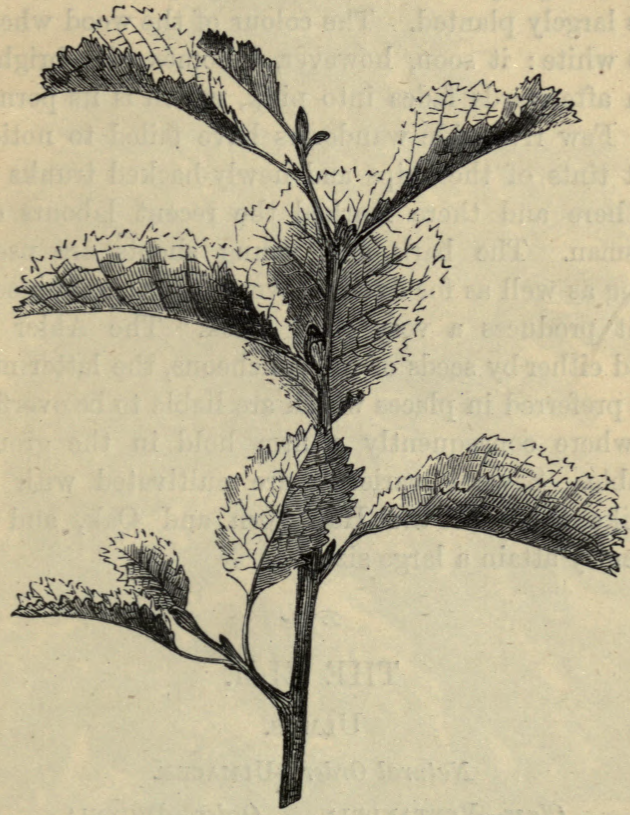

LEAVES OF THE ALDER.

is more durable. Hence it is extensively used for foundations of bridges, water-pipes, pumps, \&c.

By lying for a long time in peat bogs, it acquires a black hue, but from its softness will not take a good polish. The young branches are much used for the purpose of filling in drains, and are more durable than any other kind of brushwood. Sir T. D. Lauder says that the wood is

1 Selby. 
very valuable, even when of a small size, for cutting up into herring-band staves. Old trees which are full of knots may be made into tables and chairs, which, if protected from insects by French polish, are both beautiful and durable. The charcoal is highly valued in the manufacture of gunpowder, for which purpose it is in some places largely planted. The colour of the wood when first cut is white : it soon, however, becomes of a bright red, which afterwards fades into pink, which is its permanent hue. Few river-side wanderers have failed to notice the bright tints of the chips and newly-hacked trunks which have here and there marked the recent labours of the woodsman. The bark and young shoots are used for tanning as well as for dyeing several tints : combined with iron it produces a very good black. The Alder is increased either by seeds or by truncheons, the latter method being preferred in places which are liable to be overflowed, and where consequently a firm hold in the ground is desirable. Several varieties are eultivated with leaves cut like those of the Hawthorn and Oak, and these frequently attain a large size.

\author{
De \\ THE ELM. \\ ULMUS. \\ Natural Order-Ulmaces. \\ Class-Pentandria. Order-Digynia.
}

OF this tree, to which the cultivated parts of England are so much indebted for the richness of their landscape, there are many varieties. No less than eighteen are described by Loudon; which are all referred to the commonest species, Ulmus campestris. It is not necessary here to supply even a catalogue of these, and it would be impossible to point out the distinctive characters of each without entering into a tedious and unprofitable description, which the reader, if he wishes to study the Elms botanically, 
will be able to find in other works. Botanists are far from being agreed as to which should be termed species, and which varieties, so uncertain are the characters; nor shall I attempt any settlement of the question, but, omit-

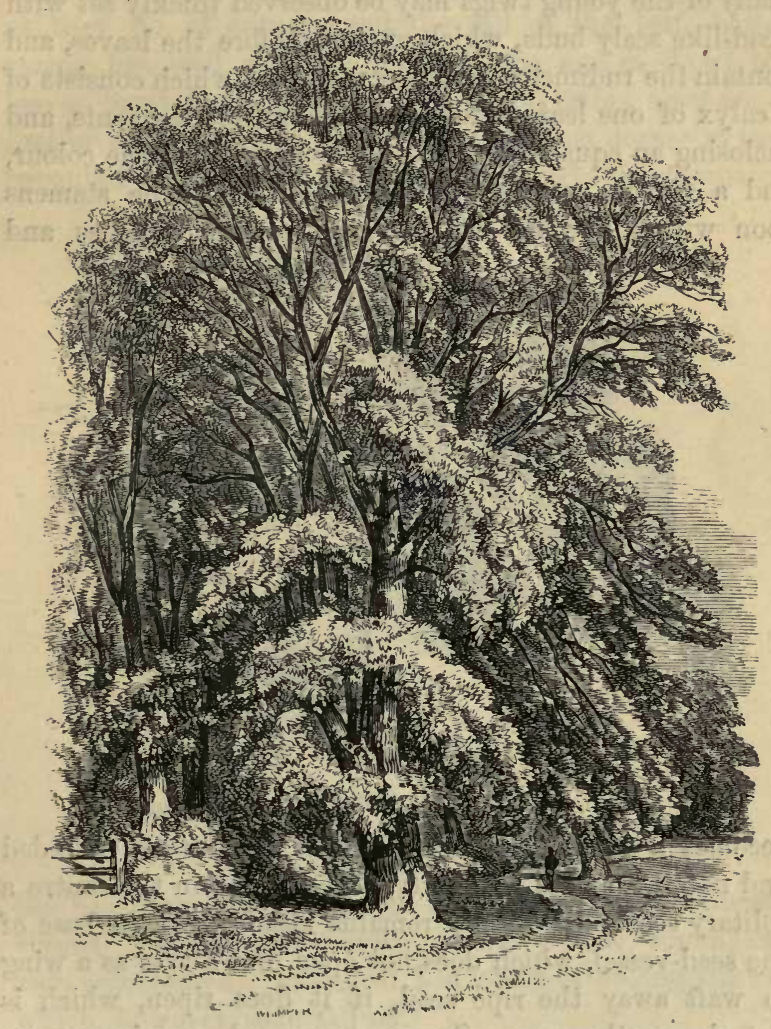

THE ELM.

ting all notice of the rarer and less strongly marked kinds, mention those only which are universally allowed to constitute either species or, at least, very distinct varieties.

All the Elms indigenous to Great Britain, or naturalized, I. 2 
agree in the following characters:-They are lofty trees, having a straight columnar trunk, with hard wood, a rugged bark, and zigzag, slender branches, which, when young, are either downy or corky. In winter and early spring many of the young twigs may be observed thickly set with bead-like scaly buds, which expand before the leaves, and contain the rudiments of flowers, each of which consists of a calyx of one leaf divided into five purple segments, and inclosing an equal number of stamens of the same colour, and a cloven germen bearing two styles. The stamens soon wither and fall off, but the germen enlarges and

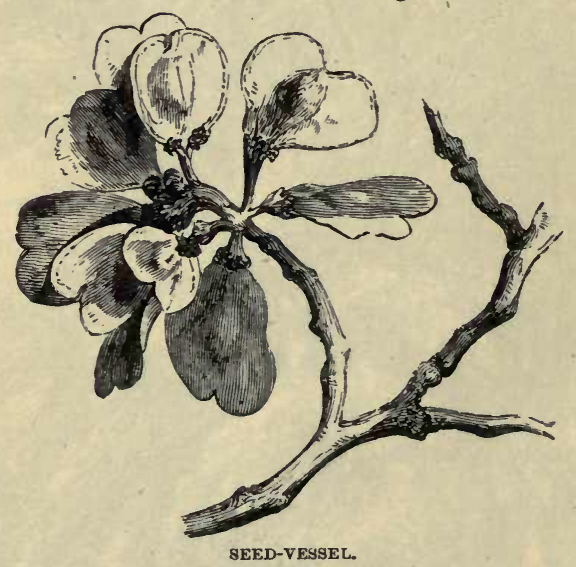

becomes a thin, pale, membranous seed-vessel, rounded and notched at the extremity, and bearing in the centre a solitary seed. The calyx remains attached to the base of the seed-vessel, which does not open, but serves as a wing to waft away the ripe seed, if it does ripen, which is not always the case. So numerous and conspicuous are these seed-vessels, that they might be mistaken, as indeed they sometimes are, when seen from a distance, for tufted foliage-an error which is all the more likely to occur, because the leaves rarely begin to expand until the seeds are nearly ripe. Few persons can have failed to notice the 
numerous leaf-like plates fluttering tremulously through the air during the high winds of April, or sweeping in eddies along the road in the neighbourhood of Elm-rows. These are the seed-vessels just described; and there is something melancholy in the sight of them, reminding us as they do of autumn and the fall of the leaf, before spring has well set in. Towards the end of April the leaves burst forth from another set of buds; they are at first of a fresh, bright green, but afterwards deeper in tint, irregularly notched at the edge, and remarkably unequal at

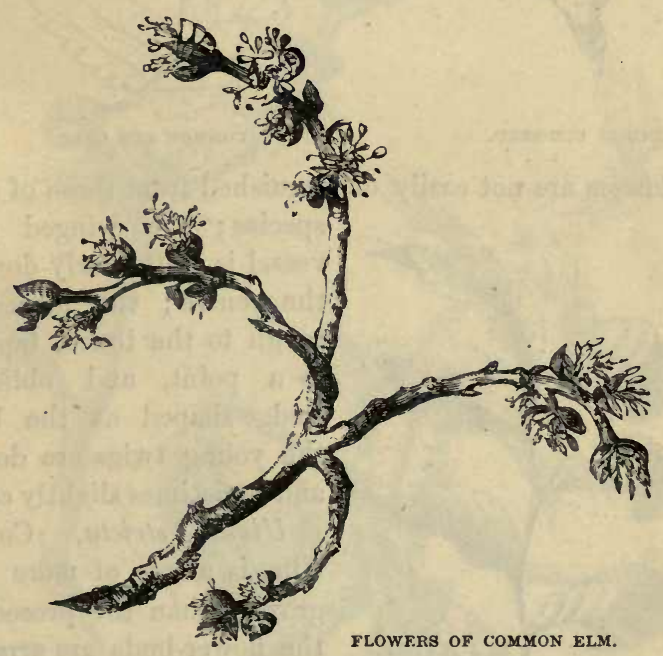

the base, more or less rough on both sides, prominently veined beneath, and having a downy tuft where each vein commences. Each leaf has a pair of oblong stipules, which, however, soon fall off.

Thus far the description given will apply to all the species of EIm : we will now proceed to consider the leading characters which distinguish the four commonest species.

Ulmus campestris, Common Small-leaved Elm. This is the most generally distributed species of all. It is a lofty, 
upright tree, composed of many tiers of spreading branches, which often hang in graceful festoons at the extremities;

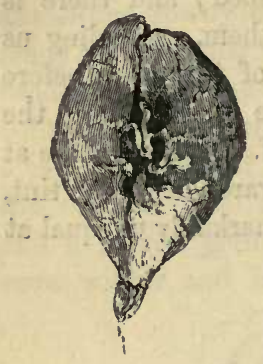

COMMON ELM-SEED.

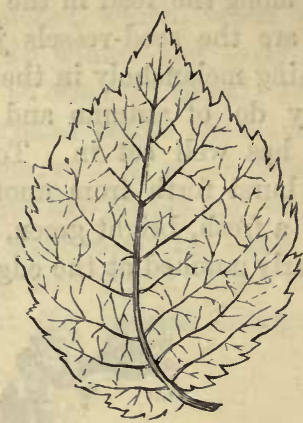

COMMON ELM-LEAF.

its flowers are not easily distinguished from those of other

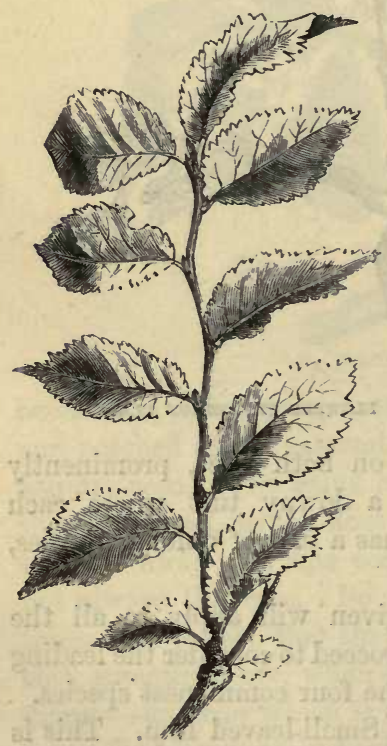

CORNISH ELM. species; the winged seedvessel is cleft nearly down to the centre; the leaves are rough to the touch, tapering to a point, and obliquely wedge-shaped at the base; the young twigs are downy, and sometimes slightly corky.

Ulmus stricta, Cornish $\mathrm{Elm}$, is a tree of more rigid growth than the preceding; the flower-buds are arranged more regularly on the twigs; the leaves are much smaller, more evenly notched, and nearly smooth. It is mostly confined to the counties of Devon and Cornwall. In these two species the main trunk is generally continuous nearly to the summit. 
Loudon says of this variety (as he calls it), that in the climate of London it is a week or fortnight later in coming into leaf than the Common Elm. It attains a very great height, and has a somewhat narrower head than the other kinds. This is also the character of the tree in the West of England; but as it is generally grown in hedges, where frequent loppings prevent it from assuming its natural shape, it is by no means a picturesque

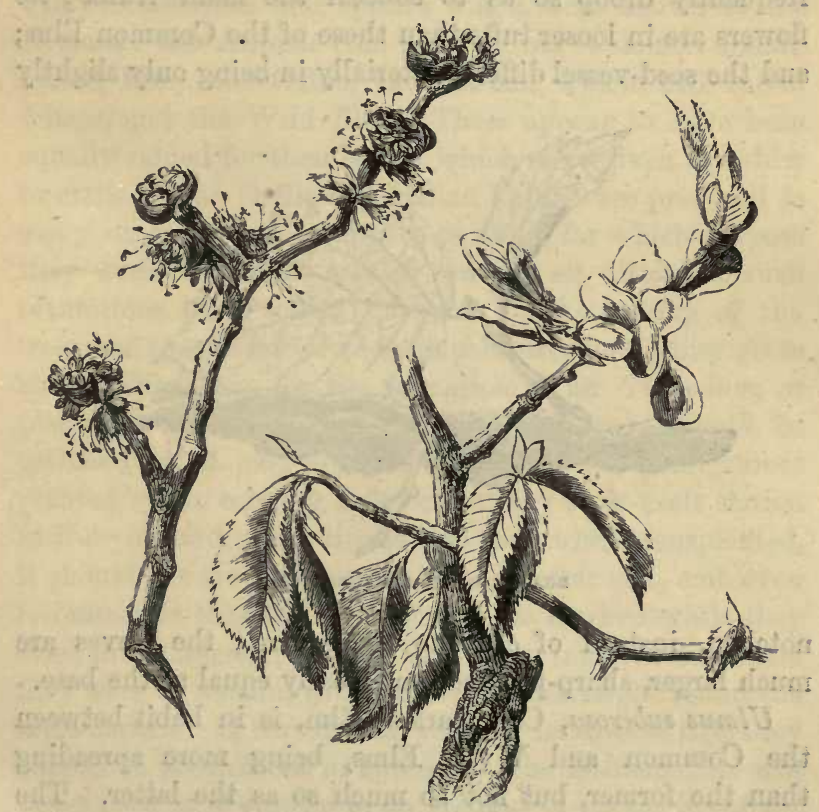

FLOWERS AND SEED-VESSELS OF WYCH ELM.

tree. The timber is said by many to be superior to that of any of the other Elms.

Lindley describes, under the name of Ulmus parvifolia, a variety with much smaller leaves; but this appears to be little known. Loudon mentions also another Cornish variety of Elm, which is almost evergreen in a mild winter, 
and as such is the most ornamental tree of the genus. It is called the Kidbrook Elm.

The Cornish Elm cannot be considered a picturesque tree. It is of a rigid growth ; the foliage is meagre, and rarely hangs in graceful clusters. The timber, however, is considered very good.

Ulmus montana, Wych Elm, is well distinguished from the preceding by its numerous spreading branches, which frequently droop so as to conceal the main trunk; its flowers are in looser tufts than those of the Common Elm; and the seed-vessel differs materially in being only slightly

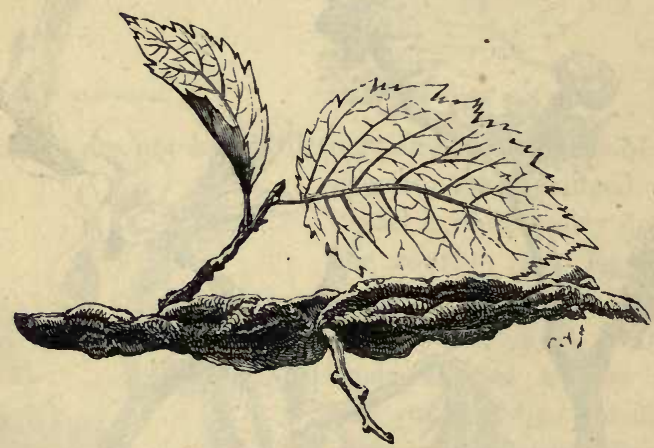

BRANCH OF ULMUS SUBEROSA.

notched, instead of cleft to the centre; the leaves are much larger, sharp-pointed, and nearly equal at the base.

Ulmus suberosa, Cork-barked EIm, is in habit between the Common and Wych Elms, being more spreading than the former, but not so much so as the latter. The leaves are very large; but the best distinctive characters are afforded by the branches, which, when one year old, are very hairy, and in the second year are thickly coated with a cracked, corky excrescence, from which the tree derives its name. A foreign species, called Dutch Elm, has also corky branches, but the young twigs are always smooth. 
Two other British EIms are described by botanists, but, as they are of local occurrence, a notice of them will not interest the general reader. The above characters, it is hoped, will be sufficient to enable the student to determine the species of any Elm which he is likely to meet with.

The Elm was well known both to the ancient Greeks and Romans: the former were acquainted with two species, which grew severally in the mountains and the plains. Pliny enumerates four species which were known to the Romans: the Atinian (the same as our Cornmon Smallleaved Elm), the Gallic, the Italian, which had tufted foliage, and the Wild Elm. These appear to have been equally valued for their leaves, which were given as fodder to cattle. The Gallic and Italian kinds were preferred to every other tree as a support to vines, for which purpose they were planted in regular rows at set distances, such plantations being called "arbusta." The rearing of the trees was considered of such importance, that Pliny gives specific directions for the formation of an Ulmarium, or plantation of Elms, directing that the seeds should be gathered in March, sown in beds, and the young trees planted out in nursing beds before they took their station in the vineyard. He directs also that, when transplanted, it should always be to a similar or better soil, and even recommends that the bark should be marked while they stood in the nursery, in order that, when transplanted where they were to remain, their northern sides might retain the same aspect. If reared from suckers, he directs that they should be planted out in autumn. The Atinian Elm was never used as a vine-prop, on account of its too luxuriant foliage, which kept off the sun from the ripening grapes. An important part of the vine-dresser's occupation was to prune the Elms, which, when the Vine was trained to them, were said to be "married." The minuteness of these directions, which are also alluded to by the Roman poet Virgil, proves the estimation in which the tree was held; and the name of the fourth species, "wild," would 
seem to show that that species was not considered to be so well adapted to the purpose as the cultivated kinds. The leaves and bark were supposed to have an astringent property, and were therefore used in the curing of wounds; the timber was recommended, for its rigidity and toughness, as fit for the hinges, or rather pivots, of gates ; and Virgil tells us, that young Elms were bent down while in a growing state, and kept in a curved position until they had acquired the necessary shape in order to be converted into plough-tails, a process which has been imitated in modern times with respect to Oak-trees, for the production of what is called knee-timber in ship-building. The wedding of the Vine to the Elm is frequently mentioned by the Roman poets among the tranquil and healthful occupations of rural life. Some authors are of opinion that the Elm was introduced into Britain by the Romans along with the Vine; and this opinion borrows weight from the fact, that it rarely matures its seeds, and therefore would require the assistance of man to secure its continued propagation. Since, too, the Elm was one of the trees frequently planted on funeral mounds, it may have been introduced for that purpose, while the similarity of the English name, Elm, to the Latin Ulmus, seems to confirm the opinion of the foreign origin of the tree.

Evelyn sagely remarks: "It seems to be so much more addicted to some places than to others, that I have frequently doubted whether it be a pure indigene or translatitious [introduced] ; and not only because I have hardly ever known any considerable woods of them, but almost continually in tufts, hedge-rows, and mounds ; and that Shropshire, and several other counties, have rarely any growing in many miles together. In the meantime, some affirm they were first brought out of Lombardy, where indeed I have observed very goodly trees about the rich grounds, with Pines among them." Dr. Hunter, however, Evelyn's editor, is of opinion that "the Elm is certainly a native of this country;" and he has much 
reason on his side, for the Atinian Elm, which is universally considered to be the same with our Common Elm, did not, according to Pliny, ripen its seeds in Italy, any more than it does in England. But in this country, as well as in that, it produces abundance of suckers ; and it is by no means uncommon for plants that increase freely by rocts to produce abortive seed-vessels. The Great White Convolvulus ${ }^{1}$ or Bindweed, for instance, and the Lesser Periwinkle, ${ }^{2}$ which are most prolific by their roots, and are undoubted natives, rarely perfect their seeds. Besides which, the authors who maintain that the Elm was introduced into Britain as a companion of the Vine appear to have lost sight of Pliny's assertion that the Atinian or Common Elm was never used for the purpose, on account of its excessive foliage. On the whole, then, the Elm has as good a claim to be considered a native of Britain as of any of the other European states, not excepting even Italy, from which it is said to have been brought.

The Common Elm is generally propagated by suckers, which spring up in great abundance round the trunk, or by grafting on young plants of Wych Elm which have been raised from seed. It grows most rapidly in light land, but requires a stiff strong soil to produce good timber. It will bear any amount of pruning, but needs none: the custom of lopping IIms in hedge-rows, and converting them into gigantic brooms, is as injurious to the timber as it is destructive of picturesque effect. It is to be presumed, however, that farmers who adopt this practice are remunerated by the additional produce of their lands thus thrown open to the sun and air. The Elm bears transplanting remarkably well even at an advanced age; hence it is well adapted for planting in the neighbourhood of modern houses where a speedy shade is desired. For avenues it is unrivalled, forming a delightful shade, and crossing at a lofty elevation and at the exact angle which is most pleasing to the eye. The 
avenue of these trees at Strathfieldsaye, the seat of the Duke of Wellington, is a mile in length, and is greatly admired.

In ancient times the leaves of the Elm were much used as fodder for cattle; and this is still the case in many parts of the Continent. Evelyn recommends the revival of this practice in England in seasons when the hayharvest is defective: he states that cattle prefer them to oats, and thrive exceedingly well on them. The inner bark is very tough, and, like that of the Lime, is made into bast mats and ropes ; the timber is fine-grained and tough, and is remarkable for its durability under water. Hence it is highly prized in naval architecture, being used for the keels of large vessels, and many parts of the rigging which are most liable to exposure to wet. It was formerly also much used for making water-pipes, but has within the last few years been almost superseded for this purpose by cast-iron pipes.

The Elm, growing in a forest, and in good soil, arrives at perfection in a hundred and fifty years, but it will live for five or even six hundred years. Large forest Elms are cut down with advantage when of an age between one hundred and one hundred and thirty years, and then furnish a large quantity of building material. Elms which have been lopped live for a shorter period than others, and should therefore be cut down when no more than seventy or eighty years old.

A small-leaved species of Elm is selected by the Chinese to be treated in the way described at page 140, as being adopted with regard to the Apple. A young tree is planted in a pot, and surrounded with pieces of rough stone to represent rocks, among which mosses and lichens are introduced. It is not suffered to rise higher than about a foot or fifteen inches. No greater supply of water is given than just enough to keep it alive, and every means is used to give it a stunted appearance. The points of the shoots, and the half of every new leaf, are constantly and carefully cut off; the stem and branches are distorted by 
means of wires, and the bark is lacerated to produce a rugged character. One branch is partly broken through, and allowed to hang down as if by accident; another is mutilated to represent a dead stump. This treatment produces, in course of time, the appearance of an old weather-beaten forest-tree, and it is then, if unworthy of all the pains that have been bestowed upon it, certainly a curious object.

Several insects prey on the Elm; among which by far the most mischievous is the Elm-destroying Beetle (Scolytus destructor). The ravages committed by this minute insect would scarcely be credible, were we not informed that as many as 80,000 have been found in a single tree. Two eminent entomologists, Mr. Spence in England, and M. Audouin in France, have turned their attention to this subject, and have satisfactorily shown the importance of watching the habits of an insect less than a quarter of an inch in length. The result of their observation is that the perfect in-

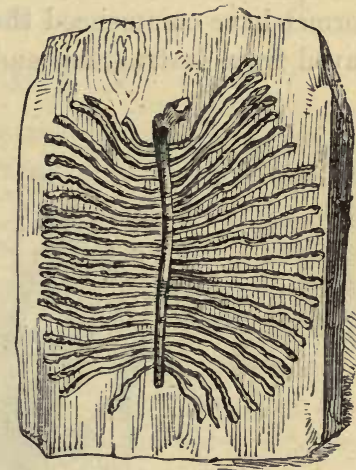

WOKK OF ELM-DESTROYING BEETLE. sect feeds on the inner bark of the Elm, to reach which it perforates the outer bark, and feasts at its leisure. The cavities thus made interrupt the ascent and descent of the sap, and retain moisture, from the combined effect of which causes the tree, in the course of a fow years, becomes sickly, and is brought into exactly that state in which the female selects it for laying her eggs; though sometimes she attacks a tree which is beginning to decay from other causes. A suitable tree having been selected about July, she perforates the bark, and eats away a vertical passage about two inches in length, laying from twenty to fifty eggs as she advances. Having completed her 
task, she dies. About two months afterwards the eggs are hatched, and the grubs immediately begin to eat their way also through the inner bark in a horizontal direction, some to the right and some to the left, but never interfering with each other's track. When each grub has finished its course of eating, it turns to a pupa and then to a beetle; after which it gnaws a straight hole through the bark, and comes out about the end of May in the year following that in which the eggs were deposited. The injury thus inflicted by the grubs is so much greater than that occasioned by the perfect insect, that, when the former have commenced their ravages, the tree cannot be saved from destruction, and the only alternative is to cut

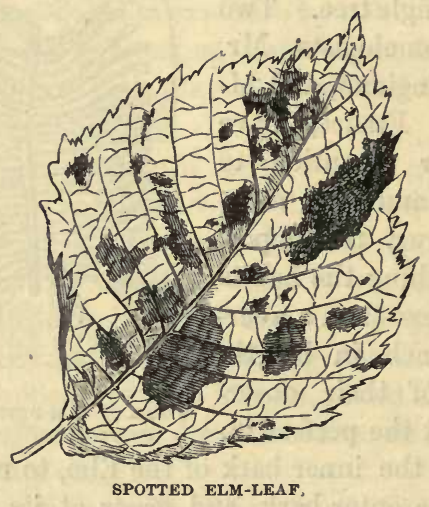

it down and to burn every particle of bark. But when a tree is attacked hy the perfect insect, it may be saved by being carefully brushed over with coal-tar, the smell of which is so offensive that the insects will desert it, and in the course of a few years it may recover its healthy condition. Had this discovery been made and acted upon at an earlier period, it is probable that an immense number of trees in the promenades of several of the principal cities of Europe, including from twenty to thirty in St. James's Park, might have been saved. 
The Elm retains its foliage till late in the autumn, the leaves assuming a rich yellow hue some time before they fall from the tree. If examined closely at this season, they will be found to be marked with dark-coloured blotches. These spots contain the instruments appointed for insuring the decay of the leaves. During the winter months the leaves remain on the ground unaltered except in colour; but in spring the spots become matured, the surface cracks, and a minute fungus appears : decomposition spreads from these points, and the leaves very soon decay.

\section{THE WYCH ELM.}

THIs species, it has been observed above, may be distinguished from the Common Elm by its larger leaves and slightly-notched seed-vessels. A practised eye will also be able to detect it readily by other peculiarities. The shoots of the young trees are of so vigorous a growth as to be nearly equal in size to the stem from which they spring; they are also so heavily laden with leaves, which are as large as those of the Hazel, or even larger, that they have an arched, drooping appearance. On the older branches the leaves are smaller, and hang in large heavy masses; they may be distinguished by being taper-pointed, and nearly equal at the base. The trunk is less upright than those of the other species, and soon divides into long, widely-spreading, somewhat drooping branches. Though less common in England than the Small-leaved Elm, it is far from rare. In Scotland it is the only indigenous species: wherice it is often called the Scotch Elm. From the leaves somewhat resembling those of the Hazel, Gerard tells us it is sometimes called the "Witch-hasell." " Old men affirm," he adds, "that when long bows were in use, there were very many made of the wood of this tree; for which purpose it is mentioned in the English statutes by this name of Witch-hasell." The meaning of its name is 


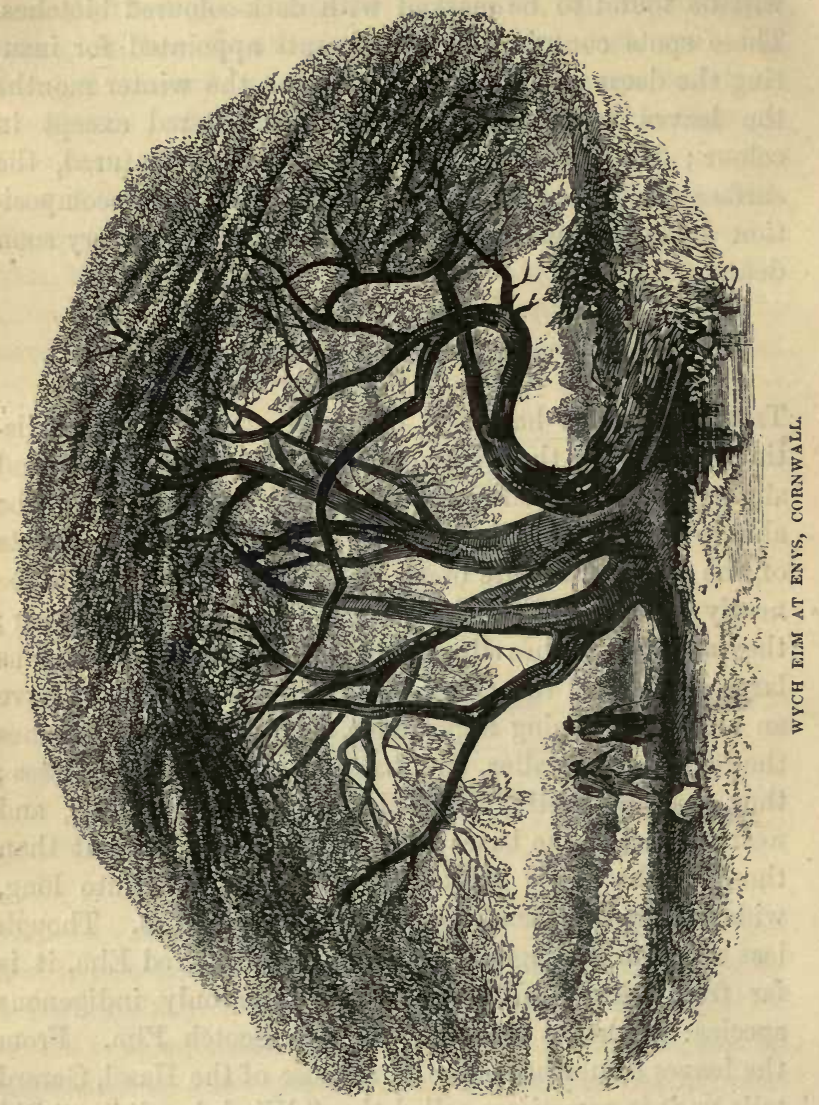


unknown; hence it is variously spelt by authors, wych, wich, witch, and weech. In some of the midland counties the name seems to have originated the notion that it is a preservative against witchcraft, and a sprig is inserted into a hole in the churn by dairymaids, in order that the butter may come freely. The foliage withers much earlier than that of the Common Elm, curling up and becoming brown before almost any other tree has acquired its autumnal tint.

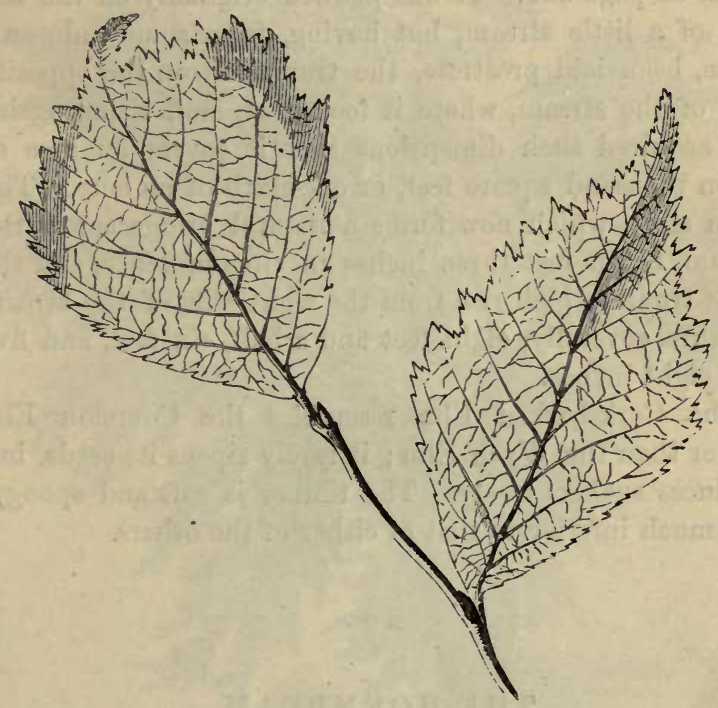

LEAF OF WYCH ELM.

The Wych Elm ripens its seeds freely in June, but produces no suckers; it grows more rapidly than the common kind: and this probably is the reason why its timber is inferior for most purposes. It is nevertheless valuable to the wheelwright and millwright, and the excrescences are highly prized by the cabinet-maker, who makes of them a beautiful veneer for tables, work- 
boxes, \&c. The bark of the young limbs is very tough and flexible, and is often stripped off in long ribands, and used, especially in Wales, for securing thatch, and for other similar purposes.

Though the Wych Elm does not produce suckers, it strikes from layers with great facility, and if a growing branch or twig by any accident touches the ground, it is sure to take root. A striking instance of this is afforded by a tree at Enys, in Cornwall, of which an engraving is given at page 232. It was planted originally on the left side of a little stream, but having, from some unknown cause, been laid prostrate, the trunk fell on the opposite side of the stream, where it took root, and, rising again, has acquired such dimensions that it covers an area of seven thousand square feet, or one-sixth of an acre. The naain stem, which now forms a natural bridge across the stream, is ten feet three inches in circumference, and the three trunks which rise from the right side of the stream measure, severally, eight feet and a half, six feet, and five feet eight inches.

The Cork-barked Elm resembles the Common Elm rather than the Wych Elm; it rarely ripens its seeds, but produces suckers freely. The timber is soft and spongy, and much inferior to that of either of the others.

\section{THE HORNBEAM.}

\section{Carpinus Betulus. \\ Natural Order-A MENTACEE. \\ Class-Monøcia. Order-Polyandria.}

OF all our indigenous forest-trees perhaps no one is so little known as the Hornbeam ; nor is this surprising, for, although it frequently reaches a height of fifty or sixty feet, it has no strongly-marked distinctive character, and 
is often mistaken for some kind of Elm, to which its foliage bears a great resemblance. It is found in most of the temperate countries of Europe and Asia, and is far

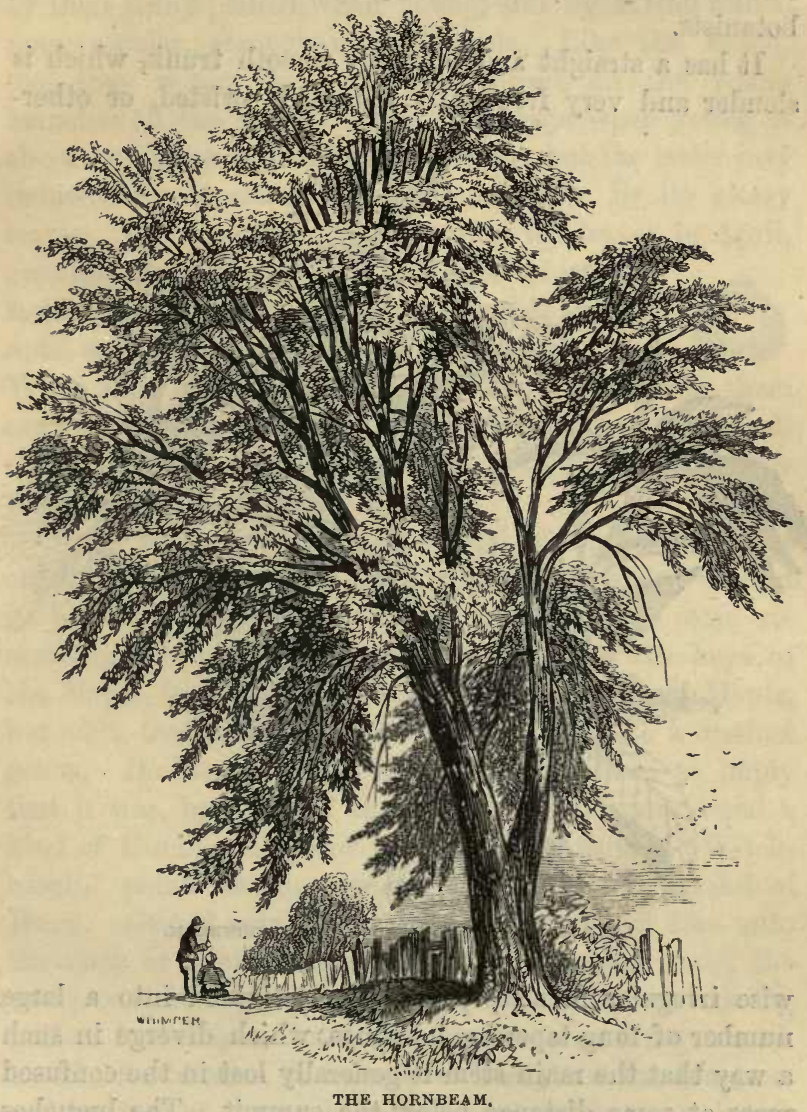

from uncommon in several of the counties of England: in some it is so abundant that it forms (as Sir J. Smith observes) a principal part of the ancient forests on the 
north and east sides of London: such as Epping, Finchley, \&c. By the Greeks it was called Zugia, or "yoke-tree," from the use to which its timber was applied: the Latins called it Carpinus, the name by which it is still known to botanists.

It has a straight and tolerably smooth trunk, which is slender and very frequently flattened, twisted, or other-

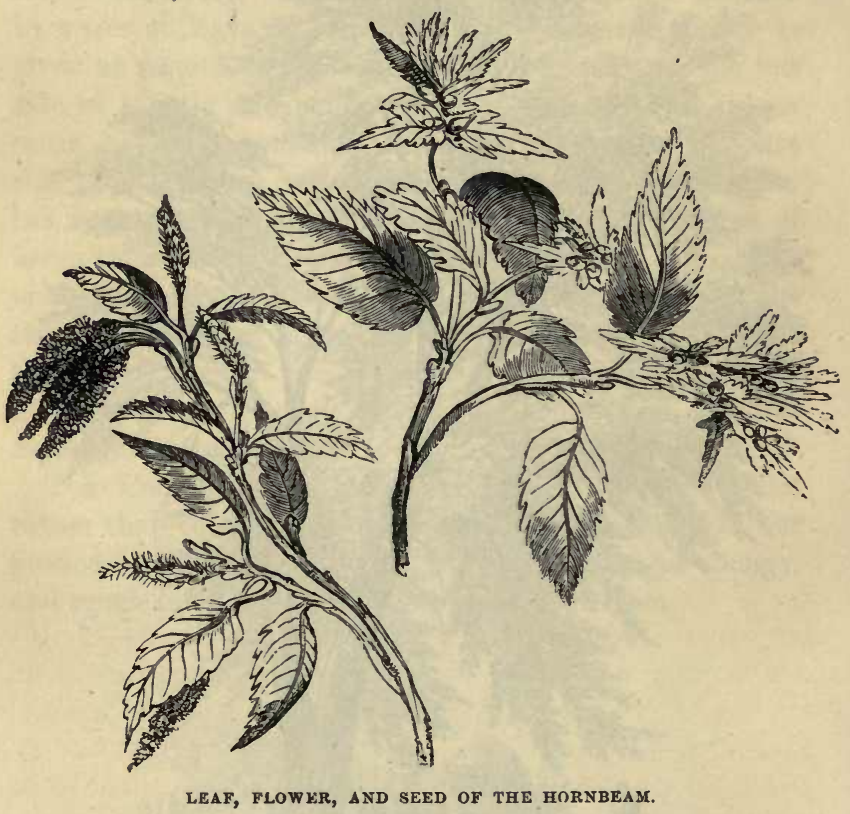

wise irregular in shape, and is subdivided into a large number of long tapering branches, which diverge in such a way that the main stem is generally lost in the confused mass at some distance below the summit. The branches are remarkably liable to unite when they touch in crossing; hence very curious appearances are sometimes produced. The outline of the head is round, and possesses little 
picturesque beauty. The leaves are shaped somewhat like those of the Beech, but are rough and notched at the edge like those of the Elm: they may be distinguished from the former by their roughness, and from the latter by their being plaited when young, and by having numerous, regular, strongly-marked veins. Like the Beech, too, they retain their withered foliage on the young branches all the winter. The Hornbeam when young is also very similar in habit to the Beech; but the latter may immediately be detected, on examination, by its glossy leaves. The flowers appear soon after the leaves, in April, growing in catkins of two kinds, of which the fertile are succeeded by clusters of small angular nuts, each seated at the bottom of a leafy cup. When these are once formed, the tree which bears them cannot be mistaken, for no other British tree bears fruit of the same kind. The leaf-buds are longer and sharper than those of the Elm.

Owing to its partaking of several of the properties of other trees, some of the old writers were puzzled to find its place in the system. Pliny probably saw some resemblance between its clusters of nuts and the keys of the Maple, for he places it among the ten kinds of Maple, but adds, that others considered it to belong to a distinct genus. Its second name, Betulus, would seem to imply that it was, by some of the early botanists, considered a kind of Birch, and one of its old English names, "Witchhasell," points to the supposition that it was a kind of Hazel. Gerard says, "It growes great and very like unto the elme or wich hasell tree; having a great body, the wood or timber whereof is better for arrowes and shafts, pulleys for mils, and such like devices, than elme or wich hasell; for in time it waxeth so hard, that the toughnes and hardnes of it may be rather compared unto horn than unto wood; and therefore it was called hornbeam or hardbeam. The leaves of it are like the elme, saving that they be tenderer: among these hang certain triangled 
things, upon which are found knaps, or little buds of the bignesses of ciches (vetches), in which is contained the fruit or seed. The root is strong and thicke."

Evelyn is loud in his praises of the Hornbeam; for the tree being, as it is called, "tonsile," or very patient of being clipped by the shears, it was highly prized in the formal gardens of his day.

The taste for forming "labyrinths," "stars," "alcoves," and "arcades" happily having now passed away, the Hornbeam is only admitted into gardens for the purpose of forming hedges to shelter tender plants ; and for this its numerous branches, and the property which it possesses of retaining its withered leaves during winter, well adapt it. Another recommendation is, that it grows well in the coldest and hardest soils, and may consequently be employed where other trees would not thrive.

The wood of the Hornbeam is white and close-grained, and, though not elastic, surpasses in toughness the timber of any other British tree. The unevenness of the trunk described above is, however, communicated to the fibre of the wood, and hence it does not take a good polish. This defect does not exist in the young wood, which is exceedingly well adapted for the yokes of cattle and all kinds of wheelwright's work, especially mill-cogs. Selby recommends that it should be planted extensively in cold, stiff, clayey soils, for the staves of fish-barrels. It ranks among the best of fuels, burning freely, and giving out a great deal of heat; it is highly inflammable, lighting easily and making a bright flame. This property was known to the ancients, for Pliny speaks of its being used for marriage torches. Its charcoal is highly prized, not only for ordinary purposes, but for the manufacture of gunpowder. The inner bark is also used, according to Linnæus, for dyeing yellow.

The Hop Hornbeam, occasionally met with in gardens and pleasure-grounds, approaches the common Hornbeam in character, but belongs to the genus Ostrya. It is not a native of Britain. 


\section{THE HAZEL. \\ Corylus Avellana. \\ Natural Order -AMENTACEA. \\ Class-MONGCIA. \\ Crder-Polyandria.}

Althovgir the Hazel never acquires the full dimensions of a tree, it gives so decided a character to most of our woods.and hedges, that it requires a specific notice among our most remarkable forest-trees. It possesses, too, a peculiar claim on our attention from being the only British tree which in its wild state produces edible fruit.

The tree described by Pliny, under the name of Avellana or Abellina, appears to have been the variety familiar with us by the name of Spanish-nut. It was introduced, he says, into Greece from Pontus, whence it was called the Pontic-nut, Avellana being a provincial term derived from the place where it was extensively planted, now called Avellino, a city of Naples. The wild European Hazel he does not mention, although several modern authors quote from him passages which refer not to this tree but to the Walnut. The nuts sent by Jacob as a present to his son Joseph in Egypt were in all probability Pistachio-nuts, a kind of fruit which may justly be reckoned among the finest productions of Palestine, and therefore well worthy of being associated with the other offerings. They are about the size of the Hazel-nut, but of an oblong, angular form; the kernel is of a peculiar greenish colour, and, though somewhat oily, has a very agreeable taste. All the Eastern versions of the Bible render the passage (Genesis xliii. 11) by Pistachio-nuts.

The Hazel was considered by the Romans as injurious to the Vine, and was not allowed to be planted in the vineyard. In the rustic festivals of the same people the goat, which was also an enemy to the Vine by browsing 
on the young shoots, was roasted on a spit made of Hazelwood. The Hazel grows wild in all the temperate climates of Europe and Asia, and is found in England at an elevation of 1,600 feet.

Evelyn derives his family name from this tree; he says: "I do not confound the Filbert, Pontic, or Filbord, distinguished by its beard, with our foresters or bald Hazelnuts, which doubtless we had from abroad, and bearing the names of Avelan, Avelin, as I found in some ancient records and deeds in my custody, where my ancestors' names were written Avelan, alias Evelyn, generally." He also mentions several places which received their names from the abundance of these trees growing near them. "For the place," he says, "they all affect cold, barren, dry, and sandy grounds ; mountains, and even rocky soils, produce them; they prosper where quarries of freestone lie underneath, as at Hasellwry in Wilts, Haselingfield in Cambridgeshire, Haslemere in Surrey, and other places; but more plentifully, if the ground be somewhat moist, dankish and mossy, as in the fresher hollows and sides of hills, hoults, and in hedge-rows." In the legendary history of the early English Church the Hazel stands beside the Whitethorn." "The most signal honour it was ever employed in, and which might deservedly exalt this humble and common plant above all the trees of the wood, is that of hurdles, especially the flexible white, the red, the brittle; not for that it is generally used for the folding of our innocent sheep, an emblem of the Church, but for making the walls of one of the first Christian oratories in the world, and particularly in this island, that venerable and sacred fabrick at Glastonbury, founded by St. Joseph of Arimathea, which is storied to have been first composed but of a few small Hazel-rods interwoven about certain stakes driven into the ground; and walls of this kind, instead of laths and punchions, superintended with a coarse mortar 
made of loam and straw, do to this day inclose divers humble cottages, sheds, and out-houses in the country."

The Hazel was formerly, and indeed in some of the mining districts of England is still, believed to have an affinity for metals, being employed in the discovery of mines. The professor of this questionable science, as it was deemed, selected for this purpose a forked Hazel-rod (called a dowsing-rod), a branch of which he held with each hand in front of his chest, with the other end slightly pninting outwards. $\mathrm{He}$ then walked forward over the ground to be examined, and when he reached a spot under which there lay a load or mass of metal, the end of the rod, in spite of his utmost efforts to restrain it, bent down, and pointed towards the buried mineral. Still more wonderful properties were attributed to the Hazel in Evelyn's time; but he expresses himself on the subject very cautiously :- "Lastly, for riding switches, and divinatory rods for the detecting and finding out of minerals; at least, if that tradition be no imposture. By whatsoever occult virtue the forked stick, so cut and skilfully held, becomes impregnated with those invisible steams and exhalations, as by its spontaneous bending from an horizontal posture to discover not only mines and subterraneous treasure, and springs of water, but criminals guilty of murder, \&c., made out so solemnly, by the attestation of magistrates, and divers other learned and credible persons, who have critically examined matters of fact, is certainly next to a miracle, and requires a strong faith."

The usual form of the Hazel in its wild state is a straggling bush, consisting of a number of long flexible stems from the same root. The bark on the young branches is ash-coloured and hairy, that on the old stems mottled with bright brown and grey. The leaves are rounded, stalked, and rough, and furnished at the base with oblong stipules, which soon fall off. The flowers are among the very earliest harbingers of returning spring, reminding us, that though winter is the season of rest with 
the vegetable world, that rest is not the sleep of death. Almost before the Snowdrop has ventured to peep out from its icy home, the nut-trees are plentifully decorated with their yellow catkins; and if we search very closely, we shall find, towards the end of January, the crimson pistils of the fertile flowers timidly pushing forth from

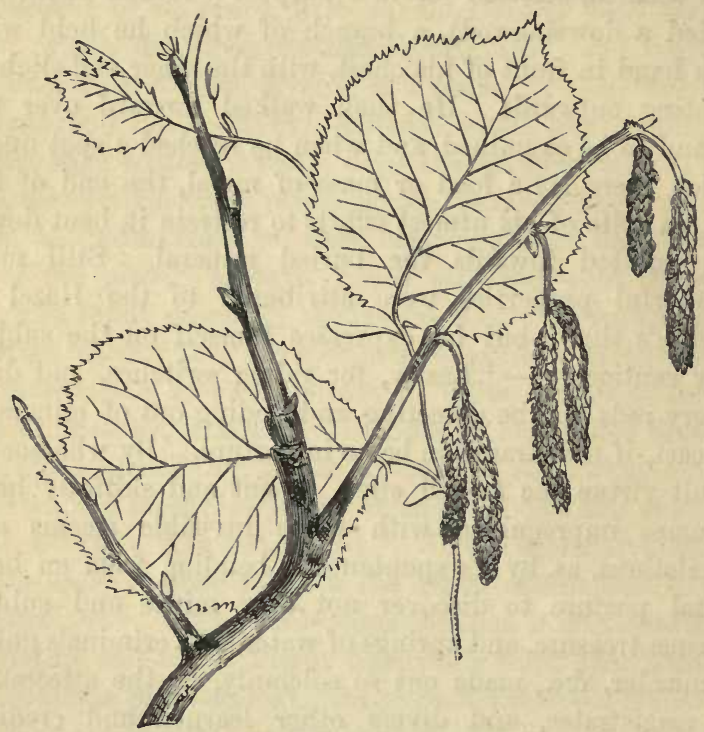

WLOWERS AND FOLIAGE OF HAZEL.

some of the scaly buds, not less beautiful than the more conspicuous catkins, though scarcely known to any but the all-observing botanist. The former, as soon as they have shed their pollen, turn brown and fall off ; the latter, too, disappear, but in the course of a few months may be detected, as bunches of nuts, hiding themselves under the

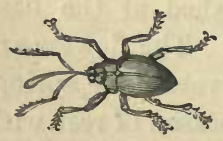
now fully expanded foliage. At this season a beautiful little beetle, Balaninus nucum, guided by a mysterious instinct, pierces the yet tender shell of the nut 
and lays a single egg. The soft pithy substance which it contains not being adapted for the sustenance of the grub, the egg remains without undergoing any change for some weeks; but when the kernel has nearly acquired its full size, a small white grub is hatched, which immediately begins to feed on the nut, and when full-grown shows, that although its sole food has hitherto been of the softest kind, it is provided with a powerful apparatus for gnawing a very hard substance. About the time that the nut is ripe, the insect prepares for a change of habitation by boring a hole through the shell and forcing its way out. It then falls to the ground and buries itself in the earth, where it constructs a cell and is changed into a pupa, and in the following season comes forth as a perfect insect. We may well wonder at the instinct which directs this little beetle to choose, from among all the trees of the forest, the one which alone will afterwards bear abundance of food for its offspring, and food too which it never eats itself; and it is no less remarkable that it appears to know if the nut has been already occupied by some other insect of the same kind, for we never find two grubs inclosed in the same shell. It can have gained its knowledge neither by experience nor by education; for it lives but a single year in its perfect state, and it can have had no communication with others wiser than itself, for all are equally ignorant of their own history. We can therefore only conclude that in all its operations it has been guided by an intelligence superior to its own, by Him, namely, whose care is equally bestowed on the minutest and on the most important of His works.

The larvæ of other insects feed on the nut; but the depredations committed by squirrels, where these beautiful but mischievous little animals abound, exceed those of all the others. The food of the squirrel varies with the seasons: in winter and spring it feeds on buds and the bark of trees, and is said also to devour insects. In plantations of Larch it often does great mischief, by stripping 
off the bark from the young branches, and checks the growth of the trees by destroying the leading shoots. As soon as the kernel of the nut begins to swell, it makes this its principal food, and from July to October enjoys many a dainty repast. So eager is it in its search after nuts, that it will resort to trees growing close to dwellinghouses, and unless scared away (which is no easy task) will appropriate a large proportion of the fruit to its own use. If it only attacked the ripe nuts, its ravages would be limited, and perhaps be compensated by the activity and intelligence displayed in its movements; but as it sets to work from six to eight weeks before the nuts are ripe, and destroys more than it actually devours, its share in the produce is more than an equitable one. The

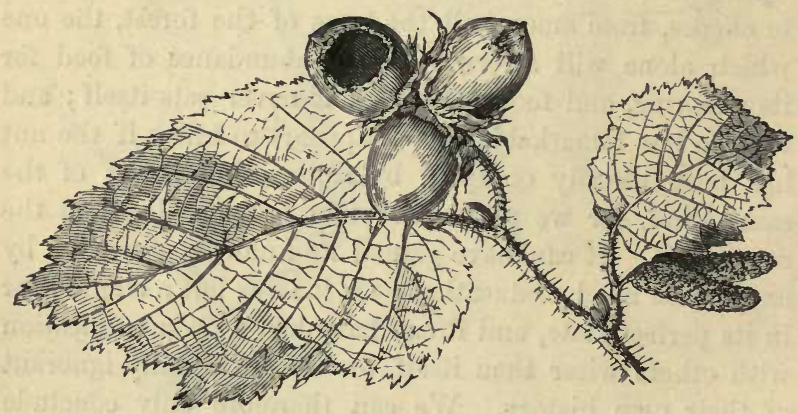

HAZEL-NUT.

annexed woodcut represents a bunch of nuts which has been visited by a dormouse. The depredator does not waste his strength by cutting through the stem, but having first nibbled away the husk, gnaws a hole through the shell, and extracts the kernel piecemeal. If the nut should happen to fall off before it is consumed, he does not take the trouble to descend in quest of it, but begins upon another, and proceeds until his appetite is satisfied. Not unfrequently a nut falls in his way the kernel of 
which is not matured : this he either avoids altogether, or commences nibbling, but finding, probably from the hollow sound emitted, that his labours will not be rewarded, he deserts it before he has pierced through the shell. This power of detecting a worthless nut appears to be gained by experience ; for we sometimes, though very rarely, find a hollow nut the shell of which has been perforated.

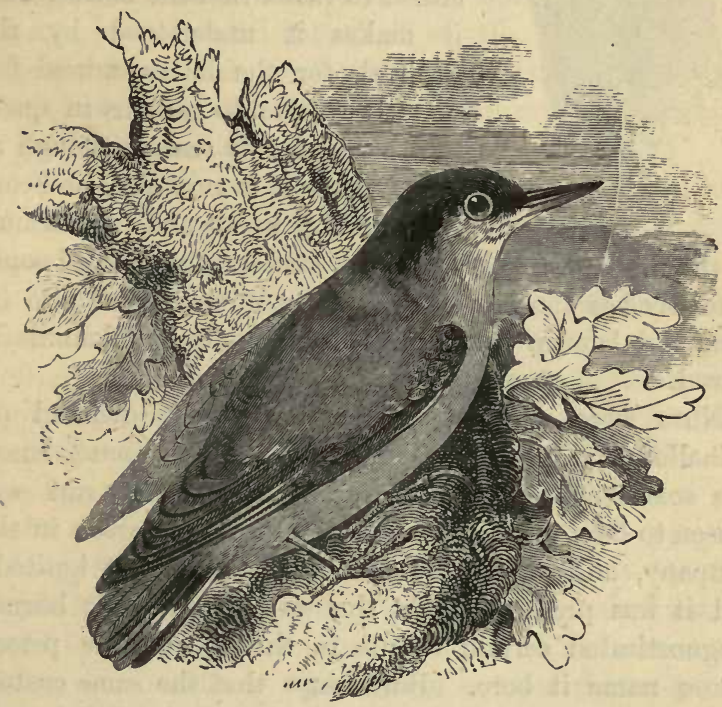

THE NUTHATCH.

The nuthatch displays no less ingenuity than the squirrel in procuring a meal from the Hazel-tree. It has a strong and powerful beak, but having no means of holding its food, like the squirrel, while at work on the shell, it gathers the nut by the stem, and carries it away in its mouth to some rough-barked tree, generally an Oak, strips off the husk, and fixes the nut in an angular crack in the bark, always selecting, as far as I have observed, a 
fissure so shaped that every blow which it deals with its beak wedges the nut more firmly: it thus cracks the shell and regales itself on its contents. In the months of

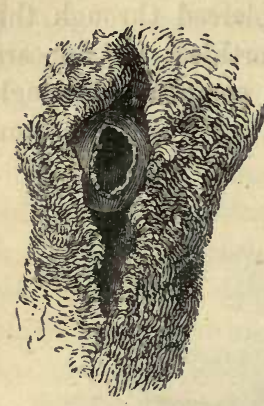

NUT IN BARK. July and August, when the woods are quieter than at any other season of the year, a succession of loud and quickly-repeated tappings is a certain guide to its haunts. I am even inclined to think that the noise which it makes is understood by the squirrel, for the latter animal frequently resorts to gardens in quest of filberts at this season, though at other times it is very shy, and confines itself to woods and plantations. In the midland counties an Oak standing in a Hazel-copse generally has the remains of a few nuts wedged into its bark, and, later in the season, acorns may be found similarly placed.

Nuts were, in ancient times, in great demand on Allhallow Eve, Oct. 31st; which, from that circumstance, was sometimes called "Nutcrack Night." A nut was chosen to bear the name of each unmarried person in the company, and placed close to the fire until it ignited: and it was pretended that the way in which it burned prognosticated certain events in the life of the person whose name it bore. Burns says that the same custom was observed in Scotland; and in Ireland this and other antiquated customs sometimes afford amusement to parties of young people at the present day.

The Hazel rarely attains such a size as makes it important in the landscape : it is nevertheless valuable when fulness of foliage is desired, its leaves retaining their place until almost every other tree has been dismantled, and assuming a bright warm yellow which gives to autumn a lingering beauty that it would otherwise want. Even when the leaves have fallen, the tree is not bare; 
for the barren catkins begin to expand very soon after, and remain in flower all the winter.

Dr. Plot relates, in his "Natural History of Oxfordshire," that some workmen digging a pit at Watlington Park found, at a depth of fifty or sixty feet, a large number of entire Oak-trees, lying in confusion, and " all along as they dug, they met with plenty of Hazel-nuts, from within a yard of the surface to the bottom of the pit, which Time's iron teeth had not yet cracked; and that which amazed me most of all, I. think they lay thicker than ever they grew. The shells of the nuts were very firm without, but nothing remained within of a kernel but a show of the dry outer rind."

A still more remarkable discovery of nuts was made about thirty or forty years since at Carrickfergus, county Antrim, Ireland. These were found in great numbers, and at various depths on the sea-shore; the husk, in all that I examined, had disappeared; the shell was much softer than in recent specimens, and liable to crack unless kept in water, and the kernel was converted into a whitish, semi-opaque stone. They were decidedly of the same species as the common Hazel-nut, and indeed were only to be distinguished from the old nuts which one commonly finds on the ground in Hazel-copses by their superior weight. How they came into this situation, and were subsequently submitted to a partial conversion into stone, are questions which have not satisfactorily been accounted for.

The Hazel is rarely found of a sufficient size to supply building materials : but the young rods, being tough and flexible, are much used for hoops, walking-sticks, fishingrods, \&c.; and from their smoothness and pleasing colour they are well adapted for making rustic seats, and tables for summer-houses. For this purpose they are split, cut to a suitable size, and nailed, in various patterns, to smooth boards of some other wood. They are also excellent as firewood, and when converted into charcoal 
make the best gunpowder. The charcoal crayons used by artists for drawing outlines are also prepared from Hazel-wood.

One of the most beautiful of the British fungi (Peziza coccinea) grows on decaying branches of the Hazel and Bramble, and may be found lying on the ground in damp places from December to April. In their early stage they are whitish, club-shaped columns : but soon the summit opens and exposes an intensely-bright crimson surface,

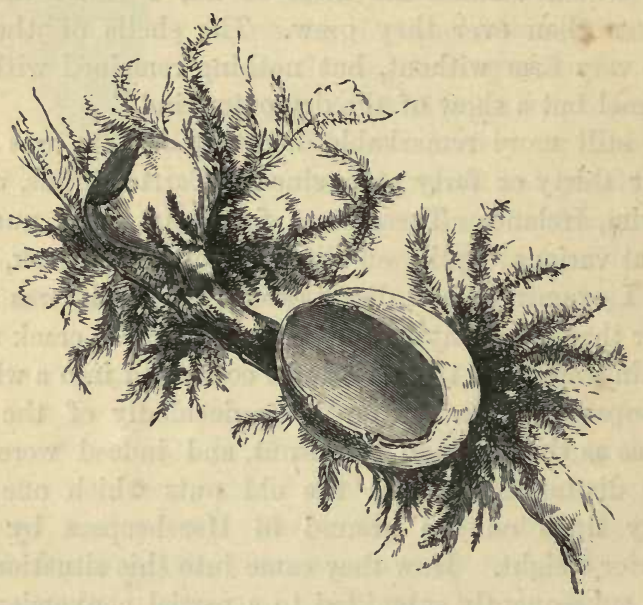

PEZIZA CUCCINEA.

which expands at first into a deep cup, and finally into a spreading bowl, as large over as a crown-piece. When in this state, if they are touched while the sun is shining warmly, they will sometimes send up a fine jet of smoke; at least so it is in appearance: but so rapid is this process, that before one has had time to discover from what part of the surface the puff proceeded, it has vanished, and not a pore, as large even as the point of a needle, can be detected. The particles of which this apparent smoke is composed are, undoubtedly, seeds; but how infinitely 
minute and yet how incalculably numerous must they be, that they should vanish from the sight too rapidly for the eye to follow them, and yet exist in such numbers as to be visible at all!

The principal varieties of Hazel cultivated in Great Britain are the Filbert and Cob-nut; the former of which

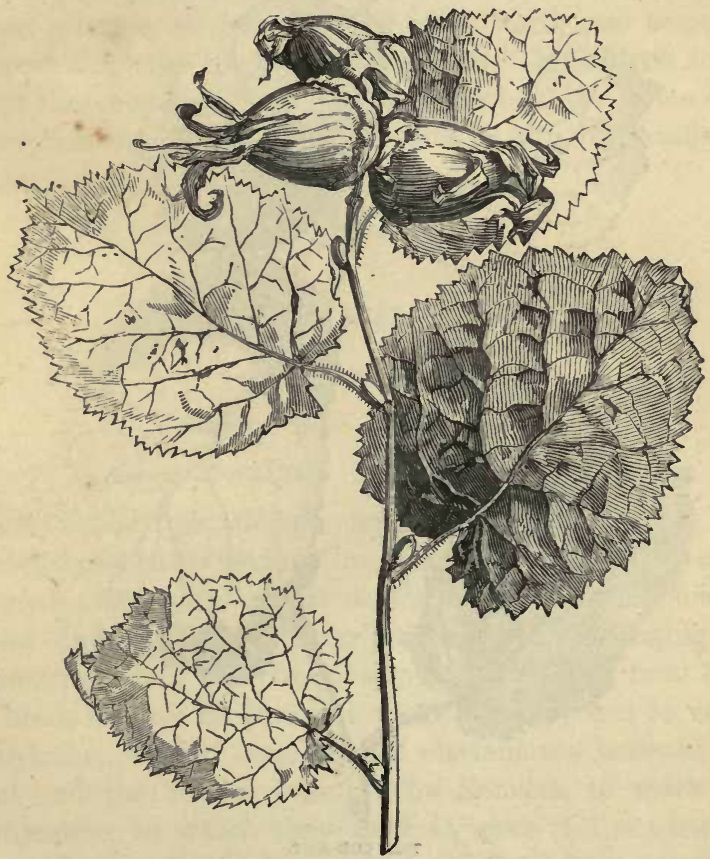

THE FILBERT.

is distinguished by its ample husk (which entirely conceals the nut), the latter by its larger size. In mode of growth and character of foliage neither of these differs materially from the common Hazel. The name Filbert is supposed to be a corruption of full beard, from the lengthened appendage to the nut; an etymology which, unsatisfactory 
as it is, is the only plausible one which has been given. Considerable skill is requisite in the cultivation of the Filbert, in order to insure an abundant crop. In the neighbourhood of Maidstone, in Kent, where they are grown in greater abundance and perfection than anywhere else in England, the trees are trained with short stems,

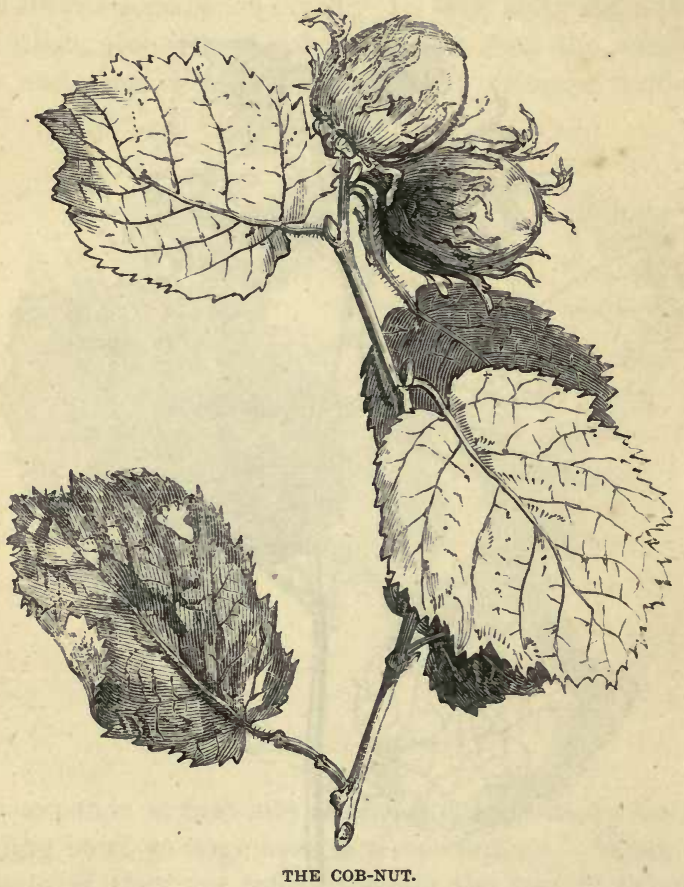

like gooseberry bushes, and are pruned into the shape of a bowl, very thin of wood, and never exceeding six feet in height. The produce from trees thus treated is in certain situations enormous; as much as a ton and a half having been gathered from a single acre : a ton an acre is, however, considered a large crop, and, as total failures are very common, five hundredweight per acre is 
considered a fair average. The treatment of the Cob-nut is the same as that of the Filbert-tree.

The nuts exposed for sale under the name of Barcelona or Spanish nuts are the produce of a tree differing little from the varieties known in this country. They are imported from different parts of France, Portugal, and Spain, and especially from Tarragona, in the last-named country, from whence no less than $25,000 l$. worth are annually exported for the English market alone. M'Culloch states that the entries of nuts (from all quarters) for home consumption amount to from 100,000 to 125,000 bushels a year.

\section{ac \\ THE WALNUT. \\ JUGLANS REGIA. \\ Natural Order-JUGLANDACEE. \\ Class-Mongeis. Order-PoLTandRIa.}

THis noble tree, though not a native of Europe, was extensively cultivated in Greece and Italy at a very early period. Its most ancient names were Persicon (Persiantree) and Basilicon (Kingly-tree), both indicating its eastern origin. The Greeks also call it Caryon, from kara a head, because its powerful odour was supposed to cause headache, or from some fancied resemblance between the nut and the human brain. The Romans, to mark the estimation in which they held it, gave it the name of Juglans, or Jupiter's mast, from its being as much superior to other kinds of mast as their false god was supposed to be superior to men.

Its shade was thought, in Pliny's time, to be injurious not only to the human body, but to all kinds of vegetables; nevertheless its nuts were highly prized, both as an article of food, and for numerous medicinal properties, especially as an antidote to poison and the bite of a mad 
dog. The husk of the nut was used as a dye, and an oil was expressed from the kernel, which was also considered a valuable medicine.

It was customary at weddings in Rome for the bride-

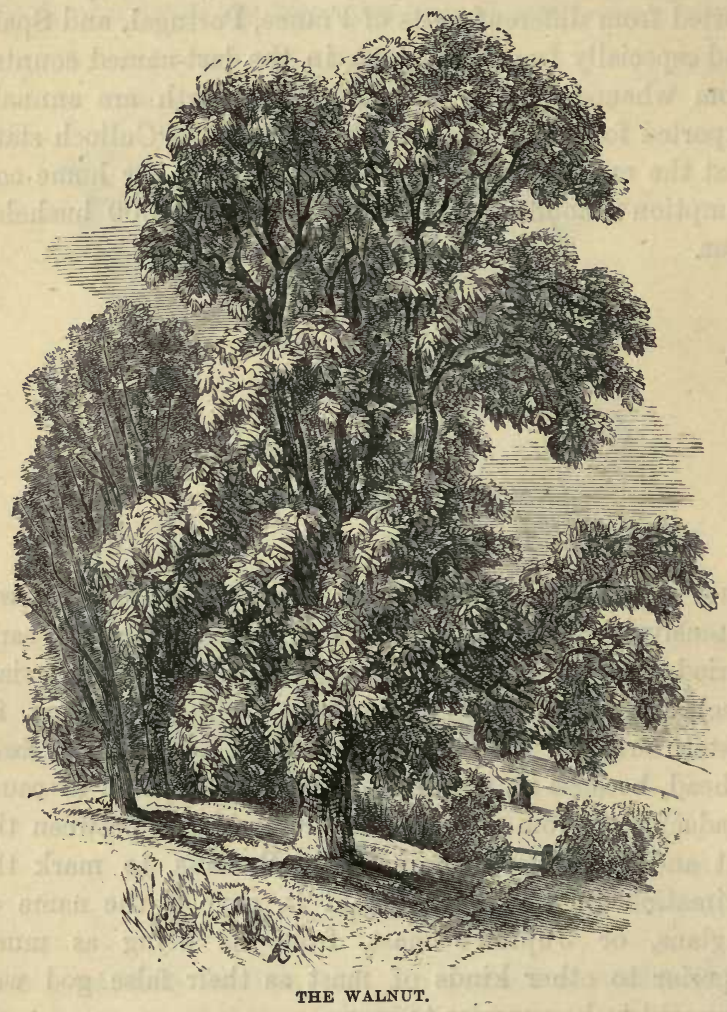

groom to throw about handfuls of nuts to be scrambled for by boys, as a sign that he had now laid aside childish amusements, a custom to which frequent allusion is made by the Latin poets.

The Walnut is a large spreading tree, with a rough 
trunk, and strong, crooked branches, which diverge from the main stem somewhat after the manner of the Oak. The leaves are pinnate, like those of the Ash, but much larger: when young they are tinged with red, and at all periods, until they wither, emit a powerful and fragrant perfume when slightly bruised. The young branches are brittle, and remarkably stout to the very extremity : the

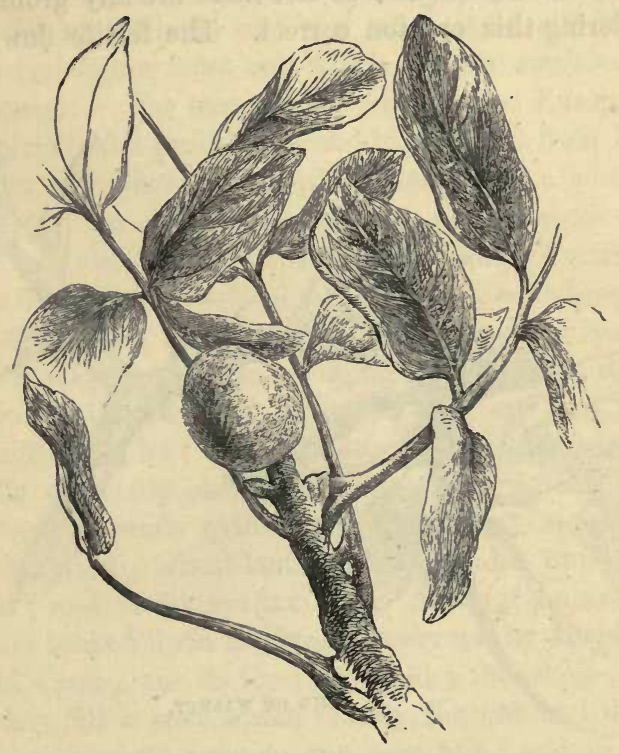

FRUIT OF WALNUT.

bark on these is smooth and shining. The rudiments of the barren flowers appear early in the summer previous to their expansion, and are conspicuous in the axils of the leaves, in the shape of short conical spurs, which are smooth, and of a greenish-brown hue. In the following summer these lengthen into drooping, cylindrical catkins. The fertile flowers do not show themselves before the year that they bear fruit, when they appear among the 
leaves at the extremities of the shoots, and are at no time so conspicuous as the barren flowers.

The poet Virgil remarks, that when the Walnut produces an abundance of blossom, a good corn-harvest may be expected, and that the reverse will be the case when it bears a profusion of leaves and few flowers. Agricultural maxims of this kind are frequently founded in truth; but I am not aware whether or not there are any grounds for considering this opinion correct. The fertile flowers are

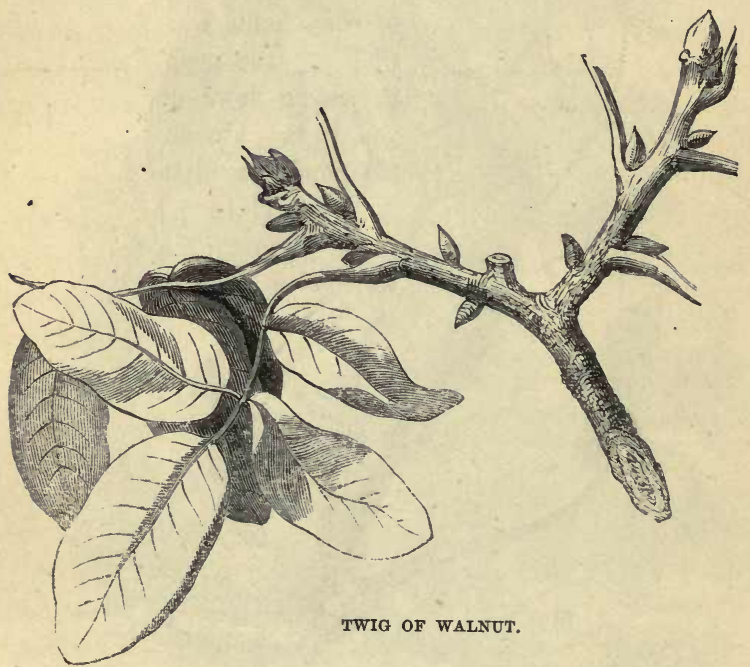

succeeded by bunches of smooth nuts, which in their young state are firm, but not hard, and abound in juice of a strong and offensive odour, which, on exposure to the air, turns - dark yellow, and subsequently black. In September or October the outer case becomes mealy, and splits irregularly, disclosing the nut, which is too well known to need any description. The latter then falls off, generally bringing the case with it. About the same time the leaves turn yellow and fall off, and the tree is more than ever marked 
by its wide-spreading crooked arms and its thick terminal branches, plentifully furnished with the conical flowerbuds described above.

The Walnut, besides being a native of Persia, grows wild in Tartary, where a single tree is said to produce as many as from forty to sixty thousand nuts yearly. We learn from Dr. Clarke, that the Tartars pierce the Walnuttrees in the spring, when the sap is rising, and put in a spigot for some time; and that when it is withdrawn, a clear sweet liquor flows out, which, when coagulated, they use as sugar. The tree was introduced into Europe at an early period, and probably passed into Britain from France, the first syllable of the word Walnut being a corruption of "Gaul," in accordance with an etymological change observable also in the words "Wales" and "Cornwall."

"It delights," says Evelyn, "in a dry, sound, and rich land, especially if it incline to a feeding chalk or marl, and where it may be protected from the cold (though it affects cold rather than extreme heat), as in great pits, valleys, and highway-sides; also in stony grounds, if loamy, and on hills, especially chalky; likewise in corn-fields. Thus Burgundy abounds with them, where they stand in the midst of goodly wheat-lands, at sixty and a hundred feet distant; and so far are they from hurting the crop, that they are looked upon as great preservers, by keeping the ground warm; nor do the roots hinder the plow. Whenever they fell a tree, which is only the old and decayed, they always plant a young one near him ; and in several places betwixt Hanaw and Frankfort, in Germany, no young farmer whatsoever is permitted to marry a wife till he brings proof that he hath planted and is a father of such a stated number of Walnut-trees : and the law is inviolably observed to this day, for the extraordinary benefit which this tree affords the inhabitants."

In Evelyn's time there were extensive plantations of Walnuts, particularly on the downs near Leatherhead in Surrey, at Godstone, and at Carshalton, "where many thou- 
sands of these do celebrate the industry of the owners;" and this is still the case in many parts of the Continent. In the south of France, especially, the fruit, oil, and wood form some of the principal articles of commerce; and here, as well as in the north of Italy and in Switzerland, the roads are lined for miles together with Walnut-trees. During August and September, when the fruit is ripe or nearly so, and the weather so warm that the shelter of a bouse is not required to protect the traveller from cold, he may walk under the shade of the tree, eating the fruit by day, and sleeping under it by night.

Walnuts in their young state are both pickled and preserved. For this purpose they should be gathered at the end of June or beginning of July. If intended for pickling, they should be soaked in salt and water for a fortnight before they are placed in the vinegar. "They may be preserved," says, Loudon, "either with or without their husks; in the latter state they are the most agreeable, but in the former most strengthening to the stomach." Gerard says: "The green and tender nuts, boyled in sugar, and eaten as suckarde (sweatmeat), are most pleasant and delectable meate, comfort the stomache and expelle poyson." A fine stomachic liqueur is made from the young nuts about the beginning of June; and in August, before the shells become hard, they are eaten (what the French call) en cernaux-that is, with the kernel while green scooped out with a short brass knife, and seasoned with vinegar, salt, pepper, and shallots. When ripe, they are considered wholesome as long as the skin can easily be separated from the kernel, soon after which they become oily and indigestible. When they have been kept for a few months, they are in a fit state to be converted into oil, which is either used for culinary purposes and burning, or, more generally, is employed by artists in the preparation of fine colours : it is preferred to any other kind of oil for this purpose, on account of its fluidity and the rapidity with which it dries. 
As a timber-tree, the Walnut holds a high rank : in young trees the wood is white and comparatively soft; but in full-grown trees it becomes compact, and of a darkbrown colour, beautifully veined and shaded with lightbrown and black. Before the discovery of mahogany it was much used for furniture, and many a curiously-wrought cabinet or book-case is still to be found in old-fashioned houses : its principal use, however, at the present time is for gunstocks, for which it is admirably adapted, combining the necessary qualities of lightness and strength, and being at the same time not liable to warp. "It is a remarkable fact in the history of this tree," says Loudon, "that in the winter of 1709 the greater part of the Walnut-trees of Europe were killed, or so far injured as to render it advisable to fell the trees. The Dutch at that time, foreseeing the scarcity of Walnut-timber that was likely to ensue, bought up all the trees that they could procure in every direction, and sold them again, according to the demand, for many years afterwards, at a greatly advanced price."

During the wars of Napoleon Buonaparte the demand for Walnut-timber became so great and the price rose so high, that $600 l$. are said to have been given in England for a single tree.

The juice of the Walnut-tree, both that derived from the leaves and the husk, especially the latter, imparts a rich brown stain. Gipsys use this to dye their skin, and it is also employed in the staining of floors to which it is desired to give a dark hue and a high polish.

The Walnut-tree sometimes produces a considerable quantity of manna; and it bas been observed, in France, that whenever the trees happen to yield more than ordinary, they usually perish the following winter. 
THE LIME-TREE.

\author{
Tilia Europea. \\ Natural Order-TiLIACEx. \\ Class-Polyandria. Order-Polygynia.
}

THE Lime or Linden-tree was well known to the Greeks under the name of Philyra ; and the Romans, Pliny tells us, held it in great repute for its "thousand uses." The timber was employed in making agricultural implements, and was also considered to be well adapted for shields, as it was said to deaden the blow of a weapon better than any other kind of wood. Pliny states, also, that it was not liable to be worm-eaten. The bark was a common writing material, and when split into ribands was made into head-dresses, which were worn on festive occasions. In medicine its supposed virtues were very great; the leaves and bark had a healing power, and decoctions of various parts beautified the skin and promoted the growth of the hair. The seed was said to be eaten by no animal. Evelyn mentions that a book written on the inner bark of the Lime "was brought to the Count of St. Amant, governor of Arras, 1662, for which there were given eight thousand ducats by the Emperor : it contained a work of Cicero, De ordinandâ Republicâ, et de inveniendis orationum exordiis; a piece inestimable, but never published, and now in the library at Vienna, after it had formerly been 'the greatest rarity in that of the late Cardinal Mazarin."

In the Middle Ages the same honours were paid to the Lime-tree which belonged to the Poplar, a tree which derived its name from being the emblem of popular freedom. During the struggles of the Swiss and Flemish to recover their liberty, it was their custom to plant a Limetree on the field of every battle that they gained over their oppressors; and some of these trees, particularly those 
planted by the Swiss in commemoration of their victories over Charles the Bold, are still remaining, and have been the subject of many ballads. "At Fribourg," Loudon informs us, "there is a large Lime, the branches of which

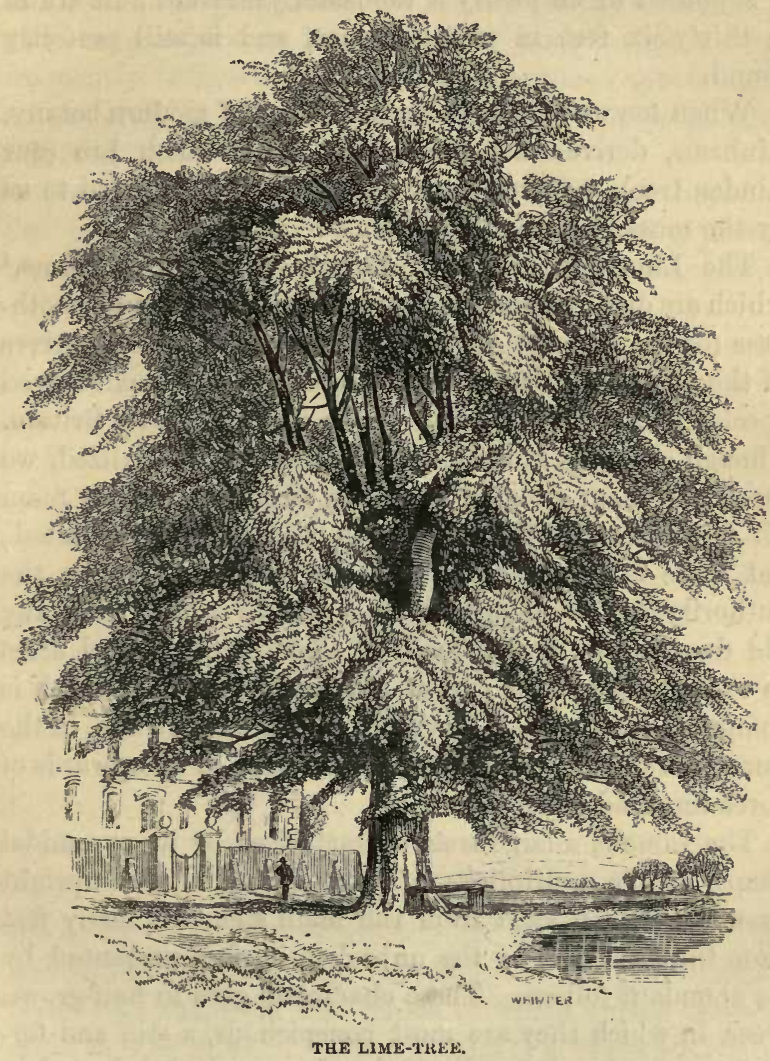

are supported by props of wood. This tree was planted on the day when the victory of the Swiss over the Duke of Burgundy, Charles the Bold, was proclaimed, in the year 1476 ; and it is a monument admirably accordant 
with the then feebleness of the Swiss Republics, and the extreme simplicity of their manners. In 1831 the trunk of this tree measured thirteen feet nine inches in circumference." Another tree stands near the same place, which is supposed to be nearly a thousand years old; its trunk is thirty-six feet in circumference, and is still perfectly sound.

When too we recollect that the father of modern botany, Linnæus, derived his name from the Swedish Lin (our Linden-tree), we must allow that it is recommended to us by the most pleasing associations.

The Lime-tree occurs in Europe under three forms, ${ }^{1}$ which are distinguished principally by the size and smoothness (or the reverse) of their leaves. They are all natives of the middle and north of Europe, but the small-leaved species alone is considered to be indigenous to Britain. Though all these kinds have long become naturalized, we rarely see them growing in places where there is no room for suspicion that they may have been originally planted; yet there is in the neighbourhood of Worcester, on the authority of Mr. Edwin Lees, a wood, remote from any old dwelling or public road, of above five hundred acres in extent, the greater part of the undergrowth of which is composed of the small-leaved Lime. There are also, in the same part of the country, trees estimated to be upwards of three hundred years old.

The Lime is a large tree, characterised by its pyramidal shape, by the multiplicity of its long, slender, and upright branches, which start from the main stem not many feet from the base, and by the unbroken surface presented by its abundant foliage. These characters give to half-grown trees, in which they are most conspicuous, a stiff and formal appearance, especially if they happen to be planted in rows. In older specimens the weight of the lower branches frequently bends them down to the ground so as entirely to conceal the trunk; the middle part of the tree is thus

1 Tilia Europcea, T. platyphylla, and T. parvifolia. 
thrown open, and the pyramidal outline destroyed: the summit too becomes somewhat more tufted. Under these circumstances the Lime is a stately and even picturesque tree, especially when standing alone or in groups of three or four on a sloping lawn. It is very patient of clipping, and, consequently, in the suburbs of large towns it more frequently disfigures than adorns, sometimes appearing as a mere leafy hedge, unmeaningly elevated on equidistant columns.

The leaf is bright green, pointed, and heart-shaped at the base, smooth above, and either uniformly downy beneath, or bearing small tufts of down in the angles of

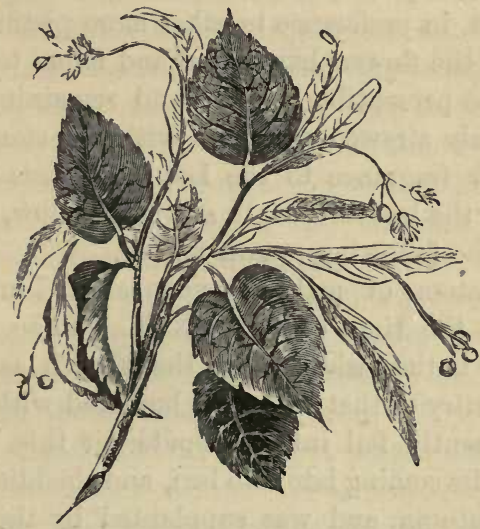

LEAF AND FLOWER OF THE LIME-TREF.

the veins. The flowers are scarcely less profuse than the leaves, and rendered very conspicuous by large yellowishgreen bracteas, from the centre of which spring three or more stalked flowers. These consist of a five-parted calyx and five petals, which are nearly of the same colour as the bracteas. The stamens are numerous, and the whole flower is deliciously fragrant, especially towards evening,-

Diffusing odours."

"At dewy eve 
The seed-vessels are globular and downy, but rarely perfect the seeds in England. While the Lime-tree is in flower, it is frequented by myriads of bees, which

"Sit on the bloom, extracting liquid sweets Deliciously."

Honey from the Lime is considered superior to all other kinds for its delicacy of flavour : it is to be obtained in a perfectly pure state only at the little town of Kowno in Lithuania, which is surrounded by an extensive forest of Lime-trees. The pleasing sound produced by the busy collectors, joined to the fragrant perfume diffused by the flowers, frequently gives occasion for its being planted near houses, in preference to other more picturesque trees. Even after the flowers have faded and fallen to the ground the odour is perceptible, the ground remaining for a long while thickly strewed with the withered stamens, which retain their fragrance to the last. Towards the end of September the leaves turn to a bright yellow, and in the course of the following month fall off.

The custom of making avenues of Lime-trees was adopted in the time of Lewis XIV., and accordingly the approaches to the residences of the French as well as the English gentry of that date were bordered with Lime-trees. It subsequently fell into disrepute for this purpose, on account of its coming late into leaf, and shedding its foliage early in autumn, and was supplanted by the Hornbeam and Elm : but many of the cities of continental Europe still boast of their public walks of Lime-trees, which in the hours of relaxation are numerously frequented by persons of all classes and ages. The Dutch, especially, plant them in lines along their widest streets, and by the sides of their canals, and the whole country is perfumed by them during the months of July and August. Evelyn, in whose time straight walks and formally-grown trees were in vogue, recommends the Lime as, " of all other, the most " proper and beautiful for walks, as producing an upright 
body, smooth and even bark, ample leaf, sweet blossom, the delight of bees, and a goodly shade at the distance of eighteen or twenty-five feet."

The Lime-tree, though not applied to so many uses as it was in the time of Pliny, is valuable for many purposes. In the Belgian "Horticulturist" it is stated, that "the flowers infused in cold water are antispasmodic; and in hot water they make an agreeable kind of tea. The leaves and young shoots are mucilaginous, and may be employed in poultices and fomentations. The timber is better adapted than any other for the purposes of the carver: it will take any form whatever; it admits of the greatest sharpness in the minute details, and it is cut with the greatest ease. It is also used for sounding-boards for pianos and other musical instruments. But the peculiar use of the Lime is for the formation of mats from its inner bark. In June, when the leaves begin to develop themselves, and the tree is full of sap, branches or stems of from eight to twenty years' growth are cut and trimmed, and the bark is separated from them from one end to the other. This is easily done by simply drawing the edge of a knife along the whole length of the tree or branch, so as to cut the bark to the soft wood. It then rises on each side of the wound, and almost separates of itself. If mats are to be made immediately, the bark is next beaten with mallets on a block of wood, and children are employed to separate the inner bark, which comes off in strands or ribands, while the outer bark detaches itself in scales. If mats are not to be made for some time, the bark is dried in a barn or shed, and either kept there or stacked till it is wanted. It is then steeped twenty-four hours in water, beaten as before, and put into a heap, where it remains till it undergoes a slight fermentation. When this has taken place, the inner bark separates in ribands and shreds as before. With the shreds cords of different kinds are twisted in the usual manner; and mats are formed with the ribands in the same way as rush mats. The ribands which are to 
be used in forming mats for gardens undergo a sort of bleaching, for the purpose of depriving them of part of their mucilage, which would otherwise render them too liable to increase and diminish in bulk by atmospheric changes. The great advantage of Lime or bast mats, over all others, in gardens, is that they do not so easily rot from being exposed to moisture."

The superiority of Lime-wood for the purposes of sculpture is confirmed by the fact that Gibbon, the celebrated carver in wood, preferred it to any other. This remarkable person was first introduced to public notice by Evelyn, the author of the "Sylva," himself a man who, whether as a churchman, a citizen, or a man of taste, may serve as a model to his countrymen.

To the above-mentioned uses to which the Lime may be applied Loudon adds the following. The Russian peasants weave the bark of the young shoots for the upper part of their shoes; the outer bark serves for the soles : and they also make of it baskets and boxes for domestic purposes. The fishermen of Sweden make nets for catching fish of the fibres of the inner bark separated by maceration, so as to form a kind of flax; and the shepherds of Carniola weave a coarse cloth of it, which serves them for their ordinary clothing. The sap drawn off in the spring affords a considerable quantity of sugar; and the seed may be converted into an oily substance resembling chocolate, but unfortunately of little value, as it soon becomes rancid.

Several American species of Lime have been introduced into England; but none of these require a particular notice.

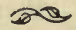




\section{THE BARBERRY.}

\section{Berberis vUlgaris. \\ Natural Order-BerBERIDEE. \\ Class-Hexandria. Order-Monogria.}

ThIs pretty shrub grows wild in many parts of England, and is of still more common occurrence in gardens and shrubberies, where it is cultivated for the sake of the pleasing appearance presented by its numerous clusters of yellow flowers and drooping bunches of scarlet berries. It is indigenous to most of the countries of Europe and Asia, and is also found in North America, preferring a temperate climate, but also inhabiting warmer regions : in which latter case it grows at a high elevation in the mountains.

In its wild state, in England, it appears in the form of a low bushy shrub; but, when cultivated, attains a height of twenty feet or more. The branches are covered with smooth bark of a remarkably light hue, and, with the three-forked thorns, sufficiently distinguish it from every other shrub, even when it is bare of foliage. The leaves are nearly elliptical, smooth, and beautifully fringed at the edge. The flowers consist of a calyx of six unequal

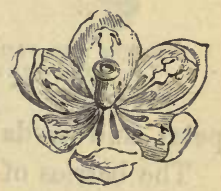
leaves, and as many concave yellow petals, in each of which is concealed a stamen with a flattened filament. The flowers last only a short time, during which they are showy, but emit a very unpleasant odour. Near the base of each filament is a small spot, which possesses a high degree of irritability. If this be touched by any small body while the bloom is in perfection, the stamen suddenly bends forward and closes on the pistil, and, if allowed to remain for a few hours, gradually returns to its original 
position, ready to perform the same movement when again excited. It is a well-known fact that no flower will bear fertile seeds unless some portion of pollen be lodged on the pistil while the latter

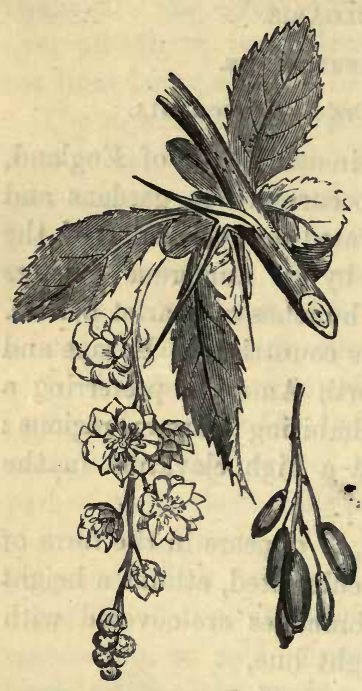

FLOWERS AND FRUIT OF THE BARBERRY. is in its mature state. In the Barberry, when the flower is expanded, the anthers containing the pollen are bent so far away from the stigma or summit of the pistil, that they could scarcely perform their office were they not by some means raised and brought forward, and that too in bright, sunny weather. This is just the time when insects are most busily occupied in exploring for food; and they, in their search after honey, visit the flowers of the Barberry, and cannot fail to touch some one or other of the stamens, which instantaneously springs forward from the shelter of its petal, and sheds a portion of the pollen on the pistil. The berries of the Barberry are oblong, and, when ripe, scarlet, and covered with a bloom like that of the plum. They are intensely acid; so much so as to be refused by birds : they therefore remain a long time on the tree, and when produced in abundance are very ornamental. At Chamounix, and elsewhere in Switzerland, the bases of the mountains are in many places tinged of a red hue by the berries, so numerous are the trees and so prolific.

The inner bark and wood are bitter and astringent, and of a bright yellow colour, which may be extracted, and furnishes good dye. The leaves are acid, but are not now applied to any use. The berries, preserved in various 
ways, are made into jelly, comfits, cooling drinks, and pickles. For these purposes a variety is preferred which bears seedless berries.

A notion was formerly prevalent that the Barberry caused mildew or rust in corn, and consequently many persons destroyed it whenever it was found growing near arable land. Botanists, however, have sufficiently proved that the orange-coloured mildew which infests the leaves of the Barberry, thaugh nearly of the same colour as the mildew of corn, is totally different from it, and cannot be transferred to any other plant. ${ }^{1}$ It is, therefore, to be hoped that the Barberry will be allowed to retain its place as a hedge shrub, for which its habit of growth and numerous stout prickles admirably adapt it.

Several foreign species of Barberry are cultivated in gardens; some of which, from the north-west coast of North America, are among the most ornamental evergreen shrubs that have ever been introduced. These are placed by some botanists in a distinct genus, Mahonia, but with questionable propriety.

\section{THE TAMARISK.}

\section{Tamarix gallica.}

Natural Order-Tamariscinere.

\section{Class-Pentandria. Order-Trigynia.}

THE Tamarisk is a native of most of the countries of Southern Europe, Asia Minor, Tartary, Japan, Barbary, and Arabia, assuming a great variety of forms, accorling to the soil, situation, and climate in which it grows. It

* "The mildew of wheat is not produced by a superficial fungus like an Erisyphe (the rust of the Barberry), but an intestinal fungus of the genus Puccinia; and, consequently, to place such leaves among wheat is not likely to injure it."-Gardeners" Chronicle. 
was known to the Greeks and Romans under the name of Myrica, and frequent mention of it occurs in the writings of the ancients. Pliny describes it as an evergreen; but this title it scarcely merits with us, for it only partially retains its foliage during the winter. It is, however, a very pleasing shrub, remarkable for the rich purple of its long tapering branches, and the light feathery appearance of its spray. The flowers are produced in July, growing in bunches of spikes near the ends of the shoots: they are flesh-coloured, with red stamens.

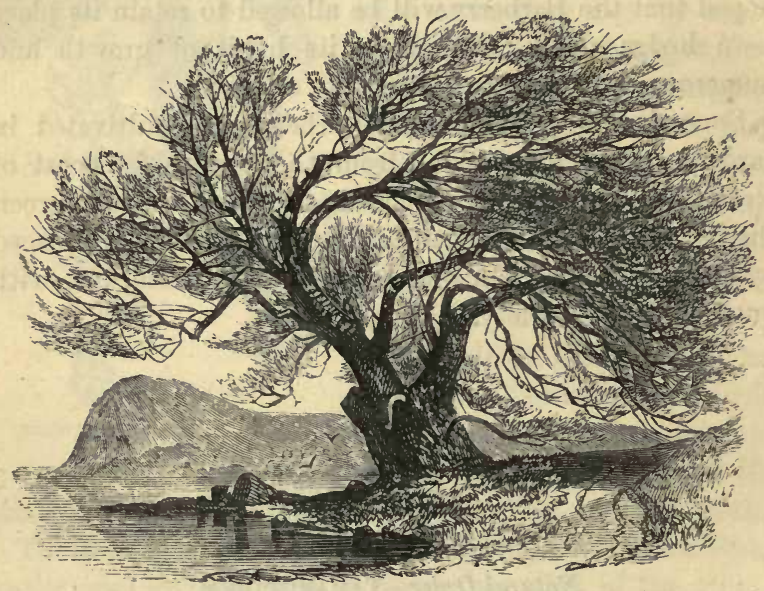

THE TAMARISK.

The Tamarisk is scarcely indigenous to Britain; for though it is said by some to be wild in Cornwall and on other parts of the coast, it bears every appearance of having been planted. It was first observed in an apparently wild state on St. Michael's Mount, whither, perhaps, it may have been brought from the opposite coast of France by smugglers. It is now a common hedge-plant in many parts of the Cornish coast, having been introduced, it is said, into the Lizard district by 
a carter, who, having lost his whip, gathered one of the long flexible branches at the Mount, and at the conclusion of his journey stuck the rod into the ground, where it grew, and was soon extensively propagated. It is far from improbable that it was introduced in some such way from

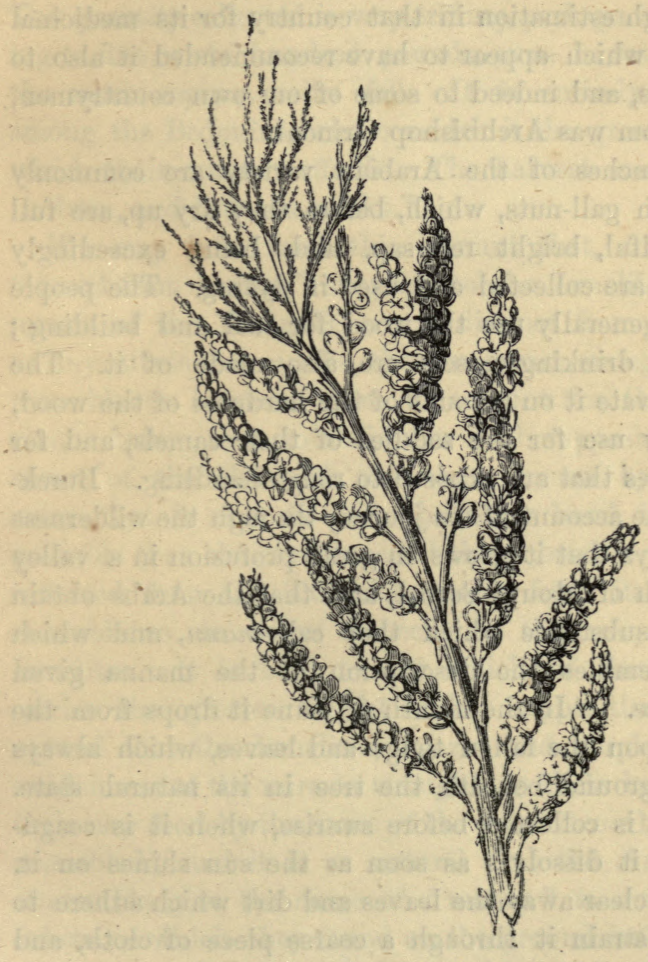

FLOWERS OF THE TAMARISK.

France, for it grows from cuttings as freely as the Willow, provided that it be planted in autumn or early in spring. On the Continent it is said to grow in the greatest abundance on the banks of rivers; but in England it flourishes 
in very dry situations, and will bear exposure to any degree of wind, thriving best when within reach of the sea-breeze. The stems and leaves contain a large quantity of sulphate of soda, a fact which accounts for its flourishing not only in such situations, but in the valleys of Arabia, where the springs are often impregnated with salt. It is held in high estimation in that country for its medicinal properties, which appear to have recommended it also to the Romans, and indeed to some of our own countrymen, among whom was Archbishop Grindal.

The branches of the Arabian variety are commonly loaded with gall-nuts, which, before they dry up, are full of a beautiful, bright red sap, and, being exceedingly astringent, are collected and used in dyeing. The people of Egypt generally use the wood for fuel and building ; bowls and drinking-vessels are also made of it. The Arahs cultivate it on account of the hardness of the wood, which they use for the saddles of their camels, and for other articles that are exposed to rough handling. Burckhardt, in the account of his journey through the wilderness of Sinai, says that it grows in great profusion in a valley to the north of Mount Serbal, and that the Arabs obtain from it a substance which they call mann, and which closely resembles the description of the manna given in Scripture. "In the month of June it drops from the branches upon the fallen twigs and leaves, which always cover the ground beneath the tree in its natural state. The manna is collected before sunrise, when it is coagulated; but it dissolves as soon as the sun shines on it. The Arabs clear away the leaves and dirt which adhere to it, boil it, strain it through a coarse piece of cloth, and put it into leathern skins. In this way they preserve it till the following year, and use it, as they do honey, to pour over their unleavened bread, or to dip their bread into. I could not learn that they ever made it into cakes or loaves. The manna is found only in years when copious rains have fallen: sometimes it is not produced at 
all. It never acquires that degree of hardness which will allow of its being pounded, as the Israelites are said to have done with the manna with which they. were miraculously supplied; nor does it possess the same nutritive properties. Some travellers suppose this substance to be the produce of an insect which infests the Tamarisk. The quantity collected is very trifling, perhaps not amounting to five or six hundred pounds, even in seasons when the most copious rains fall. It is entirely consumed among the Bedouins, who consider it the greatest dainty which their country affords. The harvest usually begins in June, and lasts six weeks."

We may infer from this account that, although the "bread from heaven" supplied to the Israelites and the manna of the Tamarisk are as distinct from each other as any substances can be, there was just enough outward resemblance between them to account for the name of manna being given to their new food, supposing that the mann of the Tamarisk was then known by the same name that it now is. On the other hand, it is highly probable that the Arabs called the substance which they collected from the Tamarisk mann, from its bearing a resemblance in some respects to the manna of the Israelites. It is hard to say which of these opinions carries the greater weight: the supposition is quite natural that the Israelites, amazed and perplexed at the suddenness of the miracle wrought on their behalf, called their new food by the name of the substance which it most resembled; and it is as natural that the Arabs should afterwards give the name of "manna" to a white sweet substance which they found on the ground before sunrise, although produced for a few weeks only in every year, and unaccompanied by the signs of miraculous origin which characterised the food with which the Israelites were fed for forty years in the wilderness. But if, as Josephus tells us, the word manna means "What is this ?" and indicates ignorance of its nature and origin, there can 
be no doubt that the second opinion is the correct one. In no case is there any real connexion between the two substances. .

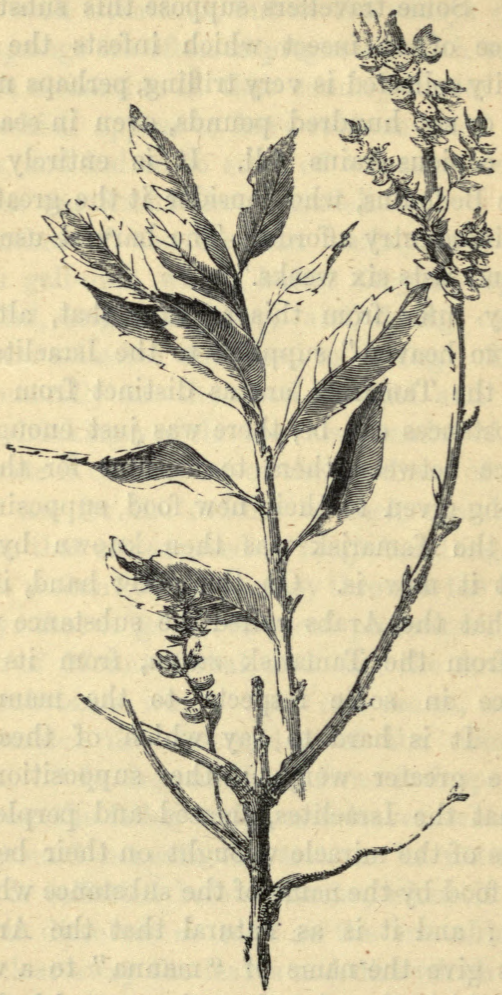

DUTCH MYRTLE, OR SWEET GALE.

The manna of commerce, as has been stated before (p. 65), is the produce of a European tree, Ornus Europaea.

The Tamarisk was by the Greeks called Myrica; but the plant known to modern botanists by this name is a 
low shrub, composed of numerous upright stems, and producing in spring abundance of purplish-brown catkins, which appear before the leaves begin to expand. It is commonly known as Dutch Myrtle, or Sweet Gale ; and to the latter name at least it is justly entitled, for both at the season when it is in flower, as well as when it is in leaf, it diffuses a rich aromatic perfume, which scents the air to a great distance.

\section{"And as he flies,}

Like the winged shaft, the wanton zephyrs breathe

Delicious fragrance ; for upon his banks-

Beautiful ever-Nature's hand has thrown

The odorous Myrica."

Carrington.

The catkins and leaves when bruised are clammy to the touch, and impart a permanent fragrance to the fingers.

It is a native of Great Britain, North America, and all the colder and temperate regions of Europe and Asia, always growing in bogs. The whole plant abounds with a resinous substance, to which it owes its fragrance. The leaves are bitter, and are sometimes used as a substitute for hops. The catkins when boiled throw up a resinous wax, which may be made into candles. This substance is found in much greater quantities in a North American species of Myrica, called the Candleberry Myrtle. The plant which produces it is an evergreen, larger than the Sweet Gale, and furnished with leaves like those of the Sweet Bay. Candles formed of this wax burn long, and yield a grateful smell, and they are said to have the advantage of producing an agreeable aromatic fragrance when extinguished. Another species, which grows at the Cape of Good Hope, produces a similar wax, which is applied to the same purpose. 


\title{
THE STRAWBERRY-TREE.
}

\author{
Arbutus unedo. \\ Natural Order-ERICACEAT. \\ Class-Decandria. Order-Monogynia.
}

THIS beautiful evergreen shrub is better known by its ancient name of Arbutus ${ }^{1}$ than by the name which it derives from the fruit to which its berries bear a considerable resemblance. It is frequently mentioned by the Latin poets as an ornamental tree, which added much grace to the wild rocky scenery of Italy, affording a shady retreat to the weary traveller, and food to the wild goat.

We learn from Pliny that it was also called Unedo, or One-I-eat, the fruit not being nice enough to tempt any one to taste a second. $\mathrm{He}$ also notices the similarity between its fruit and that of the strawberry, for he says that it is the only tree which bears fruit like ground-fruit. $\mathrm{He}$ also states, but not on his own authority, that in Arabia it attains an extraordinary height, evidently confounding it with some other tree.

The Arbutus is a native of the mountainous districts of Southern Europe and Northern Africa, and of many parts of Asia. In England it only appears in the shrubbery and park. Among the rocky cliffs of Mount Edgecumbe, in Devonshire, it flourishes in the immediate neighbourhood of the sea, but it never attains the dimensions of a tree. In Ireland it grows in great abundance about the hills and islands of Killarney ; and here it is undoubtedly wild, though unfounded stories are told of its having been introduced by the monks of St. Finnian in the sixth

1 The correct pronunciation of Arbutus unedo is with the accent on the first syllable of each word. 
century. The country people in this neighbourhood eat the fruit, and Babington, whose judgment as a botanist ought to carry weight, pronounces it excellent. English berries, when thoroughly ripe, are of a mealy consistence, and of a somewhat insipid flavour, not unlike that of the haw. At

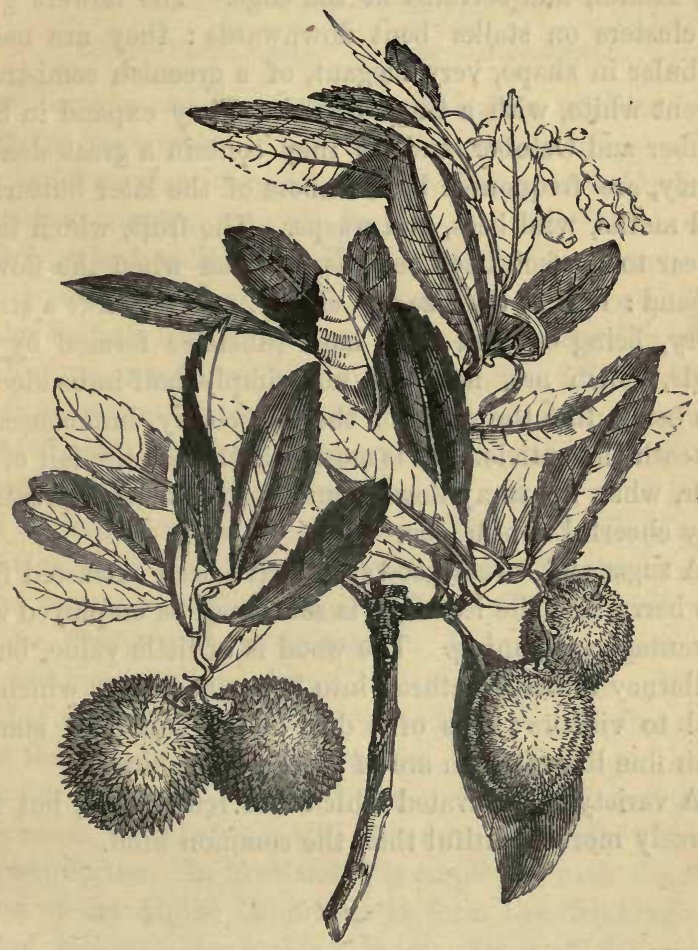

FLOWER AND FRUIT OF ARBUTUS.

Smyrna and Padua it is exposed for sale in the markets; and the fruit which it produces near Miletus, in Asia Minor, is said to resemble a strawberry, both in size and flavour. It is very probable, therefore, that, when growing under certain conditions, the fruit improves in quality; 
indeed, Pliny intimates that the produce of the tree varies, and Sir James Smith tells us that in the Levant it is agreeable and wholesome.

The Arbutus is an evergreen shrub, with a scaly stem, and with dark green, glossy leaves, smaller than those of the Laurel, and serrated at the edge. The flowers grow in clusters on stalks bent downwards : they are nearly globular in shape, very elegant, of a greenish semi-transparent white, with a tinge of red. They expand in September and October, and, as they contain a great deal of honey, are frequented by numbers of the later butterflies and moths, wild bees, and wasps. The fruit, which takes a year to perfect itself, begins to ripen when the flowers expand : it is of the size of a cherry, and very like a strawberry, being covered with hard tubercles formed by the seeds, which are, however, not simply half-imbedded in the berry, like the seeds of the strawberry, but concealed beneath the cuticle. It is most beautiful at the fall of the year, when its waxy flowers and scarlet berries present a very cheerful appearance.

A sugar and a very good spirit have been extracted from the berry, and the leaves, it is said, may be employed with advantage in tanning. The wood is of little value, but at Killarney is manufactured into boxes and toys, which ure sold to visitors : it is of a dull brown tint, and marked with fine lines, which are of a yet darker hue.

A variety is cultivated which has red flowers, but it is scarcely more beautiful than the common kind. 


\section{THE SPINDLE-TREE.}

\section{EuONYMUS EUROpaus.}

Natural Order-Celastracee.

Class-Tetrandria. Order-Monogynia.

FEw persons can have walked through a woodland district in September or October without noticing among the brushwood a straggling shrub with remarkably green branches, narrow smooth leaves, and four-lobed seedvessels, which split vertically and disclose as many seeds, which are wrapped up in a bright scarlet membrane. This is the Spindle-tree, a common shrub throughout the whole of Europe, sometimes attaining a height of from fifteen to twenty-five feet, but more generally ranking only as a hedge-bush. Its flowers appear in May : they are of four petals, small, and of a whitish-green colour. The leaves and bark are acrid and poisonous. The wood, like that of the Cornel, is of a very close grain, and being used for the same purposes as that tree, is often called by the same names, Prickwood and Dogwood. It has long been used for making spindles, whence it derives its name. In Ireland it is commonly called Pegwood, from its being made into the pegs used by shoemakers. Loudon says that it was formerly employed in the manufacture of musical instruments, and that it is still occasionally used for the keys of pianofortes. In Scotland it is employed with the dark wood of the Alpine Laburnum to form the drinking-cups called bickers. In making these, staves of the yellow wood of the Spindle-tree and of the dark wood of the Laburnum are arranged alternately, and produce a pleasing effect. In Germany spindles are still made of the wood, and in this country watchmakers prefer it to any other kind of wood for the slender spills which they use in cleaning watches. When reduced to charcoal, it makes an 
excellent crayon for artists, being of a strong texture, and making a mark which is easily effaced. Loudon also states that the fruit is sometimes employed by dyers, who derive a yellow dye from the seeds boiled alone, a green dye from the seeds boiled with alum, and a red dye from the seed-vessels.

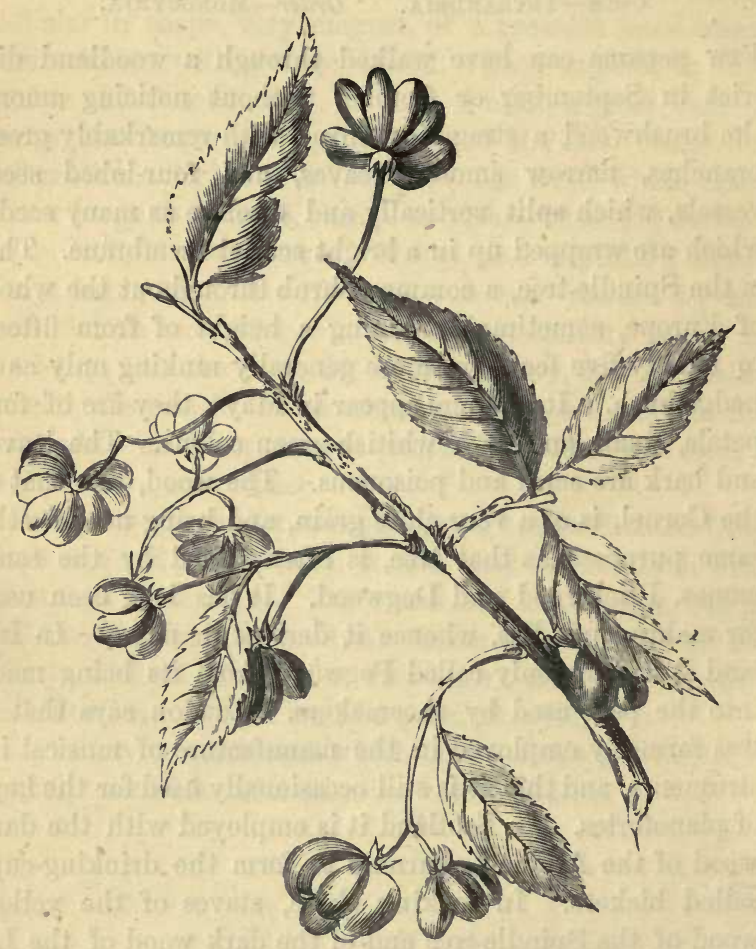

BRANCH OF THE SPINDLE-TREE.

A variety of this tree is found in Hampshire which bears scarlet seeds in a white seed-vessel. Several foreign species are also cultivated, all of which, as well as the 
common one, are liable to be entirely stripped of their foliage by the caterpillars of a moth, which cover the branches with festoons of a web spun by them in the course of their feeding.

a)

THE DOGWOOD.

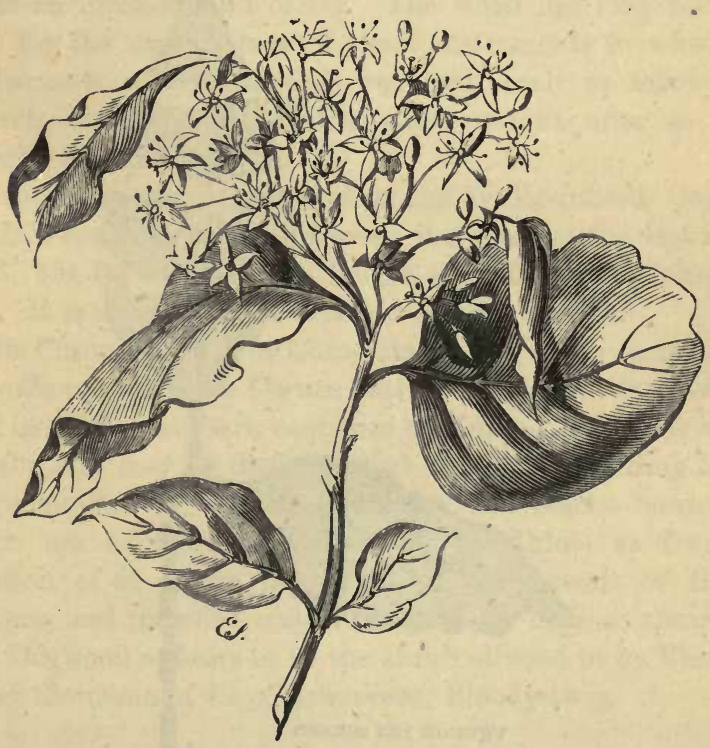

LEAF AND FLOWER OF THE DOGWOOD.

Cornus sanguinea.

Natural Order-CORNEA.

Class-Tetrandria. Order-Monogynia.

THIs common hedge-shrub derives its Latin name from cornu, a horn, from the toughness of its wood. It is called Dogwood because "the fruit is not fit even for a dog;" on which account, also, it was formerly named Dogberry and 
Hound's-tree. It is also called Prickwood, from its wood being frequently made into toothpicks and skewers.

It usually grows in the form of a thick bush, but may occasionally be seen trained up to be a round-headed tree, from fifteen to twenty feet high, and with a stem six inches in diameter. Unlike most other trees, it is best

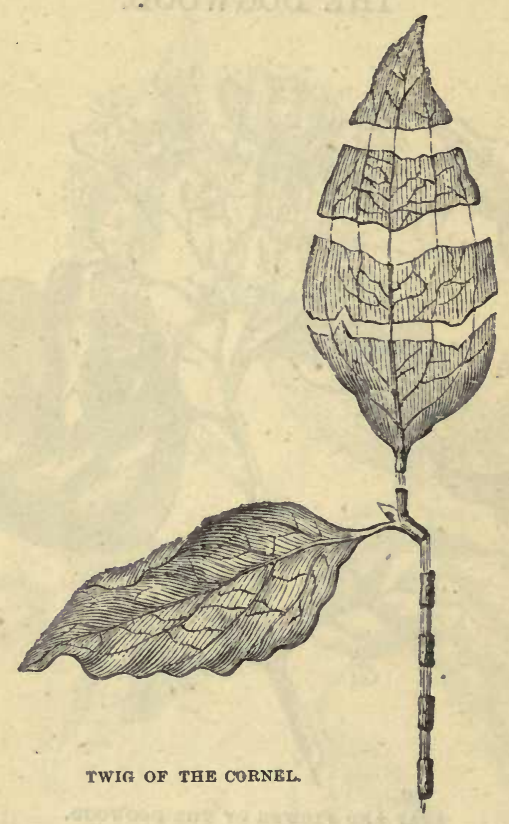

distinguished in winter, when its bright red branches (which in some places give it the name of Bloody-twig) are very conspicuous. In early spring it bears at the extremities of the twigs numerous white flowers, which consist of four spreading petals; and these are succeeded by small berries, which in August and September become dark purple, or almost black. Towards the end of September the leaves turn bright red, and finally deep purnle. 
The leaves and young shoots are remarkable for the number and strength of their spiral vessels. So tenacious are these, that if a tender twig or leaf (in any stage of growth) be snapped asunder in several places, the spiral vessels may be discovered, by the naked eye, holding the pieces so firmly together, that if one fragment be lifted up, all the others will remain suspended.

The fruit of the Dogwood is bitter and styptic, and yields an inferior kind of oil. The wood has long been used for the manufacture of small instruments in which compactness of substance is required, such as arrows, ramrods, \&c., and it is still much sought after as a material for skewers.

Another species, Cornus alba, the White-fruited Dogwood, is common in shrubberies : it resembles the last in habit, but its branches are longer and of a yet brighter red. It is a native of Siberia and North America.

The Cornus, Cornel, or Cornelian Cherry of the ancients, is another species, the Cornus mas of botanists. It grows wild in all the southern countries of Europe, except Great Britain, and may be distinguished from the preceding by its yellow flowers, ash-coloured twigs, and scarlet berries, which are as large as acorns, but worthless as fruit. Mention of it occurs in several of the legends of the Romans, and its wood was much used for making spears. Our Dogwood appears to be the shrub alluded to by Pliny under the name of Virga sanguinea, Bloody-twig. 


\section{THE ORIENTAL PLANE.}

\section{Platanus orientalis.}

\section{Natural Order-Platanacee. \\ Class-Mongcia. Order-Polyandria.}

"Trees," says the Roman naturalist, Pliny, "afforded the first inducement to the barbarous tribes of Gaul to cross the Alps, and spread themselves over Italy. A certain Swiss once came to Rome to learn the art of a smith, and on his return took with him raisins, dried figs, oil, and wine; the taste of which incited his countrymen to invade Italy with a hostile army. But who would have thought it possible that a tree should have been brought from a remote region of the world for the sake of its shade only? Yet such was the case: the Plane was first carried across the Ionian Sea to shade the tomb of Diomede, who was buried in one of the small islands off the coast of Apulia ; thence it was introduced into Sicily; from Sicily it was brought to Rhegium in Italy by the tyrant Dionysius ; and has now extended so far, that the Morini (people of Calais) are taxed for its shade. Dionysius held it in high honour, and since his time it has so much increased in estimation that its roots are nourished with wine instead of water."

Diomede was a Grecian hero, and to honour his tomb the tree was planted which had of old been venerated in Greece, and even in Asia. Herodotus informs us, that when Xerxes was about to invade Europe with his mighty army, and had arrived at Lydia, in Asia Minor, he fell in with a Plane-tree, which, on account of its excessive beauty, he decorated with golden ornaments, and left behind him a warrior seleeted from the Immortal Band to take care of it. "Allian, and other authors tell us," says Evelyn, "he made halt, and stopped his prodigious army of 170,000 soldiers, which even covered the sea, exhausted 
rivers, and thrust Mount Athos from the continent, to admire the pulchritude and procerity of one of them; and became so fond of it, that, spoiling both himself and his great persons of all their jewels, he covered it with gold,

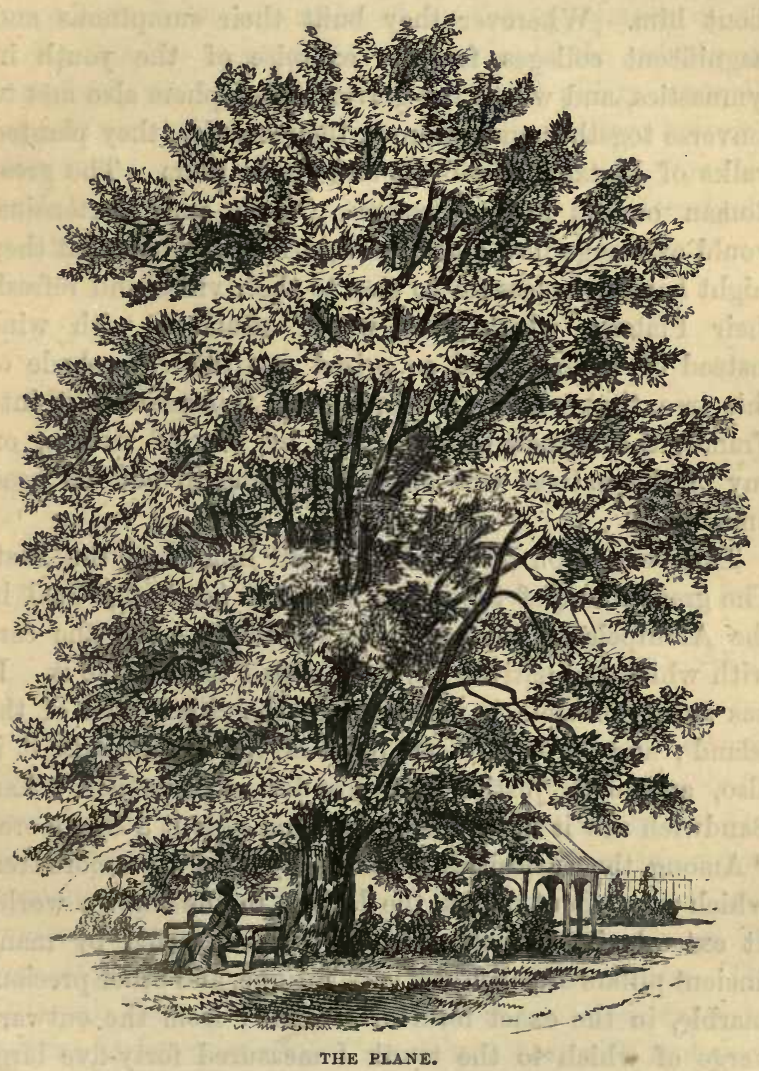

gems, necklaces, scarfs and bracelets, and infinite riches. In sum, he was so enamoured of it, that for some days neither the concernment of his grand expedition, nor 
interest of honour, nor the necessary motion of his portentous army, could persuade him from it. He styled it his mistress, his minion, his goddess; and when he was forced to part from it, he caused the figure of it to be stamped on a medal of gold, which he continually wore about him. Wherever they built their sumptuous and magnificent colleges for the exercise of the youth in gymnastics, and where the graver philosophers also met to converse together and improve their studies, they planted walks of Platans, to refresh and shade them. The great Roman orators and statesmen, Cicero and Hortensius, would exchange now and then a turn at the bar, that they might have the pleasure to step to their villas and refresh their Platans, which they would often do with wine instead of water. And so prized was the very shade of this tree, that when afterwards they transplanted it into France, they exacted a solarium, by way of tribute, on any of the natives who should presume to put his head under it."

This veneration for the Plane still lingers in the East. The great Plane of the island Stanchio (anciently Cos), in the Archipelago, is remarkable for its size and the care with which the natives have attempted to preserve it. It has stood for time immemorial in the chief town of the island ; and while it is the boast of the inhabitants, it is also, and with justice, the wonder of strangers. Earl Sandwich saw it in the year 1739, and calls it a Sycamore : "Among the curiosities of this city is a Sycamore-tree, which is, without doubt, the largest in the known world. It extends its branches, which are supported by many ancient pillars of porphyry, very antique, and other precious marble, in the exact form of a circle; from the outward verge of which to the trunk I measured forty-five large paces. Beneath the shade of this Sycamore is a very beautiful fountain, round which the Turks have erected several chiosks, or summer-houses, to which they retire in the heat of the summer, and regale themselves with their 
afternoon coffee and pipe of tobacco." Dr. Clarke saw the same tree many years after: one enormous branch had then given way, notwithstanding its being supported by pillars of granite; and this loss considerably diminished its bulk. "Some notion," he says, "may be formed of the time those props have been so employed by the appearance of the bark : this has encased the extremities of the columns so completely that the branches and the pillars mutually support each other; and it is probable, if those branches were raised, some of them would lift the pillars from the earth." A specimen of this tree was given by Hasselquist to Linnæus, and it is now in the Linnæan Herbarium.
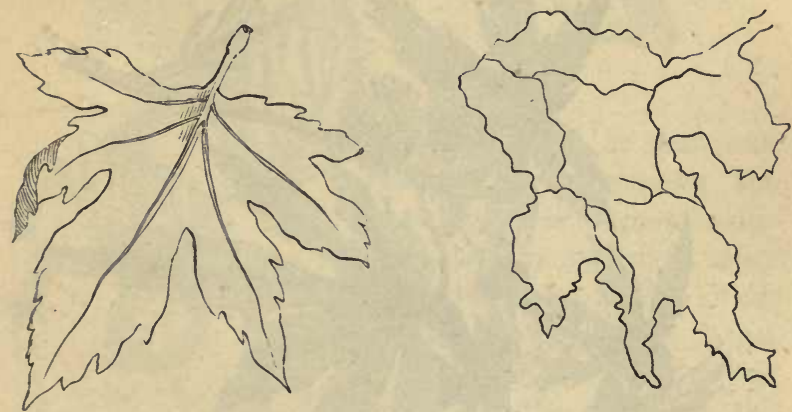

The Plane is a majestic tree, with a massive smooth trunk. The bark is of an ash-gray, and is remarkable for peeling off in large thin flakes; so that the trunk does not borrow anything in size, like most other trees, from numerous deposits of bark. The leaves are large, and present a wide, flat surface, from which circumstance the tree derives both its Greek and English names. The Oriental Plane is distinguished from the Occidental by having its leaves cut into five deep lobes, with numerous secondary notches, bearing a not altogether fanciful resemblance, pointed out by the ancient geographers, to the outline of the Morea, with its numerous bays and promontories. The flowers, which are produced in globular 
drooping heads, several together, appear with the leaves in spring, and are succeeded by balls of seed, which are much smaller than those of the other species, and remain attached to the tree all the succeeding winter. By these the tree may be distinguished when every leaf has disappeared, as it may also be by the light-coloured irregular patches on the trunk, occasioned by the shedding of the bark described above. The seeds are imbedded in soft bristly down, which, when the balls open, serves to waft them away.

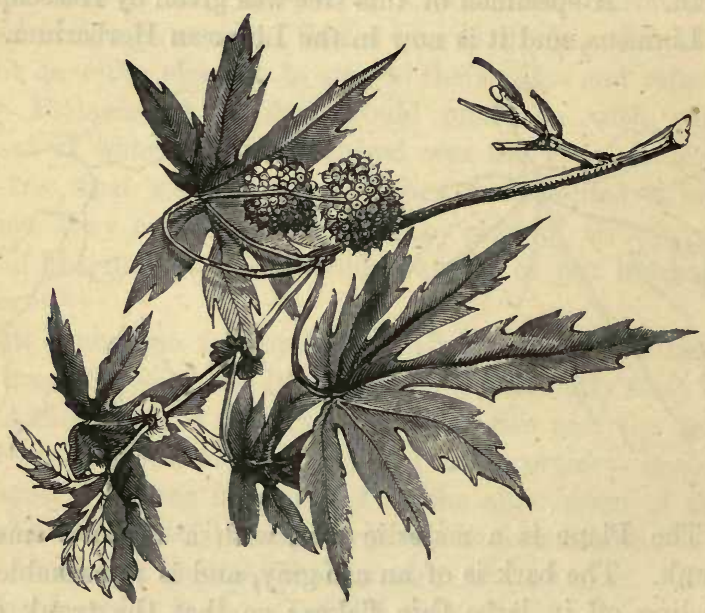

WEAF AND FLOWER OF ORIENTAL PLANE.

The Plane is now, as it was in Pliny's time, only valued as an ornamental tree. Its wood is smooth-grained, and susceptible of a high polish. Loudon says that it is not much used in the West of Europe, but that in the Levant and Asia it is employed in carpentry, joining, and cabinetmaking. It is yellowish-white till the tree attains a considerable size; after which it becomes brown, with jasperlike veins; and wood of this kind, being rubbed with oil, and then highly polished, resembles the wood of the Walnut. 
It is a fast-growing tree, and prefers a good soil near running water, and is propagated either by layers, cuttings, or seeds, the first method being preferred.

बe

THE OCCIDENTAL PLANE.

Platanus occidentalis.

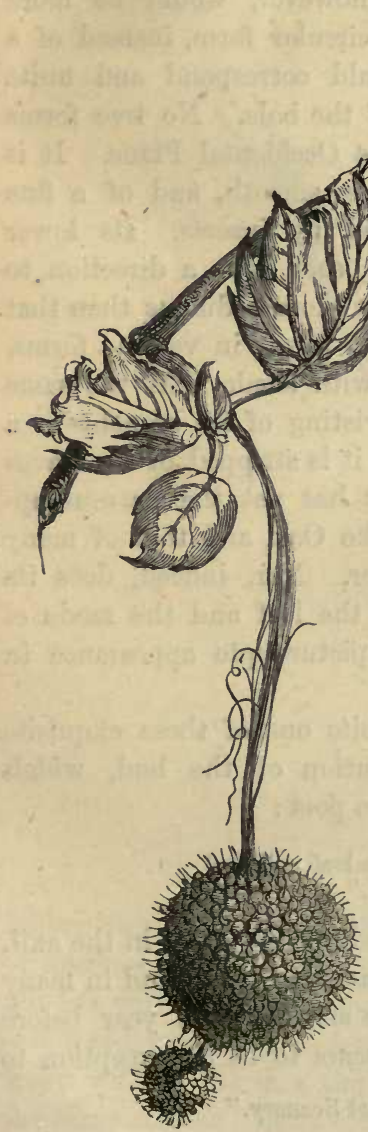

The Occidental, or American Plane, closely resembles the preceding; but it may be distinguished by its leaves being larger and less deeply lobed, and in winter by its larger seed-balls. These remain attached to the tree till the leaves expand in the following spring, and present a very singular combination of decaying stems with the delicate green of the expanding leaves. "Its stem is very picturesque. It is smooth, and of a light ash-colour, and has the property of throwing off its bark in scales ; thus naturally cleansing itself, at least its larger boughs, from moss and other parasitical encumbrances. This 
would be no recommendation of it in a picturesque light, if the removal of these encumbrances did not substitute as great a beauty in their room. These scales are very irregular, falling off sometimes in one part, and sometimes in another; and as the under bark is, immediately after its excoriation, of a lighter hue than the upper, it offers to the pencil those smart touches which have so much effect in painting. These flakes, however, would be more beautiful if they fell off in a circular form, instead of a perpendicular one. They would correspond and unite better with the circular form of the bole. No tree forms a more pleasing shade than the Occidental Plane. It is full-leaved, and its leaf is large, smooth, and of a fine texture, and is seldom injured by insects. Its lower branches, shooting horizontally, soon take a direction to the ground, and the spray seems more sedulous than that of any tree we have, by twisting about in various forms, to fill up every little vacuity with shade. At the same time, it must be owned, the twisting of its branches is a disadvantage to this tree when it is stripped of its leaves and reduced to a skeleton. It has not the natural appearance which the spray of the Oak, and that of many other trees, discovers in winter. Nor, indeed, does its foliage, from the largeness of the leaf and the mode of its growth, make the most picturesque appearance in summer." 1

The leaf of the Plane exhibits one of those exquisite arrangements for the preservation of the bud, which confirms the exclamation of the poet:

"Each leaf and bud

Doth know I AM."

Trees, for the most part, produce new buds in the axil, or angle between the leaf-stalk and the stem; and in many cases these buds attain a large size nearly a year before they expand. The Plane appears to be an exception to

1 Gilpin's "Forest Scenery." 
this rule; for if the tree be examined while in full foliage, not a single bud can be detected. On a closer inspection, however, it will be observed, that the leaf-stalk is much swollen at the base, being there as thick as the twig which supports it. Carefully detach it, and it will be found to be hollow, and to inclose a green bud, which remains behind after the leaf has been removed. The use of the

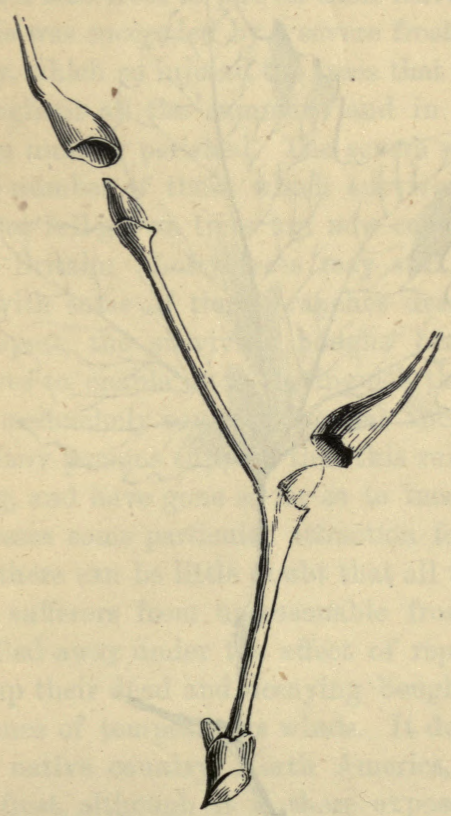

LEAF-STALK OF OCCIDENTAL PLANE.

hollow stem is to shelter the young bud during the colds of autumn. But when the leaf has fallen off, the bud is not left without protection, for it is enveloped in a tough case lined with a kind of resin, which is impenetrable to wet; within this is a similar case lined externally with the same coating; next come a number of scales covered 
with a dense coat of fur, which must serve as an admirable safeguard against cold; and within all lie the leaves, wrapped up in a mantle of silk, waiting till the succeeding spring shall give them new vigour and enable them to burst all their envelopes. For some time after their

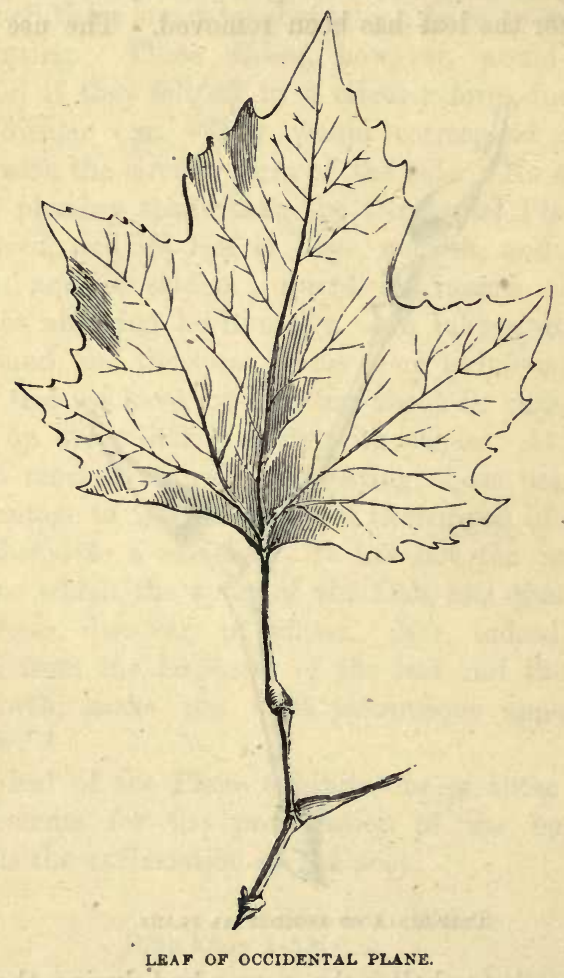

expansion the leaves have their under surfaces covered with a thick coat of down, which circumstance has given to this plant the name of Cotton-tree. Nor is this complicated protection against cold more than is requisite; for stout and lusty as the tree appears to be, it would without 
it be unable to withstand the insidious frosts of an English spring. In confirmation of this statement I may observe, that at the beginning of the present century large specimens of the Occidental Plane were not uncommon. In the January of 1809 , however, there was a great flood, occasioned by a sudden thaw; and in the March and April following there was very mild weather, which tempted the Plane-trees to put on their leaves earlier than usual. This was succeeded by a severe frost in the beginning of May, which so injured the trees that they appeared sickly throughout all the summer; and in the spring of 1810 a large number perished. The severe winter of 1813 destroyed a number of those which survived the frost of 1810 ; so that full-grown trees are now comparatively rare throughout Britain. Lofty trees may still be seen here and there with some of their branches dead or shivered by the tempest, the surviving boughs bearing scarcely enough leaves to enable us to distinguish the species, and affording a melancholy contrast to their ancient crown of foliage. Many persons suppose that this ruin is the effect of lightning, and have gone so far as to imagine that the Plane possesses some particular attraction for the electric fluid; but there can be little doubt that all these trees are among the sufferers from unseasonable frosts, that they have dwindled away under the effect of repeated shocks, and given up their dead and decaying boughs one by one to the violence of tempestuous winds. It does not appear that in its native country, North America, the Plane is injured by frost, although it is there exposed for a long period in every year to an intensity of cold unknown in Britain : hence it would appear that as long as the buds, the vitals of the tree, are protected by their many mantles, they defy the frost; but that if cold weather skould return after the leaves have begun to expand, they become frost-bitten, and perish.

In the swampy forests of America it flourishes in unimpaired magnificence, and surpasses in size and height 
every tree with which it is associated. It often sends up a massive trunk seventy or eighty feet before it begins to branch, and then sends out huge arms, any one of which exceeds in dimensions the other trees which stand around. Michaux mentions one growing on a small island in the Ohio, which measured forty feet in circumference at five feet from the ground; and another on the right bank of the same river, which sent up a columnar mass of timber forty-seven feet in circumference to the height of twenty feet before it began to branch. His host offered to show him others equally large, a few miles off from this last station.

In the Atlantic States of America the Plane is commonly known by the name of Buttonwood, from the resemblance between its seed-balls and old-fashioned buttons. In other States it is called Water Beech, Sycamore, or Cottontree. In some parts, where it is very abundant, the inhabitants regard it with dread, as they think that the down, which in summer detaches itself from the leaves and floats about in the air, has a tendency, when inhaled, to produce irritation of the lungs, and finally consumption.

The timber of the Plane is of no great value, on account of its liability to warp; it is, however, remarkable for having its concentric circles interrupted by bright medullary rays, and it will take a good polish. It is used for the commonest purposes only.

\section{THE BUCKTHORN.}

Rhamnus.

Natural Order-RHAMNEA.

\section{- Class-Pentandria. Order-Monogynia.}

Of this tree, little known though it probably is, there are two very distinct species indigenous to Britain, and one of them is far from uncommon. This species, Rhamnus 
Frangula, or Alder-Buckthorn, is a woodland shrub of upright growth, with a slender purplish-brown stem, and scanty roundish leaves, which are remarkably smooth both above and below, of a deep glossy green, entire at the edge, and conspicuously marked by many parallel veins. The flowers are green, small, and inconspicuous, and are succeeded by globular two-seeded berries, which

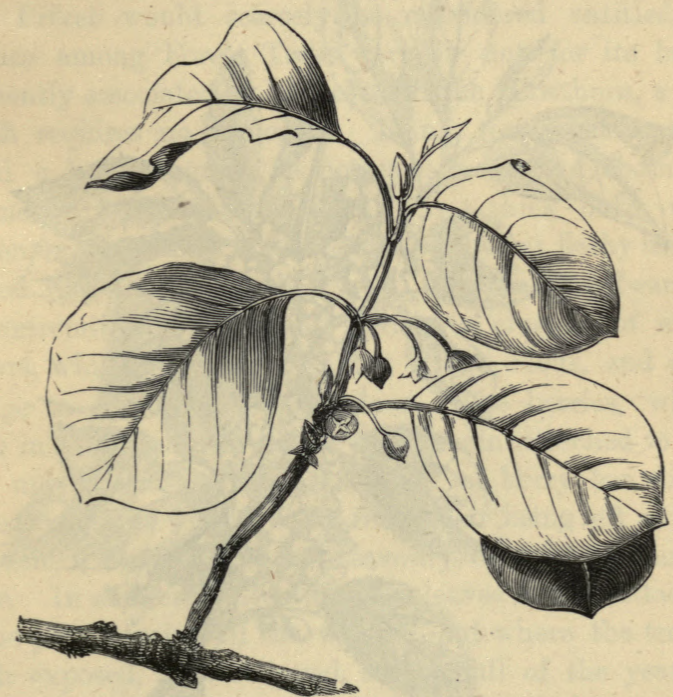

ALDER-BUCKTHORN.

when ripe, are dark purple, and as large as peas. It is frequently to be met with in coppices, and among the undergrowth of woods, growing from six to ten feet high.

The other species, Rhamnus catharticus, resembles the last in habit, and grows in similar situations : it is, however, more bushy, and bears its flowers in clusters ; the branches are more rigid; and the older branches are rough and terminate in strong thorns. It may further be distinguished by its serrated leaves and four-celled berries, 
which are violently cathartic. This species attains a arger size in Siberia than with us. I have never observed it in the West of England, where the other species is common.

According to Loudon, "The juice of the unripe berries has the colour of saffron, and it is used for staining maps or paper; they are sold under the name of French berries.

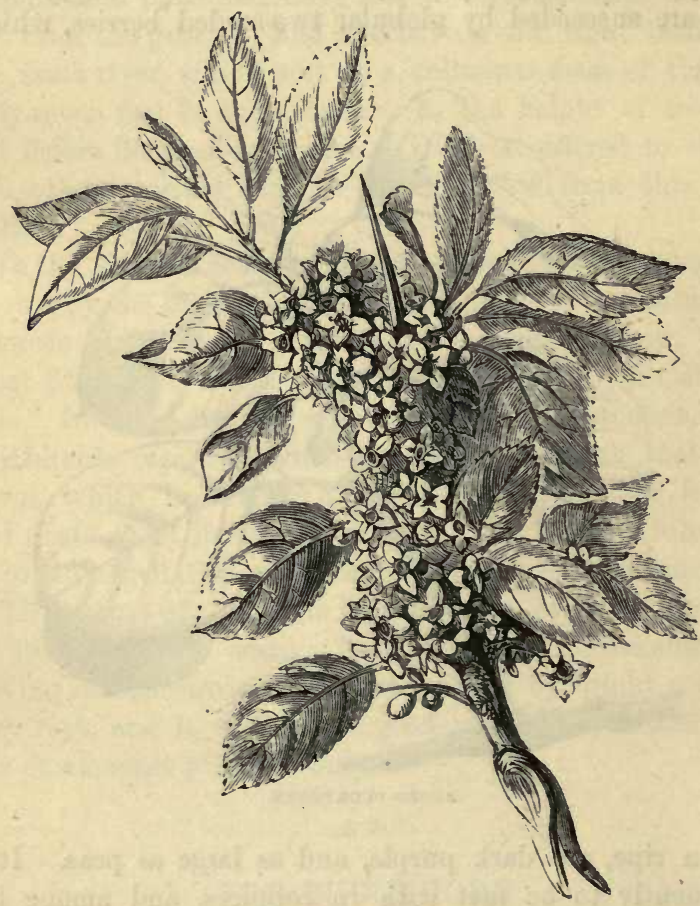

COMMON BUCKTHONN.

The juice of the ripe berries, mixed with alum, is the sapgreen of painters; but if the berries be gathered late in autumn, the juice is purple. The bark affords a beautiful yellow dye. The tree does not make much show in spring, while in flower; but in autumn and winter, when profusely covered with black berries, it is very ornamental." 


\section{THE PRIVET. \\ Ligustrum vUlgare. \\ Natural Order-OLEACEE. \\ Class-Diandria. Order-Monogynia.}

The Privet would scarcely be considered entitled to a place among Forest Trees were it not for its being frequently associated in hedges with the Hawthorn, a tree which requires no apologist. Being, too, what may be called a half-evergreen, it possesses a sort of clain on our notice. In its usual state it is a thick bush, with numerous wiry stems, and smooth, somewhat fleshy leaves, shaped like those of the myrtle. In June it bears at the extremities of the shoots pyramidal clusters of white flowers, which have a sweet but sickly odour, and soon change to a reddish-brown colour. The berries, which ripen in profusion, are black, and remain attached to the tree until almost every other kind of berry has disappeared, when, as we may infer from their being left so long untouched, they afford an unsavoury banquet to hungry birds. In sheltered situations the leaves remain attached to the plant during all the winter; but where the tree is much exposed, it is stripped, at the fall of the year, of everything but its clusters of dark fruit, which are sometimes so numerous as to be very conspicuous.

The Privet is commonly employed, either alone or in conjunction with the Hawthorn, in the formation of hedges. Being very patient of the drip of trees, it is also often planted in shrubberies, to produce thickness of undergrowth ; and, from its indifference to the presence of coalsmoke, it is extensively used in the squares of large cities.

Loudon states that a pink and a green dye may be prepared from the berries of the Privet, and that they also furnish, on pressure, a mild oil, which may be used for 
culinary purposes, as well as for lamps and making soap. In Belgium and Silesia the young twigs are used by the tanners; and the shoots are used, like those of the Osier,

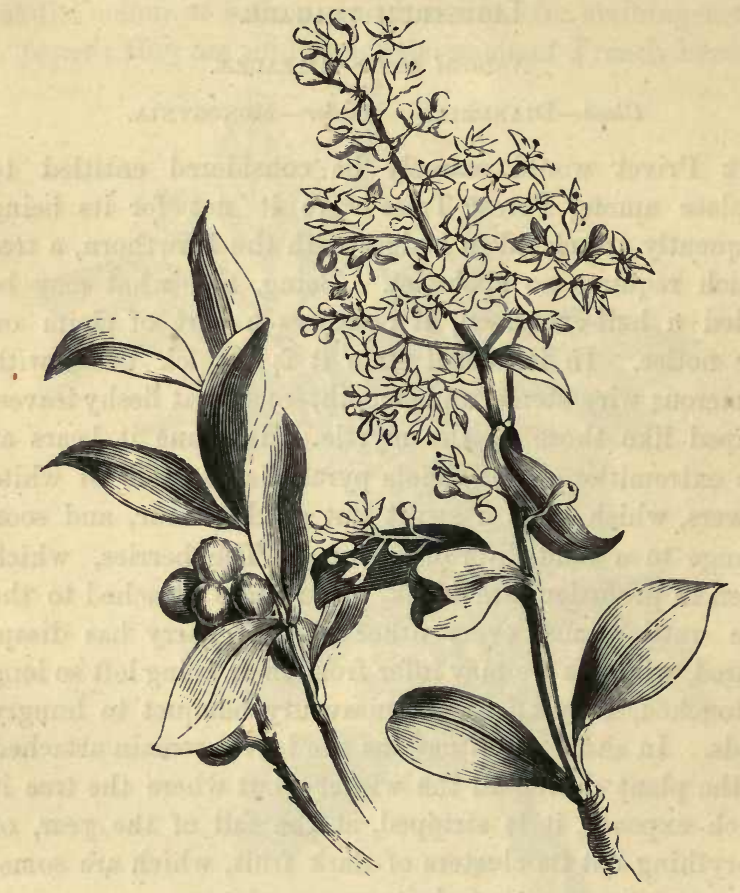

FLOWER OF THE PRIVET.

in basket-making, and for tying articles. From this last application, which was known to the Romans, it acquired the name of Ligustrum, from ligo, to bind.

A variety with greenish-white berries is occasionally met with. 


\section{THE ACACIA. \\ Robinia Pseud-Acacia. \\ Natural Order-LegumiNosa. \\ Class-Diadelphia. Order-Decandria.}

The Acacia, or, more properly, the False Acacia, though an American tree, is entitled to a distinct notice among British trees, from its having been one of the first trees introduced into England from North America, from its common occurrence, from the large size which it attains, and from the value of its timber. It was formerly supposed to be identical with the Acacia of Egypt, a tree which was imagined by the early missionaries to have supplied John the Baptist with food in the wilderness. From this circumstance it acquired the name of Locust-tree. The French called it Robinia, after M. Jean Robin (nurseryman to King Henry IV. of France), whose son was the first person who cultivated it in Europe.

The Acacia is a rough-barked tree, with straggling, twisted branches, which are elegantly feathered with bright green, pinnated foliage. The flowers are shaped like those of the Laburnum, but larger, flesh-coloured or lilac, sweet-scented, and hang down in dense clusters. The young shoots are smooth, of a purplish-brown hue, and armed with rigid prickles. It was originally introduced and cultivated for its beauty, and during the summer months it is a most elegant object. The principal objection alleged against it is, that it is late in coming into leaf, and sheds its foliage very early : the branches, ton, being very brittle, are liable to be snapped off by the wind, even in situations which are not particularly exposed. Evelyn recommends it as "deserving a place among our avenue trees, adorning our walks with its exotic leaves and sweet flowers; very hardy against the pinching winter; but not so proof against its

$$
0: 3
$$


blustering winds." Gilpin says that it is often a very beautiful tree, whether it feathers to the ground, as it sometimes does, or whether it is adorned with a light

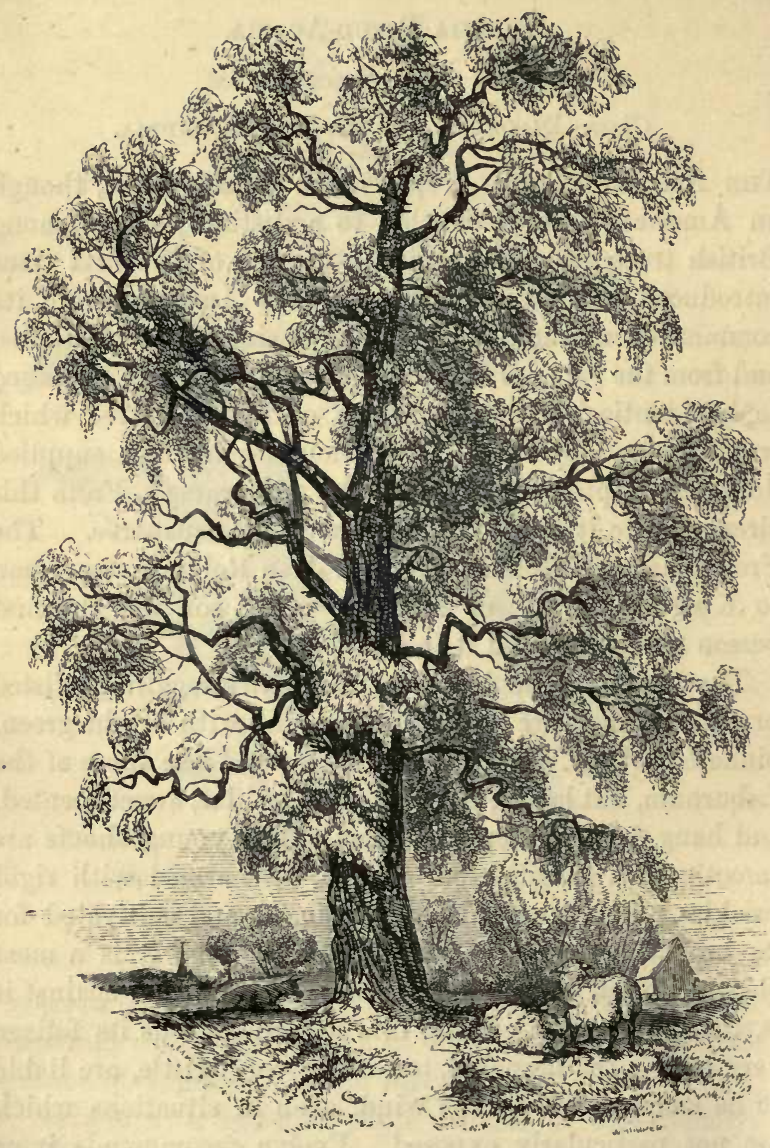

THW ACACIA.

foliage hanging from the stem. But its beauty is very frail. It is of all trees the least able to endure the blast. 
In some sheltered spot it may ornament a garden, but it is by no means qualified to adorn a country. Its wood is of so brittle a texture, especially when it is incumbered with a weight of foliage, that you can never depend upon its aid in filling up the part you wish. The branch you admire to-day may be demolished to-morrow. The misfortune is, the Acacia is not one of those grand objects, like the Oak, whose dignity is often increased by ruin. It depends on its beauty rather than on its grandeur which is a quality more liable to injury.

The Acacia grows with great rapidity when young; seedlings often attain a height of from twenty to forty feet in ten years, and established young plants produce shoots eight or ten feet long in one season. But when it has reached a height of about forty or fifty feet, it grows very slowly, and never acquires the dimensions of a timber-tree. Loudon, who gives a long and elaborate account of the Acacia, attributes this peculiarity to the fact, that its principal roots extend themselves close to the surface of the ground, where the soil is always richest. Hence the growth is at first very rapid; but when the roots cease to extend, all the surface-soil which they traverse being exhausted, the growth of the tree is retarded. But though it alters little in size after it has reached its fiftieth or sixtieth year, it is long-Jived. The first tree that was introduced into Europe by Monsieur Robin, and planted in the Jardin des Plantes at Paris, in 1635, is still in existence, and is now seventy-five feet high. About the year 1815 it showed symptoms of decay, but the branches being lopped, the trunk has shot out with redoubled vigour. This is, in all probability, the oldest American tree in the eastern hemisphere.

The wood of the Acacia is supposed to unite the qualities of strength and durability to a degree unknown in any other kind of timber : in consequenee of which it has for many years been employed throughout America and Europe in the construction of the wooden pins, called trenails 
(tree-nails), which are used to fasten the planks to the ribs or timbers of ships. The history of the first application of the Acacia to this purpose is given at length in Dr. Hunter's edition of Evelyn's "Sylva," and is well worthy of repetition. It is contained in a letter, dated July 25, 1782, from Joseph Harrison, Esq., of Bawtry, to Dr. Hunter. Instead of decaying, it acquires an extraordinary degree of hardness with time. In 1819 from 50,000 to 100,000 trenails of this wood were exported to England, and their excellence has been confirmed by the highest authorities, so that Oak-wood grown in Sussex, which was formerly considered the best for this purpose, is now only partially used, Locust trenails being still imported from America to a very great extent.

It may seem strange that the timber of a tree so liable to be broken by the wind, as we find the Acacia to be, should be considered the very best for a purpose where extraordinary strength is required; but it must be remembered that the Acacia, in its 'native country, prefers barren, sandy, or light soils, in which situations it matures its timber slowly. With us, on the other hand, it is usually planted in rich soils and sheltered situations, where, though the tree is botanically the same, the character of the timber is materially impaired.

In the year 1823 Cobbett drew public attention to the Locust-tree (then scarcely known by that name), and recommended that it should be extensively planted in England, for the sake of its timber, which he asserted to be superior to anything else for a variety of purposes, and predicted that "the time would come when the Locusttree would be more common in England than the Oak." To supply the demand which he had himself created, he imported enormous quantities of seeds from America, turned his garden into a nursery, and "sold altogether more than a million of plants." But still, not being able to raise enough plants to supply all his customers, he purchased large numbers from the London nurserymen; 
and fortunate did the applicant consider himself, who could purchase at a high price from Mr. Cobbett the very same Locust-trees that, under the name of Robinia PseudAcacia, were standing unasked-for in the nurseries. We are undoubtedly indebted to Mr. Cobbett for very many of the Acacias that now adorn our parks and pleasuregrounds; but it is far from proved that the ground which has been devoted to plantations of these trees might not have been more profitably employed. Loudon has shown satisfactorily that Cobbett's recommendation of the wood cannot, in many instances, be confirmed by fact, but allows that "sound Acacia wood is heavier, harder, stronger, tougher, more rigid, and more elastic than that of the best English Oak; and, consequently, that it is more fit than Oak for trenails." $\mathrm{He}$ adds, moreover, that "it is very suitable for posts and fencing, and also for the axle-trees of timber-carriages ; but that there is no evidence of its being applicable to the general purposes of construction."

Other parts of the tree are not without use : the roots are very sweet, and afford an extract like that obtained from liquorice-root; and the foliage forms an excellent substitute for clover as provender for cattle.

There are many fine specimens of the Acacia growing in England, varying in height from fifty to eighty feet, and from six to ten feet in circumference; but none of these demand particular notice. 


\section{THE WILLOW.}

\section{SALIX. \\ Natural Order-AMentaces. \\ Class-Diøcia. Order-Triandiria.}

By the common consent of mankind trees have in all ages been selected as affording the most appropriate emblems of the passions by which both states and individuals have been swayed, as well as to indicate the various changes in condition to which, from time to time, they have been subjected. I need only mention the Palm, the Olive, the Bay, the Cypress, and I recall at once the ideas of rejoicing, peace, victory, and mourning. The Willow is remarkable among these for having been in different ages emblematic of two directly opposite feelings; at one time being associated with the Palm, at another with the Cypress. The earliest mention of the Willow which occurs in any composition is to be found in the Pentateuch, ${ }^{1}$ where the Israelites were directed at the institution of the feast of Tabernacles to "take the boughs of goodly trees, branches of Palm-trees, and the boughs of thick trees, and Willows of the brook, and to rejoice before the Lord their God seven days."

To wanderers in a dry and barren wilderness the bare mention of a tree bearing the name of the "Willow of the brook" must have come associated with the most pleasurable feelings; and even when the Israelites were settled in a land which was "the joy of all lands," this tree still continued to be emblematical of joyful prosperity. The prophet Isaiah, foretelling the glorious restoration of Israel, says, "They shall spring up as among the grass, as Willows by the water-courses." 2 But while the Jews

1 Lev. xxiii. 40. $\quad 2$ Isaiah xliv. 4. 
were in captivity in a strange land, an incident occurred which, to that nation at least, made the Willow an emblem of the deepest of sorrows, namely, sorrow for sin found out and visited with its due punishment :- " $\mathrm{By}$ the rivers of

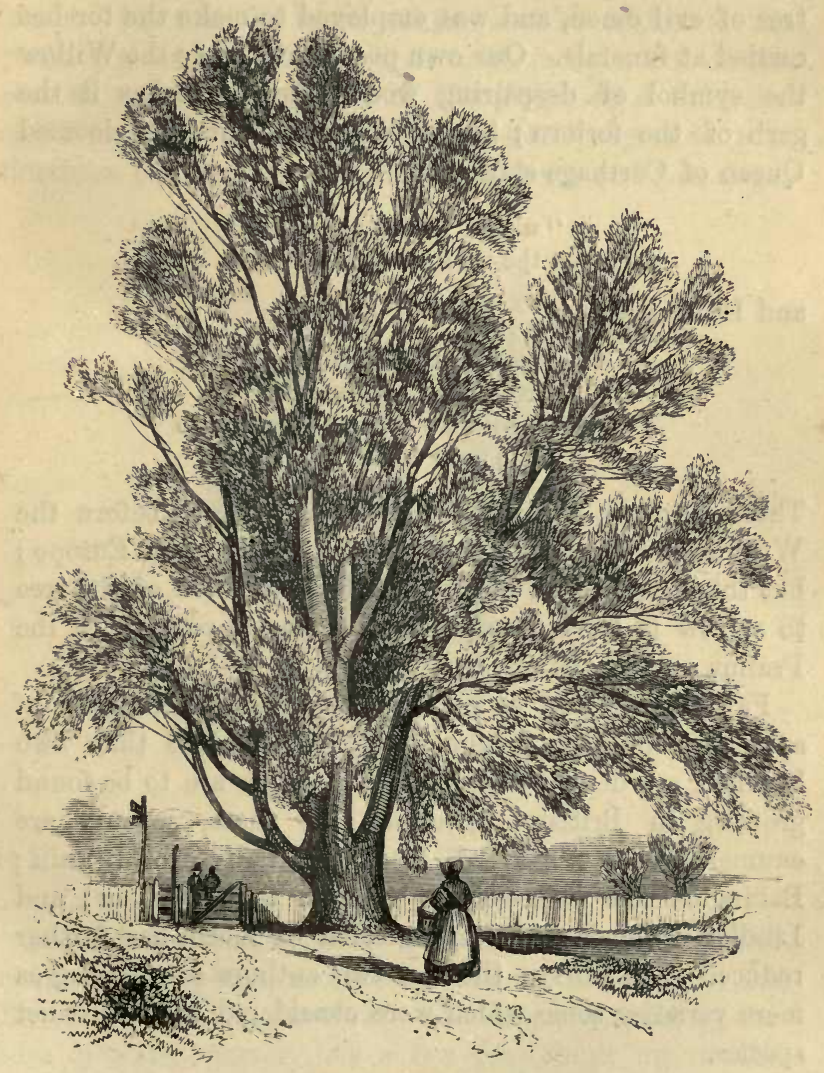

THE HUNTINGDON WILLOW.

Babylon, there we sat down, yea, we wept, when we remembered Zion. We hanged our harps upon the Willows in the midst thereof. For there they that 
carried us away captive required of us a song ; and they that wasted us required of us mirth."

From that time the Willow appears never again to have been associated with feelings of gladness. Even among heathen nations, for what reason we know not, it was a tree of evil omen, and was employed to make the torches carried at funerals. Our own poets have made the Willow the symbol of despairing woe: Spenser makes it the garb of the forlorn; Shakspeare represents the doomed Queen of Carthage standing

"with a Willow in her hand

Upon the wild sea banks ;"

and Herrick says,

"As beasts unto the altars go

With garlands dressed, so I

Will, with my Willow wreath, also

Come forth and sweetly die."

These poets; it should be remembered, wrote before the Weeping or Babylonian Willow was known in Europe; but there can be no doubt that the dedication of the tree to sorrow is to be traced to the pathetic passage in the Psalms quoted above.

Few persons are aware how very large a number of species belong to the genus Willow. More than two hundred are described by Loudon, which are to be found growing in British collections: of these, seventy are enumerated by Sir W. J. Hooker as natives of Britain; Babington has reduced this number to fifty-seven; and Lindley, following the arrangement of Koch, has further reduced it to thirty ; the last two authors considering as mere varieties some which were considered to be distinct species.

If modern science has done so little towards reducing this unruly tribe to order, we must not expect much accuracy from the older naturalists. Accordingly, we find that Pliny mentions only eight species; and it cannot now be 
ascertained what these were, for he distinguishes them more by the names which they bore in his time than by description. He places them among the most useful of aquatic trees, furnishing vine-props, cordage, osiers for fine and coarse basket-work, and rural implements of many kinds. No tree, he says, affords a safer return to the planter, gives less trouble, or is more independent of the seasons. On the authority of Cato, he assigns to it the third rank among the most valuable of vegetable productions, placing it before oliveyards, corn, and pasturage.

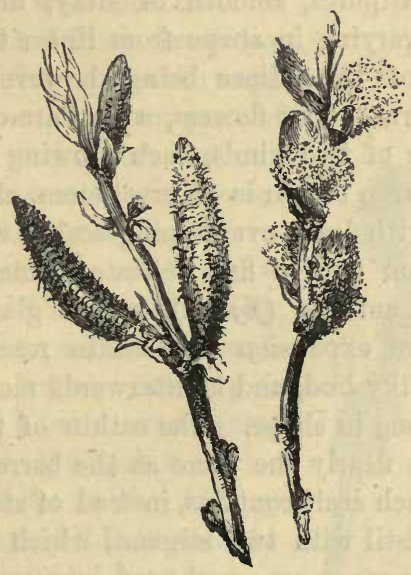

BLOSSOM OF THE CRACK WILLOW.

The willows are natives of the temperate regions of the northern hemisphere, and are much more numerous in the Old World than in the New. The majority grow by the sides of water-courses, but a few grow high up in the mountains, and are found nearer to the North Pole than any other shrubby plants. As far as it is possible to include under a general description so extensive an array of species, they may be characterised as trees or shrubs 
varying in height from sixty feet to a few inches. They grow rapidly, and readily shoot from cuttings. The wood is white: the bark of the trunk rather smooth than otherwise; that of the branches downy or smooth; in the latter case sometimes to such a degree as to appear varnished. In most species it is stringy and unusually tough, and in all is of a bitter taste, owing to the presence of a chemical principle called salicine, which possesses nearly the same medicinal properties as quinine, the substance which is extracted from Peruvian bark. The leaves are undivided, either notched at the edges or even, stalked, often furnished with stipules, smooth or silky, downy or even cottony, and varying in shape from linear to round, some modification of the ellipse being, however, by far the commonest form. The flowers, which are catkins, appear early, and are of two kinds, each growing on a separate tree. The barren catkin is an erect stem, closely invested on all sides with leafy overlapping scales, within each of which are from two to five delicate stamens, with twolobed yellow anthers (fig. n), and a gland containing honey. Before expansion the catkin resembles a large

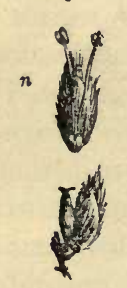
silky bud, and is afterwards more or less oblong in shape. The catkin of the fertile tree is nearly the same as the barren catkin, but each scale contains, instead of stamens, a single pistil with two stigmas, which as it enlarges becomes an egg-shaped germen ( f g . o) of one cell and two valves. The seed-vessel, when ripe, splits on its two opposite sides, the valves roll back ( $f g ., p)$ and disclose numerous minute seeds, each of which is tufted with downy or silky hair (fig. $r$ ). Some species of Willow are in full flower by the third week in March; and whenever a bright, warm day occurs after this time, the bees sally forth and resort in swarms to the fragrant catkins for a spring breakfast. I have noticed them busily engaged as early as the 
$22 \mathrm{~d}$, and others have observed them yet earlier. The value of Willow-bushes near hives can scarcely be overstated, for this is just the season when the combs are likely to be exhausted, and there are as yet few other flowers in bloom capable of affording a considerable supply.

Before the discovery of sugar, honey was far more valuable than it is at present, and it appears from Virgil that, in his time, Willows were commonly planted in apiaries, for the special purpose of affording nourishment to the bees at this critical season.

Owing perhaps to the association of the Willow with the Palm in the passage quoted from Leviticus, blossoms of Willow, under the name of "Palms," are in some parts of Great Britain worn on the day which commemorates our blessed Lord's triumphal entry into Jerusalem. At Lanark, according to ancient usage, the boys of the Grammar-school parade the streets on the day before, carrying a Willow-tree in blossom ornamented with daffodils and other spring flowers. A writer in the "Everyday Book" says : "It is still customary with men and boys to go apalming in London early on Palm Sunday morning; that is, by gather-

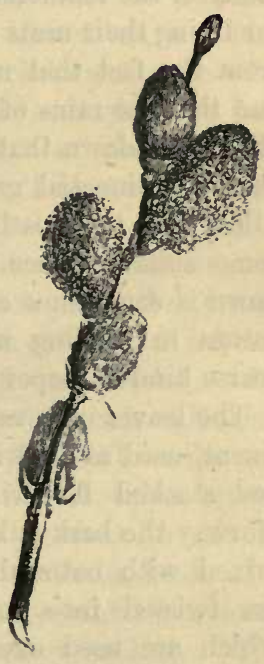

WILLOW ing branches of the Willow, with their gray, shining, velvet-looking buds, from those trees in the vicinity of the metropolis : they come home with slips in their hats, and sticking in the breast button-holes of their coats, and a sprig in the mouth, bearing the Palm-branches in their hands. This usage remains among the ignorant from poor neighbourhoods : and there is still to be found a basket-woman or two at Covent Garden, and in the chief 
markets, with this 'Palm,' as they call it, on the Saturday before Palm Sunday, "which they sell to those who are willing to buy; but the demand of late years has been very little, and hence the quantity on sale is very small. Nine out of ten among the purchasers buy it in imitation of others, they care not why; and such purchasers, being Londoners, do not even know the tree which produces it, but imagine it to be a real Palm-tree, and 'wonder they never saw any Palm-trees, and where they grow.'"

The Willow ripens its seeds early enough to furnish many of the feathered tribe with a soft and warm material for lining their nests; and this too is all the more valuable from the fact that no other downy seeds are as yet ripe, and that the rains of winter have beaten into the earth all the thistle-down that had not been dispersed by the preceding equinoctial gales. In fine weather the air is often filled with the floating seeds, as they are wafted away to some suitable place of growth. ${ }^{1}$ Loudon says that this down is sometimes collected and used as a substitute for cotton in stuffing mattresses; and that in Germany a coarse kind of paper is made of it.

The leaves of several kinds of Willow are, on the Continent, used as fodder for cattle, being collected in summer, and stacked for winter consumption. In Sweden and Norway the bark is kiln-dried in seasons of scarcity, and mixed with oatmeal. In the same countries the twigs are twisted into ropes, as they were in Pliny's time, which are used even for the cordage of vessels. The inner bark is applied to the same purposes as that of the Lime, and in Tartary is woven into a coarse cloth. The wood is soft, smooth, and light, and is applied to a great variety of purposes, especially for fast-sailing sloops of war and cricket-bats. Split into thin strips it is manu-

1 A part of the kitchen-garden at Versailles having been neglected during the first Revolution, and for many years after, indeed until 1819, the light downy seeds from Poplars and Willows in the neighbouring woods sprung up, and converted the whole place into a wood of timber-trees. 
factured into hats. The boats used by the early Britons were constructed of Willow-rods, covered with hides; they were called coracles: and it is curious that very similar vessels, called by the Irish currack, are in partial use to this day. "Coracles thus made," says Southey, "and differing only in the material with which they are coated, and carrying only a single person, are still used upon the Severn, and in most of the Welsh rivers. They are so small and light, that when the fisherman lands he takes his boat out of the water, and bears it home upon his back." Boats of this description were in common use on the Euphrates in the time of Herodotus, B.c. 444. He says that the Armenians, who carried on a traffic with Babylon, built their boats of Willow, ${ }^{1}$ covering the outsides with skins, making them circular like a shield, without distinguishing the prow from the stern. Having placed their merchandise, principally Palm-wine, on board, they cover it with straw, and float down the stream. The crew consists of two men, who guide the vessel by oars. Each boat contains, besides goods and rowers, a living ass, or, if the vessel be a large one, several. On their arrival at Babylon they dispose of their merchandise, take their vessels to pieces, sell the Willow-ribs and straw, and having laden their asses with the skins, return home by land, the current not allowing them to sail up the stream. On some of the rivers of India boats of a precisely similar form are used at the present time, some of them large enough to transport heavy artillery. The only difference appears to be that Bamboo is now used to form the ribs instead of Willow.

Pliny, quoting a more ancient author, says that the Britons used to make voyages to an island called Mictis, distant six days' sail, in vessels of the same construction as those described above, and to return with cargoes of tin. Julius Cresar relates, in his History of the Civil War, that 
his recollection of the coracles which he had seen durine his invasion of Britain was on one occasion the means of extricating his army from a critical position; for, being hemmed in by the enemy, and being unable to throw a bridge across a river which impeded his movements, he set his troops to work, and quickly completed enough boats to transport his army.

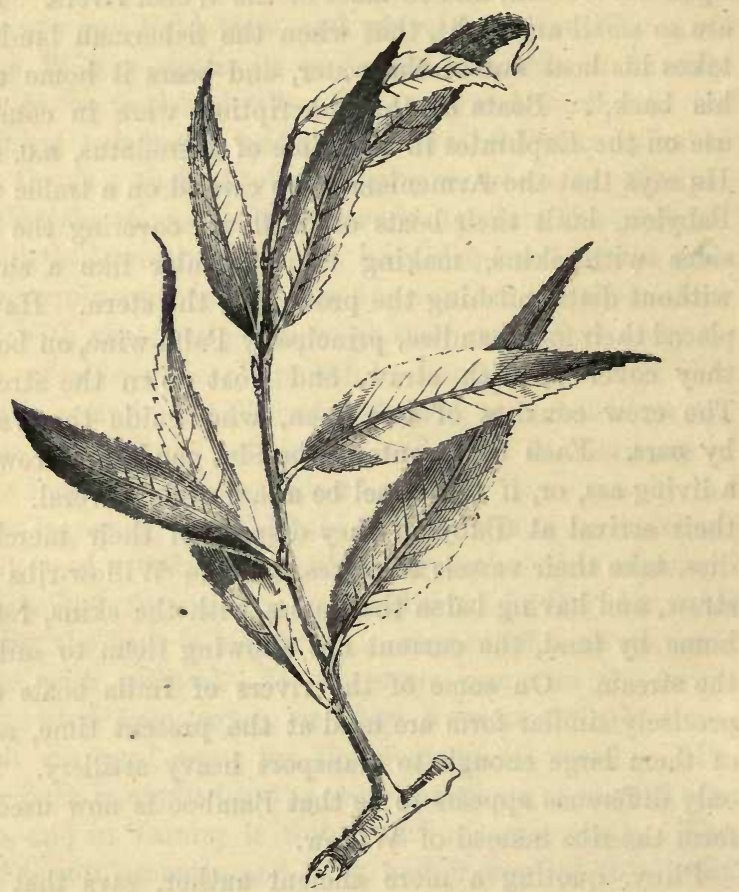

FOLIAGE OF HUNTINGDON WILLOW.

In a picturesque point of view, the Willows do not rank high : they are formal in their mode of growth, and are loaded with bundles of twigs, rather than with ramified branches; the foliage too is meagre, and is not disposed 
to form pleasing tufts. Gilpin does not recommend their use in artificial landscape, "except as pollards, to characterise a marshy country ; or to mark in a second distance the winding banks of a heavy, low-sunk river, which could not otherwise be noticed. Some Willows, indeed, I have thought beautiful, and fit to appear in the decoration of any rural scene. The kind I have most admired has a small narrow leaf, and wears a pleasant, light, sea-green tint, which mixes agreeably with foliage of a deeper hue. I am not aquainted with the botanical name of this species, but I believe the botanists call it Salix alba." This is the Huntingdon or White Willow, a good specimen of which is figured at page 303 : it derives its name from the silky whiteness of the under side of the leaf.

This species is said to be one of the most useful of the genus as a timber-tree: like the rest of the Willows, it grows rapidly, and acquires considerable magnitude within the usual period of human life, and may therefore, in the natural course of events, be cut down, a full-grown tree, by the same hand that planted it. "It groweth incredibly fast," says Fuller, "it being a byword in this country, that the profit by Willows will buy the owner a horse before that by other trees will pay for his saddle." The wood is soft but elastic, and is well adapted for the lining of barges and carts which are used for carrying heavy loads of hard substances. It is durable, and makes good roofing. The bark is used by tanners, and it makes excellent firewood. Added to which, it grows without trouble from cuttings, and thrives in any soil except peat, in which situation only the smaller species will grow.

The Bedford Willow, Salix Russelliana, is another of the tribe which attains a large size. It was named in honour of the late Francis Duke of Bedford, by whom it was first brought into notice. Its leaves are in shape very like those of the White Willow, but differ in being smooth on both sides.

The timber of the Bedford Willow is said by Loudon 
to be more valuable than that of any other species. The bark contains more of the tanning principle than the Oak. It is in this species also that salicine is most abundant.

The Crack Willow, Salix fragilis, derives its name from the brittleness of the branches, which start from the trunk under the slightest blow. Its leaves closely resemble those of the Bedford Willow, but, according to Selby, "the ramification is more oblique, and the branches in consequence cross each other more. It is also less beautiful and imposing in appearance, and seldom attains so great a size. It is very subject to become naked, or stag-headed, by the decay of its uppermost branches, though it continues to live and throw out long annual shoots for many years afterwards." When first cut, the sap-wood of the Crack Willow is white, the heart-wood pale red; upon exposure to the air, and when seasoned, both become of a fine salmon colour. The roots afford a purple-red dye, and are still used in Sweden and in France to colour Easter eggs.

The Goat Willow, Salix caprea, is the common coppice and hedge Willow, which affords so early a banquet to the bee. It may readily be distinguished by its purplishbrown branches, which are covered with minute down when young, and by its large broad leaves, which are wavy at the edge, and densely clothed beneath with soft, white, cottony down.

This species never attains a large size, but it forms a valuable underwood. In Scotland, where it is called the Saugh-tree, the wood is said to be much used for the handles of hatchets, rake-teeth, and other articles which require to be made of a light and tough material. The branches, also, when two or three years old, make good hoops for casks.

The species of Salix which are used for basket-making are usually called Osiers. Several kinds are in common cultivation, all agreeing in bearing long, flexible, tough 
shoots, and narrow, pointed leaves. These being planted for the sake of their young rods, are rarely suffered to attain their full size, with the exception of the Golden Osier, which is often to be found in gardens and shrubberies, where its bright yellow branches are very ornamental, especially in winter.

Those which are best adapted for basket-making are the Common Osier, S. viminalis, and the Three-stamened Osier, S. triandra. They should be planted in low and naturally moist situations, and in a deep, well-drained soil, which, to be productive, should be kept well cleared of weeds. In the second autumn after planting the shoots are fit to be cut; and the process is repeated every year, immediately after the fall of the leaf, when the wood is thoroughly ripe. If they are not wanted to be used with the bark on, they are tied up in bundles, and placed on end in standing water until the following spring. When the buds begin to shoot, the rods are ready for peeling; and after this process they will keep for a very long time. Of late years large quantities of Osiers have been imported from Holland, in consequence of which Willow-holts in England are far less profitable than they used to be.

Osiers are not unfrequently planted by the wayside and in low meadows, as pollards, for the purpose of supplying poles and stakes. The centres of these trees very soon decay, and the young buds send down roots into the mass of rotten wood, sometimes until the cavity is nearly filled. Dr. Plot, in his Natural History of Oxfordshire, mentions some Pollard Willows, on which seeds of Ash had been accidentally lodged and germinated, so that "the roots of the Ashes had, some of them, grown down through the whole length of the trunks of the Willows, and at last, fastening into the earth itself, so extended themselves that they burst the Willows in sunder, whose sides falling away from them, and perishing by degrees, what before were but the roots are now become the bodies of the Ashes themselves." Loudon records a yet more remarkabie 
incident connected with this tree. An old Willow at Carlsruhe having been nearly thrown down by a storm, was supported by an oaken prop. Into this it sent down a root, which fixed itself in the earth, and as it increased in size, split off the bark from the prop, and eventually became so stout as to render the artificial support no longer necessary.

A beautiful species of Willow, which is not so generally cultivated as it deserves to be, is the Five-stamened Willow, Salix pentandra. This is easily distinguished by its large glossy leaves, more like those of the Portugal Laurel than of the other Willows. During the whole of summer it has quite the appearance of an evergreen, and towards the end of June is very conspicuous with its seedvessels, which, being then ripe, burst and disclose a great abundance of glossy silk attached to the seeds. It has this further recommendation, that the foliage emits a fragrant aromatic perfume. It grows in watery places in the north of England and Ireland. In the latter country I have seen bushy hedges of it stretching across the extensive bogs which abound in the neighbourhood of the - Giant's Causeway, scenting the air, and giving a cheerful appearance to the otherwise gloomy landscape. It forms a more compact tree than the other kinds, but the shoots are too brittle to be of much value.

The little Willow which in some districts is so abundant on commons, trailing its wiry branches along the ground, or occasionally availing itself of the support afforded by Heath and Furze to assume the form of a dwarf shrub, is the Brown Willow, Salix fusca. Its leaves are glossy above, and very silky beneath; and its long twigs are conspicuous in May and June, from the numerous yellow catkins arranged at regular intervals along opposite sides of the stem. During the latter part of summer the geeds of the fertile plant give to the ground the appearance of having been strewed with cotton.

Last and least among the British trees of this family 
comes the Herbaceous Willow, Salix herbacea. The ordinary height of this diminutive tree is about four inches. It is a native of many parts of Europe, and of North America, and in Great Britain is the last plant furnished with a woody stem which we meet in ascending the mountains.1 "In Switzerland," De Candolle observes, "some species of Willow spread over the uneven surface of the soil ; and as their branches are often covered with the earth which the heavy rains wash over them, they present the singular phenomenon of trees which are more or less subterranean. The extremities of these branches form sometimes a kind of turf, and the astonished traveller finds himself, as we may say, walking on the top of a tree.

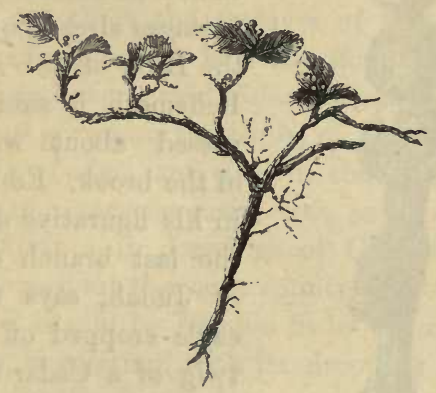

HERBACEOUS WILLOW.

Salix herbacea is the species that most frequently presents this remarkable appearance, because it generally grows on steep slopes of loose soil." The leaves are employed in Iceland in the tanning of leather.

The Willow is liable to the attacks of a gall-fly, which, in the summer, lays its eggs in the young twigs. The effect is, that the juices of the tree, diverted from their natural use, harden into an irregular mass, which, when the young grubs are hatched, serves them both for food and dwelling. While the trees are in leaf, these galls are

I See "Botanical Rambles," page 123, 16mo edition. P 2 
generally hidden from sight; but in winter they are often to be seen on the extremities of the branches, each con-

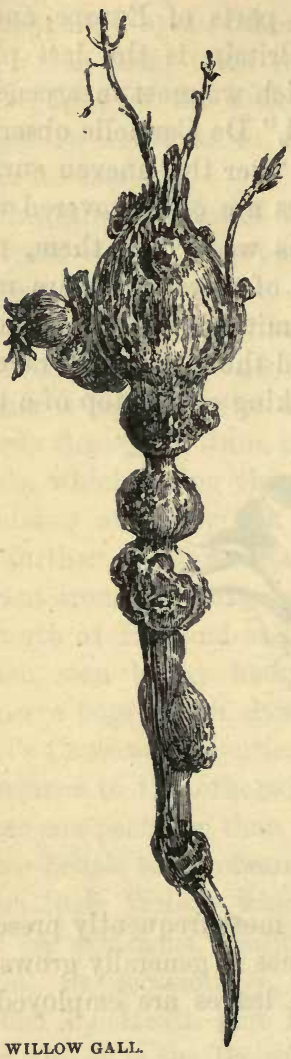
taining a number of small white larvæ. They are of the same colour as the bark, and of a corky consistence; but when once formed, they have no vegetative power, the twigs which seemingly pass through them being always withered and dead.

Willows are common in the East, and are frequently mentioned in the Bible, as in the passages already quoted, and in the Book of Job xl. 22, where Behemoth is said to be compassed about with Willows of the brook. Ezekiel (xvii. 5), in his figurative description of the last branch of the house of Judah, says that a great eagle cropped off the topmost twig of a Cedar-tree, and set it by great waters as a Willowtree.

Rauwolf states that near "Halepo (Aleppo), about the rivulets, there is a peculiar sort of Willow-trees, called Saf-caf, \&c. These are not all alike in bigness and height, and in their stems and twigs they are not very unlike to Birch-trees (which are long, thin, weak, and of a pale yellow colour): they have soft ash-coloured leaves, or rather like unto the leaves of the Poplar-tree; and on their twigs here and there are shoots of a span long, like unto those of the Cypriotish wild Fig-tree, which put 
forth, in the spring, tender and woolly flowers like unto the blossoms of the Poplar-tree, only they are of a more drying quality, of a pale colour, and a fragrant smell. The inhabitants pull off these (because they bear no fruits) in great quantities, and distil a very precious and sweet water out of them, very comfortable and corroborative to the heart."

In Babylonia Willows were so abundant that Bochart says of the channels of the Euphrates, "The banks were so thickly lined with Willows, that Babylonia was called from them 'the Valley of Willows." Burckhardt also mentions a fountain in Syria, called Ain Saffaf, or the Willow Fountain.

The trees on which the captives of Israel hung their harps belonged, there can be little doubt, to the species which botanists have named Salix Babylonica, or Weeping Willow, which grows on the banks of the Euphrates, and in other parts of Asia, and also in the North of Africa. In China it is a very favourite tree, as appears from its frequent occurrence in drawings of Chinese ornamental scenery. Throughout the same country, as well as Turkey and Algiers, it is said by Loudon to be commonly planted in cemeteries, suggesting, with its drooping branches, the idea of grief for the departed.

Gilpin considers the Weeping Willow to be a very picturesque tree. It is a perfect contrast to the Lombardy Poplar. The light airy spray of the Poplar rises perpendicularly; that of the Weeping Willow is pendent: the shape of its leaf is conformable to the pensile character of the tree, and its spray, which is still lighter than that of the Poplar, is more easily put into motion by a breath of air. The Weeping Willow, however, is not adapted to sublime subjects. We wish it not to screen the broken buttresses and Gothic windows of an abbey, nor to overshadow the battlements of a ruined castle : these offices it resigns to the Oak, whose dignity can support them. The Weeping Willow seeks a humble scene-some romantic 


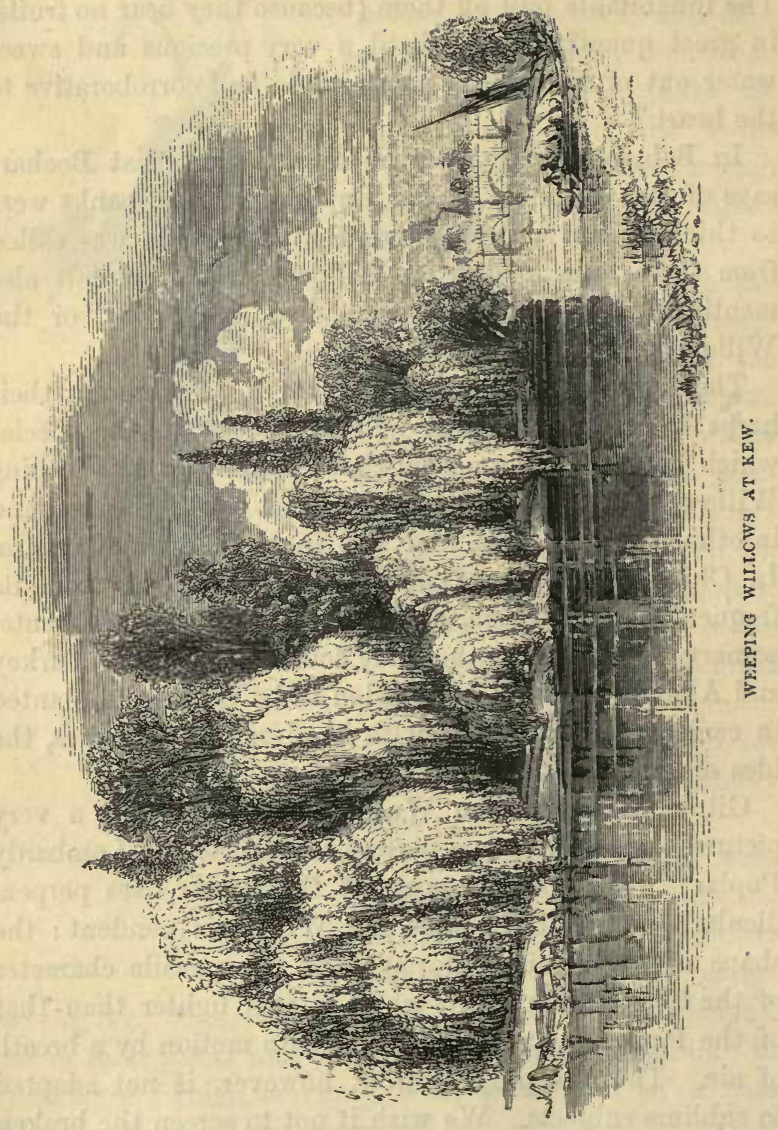


footpath bridge, which it half conceals, or some glassy pool, over which it hangs its streaming foliage,

" and dips

Its pendent boughs, stooping as if to drink."

In these situations it appears in character, and of course to advantage. Nowhere is it more beautiful than on the banks of the Thames, where are some of the finest specimens in England.

The date of the introduction of this tree into England is unknown; but it is certainly not earlier than the beginning of the last century, or the close of the seventeenth, when the first tree was planted at Twickenham, either by Mr. Vernon, a merchant of Aleppo, or by Pope. This was a favourite tree with the poet, and after his death became the object of so much curiosity that the possessor of his villa cut it down, to avoid being annoyed by persons who came to see it. Another account states that it was first planted at Kew, in $\mathbf{1 6 9 2 .}$

Few trees have obtained greater celebrity from their locality than that known as Napoleon's Willow. Loudon informs us that this tree was introduced into St. HeJena from Britain by General Beatson, 1810. It was planted among other trees on the side of a valley near a spring; and having attracted the notice of Napoleon, he had a seat placed under it, and used to go and sit there very frequently, and have water brought to him from the adjoining fountain. About the time of Napoleon's death, in 1821, a storm shattered the Willow in pieces, and after the interment of the emperor Madame Bertrand planted several cuttings from it on the outside of the railing which surrounded the grave. As none of these flourished, they were renewed in 1828 ; and from one of them, which outstripped the rest, were brought most of the cuttings which have been reared in various parts of the country. The oldest now in existence in Europe derived from this stock stands in the garden of the Roebuck Tavern on Richmond Hill, having 
been planted in 1823. Previously to 1810 the Willow did not grow in St. Helena; but Darwyn states that Weeping Willows are now common on the banks of the rivulets, associated with so many other plants of British origin that the imported species have excluded many of the native kinds, and given to the scenery a character decidedly British ; it being only on the highest and steepest ridges that the indigenous flora is now predominant.

So popular has the Weeping Willow become as an ornamental tree, that it is said to be commoner in almost every country than in its native habitat, the hanks of the Euphrates.

The opinion, that under the Hebrew name for the Willow was included the Oleander, a beautiful flowering shrub that copiously lines the course of the Jordan, however poetical it may be, appears to be based on conjecture alone, and must therefore be received with caution.

\section{THE ELDER.}

\section{Sambucus Nigra.}

Natural Order-CAPRIFOLIACEN.

Class-Pentandria. Order-Trigynia.

THIs tree, which possesses neither picturesque beauty nor fragrance, comes to us recommended by ancient authors for its numerous medicinal properties. Pliny furnishes us with a long list of the virtues supposed to reside in the various parts of the Elder, and our own historian of trees, Evelyn, is no less eloquent in its praises: "If," he says, "the medicinal properties of the leaves, bark, berries, \&c. were thoroughly known, I cannot tell what our countrymen could ail, for which they might not find a remedy from every hedge, either for sickness or wound. The inner bark of Elder applied to any burning takes out the fire immediately; that, or, in season, the buds boiled in water- 
grewel for a breakfast, has effected wonders in a fever; and the decoction is admirable to assuage inflammation. But an extract may be composed of the berries, which is not only greatly efficacious to assist longevity, but is a kind of catholicon [universal preventive] against all infirmities whatever : and of the same berries is made an incomparable spirit, which, drunk by itself, or mingled with wine, is not only an excellent drink, but admirable in the dropsy. The ointment made with the young buds and leaves in May with butter is most sovereign for aches, shrunk sinews, \&c., and the flowers macerated in vinegar not only are of a grateful relish, but good to attenuate and cut raw and gross humours. And less than this could I not say (with the leave of the charitable physician), to gratify our poor woodman." Some of the above properties the Elder certainly does possess, others perhaps are imaginary ; nevertheless, Elder ointment, Elder-flower tea, and Elder-berry wine are still popular medicines in the country.

The Elder is a rapidly growing tree while young, and is remarkable for the stoutness of its shoots, which when a year old are as large as those of most other trees at two or three years of age. They are covered with a smooth gray bark, and contain an unusual proportion of pith, which is frequently used in electrical experiments. This pith being easily removed, young branches are often made into popguns and other toys; and on this account the Elder is sometimes called the Bore-tree. In ancient times they were made into flutes and pipes; hence the tree acquired the name Sambucus, from sambuca, a kind of musical instrument. ${ }^{1}$ The branches do not grow so rapidly after the first year: no new pith is formed, and that which is formed already is compressed by the fresh layers of wood, so that in old stems the quantity scarcely exceeds the proportion usually found in other trees. The leaves

1 "Countrymen believe," says Pliny (book xvi. chap. xxxvii.), "that the most sonorous horns are made of Elder which has grown where it never heard the cock crow." 
are pinnate, slightly notched, and of a peculiarly strong and offensive odour, which is said to be unwholesome. "I do by no means," said Evelyn, "commend the scent of it, which is very noxious to the air; and therefore, though I do not undertake that all things which sweeten the air

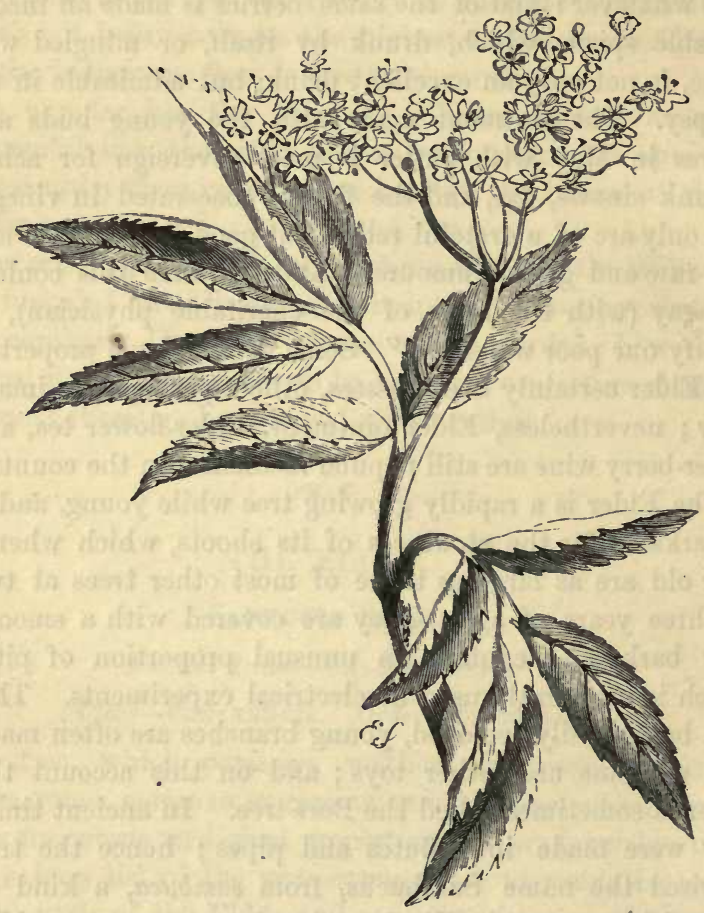

LEAF AND FLOWER OF THE ELDER.

are salubrious, nor all ill savours pernicious, yet, as for its beauty, so neither for its smell would I plant Elder near my habitation; since we learn from Biesius, that a certain house in Spain, seated among many Elder-trees, diseased and killed almost all the inhabitants, which, when at last they were grubbed up, became a very healthy and whole- 
some place." Sir James Smith says that an infusion of the leaves proves fatal to the various insects which thrive on blighted or delicate plants; nor do many of this tribe in the caterpillar state feed on them. Cattle scarcely touch them, and the mole is driven away by their scent. Carters often place them on their horses' heads to keep off flies. The flowers are white, and grow at the extremities of the shoots, in the flat clusters which botanists call cymes. The berries are globular, black, and of a faint sickly taste, which no doubt often protects them from depredation. This flavour they lose when boiled and made into wine; they are said to form one of the (least injurious) ingredients of fictitious port-wine. The wood of the old branches is yellow, very hard and compact, and is used for making skewers and shoemakers' pegs. The bark, which on the old branches becomes rugged, is used in Scotland as a dye. It is there called the Arn-tree.

Miss Kent observes that the Elder is sometimes coupled with the Cypress and other trees considered to be emblematical of death or sorrow.

"The water-nymphs, that wont with her to sing and dance,

And for her girlond olive-branches bear,

Now baleful boughs of cypress done advance:

The muses, that were wont green bays to wear,

Now bringen bitter Elder branches sere:

The fatal sisters eke repent

Her vital thread so soon was spent.

$O$ heavy herse !

Mourn now, my muse, now mourn with heavy cheer :

O careful verse!"

SPENSER.

This notion may have originated in the tradition that Judas Iscariot hanged himself on an Elder-tree.

'The Elder prefers a damp situation, but will grow anywhere, bearing exposure to the sea-breeze without receiving any injury.

"The great esteem," says Borlase, " in which the ancient Cornish held the Elder (or Sambucus) is very 
remarkable. The Cornu-British words for it are scau and scauan; and hence we have many villages ${ }^{1}$ and two ancient ${ }^{2}$ families denominated. ${ }^{3}$ It may at first seem to be owing to the general scarcity of trees that even this humble shrub was thought considerable enough to give name to so many places; but if we consider the great virtue of this plant in all its several parts and stages, we shall be convinced that few shrubs deserve a greater regard. It is very hardy, enduring all weathers, suiting all soils, easily propagated by seeds and cuttings; the medicinal use of its several parts is extraordinary ; its leaves, buds, blossoms, berries, pith, wood, and bark have more virtues than can possibly have room here without entering into too minute detail: the following are most obvious and most generally applied to for relief.-The buds and leaves, as soon as they appear, are gathered to maek baths, fomentations, and cataplasms for wounds, and are a remedy for inflammations, \&c. As soon as the flower-buds come on, they serve to make a pickle of very good flavour: the flowers at their opening, infused, communicate their taste and smell to vinegar; infused and let to stand in best Florence oil, excellent to be laid over bruises and external swellings; and taken internally, very healing and cooling : the flowers in their natural state are very sudorific, and assuage pains; distilled with simple water, make a sweet cooling wash for the face in summer, which takes off inflammations of the eyes (as a collyrium); is good for the wind in children, and a very innocent vehicle in fevers; distilled in spirits, it assuages cholical pains in adult

1 Boscauan-rôs and Boscauancen in St. Berian parish; two called by the name of Penscauan in St. Enodor; Enyscauan in St. Denis ; Lescauan in Sheviock; Fentonscauan, name of a water in St. Ives; Trescau, formerly the most considerable village in the Scilly Isles ; Trescau in Brêg, \&c.

2 That of the Right Honourable Lord Viscount Falmouth, called Boscawen, and the Scawens of Molenik in St. Germans, and of Carshalton in Surrey.

${ }_{3}$ The Elder is still called Skew-tree in Cornwall. May not the etymology of the word skewer be traced to this tree?-C. A. J. 
persons ; and there is a spirit to be drawn from the Elder, which the late Duke of Somerset, who married the heiress of Piercy, took for the gout, as I am informed, with success. When the berries are ripe, they make a very wholesome syrup in colds and fevers; and some make wines of them, by mixing Rhenish or other white wines. Of the younger sappy branches, the bark, pared off close to the wood, makes a salve efficacious beyond most others for scalds. This inner bark is also very salutary in dropsies, says Mr. Ray. The wood is close-grained, sweet, and cleanly, and beyond any other chosen by butchers for skewers, as least affecting their flesh ; it is very beautiful also for turners' ware, and fineering, and for toys, of as neat a polish as box : and the very pith of this useful shrub is proper to cool, and make ulcers and wounds digest. More uses than these may occur by way of medicine, but the above are perhaps more than sufficient to show that the Cornu-Britons did not denominate places and persons from this seemingly contemptible shrub without great propriety : its peculiar properties are not to be wondered at, though numerous; they are indeed chiefly medicinal, and those of other plants are sometimes principally nutritious and domestic. Nature has differently distributed her bounties among plants, and placed them together sometimes in great numbers. The Palm-tree, as Strabo says, has three hundred and sixty uses, and the Cocoa or Cokernut-tree yields wine, bread, milk, oil, sugar, salt, vinegar, tinctures, tans, spices, thread, needles, linen-cloth, cups, dishes, baskets, mats, umbrellas, paper, brooms, ropes, sails, and almost all that belong to the rigging of a ship, if we may believe Fr. Hernandez and other authors. Besides this Sambucus aquatilis seu palustris we have another sort, which we call Scau-au-Cûz, or the Elder of the Wood;-some call it Maiden Elder. Its uses have not been hitherto discovered to be as various and salutary as those of the foregoing, but its wood is more flexible, and will divide lengthways as perfectly almost as whalebone, and is therefore much coveted by joyners." 


\section{THE WOODBINE, OR HONEYSUCKLE.}

\section{LONICERA PERICLYMENUM.}

Natural Order-CapRIfoliaces.

Class-Pentandria. Order-Monogynia.

No British shrub claims our favourable notice so early in the season as the Honeysuckle; for even before the earliest Snowdrop has ventured to pierce the unthawed earth we may discover in the sheltered wood or hedgebank its wiry stems, throwing out at every joint tufts of tender green foliage. In this state it is even richer in promise than the fully-expanded winter flowers, for, belonging as it does to the brightest days of summer, its opening buds carry us away at once to the genial season when the fields are decked with their gayest attire, and the air loaded with the most delicious perfumes, among which its own fragrance is to occupy no mean position. Later in the year it engages our attention by its twisting stems clinging for support to some lustier neighbour, and climbing with undeviating accuracy from left to right until it has overtopped its friendly support, when it asserts its independence, loses a good deal of its twining character, and displays its numerous clusters of trumpet-shaped flowers.

As its coil of stem, when once formed, never materially enlarges, and is too tough to yield to the expanding force of the tree around which it twines, it is a mischievous neighbour to the young sapling, stopping its growth, and forming a spiral channel in its bark, which is eventually the source of disease and death.

The Honeysuckle is in most luxuriant bloom in June : its flowers, copiously stored with honey, are then rifled by such insects as are furnished with a long proboscis; while others, which cannot reach to the bottom of its 
curved tubes, obtain their booty by piercing the base, a method which is successfully pursued with other tubular flowers, such as the Jasmine. To the flowers succeed bunches of scarlet berries, which are clammy to the touch, glutinous, and sweet to the taste, but mawkish. In October the Woodbine, with praiseworthy perseverance,

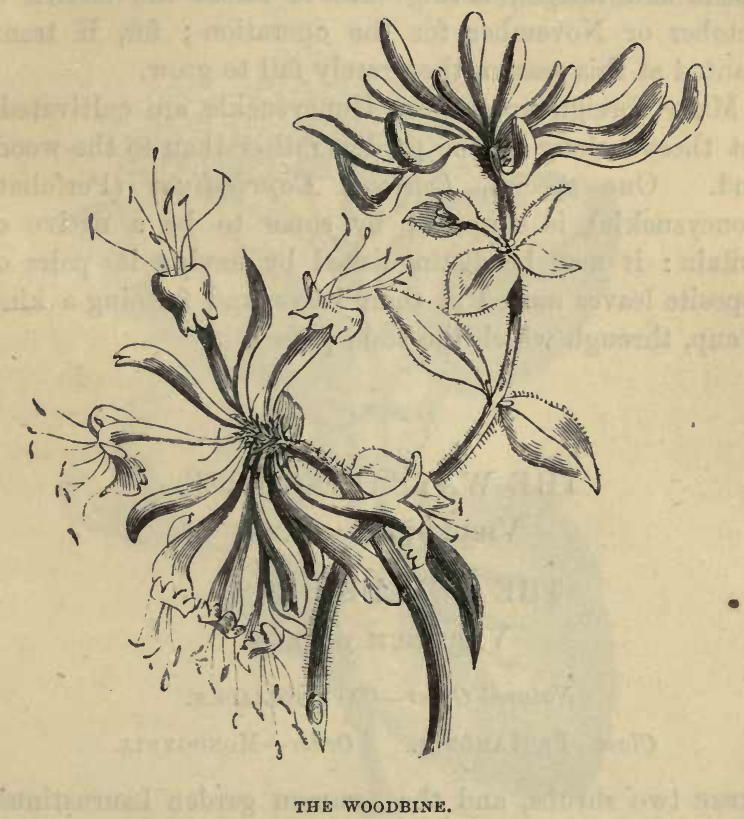

endeavours to impart a grace to the fading year by producing a new crop of flowers, which, though not so luxuriant nor so numerous as the first, are quite as fragrant. Clusters of flowers and of ripe berries may then be found on the same twig, uniting autumn with summer, as the early foliage united winter with spring.

The name Lonicera was given to it in honour of Lonicer, a German: Periclymenum is a Greek compound, and 
signifies winding about; Woodbine is evidently a corruption of Woodbind; and Honeysuckle has reference to the custom among children of sucking honey out of the flowers.

The Honeysuckle is propagated either by cuttings or layers; but a yet readier way to secure a stock of the common variety is to collect young rooted plants in the woods and hedges, taking care to select the month of October or November for the operation; for, if transplanted at this season, they rarely fail to grow.

Many foreign species of Honeysuckle are cultivated; but these belong to the garden rather than to the woodland. One species, Lonicera Caprifolium (Perfoliate. Honeysuckle), is supposed by some to be a native of Britain : it may be distinguished by having its pairs of opposite leaves united at their bases, and forming a kind of cup, through which the stem passes.

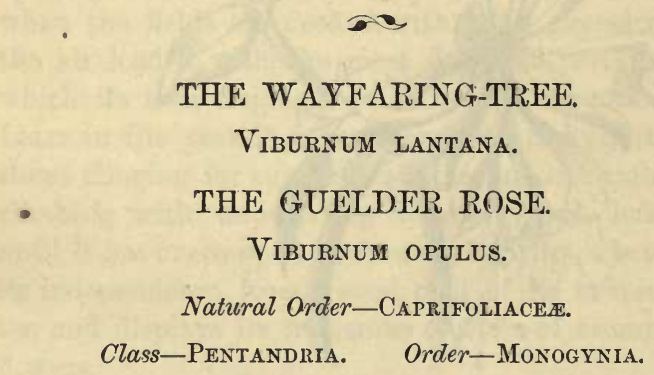

These two shrubs, and the common garden Laurustinus, Viburnum Tinus, agree in having a funnel-shaped corolla of one petal, and a calyx divided into five deep segments, which remains attached to the fruit, a single-seeded berry, until the latter is ripe.

The Wayfaring-tree may easily be distinguished at all seasons by its numerous pliant mealy branches, which in winter are ornamented by hoary, button-like buds, and in summer are clothed by heart-shaped leaves, covered with mealy down. The flowers are white, and grow in 
clusters at the extremities of the shoots, and are succeeded by flattened berries, which, as they ripen, become red, and finally black. A modern poet, William Howitt, captivated by the pleasing name, has addressed an ode to the Wayfaring-tree, and eulogises its "coronets of fragrant snow,"-a metaphor the propriety of which any one who knows the tree will find it difficult to discover, the flowers

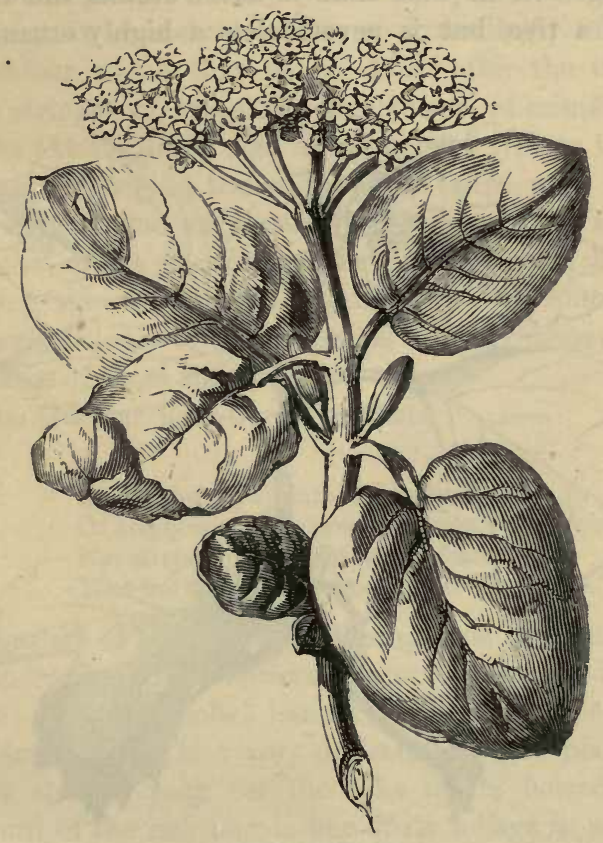

WAYFARING-TREE.

being by no means attractive. It would seem to owe its name to the soiled appearance of its leaves, which, wherever the tree is growing, give one the notion of its having been powdered with dust from the highway. The season when this tree is most conspicuous is when the berries are partially ripe; for then the scarlet and black berries 
growing in the same clusters present a very singular appearance. Loudon tells us that in Germany the young shoots are employed in basket-making, and for tying fagots and other packages; and those of two or three years old are used for the stems of tobacco-pipes. The berries are used in Switzerland for making ink.

The Guelder Rose is a much prettier shrub than the preceding. In its wild state it never attains the dimensions of a tree, but is nevertheless a highly ornamental

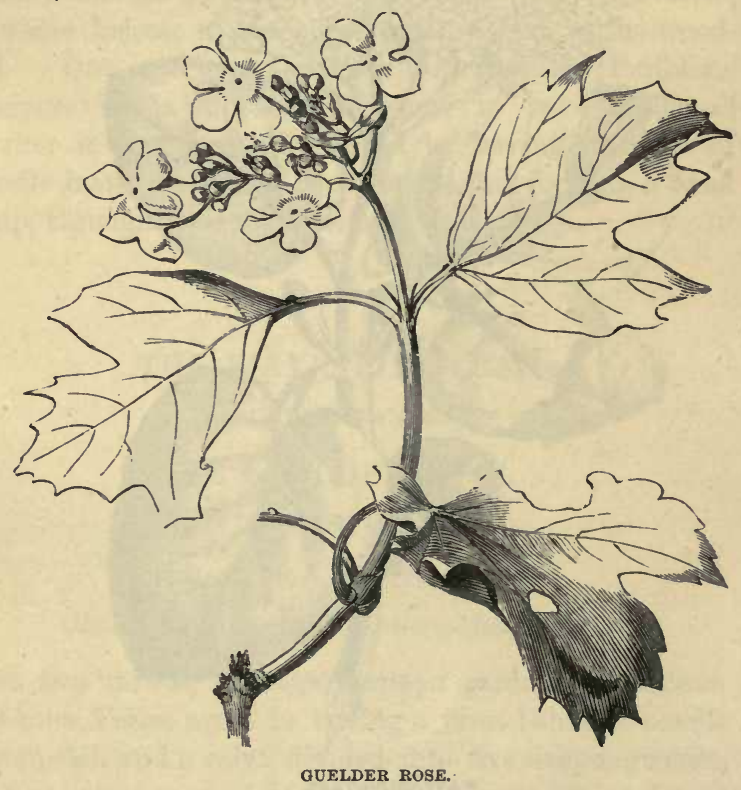

hedge-plant. The tree is smooth in every part. The leaves are large, three-lobed, and serrated. The flowers are of a brilliant white, and much more conspicuous than those of the Wayfaring-tree, growing in clusters which have the outer flowers destitute of stamens and pistils, but furnished with large and showy petals. In August and 
September its bunches of coral berries are very ornamental, and in October it is yet more conspicuous. The foliage then assumes a deep crimson-purple hue ; and if the tree, as is frequently the case, be associated with the bright yellow foliage of the Maple, no garden, however richly stocked with the most showy flowers, presents so gorgeous an appearance. It is said that in Siberia the berries are made into paste with honey and flour, and eaten as food; but this is scarcely credible, so exceedingly offensive is the odour which they emit. Long after the trees have been stripped of every leaf, the clusters of crimson berries at the extremities of the branches retain their bright appearance, drooping indeed, and shrivelled with the frost, but nevertheless very attractive to the eye. The wood, like that of the Spindle-tree and Cornel, is much used for making skewers; indeed the name of Dog-timber, which properly belongs to the Cornel, is in many places given to all three of these shrubs.

The Guelder Rose-tree of gardens,

"Tall,

And throwing up into the darkest gloom

Of neighbouring Cypress, or more sable Yew,

Her silver globes, light as the foamy surf

That the wind severs from the broken wave,"

is a variety of this species, differing from the usual character in having all its flowers barren and crowded together in the form of a globe : hence it derives its name of Snowball-tree. This is a very desirable tree to plant among other shrubs, both for the sake of its flowers and on account of the rich purple hue of its foliage in autumn. 


\section{THE IVY.}

\section{Hedera HeLIX.}

\section{Natural Order-Araliacee. \\ Class-Pentandria. Order-Monogynia.}

The Ivy is a tree of very ancient repute, occupying a prominent place in the Mythology of the Greeks and Romans, and applied to purposes which were deemed the most honourable. The warrior-god Bacchus had his brows and spear decked with Ivy; the people of Thrace adorned their armour with the foliage of the same tree ; and an Ivy crown was the highest prize that was awarded to a successful poet. The Grecian priests presented newly-married couples with a wreath of Ivy, as a symbol of the closeness of the tie which ought to bind them together; and it continues a favourite emblem of constancy among the moderns. Owing to a property which it is supposed to possess, of absorbing nourishment, by means of its ront-like tendrils, from the trees to which it clings, some consider its friendship not strictly disinterested :

\section{"He was}

The Ivy which had hid my princely trunk, And suck'd my verdure out."

With many the Ivy is the tree peculiarly dedicated to gloom : its foliage is heavy, and of a sombre hue; it shows its flowers and strives to be as gay as it can when almost every other tree has finished its summer course; it loves to creep over sepulchres and ruined buildings, as even Pliny has remarked ; it courts retirement and the shade, and if it does sometimes grow on a sunny bank, it seems sickly and ill at ease, rarely rising from the ground unless it can avail itself of the support afforded by some decaying tree that has little foliage of its own. But I am by no means disposed to allow that the Ivy deserves this 
unamiable character; for though the facts are true enough, a very different inference may be drawn from them. It certainly does grow most luxuriantly over the ruined walls of buildings, but with its verdure "never sere" rather takes from their gloominess than adds to it; and if it does begin its chilly summer when winter reigns over all the forest beside, surely it deserves not a little gratitude for exerting itself to prolong the season of flowers, and to spin out the existence of the myriads of inseets which would certainly perish were it not for the copious supply of honey afforded by its abundant clusters of flowers. Even if the accusation be true, that it is never at ease unless it be getting up in the world, its ambition is scarcely to be blamed; for it mostly avails itself of the support afforded by trees whose own vigour is irrecoverably gone, and which, but for the borrowed verdure of the visitor, would be stark and unsightly trunks.

As an ingredient in the landscape it does not need any apologist. The opinion of Gilpin, the greatest authority in such matters, is impartial and decisive: "Ivy is another mischief incident to trees which has a good effect. It gives great richness to an old trunk, both by its stem, which winds round it in thick, hairy, irregular volumes, and by its leaf, which either decks the furrowed bark, or creeps among the branches, or hangs carelessly from them. In all these circumstances it unites with the mosses and other furniture of the tree in adorning and enriching it; but when it gathers into a heavy body, which is often the case, it becomes rather a deformity. In autumn I have seen a beautiful contrast between a bush of Ivy, which had completely invested a Pollard Oak, and the dark-brown tint of the withered leaves, which still held possession of the branches. In the spring also we sometimes have a pleasing appearance of a similar kind. About the end of $\Lambda$ pril, when the foliage of the Oak is just beginning to expand, its varied tints are often delightfully contrasted with the deep green of an Ivy-bush which has overspread 
the body and larger limbs of the tree; and the contrast has been still more beautiful when the limbs are covered,

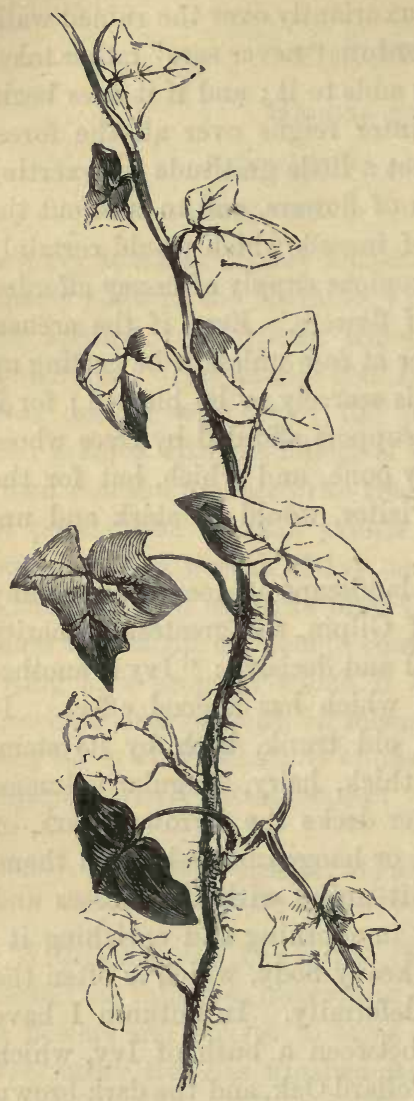

as we sometimes see them, with tufts of brimstone-coloured moss [lichen]."

Ivy is often associated with Holly and other evergreens in the decoration of our churches at Christmas, but for no other reason that $I$ an aware of than that it retains its freshness for a considerable time, and that its dark berries contrast well with the bright scarlet berries of the Holly.

The Ivy is confined to temperate climates, but grows wild neither in America nor Australia. About Smyrna in Asia Minor it is very common, forming the greatest part of the hedges, and ornamenting every garden. In the Himalayas it is very abundant, producing yellow berries. This variety is supposed to be the plant which was held in such high repute among the Grceks and Romans.

No British plant varies so greatly in its habit at different periods of growth, and in the shape of its leaves, as the Iry. In its infancy it is a brittle, climbing stem, furnished with alternate three- or five-lobed leaves, which are light 
green, or of a reddish tinge, with white ribs. As it increases in size the lobes of the leaves become wider, and the stem loses its brittle character. If it can find no support, it creeps along the ground, sending into the earth, from the lower part of the stem, tufts of fibrous roots. These are to be distinguished from the tufted fibres by the aid of which the plant clings to a wall or trunk of a tree. The former are proper roots, and are only pushed forth from those parts of the stem which are opposite to the leaves, and only appear when they can be employed with advantage in the support of the plant. The tufts of fibres, on the contrary, are produced from all parts of the stem which are nearest to the wall or tree, and are invariably absent when the plant crawls along the ground, and therefore has no use for them. Cunsequently, the opinion that Ivy is injurious to trees, by inserting its roots into the bark and absorbing their juices, is erroneous. It may sometimes happen that a tree is clasped too closely by matted Ivy-bands, and is thus prevented from developing its full growth, or, more rarely still, the weight of its massy head may overstrain the branch which supports it, and be the occasion of ruin to both; but, except under such circumstances, it does no mischief.

A remarkable instance of the compressing power of Ivy is cited in the Gardeners' Chronicle, proving that a netted mass of Ivy does not simply prevent the expansion of the body which it clasps, but as its stems increase in bulk, actually contracts the space inclosed. On removing some Ivy from an old house at Carshalton, it was discovered that a thick leaden water-pipe had been in many places deeply indented, and in some places squeozed flat, by the stem of the plant. Trees that have long been coated with a network of Ivy should not be stripped all at once, lest they should be injured by sudden exposure to cold ; and when it is desired to keep young trees in plantations clear of Ivy, the best plan is, not to cut through the stems of the intruder, as generally practised, but to 
detach them as carefully as possible from the trees, and to let them fall back. They will thus lie on the ground, and continue to grow in the same direction in which they were laid. Otherwise, new shoots will spring up from the roots which have been deprived of their leading stems, and it will soon be necessary to repeat the process. When Ivy grows over buildings, its effects depend on the nature of the structure: if the masonry be solid, no mischief can ensue, as the climbing shoots will bind and strengthen, without attempting to penetrate; but if the structure be loose and crumbling, or if earth be lodged here and there, it is very likely that roots will be formed wherever they find a convenient soil, and, as they increase in size, will penetrate into the mass, and dislodge the constituent parts. A striking example of the pernicious effects of Ivy on a structure of this kind occurred some years since in a remote county. At a period of great agricultural distress, a gentleman, in order to furnish the poor with employment, resolved to inclose his park, which was seven miles in circumference, with a stone wall. The mason who undertook the contract happened to be an unprincipled man, and, instead of fulfilling his engagement of building a solid wall of stone, erected it with a double facing of the material named, and filled the interstice with earth and rubbish. When completed, it appeared to be an honest stone wall; but in a few years Ivy climbed to the top in many places, sent down its roots into the earth, and these, as they enlarged, thrust out the stones which constituted the facings, and revealed the iniquity of the contractor. The present proprietor is subjected to a heavy annual expense in repairing the mischief done by a plant which, if the structure had been what it appeared to be, would have added greatly to its strength and durability.

It has long been a disputed question whether Ivy growing against the side of a house renders it damp or otherwise. Dr. Lindley thus pronounces his opinion, formed from a comparison of various conflicting statements 
made in the Gardeners' Chronicle: "Ivy may render a house damp by retaining snow in winter, which changes to water, trickles down the walls, and never thoroughly evaporates. But this is of rare occurrence, and may be prevented by beating the Ivy after snow-storms, and will only be an inconvenience when houses are built with mud. No doubt, when walls are not of sound brickwork or

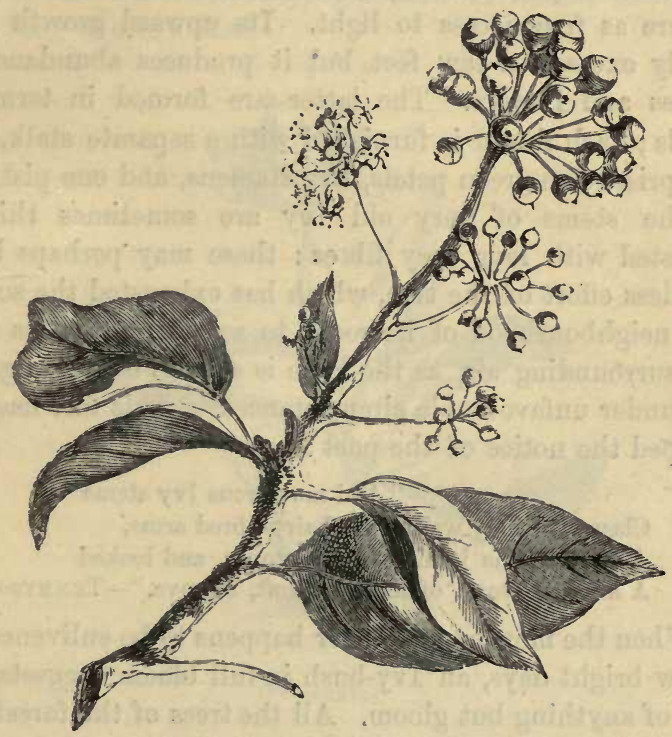

BRANCH OF IVY.

some other hard materials, the Ivy may introduce its roots into the masonry, and thus do mischief, allowing water to run down its branches and to follow them into the crevices where they have insinuated themselves. But in all cases of well-built houses we are convinced that Ivy is beneficial, so far as keeping the walls dry."

When Ivy has mounted to the summit of its support, its character and habit undergo a material alteration : it is 
no longer a climbing stem with lobed leaves, but sends out erect branches of tufted foliage, and becomes a round headed bush. Neither roots nor tendrils are formed on the stems; and the dark, glossy leaves preserve an even edge, unbroken by any indentation, but still vary considerably in width. The height at which this alteration takes place varies from a few feet to a hundred, for it seems to require not so much an elevated tract of atmosphere as free access to light. Its upward growth now rarely exceeds a few feet, but it produces abundance of leaves and flowers. The latter are formed in terminal heads; each flower is furnished with a separate stalk, and comprises five green petals, five stamens, and one pistil.

The stems of very old Ivy are sometimes thickly invested with long grey fibres: these may perhaps be a fruitless effort of the tree, which has exhausted the soil in the neighbourhood of its roots, to send out rootlets into the surrounding air, as the Vine is seen to do when growing under unfavourable circumstances. This fact has not escaped the notice of the poet:-

\section{"And monstrous Ivy stems}

Claspt the gray walls with hairy-fibred arms, And suckt the joining of the stones, and looked A knot, beneath, of snakes-aloft, a grove."-Tennyson.

When the month of October happens to be enlivened by a few bright days, an Ivy-bush in full bloom suggests the idea of anything but gloom. All the trees of the forest are plainly intimating that their glory is in the wane; a few pale flowers are scattered here and there, evidently the produce of exhausted plants - the whole insect world, with the exception of drony evening beetles, has either perished or retired to secure winter quarters,-when, after some days of storm and cloud, there comes a flash of calm, clear sunshine; then, hasten to the nearest Ivy-bush, and be convinced that summer has not taken its departure without giving one day as an earnest that it will come again. Every twig of Ivy terminates in a cluster of fresh, timely 
flowers, which, sober though they may be in hue, show no symptom of decay, and, at the same time, lengthen the existence of myriads of insects. The Red Admiral butterfly especially is sure to be a guest at this banquet, but is far from being alone; the Painted Lady regales herself close by ; and flies of all sizes and shapes, hornets, wasps, bees, all flock hither in wonderful harmony to enjoy once more a full feast before they submit to the necessity of their long winter's fast.

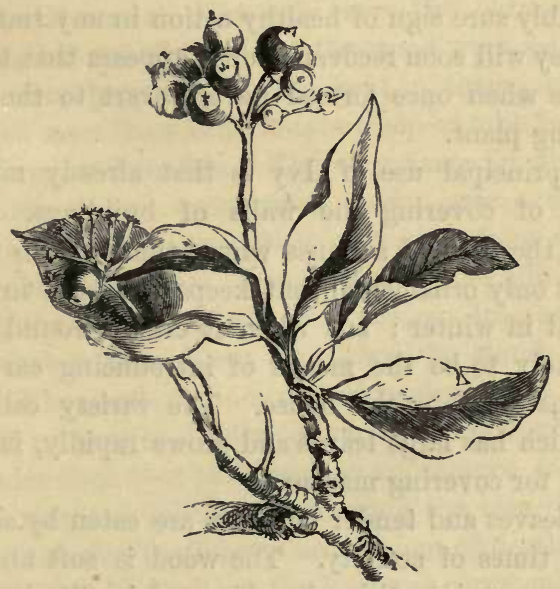

IVY-BERRIES.

A few months later, and the banquet is spread again on the same table for another winged tribe. Blackbirds, thrushes, and wood-pigeons know well where Ivy-berries grow, and now that they have stripped the Hawthorn and Mistletoe bare, resort to the Ivy-bush in quest of food by day and shelter by night, and many a cluster of barren stems shows how keen was their appetite; while the abundance yet left tells as plainly of the ample provision that their heavenly Father had made for them, during even the most inclement period of the year. It is a fact 
well worthy of note, that Ivy-berries are never injured by frost, however severe the winter may be.

- Although the Ivy never bears flowers, or assumes a bushy habit until it has had an opportunity of indulging its climbing propensities, yet, by proper management, it may be made highly ornamental as a standard shrub. For this purpose, plants that have mounted to the top of a hedge-bank, and have there rooted, should be taken up in winter, and carefully removed to their new destination, when, though they may perhaps throw off all their leaves (a tolerably sure sign of healthy action in any transplanted tree), they will soon recover ; for it appears that the bushy branches when once formed never revert to the habit of the young plant.

The principal use of Ivy is that already mentioned, namely, of covering the walls of buildings. Planted against the side of a house where there are no windows, it is not only ornamental, but keeps out heat in summer and cold in winter; but when it climbs round windows it is likely to be the means of introducing earwigs and other insects into the house. The variety called Irish Ivy, which has large leaves and grows rapidly, is the best adapted for covering masonry.

The leaves and tender branches are eaten by.sheep and deer in times of scarcity. The wood is soft and porous, and when cut into thin slices is used in filtering liquids. The roots are employed by leather-cutters to sharpen their knivès on. A fragrant resin exudes from the old stems if wounded, which, Walton says, makes bait attractive to: fish. A substance called hederine may be extracted from this, which in India is used as a medicine. 


\section{THE YEW.}

\section{TAXUS BaCcata.}

Natural Order-TAXACEE.

Class-Diøcia, Order-MoNadelphia.

THE Yew-tree, "neither verdant, nor graceful, but gloomy, terrible, and sapless," to judge from Pliny's description, is a tree of evil omen. Not only were the berries deemed poisonous, but vessels made of the wood were said to impart the same property to wine kept in them, and it was considered more than hazardous to sleep or take food under the shade of its branches. The very name for the poison with which arrows were armed, toxica, was, according to the same author, a corruption of taxica, from taxus, the Latin name of the tree. Virgil agrees with Pliny in condemning the Yew; he calls it a noxious tree, and recommends that it should not be allowed to stand near beehives. Other authors, ancient and modern, join in assigning to it properties deadly to various kinds of animals. No wonder then that the frequent appearance of the Yew in churchyards should have suggested the idea that it was planted in such situations as an emblem of death, and a fit shelter for the dead. That the Yew was commonly planted by our forefathers in churchyards there can be no doubt, for there are yet in existence a vast number of these trees so planted many centuries since; but there is far greater probability that at the period when crosses were erected in these sacred spots as emblems of the victory over death achieved by the Author of our faith, the Yew-tree was stationed not far off, to symbolize, by its durability and slowly altering features, the patient waiting for the resurrection, by those who committed the bodies of their friends to the ground in hope. Heathens, indeed, might with propriety have selected the most deadly of trees to repre- 
sent the character of what they might well consider a merciless destroyer; but such a feeling could have no place with sober Christians. They, on the other hand, would regard the perpetual verdure which overshadowed the remains of their forefathers and was shortly destined to canopy their own, as the most fitting expression of their faith in the immortality of the soul. Generation after generation might be gathered to their fathers, the Yew-tree proclaiming to those who remained, that all, like the ever-green, unchanging Yew, were yet living, in another world, the life which had been the object of their desire. The Yew, then, we may safely conclude, is not an unmeaning decoration of our churchyards, much less a heathenish symbol, or, as some will have it, a tree planted with superstitious feelings, but an appropriate religious emblem :-

"Of vast circumference, and gloom profound, This solitary tree! A living thing

Produced too slowly ever to decay;

Of form and aspect too magnificent

To be destroyed." WorDswortu.

Miss Kent quotes from Dr. Hunter a passage which quite supports this view. "Dr. Hunter thinks the best reason to be given for planting the Yew in churchyards is, that the branches were often carried in procession on Palm Sunday, instead of Palm." It is still customary in Ireland for the peasants to wear sprigs of Yew in their hats from that day until Easter-day. "Our forefathers," says Martyn, "were particularly careful to preserve this funereal tree, whose branches it was usual to carry in solemn procession to the grave, and afterwards to deposit therein under the bodies of their departed friends. Our learned Ray says that our ancestors planted the Yew in churchyards because it was an evergreen tree, as a symbol of that immortality which they hoped and expected for the persons there deposited. For the same reason, this and other evergreen trees are even yet carried in funerals, and 


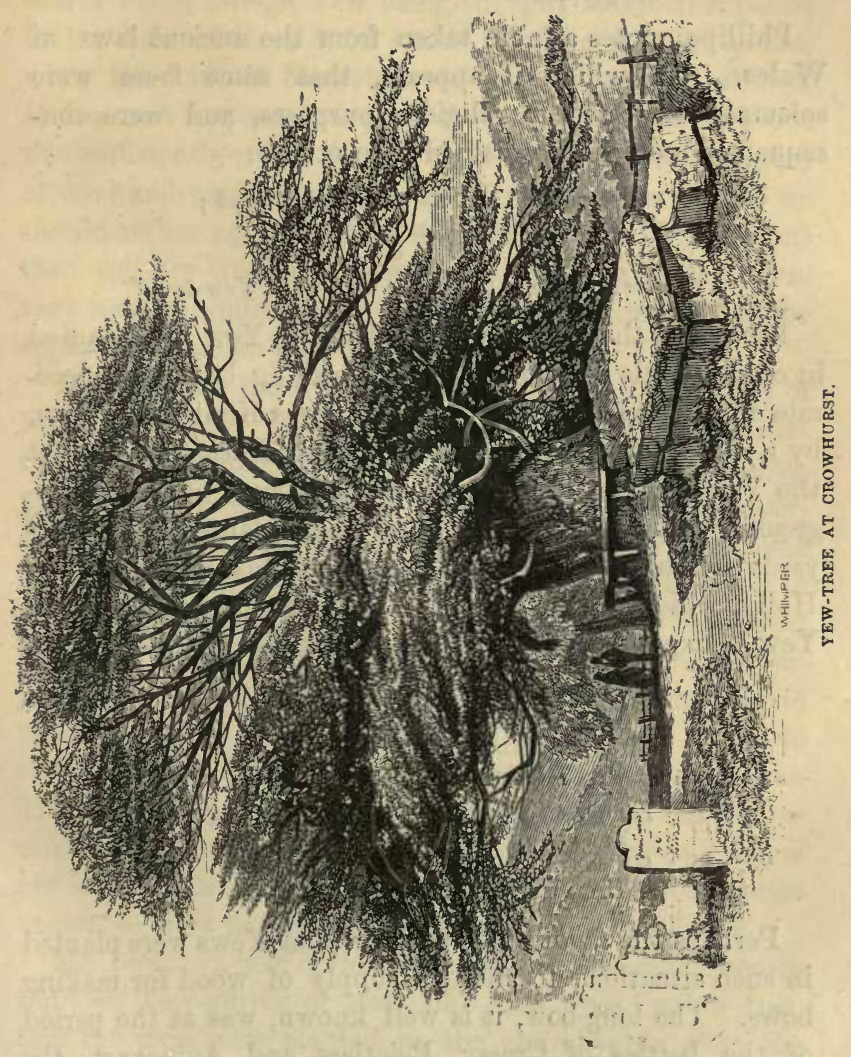


thrown into the grave with the body; in some parts of England and in Wales they are planted with flowers upon the grave itself." Shakespeare alludes to a similar custom :-

"My shroud of white, stuck all with Yew, Oh prepare it!"

Phillips quotes a table taken from the ancient laws of Wales, from which it appears, that some trees were solemnly dedicated to religious purposes, and were consequently more highly valued than others:-

"A consecrated Yew, its value is a pound ;

An Oak, its value is six score pence.

Fifteen pence is the value of a wood Yew-tree."

Dr. Aikin thinks it probable that the $\mathrm{Yew}$ was planted in churchyards for the sake of furnishing boughs to decorate the church at Christmas, but Miss Kent has shown, by a quotation from Brand's "Popular Antiquities," that the Yew was rarely used except in default of other evergreens: "Had a tree," she says, "been planted in churchyards for that use, it would more probably have been the Holly, which was never omitted." Herrick speaks of the Yew as expressly appropriate to the season of Easter :-

“"The Holly hitherto did sway, Let Box now domineer,

Until the dancing Easter-day,

Or Easter's eve appear.

"Then youthful Box, which now hath grace

Your houses to renew,

Grown old, surrender must his place

Unto the crisped Yew."

Perhaps the favourite opinion is, that Yews were planted in such situations to afford a supply of wood for making bows. The long-bow, it is well known, was at the period of the battles of Cressy, Poictiers and Agincourt, the national weapon of England. Statutes were passed by many of our sovereigns, forbidding the exportation of Yew wood, and obliging Venetian and other merchant ships to 
import ten bow-staves with every butt of wine, and by an Act passed in the reign of Edward IV. every Englishman residing in Ireland was expressly ordered to have an English bow of his own height, made of Yew, or some other wood. The best bows, however, were not made of native wood, foreign Yew being thought so much superior that a bow of it sold for six shillings and eight pence, when the bow of English wood cost only two shillings. It does not appear, therefore, that the English Yew-tree was sufficiently prized for its wood to need the protection of a churchyard; and if it had been highly valued, we should rather expect to find traces of extensive plantations than solitary trees in churohyards, which, after all, were very inappropriate places to plant trees intended to be applied to warlike purposes.

Mr. Bowman has written an article in the "Magazine of Natural History," in which he states it as his opinion that the Ancient Britons, before the introduction of Christianity, planted Yew-troes near their temples from the same superstitious motives that actuated the Canaanites, who, we are told, were in the habit of performing their idolatrous rites in groves. When Augustine was sent by Gregory the Great to preach Christianity in Britain, he was particularly en. joined not to destroy the heathen temples, but only to remove the images, to wash the walls with holy water, to erect altars, \&c. and so convert them into Christian churches. The Yew-trees, consequently, were allowed to remain, as not necessarily conveying any erroneous impression. There are still in existence Yews which, in all probability, were venerable trees before the introduction of Christianity.

Mr. Bree, too, is of opinion, that churches were frequently built in Yew-groves or near old Yew-trees, rather than that the trees were planted in the churchyards after the churches were built. Such, probably, was often the case ; but whether the church or the tree were the first to occupy the site, our Christian forefathers cannot with propriety be said to have sanctioned the custom either from 
superstitious feeling or for the sake of supplying the demand for bow.staves.

The Yew is a native of most of the temperate parts of Europe and Asia, growing in its wild state in situations little exposed to the direct rays of the sun, such as the north side of steep hills, or among tall trees, and, according to Loudon, always in a clayey, loamy, or calcareous soil, which is naturally moist. The same author also states that the Yew is rather a solitary than a social tree, being generally found either alone or with trees of a different species. This is, however, far from being always the case, for the Yew-tree Island in Loch Lomond, some twenty years ago, furnished three hundred Yews for the axe ; and there are still a number of fine specimens on it: it is also abundant on the north side of the mountains in the same neighbourhood. There are also a great number of these trees on the cliffs near Coomb Martin in the north of Devon, growing in places which are accessible only to birds. But the most remarkable assemblage of Yews in Great Britain is at a place called Kingly Bottom, about four miles from Chichester. As to when or by whom they were planted, or indeed whether they were planted by the hand of man at all, history is silent. They are about two hundred in number; one half of them form a dense, dark grove, in the depth of the Bottom; the remainder, smaller ones, are scattered over the sides of the valley, intermingled with fine plants of Juniper and Holly. The trunks of the largest vary from twelve to twenty feet in circumference at three feet from the ground; their greatest height is about forty feet, and their extreme spread sixty feet in diameter. Tradition fixes their age at nine hundred years.

The Yew-tree is characterised by a trunk peculiarly suggestive of massiveness and solidity, not being covered, like the trunks of most other trees, with a splitting bark, but seemingly composed of a number of smooth stems fused together. The bark itself is of a reddish-brown hue, and scales off in thin plates. At the height of a few feet 
from the ground, it sends out numerous horizontal branches which spread in all directions, and are densely clothed with tough twigs, which are leafy throughout their whole extent, or nearly so. The leaves are thickly set on two opposite sides of the stem, very narrow, slightly recurved, dark green and shining above, but paler below. The

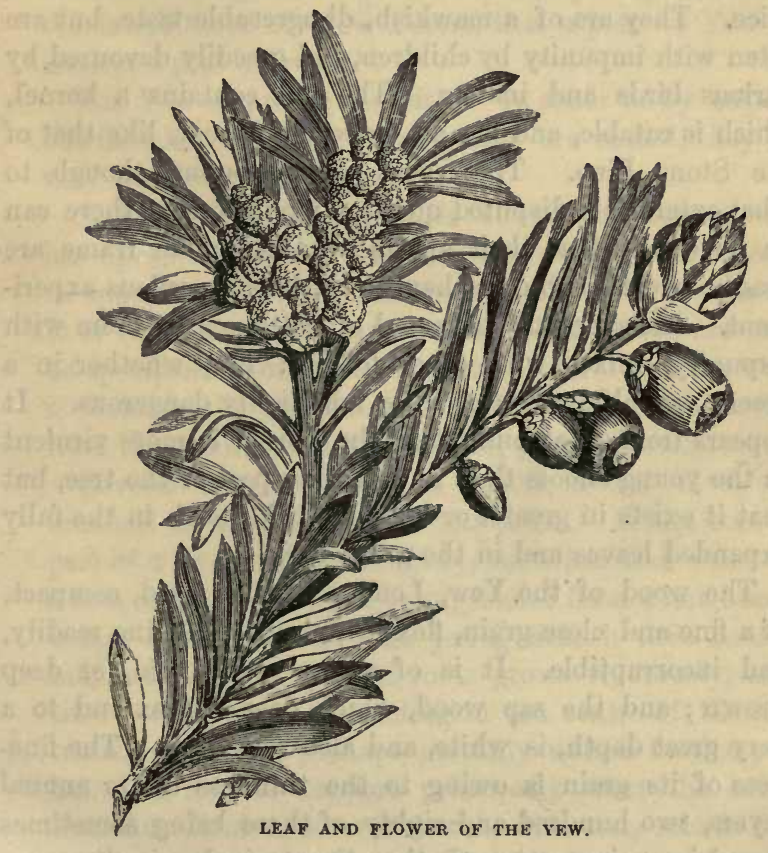

young shoots of the Yew are subject to a disease, the effect of which is a conical bunch of succulent leaves at the extremity of the twigs; this, when it has grown to about an inch in length, withers and dies off. The flowers, which are of two kinds, and grow on separate trees, appear among the leaves, and on the under-side of the twigs. The barren flowers are the most numerous, appearing in the 
form of membranous scaly buds, from the centre of each of which protrudes a slender column, terminating in a tuft of stamens. The fertile flower resembles a minute acorn, the cup of which swells, and when ripe has the appearance of red cornelian, enclosing an oval brown nut, the summit of which is uncovered. These berries, if berries they may be called, droop when ripe, and contain a sweet glutinous juice. They are of a mawkish, disagreeable taste, but are eaten with impunity by children, and greedily devoured by various birds and insects. The nut contains a kernel, which is eatable, and has an agreeable flavour, like that of the Stone Pine. The leaves are poisonous, though to what extent is a disputed question; but of this there can be no doubt, that their effects on the human frame are deadly, and that to give them to cattle is a perilous experiment. Instances are on record of cattle eating them with impunity, mixed with other fodder: but, whether in a green or half-dry state, they are highly dangerous. It appears from all accounts that the poison is more virulent in the young shoots than in any other part of the tree, but that it exists in greater or less quantities both in the fully expanded leaves and in the green bark.

The wood of the. Yew, Loudon says, is hard, compact, of a fine and close grain, flexible, elastic, splitting readily, and incorruptible. It is of a fine orange red, or deep brown; and the sap wood, which does not extend to a very great depth, is white, and also very hard. The fineness of its grain is owing to the thinness of its annual layers, two hundred and eighty of these being sometimes found in a piece not more than twenty inches in diameter. "The Yew was formerly what the Oak is now, the basis of our strength. Of it the old English yeoman made his long-bow, which, he vaunted, nobody but an Englishman could bend. In shooting he did not, as in other nations, keep his left hand steady, and draw his bow with his right; but keeping his right at rest upon the nerve, he pressed the whole weight of his body into the horns of his 
bow. Hence probably arose the English phrase of bending a bow, and the French of drawing one. Nor is the Yew celebrated only for its tonghness and elasticity, but also for its durable nature. Where your paling is most exposed either to winds or springs, strengthen it with a post of old Yew. That hardy veteran fears neither storms - above nor damps below. It is a common saying amongst the inhabitants of New Forest, that a post of Yew will outlast a post of iron." 1

The Yew is propagated either by seeds or by cuttings; but in whatever way young plants are reared, they grow very slowly.

A variety, called the Irish Yew, is cultivated, which has upright branches, and leaves which are not arranged in opposite ranks, but scattered on all sides of the stem. It is very plentiful near Antrim, where there are said to be specimens more than a century old. Another variety is found in the grounds of Clontarf Castle, which differs from the common kind in bearing yellow berries.

Several instances are on record of old Yews being renewed by a singular natural process. When the upper part of a trunk begins to decay, the crumbling wood forms a rich soil, into which a young shoot from a neighbouring bough sends a root. The young branch thus nourished independently of the old roots grows vigorously, and in time becomes a tree, standing in the centre of the hollow trunk, remaining perhaps partially united to the parent, but deriving its support principally from the soil. A tree thus formed, several feet in diameter, stands in the centre of the great Yew at Mamhilad, and will probably continue to flourish for centuries after the wooden walls with which it is enclosed have crumbled to dust. A similar phenomenon has been observed in the Willow.

1 Gilpin's “Forest Scenery." 


\section{THE FIR TRIBE.}

\section{Coniferae.}

\section{Class-Monecia. Order-MoNadelphia.}

The trees of this Order seem, from their structure and habit, to be especially designed to occupy stations which are, in more than an ordinary degree, exposed to the violence of wind and weather. Accordingly we find all the species, with very few exceptions, flourishing in extreme magnificence on the mountains of the cold and temperate regions of the earth ; but, even when planted on the lowlands, they retain their characters so constantly, that we can at a glance distinguish them from any other trees with which they may be associated, whether deciduous or evergreen. The mountains are their natural haunts, but some of them will flourish with tolerable luxuriance in other situations, while others, like human mountaineers torn from their beloved Alpine homes, dwindle away and soon perish, their very decay being accelerated by the nursing and pruning and other means adopted to promote their welfare.

The principal characters by which the Fir-tribe are fitted for their native haunts are these:- Springing from the bare crags, or a stratum of dry soil, which is incapable of affording nourishment to any moderately-sized plant furnished with roots having a downward tendency, the Firs, both young and old, extend their roots horizontally, or in a direction parallel to the surface of the ground,-tap-root they have none, for such an appendage would be useless to trees often growing in soil but a few inches deep. The roots being, moreover, close to the surface, or even partially above it, acquire a hardness and toughness which enable them to resist the action of the wind on the head of the tree much more effectually than in the case of trees whose 
juicy roots run deep into the ground. It is a well-ascertained fact in physics, that any given number of separate strings will support a much heavier weight than if they were united into one rope. This fact might have been inferred from the roots of the Fir-tribe, for being required to resist a greater degree of force than the roots of other trees, they are smaller, and proportionally more numerous; thus being stronger in themselves, and presenting a larger surface of resistance to the surrounding soil, that is to say, being both less liable to snap, and to be torn out from the ground. Moreover, as they extend in all directions, they are prepared to resist the violence of the mauntain tempest, no matter from what quarter it may proceed.

From the centre of this web of wiry roots rises a stiff column of solid timber, the strength of which is not impaired by being divided into branching arms, but the whole substance is thrown into one trunk; so that here the least possible amount of surface is exposed to the action of the wind. The Firs, too, are eminently social trees; it rarely happening in the mountains that one stands alone: but though social among themselves, they are strictly exclusive as it regards other trees ; they are generally found covering extensive tracts of country, and being evergreen, they shut out the light from every other tree that attempts to germinate beneath their unfriendly shade. For the most part, they stand as close together as is consistent with their healthy growth; hence they not only borrow from each other a firmer hold of the ground by interlacing their roots, but prevent a free circulation of air round their stems, and consequently the small lateral branches which are formed soon grow sickly and perish. This effect is perhaps increased by the rarefied state of the air at great elevations. The decay of the lateral branches does not, however, in any case extend to the bole, for the dead wood of the Firs does not rot, as is the case in other trees, but "as soon as vegetation ceases, the consistence of the wood changes; the sap disappears, and the wood already 
impregnated with resinous juice, becomes surcharged to such a degree as to double its weight in a year." 1 Meanwhile the trunk increases in dimensions, and encloses the hard stump in its substance; and hence originate the dark circular knots, so common in most kinds of Fir-wood. In the main stem the woody fibres are less close than in most other trees ; the effect of which is, that the wood is more elastic, bending before the blast, but not breaking; and the resinous nature of the juices in every part of the tree defies the influence of the severest frost.

On examining the leaves, we find an equally beautiful adaptation of these organs to the circumstances in which they are placed. The thin dilated leaves commonly to be found during the summer months on deciduous trees in the plains, would here be soon torn to pieces or scattered by the wind; if, on the other hand, they partook of the character of the lowland evergreens, such as the Laurel and Bay,- that is to say, if they had a broad surface and a tough substance, - the very resistance they offered would bring destruction on the tree they clothed. The wind would act on them mechanically, like the force exerted on the long arm of a lever, and the breeze, instead of passing freely through the branches with a low murmur (one of the pleasantest sounds in nature), would be as destructive as the most terrific hurricanes which occasionally devastate the forests of countries within the Tropics.

But besides being admirably adapted for withstanding the violence of the storms, to which the Firs are, from their situation, peculiarly liable, the leaves of these trees are no less remarkable in other respects. Subject to almost uninterrupted exposure to cold, the resinous juices in which they abound serve as a safeguard against its injurious effects, and yet their shape is such as to be naturally the cause of their temperature being lower than that of surrounding bodies. A person walking through a 
mist will soon find his eyelashes and hair covered with small drops of water, while the rest of his person remains dry; if he examines the ground, he will also find that the blades of grass by the wayside are fringed with dew-drops, while the road itself is quite free from moisture. This phenomenon is owing to the excessive radiation of heat from bodies which present a large surface in proportion to their bulk, and the consequent condensation of moisture on cold substances. Precisely the same effect is produced on the leaves of the Firs, which are therefore said, though inaccurately, to attract moisture; the true state of the case being that they are reduced to a low temperature by excessive radiation of heat into space, and are consequently subject to a constant deposition of moisture in the shape of clear globules, which soon becoming too heavy to remain suspended on the leaves, fall to the ground, and, having supplied the scanty soil with a sufficiency of nourishment for the thirsty roots, trickle away in little rills. These either sink into the ground, and reappear below as mineral springs, or flow along the surface, continually increasing from the accession of similar tributaries, and fertilizing the valleys through which the very same mists had previously been carried, where they had encountered no substances of a temperature low enough to arrest their progress.

There is yet another peculiarity of the Fir-tribe connected with this subject which deserves notice. The perfection of the Fir, as has been already noticed, consists in height rather than lateral expansion. In all other trees (except the Palms) a bud is produced in the axil of every leaf. This is not the case in the Firs, but buds are produced very sparingly, and nearly always at the extremities of the shoots. Provision is thus made for the upward growth of the tree, but not for its lateral expansion. In other trees again, the unfolding of all the buds on an individual is simultaneous, or nearly so; but in the case of the Fir-tribe, "the bud which terminates 
the summit of the tree, and is destined to form its leading shoot and increase its height, is developed the last; and this delay seems a provision of nature for the safety of the most important shoot which the tree can produce; thus insuring its height rather than its breadth, and the production of timber by the preservation of its permanent trunk rather than of its temporary and comparatively useless branches." 1

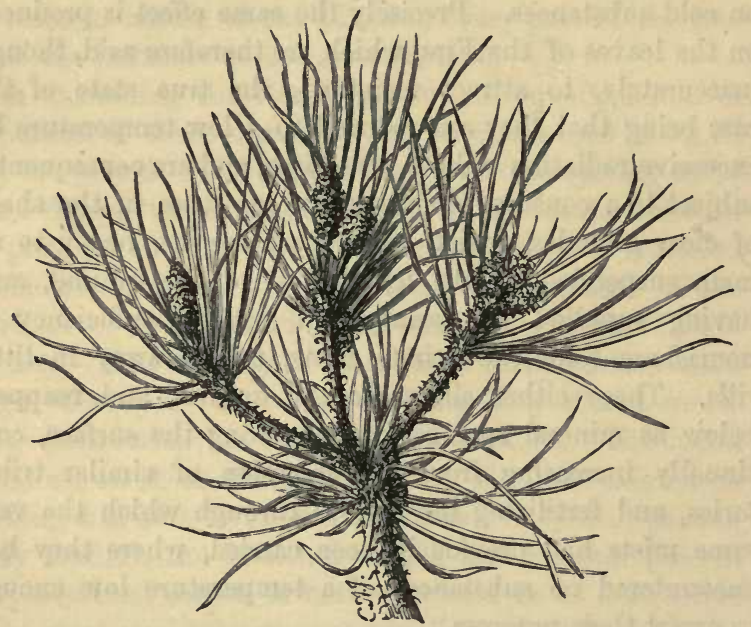

BUDS OF STONE-PINE.

It might be supposed that the Firs, exposed as they are to the action of the most violent thunderstorms, would be liable to be shattered by discharges of the electric fluid to an extent not known in the case of any other trees. The reverse of this is the case; for they are furnished with a natural apparatus, which not only in most cases protects themselves from the effects of lightning, but tends to equalize the electric condition of the atmosphere, and so to extend their influence to districts indefinitely remote. Fresh vegetables in general conduct the electric 
fluid with facility, owing to the good conducting properties of the fluids which they contain. If a small blade of grass be placed in contact with the conductor of a powerful electrical machine in operation, the whole of the electricity will be found to be carried off by the blade of grass. Pointed conductors, and especially vegetable conductors, are admirably fitted to receive and disperse electricity, it having been found by experiment that a few blades of grass placed near the brass knob at the top of a Leyden jar will quickly and silently discharge it. It has been found impossible to give an electric shock to a circle of people standing on a lawn, as the electricity took the shorter and better conducting course through the grass; and it has also been found, that when the electroscope (an instrument for measuring the degree of electricity) indicated abundance of electricity in the free open air, it showed none in the vicinity of a tree with pointed leaves. It is not unfair, therefore, to assume that every one of the myriads of pointed conductors in the Pine forests of Norway and Russia is continually employed in withdrawing electricity from the atmosphere, and contributing to promote an equable electrical condition in the atmosphere of places far remote.

The flowers of the Pine are of two kinds, both of which are of a simple structure, being destitute both of calyx and corolla, and therefore not liable to be torn by the wind. The barren flowers are scaly catkins, and contain an unusual quantity of pollen, which is sometimes carried away by storms, and descends in remote districts in the shape of clouds of sulphur-coloured dust, to the great terror of the superstitious. The fertile flower is a solid catkin, composed of thick overlapping scales, at the base of each of which are generally two ovaries. The whole of the fertile flower is persistent, increasing in size, but not altering materially in shape until it becomes a woody cone. Meanwhile the ovaries have grown into seeds, furnished each with a membranous wing, which, though not buoyant 
like the down of the thistle, flies away lightly enough before the mountain breeze. Until the seeds are ripe, that

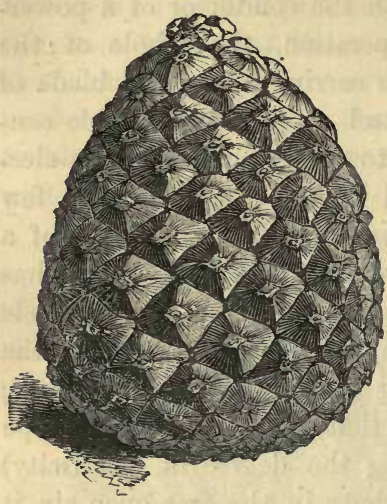

CONE OF STONE-PINE. is, for a year or more after flowering, the cones are hard balls of wood, composed of a number of distinct pieces, so closely adhering together that not a drop of water can penetrate them, and firm enough to bear the shock of dropping from the loftiest trees, or of leaping from rock to rock without injury. When the seeds are thoroughly ripe, but not before, the cones, whether - remaining attached to the tree or lying on the ground, open spontaneously, and allow the seeds to escape.

Thus a constant succession of SEED OF SCOTCH PINE. young plants is kept up, a provision which, in the case of this tribe, is the more necessary from the fact that they send up no suckers from the roots, and when eut or blown down they never send up new shoots from the mutilated trunk. Their duration, too, in most instances, is less than that of other forest trees.

- Seedling Firs are remarkable for being composed of five or six seed-leaves, which in their youngest stage are united at their points by the shell of the seed. When this falls off they spread, and a bud containing true leaves rises from the centre.

The geographical range of the Fir-tribe SEEDLING. is extensive, but they are most abundant in 
the temperate parts of the northern hemisphere. Some species are found both in Europe and America, so far north as to border on the regions of perpetual snow; and others, in Central Europe and in Asia, on the Alpine and Himalayan mountains, where, from their great elevation, the climate is equally cold. Other species occupy the same position in the mountains of America, extending to the height of more than twelve thousand feet, beyond which altitude vegetation entirely beases.

Frequent mention occurs in the Sacred Writings of the Cedar and Fir, the wood of both trees being peculiarly adapted for building. The Cedar still flourishes on the same site which it occupied in the days of Solomon; the Fir(Beroth) is supposed to be the same with the Cupressus of the Latins and our Cypress, a common tree in the East. Solomon employed both Cedar and Fir in the erection of the Temple, the floor of which was of Fir ; the musical instruments of David were of the same wood. Pliny mentions that the doors and other parts of the Temple of Diana, at Ephesus, were made of Cypress-wood. The Thyine-wood (Rev. xviii. 12) is supposed to be another species of Cypress. The wealthy among the Romans adorned their villas with this wood: Varro, describing the splendour of a certain villa, celebrates the golden decorations, but praises in still higher terms the wainscoting of precious Thyia-wood. Being so much in demand, it became an important article of trade, and is therefore classed among the precious merchandise of fallen Babylon. The Gopher-wood, of which the Ark was built, is thought to be another species of Cypress : being at once light, and not subject to rot, it was often used in shipbuilding. Alexander the Great caused the great fleet which he prepared to be constructed of Cypress-wood, which was brought from Assyria.

The Talmudists relate, that it was customary in Judæa for each family to plant a Cedar before the house at the 
birth of a son, and a Fir at the birth of a daughter. These trees were deemed sacred, and were not cut down till the children were grown up and needed the timber for their household furniture. At the time when Judæa was subject to the Romans, after the destruction of Jerusalem by Titus, the daughter of the Emperor Hadrian happened to be travelling through that country, when her chariot was injured, and her attendants proceeded, in an overbearing manner, to cut down one of the sacred trees, to be used in repairing it. The inhabitants of the place rose and massacred the train of the princess, who was so enraged that she forced her father to make war against the Jews, to humble their pride.

Herodotus tells us, that Miltiades, at the head of the Thracian Dolonci, having made war on the people of Lampsacus, was taken prisoner by an ambuscade. His friend Crœesus, having heard of his misfortune, sent a herald to the Lampsacans, threatening them, that unless they released their prisoner he would cut them down like a Fir-tree. The Lampsacans were at first perplexed; but when one of their wise men reminded them that the Firtree, if once cut down, never shoots again, they were so terrified that they dismissed their prisoner forthwith.

The victors at the Isthmian games held at Corinth were crowned with garlands of Pine-branches. The cones were used by the Romans to flavour their wines, being thrown into the vats, and suffered to float, - a custom which is still in existence in Italy. Hence the thyrsus, or wand of Bacchus, terminates in a Fir-cone. The timber was employed by both Greeks and Romans in naval and domestic architecture; and the various resinous productions were extracted by a method very similar to those now adopted. The Pine appears to have been held sacred by the Assyrians. Mr. Layard informs us that on the sculptures discovered by him during his excavations at Nimroud, the ancient Nineveh, there are many representations of figures bearing a Fir-cone. 
Linnæus well describes the danger by which he was surrounded when traversing one of the burning forests in Lapland :-

"Several days ago the forests had been set on fire by lightning, and the flames raged at this time with great violence, owing to the drought of the season. In many different places, perhaps nine or ten that came under my notice, the devastation extended several miles' distance. I traversed a space of three quarters of a mile in extent (about four miles and a half English), which was entirely burnt, so that Flora, instead of appearing in her gay and verdant attire, was in deep sable,-a spectacle more abhorrent to my feelings than to see her clad in the white livery of winter; for this, though it destroys the herbage, leaves the roots in safety, which the fire does not. The fire was nearly extinguished in most of the spots we visited, except in ant-hills and dry trunks of trees. After we had travelled about half a quarter of a mile across one of these scenes of desolation, the wind began to blow with rather more force than it had previously done, upon which a sudden noise arose in the half-burnt forest, such as I can only compare to what may be imagined among a large army attacked by an enemy. We knew not whither to turn our steps; the smoke would not suffer us to remain where we were, and we durst not turn back. It seemed best to hasten forward in hopes of speedily reaching the outskirts of the wood, but in this we were disappointed. We ran as fast as we could, in order to avoid being crushed by the falling trees, some of which threatened us every minute. Sometimes the fall of a large trunk was so sudden that we stood aghast, not knowing which way to turn to escape destruction, and throwing ourselves entirely on the protection of Providence. In one instance a large tree fell exactly between me and my guide, who walked not more than a fathom from me; but, thanks to God, we both escaped in safety. We were not a little rejoiced when this perilous adventure 
terminated, for we had felt all the while like a couple of outlaws in momentary fear of surprise." 1

The burning of these forests, however, is incorrectly attributed to the effects of lightning. Fires of this kind have been traced to the carelessness of the Laplanders and boatmen on the rivers, who, using German tinder to light their pipes, suffer it to fall in an ignited state among the dry leaves and moss. They also leave large fires burning, which they have kindled in the midst of the woods to drive away the mosquitoes; and in either of these ways the fire is easily communicated to the surrounding trees.

In the forest districts of the Alps, of Germany, and of Norway, where the people derive a good part of their existence from the timber of their trees, the nodes of transporting the produce to the markets are often highly curious. In some cases the woodmen cut down the trees, hurl or roll them into a mountain stream, and let them float down to the sea, or a lake, or to any place where they can be conveniently disposed of. This is comparatively easy, so long as the forest is not far from a stream; but when it is inland, or situated at a great height, or separated from a stream by a rugged and mountainous district, the ingenuity of the woodman is taxed to the utmost to devise means of transporting the timber. One of the means adopted is to construct a slide, down which the trunk may run by its own impetus. Early in spring the woodmen set off, to begin their business of cutting down the trees in the forest, perhaps many miles from their homes; they have to construct rude huts, in which they live during the summer and autumnal months, and throughout the whole of this period they employ themselves in cutting down the noble trees which surround them. Every tree is classed according to its fitness for practical purposes, and cut up into logs; and the logs so accumulated are heaped up into huge piles. When winter arrives, all these logs are transported down to some stream or lake, by means of a slide 1 "Lachesis Lapponica." 
or trough. This trough is usually constructed of six or eight Fir-trees, placed side by side lengthways, so as to form a semicircular channel, made smooth by stripping the bark from the trees. The trees are laid side by side, and end to end, till the slide is of considerable length, having a gradual descent, curving round the shoulders of mountains, spanning over valleys and yawning ravines by means of viaducts, and even perforating solid rocks by means of tunnels. In the year 1810, when the price of Baltic timber had attained its greatest height, a stupendous, and at the same time successful, effort was made to convey the timber of Mount Pilate to the Lake of Lucerne, whence it might be floated down the Rhine to the sea. Under the superintendence of M. Rupp, a slide was constructed, six feet broad, and from three to six feet deep, and extending to a distance of forty-four thousand feet (eight miles). It was completed in 1812, and twenty-five thousand Pinetrees were employed in its construction. It was called the Slide of Alpnach, from the name of a village near it. The logs were drawn to the trough either by hand-sledges or by oxen, and placed in at the top; the snow was partially cleared away from the trough, and a few logs were thrown to clear the channel. Water was next poured upon it, which quickly froze, forming a surface of ice through its entire extent. The logs placed on the upper surface of this slippery trough immediately descended, slowly at first, but with almost inconceivable velocity as their momentum increased. When the operations were to begin, workmen were posted at regular distances ; and as soon as everything was ready, the workman at the lower end of the slide cried out to the one above him, "lâchez" (let go). The cry was repeated from one to another, and reached the top of the slide in three minutes. The workman at the top then cried out to the one below him, "il vient" (it comes); and the tree was instantly launched down the slide, preceded by the cry, which was repeated from post to post. As soon as the tree had reached the bottom, and plunged 
into the lake, the cry of "lâchez" was repeated as before, and a new tree was launched in a similar manner. By these means a tree descended every five or six minutes. The velocity with which the trees descended is almost inconceivable; the descent of eight miles was usually made in six minutes, but in wet weather it was frequently effected in three, being at the rate of a hundred and eighty miles an hour! Perhaps the best way of conveying an idea of this amazing velocity is to state, that a spectator standing by found it quite impossible to give two successive strokes with his stick to any, even the longest tree, as it passed him. The logs entered the lake with so much force that many of them seemed to penetrate its waters to the very bottom. Much of the timber of Mount Pilate was thus brought to market; but the expense attending the process rendered it impossible for the speculator to undersell the Baltic merchant after the arrival of peace had opened the market for his timber, and so the Slide of Alpnach fell into ruin.

An interesting description has been given by Howison of the mode of bringing timber to market in the heart of Russia. A Russian proprietor who wishes to dispose of the timber on his property, having completed a bargain with a St. Petersburg merchant, sets his peasantry to work in selecting and felling the trees and dragging them from the forests to the lakes and rivers. This work usually takes place during the winter months, in order that everything may be ready for floating the timber to the capital as soon as the ice in the rivers and lakes breaks up. As the ground is generally covered several feet deep with snow, and as the trees judged to be sufficiently sound and large for the market lie widely apart, the workmen employed in selecting them are compelled to wear snowshoes to prevent themselves from sinking in the snow. When the trees are found, they are cut down with hatchets, and the heads and branches lopped off. The trunk is stripped of its bark, and a circular notch is cut round the narrow end 
of it, to facilitate the fixing of the rope by which the horses are to drag the trunk along; and a hole is made in the other end to receive a handspike to steer the log over the many obstacles that lie in its way. Many of these trees are seventy feet in length, and of proportionate diameter; and they are drawn by from four to nine horses each, yoked in a straight line one before another, since the intricate narrow paths in the woods will not permit any other arrangement. One man mounts upon the leading horse, another upon the middle one, while others support and guide with handspikes the large and distant end of the tree, to raise it over the elevations of snow and make it glide smoothly along. The conveyance of these large trees, the long line of horses, and the number of peasants accompanying them through the forest, present a very picturesque appearance. In many cases the trees are brought nearly a thousand miles before they are delivered to the merchant; and they generally remain under his care till another winter, to be shaped and fitted for exportation in such a manner as to take up as little room as possible on shipboard; so that this timber does not reach the foreign consumer till two years after it has been cut down. When the trees are delivered to the merchant, they are carefully examined to ascertain their soundness; and for this purpose a hatchet is struck several times against them, the emitted sound affording the means of estimating the soundness of the tree: those which are defective constitute about one-tenth of the whole. The trees are not conveyed from the forests the whole way to St. Petersburg by horses. but only to the margin of some stream or lake, from whence they may be floated down to the capital.

"The most striking examples of the floating of timber by rafts are presented on the Danube and Rhine. The immense forests of southern and western Germany are in most cases within reach of some stream or other which flows into the Rhine, the Danube, the Rhone, or one of the other large rivers; and in such cases the logs of timber, 
precipitated into the smaller streams by the troughs or by some other contrivance, are floated singly down these small streams until they reach the larger rivers, when they are made into rafts. Below the bridge at Plattning, on the Danube, the raft-masters of Munich, who leave that city every Monday for Vienna, unite their rafts before they enter the Danube. They descend the Isar upon single rafts only, but upon reaching this point they lash them together in pairs; and in fleets of three, four, or six pairs they set out for Vienna. A voyage is made pleasantly enough upon these floating islands, as they have all the advantages of a boat without the confinement. A very respectable promenade can be made from one end to the other, and two or three huts erected upon them afford shelter in bad weather, and repose at night." 1

"A little below Andernach, the Rhine forms a small bay or inlet, where the pilots are accustomed to unite together the small rafts of timber floated down the tributary rivers, and to construct enormous rafts, which are floated down the Rhine to Holland, and there sold. These huge rafts have the appearance of floating villages, each composed of twelve or fifteen little huts, on a large platform of timber. The raft, which is frequently eight or nine hundred feet long by sixty or seventy wide, is composed of several layers of timbers or trees placed one on another and tied together, the whole drawing about six or seven feet of water. Several smaller rafts are attached to the large one, besides a string of boats loaded with anchors and cables, and used for the purposes of sounding the river and going on shore. The rowers and workmen sometimes amount to seven or eight hundred, superintended by pilots; and over the whole is placed a proprietor or manager, whose habitation is superior to the others. As the men live on board the raft, the arrangements for their comfort are very extensive. Pigs, poultry, and other animals are kept on board, and butchers accompany the 1 M. Planché. 
troop. A well-supplied boiler is at work night and day in a kitchen built on the raft. The dinner-hour is announced by a basket stuck on a pole, at which signal the pilots give the word of command, and the workmen run from all quarters to receive their rations. The consumption of provisions is enormous ; forty or fifty thousand pounds of bread, twenty thousand pounds of fresh meat, with a proportionate quantity of butter, salt meat, vegetables, \&c., are demolished in the voyage from Andernach down to Holland."1

\section{$\infty$ \\ THE SCOTCH FIR, OR PINE.}

Pinus sylvestris.

THE Scotch Fir is the only one which is a native of Britain. Julius Cæesar, it has been remarked before, ${ }^{2}$ states that the Beech and the kind of Fir which was known to the Romans by the name of Abies were not to be found in this island. With regard to the Beech, I have endeavoured to show that he was in error; but in the other case he was probably correct, for the tree which the Romans called Abies does not appear to be the same with our Pine, but with what we call the Silver Fir, which was not introduced into England until the beginning of the seventeenth century. From remote antiquity, the Pine has grown in the Highlands of Scotland, and the occasional discovery of trunks of the same tree in peat-bogs sufficiently proves that it was at one time indigenous to England. Extensive and most magnificent forests of Pine still exist in Scotland, exhibiting a character which belongs to no British forests composed of other trees-so peculiar

1 "An Autumn near the Rhine."

2 P. 143. 
indeed, and so wild, that it would be almost as hardy to doubt their native origin as to deny that the soil from which they spring is a constituent part of the country.

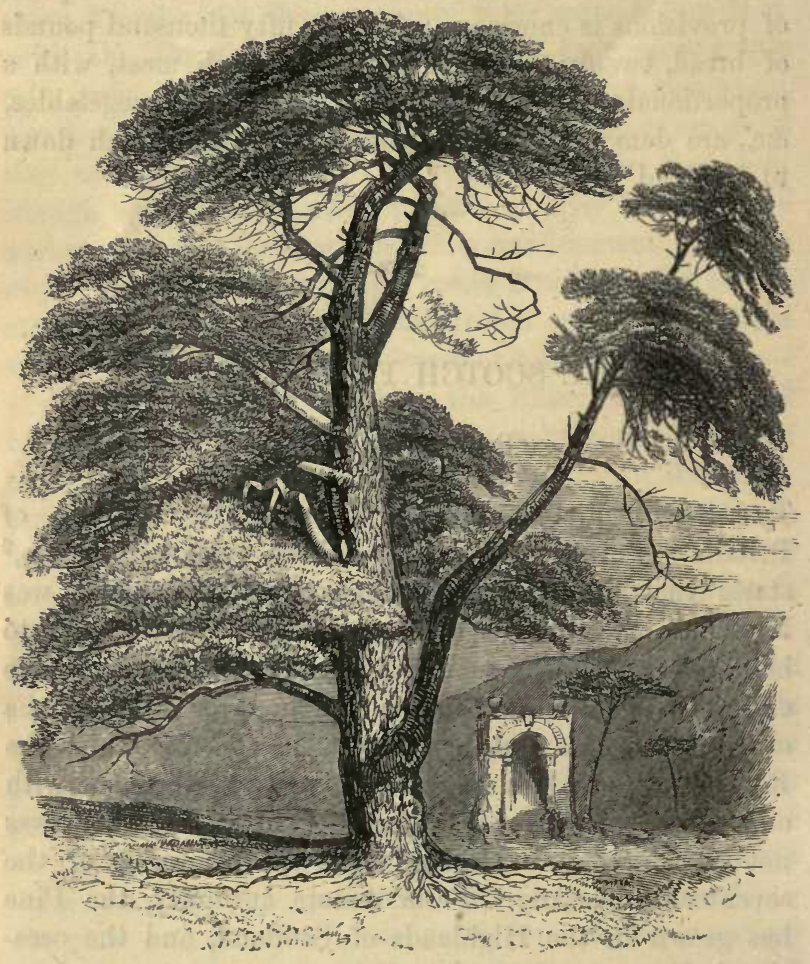

THE SCOTCH FIR.

"In the forests of Invercauld and Braemar," says Sir T. D. Lauder, "the endless Fir woods run up all the ramifications and subdivisions of the tributary valleys, cover the lower elevations, climb the sides of the higher 
hills, and even in many cases approach the very roots of the giant mountains which tower over them; yet with all this, the reader is mistaken if he supposes that any tiresome uniformity exists among these wilds. Every movement we make exposes to our view fresh objects of excitement, and discloses new scenes produced by the infinite variety of the surface. At one time we find ourselves wandering along some natural level under the deep and sublime shade of the heavy Pine foliage, upheld high over head by the tall and massive columnar stems, which appear to form an endless colonnade; the ground dry as a floor beneath our footsteps, the very sound of which is muffled by the thick deposition of decayed Pines with which the seasons of more than one century have strewed it; hardly conscious that the sun is up, save from the fragrant resinous odour which its influence is exhaling, and the continued hum of the clouds of insects that are dancing in its beams over the tops of the trees. Anon the ground begins to swell into hillocks, and here and there the continuity of shade is broken by a broad rush of light streaming down through some vacant space, and brightly illuminating a single tree of huge dimensions and of grand form, which, rising from a little knoll, stands out in bold relief from the darker masses behind it, where the shadows again sink deep and fathomless among the red and gray stems ; whilst Nature, luxuriating in the light that gladdens the little glade, pours forth her richest Highland treasures of purple heathbells, and bright green bilberries, and trailing whortleberries, with tufts of ferns and tall junipers irregularly intermingled. And then, amidst the silence that prevails, the red deer stag comes carelessly across the view, leading his whole herd behind him; and, as his full eye catches a glimpse of man, he halts, throws up his royal head, snuffs up the gale, indignantly beats the ground with his hoof, and then proudly moves off with his troop amid the glistening boles. Again the repose of the forest is interrupted by the music of distant 
waters stealing upon the ear; curiosity becomes alive, and we hurry forward, with the sound growing upon us, till all at once the roar and the white sheet of a cataract bursts upon our astonished senses, as we find ourselves suddenly and unexpectedly standing on the fearful bank of some deep and rocky ravine, where the river, pouring from above, precipitates itself into a profound abyss, where it has to fight its way through countless obstructions, in one continued turmoil of foam, mist, and thunder. The cliffs themselves are shaken, and the Pines quiver while they wildly shoot, with strange and fantastic wreathings, from the crevices in their sides, or where, having gained some small portion: of nutriment on their summits, they rear themselves up like giants aspiring to scale the gates of heaven. And here, perhaps, a distant mountain-top may appear over the deep green Fir-tops. By and by, after pursuing the windings of the wizard stream for a considerable way upwards, we are conducted by it into some wide plain, through which it comes broadly flowing and sparkling among the opposing stones, where the trees of all ages and growths stand singly, or in groups, or in groves, as Nature may have planted them or the deer may have allowed them to rise, where distant herds are seen maintaining their free right of pasture, where, on all sides, the steeps are clothed thick with the portly denizens of the forest, and where the view is bounded by a wider range of those mountains of the Cairngorum group, which are now ascertained to be the highest in Great Britain. And finally, being perhaps led by our wayward fancy to quit this scene, we climb the rough sides of some isolated hill, vainly expecting that the exertion of but a few minutes will carry us to its summit that we see rising above all its woods. And we do reach it-but not until we are toilworn and breathless, after scrambling for an hour up the slippery and deceitful ascent. Then what a prospect opens to us, as we seat ourselves on some bare rock! The forest is seen stretching away in all directions 
from our feet, mellowing as it recedes into the farthest valleys amid the distant hills, climbing their bold sides, and scattering off in detachments along their steeps like the light troops of some army skirmishing in the van; and, above all, the bold and determined outlines of Benmachdhuie, that king of British mountains, and his attendant group of native Alps, sharply yet softly delineated against the sky, look down with silent majesty on all below."

These mighty forests are indebted for their renewal to the membranous wings with which Pine-seeds are furnished. By help of these the seeds are carried to a great distance by the violent winds to which mountainous tracts are liable, and everywhere find soil enough to supply their slender wants. The rook, too, is one of Nature's planters of Pine-woods. Forsyth ${ }^{1}$ tells us that from the Highland forests there come clouds of rooks in search of food, sometimes in such heavy columns as to create alarm among farmers as to where and on what they are to dine; and if it were not for the Pine, which yields them food as well as lodging, they would soon be called by dishonest names, which they would no doubt deserve. Yet of these clouds of rooks, as they fly high, and glide harmlessly overhead on their homeward passage in autumn evenings, Scotland may be proud; for these sable birds have had their homes in the Highland glens time out of mind, and have sown the seeds of almost all the Fir-trees that are to be found in the natural forests. It is well known that the rook has a natural propensity to steal away to some lonely quiet place with its booty, such as a Fir-cone or a potato, and there to eat what he can, leaving the rest: which, in the case of the Pine-cone, is just what is necessary for the production of timber; for the first heavy snow presses the shattered cone, with any seeds that may remain in it, close to the ground, and these seeds, finding themselves in good circumstances as to soil, moisture, and

* "Gardeners' Chronicle."

R 3 
heat, soon vegetate in the open heath, and eventually become trees. Some of the rooks, it is said, do even more than this; they not only convey the cones to some lonely place, but take advantage of the workings of an underground quadruped as black as themselves, and may be sometimes seen actively employed in burying the cones in molehills.

"It is curious to observe," says $\operatorname{Sir}$ T. D. Lauder in another place, "how the work of renovation goes on in a Pine-forest. The young seedlings come up as thick as they do in the nurseryman's seedbeds; and in the same relative degree of thickness do they continue to grow till they are old enough to be cut down. The competition which takes place between the adjacent individual plants creates a rivalry that increases their upward growth, whilst the exclusion of the air prevents the formation of lateral branches, or destroys them after they are formed. Thus Nature produces by far the most valuable timber; for it is tall, straight, of uniform diameter throughout its whole length, ard free from knots; all which qualities combine to render it fit for spars, which fetch double or treble the sum per foot that other trees do. The large and spreading trees are on the outskirts of the masses, and straggle here and there in groups or single trees."

How little the hand of man has had to do at any period, except within the last fifty years, in planting the Pine in Scotland, appears from the numerous extensive tracts which were once crowded forests, but have been dismantled by human agency. Almost every district of the Highlands bears the trace of the vast forest with which, at no very distant period, the hills and heaths were covered; some indeed have decayed with age, but large tracts were purposely destroyed in the latter end of the sixteenth and beginning of the seventeenth centuries. On the south side of Ben Nevis a large Pine-forest, which extended from the western braes of Lochaber to the black water and mosses of Ranach, was burned to expel the wolves. In 
the neighbourhood of Loch Sloy, a tract of woods, neatly twenty miles in extent, was consumed for the same purpose; and at a llater period a considerable part of the forests adjoining Lochiel was laid waste by the soldiers of Oliver Cromwell in their attempts to subdue the Clan Cameron. It is not above eighty years since Glen Urcha was divested of a superb forest of Firs some miles in extent. The timber was bought by a company of Irish adventurers, who paid at the rate of sixpence a tree for such as would now have been valued at five guineas. After having felled the whole of the forest, the purchasers became bankrupt and dispersed; the overseer of the workmen was hanged at Inverary for assassinating one of his men ; the laird never received the purchase-money of his timber, and a considerable number of the trees were left upon the spot where they fell, or by the shores of Loch Awe, whither they had been carried for conveyance, and gradually consumed by the action of the weather. The mosses where the ancient forests formerly stood are filled with the short stumps of trees still standing where they grew. Age has rendered them almost rotten to the core, and the rains and decay have cleared them of the soil ; yet their wasted stumps and the fangs of their roots retain their original shape. Abundance of similar remains are to be seen in other parts of the Highlands, sometimes interspersed with living and flourishing trees, but surrounded on all sides by the shattered stumps, fallen trunks, and blasted limbs of a departed forest. ${ }^{1}$

A like fate has overtaken the forest of Glenniore, once famous for the size and age of its timber, whose magnificent Pines clothed one of the romantic glens between the Cairngorum range and the river Spey. This noble forest was purchased of the Duke of Gordon in 1783, and fur nished materials for building no less than forty-one sail of ships, including a frigate of one thousand and fifty tons. A specimen of timber from one of these trees, preserved in

J. H. Allan's "Last Deer of Beann Doran." 
Gordon Castle, is six feet two inches long, and five feet five inches broad, with the texture of the finest Red-wood Pine, and showing annual growths to the number of two hundred and thirty-five. The spot was visited about twenty-five years since by Mr. Selby, who thus describes its appearance: "Scattered trees, some of which were in a scathed or dying state, of huge dimensions, picturesque in appearance from their knotty trunks, tortuous branches, and wide-spreading heads, were seen in different directions, at unequal and frequently at considerable distances from each other,-the solitary and mournful-looking relics of the departed glories of this once well-clad woodland scene, and which had only escaped the axe from their previous decay or the comparative worthlessness of their knotty trunks; while the surface of the ground in almost every direction was littered and bristling with the decaying tops and loppings of the felled trees, among which mosses of various species were growing with a luxuriance we never saw equalled-nourished, it would appear, and encouraged by the partial stoppage and stagnation of the surface-water thus impeded in its course, and threatening to convert a large proportion of the surface that had once been forest into a peat moss." Sir T. D. Lauder, describing the same scene, says : "Many gigantic skeletons of trees, above twenty feet in circumference, but which had been so far decayed at the time the forest was felled as to be unfit for timber, had been left standing, most of them in prominent situations, their bark in a great measure gone,many of them without leaves, and catching a pale unearthly-looking light upon their grey trunks and bare arms, which were stretched forth towards the sky like those of wizards, as if in the act of conjuring up the storm which was gathering in the bosom of the mountains, and which was about to burst forth at their call."

Tradition favours the Pine's being considered a native Forest Tree of England as well as of Scotland. Gerard says: "I have seene these trees growing in Cheshire, 
Staffordshire, and Lancashire, where they grew in great plentie, as it is reported, before Noah's floud, but then being overflowed and overwhelmed, have been since in the mosses and waterie moorish grounds, very sound and fresh until this day; and so full of a resinous substance, that they burne like a torch or linke, and the inhabitants of those countries do call it Firre wood and Fire woode unto this day."

Logs of Pine-wood intermixed with brick have also been found imbedded in the soil, and serving as the foundation of an ancient Roman road. Pine-woods are scarcely to be found in England of so romantic a character as the Highland forests; but some of the wilds of Hampshire and other English counties are covered with these trees, self-sown and unpruned, and presenting on a less grand scale many of the features described as characteristic of the Scottish forests.

That the Scotch Fir was formerly very abundant in Ireland is proved by the vast quantities of timber still found in many of the extensive bogs for which that country is noted. In the counties of Down, Fermanagh, Donegal, Sligo, Antrim, \&c. peat-cutters frequently arrive at layers of these trees in different states of preservation; some are much decayed, others are perfectly sound, and measure as much as seventy feet in length. The depth at which they lie beneath the surface varies from eight to fifteen feet. In some instances they all lie with the top towards the north, the base of the trunks and the upper parts of the stumps, which still remain fixed in the peat, bearing evident marks of fire. Some had attained a large size before they fell, measuring from eight to twelve feet in circumference; in other instances, where the trunk has decayed, the stumps are found imbedded in the peat, still quite sound, the roots averaging more than a foot in diameter, and occupying a space varying from thirty to ninety feet in circumference, but never descending to any considerable depth. A single stump frequently furnishes 
from sixty to seventy bushels of chips. Trunks of Oak are often found lying in the gravel beneath the peat, but Fir has never been noticed in such situations. These trees are invariably rooted in the peat, but at various depths, evidently proving that their growth did not commence until the bog was actually in the course of formation, and that they sueceeded each other as in the Highland forests. Instances, indeed, occur in which a large stump is fixed in the peat immediately over another; more rarely a prostrate trunk is found at such a distance beneath the roots of another that more than a century must have elapsed between the destruction of the first and the growth of its successor.

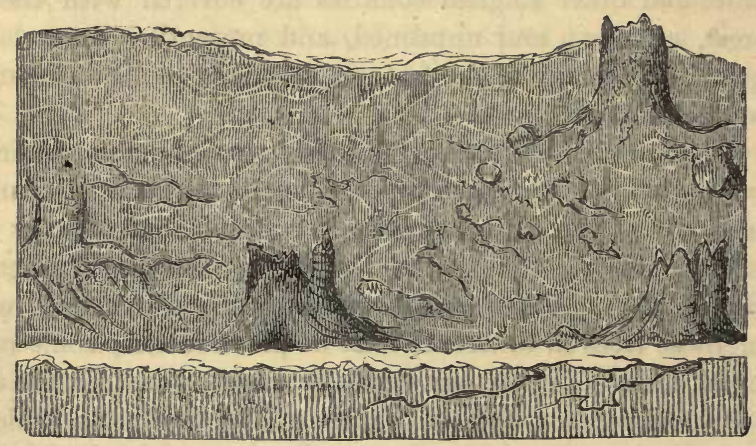

SECTION OF A BOG CONTAINING FIR-STUMPS.

In the bog districts, the wood obtained from these sources forms the principal fuel. It makes a brilliant and fragrant fire, a property of no little value in the cheerless districts where it abounds; though one is by no means disposed on that account to forgive the bogs for having swallowed up the noble forests, the place of which they have usurped. This wood is also much used as a building material, especially when it is likely to be exposed to wet, its long seasoning having rendered it indestructible by damp. For the same reason it is preferred to 
any other wood for making washing-tubs, axles of millwheels, \&c.

The range of the Pine is very extensive; it is to be met with throughout the greater part of Europe, from the Mediterranean to Norway, varying in elevation from seven hundred to nearly four thousand feet, in favourable situations attaining a height of a hundred feet or more, with a trunk upwards of four feet in diameter, and dwindling as it ascends the mountains to a mere bush. A variety is said to grow at Nootka Sound in North America, and it is found also in Siberia, Kamschatka, Caucasus, and Japan. There are immense forests of it on the table-lands of Russia, and on most of the mountain-ranges of Europe, as far south as the Pyrenees. The seeds are sometimes carried by the wind from these latter situations to marshy places and peat-bogs; but here, though the seeds germinate, the trees are always stunted in growth, and soon sicken and die. The finest specimens grow in a dry soil, and it has been remarked that in native forests the roots run along the surface, and even rise above it, and the tree seems to derive a great part of its nourishment from the black vegetable mould formed by the decay of its own leaves. The trunk is generally straight, and covered with a scaly bark of a reddish hue. The leaves grow in pairs, sheathed at the base, from two to three inches in length on young trees, but in old trees they are much shorter. They are convex on one side, and nearly flat on the other, so that when pressed together they form a cylinder; the edges are minutely notched, and the colour is a light blueish green, especially beneath, or on the convex surface. They remain attached to the tree four years, and, long before this, exchange the glaucous hue for a dark green. The flowers appear in May and June, the barren ones arranged in whorls around the extremities of the last year's shoots, and producing pollen in great abundance. The fertile catkins grow most frequently in pairs at the summit of the new shoots, and gradually assume the 
form of cones, which are not ripe until eighteen months old. They are stalked, brown, rugged, and more or less tapering to a point. In the autumn of the second year they begin to open at the extremity, and shed the seeds, which are situated in pairs at the base of each scale : they are small, and each furnished with a long membranous wing.

There are two principal varieties of the Scotch Fir: in

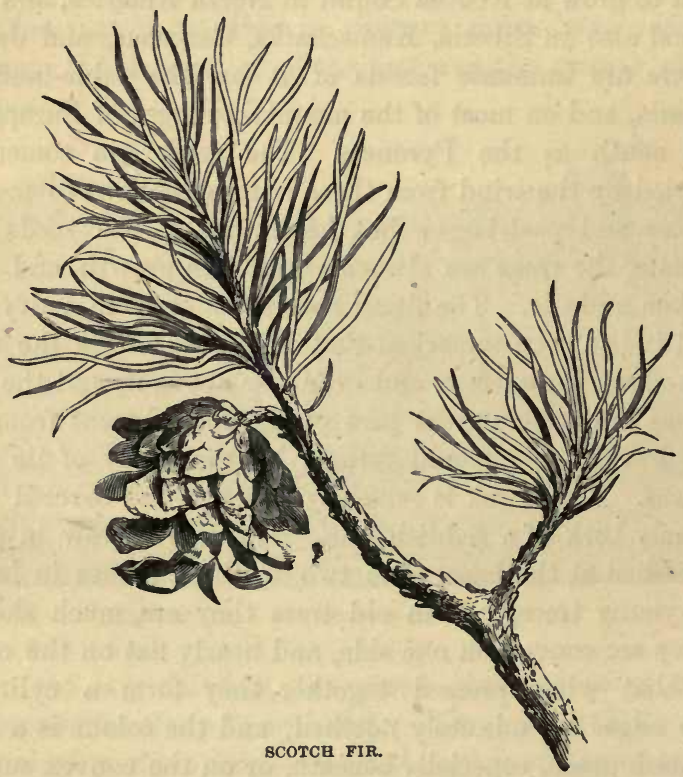

one, the trunk is red and nearly smooth, the branches form a pyramidal head, and the cones are abundant, tapering almost to a point; in the other, the trunk is rugged and yellowish brown, the branches take a horizontal direction or bend downwards, the cones are less numerous and not so much pointed, and the leaves are shorter, of a much lighter, and decidedly glaucous, hue. The timber of the 
former variety is white, soft, and of little value; that of the latter is red, firm, resinous, and durable.

In the natural forests of Pine, the young plants, being the produce of different years, and consequently of various sizes, the stronger gradually destroy the weaker, until the wood is reduced to the distances at which the trees can ultimately stand, whilst the lateral branches gradually decay and fall off, so that thinning and pruning are quite unnecessary. In short, a natural or self-sown forest of Pines is left entirely to Nature. Nature sows the seed, rears the tree, prunes and thins the wood; and the hand of man is applied only to cut it down when fit for timber. In planted woods, the Pines are commonly of the same age and size; and then it is absolutely necessary to thin them, as their tops rise equal, and form a surface parallel to that of the ground on which they stand; therefore, without relief by thinning, the whole are to a certain extent injured.

The timber of the Scotch Fir, especially the horizontal variety described above (which is generally considered to be the true Highland Pine), is similar in every respect to the best Baltic Pine, and is highly prized. The best is obtained from trees the age of which averages about a hundred and twenty years, and which, from their growing in a cold climate, have matured their timber slowly. The earlier the age at which the side branches die and drop off, the clearer is the wood of knots, and proportionally the more valuable. When fully matured, it is of a red hue, and is considered scarcely less valuable than the Oak, instances being on record where timbers of Pine in the roofs of old buildings have, after the lapse of several centuries, been found perfectly sound. It is light, stiff, and strong, easily worked, and freer from knots than that of any other kind of Fir-qualities which render it admirably adapted for all kinds of house carpentry. Its size, length, and straightness of trunk fit it also for the main timbers of buildings, such as rafters, joists, \&c., which are almost universally 
made of it. In naval architecture it is very extensively used, and the best masts are considered to be those made of the Pine imported from the Baltic. In Russia many of the roads are formed of the trunks of the Pine, trees being selected which are from six to twelve inches in diameter at their largest end. The ground being marked out for the road, the trunks are laid down side by side, the thick end of the one alternately with the narrow end of the other, and the branches being left at the summit to form a sort of edge on each side of the road, which is very useful as a guide to travellers when the ground is covered with snow. The interstices are then filled in with earth, and the road is finished. In Lapland and Northern Russia the outer bark, like that of the Birch, is frequently used by the natives for covering their huts, or as a substitute for cork, to float the nets of the fishermen. The inner bark is made into ropes, and sometimes woven into mats, like those made from the Lime-tree. In Norway, where it is the custom to kiln-dry oats to such a degree, that both the grain and the husks are made into a meal almost as fine as wheaten flour, in seasons of scarcity, the dried inner bark of the Pine is ground with the oats and made into thin cakes, which, when baked upon a girdle, are said to be not unpalatable.

From the growing tree turpentine may be procured by stripping off a piece of bark from the trunk in spring, when the sap is in motion, and the resinous juice that exudes is received in a notch or hollow cut in the tree; this juice, as it accumulates, is ladled out into a basket, and the liquid that passes through is the common turpentine. The thick matter which remains is distilled with water, and produces spirits of turpentine, leaving the common yellow resin of the shops. But the greatest quantity of turpentine used in this country is imported from America, where it is obtained from the Carolina Pine.

Tar is obtained from the wood of the Pine after it has been felled. Dr. Clarke thus describes the method of 
procuring it: "The inlets of the Gulf of Bothnia everywhere appeared of the grandest character, surrounded by noble forests, whose tall trees, flourishing luxuriantly, covered the soil quite down to the water's edge. From the most southern parts of Westro-Bothnia to the northern extremity of the gulf the inhabitants are occupied in the manufacture of tar, proofs of which are visible along the whole extent of the coast. The process by which the tar is obtained is very simple; and, as we after witnessed it, we shall now describe it from a tar-work we halted to inspect upon the spot. The situation most favourable to the process is in a forest near to a marsh or bog, because the roots of the Scotch Pine, from which tar is principally extracted, are always most productive in such places. A conical cavity is there made in the ground (generally in the side of a bank or sloping hill); and the roots, together with logs and billets of the wood, being neatly trussed in a stack of the same conical shape, are let into this cavity. The whole is then covered with turf, to prevent the volatile parts from being dissipated, which, by means of a heavy wooden mallet and a wooden stamper, worked separately by two men, is beaten down and rendered as firm as possible above the wood. The stack of billets is then kindled, and a slow combustion of the kiln takes place, as in making charcoal. During this combustion the tar exudes; and a cast-iron pan being fixed at the bottoin of the funnel, with a spout that projects through the side of the bank, barrels are placed beneath this spout to collect the fluid as it comes away. As fast as these barrels are filled, they are bunged, and are then ready for immediate exportation. From this description it will be evident that the mode of obtaining tar is by a kind of distillation per descensum (downwards), the turpentine, melted by fire, mixing with the sap and juices of the Pine, while the wood itself, becoming charred, is converted into charcoal." Dr. Clarke, after stating that tar was made by the Greeks more than two thousand years ago, 
remarks: "There is not the smallest difference between a tar-work in the forests of Westro-Bothnia and those of Ancient Greece. The Greeks made stacks of Pine, and having covered them with turf, suffered them to burn in the same smothered manner; while the tar, melting, fell to the bottom of the stack, and ran out by a small channel cut for the purpose."

The country people of Scotland obtain tar by a method similar in principle to that above described, although differing slightly in the details. They hew the wood into billets, put these into a pit dug in the earth, and ignite them; the top is covered with rude tiles; and the tar, as it leaves the wood, flows out through a small orifice at the bottom of the pit. When pitch is to be made, the tar is put into large copper vessels, and is then suffered to boil for some time; the volatile part flies off, and what remains, when cold, hardens and becomes pitch.

In seasons of scarcity, the bark of the Pine is converted by the Swedish peasants into bread.

"In the character of the Swedish peasant many traits present themselves well worthy of imitation in the other ranks of society. Placed in a part of the world where the influence of winter is felt for more than half the year, and where the general barrenness of the soil must subject him to great privations, he is, notwithstanding, cheerful and contented.- In the northern parts, where the early approach of the frost, even in the midst of summer, sometimes cuts off the whole of his scanty crop, and deprives him of his winter provision, he finds bread even in the heart of the forest; and with the bitter bark of the Pine, beaten till it is reduced to a fine pulp, he continues to support existence, living by means of this unpalatable food where others would die. Fortunately, it is only in years of great scarcity that he is compelled to have recourse to these means; nor did I, during my travels in the North, ever meet with this barke bröd, or bark bread, used as food by the poorer classes. Hard as his fare is at all 
times, the Swedish peasant exhibits no sign of discontent; and if his countenance do not portray a great flow of spirits or hilarity of manner, it shows him to be what he really is, humble, serious, devout, and happy. Give him but the smallest trifle, he receives it with thankfulness, and you are doubly repaid by the grateful and contented manner in which it is accepted." 1

\section{PINUS PINASTER.}

The Cluster Pine, or Pinaster.

THE Pinaster is one of the most extensively planted in this country of all the foreign Pines. In its younger stage it is a pyramidal bushy tree, well marked by its erect growth and regular whorls of ascending branches from a foot to a foot and a half apart, by its tufts of long deep green leaves, and by its clusters of large cones, which are perfected on very young trees. From the starlike arrangement of these cones it derives its name of Pinaster,-Star Pine. The clusters are situated beneath the whorls or tiers of brauches, and contain from four to a dozen cones; but it is far from uncommon to see as many as twenty or thirty in a mass, the lowermost being forced, by the pressure of thuse above, to point downwards. They often remain attached to the tree many years after they have attained maturity, and indeed may sometimes be seen, covered with gray lichen, adhering to the main stem, on which, while it was a mere twig, they were produced a dozen years before. For the first five and twenty years of its growth the age of the Pinaster may be discovered with tolerable accuracy from observing the number of tiers formed by its branches, each interval between two tiers being the result of a year's growth. As the tree grows older, the lower limbs die off, and the trunk

1 Brook's "Sweden." 
becomes covered with a purplish bark, marked with numerous deep fissures, and, in exposed situations, often invested with the gray lichen alluded to above. The bark

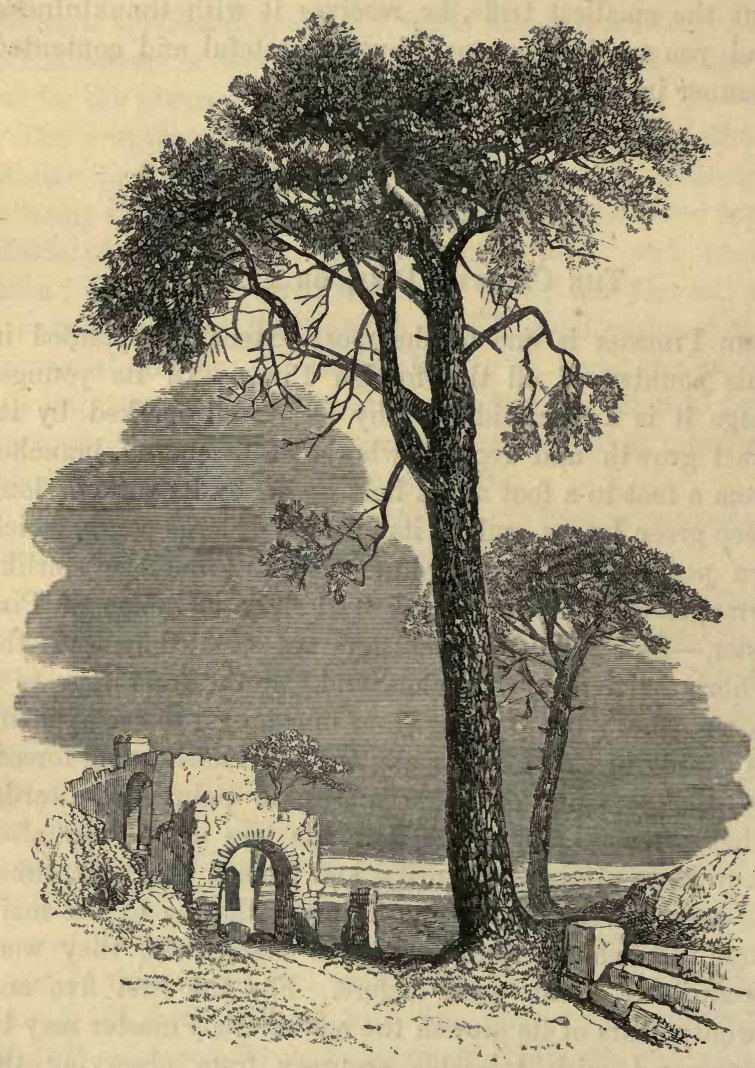

THE PINASTER.

itself is of a soft, pithy texture, and readily splits into plates about two inches wide and from four to six in length, having an even surface on both sides. From the 
number of these plates also the age of a tree may be nearly computed, for unless any of the outer scales have peeled off, which sometimes happens, the age of the tree corresponds with the number of annual deposits. The

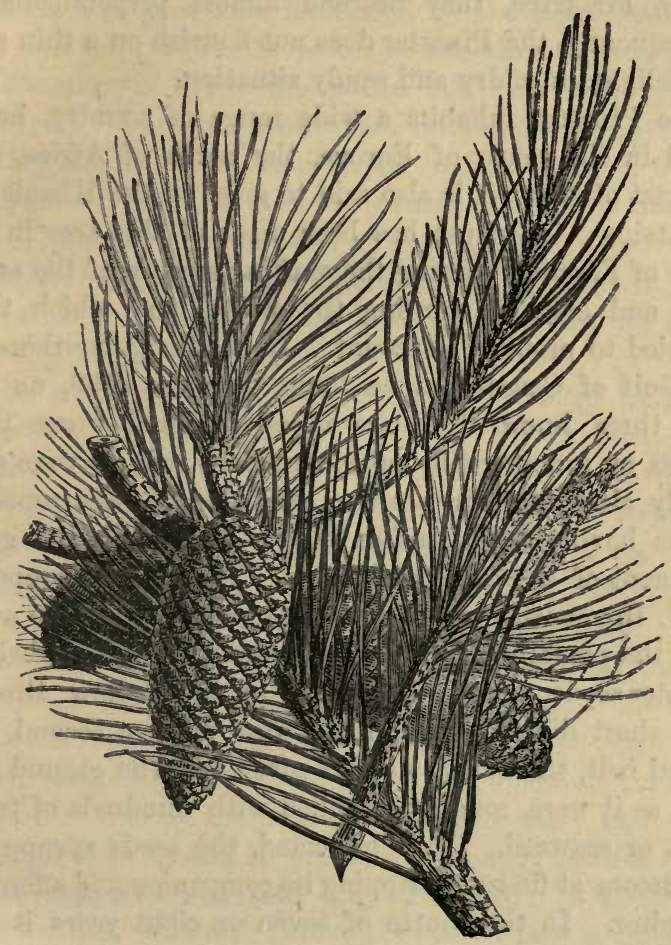

CONES OF PINASTER.

trunks of old trees generally ineline a little on one side, this effect having been produced by the weight of the foliage, \&c. while they were young. The lower part of the trunk is entirely bare of branches, but higher up there usually project the stumps of numerous dead branches of 
unequal lengths and diameters, and the head bears a close resemblance to that described below as characterising the Stone Pine, except that it does not spread so widely. The roots are few in number, but unusually stout, and instead of extending themselves laterally, as is the case with most of the Fir tribe, they descend almost perpendicularly. Consequently, the Pinaster does not flourish on a thin soil, but delights in a dry and sandy situation.

The Pinaster inhabits a wide range of country, being found in the south of Europe, the north of Africa, and the west of Asia; it is also said to grow on the Himalayan mountains. Great use has been made of this tree in the south of France, in fixing the shifting surface of the sandhills, and even in turning the waste land which they occupied to profitable account. In the neighbourhood of the Gulf of Gascony alone there were, in 1789, no less than three hundred square miles rendered worse than useless by innumerable naked sandhills, which were constantly altering their position, and on the occurrence of storms having their surface blown inland, to the great detriment of the cultivated lands. The remedy proposed by M. Bremontier was to erect a fence of hurdles so as to front the prevailing wind, and to sow within this a belt of Pinaster-seeds mixed with those of the Yellow Broom. At a short distance within this were sown a second and a third belt, till the whole was covered. The ground was then, as it were, roughly thatched with hundreds of trees, reeds, or seaweed. Thus protected, the seeds sprung up, the Broom at first outstripping its companion and affording:. it shelter. In the course of seven or eight years it was found that the Pinaster began to choke its foster-nurse, which quietly submitted and gave up its decaying leaves and twigs to the fertilization of the soil.

In about ten or twelve years the plantations were thinned, the branches being applied to the sheltering of ground not hitherto enclosed, and the trunks being burned to make tar. When about twenty or thirty years of age 
the trees are fit for producing resin; and when exhausted for this purpose they are cut down to make room for their self-sown progeny. In this way many thousands of acres have been reclaimed and converted into plantations, which afford occupation to the inhabitants of the surrounding districts, who gain their livelihood by the manufacture of resin and tar. From its power of resisting the sea-blast, the Pinaster is sometimes called the Sea Pine (Pinus maritima). I am not aware that its valuable property of binding sandhills has been tested in this country, but in the west of England it is frequently planted on the seaside of plantations composed of other trees, and proves an effectual shelter, never showing the least tendency to bend before the prevailing wind, and never having its outer branches blighted.

The common resin of commerce is extracted from the Pinaster while it is in a growing state. In summer, trees are selected which have a trunk about four feet in diameter, and longitudinal cuts are made through the bark about six inches wide and a foot long, with a cavity at the base. Into this the resin flows from between the bark and the wood, and is scooped out occasionally with a ladle. It is found necessary to lengthen the cut very frequently, as the resin does not flow freely from an old wound. In a few years the tops of the grooves are too high to be reached by a man standing on the ground; the operator therefore climbs the tree by the help of a notched pole: and when the trees have ceased to produce resin, they are cut down to be manufactured into tar. The resin is melted in caldrons, and strained through straw to free it from impurities : it is then stored away in barrels and is fit for the market.

To make the best lamp-black, the straw through which resin has been strained is put into a stove and kindled: the smoke passes through a chimney into a chamber which has an opening in the roof; over the opening is placed a flannel bag, supported by wooden rods in the form of a 
pyramid. The soot is deposited either on the walls of the chamber or on the flannel bag,- - the flannel acting as a filter to the lighter part of the smoke, by retaining the soot and allowing the heated air to escape. The soot is detached from the flannel bag by striking the outside

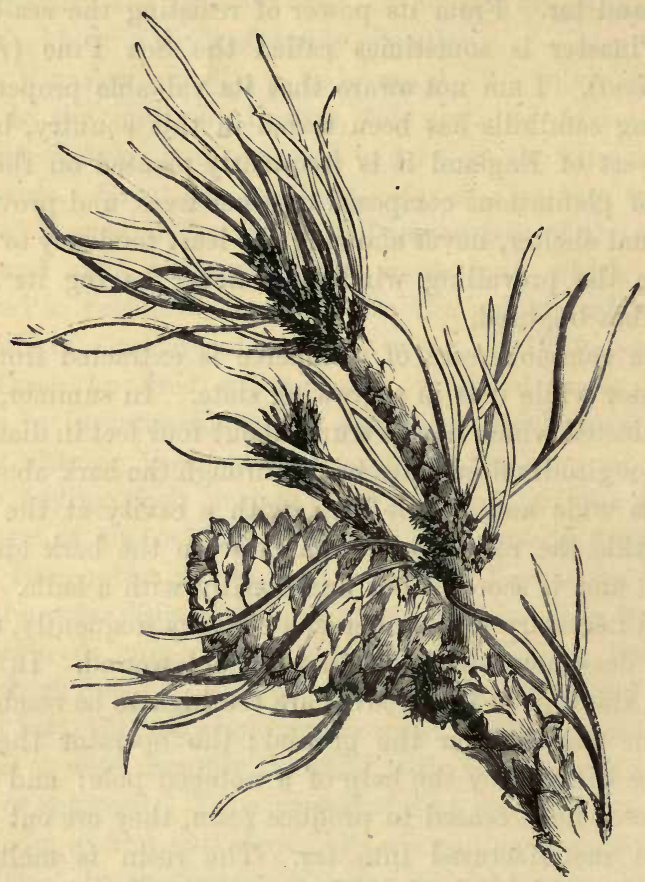

PINUS LEMONIANA.

smartly with a stick; and, the door of the chamber being opened, the lamp-black is swept out and packed in small barrels. Tar is sometimes substituted for resinous straw ; and lamp-black is sometimes obtained by burning resin in a kind of lamp furnished with a chimney, which is surrounded by a flannel, and which retains the soot. It 
was from this mode of obtaining lamp-black that that substance derived its name.

The Pinaster also produces tar, pitch, and oil of turpentine, but not of a fine quality.

A singular variety of Pinaster was noticed by Sir Charles Lemon at Carclew in Cornwall, which has been named Pinus Lemoniana. The peculiarity of this tree is, that it bears at the extremity of every branch a solitary cone

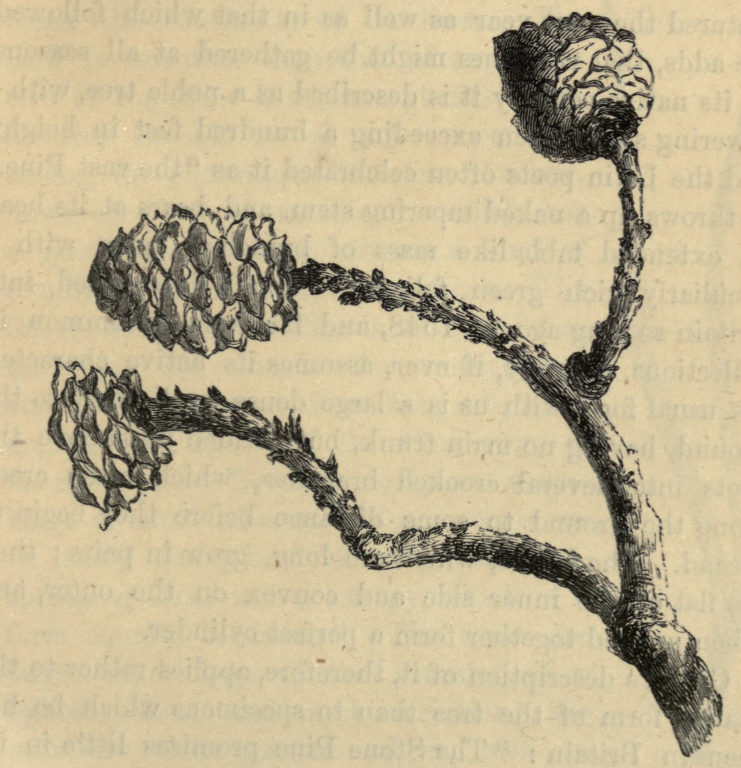

DEAD BRANCH OF PINUS LEMONIANA.

instead of a new shoot, the side shoots rising from beneath the base of the cone. Hence the tree has a singular zigzag appearance in its young stage, and, when old, is more bushy than the common Pinaster.

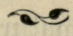




\section{THE STONE PINE.}

\section{Pinus pinea.}

Turs is the Pine of Italy and the Tyrol, much prized for its nuts even in Pliny's time, who says that it bore at the same time ripening fruit, fruit destined to be matured the next year as well as in that which followed. He adds, that ripe ones might be gathered at all seasons. In its native country it is described as a noble tree, with a towering stem, often exceeding a hundred feet in height, and the Latin poets often celebrated it as "the vast Pine." It throws up a naked tapering stem, and bears at its head an extended table-like mass of branches, laden with a peculiarly- rich green foliage. Though introduced into Britain so long ago as 1548, and far from uncommon in collections, it rarely, if ever, assumes its native character. Its usual form with us is a large dense bush, leafy to the ground, having no main trunk, but divided just above the roots into several crooked branches, which often creep along the ground to some distance before they begin to ascend. The leaves, which are long, grow in pairs ; they are flat on the inner side and convex on the outer, and when pressed together form a perfect cylinder.

Gilpin's description of it, therefore, applies rather to the Italian form of the tree than to specimens which he has s̀een in Britain: "The Stone Pine promises little in its infancy in point of picturesque beauty. It does not, like most of the Fir species, give an early indication of its future form. In its youth it is dwarfish and round-headed, with a short stem, and has rather the shape of a full-grown bush than of an increasing tree. As it grows older, it does not soon lay aside its formal shape. It is long a bush, though somewhat more irregular, and with a longer stem; but as it attains maturity, its picturesque form 
increases fast. Its lengthening stem assumes commonly an easy sweep. It seldom, indeed, deviates much from a straight line, but that gentle deviation is very graceful, and above all lines difficult to imitate. If accidentally either the stem or any of the larger branches take a larger sweep than usual, the sweep seldom fails to be graceful. It is also among the beauties of the Stone Pine, that as the lateral branches decay, they leave generally stumps, which, standing out in various parts of the stem, break the continuity of its lines. The bark is smoother than that of any other tree of the Pine kind, except the Weymouth; though we do not esteem this among its picturesque beauties. Its hue, however, which is warm and reddish, has a good effect; and it obtains a kind of roughness by peeling off in patches. The foliage of the Stone Pine is as beautiful as the stem. Its colour is a deep warm green; and its form, instead of breaking into acute angles, like many of the Pine race, is moulded into a flowing line by an assemblage of small màsses. As age comes on, its round clump-head becomes more flat, spreading itself into a canopy, which is a form equally becoming." The cones are larger than those of the Pinaster, of a lighter colour, and more orbicular; the nuts are three-quarters of an inch in

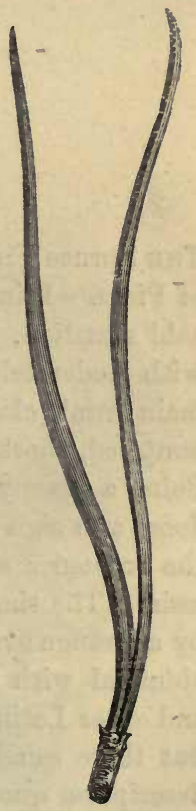
length, and furnished with a very short wing. The seeds, after being detached from their strong outer shell, are commonly sold in large quantities all the winter in Florence, Pisa, and other places within reach of the extensive forests of this Pine, under the name of Pinocchi. They are about the same size as the common hazel-nut, only much more oblong, and not very unlike them in taste, except that they have a slight and not disagree- 
able resinous flavour. Remains of the kernels were found among the domestic stores during the excavations at Pompeii. Sir George Staunton also informs us that they are much prized by the Chinese. In Italy and the South of France, where this tree is called by English visitors the Umbrella Pine, the empty cones, which are highly inflammable, are commonly used for lighting fires.

\section{THE SPRUCE FIR.}

\section{Abies excelsa.}

The Spruce Fir was known to the ancients by the name of Picea. Pliny describes it as delighting in a lofty and cold situation. He compares its form to that of the Larch, with moderately long branches, or arms spreading from the main trunk close to the root; but the leaves, he says, are scattered, short, rigid, and prickly, and abound in resin. Being a gloomy tree, its branches were used to attach to doors as a sign of a funeral about to take place. ${ }^{1}$ Under the influence of the sun, it sometimes exudes drops of resin. The timber is used for beams, laths, \&c. Linnæus, by a strange oversight, considered the Picea of the ancients identical with our Silver Fir, and the Abies of Pliny and other Latin writers he supposed to be our Spruce Fir: but there can be no doubt that he was here in error, the description quoted above being much more applicable to the tree now under consideration.

The Spruce or Norway Spruce Fir is a native of the mountainous parts of Europe and Asia, preferring a moist soil and cold climate. It is most frequent in the north,

1 In Sweden and Norway at the present day, when a funeral is about to take place, the road into the churchyard and to the grave is strewn with these green sprigs, the gathering and selling of which is a sort of trade for poor old people about the towns. 
but is found at a great elevation on the Alps, Pyrenees, and other mountains of central Europe, flourishing in situations which are too cold and wet for the Scotch Pine.

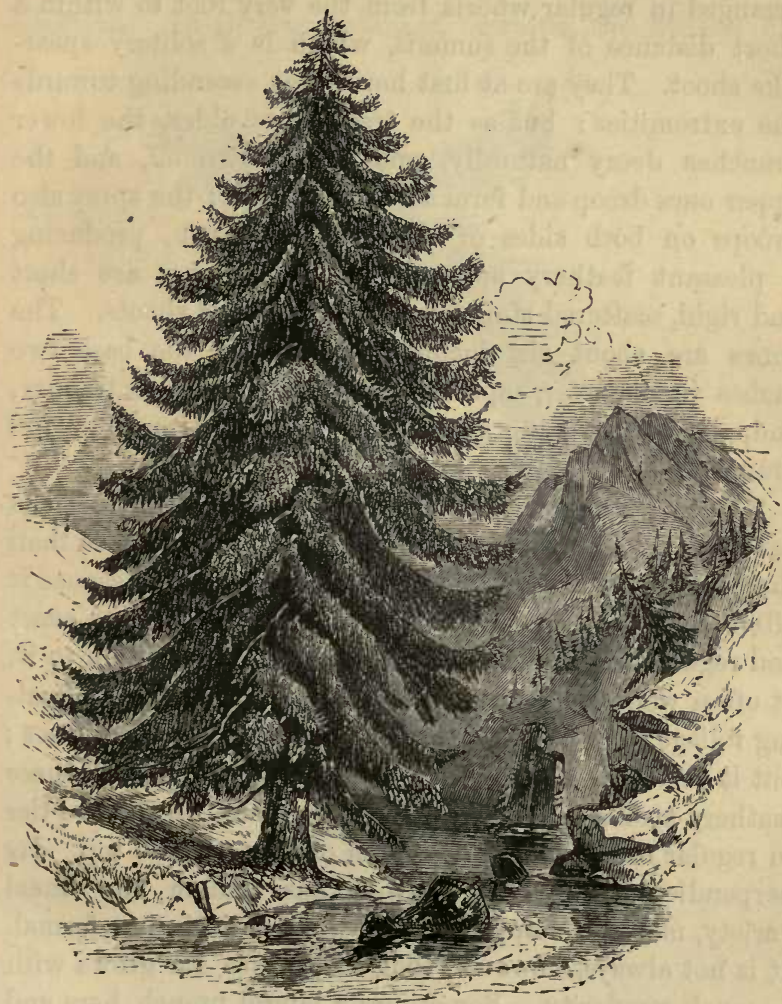

THE HPRUCE FIR.

In Lapland it grows at an elevation of a thousand feet, in Norway and Sweden at an elevation of from two to three thousand, and among the Alps of Switzerland it attains perfection at a much greater height. 
The usual form of the Spruce Fir is a perfectly erect pyramidal tree, upwards of a hundred feet in height, with a solid trunk, which at the base is from three to six feet in diameter. In young trees the lateral branches are arranged in regular whorls from the very root to within a short distance of the summit, which is a solitary spearlike shoot. They are at first horizontal, ascending towards the extremities : but as the tree grows older, the lower branches decay naturally, and are thrown off, and the upper ones droop and form a graceful curve ; the spray also droops on both sides of the leading branch, producing a pleasant feathery appearance. The leaves are short and rigid, scattered singly on all sides of the shoots. The cones are about six inches long, and at the base two inches in diameter, tapering, and blunt at the extremity, and, when ripe, hang downwards from the ends of the branches.

"In a picturesque point of view, the Spruce Fir is generally esteemed a more beautiful and elegant tree than the Scotch Fir ; and the reason, I suppose, is, because it often feathers to the ground, and grows in a more exact and regular shape. But this is a principal objection to it. It often wants both form and variety. We admire its floating foliage, in which it sometimes exceeds all other trees; but it is rather disagreeable to see a repetition of these feathery strata, beautiful as they are, reared tier above tier in regular order, from the bottom of a tree to the top. Its perpendicular stem, also, which has seldom any lineal variety, makes the appearance of the tree still more formal. It is not always, however, that the Spruce Fir grows with so much regularity. Sometimes a lateral branch, here and there taking the lead beyond the rest, breaks somewhat through the order commonly observed, and forms a few chasms, which have a good effect. When this is the case, the Spruce Fir ranks among picturesque trees. Sometimes it has as good an effect, and in many circumstances a better, when the contrast appears still stronger-when the 
tree is shattered by some accident, has lost many of its branches, and is scathed and ragged. A feathery branch here and there, among broken stumps, has often an admirable effect, but it must arise from some particular situation. In all circumstances, however, the Spruce Fir

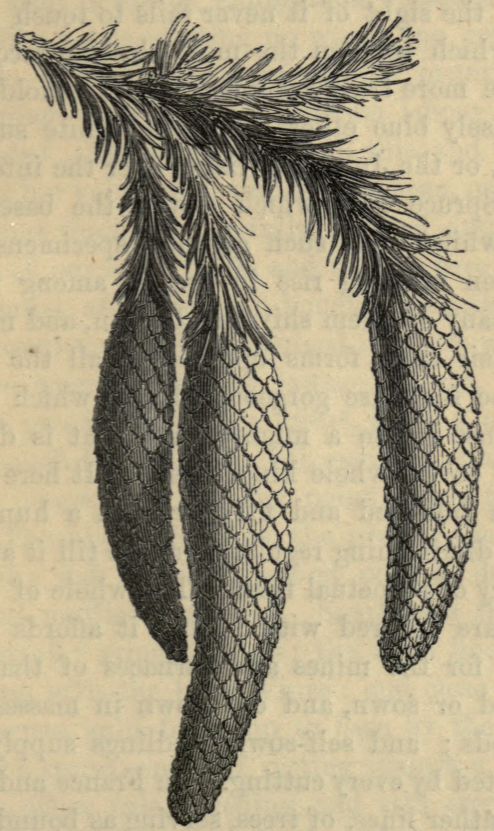

CONES OF SPRUCE FIR.

appears best either as a single tree, or unmixed with any of its fellows: for neither it nor any of the spear-headed race will ever form a beautiful clump without the assistance of other trees." 1

It is, however, only in its native haunts, the sides of mountain ravines, that the real picturesque beauty of the 1 Gilpin. 
Spruce Fir can be appreciated : and it is not altogether just of the author just quoted to measure the excellences of a tree essentially mountainous by the same rules which he. applies to the humbler inhabitants of the lowlands. "It is," says Sir T. D. Lauder, "the great tree of the Alps, and is so mentally associated with the grandeur of Swiss scenery that the sight of it never fails to touch chords in our bosom which awaken the most pleasing recollections. What can be more truly sublime than to behold, opposed to the intensely blue ether, the glazed white summits of Mont Blauc, or the Jungfrau, rising over the interninable forests of Spruce Firs which clothe the bases of the mountains, whilst some such gigantic specimens as those we have been noticing rise in groups among the rocks before us, many of them shivered, broken, and maimed by tempests, their dark forms opposed to all the prismatic hues of some immense gorgeous glacier, which nourishes in its immense bosom a mighty river that is doomed to fertilize and enrich whole kingdoms?" It here attains a height of a hundred and fifty, or even a hundred and eighty feet, diminishing regularly in size till it approaches the boundary of perpetual frost. The whole of the Hartz Mountains are covered with it, and it affords both fuel and timber for the mines and furnaces of that district. It is planted or sown, and cut down in masses, like our coppice woods; and self-sown seedlings supply the vacancies created by every cutting. In France and Germany hedges, or rather lines, of trees, serving as boundary fences and at the same time as sources of shelter and shade, are used in the same way as thorn-hedges are in England. They produce an enormous quantity of timber for fencing and fuel every twenty or thirty years ; and every year the fall of their leaves supplies manure. With us, however, the Spruce Fir, unless planted in peculiar situations, both with regard to soil and aspect, does not thrive. It produces abundance of cones at an early age, but soon dwindles away and dies. 
In the country bordering on the Baltic a Spruce forest is a very different thing. "This is the land of Pineslofty, erect battalions : their bark is smooth as the mast of a ship; their branches regular as a ladder, varying scarce an inch in girth in fifty feet of growth: for miles interrupted only by a leaning, never by a crooked, tree ; with an army of sturdy Lilliputians clustering round their bases - fifty heads starting up where one yard of light is admitted. What becomes of all the pruning, trimming, and training-the days of precious labour spent on our own woods? Nature here does all this, and immeasurably better for her volunteers, who stand closer, grow faster, and soar higher than the carefully planted and transplanted children of our soil. Here and there a bare jagged trunk, and a carpet of fresh-hewn boughs beneath, show where some peasant urchin has indulged in sport which with us would be amenable to the laws, - namely, mounted one of these grenadiers of the forest, hewing off every successive bough beneath him, till, perched at a giddy height aloft, he clings to a tapering point which his hand may grasp. The higher he goes, the greater the feat, and the greater the risk to his vagabond neck in descending the noble and mutilated trunk." Sometimes the woods are composed of "mingled trees; the fresh hues of the Oak contrasting with the black Pines: and close to us stood a noble Spruce, split from top to base by the lightning of last week's storm, one half resting against a neighbouring stem, the other pale, bleeding, and still erect; below lay forty feet of the luxuriant head, with enormous splinters, rent in longitudinal lines, while the ground was furrowed in deep angular troughs by the last strength of the fluid : here and there the sun shooting across a Silver Birch trunk like the light across a liquid human eye, or illuminating the red bark of a veteran Scotch Fir with a fiercer glow, or stealing, few and far between, in slender bars of gold along the tender grass." 1

1 "Letters from the Baltic." 
The timber of the Spruce Fir has for an unknown period been imported into Britain from Norway, chiefly in the form of entire trunks, which are used for scaffoldingpoles, spars, oars, and masts for small craft; but partly, also, sawn into planks or deals, known in common as white deal, white Baltic deal, and white Christiania deal, the wood having a red hue only when the tree is grown in certain soils and situations. The poles, spars, and oars are the thinnings of the Norwegian woods; and the deals and planks are made from the larger trees which are left. The slenderest poles are taken from the largest and oldest woods, and are called seedlings ; they are always found where the wood is most dense, and very often close by the side of a larger tree. They grow very tall and slender, wholly without branches except at the summit, and, though often only a few inches in diameter, are of great age.

Nothing can be finer than the Spruce-timber of the Alps, which is so tough, that the natives are actually in the habit of kindling fires about the trees so as to burn them down, to save their own trouble and the edge of the axe.

The Spruce Fir, besides furnishing large quantities of valuable timber, produces the substance known by the name of Burgundy pitch. To produce this resin, the collector, in the spring, before the sap begins to ascend, cuts off a long vertical strip of bark from the south side of the tree, as deep as the soft wood, but without wounding it. The sap exudes very slowly from between the bark and the wood, and hardens on exposure to the air. In about three or four months afterwards the groove is found filled with dry resin, which is then collected and purified by being melted in boiling water.

The uses of deal are too numerous and well known to be noticed here. The bark is used in tanning. In Sweden and Norway the inner bark is made into baskets; and the canoes, which are made of the timber of the large trees, 
and which are so light that they may be carried on a man's shoulders when the navigation is interrupted by a rapid or cascade, have their planks fastened together by strings made of the roots, so that not a single nail is used in their construction. The long and slender roots are chosen for this purpose ; they are rendered flexible by splitting them down the middle, and by boiling them for two or three hours in water, mixed with alkali and sea-salt. They are

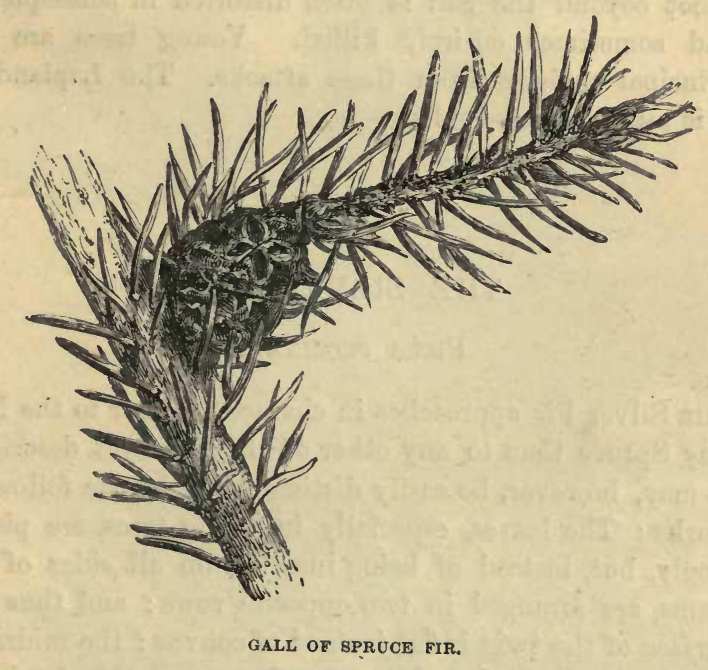

then dried and twisted into cordage, which is used instead of hemp, both for naval and agricultural purposes. From a decoction of the young shoots Spruce beer is made.

Spruce Firs in this country are liable to serious depredations either from squirrels or crossbills, which gnaw off about six inches of the young shoots, and let them fall to the ground, sometimes in such quantities as to carpet the soil. It is scarcely decided which of the two animals is the culprit; but the visits of either are much dreaded by 
foresters. The only insect which injures the Spruce Fir is a kind of aphis, which in the autumn lays its eggs. on the under side of the buds on the side branches. When these begin to burst in spring, the young leaves grow together into a solid mass, composed of a number of cells. Each of these contains an embryo insect, and towards the end of-summer opens and suffers the perfect insect to escape. These galls somewhat resemble imperfect cones, bearing a shoot at the summit: the part of the shoot beyond the gall is often distorted in consequence, and sometimes entirely killed. Young trees are the principal sufferers from these attacks. The Laplanders, it is said, eat these galls.

\section{$\infty$ \\ THE SILVER FIR.}

\section{Picea pectinata.}

The Silver Fir approaches in character nearer to the Norway Spruce than to any other of the trees yet described. It may, however, be easily distinguished by the following marks : The leaves, especially in young trees, are placed singly, but, instead of being inserted on all sides of the stems, are arranged in two opposite rows; and thus the surface of the twig is flat instead of convex : the midrib is visible on the under side only, the upper side having a furrow down its centre. On each side of the midrib beneath is a white silvery line, from which the tree derives its name; and as the point of the leaf is always turned up, these lines make a conspicuous appearance. The cones are large and cylindrical, and each scale terminates in a deflexed point. Their position, also, which is erect, affords an infallible mark of distinction, the cones of the Spruce Fir being pendent. When young they are green, but as they advance towards maturity they acquire a rich 
purplish hue, and when quite ripe are of a deep brown. They remain upwards of a year on the tree, appearing in May, and ripening the seed in the October of the following year. The general outline of the tree, when standing

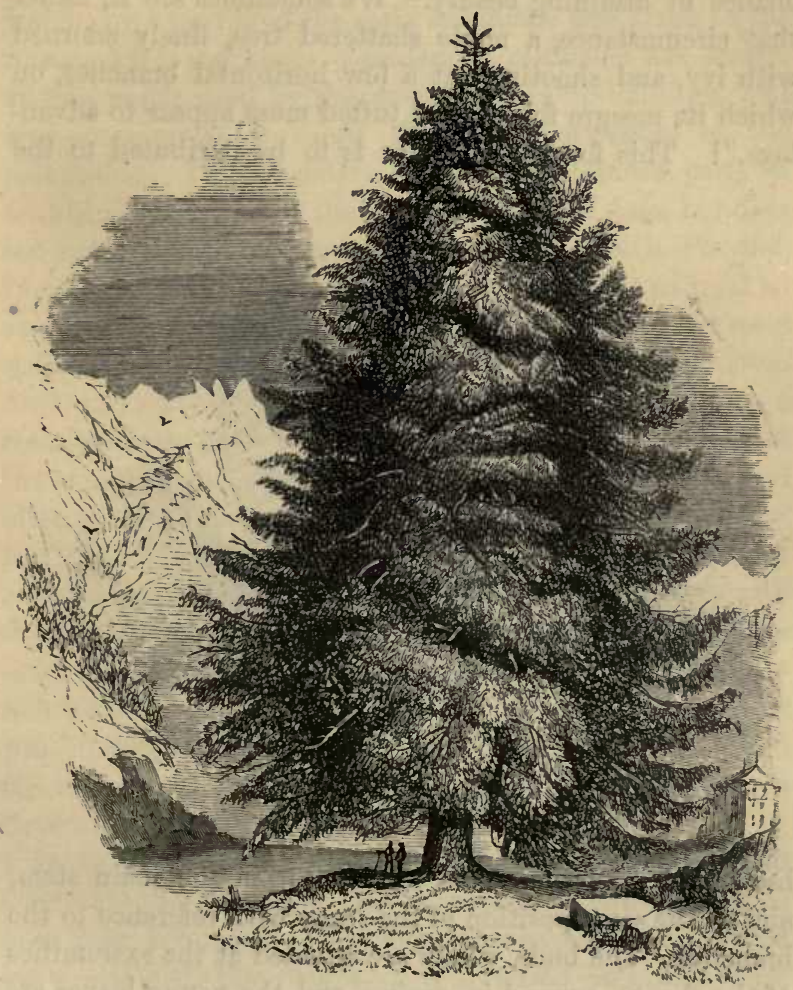

THE SILVER FIR.

alone, is a lengthened pyramid. "It has all the regularity of the Spruce without its floating foliage. There is a sort of harsh, stiff, unbending formality in the stem, the branches, and the whole economy of the tree, which 
makes it disagreeable. We rarely see it, oven in its happiest state, assume a picturesque shape : assisted it may be in its form when broken and shattered, but it will rarely get rid of its formality. In old age it stands the best chance of attaining beauty. We sometimes see it, under that circumstance, a noble shattered tree, finely adorned with ivy, and shooting out a few horizontal branches, on which its meagre foliage and tufted moss appear to advantage." 1 This formal character is to be attributed to the

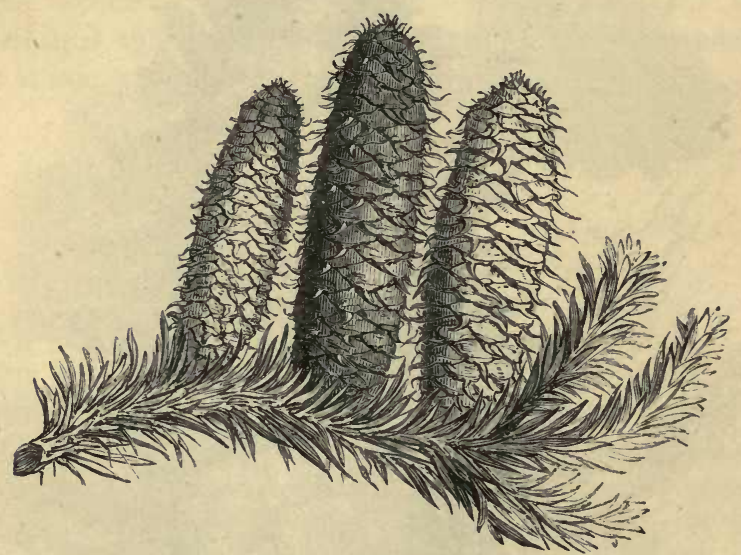

CONES OF SILVER FIR.

horizontal direction of its branches from the main stem, and to the same position of the spray with reference to the branches. The buds, which are situated at the extremities of the shoots, expand in spring, and the young leaves are of a pale green, almost as delicate as the tint of the primrose. I have observed that the Sulphur butterfly, which makes its appearance about the same time with these tender shoots, loves to settle on their under side, either attracted by their flower-like semblance, or taught by

1 Gilpin. 
instinct to rest where its enemies may be unable to distinguish its yellow wings from the surrounding foliage. If driven from one of these places of retreat, it flies a short distance and alights on another.

The Silver Fir was called by the Romans Abies, a name which, by an error of the early botanists, was given to the Spruce Fir ; and hence considerable confusion has arisen. It was much used by the ancients in ship-building, and was considered by Virgil the fairest ornament of the mountains. It is a native of the mountainous parts of central Europe, and of the west and north of Asia, but does not extend so far north as the Spruce or Scotch Fir, nor, from its preferring a milder climate, is it found at so great an elevation as these trees. In dimensions it is one of the most striking of the tribe, rising frequently to the height of a hundred and sixty or even a hundred and eighty feet, with a stem perfectly erect and generally clothed from the base to the summit with regular tiers of horizontal branches, and often measuring as much as six or eight feet in diameter. For many years the bark is smooth and of a greenish grey colour; but as the tree gains age, it becomes rough with small fissures ; and when very old, it often throws off the outer part in large flakes, leaving the recent bark of a deep rich brown. Pliny relates that an enormous ship, which was built to transport an obelisk from Egypt to Rome, had for its mast a Silver Fir measuring twenty-four feet in circumference.

It is supposed to have been introduced into England about the beginning of the seventeenth century, and is now very common. Specimens are in existence which have attained the height of a hundred and fifty feet, with a trunk sixteen feet in diameter. "The timber of British growth is found to be of excellent quality, and adapted for almost all purposes to which the wood of the Pine is applicable; it possesses both elasticity and strength; its grain being straight and even, it is not subject to warp or twist, even when sawn out of the green 
or newly-cut log. On the Continent the forests of Silver Fir, besides affording a large supply of naval timber for masts, yards, \&c., produce much of the wood used in building; and as it is found to endure a long time when driven as piles under water, it is extensively used for that purpose in Holland and other places."1

The resinous products of the Silver Fir are highly valuable. The substance called Strasburg turpentine (from a large forest of these trees near Strasburg) is collected from small tumours or blisters under the cuticle of the bark. The method of procuring this is thus described by Loudon: "Every year, about the month of August, the Italian peasants who live near the Alps make a journey into the mountains to collect the turpentine. They carry in their hands cornets of tin, terminating in a sharp point, and a bottle of the same metal suspended to the girdle round their waists. Thus accoutred, the peasants climb to the summits of the loftiest Silver Firs, their shoes being armed with cramping-irons, like spurs, which enter into the bark of the trees and thus support the climber, who also clings to the trunk of the tree with his knees and one arm, while, with his other hand, he presses his cornet to the little tumours which he finds in the bark, to extract the turpentine within them. As soon as a cornet is filled with the clear turpentine, it is emptied into the tin bottle which is suspended from his waist; and when this bottle is full, its contents are strained into a large leathern bottle of goatskin. The straining is to free the turpentine from the leaves and bits of bark and moss which may have fallen into it: and this is the only preparation that is given to this kind of turpentine, which is kept in the goatskins for sale. Besides the turpentine collected from the tumours or blisters, an inferior kind is produced by slightly wounding the bark of the tree. In rich soils the trees will yield their sap twice a year, namely, in spring and August; but in general the tumours are formed only once a year, 
namely, in spring, and are full of turpentine in August. The tumours are sometimes round, and sometimes oval; but when the latter, their greatest length is always in a horizontal direction. It is employed, as well as the essential oil which is distilled from it, both in medicine and in the arts. It is the only kind of turpentine, produced by any kind of Pine or Fir, which is used in the preparation of the clear varnishes, and by artists for their colours." The bark may be employed for tanning leather, and is used generally in some parts of Switzerland. In some parts of Europe the young cones, reduced by boiling to a pulp, and preserved with sugar, are eaten as a sweetmeat.

The Silver Fir is very liable to the attack of an insect belonging to the genus Eriosoma, which is not only injurious by disfiguring the individual it infests, but frequently causes the death of the tree by the absorption of its juices. It always attacks the main trunk or the under sides of the branches, appearing in patches, and covered with a white cottony substance. Not only are young trees killed by these destructive insects, but full-grown trees measuring eleven or twelve feet in girth. The only remedy which has been found effectual is to rub the insects to death with a brush or coarse canvas eloth in spring. It does not appear to extend its ravages to any others of the Fir tribe, nor has it been known for more than fifty or sixty years; but it is said to be greatly on the increase.

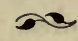

\section{THE LARCH.}

\section{LARIX EUROPAa.}

Tun Larch may hest be distinguished from the rest of the Fir-trees at the season when most other trees throw off their distinctive character. In winter its lofty, undivided 
stem, pyramidal form, and tiers of drooping branches still bearing the cones formed during the preceding summer, decisively attest its relationship with the Firs; and the absence of leaves at once distinguishes it from any other of that tribe with which we are familiar. There is, however, no difficulty in detecting it, no matter what may be

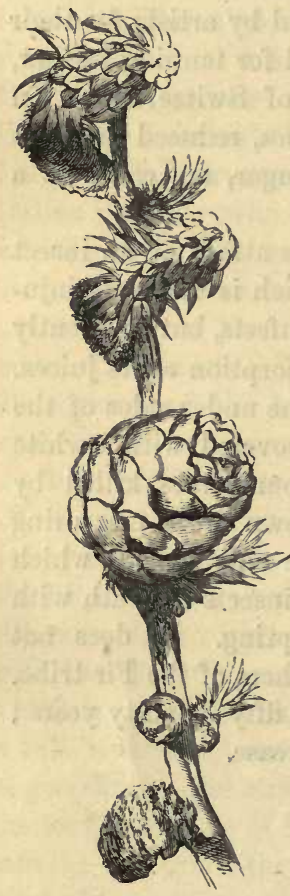

TWIG OF LARCH.

its associates, when in full foliage. A favourable specimen of the Larch may be described as an erect tree, of a pyramidal form, clothed with long slender branches from its pointed summit almost to the ground, the lower ones being more or less pendulous, as also is the spray throughout. The leaves are. bright green, growing in tufts, of a soft texture, spreading, and slightly recurved. The cones, which are small, are numerous, and arranged along the twigs in rows more or less regular. In their young state they vary in colour from greenish white to bright red, and when ripe are brown, being formed of overlapping scales, which are not united into a compact woody mass, but are detached at the edges.

Though it possesses little claim to picturesque beauty, - at least, in its British garb, - " it must be acknowledged,"- says Wordsworth, "that the Larch, till it has outgrown the size of a shrub, shows, when looked at singly, some elegance in form and appearance, especially in spring, decorated as it then is by the pink tassels of its blossoms; but, as a tree, it is less than any other pleasing. Its branches (for boughs it has none) have no variety in the 
youth of the tree, and little dignity even when it attains its full growth. Leaves it cannot be said to have; and consequently it affords neither shade nor shelter. In

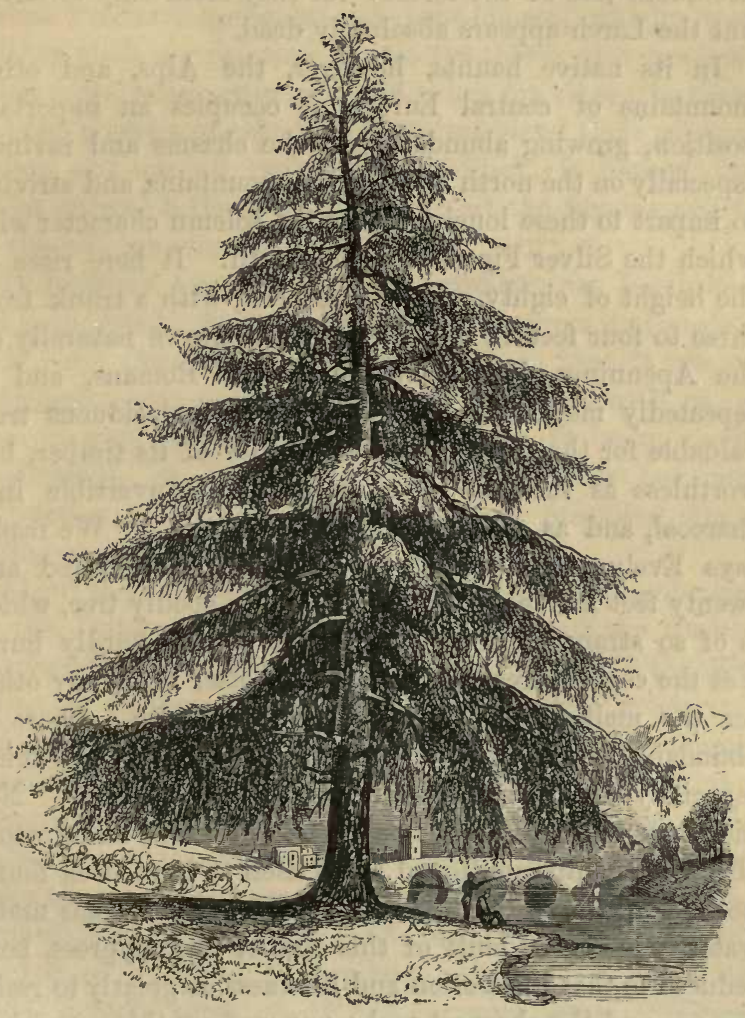

THE LARCH.

spring the Larch becomes green long before the native trees; and its green is so peculiar and vivid, that finding nothing to harmonize with it wherever it comes forth, a disagreeable speck is produced. In summer, when all the 
other trees are in their pride, it is of a dingy, lifeless hue; in autumn of a spiritless unvaried yellow; and in winter it is still more lamentably distinguished from every other deciduous tree of the forest : for they seem only to sleep; but the Larch appears absolutely dead."

In its native haunts, however, the Alps, and other mountains of central Europe, it occupies an important position, growing abundantly in the chasms and ravines, especially on the north sides of the mountains, and striving to impart to these lonely regions the solemn character with which the Silver Fir clothes the south. It here rises to the height of eighty or a hundred feet, with a trunk from three to four feet in diameter. As it grows naturally on the Apennines, it was known to the Romans, and is repeatedly mentioned by Pliny as a lofty deciduous tree, valuable for the strength and durability of its timber, but worthless as fuel, its wood being not convertible into charcoal, and as uninflammable as a stone. "We read," says Evelyn, "of beams of no less than a hundred and twenty feet in length made out of this goodly tree, which is of so strange a composition that it will hardly burn. Yet the coals thereof were held far better than any other for the melting of iron, and the locksmith. There is abundance of this Larch timber in the buildings at Venice, especially about the palaces in Piazza San Marco. Nor did they only use it in houses, but in naval architecture also. The ship mentioned by Witsen to have been found not long since in the Numidian Sea twelve fathoms under water, was chiefly built of this timber and Cypress, both reduced to that induration and hardness as greatly to resist the fire and the sharpest tool ; nor was anything perished of it, though it had lain above a thousand and four hundred years submerged. Tiberius, we find, built that famous bridge to his Naumachia with this wood; and it seems to excel for beams, doors, windows, and masts of ships: it resists the worm. Being driven into the ground, it is almost petrified, and will support an incredible weight: 
which, and for its property of long resisting fire, makes Vitruvius wish they had greater plenty of it at Rome to make joists of ; for that, being attempted with fire, it is long in taking hold, growing only black without. It makes everlasting spouts and pent-houses, which need neither pitch nor painting to preserve them; also excellent pales, posts, rails, pediments, and props for vines ; to these add the palettes on which our painters blend their colours. Before the use of canvas and bed-tick, it formed the tables on which the great Raphael and the famous artists of the last age eternized their skill."

In Evelyn's time the value of British-grown Larch had not been tested ; for though he says, "We grow it of seeds," it is clear from what he afterwards says that it was of uncommon occurrence. "That it flourishes with us, a tree of good stature, not long since to be seen about Chelmsford, in Essex, sufficiently reproaches our not cultivating so useful a material for many purposes, when lasting and substantial timber is required."

About the middle of the last century some trees planted by the Duke of Athole were cut down, and the timber was found to be superior to that of any other of the Fir tribe. A further acquaintance with the tree confirmed this opinion, and Loudon tells us that it has been more extensively planted in Britain, particularly since the commencement of the present century, than any other timber-tree whatever, not even excepting the Oak. John, Duke of Athole, successor of the duke mentioned above, planted, between the years 1764 and 1826, the enormous number of 14,096,719 Larches, occupying a space of 8,604 Scotch acres, or 10,324 imperial acres. "There is no name that stands so high, and so deservedly high, in the list of successful planters, as that of the late John, Duke of Athole. His Grace planted, in the last years of his life, 6,500 Scotch acres of mountain ground solely with Larch, which, in the course of seventy-two years from the time of planting, will be a forest of timber 
fit for the building of the largest class of ships in his Majesty's navy. Before it is cut down for this purpose, it will have been thinned out to about four hundred trees per acre. Each tree will contain at the least fifty cubic feet, or one load of timber, which at the low price of one shilling per cubic foot (only half of its present value) will give a thousand pounds per acre; or, in all, a sum of $6,500,000 l$. sterling. Besides this, there will have been a return of seven pounds per acre from the thinnings, after deducting all expense of thinning and the original outlay of planting. Further still, the land on which the Larch is planted is not worth above from ninepence to a shilling per acre. After the thinnings of the first thirty years the Larch will make it worth at least ten shillings an acre, by the improvement of the pasturage, upon which cattle can be kept both summer and winter." 1

Mr. Gorrie, who admits that the above statement of the probable value of the Larch timber is over-estimated, remarks that Larch is by far the best improver of heath or moor pasturage known in this country. If planted thick, it will in a few years choke the heath and coarser grasses; and these plants will be succeeded by finer grasses, with a foliage possessing a softness and luxuriance never acquired in open situations. The Larch ripens its seeds freely in Britain, and is now raised by the Scotch nurserymen in larger quantities than any other timber-tree.

Larch timber is said to be superior to foreign Fir in the following respects : it is clearer of knots, more durable, the dead branches even being never found to be rotten; it is much less liable to shrink or split; it may be seasoned in a much shorter time ; it is more tough; it is of a better colour, and susceptible of a polish superior to that of the finest mahogany; and more durable, bearing exposure to changes of climate and moisture for many years without undergoing any change. 
From possessing these properties it is considered by good judges to be better adapted for naval architecture than any other timber. It becomes harder and more durable by age in a ship. It holds iron as firmly as Oak, but, unlike Oak, it does not corrode iron. It does not shrink; it possesses the valuable property of resisting damp. It catches fire with difficulty, and it does not splinter when struck by a cannon-ball. These qualities have been tested in the case of the Athole, a 20-gun frigate which was launched in 1820, the keel, masts, and yards of which were made wholly of Larch.

The timber is found to be equally well suited for house carpentry, joining, \&c.; and for hop-poles, vine-props, and rails for fencing, it is preferred to any other wood, bearing exposure to all weathers without showing any symptom of decay in the course of many years. For the same reason it is in great demand for the sleepers of railways. The bark possesses tanning properties to a considerable extent, but being in this respect far inferior to Oak, it. will not pay the expenses of peeling and carriage.

From the trunk of the full-grown Larch is procured the substance known by the name of Venice turpentine. This is a liquid resin found in large cavities, which measure sometimes several inches across, and are situated in the solid wood five or six inches from the heart of the tree. In order to obtain it, holes are pierced with augers, and into them are inserted wooden tubes, through which the turpentine flows into little buckets suspended at the other end to receive it. The season for collecting it lasts from May to October. It is perfectly clear, and needs no further preparation than straining through a coarse hair cloth to free it from impurities. It derives its name from the city of Venice, from which it was formerly exclusively exported. It is used in medicine, and for making several kinds of varnish.

A manna is also produced from the shoots of the young Larches, which resembles that of the Ash; it is called 
Manna of Briançon, from the name of the place where it is collected.

\section{बe \\ THE CEDAR OF LEBANON.}

\section{Cedrus libani.}

MANY years ago a Frenchman who was travelling in the Holy Land, found a little seedling among the Cedars of Lebanon, which he longed to bring away. as a memorial of his travels. He took it up tenderly, with all the earth about its little roots, and, for want of a better flower-pot, planted it carefully in his hat, and there he kept it and tended it.

The voyage home was rough and tempestuous, and so much longer than usual, that the supply of fresh water in the ship fell short, and they were obliged to measure it out most carefully to each person. The captain was allowed two glasses a day; the sailors who had the work of the ship on their hands, one glass each; and the poor passengers but half a glass. In such a scarcity you may suppose the poor Cedar had no allowance at all. But our friend the traveller felt for it as his child, and each day shared with it his small half glass of precious water; and so it was, that when the vessel arrived at the port, the traveller had drunk so little water that he was almost dying, and the young Cedar so much that, behold, it was a noble and fresh little tree, six inches high!

At the Custom-house the officers, who are always suspicious of smuggling, wished to empty the hat, for they would not believe but that something more valuable in their eyes lay hid beneath the moist mould. They thought of lace or of diamonds, and began to thrust their fingers into the soil. But our poor traveller implored them so earuestly to spare his tree, and talked to them so eloquently of all that we read in the Bible of the Cedar 
of Lebanon, telling them of David's house and Solomon's Temple, that the men's hearts were softened, and they suffered the young Cedar to remain undisturbed in its

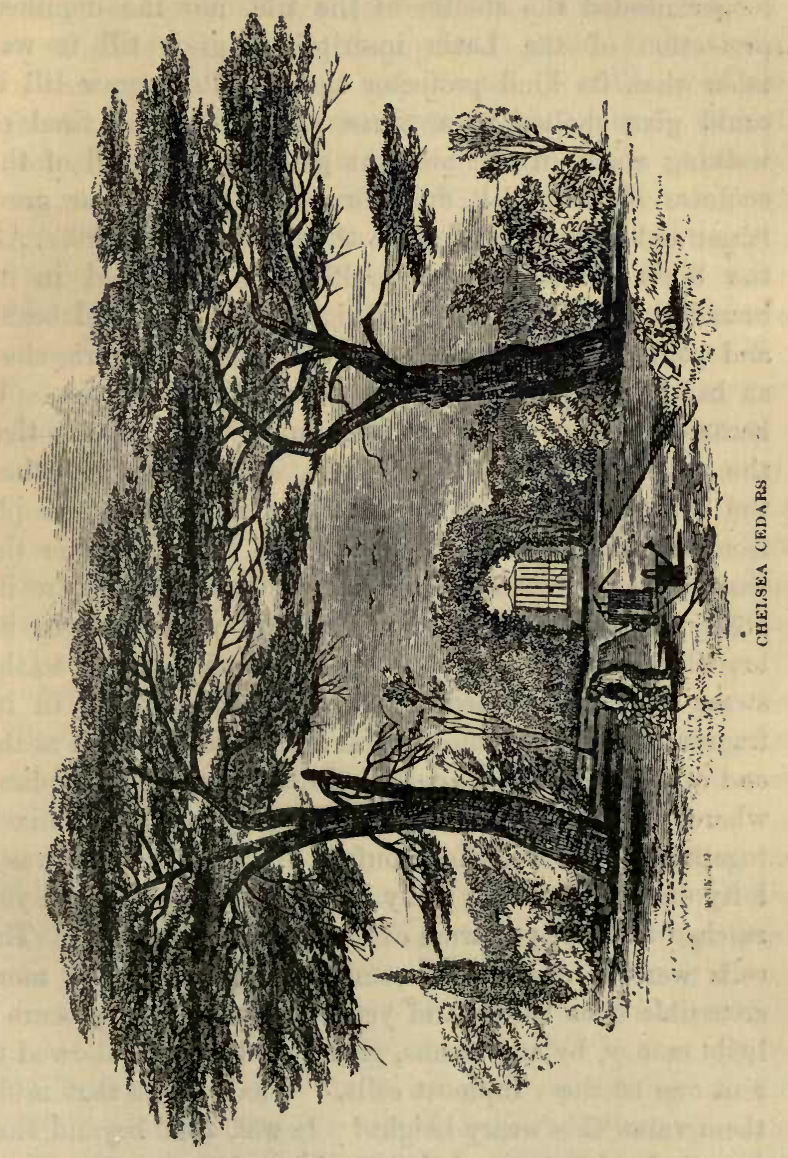

strange dwelling. From thence it was carried to Paris, and planted most carefully in the Jardin des Plantes. A large tile was set against it as a protection and a shade, 
and its name was written in Latin and stuck in front, to tell all the world that it was something new and precious. The soil was good and the tree grew; grew till it no longer needed the shelter of the tile, nor the dignified protection of the Latin inscription; grew till it was taller than its kind protector the traveller; grew till it could give shelter to a nurse and her child, tired of walking about in the pleasant gardens, and glad of the coolness of the thick dark branches. The Cedar grew larger and larger, and became the noblest tree there. All the birds of the garden could have assembled in its branches. All the lions and tigers, and apes and bears, and panthers and elephants of the great menagerie close at hand, could have lain at ease under its shade. It became the tree of all the trees in the wide garden that the people loved the best; there, each Thursday, when the gardens were open to all the city, the blind people from their asylum used to ask to be brought under the Cedar; there they would stand together and measure its great trunk, and guess how large and wide must be its branches. It was a pleasure to see them listening to the sweet song of the birds overhead, and breathing in its fragrant Eastern perfume. There was once a prison at the end of these gardens, a dark and dismal and terrible place, where the unfortunate and the guilty were all mixed together in one wretched confusion. The building was a lofty one, divided into many storeys, and, by the time you reached the top, you were exhausted and breathless. The cells were as dreary and comfortless there as the more accessible ones below, and yet those who could procure a little money, hy any means, gladly paid it to be allowed to rent one of these topmost cells. What was it that made them value this weary height? It was, that beyond that forest of chimneys and desert plain of slates, they could see the Cedar of Lebanon! His cheeks pressed against the rusty bars, the poor debtor would pass hours looking upon the Cedar. It was the prisoner's garden; and he 
would console himself in the weariness of a long, rainy, sunless day, in thinking, "The Cedar will look greener to-morrow." Every friend and visitor was shown the Cedar, and each felt it a comfort in the midst of so much wretchedness to see it. They were as proud of the Cedar in this prison as if they had planted it. Who will not grieve for the fate of the Cedar of Lebanon? It had grown and flourished for a hundred years, - for Cedars do not need centuries, like the Oak, to attain their highest growth, - when, just as its hundredth year was attained, the noble, the beautiful tree was cut down to make room for a railway; and now the hissing steam-engine passes over its withered roots. Such things, it seems, must be ; and we must not too much grieve or complain at any of the changes that pass around us in this world of changes : and yet we cannot but feel sorry for the Cedar of Lebanon.

Such is the history of the introduction of the Cedar into France; a tale which has often been told, but nowhere in a more pleasing manner than in the foregoing extract from Sharpe's London Magazine. The date of its introduction into Great Britain is not known.

The Cedar first produced cones in England in the Chelsea Garden about 1766, since which time vast numbers of trees have been raised both from native as well as foreign cones.

The Cedars of Lebanon are frequently mentioned in the Sacred Volume, and from their majestic growth are made an emblem of regal state, and so of the prosperity of the kingdom typified. They were formerly very abundant, but being much sought after for their timber, which was considered imperishable, their number is now greatly diminished. It was used in great quantities in the building of the Temple and Solomon's Palace at Jerusalem, and by the Tyrians the masts of ships were made of Cedar. The needle-shaped leaves are shorter than those of the Scotch Fir, and grow in bunches of more than twenty, like those of the Larch, but they are of a 
firmer texture, and are not deciduous. The cones, which stand erect, and in their young state are very conspicuous, are of a bright green colour and an oval shape; they adhere firmly to the branches, which are covered with a greyish brown bark. The horizontal branches, which are very large in proportion to the size of the trunk, are arranged in distinct layers or stages, and form a broadly pyramidal head. The extremities of the lower branches generally droop so as almast to touch the ground, when the tree stands alone; but if planted in masses, it bears a

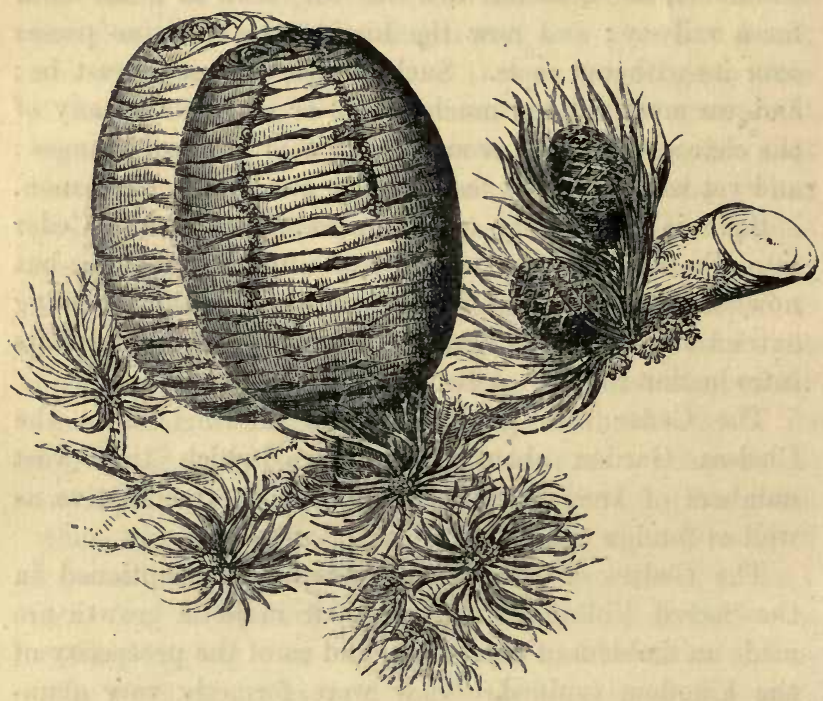

CONES OF CEDAR.

clean straight trunk, crowned by a depressed head. The beauty of the tree consists in the strength and elegant symmetry of its widely spreading branches. The resin which exudes from the stem and cones is said to be as soft as balsam; the sinell is very similar to that of the balm of Mecca. Everything, indeed, about this tree has 
a strong balsamic perfume, and hence the whole forest is so perfumed with fragrance that a walk through it is delightful. This is probably the "smell of Lebanon" to which reference is made in Hosea xiv. 6 .

So durable was Cedar-wood considered by the ancients, that, "to be worthy of being kept in Cedar," dignus cedro, passed into a proverbial expression for anything thought worthy of immortality. An oil extracted from it, and called cedreum, was said to render imperishable all substances which were anointed with it.

The value of the timber of the Cedar as a building material is now thought to have been overrated by the ancients. It is reddish white, with streaks, and does not seem to be much harder than deal. It is sweet-scented only for the first year after being felled: it soon begins to shrink and warp, and is said to be by no means durable. But this is rather the character of English-grown Cedar than of timber which has come to maturity in its native mountains.

Southey, in his "Thalaba," alludes in the following lines to a singular superstitious belief entertained by the Maronites of Mount Lebanon:-

\section{"It was a Cedar-tree}

Which woke him from that deadly drowsiness;

Its broad, round-spreading branches, when they felt

The snow, rose upward in a point to heaven,

And, standing in their strength erect, Defied the baffled storm."

"The Maronites say that the snows have no sooner begun to fall than these Cedars, whose boughs, in their infinite number, are all so equal in height that they appear to have been shorn, and form, as it were, a sort of wheel or parasol-than these Cedars, I say, never fail at that time to change their figure. The branches, which before spread themselves, rise insensibly, gathering together, it may be said, and turn their points upwards towards Heaven, forming altogether a pyramid. It is Nature, they say, who inspires this movement and makes 
them assume a new shape, without which these trees never could sustain the immense weight of snow remaining for so long a time." 1

The Cedar is a native not only of the mountain from which it derives its name, but of Northern Africa, where it was found in aburdance by Mr. Drummond Hay. Of the many accounts that have been published of the famous grove of Cedars on Mount Lebanon, it will be sufficient to quote the following:- "These noble trees grow amongst the snow, near the highest part of Libanus; and are remarkable as well for their own age and largeness as for the frequent allusions made to them in the Word of God. Here are some very old, and of a prodigious bulk; and others younger, of a smaller size. Of the former I could reckon up only sixteen; the latter are very numerous. I measured one of the largest, and found it twelve yards six inches in girth, and yet sound, and thirty-seven yards in the spread of its boughs. At about five or six yards from the ground it was divided into five limbs, each of which was equal to a great tree." 2

"We are informed, from the "Memoirs of the Missionaries in the Levant,' that, upon the day of Transfiguration, the Patriarch of the Maronites (Christians inhabiting Mount Libanus), attended by a number of bishops, priests, and monks, and followed by five or six thousand of the religious from all parts, repairs to these Cedars, and there celebrates the festival that is called 'The feast of Cedars.' We are also told, that the Patriarch officiates pontifically on this solemn occasion; that his followers are particularly mindful of the Blessed Virgin on this day, because the Scripture compares her to the Cedars of Lebanon; and that the same Holy Father threatens with ecclesiastical censure those who presume to hurt or diminish the Cedars still remaining." 3

"The famous Cedars of Lebanon are situated on a
1 De la Roque, 1772.
2 Maundrell.
3 Dr. Hunter. 
small eminence, in a valley at the foot of the highest part of the mountain. The land on the mountain's side has a sterile aspect, and the trees are more remarkable, as they stand all together in one clump, and are the only trees to be seen in this part of Lebanon. There may be about fifty of them, but their present appearance ill corresponds with the character given of them in Scripture. There was not one of them at all remarkable for its dimensions or beauty ; the largest among them is formed by the junction of four or five trunks into one tree. Numerous names carved on the trunk of the larger trees, some with dates as far back as 1640 , record the visits of individuals to this interesting spot, which is nearly surrounded by the barren chain of Lebanon, in the form of an amphitheatre of about thirty miles' circuit, the opening being towards the sea." 1

"These trees are the most renowned natural monuments in the universe; religion, poetry, and history have all equally celebrated them. The Arabs of all sects entertain a traditional veneration for these trees. - They attribute to them, not only a vegetative power which enables them to live eternally, but also an intelligence which causes them to manifest signs of wisdom and foresight, similar to those of instinct and reason in man. They are said to understand the changes of seasons; they stir their vast branches as if they were limbs; they spread out or contract their boughs, inclining them towards heaven or towards earth, according as the snow prepares to fall or melt. These trees diminish in every succeeding age. Travellers formerly counted thirty or forty ; more recently, seventeen; more recently still, only twelve. There are now but seven. ${ }^{2}$ These, however, from their size and general appearance, may be fairly presumed to have existed in Biblical times. Around these ancient witnesses of ages long since past there still remains a little grove of yellower Cedars, appearing to me to form a group of

1 Irby and Mangles.

2 Warburton maintains that there are still twelve of the very largest trees, and about a thousand of all ages. 
from four to five hundred trees or shrubs. Every year, in the month of June, the inhabitants of the neighbouring valleys and villages climb up to these Cedars and celebrate mass at their feet. How many prayers have resounded under these branches! and what more beautiful canopy for worship can exist?" 1

\section{THE JUNIPER.}

Juniperus COMmunis.

Class-Diguia, Order-Monadelpila.

THe Juniper is well known to the readers of the English version of the Bible as the tree under which the prophet Elijah, wearied with his journey through the wilderness, sat down to rest, when flying from the persecution of Jezebel (1 Kings xix. 4). This tree, or rather shrub, is generally supposed to be a species of Broom (Genista monosperma), which is one of the few plants to be found in the Arabian deserts. Burckhardt mentions it as growing also in the deserts to the south of Palestine, so that the Juniper which sheltered the prophet may possibly be the tree in question, though other travellers have looked for it in the neighbourhood of Mount Horeb, instead of at the distance of a day's journey from Jerusalem. Lord Lindsay speaks of his having frequently sheltered himself under a Broom in the valley of Mount Sinai, an incident which I)r. Kitto fixes on as conclusive, seemingly forgetting that Elijah was as yet distant a journey of forty days from the same spot. Nevertheless the similarity of the Hebrew name Rothem to the Arabic Rethem, makes it highly probable that the two trees are identical.

The Juniper is a native of all the northern parts of Europe, and in Great Britain is generally found on hills 1 Lamartine. 
and heathy downs, especially where the soil is chalky. It usually appears as a bushy, evergreen shrub, with narrow sharp-pointed leaves, which are arranged in threes, and are of a glaucous hue above, and dark green beneath. Instead of bearing dry cones, like most other trees belonging to this tribe, the Juniper produces fleshy berries, which are formed of the united scales of the calyx, and contain three oblong seeds. The barren flowers are small,

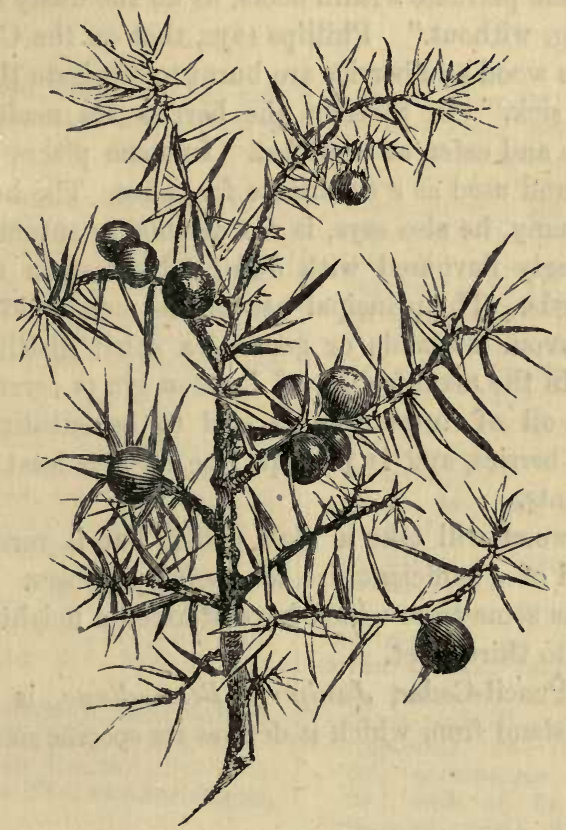

THE JUNIPER.

and grow on separate plants from the fertile flowers, in the axils of the leaves; the Juniper was consequently placed by Linnæus in a different class from the rest of the Fir tribe, though naturally closely allied to them.

The Juniper of the ancients was probably a different 
species from that which is indigenous to Britain. The common species, in Evelyn's time, was frequently transplanted from the open commons to make hedges and arbours. The berries were used as a spice, and were also employed medicinally. "If it arrive to full growth, spits and spoons, imparting a grateful relish, and very wholesome where they are used, are made of this wood, being well dried and seasoned: and the very chips render a wholesome perfume within doors, as do the dusty blossoms in spring, without." Phillips says, that on the Continent both the wood and berries are burnt to fumigate the rooms of the sick. In Sweden the berries are made into a conserve and eaten at breakfast. In some places they are roasted and used as a substitute for coffee. The heathcock of Germany, he also says, is not eatable in autumn, being so strongly flavoured with Juniper-berries, on which it then feeds. The principal use of the berries at present is to flavour hollands or geneva, a spirit distilled from corn. In the manufacture of London gin (a corruption of geneva) oil of turpentine is said to be substituted for Juniper-berries, and is perhaps one of the least noxious ingredients.

The wood will take a high polish, but is rarely to be obtained of a sufficient size for useful purposes. Loudon mentions some trees which have attained a height of from sixteen to thirty feet.

The Pencil-Cedar, Juniperus Bermudiana, is a native of the island from which it derives its specific name. 


\section{N D E X.}

Abele, see Poplar.

A bies, 390 ; see Spruce Fir ; said by Cæsar to be not a native of Britain, 144, 365.

Acacia, 108.

Acacia, False, described, 297 ; why called Locust-tree, $i b$. ; picturesque character, $i b$. ; timber, 299; uses in shipbuilding, 300 ; extensively planted by Mr. Cobbett, $i b$.

Acer, 49 ; see Sycamore and Maple.

Acerinæ, 42, 52.

Acorn,erlible, 3, 24,41 ; see Oak. Esculus, see Horse Chestnut.

Age of trees, how ascertained, 31 .

Agricultural maxims, 254.

Ain Saffaf, 317.

Albert Durer, 78.

Alder, described, 212 ; a widely diffused tree, 213 ; picturesque character, 214 ; uses of, 216 , 218.

Alder Buckthorn, see Buckthorn. Aleppo, Willows at, 316, 319.

Alhagi, see Manna.

Allhallow Eve, nut burning on, 246.

Allon, 2.

Alnus, see Alder.

Alpnach, Slide of, 361.

Alps, Spruce Fir of, 392 ; Larclı of, 406 .

Alum, 63.

Amentaceæ, 1, 39, 143, 159, $170,204,212,231,239,302$.

America, South, treatment of Apple-trees in, 140.
American Blight, 141 .

Lime, 264.

Plane, 287, 292.

Andrew Undershaft, St., 91.

Apple-tree, described, 137 ; ancient history, 138; superstitions, ib.; Crab, 139 ; Pomatum, $i b$. ; varieties, $i b$. ; treatment of, in S. America, 140 ; in China, 141 ; insects, $i b$.; American blight, $i b$; parasites, 142 ; Mistletoe thrush, $i l$.

Apple-John, 140.

Aquifolium, 194, 198.

Araliaceæ, 332.

Arbela, 161.

Arbutus, described, 274, etymology of Unedo, $i b$; ; of what countries a native, $i b$.; at Killarney, $i b$.

Aria, see Beam, White.

Arn-tree, 323 ; see Elder.

Arthur's Round Table, 27.

Ash, described, 57 ; known to the ancients, $i b$.; superstitions respecting, 58; etymology, 60 ; picturesque character, 63 ; seeds of, 64 ; singular place of growth, 65 ; Manna, 66 ; uses of timber, 67 ; used as fodder, 69 ; Woodpeckers, $i b$. ; Weeping, $i b$.

Ash, Mountain, described, 125 ; why rarely seen large, $i b$.; various names, 127 ; superstitions respecting, $i b$; of what countries a native, 128; yellow berried variety, 131 ; fruit, $i b$.; timber, $i b$. 
Aspen, 167.

Athole, Duke of, his Larch plantations, 407, 408.

Atinian Elm, 225.

Aucuparia, see Ash, Mountain. Augustine in Britain, 345.

Avellana, 339 ; see Hazel.

Avelon, Isle of, 85 .

Avenues of Lime, 262.

Babylon, boats used at, 309 .

Babylonian Willow, see Willow.

Balaninus, 242.

Baltic, Spruce-Firs of the, 377 , 395 ; deal, 396.

Barberry, described, 265 ; irritability of stamens, $i t$.; falsely said to cause mildew in corn, 267.

Bark, Jesuits',108; of 1'lane-tree, 285,287 ; bread made of, 378 , 380 .

Barnacle-goose, 14, 73.

Bartholomew's day, 85.

Basilicon, see Walnut.

Beam, Quick, 127 ; White, 132.

Bedford Willow, 311.

Beech, described, 143 ; not a native of Britain, 144 ; how connected with the origin of printing, 145 ; grafted on Chestnut, ib.; where indigenous, 147 ; picturesque character, 147, 151; Beech-wood in winter, 147; knurs on Beech,150 ; drip injurious to other vegetables, 151; foliage and fruit, ib.; coolness of woods, $i b$. ; mast, 153 ; etymology, 152, 153 ; ancient writing materials, $i b$.; uses of, 153 : succeeds Oak, 154 ; leaves, $i b . ;$ uses of wood, 155 ; Purple, $i b$. ; morells and trufflos, 156 ; fungi growing on, ib.; Purley Beeches, 144; singular, 158.

Beech, Water, see Plane.

Beetle infesting the Apple, 142; the Elm, 229 ; the nut, 243.

Berberis, Berberidæ, 265; see Barberry.

Beroth, 357 ; see Fir.

Betula, see Birch.
Betulus, see Hornbeam.

Bewick, 79.

Bible, Poor Preachers', 78.

Biblia Pauperum, 78.

Birch, described, 204 ; of what countries a native, 206 ; resin from, 207 ; weeping, 208; durability of bark, $i b$.; canoe, 209 ; wine, ${ }^{\top} i b$.; other uses, 210 ; dwarf, 212 ; insects, $i b$.

Bird-catcher's Service, see Ash, Mountain.

Black Poplar, 164, 166.

Blackthorn, described, 103; in winter, 104; used to adulterate tea and port-wine, 107 ; pickled sloes, 108 ; bark, $i b$.; quinine, $i b$.; Thorns and Thistles, 109 ; Bullacetree, ib.; Myrobalan plum, 110 ; Magnum-bonum, ib. ; Green-gage, $i b . ;$ Brignoles, 111 ; Damsons, 112.

Blight, American, 141.

Bog Fir, 374.

Boldre Church, Maple at, 54 .

Bolts in ship-building, 300.

Book, etymology of, 153 ; ancient, 258.

Borrera, 142.

Bows, 268, 308 ; made of Yew, 342.

Box, description of, 70 ; where indigenous, $i b$. ; in gardens. 72 ; virtues of, 73 ; uses of wood, 74 ; history of woodengraving, 78 .

Box, Dwarf, 81 .

Boxhill, 70, 81.

Boxley, 70.

Brignoles, 111.

Broom, the Juniper of Scripture, 418 ; Yellow, useful as sheiter for Pines, 385; Butcher's, 203.

Brundusium, ancient Oak-timber at, 28 .

Bruscum, 56.

Buck, see Beech.

Buckthorn, described, 292 ; use of berries, 294.

Bud of Plane-tree, 288.

Bullace-tree, 109.

Burgundy pitch, 396. 
Burning Forest, 359.

Bury St. Edinunds, Poplar at, 166.

Butcher's Broom, 203.

Butterflies on Ivy-blossoin, 339.

Buttonwood, 292 ; see Plane.

Buxus, see Box.

Buyukdere, largest tree in the world at, 284 .

Cresar, Jnlius, his statement respecting the Beech, 144.

Cairr, 4.

Calaf, 259.

Candleberry Myrtle, 273.

Canoe, 209.

Caprifoliaceæ, 320, 326, 328.

Caprifolium, 328 ; see Honeysuckle.

Carclew, Pinaster at, 387.

Cards, Playing, 75, 77.

Carlsruhe, Willow at, 314.

Carpinus, 234 ; see Hornbeam.

Carrickfergus, fossil nuts at, 247.

Carshalton, Ivy at, 325.

Carving in wood, 74.

Castanea, 176, 181 ; see Chestnut.

Catechu, 108.

Caxton, 78.

Cedar of Lebanon, described, 410 ; story of first introduction into France, $i b$.; introduced into England, 413 ; notice of, in the Bible, $i b$.; durability of timber, 415; superstition connected with, $i b$.; Cedars on Mount Lebanoll, 416.

Celastraceæ, 277.

Cerasus, 117, 123 ; see Cherry. - - , Pado ; see Bird-Cherry. Chaffinch, 142.

Charles I. anecdote of, 14, 89 .

Chelsea, Thorns at, 98 ; Cedars at, 413.

Cherry, described, 112; black and red fruited, 115, 117 ; etymology, $i b . ;$ whence and by whom introduced, $i b$.; Cornel, 116; when brought to Britain, $i b$.; varieties, 117 ; in America, 118 ; fruit, 26. ; gum, 119 ; wood, 120 ; doubleflowered, $i b$; insects, 121.

Cherry, Bird, described, 121 ; various names, $i b$.; Laurel, 123 ; Bay-tree, 124 ; Portugal Laurel, $i b$.

Chestnut, described, 170 ; claims to be considered a native, $i b$.; timber in old houses, $i b$; early use in Normandy, 171 ; Parliament-house, Edinburgh, places named from, 172 ; ancient forest, Spanish Chestnuts, originally brought from Asia to Italy, 173 ; resemblance of Oak and Chestnut timber, $i b$.; Milton Forest, Forest of Dean, $i b$; various names, 174; of what countries a native, 175 ; mention in the Bible, 176 ; picturesque character, 177 ; soil, 178 ; description of flower, 179 ; nuts, 180 ; used as food, 181 ; modes of cooking, 183 ; tim. ber, 184 ; see Horse Chestnut.

China, treatment of trees in, 141, 228.

Christiania Deal, 396.

Christmas, 89; decorations of churches at, 196, 334 .

Christopher, St., 76, 77.

Citron-wood, 138.

Clontarf Castle, yellow-berried Yews at, 349.

Cluster Pine, see Pinaster.

Cobbett, Mr., anecdote of, 300 .

Cobnuts, 249.

Cocoa-nuts, uses of, 325 .

Coker-nut, see Cocoa-nut.

Coniferæ, 350.

Conveyance of timber, 360,361 .

Coolness of woods, 153.

Coomb-Martin, Yews at, 346.

Coracle, 309.

Cork Elm, 224, 234.

Corneæ, 279.

Cornel, 116.

Cornish Elm, 224, 234.

Cornwall, etymology of, 255 .

Corone, 117.

Corylus, 239 ; see Hazel.

Cos, Plane-tree at, 284. 
Costorphine Plane, 48.

Cotton from Willow-tree, 308.

Cotton-tree, 290 ; see Plane.

Crab, 139; Siberian, 133.

Crack Willow, 305, 312.

Cratægus, 96 ; see Hawthorn.

Crayons, 248.

Crowhurst, Yew at, 343.

Cuckoo, 117.

Cudbear, 107.

Currack, 309.

Cynips, 18, 20 ; see Gall-flies.

Cypress, 302, 312, 406.

Damascus Plum, 112.

Damson, 112.

Dartmoor, 5, 139.

Darwin, singular custom described by, 83 ; his account of Apple-trees in S. America, 140 ; fungus described by, 156.

Dean, Forest of, Chestnuts in, 173.

Devonshire, Cherries in, 117 ; custom in, 139, 346.

Diomede, tomb of, 282.

Divining rod, 240.

Dogwood, 277, 279; spiral vessels in, 281.

Dowsing-rod, 240.

Drip of. Beech injurious, 151.

Druids, 4, 138 ; see Oak.

Durmast Oak, 29, 185.

Dutch Myrtle, 272.

Eddystone Lighthouse, 10.

Edinburgh, Chestnut timber in, 172.

Egypt, Willows in, 316.

Elah, 7.

Elder, described, 3:0 ; Evelyn's praises of, $i b$.; why called Bore-tree, 132 ; uses of, $i b$. ; emblematical of sorrow, 323 ; tradition respecting, $i b$.; medicinal virtues, 324 .

Electricity, conducting power of Firs, 355.

Elijah, the Juniper of, 419.

Elm, described, 218; early in shedding their seeds, 221 ; small-leaved, $i b$.; Cornish,
222, 224; Wych, 224; Corkbarkel, 224, 234; ancient history, 225; what species are indigenous, 226 ; picturesque character, 227; propagation, $i b$.; uses of, $i b$. ; treatment of, by the Chinese, $i h$.; insects which prey on, 229 ; decay of leaf, 231 ; remarkable specimens, 234; Wych Elın described, 231.

Enys, Elm at, 234.

Ericaceæ, 274.

Etna, Mount, Chestnuts on, 180.

Euonymus, see Spindle-tree.

Euphorbiaceæ, 70.

Evaporation, effects of, 351, 353.

Evelyn, derivation of the name, 240.

Evergreen Oak, see Ilex.

Fagopyrus, 152.

Fagus, 143, 145, 176 ; see Chestnut.

Faust, John, 79 note.

Filbert, 240, 249.

Fir tribe, remarks, 350 ; habit and place of growth, 350,351 ; why said to attract moisture, 353; effects of snow, ib. ; terminal buds, $i b$. ; electrical agency, 355 ; flowers, cones, and seeds, 355, 356 ; geographical distribution, 357 ; notice in Scripture, $i b$.; and in profane history, 358; Pine forests in the north of Europe, 359 ; effects of fire on Pine forests, $i b$. ; ice-storm in a Pine forest, 360 ; methods of conveying timber, $i b$.; slide of Alpnach, 361 ; timber in Russia, 362 ; rafts on the Rhine, 364 ; see Scotch Fir, Pinaster, Silver Fir, \&c.

Folio, etymology of the word, 153.

Forest of Dean, 175.

Forest, New, 17, 37, 349.

France, Chestnuts as food in, 182.

Frangula, see Buckthorn.

Fraxinus, see Ash. 
French berries, 294.

French Revolution, 166, 308.

Funerals, customs at, 341 .

Fungi, edible, 156 ; on Hawthorn leaves, 213 ; on Elm leaves, 117.

Gale, sweet, 272, 273.

Galls, Gall-flies, 17-23, 398.

Gardening, remarks on, 106, 135.

Gascony, plantations of Pinaster in, 384 .

Geans, 117.

Geneva, Horse Chestnuts at, 193.

Genista monosperma, the Juniper of Scripture, 419.

Germany, planting of Walnuts in, 255 ; Firs in, 360.

Gibbon the sculptor, anecdote of, 264.

Gilliflower, Cornish, 139.

Gilpin's Maple, 55.

Glastonbury Thorn, 86, 89 ; Hazel, 240.

Goat Willow, 312.

Golden Pippin, 139.

Willow, 313.

Gopher-wood, 357.

Graves, custom of decorating, 341.

Greengage, 110.

Guelder Rose, 328 ; garden variety, 331.

Gum, Cherry, 119.

Hawfinch, 102.

Hawthorn, described, 82 ; Maybush, 83 ; when it flowers, $i b$.; May-day, $i b$; emblem of hope, 85 ; superstitions respecting, 85-87 ; Glastonbury, 86 ; superstitions respecting, in Ireland, 87 ; badge of the House of Tudor, 90 ; May-pole, $i b$.; perfume of flowers, 93, 95, 99; picturesque beauty, 93 ; poetical descriptions, 90-95, 101 ; etymology, 96 ; Quickthorn, $i b$; of what countries a native, $i b$. ; appearance when old, 102 ; at Newharn, 84 ; Whitethorn, 98 ; haws, 99 ; Pink, ib. ; uses of Quickthorn,
100 ; hedges, ib.; Hawfinch, 102 ; uses of wood, $i b$.

Hazel, described, etymology of, 239 ; Evelyn, whence he derives his name, 240 ; at Glastombury, dowsing-rod, ib. ; catkins of, 242 ; nuts punctured by beetle, $i b$.; dormice, squirrels, 244 ; nuthatch, 245; pleasures of nutting, 246 ; Allhallow Eve, $i b$.; fossil nuts, 247 ; use of young rods, ib. ; fungus on, 248 ; filberts and cobnuts, 249; Spanish nuts, 251.

Hedera, see Iry.

Helena, St., Willow at, 319.

Helix, see Ivy.

Herbaceous Willow, 215.

Hercules, Poplar dedicated to, 162.

Hippocastaneæ, Hippocastanum, 187.

Holly, described, 194 ; custom of decorating churches, 196 ; various names, 198; of what countries a native, $i b$. ; stem marked with a lichen, 199 ; flowers, $i b$; picturesque character, $i b$.; hedges of, $i b$.; soil, ib. ; knots on stem, 200 ; cultivated varieties, 201 ; insects on, 202 ; wood, birdlime, $i b$. ; fine specimens, Knee Holly, 203.

Holm Oak, see Ilex.

Holme Lacy, Pear-trce at, 136.

Honey, ancient value of, 307 ; from the Lime, 262.

Honey-dew, 45.

Honeysuckle, described, 326 ; various names, $i b$; propagation, 327 ; Perfoliate Holleysuckle, 328.

Hop-Hornbeam, 238.

Hornbeam, described, 234; meaning of name, 236 ; mazes of, 238 ; timber, $i b$.

Horse Chestnut, described, 187 ; buds of, 190 ; when introduced ir Europe, origin of name 187 ; various names, 189 , picturesque character, ib.; 
drooping leaves in spring, 190 ; use of nuts, 192 ; soil and growth, 194.

Hulver, see Holly.

Huntingdon Willow, 303, 311.

Ice-storm, 360.

Ilex, described, 39 ; Teil-tree, 40; when introduced, 41; where it grows naturally, $i b$.; Holm Oak, ib.; Quercus Gramuntia, $i b$.; wood of Ilex, 42 ; see Holly.

Ilicineæ, 194.

Invercauld, Forest of, 367.

Irish Yew, 349.

Irritability of stamens, 265.

Isthmian games, 358 .

Ivy, described, 332 ; mythological history, $i b$.; not a gloomy tree, 332,338 ; picturesque character, 333 ; used in the decoration of churches, 334 ; of what countries a native, $i b$.; varieties of growth, 334, 335 ; compressing power of stem, 335 ; whether injurious to masonry, 336 ; lateness of flowering, 338 ; berries not injured by frost, 340 ; uses of wood, $i b$.

Jardin des Plantes, 299 ; Cedar in, 412.

Joseph of Arimathæa, 240 ; his staff, $85,89$.

Judas Iscariot, tradition respecting, 323.

Jugrlandaceæ, Juglans, see Walnut.

Julius Cæsar, coracles used by, 309 ; his testimony respecting British trees, 143, 365.

Juniper described, 418; the Juniper of Scripture a kind of Broom, 419 ; of what countries a native, $i b . ;$ use of berries, 420 .

Kerasoun, 115.

Killarney, Arbutus at, 274.

Kingly Bottom, Yews at, 346.

Kippencross, Sycamore at, 43.
Kirschwasser, 119.

Knee Holly, 203.

Knee-timber, 13.

Knees in ship-building, 300 .

Knurs on Beech, 150.

Koster, Lawrence, 145.

Labyrinths and mazes, 238.

Lady of the Woods, see Birch.

Lamp-black, how obtained, 386 .

Lampsacans, anecdote of, 358 .

Lantana, 328.

Larch, described, 404 ; picturesque character of, 405 ; mention of, by the ancient writers, 406 ; uses of timber, 407 ; extensively planted by the Duke of Athole, $i b$.; value in ship-building, 408 ; Venice turpentine, 409 ; manna, 410.

Larix, see Larch.

Laurel, 123.

Laurel, Portugal, 124.

Laurus, 123.

Laurustinus, 124.

Leaves of a book, why so called, 152 ; of trees used as a bed, 154; used as fodder, 228.

Leguminosæ, 297.

Lepas, 16 ; see Barnacle Goose.

Liber, books made of, 153 .

Liberty, tree of, 160, 259.

Library, 153.

Ligustrum, see Privet.

Lime-tree, described, 258 ; ancient reputation, $i b$. ; tree of liberty, 259; Linnæus derived his name from, 260 ; whether a native tree, $i b$. ; picturesque character, 261 ; fragrance of its flowers, $i b$.; honey from, avenues of, 262 ; use of wood and bark, 263 ; bast mats, 264 ; Gibbon, the sculptor, $i b$. Linden-tree, see Lime.

Linnæus, 80 ; etymology of name, 260 ; his description of a burning forest, 359 .

Lizard, Tamarisks at, 268.

Loch Lomond, Yew Island in, 346. 
Locust-tree, see Acacia.

London Bridge, Uak timber in old, 30.

Lonicera, 326, 328.

Lucullus, cherries introduced by, 116.

Lydia, Plane-tree in, 282.

Magnum-bonum Plum, 111.

Mahonia, 267.

Malns, see Apple.

Mamhilad Yew, 349.

Manna, 66, 257, 270, 271, 410.

Maple, Great, see Sycamore. - Field, described, 52 ; Gilpin's, 55 ; wood prized by the ancients, $i b$.

Maraschino, 119.

Maronites, superstitious belief of, 415 ; ceremonies of, 416 .

Marrous, 184.

Mast, 24, 154, 414.

Mats, 263, 378 .

May-bush, see Hawthorn.

May-day, 83 note, 91.

Maydukes, 118.

May-pole, 92.

Meal-tree, 132.

Medlar, 101, 133, 135.

Mehl-Baum, 132.

Mère-du-bois, 105.

Merries, 117.

Mespilus, 96.

Michael's Mount, Tamarisks at, 268.

Mildew in corn, 267.

Milton, Chestnut wood at, 174.

Mistletoe, 4, 142 ; thrush, $i b$.

Molluscum, 56 .

Morchella, 156.

Morea shaped like a Plane-leaf, 285.

Morel, 15, 156.

Noscow, Poplars at, 166.

Mother-of-the-wood, 105.

Mount Edgecumbe, Arbutus at, 274.

Myrica, ancient name of Tamarisk, 268: Galé, 273.

Myrobalan Plum, 110.

Myrtle, Dutch, 272.

Napoleon's Willow, 319.
National debt, speculation to pay off, 155.

New Forest, remarkable Oak in, 37.

Newham, Hawthorn at, 84.

Nineveh, Fir-cone on sculptures at, 358 .

Normandy, Chestuut timber in, 171.

Norway Spruce, see Spruce Fir. Nut, see Hazel, Chestnut, Walnut.

Nuthatch, 245.

Nutting, pleasures of, 246.

Oak, described, 1 ; the Oaks of Mamre, 2 ; of Shechem, $i b$; groves of, 4 ; acorns used as food, 3, 25; Yule-log, 4; Druids, 4, 8; etymology of acorn, 4 ; the Mistletoe, 5 ; popular chorus, $i b$.; Wistman's Wood, Dartmoor, 6 ; etymology of Oak, Quercus Robur, 7 ; growth of, 8 ; character, 9 ; Gilpin's description, 9, 12 ; Eddystone Lighthouse, 10 ; strength of Oak, 11 ; kneetimber, 13; shape of Oak, $i b$; appearance in winter, 14 ; Lammas-shoots, $i b$. ; civic crown, ib. ; King Charles's Oak, 14, 34 ; insects which feed on Oak, 15, 17 ; gall-flies, 17 ; Oak apples, 18 ; flower and fruit of the Oak, 19, 22 ; Quercus infectoria, 21; rooks, 25 ; Q. Egilops, 26 ; timber, 27 ; Westminster Abbey, $i b$.; shrine of Edward the Confessor, $i b$.; Arthur's round table, $i b$.; Brundusium, 28 ; uses of timber, $i b$; old English or Durmast Oak, 29; Old London Bridge, 30 ; ground Oak, 31 ; Oak copse, ib.; picturesque character of, 32 ; barking, $i b$.; Boscobel, 34 ; New Forest, 37; value of the timber, 38 ; succecded by Beceh, 154 ; Evergreen Oak, see Ilex.

Oakweb, 15. 
Occidental Plane, 287; see Plane. Old style, 83.

Oleaceæ, 56, 295.

Ononis, see Manna.

Opegrapha scripta, 199.

Opulus, 328.

Oriental Plane, see Plane.

Oruus Europæa, 66.

Osier, 313 ; see Willow.

Ostrya, 238.

Oxyacantha, 96; see Hawthorn.

Padus, see Cherry Bird.

Palm Sunday, 308, 344.

Palms, 307, 325, 344.

Paper, 152.

Paper Birch, 209.

Papyrus, 152.

Peach, 101.

Pear-tree, described, 134 ; character of wild, $i b$. ; varieties, 135 ; remarkable tree, 136.

Pegwood, 277.

Penrose, Oaks at, 14.

Periclymenum, 327.

Perry, 136.

Persicon, see Walnut.

Peziza, 248.

Phaeton, story of, 164 .

Philyra, see Lime.

Pickled Sloes, 108; Walnuts, 256.

Pine, see Fir, Scotch Fir.

Pinaster, described, 381; geographical distribution, 384 ; use on sandhills near the sea, $i b$. ; resin, 385 ; lampblack, 386.

Pinus Lemoniana, 386.

Pinus, 365 ; see Pine.

Pipes, Cherry-stick, 120.

Pippin, 140.

Pistachio-nuts, 239.

Pitch, how procured, 387.

Plane-tree, Sycamore so called, 48 ; Oriental, described, 282 ; shaded the tomb of Diomede, $i b$.; of Xerxes, $i b$.; at Stanchio, 284 ; leaf shaped like the Morea, 285; singular shedding of bark, $i b$.; timber, 286 ; largest tree in the world, 284 ; Occidental, described, 287 ; picturesque character, 288 ; protection of buds, $i b$; impatience of cold, 289 ; called Buttonwood in America, 292.

Platanaceæ, 282.

Platanus, see Plane.

Playn, see Plane.

Plum, Myrobalan, 110; Citizen, $i b$.

Pollard Willows, 313.

Polygonum, 152.

Pomatum, 139.

Pompeii, nuts of Stone Pine found at, 390 .

Pope's Willow, 319.

Poplar, described, 159 ; character of, $i b$.; etymology, $i b$.; White, Grey, Dutch or Abele, 161 ; consecrated to Hercules, 162 ; uses of wood, 163; Black, 164; Phaeton, story of, $i b$.; of easy growth, 165 ; uses of wood, 166 ; large, $i b$, ; Trembling, or Aspen, 167 ; superstition respecting, $i b$; ; populine, 169 .

Populus, 161 ; see Poplar.

Portugal Laurel, 124.

Port-wine, adulterated, 107, 323.

Prick-wood, 277.

Printing, origin of, 145 note.

Privet, described, 295 ; patience of smoke, $i b$.; use of, $i b$.

Prunus, 103, 109, 117.

Pseudo-Acacia, see Acacia.

Pseudo-Platanus, see Sycamore. Publican's Guide, 107.

Purley Beeches, 144.

Purple Beech, 155.

Pyrus, 125, 132-134, 137.

Quercus, 1, 7, 21, 38; see Oak. Quick, 96.

Quick-Beam, 127.

Quickset, Quickthorn, 96.

Quinine, 108, 306.

Radiation of heat, effects of, 353.

Rafts, 364 .

Ratafia, 119.

Red Sandars, 107.

Reine Claude Plum, 111.

Resin, 207, 385, 389, 396. 
Rhamnacex, 292.

Rhamnus, $i b$.; see Buckthorn.

Ribston Pippin, 140.

Richmond Hill, Weeping Willow at, 319.

Roads in Russia, 378.

Roan-tree, 133.

Robinia, see Acacia.

Robur, see Oak.

Rooks, services performed by, 25,369 .

Rosaceæ, 82, 103, 112, 125.

Royal Oak, 34, 37.

Rufus Stone, Frontispiece.

Ruscus, 203.

Russian leather, 212.

Rust in corn, 267.

Sabot, 155.

Saf-caf, 316.

Salicine, 306.

Salix, 302, 311, 317; see Willow.

Sallow, see Willow.

Salvator Rosa, 177.

Sambucus, see Elder.

Sandhills, how fixed, 384.

Sardian nut, 175.

Saugh-tree, 312 ; see Willow.

Savoy Palace, 28.

Scau, Scauan, the Elder-tree so called, 324.

Scolytus, 229.

Scotch Fir, described, 365 ; ancient forests in Scotland, 366; seeds planted by rooks, 369 ; destruction of forests, 370 , 372 ; native of England, 373; formerly abundant in Ireland, $i b$.; Bog Fir, 374; geographical distribution, 375 ; cones and seeds, 376 ; two varieties of, 377 ; picturesque character, $i b$.; timber and other products, 377,379 ; bark made into bread, 380 .

Sculpture in wood, 77,78 .

Sea Pine, 385 ; see Pinaster.

Selborne, village of, 58 .

Serbal Mount, Tamarisks at, 268, 270.

Service-tree, 133 ; Maple, $i b$. ; Wild, ib.; True, 134.

Severn, boats used on, 309 .
Shechem, 2.

Ship-building, 300 ; ships built of Larch, 409 ; masts of Cedar, 414.

Shrew-ash, 59.

Silver Fir, 391 ; described, 398 ; picturesque character, 400 ; mention of, by the Romans, 401 ; Strasburg turpentine, 402 ; insects destructive of, 403.

Sinai, Mount, Tamarisks at, 270.

Slide of Alpnach, 361.

Sloe-tree, 105.

Snow, effect of, on Firs, 353.

Solarium, 284.

Sorbus, 134; see Ash, Mountain.

Spanish nuts, 173, 251.

Spina Christi, see Paliurus.

Spindle-tree, 277.

Spiral vessels, 199.

Spruce Fir, described, 390 ; native country, 391 ; picturesque character, 392 ; of the Alps, $i b$; in the countries bordering on the Baltic, 395 ; forests of, $i b$; ; effects of storm on, $i b$; Burgundy pitch, 396; deal, 397 ; galls of, 398 .

Squirrel, 58, 243, 398.

Stanchio, Plane-tree at, 284.

Star Pine, see Pinaster.

Stone Pine, described, 388 ; picturesque character, 389 ; nuts, 390.

Storm-cock, 142.

Strasburg turpentine, 402.

Strawberry-tree, see Arbutus.

Style, in writing, 152.

Sugar, from Sycamore, 56.

- Maple, 56. Lime, 264.

Superstitions respecting trees, 3 , $14,58,59,85,87,127,138$, $167,415$.

Sweden and Norway, Fir forests in, 358,360 .

Swedish peasants, character of, 380.

Swine, 24, 69 ; in New Forest, 154.

Switzerland, 193; Willows in, 315. 
Sycamore, described, 39, 42 ; not a native tree, 43 ; infested by insects, 44 ; picturesque qualities, $i b$; ; etymology, $i b$. ; parasites, 45 ; honey-dew, $i b$. ; bees, $i b$. ; winged seeds, 47 ; called Plane, 48, 284, 292 ; sugar produced from, 49 ; Sugar Maple, $i b$.; uses of timber, 51 ; large tree, $i b$.

Tabernacles, Feast of, 197, 302.

Tables of weights, 152 .

Talmudists, tradition of, 357 .

Tamariscineæ, 267.

Tamarisk, described, 267 ; not indigenous, 268; manna from, 270 ; Dutch Myrtle, 272; Candleberry. Myrtle, 273.

Tar, how prepared, 379.

Taxaceæ, Taxads, Taxus, 341 ; see Yew.

Tea, adulterated, 107.

Teil-tree, 2, 40.

Terebinth, 2.

Thorns and Thistles, 109.

Thyine-wood, 357.

Thyrsus, 358.

Tilia, see Lime.

Tiliaceæ, 258.

Timber carriages, 360 .

Timber-rafts, 361,364 .

Topiary-work, 72.

Tortworth Chestnut, 172.

Toxica, 341.

Trembling Poplar, 167.

Trenails, 300.

Truffle, 157.

Tuber, 156.

Turpentine, whence procured, 379 ; Venice, 409.

Turpentine-tree, 2.

Twickenham, Willow at, 319.

Tyningham, Holly-hedge at, 203.

Ulmaceæ, 218.

Ulmarium, 225.

Ulmus, 98, 218; see Elm, Wych Elm.

Undershaft, St. Andrew, 91.

Unedo, see Arbutus.

Valombrosa, Chestnuts at, 178.
Venice Turpentine, 409.

Versailles, Poplars at, 166; Willows at, 308.

Vine wedded to Elm, 225, 226.

Volume, why so called, 153.

Wales, etymology of, 255 ; custom in, 344.

Walnut, described, 251 ; shade said to be injurious, $i b$.; ancient custom, 252; etymology of, 255 ; soil, $i b$.; uses of, 256 ; timber, 257 ; stain caused by leaves, manna from, $i b$.

Wayfaring-tree, 328.

Weather-tree, 162.

Weddings, ancient custom at, 252, 255.

Wedding Vine to Elm, 225.

Weeping Oak, 2; Ash, 69 ; Beech, 156; Birch, 208; Wil. low, 317, 320.

West Hay Wood, Beech in, 158.

Westminster Abbey, 27.

Whitethorn, see Hawthorn.

White-tree, $13 \%$.

Wicken-tree, 127.

Wiggen-tree, $i b$.

Willow, described, 302 ; earlies mention of, in Scripture, $i b$.; of what emblematic, $i b$.; num. ber of species, 304; notice of, by the ancients, 305 ; characters of, 306 ; "Palnis," 307 ; seeds, 308 ; various uses of, wicker-boats, 309 ; picturesque character, 311 ; Huntingdon, ib.; Bedford, $i b$. ; Crack, 312; Goat, Osier, ib. ; singular place of growth, 313; Fivestamened, 314 ; Brown, ib.; Herbaceous, 315 ; gall-fly, $i b$.; Eastern species, 316 ; Babylonian, 317 ; picturesque character, $i b$.; when introduced, 319 ; Napoleon's Willow, $i b$.

Willow-holts, 313.

Winter, Beech-wood in, 147.

Wistman's Wood, 6, 7 .

Witchen-tree, 127.

Witch-hasell, 231.

Wolves, extirpation of, 371 . 
Woodbine, see Honeysuckle.

Wood-engraving, history of, 78 .

Woodpeckers, 69.

Worcester, I,ime-wood near, 260.

Writing-materials, ancient, 152.

Wych Elm, 224, 231 ; see Elm.

Xerxes, Plane-tree of, 282.

Yew, described, 341 ; considered poisonous by the ancients, $i b$; why planted in churehyards, $i b$.; yew-bows, 344 ; of what countries a native, 346 ; remarkable grove of, $i b$; ; description of trunk, stem, and leaves, $i b$.; berries, 348 ; leaves poisonous, $i b$.; picturesque character, wood, $i b$; Irish, 49 ; remarkable trees, $i b$.

Zealand, Poplar in, 167. Zinnar-tree, see Plane.

THE END.

R. CLAY, SONS, AND TAYLOR, PRINTERS, LONUON. 



\section{PUBLICATIONS}

OF THE

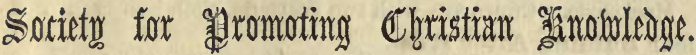

Most of these Works may be had in ornamental bindings, with gilt edges, at a small extra charge.

A Journal of the Plague Year.

Being Observations, or Memorials, of the most Remarkable

Occurrences, as well Public as Private, which happened in Lon.

don during the last great Visitation in 1665. Written by a

Citizen who continued all the while in London. Imp. $16 \mathrm{mo}$,

cloth boards. . . . . . . . . . . . . .

A Steadfast Woman.

By the Author of "Eric Thorburn" and "Cecy's Recollections." Reprinted from "The People's Magazine." Demy 8vo, cloth

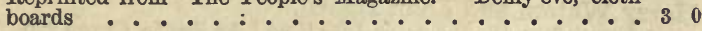

A Thousand Years; or, the Missionary Centres of the Middle Ages.

By the Rev. JomN WrsE. With four Illustrations on toned paper. Crown 8vo, cloth boards .......... 26

Alone Among the Zulus.

By a Plain Woman. The Narrative of a Journey through the Zulu Country, South Africa. Fcap. 8vo, bevelled boards, gilt edges .................... 26

Battle Worth Fighting, The; and other Stories. Fcap. 8vo, cloth boards . . . . . 20

Castle Cornet; or, the Island's Troubles in the Troublous Times.

A Story of the Channel Islands. By Loursa HAwTREY. With four Illustrations on toned paper. Crown 8vo, cloth boards................... 20

Christian Fathers, The.

Lives of Ignatius, Polycarp, Justin, Irenæus, Cyprian, Athanasius, Hilary, Basil, Gregory Nazianzen, Ambrose, Jerome, Chrysostom, Augustine, Gregory the Great, Bede, and Bernard. By the Rev. G. G. Perry, M.A. Post 8vo, cloth boards . . 36

Church of Fingland Biographies.

Hooker - Ussher - Herbert - Leighton - Lady Falkland Jeremy Taylor - Ken - Margaret Godolphin - John Newton. With four Portraits. Crown 8vo, cloth boards [Fcap. 8vo.] 
Church of England Biographies.

Second Series. Wilson-Hannah More-Joshua Watson-Legh Richmond - Heber - Blomfield - Dr. Scoresby - Longley-

Mackenzie. Crown 8vo, with two Portraits, cloth boards . . 20

Clear Shining After Rain.

(For Girls.) By Mrs. CAREY Brock. Crown 8vo, cloth boards 30

Cycle of Life, The :

A Book of Poems for Young and Old, Town and Country. Printed on toned paper, illustrated with eighteen woodcuts, handsomely bound in cloth, gilt edges, bevelled boards, fcap. 4to

Farth's Many Voices.

First and Second Series. With illustrations on toned paper. Royal 16mo, extra cloth, gilt edges ........ each

The two series in one volume ........ 40

Golden Gorse; and Uncle Mark's Snowballs.

By FLORENCE WILFORD. With three Illustrations on toned paper. Crown 8vo, cloth boards .......... 16

Grosseteste, the Iife and Times of Robert, Bishop of Iincoln.

By the Rev. G. G. Perry, M.A. Post 8vo, cloth boards . . 26

Harry Waters and John Heard.

A Lesson from the Field; or, Like Seed Like Fruit. Crown 8vo 20

Hatty and Nellie; or, Two Marriages.

A Story of Middle Class Life. By Mrs. CAREY Brock. Crown

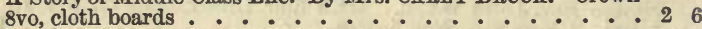

His Heart's Desire.

Crown 8vo. With three full-page Illustrations on toned paper,

cloth boards. . . . . . . . . . . . . .

Home in South Africa.

By the Author of "Alone among the Zulus." Fcap. 8vo, cloth

boards...................... 16

Janetta; or, the Little Maid-of-all-Work.

With three Illustrations on toned paper. Crown 8vo, cloth

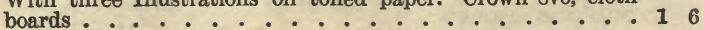

Iife in the Walls, the Hearth, and the Eaves.

With four full-page Illustrations, printed on toned paper.

Royal $16 \mathrm{mo}$, cloth boards ............. 10

Ling Bank Cottage : a Tale for Working Girls. With two Illustrations on toned paper. Crown 8vo, cloth

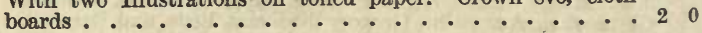

Lionel's Revenge; or, The Young Royalists.

Fcap. 8vo, cloth boards........... 20

Marion; or, The Smuggler's Wife.

With four full-page Illustrations on toned paper. Crown 8vo, cloth boards 
Mary : a Tale of Humble Iife.

With three Illustrations on toned paper. Crown 8vo, cloth

boards................. 20

Mays of Lorton, The.

A Tale of Village Life. 18mo, cloth boards . . . . . 16

Natural History of the Bible, The.

By the Rev.H. B. TristraM, M.A., LL.D., F.R.S. . . . . 76

New Stories on Old Subjects.

By C. E. BowEv, Author of "Stories on my Duty towards God and my Neighbour," \&c. With four full-page Illustrations on toned paper. Crown 8vo, cloth boards ....... 30

Panelled House: a Chronicle of Two Sisters' Lives.

Crown 8vo, cloth boards . . . . . . . . 36

Parables of Life.

By the Author of "Earth's Many Voices." Royal 16mo, on

toned paper, with seven Illustrations. Cloth boards, gilt edges 20

Poor Little Gaspard's Drum.

A Tale of the French Revolution. Fcap. 8vo, cloth boards . . 16

Right Way, The, and the Wrong Way; or, The Ardingley Lads.

By A. R. N., Author of "Woodbury Farm," "Margaret Vere," \&c. With three full-page Illustrations on toned paper. Crown

$8 \mathrm{vo}$, cloth boards . . . . . . . . . 16

Rina Cliffe.

(For Girls.) A Village Character. By E. M. L. With three full-page Illustrations on toned paper. Crown 8vo, cloth boards

Sandwich Islands and their People, The.

By M. A. Donne, Author of "Denmark and its People," \&c.

Fcap. 8vo, cloth boards ............. 2

Scenes in the East.

Consişting of Twelve Coloured Photographic Views of Places mentioned in the Bible, beautifully executed. With descriptive Letterpress, by the Rev. H. B. TRIsTRAM, M.A., LL.D., F.R.S., \&c., author of "The Land of Israel," \&c., \&c. 4to, cloth, bevelled boards, gilt edges . . . . . . . . 76

School and Holidays.

A description of German Upper Class Life for Girls. Translated from the German. With three Illustrations on toned paper. Fcap. 8vo, eloth boards . . . . . . . . .

Selborne, The Natural History of.

By the late Rev. GilbBrRT White, M.A., Fellow of Oriel College, Oxford. Arranged for Young Persons. New Edition. Cloth

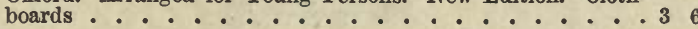

Silent Jim.

A Cornish Story. By JAmes F. CoBB, Esq., Author of "A Tale of Two Brothers." With four full-page Illustrations on toned

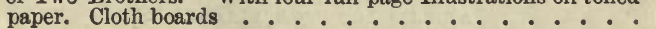


Sinai and Jerusalem; or, Scenes from Bible Lands.

Consisting of Coloured Photographic Views of Places mentioned in the Bible, including a Panoramic View of Jerusalem. With descriptive Letterpress, by the Rev. F. W. HoLla ND, M.A., Honorary Secretary to the Palestine Exploration Fund. Cloth, bevelled boards, gilt edges ......... 76

St. Cedd's Cross : a Tale of the Conversion of the East Saxons.

By the Rev. E. CurTs, B.A. Tcap. 8vo, cloth boards, gilt edges 26

Stories for every Sunday in the Christian Year.

Fcap. 8vo, cloth boards ............ 20

Stories on "My Duty Towards God."

Crown 8vo, cloth boards .............. . 16

Stories on "My Duties Towards My Neighbour."

Crown 8vo, cloth boards . . . . . . . . . 16

Stories of Success, as illustrated by the Lives of humble Men who have made themselves great.

By JAMEs F. СовB, Esq., Author of "Silent Jim." With four

Illustrations on toned paper. Crown 8v0, cloth boards. .30

Stranger than Fiction.

A Story of Mission Life. By the Rev. J. J. Halcombe, M.A. With eight full-page Illustrations on toned paper. Post 8vo, cloth boards . . . . . . . 26

The Topography of the Holy Land; or, The Places, Rivers, and Mountains mentioned in the Bible.

By the Rev. H. B. Tristram, M. A., LL. D.; F.R. S. Crown 8vo, cloth boards ............... 40

To San Francisco and Back.

By a LoNdon Parson. With numerous Illustrations. Crown 8 vo, cloth bqards .............. 26

Wanderer, The.

(For Boys.) By Mrs. Pearless (late Annr Pratt). Crown 8vo, with three full-page Illustrations, cloth boards . . . 20

What Friends are Meant For.

Royal $16 \mathrm{mo}$, cloth boards ........... 16

Year in the Country, $\mathbf{A}$.

koyal 16mo, cloth boards .......... 16

\section{Aeprositories:}

77 Great Queen Street, Lincoln's-ixn Fields;

4 Royal Exchange; 48 Piccadilly; AND BY ALL BOOKSELLERS. 




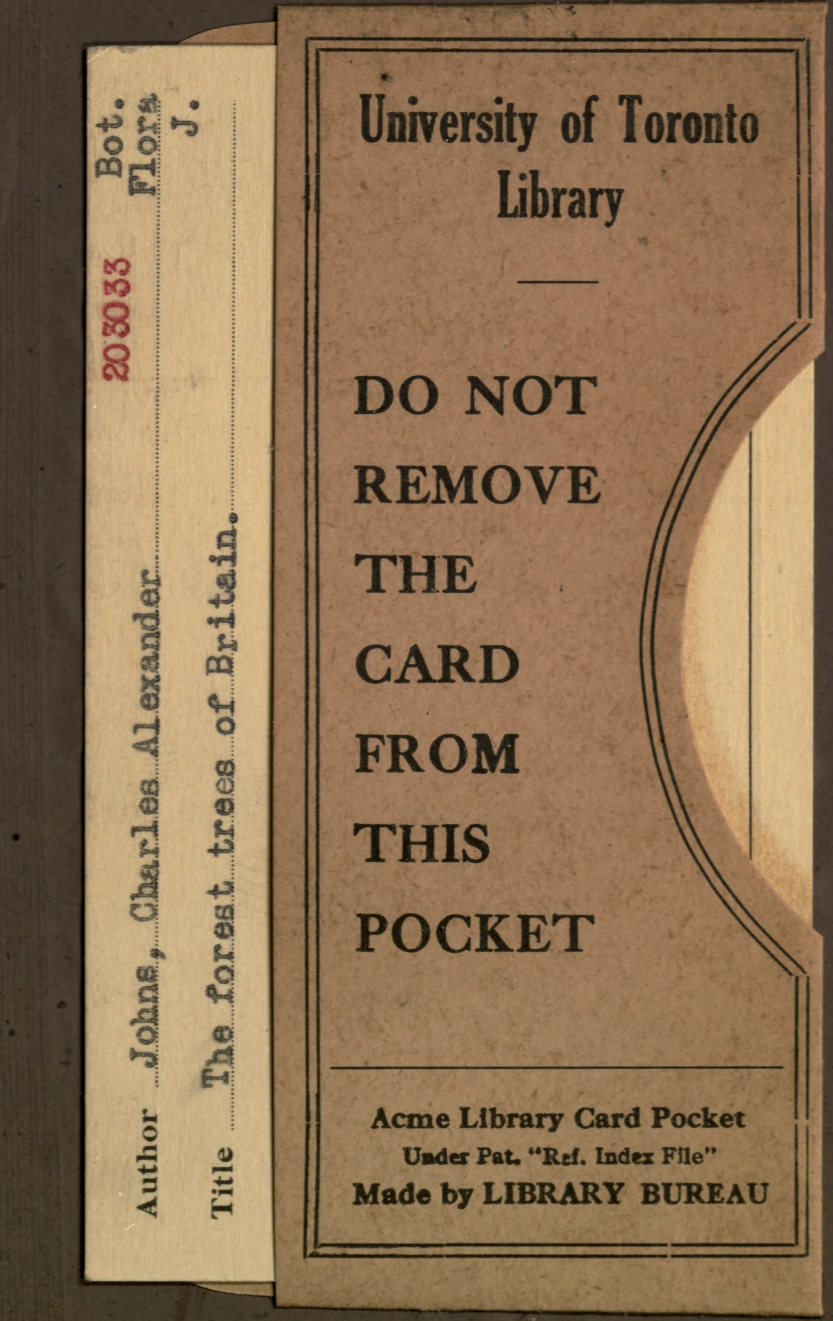


